Luiz Antonio Pereira de Souza

\title{
REVISÃO CRÍTICA DA APLICABILIDADE DOS MÉTODOS GEOFÍSICOS NA INVESTIGAÇÃO DE ÁREAS SUBMERSAS RASAS
}

Tese apresentada ao Instituto Oceanográfico da Universidade de São Paulo, como parte dos requisitos para a obtenção do título de Doutor em Ciências, área de Oceanografia Química e Geológica.

Orientador:

Prof. Dr. Moysés Gonsalez Tessler

São Paulo

2006 
Universidade de São Paulo

Instituto Oceanográfico

\title{
REVISÃO CRÍTICA DA APLICABILIDADE DOS MÉTODOS GEOFÍSICOS NA INVESTIGAÇÃO DE ÁREAS SUBMERSAS RASAS
}

\author{
Luiz Antonio Pereira de Souza
}

Tese apresentada ao Instituto Oceanográfico da Universidade de São Paulo, como parte dos requisitos para a obtenção do título de Doutor em Ciências, área de Oceanografia Química e Geológica.

Julgada em I___ I_ 2006

Prof. Dr.

Conceito

Conceito

Prof. Dr.

\section{Conceito}

Conceito

Prof. Dr.

Conceito

Prof. Dr.

Conceito

Prof. Dr.

Conceito 
S729r Souza, Luiz Antonio Pereira de

Revisão crítica da aplicabilidade dos métodos geofísicos na investigação de áreas submersas rasas. / Luiz Antonio Pereira de Souza. São Paulo, 2006. $311 \mathrm{p}$.

Tese apresentada ao Instituto Oceanográfico da Universidade de São Paulo, como parte dos requisitos para obtenção do título de Doutor em Ciências, área de Oceanografia Química e Geológica.

Orientador: Prof. Dr. Moysés Gonsalez Tessler

$\begin{array}{llll}\text { 1. Oceanografia geológica } & \text { 2. Estratigrafia rasa } & 3 \text {. Área submersa rasa } 4 .\end{array}$ Geofísica aplicada 5. Sísmica 6. Tese I. Universidade de São Paulo. Instituto Oceanográfico II. Título 
"Affirmatio unius non est negatio alterius"

Aristóteles (384-322 a.C.)

("A afirmação de uma coisa não é a negação de outra”) 
Dedico esta Tese: à Ligia, minfra companfeira de todos os momentos aos me us pais, Luize Rita aos meus irmãos Mauro, Suely e Ronaldo aos meus amigos 


\section{SUMÁRIO}

Lista de Figuras.............................................................................................................................

Lista de Tabelas..............................................................................................................................

Lista de Anexos.. ......................................................................................................................

Lista de Símbolos e Unidades..........................................................................................xvi

Agradecimentos......................................................................................................................xviii

Resumo

Abstract..................................................................................................................

1 INTRODUÇÃO......................................................................................... 1

1.1 ÁREAS COSTEIRAS E PLATAFORMA CONTINENTAL ….......................................... 1

1.2 ÁREAS SUBMERSAS INTERIORES ........................................................................... 5

1.3 A GEOFÍSICA NA INVESTIGAÇÃO DE ÁREAS SUBMERSAS ....................................... 5

2 OBJETIVOS ……...........................................................................................................10

3 JUSTIFICATIVAS ……...................................................................................................... 12

3.1 POR QUE ÁGUAS RASAS? ..............................................................................................13

3.2 POR QUE MÉTODOS GEOFÍSICOS? ........................................................................... 14

4 MATERIAL E MÉTODOS .......................................................................................15

5 SEDIMENTOS INCONSOLIDADOS......................................................................16

5.1 HISTÓRICO...................................................................................................................16

5.2 IMPORTÂNCIA DOS SEDIMENTOS .............................................................................18

5.3 MEDIDAS EM SEDIMENTOS......................................................................................... 19

6 ÁREAS COSTEIRAS E PLATAFORMA CONTINENTAL INTERNA..................................................................................................................................20

7 ÁREAS SUBMERSAS INTERIORES: LAGOS, RESERVATÓRIOS E RIOS .......................................................................................23

7.1 ESTUDOS DE LAGOS, RESERVATÓRIOS E RIOS NO BRASIL E A

INVESTIGAÇÃO GEOFÍSICA ........................................................................................25

8 INVESTIGAÇÃO DE ÁREAS SUBMERSAS....................................................31

8.1 ASPECTOS GERAIS ...........................................................................................31

8.2 INVESTIGAÇÃO GEOFÍ́SICA DE ÁREAS SUBMERSAS .............................................34

8.3 MÉTODOS SíSMICOS.............................................................................................36

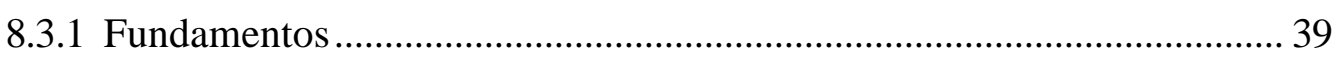

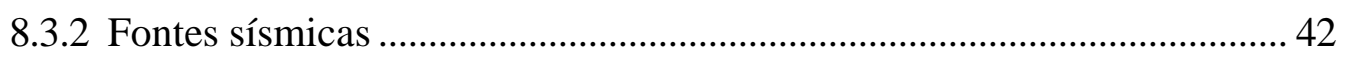

8.3.2.1.. Fontes ressonantes....................................................................... 43

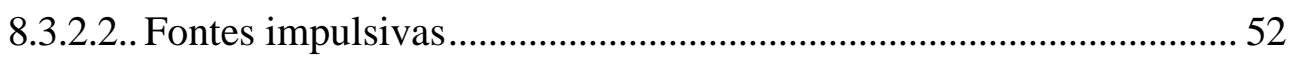




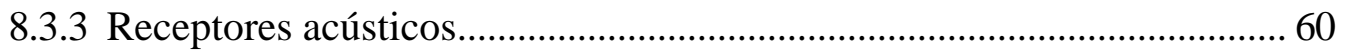

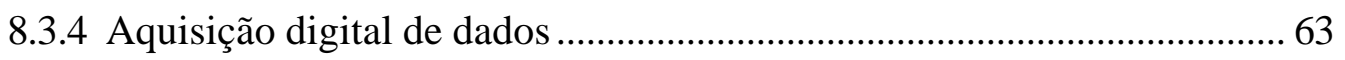

8.4 INVESTIGANDO A MORFOLOGIA E A NATUREZA DA SUPERFÍCIE DE

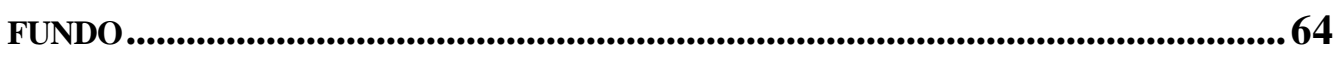

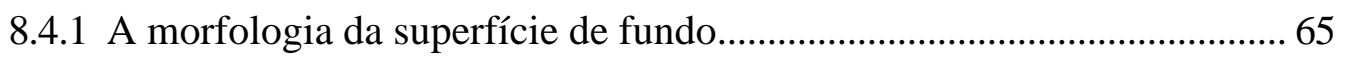

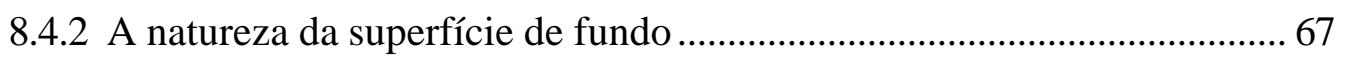

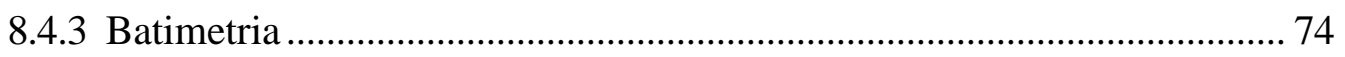

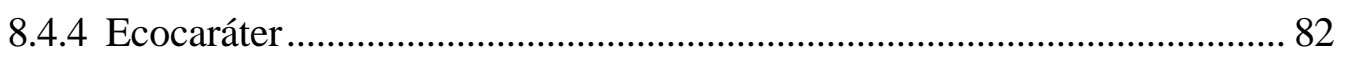

8.4.5 Classificadores de fundo ou AGDS (Acoustic Ground

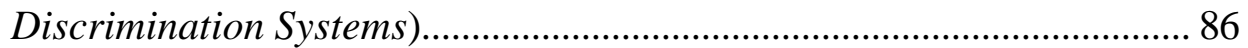

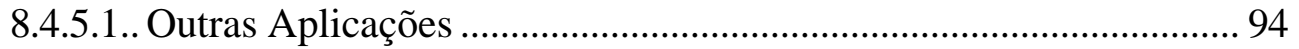

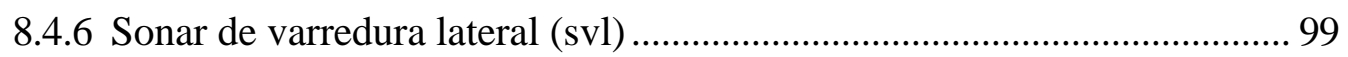

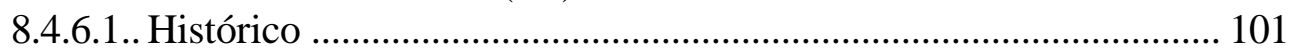

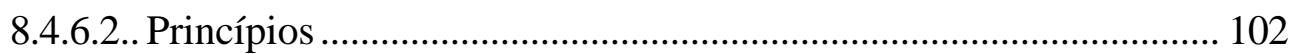

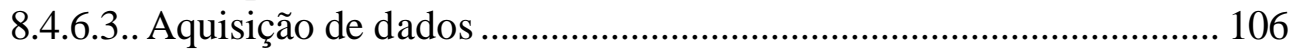

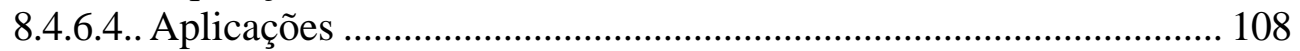

8.4.6.5.. Os registros do sonar de varredura lateral ....................................... 118

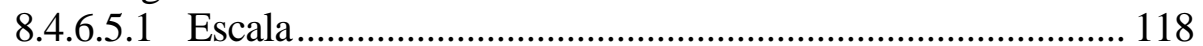

8.4.6.5.2 Alcance Lateral................................................................ 118

8.4.6.5.3 Geometria dos registros analógicos e digitais................... 122

8.4.6.5.4 Resolução ....................................................................... 125

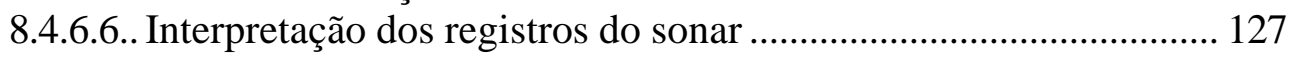

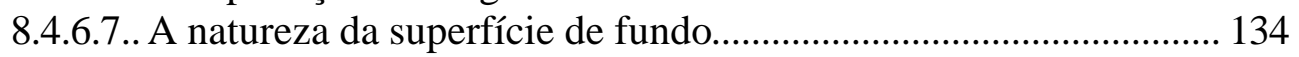

8.5 INVESTIGANDO A NATUREZA E A GEOMETRIA DOS ESTRATOS

SEDIMENTARES .........................................................................................................134

8.5.1 Aspectos gerais da investigação de subsuperfície ................................. 140

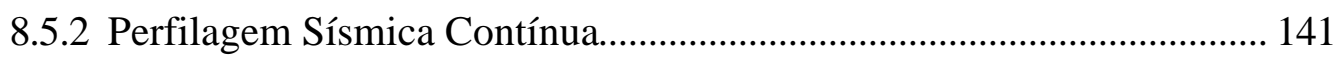

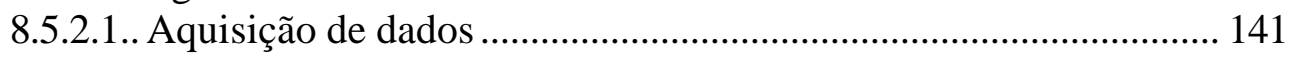

8.5.2.2.. O registro de campo e sua interpretação ......................................... 144

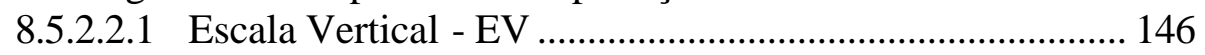

8.5.2.2.2 Escala Horizontal - EH....................................................... 148

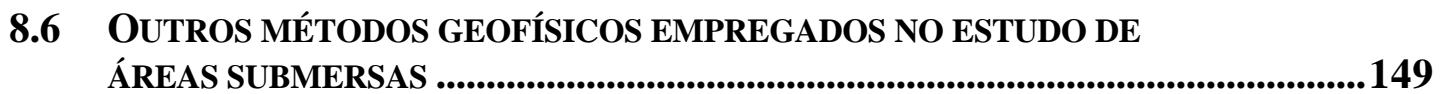

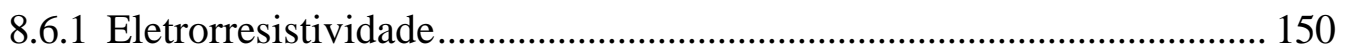

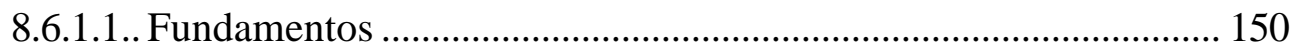

8.6.1.2.. Sondagem Elétrica Vertical (SEV) .................................................. 153

8.6.1.3.. Caminhamento Elétrico (CE) ........................................................ 153

8.6.1.4.. Eletrorresistividade em áreas submersas ........................................ 154

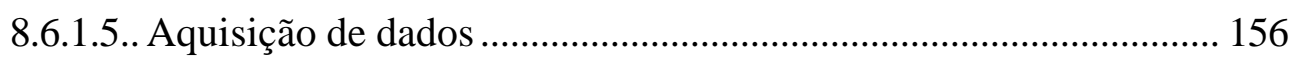

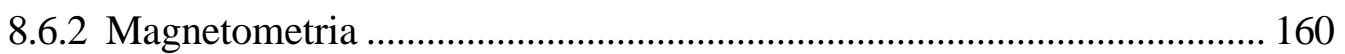

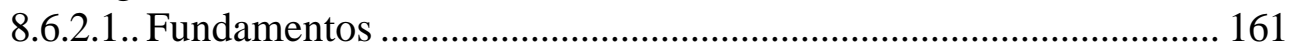

8.6.2.2. Aplicação da magnetometria na investigação de áreas

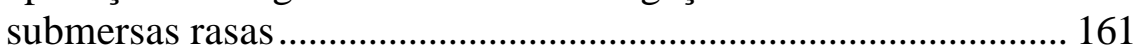

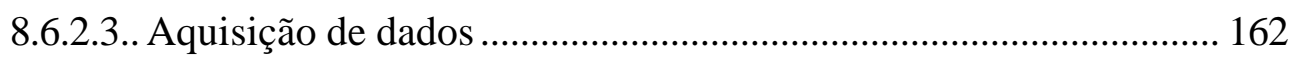

8.6.3 Radar de Penetração do Solo (GPR)............................................................ 165

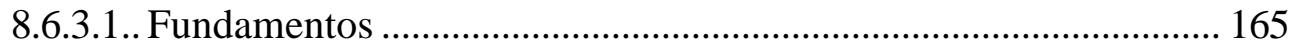

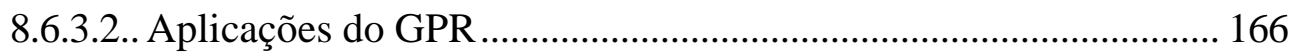




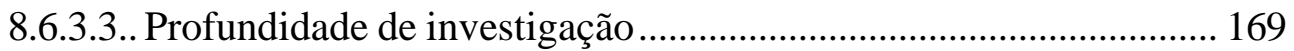

8.6.3.4.. A utilização do GPR na investigação de áreas submersas ............. 171

8.6.3.4.1 Equipamentos................................................................. 175

9 CONSIDERAÇÕES SOBRE A APLICABILIDADE DOS MÉTODOS GEOFÍSICOS NA INVESTIGAÇÃO DE ÁREAS

SUBMERSAS RASAS........................................................................181

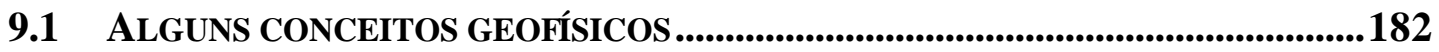

9.2 CONSIDERAÇÕES SOBRE A BATIMETRIA E CARÁTER DO ECO ..........................187

9.2.1 Características da fonte acústica ........................................................... 188

9.2.2 Topografia da área estudada ................................................................. 191

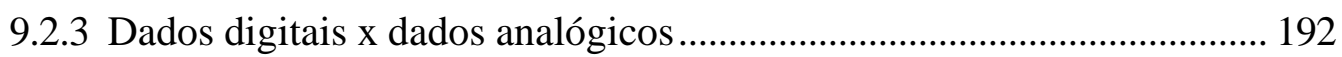

9.3 CONSIDERAÇÕES SOBRE OS CLASSIFICADORES DE FUNDO (AGDS) ...................197

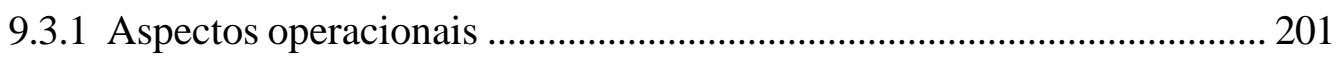

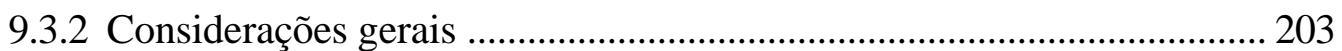

9.4 CONSIDERAÇÕES SOBRE O SONAR DE VARREDURA LATERAL ...........................204

9.5 CONSIDERAÇÕES SOBRE A INVESTIGAÇÃ̃ DE SUBSUPERFÍCIE ......................206

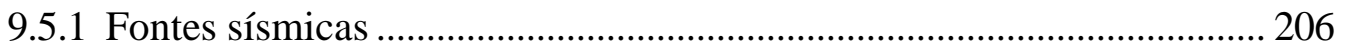

9.6 CONSIDERAÇÕES SOBRE A UTILIZAÇÃO DO GPR NA INVESTIGAÇÃO

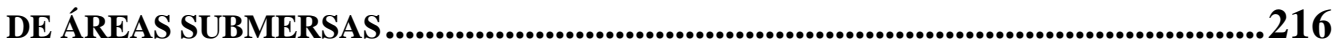

9.7 CONSIDERAÇÕES SOBRE A UTILIZAÇÃO DA ELETRORRESISTIVIDADE NA INVESTIGAÇÃO DE ÁREAS SUBMERSAS..............217

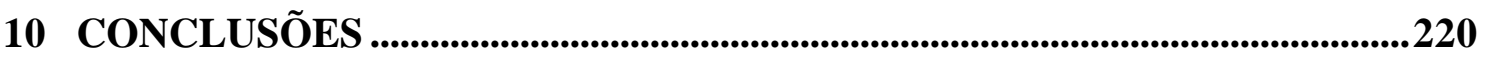

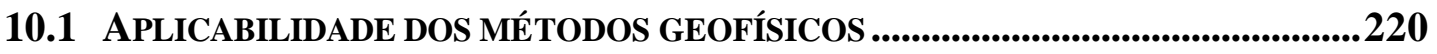

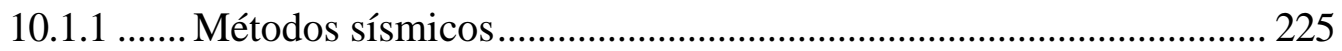

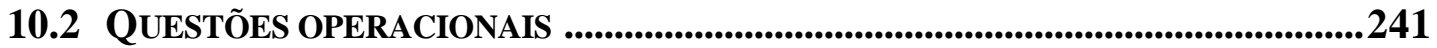

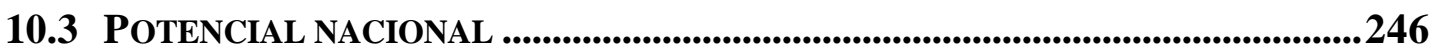

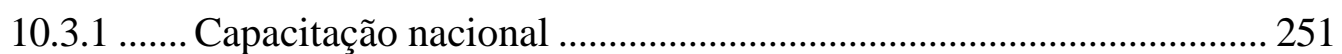

10.4 DESENVOLVIMENTO FUTURO DA INVESTIGAÇÃO GEOFÍSICA DE

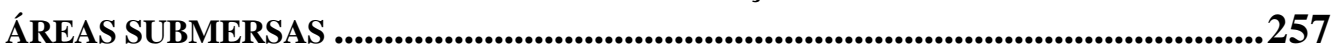

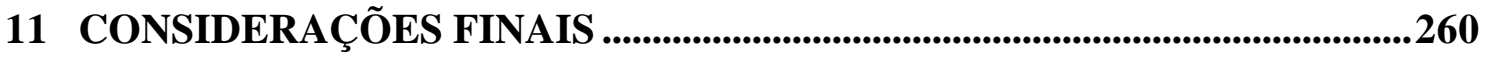

12 BIBLIOGRAFIA..........................................................................................................263 


\section{FIGURAS}

Figura 1.1: Proposta de abordagem da investigação de áreas submersas rasas: a) investigação da superfície por meio da ecobatimetria, que utiliza equipamentos com fontes acústicas que emitem freqüencias a partir de $30 \mathrm{kHz}$; b) investigação da superfície por meio do imageamento de fundo utilizando-se de equipamentos com fontes acústicas que emitem freqüencias geralmente superiores a $100 \mathrm{kHz}$; c).investigação de subsuperfície (perfilagem) utilizando-se de equipamentos com fontes acústicas que emitem freqüencias geralmente inferiores a $20 \mathrm{kHz}$, e que no âmbito desta discussão foram subdivididos em dois grupos: aqueles métodos que priorizam a resolução e aqueles que priorizam a penetração.

Figura 6.1: a) exemplo de intensa ocupação em área costeira: Santos-SP (foto: Flávio R. Berger disponível em <http://www.portodesantos.com.br/> - acesso: abril/2006); b) Vila de Cabeço, foz do rio São Francisco (SE), destruída em consequência da retenção de sedimentos decorrente da construção de grandes barragens ao longo do rio (foto: Prof. Dr. J.M Landim Dominguez-UFBA); c) casa destruída pela ação do mar em consequência da ocupação indevida de setores instáveis da costa $\mathrm{N}$ da Ilha Comprida,SP (foto: Prof. Dr. P. C. F. Giannini-USP).

Figura 7.1: Fotografias aéreas ilustrando exemplos da densa ocupação atual ao derredor de importantes reservatórios de água, no caso, as principais represas que abastecem a cidade de São Paulo: a) Represa Billings; b) Represa Guarapiranga. Imagens cedidas por Renato H. Frazão.

Figura 8.1: Registro sísmico (de expressiva qualidade) obtido no lago Guaraciaba, município de Santo André, SP, ilustrando uma das principais propriedades dos métodos sísmicos que é a possibilidade da correlação praticamente direta, entre um perfil sísmico obtido em campo (parte superior da figura) e um perfil geológico (parte inferior da figura). Modificado de IPT (2004) e Souza et al. (2003).

Figura 8.2 : Exemplo de perfil sísmico de excelente qualidade obtido com uma fonte acústica do tipo boomer em levantamento executado na Baía de Paranaguá, PR: a) registro de campo; b) registro interpretado. Registro cedido pela empresa Microars, RJ.

Figura 8.3: Perfilagem Sísmica Contínua: geometria do arranjo para aquisição de dados: fonte acústica-sensores-embarcação (Souza, 1988).

Figura 8.4: Exemplos de forma dos sinais emitidos por fontes acústicas ressonantes ou de forma de onda controlada (McGee, 1995a).

Figura 8.5: Exemplos de fontes acústicas do tipo ressonantes ou de forma de onda controlada: a) transdutor de ecobatímetro de dupla freqüência $(38 / 200 \mathrm{kHz})$ da Kongsberg/Simrad (Noruega) pertencente ao Instituto de Pesquisas Tecnológicas do Estado de São Paulo; b) transdutor composto: chirp + Pinger $(24 \mathrm{kHz})$ da Meridata System (Finlândia), pertencente ao Instituto Oceanográfico da USP. ( $\mathrm{E}=$ transdutor emissor de sinais acústicos; $\mathrm{R}=$ transdutor sensor/receptor) - Fotos: autor; c) exemplo de perfil batimétrico obtido no rio São Francisco (AL/SE) com o eco 38/200 kHz (Registro cedido pela Georadar); d) exemplo de registro obtido com fonte do tipo chirp no canal de Santos, SP (Registro cedido pelo Prof. Dr. Michel M. de Mahiques).

Figura 8.6: Dois modelos de fontes acústicas do tipo chirp da Edgetech: a) SB216S (2-16 kHz); b) SB-424 (4-24 kHz); c) exemplo de registro sísmico obtido com o chirp modelo SB 424. Fonte: <http://www.edgetech.com>.....

Figura 8.7: a) vista do perfilador EdgeTech modelo SB-512i $(500 \mathrm{~Hz}-12 \mathrm{kHz})$; b) transdutor acoplado em catamarã, em operação no Estuário Potengi (RN); c) registro obtido por este perfilador no Estuário Potengi (Frazão \& Vital, 2006). Fotos: Dra. Helenice Vital.

Figura 8.8:Exemplo do efeito acústico denominado de efeito paramétrico. a) perfil ilustrando o baixo poder de penetração do sinal acústico de $18 \mathrm{kHz}$; b) perfil ilustrando a penetração do sinal de $3.5 \mathrm{kHz}$, resultado da emissão simultânea de $18+21.5 \mathrm{kHz}$. Modificado de Grant \& Schreiber (1990).

Figura 8.9: a) exemplo de transdutor acústico que utiliza o sistema paramétrico (modelo SES96/2000-Standard fabricado pela Innomar Technologie - Alemanha); b) notebook e equipamento de controle do sinal emitido; c) transdutor SES-96/2000 instalado numa embarcação de pequeno porte em levantamento executado na Índia (Lowag, 2000); c) exemplo de perfil ilustrando os nítidos contatos entre os diferentes estratos geológicos (sedimentos e afloramento rochoso), obtido em levantamento executado em bancos de areia 
de rios em Gâmbia. Fotos e registro sísmico, cedidos pela Dra. Sabine Mueller (Innomar Technologie / Alemanha)...

Figura 8.10: Exemplos de fontes impulsivas: boomer e airgun. McGee, 1995a...................................... 52

Figura 8.11: Exemplo de fontes acústicas do tipo boomer a) placa do boomer modelo ED-5 (5 kHz); b) placa do boomer modelo ED-10 (10 kHz) c) boomer ED-5 montado em catamarãs, à beira do rio Paranapanema, SP. Ambas, fabricadas pela Huntec (Canadá) e pertencentes ao Instituto de Pesquisas Tecnológicas do Estado de São Paulo - IPT. Fotos: autor; d) boomer da Applied Acoustic (UK) em operação no rio Waveney (UK). Foto cedida pelo Dr. Adam Darling (Applied Acoustic, UK); e) perfil sísmico obtido com a utilização de fonte acústica do tipo boomer, em projeto de prospecção de areias (material de construção) no rio Paranapanema, SP, onde se observa a penetração do sinal a profundidades de cerca de $30 \mathrm{~m}$ (IPT, 1990a.)

Figura 8.12: Gráfico comparando a penetração esperada da fonte acústica do tipo boomer (modelo GeoPulse da GeoAcoustics) com fonte do tipo sparker. Modificado de <http://www.geoacoustics.com>. Acesso: fev/2006

Figura 8.13: Espectro de energia da assinatura do sinal sísmico de uma fonte do tipo boomer de 280 J. Modificado de McGee, 1995b.

Figura 8.14: à esquerda, foto do boomer modelo AA200 da AppliedAcoustic Engineering, fonte sismica relativamente pequena (dimensões da placa $=38 \times 38 \mathrm{~cm})$, leve (peso da placa $=10$ $\mathrm{kg}$ na água) e potente, com capacidade de transmissão de energia de até $300 \mathrm{~J}$ com largura de pulso de $150 \mu$ s; à direita, espectro de freqüências $(\mathrm{Hz})$ x energia $(\mathrm{dB})$ deste modelo. Applied Acoustic Engineering, 2005b.

Figura 8.15: a) exemplo de fonte acústica do tipo impulsiva. Air-gun utilizado em levantamento sísmico monocanal no mar do Japão. (Equipametno do Serviço Geológico do Japão - GSJ). Foto: autor; b) registro sísmico de campo obtido com o air-gun (Tamaki et al., 1979). Notar a escala de investigação ilustrada no registro: bacias sedimentares com centenas de metros de espessura; c) registro interpretado.

Figura 8.16: Exemplos de fonte acústica do tipo sparkers a) vista parcial de sparker multieletrodo (de alta energia) com arranjo de $5 \mathrm{~m}$ de extensão, pertencente ao navio de pesquisa alemão Victor Hansen; b) sparker de pequeno porte (baixa energia) utilizado para levantamentos de áreas rasas, inclusive água doce, pertencente ao IPT. Neste caso a fonte é envolvida com em uma embalabem plástica contendo uma solução condutora. Fotos do autor; c) exemplo de um registro sísmico obtido com um sparker que identificam a ocorrência de paleocanais na plataforma continental riograndense (Abreu \& Calliari, 2005).

Figura 8.17: Sparker modelo Squid 500, da Applied Acoustic. Pesa apenas 3 kg, lida com energia entre 200 e $600 \mathrm{~J}$. O gráfico da direita mostra o espectro de potência desta fonte: cor magenta $=$ fonte de $1550 \mathrm{~J}, 8$ eletrodos; cor azul $=$ fonte de $1000 \mathrm{~J}, 8$ eletrodos; cor verde $=$ fonte de $1000 \mathrm{~J}, 4$ eletrodos; cor vermelha $=$ fonte de $600 \mathrm{~J}, 4$ eletrodos. Applied Acoustic Engineering, 2005a.

Figura 8.18: Sparker modelo ELC820 da SIG. Pesa pouco mais de $1 \mathrm{~kg}$, tem $1 \mathrm{~m}$ de extensão e lida com energia entre 100 e $1000 \mathrm{~J}$ e espectro de freqüencias entre 800-850 Hz. Fonte: http://perso. wanadoo.fr/sigfrance/ . Acesso: dez/2005.

Figura 8.19: Espectro de potência do sparker Squid 2000, da Applied Acoustics. Cor magenta = fonte de $1550 \mathrm{~J}, 8$ eletrodos; cor azul = fonte de $1000 \mathrm{~J}, 8$ eletrodos; cor verde $=$ fonte de 1000 $\mathrm{J}, 4$ eletrodos; cor vermelha $=$ fonte de $600 \mathrm{~J}, 4$ eletrodos. Applied Acoustics Engineering, 2005a.

Figura 8.20: Ilustração confrontando tipo de fontes sísmicas $\mathrm{x}$ espectro de freqüências emitido $\mathrm{x}$ energia da fonte acústica (quilojoules $=\mathrm{kJ}$ ) x profundidade de investigação. Modificado de Trabant (1984).

Figura 8.21: a) hidrofone do tipo monocanal, com $6 \mathrm{~m}$ de extensão e 10 sensores piezelétricos, utilizado na investigação rasa (foto: Ricardo S. Xavier); b) conjunto de hidrofones do tipo multicanal, instalados no Navio Oceanográfico Almirante Câmara, utilizado na investigação sísmica profunda. Foto: autor.

Figura 8.22: (A) geometria fonte-recepetor comumente utilizada em levantamentos sísmicos de áreas submersas; (B) relação entre profundidade da coluna d'água (D), distância fonte receptor $(\mathrm{X}=$ offset), mínimo comprimento e onda (?) ou maior freqüência de interesse e máximo comprimento do arranjo $\left(\mathrm{L}_{\max }\right)$ para a geometria fonte - receptor. (Mosher \& Simpkin, 1999). 
Figura 8.23: Variações de temperatura, salinidade e velocidade de propagação do som no Pacífico Central $-39^{\circ} \mathrm{N}, 146^{\circ} \mathrm{W}$ (Jones, 1999).

Figura 8.24: Tela de notebook acoplado a ecobatímetro de dupla frequiência (38/200 kHz) marca Kongsberg-Simrad modelo EA-400. Cada uma das frequiências emitidas produz um perfil correspondente, como resultado: na parte superior da figura, observa-se o perfil obtido com a frequiência de $38 \mathrm{Khz}$; na parte inferior, o perfil obtido com a emissão de $200 \mathrm{kHz}$. Ambos os sinais são digitalizados automatica e simultaneamente, e o sistema gera uma planilha do tipo $\mathrm{X}, \mathrm{Y}, \mathrm{Z} 1, \mathrm{Z} 2$ (coordenadas $\mathrm{X}, \mathrm{Y}$ e profundidades $\mathrm{Z1}$ e Z2, fornecidas por cada uma das frequiências). Perfil obtido em trecho do rio Ribeira de Iguape. As diferenças entres os dados obtidos de ambas as freqüências para um mesmo ponto podem significar justamente a penetração do sinal de mais baixa freqüência no substrato sedimentar.Fonte: IPT (dados inéditos).

Figura 8.25: Ilustração mostrando feixe de sinais num sistema multifeixes (multibeam). Modificado de USACE (2004).

Figura 8.26: Ilustração mostrando o produto obtido em tempo real quando da execução de levantamentos batimétricos utilizando-se ecobatímetros de varredura. Modificado de Hussong \& Fryer (1983).

Figura 8.27: Arranjo de transdutores posicionados paralelamente à rota de navegação. Modificado de USACE (2004)...

Figura 8.28: Exemplos de sistemas batimétricos multicanais utilizados pelo Serviço Geológico Finlandês, para levantamentos de detalhe de canais de navegação. Fotos: cortesia da Meridata (Finlância).

Figura 8.29 - Exemplos de tipo de caráter do eco: a) eco contínuo, homogêneo, com a linha que representa a superfície de fundo muito bem definida, sem refletores subjacentes, típico de plataforma continental com sedimentos consolidados, eventualmente com sedimentos inconsolidados, o que torna a superfície de fundo excelente refletor e, portanto, com raríssima penetração do sinal acústico; b) eco continuo, homogêneo, com a linha da superfície de fundo bem definida e com refletores subjacentes também bem definidos que, segundo os autores, podem representar a distribuição em área dos caminhos de dispersão dos sedimentos terrígenos da Bacia do Brasil, pelo menos nos tempos mais recentes; c) eco com linha irregular da superfície de fundo, presença de hipérboles, inclusive nos refletores referentes ao substrato, típicos das áreas mais acidentadas e mais profundas (plataforma continental externa, talude continental, cadeia mesoatlântica, canions e vales submarinos, morros submarinos); d) eco com linhas da superfície mais espessas, presença de hipérboles, relacionadas, provavelmente, com processos sedimentares gerados nas correntes de contorno. Damuth \& Hayes (1977).

Figura 8.30: Tipos de caráteres de eco identificados na classificação dos sedimentos de fundo da baía de Santos a partir de registros de uma fonte acústica do tipo pinger $-24 \mathrm{kHz}$ (Rocha, 2003)

Figura 8.31: Mapa da baía de Santos ilustrando rotas executadas e classificadas por meio da análise do caráter do eco (vide legenda de cores) oriundo de levantamento executado com um ecobatímetro do tipo pinger $-24 \mathrm{kHz}$ (Rocha, 2003).

Figura 8.32: Exemplos de registros de levantamentos sísmicos com perfilador $3.5 \mathrm{kHz}$ obtidos no estudo padrões de eco identificados nos estudos dos corpos sedimentares Columbia, São Tomé e Vema, na margem continental Sudeste-Sul e bacia continental adjacente. Modificado de Lima (2003)

Figura 8.33: Ilustração mostrando o princípio da análise dos sinais acústicos que retornam ao transdutor, fundamento dos sistemas de classificação automática de fundo (AGDS). Modificado de <http://www.questertangent.com/m papers.html >. Acesso: março $2006 .$.

Figura 8.34: Exemplos das variações dos parâmetros do sistema Classificador de Fundo RoxAnn E1 (dureza) e E2 (rugosidade) em área de ocorrência de afloramentos rochosos submersos. Os triângulos pretos na base da figura "a" indicam a localização dos afloramentos rochosos. Observa-se que em (a) o perfil de E1 alcança um máximo sobre o afloramento rochoso, o contrário ocorrendo (um mínimo) com o perfil de E2, indicando que o segundo eco, na verdade, não chega totalmente ao receptor. O gráfico E1 x E2 da figura "b" mostra a distribuição anômala dos dados (ocorrem fora da tendência) obtidos sobre o afloramento rochosos. Modificado de Hamilton et al. (1999). 
Figura 8.35: Mapa da baía de Santos ilustrando rotas executadas e classificadas com relação às características de fundo, por um ecobatímetro do tipo classificador de fundo (RoxAnn Marine Micro Systems Ltd, Irlanda), que emite sinais acústicos na faixa de $50 \mathrm{kHz}$ (Rocha, 2003).......

Figura 8.36: Mapa com curvas de isovalores do parâmetro E1, oriundos de levantamento com classificador de fundo do tipo RoxAnn na Baía de Selonda, na Grécia, em estudos de impactos causados por ocupação da superfície marinha por empreendimentos de maricultura. Nesta figura observa-se que a superfície de fundo da área investigada é relativamente rugosa em toda sua extensão, sendo menos rugosa na porção central, mais profunda. Esta rugosidade foi posteriormente correlacionada, por meio de observações diretas, com sedimentos grossos. Mac-Dougall \& Black (1999).

Figura 8.37: Mapa com curvas de isovalores do parâmetro E2, oriundos de levantamento com classificador de fundo do tipo RoxAnn na Baía de Selonda, na Grécia, em estudos de impactos causados por ocupação da superfície marinha por empreendimentos de maricultura. Nesta figura nota-se que, embora a superfície de fundo da área investigada seja relativamente dura em toda sua extensão, em especial nas porções marginais, detectaram-se por meio do parâmetro E2, algumas áreas cobertas por sedimentos mais inconsolidados (menos duros). Mac-Dougall \& Black (1999).

Figura 8.38: Imagem do sonar de varredura lateral $(120 \mathrm{kHz})$ mostrando elevações na superfície de fundo orientadas SW-NE, não identificadas nos dados do classificador de fundo RoxAnn e compostas de material grosso (cascalhos e fragmentos de rocha), identificado por meio de amostragens de fundo. Humborstad et al. (2004).

Figura 8.39: Mapa de classificação de fundo resultado da utilização do sistema acústico QTC-View na costa Ocidental de Portugal. Nota-se neste mapa a distribuição espacial das trê classes acústicas identificadas pelo sistema $(\mathrm{A}=$ areias grossas, inclusive com cascalhos; $\mathrm{B}=$ areais muitos finas; $\mathrm{C}=$ areia fina). Freitas et al. (2003).

Figura 8.40: Ilustração mostrando como é construída a imagem do sonar de varredura lateral à medida que a embarcação se locomove ao longo da perfil. Modificado de Mazel (1985)......

Figura 8.41: Geometria do sistema de aquisição de dados do sonar de varredura lateral. Vista do canal lateral esquerdo (Souza, 1988).

Figura 8.42: Principais características do sinal acústico emitido pelo sonar de varredura lateral: largura do feixe de sinais paralelamente à rota de navegação comumente inferior a $2^{\circ}$; inclinação do lóbulo principal de sinais, em relação à horizontal, comumente entre 10 e $20^{\circ}$; largura do feixe de sinais no plano perpendicular à rota de navegação, variando comumente entre 20 e $50^{\circ}$. Modificado de Mazel (1985)......

Figura 8.43: Características geométricas do registro de campo obtido por meio da sonografia (Souza, 1988)

Figura 8.44: Reflexão e espalhamento (backscattering) do sinal acústico emitido pelo sonar. Modificado de Mazel (1985).

Figura 8.45: Sonar de Varredura Lateral Hydroscan Klein (pertencente ao IPT) em operação na região de Abrolhos (Bahia) em novembro de 2004: a) registrador analógico; b) fonte de sinais acústicos ("peixe"); c) registro do sonar mostrando textura rugosa, indicando a presença de recifes de corais; d) registro do sonar mostrando textura lisa e homogênea indicando a ausência de recifes de corais. (IPT, 2005a; Souza \& Moura, 2005).

Figura 8.46: Exemplos de cinco modelos de "peixes" existentes no mercado a) modelo antigo Klein Hydroscan 530 (100 kHz -pertecente ao IPT); b) sistema 3000 digital da Klein (132-445 $\mathrm{kHz}) \mathrm{c}$ ) modelo $272 \mathrm{TD}$ digital da Edgetech $(100-500 \mathrm{kHz})$; d) sistema de ultra-resolução multifeixe (4 5 ou 8 feixes de cada lado) modelo 5000 - $455 \mathrm{kHz}$ da Klein; e) sistema de ultra-resolução multifeixe modelo $4300 \mathrm{MPX}-410 \mathrm{kHz}$ da Edgetech.

Figura 8.47: Imagem de altíssima resolução obtida por meio do sonar Klein System 5000 ilustrando detalhes centimétricos da superfície de fundo. Locas de lagostas de dimensões submétricas e as trilhas que as interligam são visualizadas em detalhe nesta imagem. Fonte: <http://www.l3klein.com>. Acesso: dez/2005.

Figura 8.48: a) e b) exemplos de registros de sonar de varredura lateral obtidos na região de Cananéia, litoral sul de São Paulo, mostrando de forma clara a ocorrência de estruturas sedimentares do tipo marcas onduladas; c) registro sísmico (fonte acústica do tipo chirp) obtido na mesma região, mostrando, em perfil, ondas de areia de grande porte. Importante 
notar nestas figuras a significância da visualização em planta das referidas feições sedimentares, o que só é possível por meio do sonar de varredura lateral. Paolo \& Mahiques (2005).

Figura 8.49: Exemplos de registros de sonar de varredura lateral mostrando nítidos contatos geológicos além de estruturas: a) registro com dois padrões texturais muito distintos, sendo o mais rugoso relacionado com a ocorrência de beachrocks na superficie de fundo, e o padrão liso e homogêneo, com a cobertura sedimentar (a linha vermelha delineia este contato geológico). Registro obtido no canal de São Sebastião, SP (Furtado et al., 2000); b) analogamente, dois padrões texturais distintos são evidenciados neste registro: o padrão rugoso está relacionado com afloramento rochoso; o padrão liso e homogêneo, com a cobertura sedimentar. Registros obtidos na costa sul do Japão (Souza, 1984); c) imagem do tipo mosaico, composta a partir da justaposição lateral de várias seções de sonar de varredura lateral, ilustrando pelo menos três padrões texturais distintos: um primeiro, claro e homogêneo, representando uma cobertura de sedimentos finos; um segundo, de ocorrência na porção superior da figura, constitui um padrão liso, homogêneo e escuro, relacionado com a cobertura de sedimentos grossos (em ambos os padrões foram coletadas amostras e procedidas as devidas análises sedimentológicas); e um terceiro padrão, na porção central da figura, representa um enorme afloramento rochoso. Uma cuidadosa análise desta imagem permite inclusive identificar falhas geológicas na porção central da imagem. Registro obtido na costa leste do Japão. Registro cedido pelo Dr. Y. Kinoshita do Serviço Geológico do Japão.

Figura 8.50: Imagem obtida com o sonar de varredura lateral em levantamento executado na plataforma continental interna do Estado da Bahia (Ilhéus) para subsidiar projeto de instalação de plataforma exploratória de petróleo. IPT (1985a).

Figura 8.51: Registros obtidos de sonar de varredura lateral utilizado na prospecção de material de construção (areias) no rio Paranapanema (SP/PR) em subsídio a projeto de construção de barragem: a) registro com textura rugosa característica de fundos rochosos; b) registro com textura lisa e homogênea, característico de fundos com cobertura sedimentar arenosa. IPT (1990a,b).

Figura 8.52: Três exemplos ilustrando potenciais obstáculos à navegação em hidrovias: a) afloramento rochoso no canal da Ilha Comprida-SP (Suguio et al., 1987); b) navio naufragado no canal de Santos-SP (IPT, 1999a); c) textura indicativa de presença de árvores na fundo do rio Tietê, a montante da Barragem de Barra Bonita - SP (IPT, 1998e)...

Figura 8.53: a) imagem obtida com o sonar de varredura lateral mostrando marcas na superfície de fundo de dimensões médias de $6,5 \times 4.5 \mathrm{~m}$, que foram correlacionadas pelos autores com áreas de exsudação de gases; b) perfil sísmico $(3.5 \mathrm{kHz})$ mostrando plumas geradas pela exsudação destes gases. Garcia-Garcia et al. (2202).

Figura 8.54: Exemplos de registros obtidos em áreas de recifes: a) recifes de corais em Abrolhos (BA), IPT (2005a), Souza \& Moura, (2005); b) recifes artificiais na costa do Estado do Paraná, IPT (2002a).

Figura 8.55: a) imagem obtida com um sonar de 500 kHz (Klein System 3000) mostrando detalhes do navio Empire Knight. Fonte: <http://www.l-3klein.com>; b) imagem obtida com o sonar MarineSonic $600 \mathrm{kHz}$, mostrando a evidente aplicação do SVL na investigação de acidentes aéreos (Lago Washington, EUA). Fonte: <http://www.marinesonic.com>

Figura 8.56: Exemplo do emprego de múltiplos sistemas de sonar de varredura lateral, visando a cobertura total $(100 \%)$, e em tempo real, da largura $(1.5 \mathrm{~km})$ do lago Ness, Escócia: a) vista das 24 embarcações navegando paralela e simultaneamente; b) geometria (cobertura) do arranjo de sonares. Modificado de Abril Coleções (1996).

Figura 8.57: Escalas diferenciadas nos registros do sonar de varredura lateral: à esquerda, registro analógico obtido na região de Abrolhos, BA, mostrando escalas diferenciadas em direções ortogonais; à direita, registro digital obtido na região da Ilha Comprida, SP, mostrando escalas idênticas (isométricas) em qualquer direção no registro.

Figura 8.58: Registros analógicos do sonar de varredura utilizando alcances laterais distintos: à esquerda, alcance lateral de $100 \mathrm{~m}$ para localização do objeto de busca (ver escala); à direita, alcance lateral de $25 \mathrm{~m}$ utilizado para aproximação do objeto da busca para obtenção de detalhes. Equipamento utilizado: Klein 530. Hydroscan Side Scan Sonar 100kHz. (IPT, 2001a e Rambelli, 2003).

Figura 8.59: Sonar de varredura lateral de longo alcance: Sea Marc II (11/12kHz) em operação na costa oriental do Japão. Foto: cortesia do Dr. Y. Kinoshita do Serviço Geológico do Japão. 
Figura 8.60: Sonar de varredura lateral de curto alcance modelo Klein Hydroscan Side Scan Sonar $(100 \mathrm{kHz})$, em operação no rio Paraná. Foto: autor..

Figura 8.61: Ilustração mostrando a diferença entre a distância de dois pontos na superfície, medidas ao longo da distância inclinada (DI = distância inclinada, medida no registro) e ao longo da distância horizontal (DH = distância verdadeira). Modificado de Mazel (1985).....

Figura 8.62: Ilustração que mostra, por meio de deformações em figuras geométricas regulares, o efeito da variação de velocidade de navegação sobre os registro do sonar de varredura lateral. Mazel (1985).

Figura 8.63: Resolução das imagens do sonar de varredura lateral ao longo da linha de navegação. Observa-se, neste exemplo, que objetos distintos podem ser gravados, no registro do sonar, como um único objeto, se localizados a distâncias da fonte acústica que permitam ser englobados pelo feixe de sinais. Modificado de Mazel (1985).

Figura 8.64: Registros oiginais de campo de SVL obtido num mesmo local, mostrando resoluções distintas para frequiências distintas: a) a imagem mostra registro obtido com um sonar digital de alta resolução (300 kHz) na Enseada do Flamengo, SP, onde se observam-se, com detalhes, feições na superfície de fundo interpretadas como estruturas de pesca locais; b) imagem ilustrando um registro analógico de baixa resolução $(100 \mathrm{kHz})$ onde, todavia, não se observam os detalhes identificados na imagem superior. Nesta, apenas alguns traços evidenciam elementos que poderiam ser correlacionados a estruturas de pesca. Registros cedidos pelo Prof Dr. Michel M. de Mahiques - IO-USP.

Figura 8.65: Padrão de referência utilizado para análise e interpretação da imagens de sonar de varredura lateral obtidas no rio Paranapanema, com objetivo de prospecção de material de construção: a) padrão de textura rugosa correlacionável com superfícies de fundo rochosas; b) padrão de textura lisa e homogênea característica de superfícies de fundo cobertas por sedimentos. IPT (1990a).

Figura 8.66: Exemplos de imagens do sonar de varredura lateral obtidas em setores acusticamente distintos: a) fundo arenoso homogêneo; b) fundo arenoso homogêneo com ripple marks; c) fundo arenoso com marcas onduladas de grande porte; d) fundo com sedimentos heterogêneos; e) fundo heterogêneo e irregular com seixos; f) porção interna da área com sedimentos arenosos e ripple marks; g) fundo homogêneo, mas com maior refletividade, típico de fundos com sedimentos de maior granulometria - areais grossas e seixos; h) região de transição: areais grossas e cascalhos. Modificado de Brown et al. (2002).

Figura 8.67: Registros obtidos através da sonografia ilustrando distintos padrões texturais de superfícies de fundo: a) textura rugosa representando o fundo rochoso (basalto) do reservatório Itaipu, PR (IPT, 1986a); b) textura lisa e homogênea mostrando detalhes de feições interpretadas como antigas curvas de nível utilizadas nas plantações de algodão da região hoje coberta pelas águas do Reservatório Capivara, SP (IPT, 1992a,b); c) textura mista: na porção central a textura rugosa representa um afloramento de rocha alcalina no canal da Ilha Comprida, SP; a textura lisa e homogênea nas porções adjacentes ao afloramento rochoso é resultado da baixa refletividade dos sedimentos arenosos característicos do canal. (Suguio et al., 1987).

Figura 8.68: Imagens obtidas por meio do SVL ilustrando distintos padrões texturais de superfícies de fundo: a) superfície de fundo com textura lisa e homogênea mostrando canal antigo de rio, Reservatório Capivara, PR/SP (IPT, 1992a,b); b) registro obtido no rio Tietê, SP, mostrando contrastes texturais entre uma superfície lisa e homogênea (sedimentos) e uma superfície rugosa, neste caso correlacionada com superfície gerada a partir de atividades de dragagem do rio (IPT, 1998e); c) texturas lisas e homogêneas, todavia diferenciadas em áreas claras e escuras, sendo as claras correlacionadas à ocorrência de sedimentos finos, as escuras, a sedimentos grossos (areias e cascalhos). A ratificação do padrão textural mostrado neste registro foi embasado também em fotografias submarinas e amostragens de sedimentos de fundos, com as análises sedimentológicas correspondentes (Souza, 1984).

Figura 8.69: Exemplo de classificação automática de uma imagem de sonar onde cores são atribuídas a padrões texturais distintos o que permite a obtenção de mapas detalhados de caracterização de superfícies submersas: a) registro (imagem) original; b) imagem interpretada automaticamente. Geoacoustics (2001).

Figura 8.70: Exemplo de mosaico construído a partir da justaposição lateral de 12 perfis de sonar de varredura lateral obtidos na costa leste da Ilha de Tanegashima (sul do Japão) em área de aprox. de 7x3 km: a) images do sonar justapostas lateralmente compondo um mosaico; b) 
mapa de caracterização do fundo construído com base na interpretação do mosaico e dos resultados das análises sedimentológicas das amostras coletadas. Souza, 1984.

Figura 8.71: Exemplos de utilização da investigação geofísica em escalas distintas: a) distribuição de perfis sísmicos em grande escala - de reconhecimento - em estudo amplo das ilhas do Japão. Neste caso, milhares de quilômetros quadrados foram cobertos por levantamentos sísmicos (Unoue \& Honza, 1982); b) distribuição de perfis sísmicos em estudo de trecho restrito da costa Norte do Japão, no caso, a plataforma continental interna na região de Hachinohe (Tamaki, 1978).

Figura 8.72: Ilustração mostrando uma das formas de rebocamento do sistema fonte-sensor na perfilagem sísmica contínua. Fonte acústica (boomer) e sensores (hidrofones) tracionados lateralmente à embarcação propiciam a obtenção de sinais de melhor qualidade, pois evitamse desta forma os ruídos gerados pelo motor propulsor da embarcação. Modificado de Applied Acoustic Engineering (2005a)....

Figura 8.73: Registro obtido da Perfilagem Sísmica Contínua - PSC, no canal de São Sebastião, litoral norte do Estado de SP, utilizando fonte acústica do tipo boomer. Notar o forte contraste de impedância acústica representado pelo refletor, que evidencia de forma clara e inequívoca a interface embasamento - estratos sedimentares: a) registro original de campo; b) registro interpretado. Modificado de Furtado et al. (2000).

Figura 8.74: Registro analógico obtido da perfilagem sísmica contínua no canal da Ilha Anchieta, SP, com o perfilador modelo Hidrosonde M2A-Huntec utilizando fonte do tipo boomer (5 KHz). Mahiques e Souza (1999).....

Figura 8.75: Princípio do método da eletrorresistividade. A e B representam pontos de injeção artificial no terreno da corrente elétrica (I); $\mathrm{M}$ e $\mathrm{N}$, pontos de leitura do potencial criado $(\Delta \mathrm{V})$, parâmetros estes que permitem calcular a resistividade real ou aparente do material (solo ou rocha) em subsuperfície. Fonte: geól. Regis G. Blanco (IPT).

Figura 8.76: Geometria do arranjo de eletrodos para aquisição de dados no caminhamento elétrico. AB pontos de injeção de corrente; M1N1, M2N2.... pontos de leitura da diferença de potencial gerada. Fonte: geól. Regis G. Blanco (IPT).

Figura 8.77: Ensaio de eletrorresistividade em água: a) ilustração esquemática da geometria do arranjo de eletrodos quando tracionados na superfície da água; b) vista parcial do sistema de aquisição de dados, modelo SuperSting, da AGI (USA), com arranjo de eletrodos de 8 canais e GPS. Modificado de <http://www.agiusa.com> . Acesso: fev/2006...

Figura 8.78: Exemplos de arranjos de eletrodos para levantamentos geoelétricos de áreas submersas. Modificado de Nebrija et al. (1976).

Figura 8.79: Eletrodos utilizados em levantamentos geoelétricos em água fabricados em grafite, não sofrendo, portanto, o efeito da corrosão com a passagem da corrente elétrica. Os cabos são de kevlar e à prova d'água. Fonte: <http://www.agiusa.com>. Acesso: dez/2005.

Figura 8.80: Seção de eletrorresistividade modelada obtida em um lago de água doce. A camada superior com tonalidades predominantemente azuis corresponde à lâmina d'água, que apresenta excelente correlação com os dados batimétricos (linha vermelha hachurada representa a superfície de fundo do lago obtida através da batimetria). AGI - Advanced Geoscience (2002). Disponível em <http://www.agiusa.com. Acesso em fev/2006.

Figura 8.81: Perfis de eletrorresistividade obtidos no rio São Francisco: a seção superior apresenta os dados de campo (pseudo-seção); a seção na porção inferior da figura corresponde ao modelo geoelétrico obtido pela inversão (modelamento) dos dados no processamento. Dados: cortesia da Geo-radar Levantamentos Geofísicos, MG.

Figura 8.82: Exemplos de magnetômetros de utilização na investigação de áreas submersas: a) e b) magnetômetros de pequeno porte utilizados na investigação rasa. Fotos cedidas pelo geól. Cláudio G. Gallea; c) magnetômetro de grande porte utilizado na investigação de bacias sedimentares. Sistema instalado no Navio Oceanográfico Almirante Câmara em 1986. Foto do autor.

Figura 8.83: Magnetometria em áreas submersas: geometria do arranjo sensor-embarcação. Modificado de Mello et al. (1988).....

Figura 8.84: Perfil de magnetometria obtido próximo à praia, no litoral do Rio Grande do Norte mostrando as anomalias geradas pela presença de dutos enterrados no local. Dados cortesia do geól. Claudio G. Gallea (Tethys). 
Figura 8.85: Ilustração mostrando como varia a forma de uma anomalia magnética em função da altura do sensor, neste exemplo variando de 0.2 a 4 metros de altura. Pode-se observar que, à medida em que o sensor se aproxima da superfície, as características magnéticas de cada um dos objetos enterrados influenciam diretamente na forma final da anomalia detectada. À medida em que se distancia, a influência diminui e a curva vai se aplainando e se aproximando da curva representativa do campo gravitacional global. Vogelsang (1995).

Figura 8.86: GPR em operação na Ilha Comprida, litoral sul do ESP, ilustrando algumas das diferentes formas de tracionamento do sistema de antenas sobre a superfície investigada: a) GPR com antena de $50 \mathrm{MHz}$ ( $\mathrm{Tx}=$ antena de transmissão $\mathrm{Rx}=$ antena de recepção) com dados sendo adquiridos passo a passo; b) GPR com antena de $200 \mathrm{MHz}$ com dados sendo adquiridos de forma de rebocamento contínuo. Gandolfo et al., 2001. Fotos do autor.

Figura 8.87: Diagrama ilustrando as diversas posições do par de antenas (Rx e Tx) no procedimento de aquisição de dados com o sistema GPR ao longo de um perfil. Modificado de Davis \& Annan (1989).

Figura 8.88: a) exemplo de perfil obtido com o GPR ilustrando anomalia relacionada com a presença de um duto enterrado à profundidade de $2 \mathrm{~m}$ (Galli \& Souza, 1999; IPT, 1998b); b) perfil obtido com o GPR onde se observa anomalia gerada pela presença de depósito de sais de cloro em subsuperfície (IPT, 1998d).

Figura 8.89: Perfil de GPR com antena de $100 \mathrm{MHz}$ obtido na Ilha de Outeiro, Belém (PA) ilustrando o potencial desta ferramenta no mapeamento geológico básico, neste caso, detectando paleocanias preenchidos por sedimentos arenosos (Sauck, 1998).

Figura 8.90: Perfil de GPR utilizando antena de $50 \mathrm{MHz}$ obtido na Ilha Comprinda, litoral sul do Estado de São Paulo, ilustrando a limitação de penetração do sinal eletromagnético a partir de $12-15 \mathrm{~m}$ de profundidade, devido à existência de meios condutores (água salgada), a despeito da excelente resolução do método até esta profundidade. Gandolfo et al. (2001b).

Figura 8.91: Perfil de GPR obtido com antena de $25 \mathrm{MHz}$ com leituras a cada dois metros, ilustrando a excelente penetração do sinal eletromagnético em ambientes resistivos. As linhas verticais em amarelo referem-se às sondages efetuadas ao longo do perfil, a maioria delas atingindo o topo da Fm. Barreiras. Gandolfo et al. (2001a).

Figura 8.92: Imagem de radar obtida em rio dos EUA (Connecticut), com antema de $100 \mathrm{MHz}$, mostrando vales preenchidos por sedimentos. Placzek \& Haeni, 1994.

Figura 8.93: Perfil de GPR com cerca de 300m de extensão obtido em um lago na Suécia (antena de 200MHz). Neste perfil observam-se claramente a topografia de fundo do lago, bem como refletores subjacentes, sendo possível portanto caracterizar a estratigrafia rasa do lago. Registro cortesia da Mala Geosciense.

Figura 8.94: Seção de GPR obtida na Represa Billings, SP, em estudo de assoreamento de reservatórios (Aquino et al., 1998a).

Figura 8.95: Perfil de GPR obtido no rio Paraná em trecho a jusante da Barragem de Porto Primavera, em projeto de estudo de processos de erosão e assoreamento causados pela instalação da Barragem. Neste perfil observa-se a topografia irregular do fundo do rio, resultado da grande mobilidade dos depósitos arenosos que formam a superfície de fundo na área. Registros cedidos pelo IPT (dados inéditos).

Figura 8.96: Perfil de GPR obtido no rio Taquari, MS, mostrando estruturas sedimentares (ondas de areia) definindo a conformação da superfície de fundo do rio em trecho de intensa dinâmica sedimentar (Souza et al., 2002).

Figura 8.97: Perfil de GPR, obtido no rio Taquari, MS, definindo a conformação irregular da superfície de fundo do rio em trecho de intensa dinâmica sedimentar (Souza et al., 2002)......

Figura 8.98: Levantamento GPR de áreas submersas: a) sistema instalado em um bote inflável, rebocado por outra embarcação, em operação na represa Billings pela equipe IPT/Cetesb/UFBA; b) vista de detalhe da disposição das antenas no interior do bote. Fotos do autor.

Figura 8.99: Catamarã desenvolvido pelo IPT para utilização do GPR em levantamentos de áreas submersas. Sistema em operação no rio Paraná (SP). Foto do autor.

Figura 8.100: Sistema de antenas de GPR submersíveis utilizadas pela empresa americana ArtEngineering LCC. Fotos cedidas por Erik Groenendijk (Art-Engineering LLC, EUA)). 
Figura 8.101: Interpretação de um registro de radar obtido em zona portuária da Filadélfia (EUA) onde se identifica uma camada superior de sedimentos finos e destacam-se três pontos com feições que sugerem objetos/estruturas enterradas. Modificado de ART Engineering (2005).

Figura 8.102: Pefil de GPR obtido com o sistema Ramac X3M com antena de $250 \mathrm{MHz}$ ilustrando claramente a superficie de fundo (topo da camada de sedimentos finos) e uma superfície inferior referente ao topo do embasamento (localmente relacionada com tilitos) além de dois pontos anômalos referentes a obstáculos ou objetos enterrados na fina camada de sedimmentos finos ou a afloramentos rochosos. Modificado de Mala Geoscience (2004)

Figura 8.103: Sistema GPR desenvolvido pela CSO Adviesbureau com apoio do Instituto Rijkswaterstaat (Holanda) para emprego na investigação de áreas submersas rasas: a) embarcação adaptada ao sistema GPR. As hastes de suporte das antenas do GPR, bem como do sistema de posicionamento (GPS) são posicionadas na vertical durante a aquisição de dados; b) e c) vistas, com detalhe, da antena, nas posições posterior e inferior, respectivamente. Fotos: cortesia da Dra. Pauline P. Kruiver (CSO Adviesbureau voor Milieuonderzoek).

Figura 8.104: Registro de GPR (antena de $500 \mathrm{MHz}$ ) de excelente qualidade, obtido no rio Waal, Holanda, mostrando as principais feições geológicas do substrado do rio (topografia de fundo e estratos sedimentares rasos) além da localização de dutos enterrados, objetivo principal do levantamento executado. Registro cedido pela Dra. P.P. Kruiver, da CSO Adviesbureau voor Milieuonderzoek e pelo Instituto Rijkswaterstaat (Holanda).

Figura 9.1: Resolução vertical de um pulso sísmico. Modificado de Cobo et al. (2005).

Figura 9.2: Interferências entre os sinais acústicos que condicionam a identificação das espessuras das camadas sedimentares e dos correspondentes, topo e base. Observa-se nesta figura que a espessura de um estrato será identificada se ela for maior que $1 / 4$ do comprimento de onda do sinal acústico emitido; topo e base das camadas só serão identificados se a espessura do pacote sedimentar for maior que $1 / 2$ do comprimento de onda do sinal acústico emitido. Modificado de Badley (1985).

Figura 9.3: Padrão geral da diretividade de um transdutor de um ecobatímetro. Notar a perda de amplitude do sinal com o aumento da distância da fonte acústica. Modificado de Jones (1999)... 189

Figura 9.4: Padrões de ângulos de abertura dos feixes de finais emitidos por ecobatímetros. À esquerda, ilustra-se um feixe de sinais de ângulo maior, que projeta o sinal acústico sobre grande área na superfície de fundo, tornando pobre a resolução do sistema; à direita, feixe de sinais com ângulo pequeno, o que possibilita maior resolução na informação adquirida, já que menor área da superfície de fundo é amostrada em cada pulso emitido. Modificado de Jones (1999).

Figura 9.5: a) ecobatímetro com feixe de sinais amplo $\left(18 \mathrm{kHz} / 30^{\circ}\right)$ e, à direita, o perfil obtido; b) ecobatímetro com feixe de sinais estreito $\left(30 \mathrm{kHz} / 1,3^{\circ}\right)$ e à direta o perfil obtido. Notar a melhor definição da superfície de fundo no perfil obtido com o ecobatímetro com feixe de sinais estreito. Neste perfil inclusive identifica-se um zona de reflexão (R) na coluna d'água provavelmente relacionada com a zona de atividade hidrotermal. Modificado de Jones (1999)....190

Figura 9.6: Desenho ilustrando a utilização de ecobatímetros em levantamentos de áreas com superfícies de fundo inclinadas. Z1 é a espessura real da coluna d'água no ponto A; Z2 é a espessura da coluna d'água no ponto A medida pelo ecobatímetro; e', a inclinação real da superfície de fundo; e, a inclinação detectada pelo ecobatímetro (sempre menor que a real). Modificado de Jones (1999)

Figura 9.7: Ilustração mostrando o efeito negativo na leitura dos dados batimétricos quando do movimento indevido da embarcação e do transdutor acoplado a ela. Modificado de <http://www.usace.army.mil/inet/usace-docs/eng-manuals/em1110-2-1003/>. Acesso: $\mathrm{jan} / 2006$.

Figura 9.8 - Registro de ecobatímetro EA400A de dupla freqüência (33/210Khz) da KongsbergSinrad obtido de um lago na Áustria: a) perfil obtido com a freqüência de $33 \mathrm{kHz}$ ilustrando a nítida penetração do sinal de menor freqüência no substrato; b) perfil obtido com a freqüência de $210 \mathrm{kHz}$ mostrando a plana superfície de fundo do lago, sem penetrar na coluna de sedimentos. Registro cedido pela Kongsberg-Simrad.

Figura 9.9: Registro de campo obtido com o ecobatímetro de dupla freqüência $(38 / 200 \mathrm{kHz})$ EA400A da Simrad Kongsber: a) perfil obtido com a freqüência de $38 \mathrm{kHz}$ ilustrando a nítida penetração do sinal de menor freqüência na tênue camada de sedimentos finos; b) perfil 
obtido com a freqüência de $200 \mathrm{kHz}$ mostrando a plana superfície de fundo, sem evidências de penetração do sinal na coluna de sedimentos. Registro cedido pela Kongsberg-Simrad.

Figura 9.10: Registro de campo obtido com o ecobatímetro de dupla freqüência $(33 / 210 \mathrm{kHz})$ EA400A da Simrad Kongsberg ilustrando perfis construídos por cada uma das frequiências emitidas pelo sistema. Observaram-se nos registros as diferentes espessuras da coluna d'água identificadas por cada uma das freqüências num mesmo ponto do perfil. Registro cedido pela Kongsberg-Simrad.

Figura 9.11: Comparação, num perfil de ecobatímetro, entre a detecção automática da superfície de fundo (linha escura contínua) e a real superfície de fundo que representa o contato entre a coluna d'água e os sedimentos de fundo. Modificado de Gasperini (2005).

Figura 9.12: Exemplo de utilização conjunta do sonar de varredura lateral (a) e da perfilagem sísmica contínua (b) ilustrando em planta (Sonar) e em perfil (Sísmica) as caracterísiticas correspondentes às feições lineares identificadas no litoral norte do Rio de Janeiro, nas profundidades entre 72 e $109 \mathrm{~m}$, correlacionadas a beachrocks. Dias et al. (1982).

Figura 9.13 : Perfil sísmico obtido no canal de Santos com o sistema Meridata utilizando uma fonte do tipo Pinger de 24kHz. Fonte: cortesia do Prof. Dr. M.M. Mahiques - IO-USP.

Figura 9.14: Perfil ilustrando a excelente e rara penetração de um sistema $3.5 \mathrm{kHz}$, obtido, neste caso, pelo acoplamento de nove transdutores de $3.5 \mathrm{kHz}$ ao casco do navio Hakurei Maru, do Serviço Geológico do Japão, em levantamento do Mar do Japão. Modificado de Nishimura et al. (1984).

Figura 9.15: Registro obtido em 2005 no canal de Santos, SP com perfilador acústico do tipo SBP 3.5 Khz - Geopulse modelo 5430A. Registro Sísmico cortesia da Microars Consultoria de Projetos.

Figura 9.16: Registro obtido no canal de Santos, SP com perfilador acústico do tipo chirp, pertencente ao Instituto Oceanográfico da USP. Observa-se neste figura a nítida interface entre a camada de lama e o substrato do canal, definida pelo sistema acústico utilizado. Registro Sísmico cortesia do Prof. Dr. Michel M. Mahiques - IO-USP.

Figura 9.17: Perfil sísmico executado com a utilização simultânea de três fontes acústicas distintas: a) pinger $(24 \mathrm{kHz})$; b) chirp $(2-8 \mathrm{kHz})$; c) boomer $(0.1-1.5 \mathrm{kHz})$. Observa-se nitidamente nestes perfis o desempenho diferenciado das três fontes acústicas utilizadas, com relação à penetração do sinal nos estratos sedimentares subjacentes. No perfil A obtido por meio do pinger $(24 \mathrm{kHz})$, identifica-se uma anomalia na topografia de fundo que pode ser correlacionada à ocorrência de um corpo rochoso aflorante na superfície de fundo. Características similares podem ser observadas no perfil B obtido pelo chirp $(2-8 \mathrm{kHz})$. Neste perfil observa-se ainda uma camada de sedimentos finos de espessura variável entre $1 \mathrm{e} 4 \mathrm{~m}$. Em nenhum destes dois perfis (A e B), entretanto, é possível observar o contorno do corpo rochoso em subsuperfície. No perfil $\mathrm{C}$ obtido com a utilização de uma fonte acústica do tipo boomer, delineia-se, além das características observadas nos perfis A e B, o contorno do substrato rochoso em subsuperfície, que mergulha até a profundidade de 60 metros. Registros obtido na enseada do Flamengo, litoral norte de São Paulo. Registros cedidos pelo Prof. Dr. Michel M. Mahiques - IO-USP.

Figura 9.18:: Perfil sísmico executado com a utilização simultânea de três fontes acústicas distintas: a) pinger $(24 \mathrm{kHz})$; b) chirp $(2-8 \mathrm{kHz})$ e; c) boomer $(0.1-1.5 \mathrm{kHz})$. Observa-se nitidamente nestes perfis o desempenho diferenciado das três fontes acústicas utilizadas, com relação à penetração do sinal nos estratos sedimentares subjacentes. No perfil A obtido por meio do pinger $(24 \mathrm{kHz})$ e no perfil $\mathbf{B}$ obtido pelo chirp $(2-8 \mathrm{kHz})$ não se evidencia, na superfície, qualquer anomalia na topografia de fundo que pudesse sugerir a existência de corpos rochosos em subsuperfície. No perfil obtido pelo chirp, observa-se, em subsuperfície, a ocorrência de difrações do sinal, fenômeno acústico que sugere a existência de corpos rochosos em subsuperfície, sem todavia permitir qualquer análise quantitativa da ocorrência. No perfil obtido com o chirp, identifica-se ainda uma camada de sedimentos finos de espessura variável entre 1 e $4 \mathrm{~m}$. No perfil $\mathbf{C}$, obtido com a utilização de uma fonte acústica do tipo boomer, é possível delinear-se, além da topografia de fundo, o contorno do substrato rochoso em subsuperfície, que mergulha até a profundidade de 60 metros. Registros obtido na enseada do Flamengo, litoral norte de São Paulo. Registros cedidos pelo Prof. Dr. Michel M. Mahiques IO-USP. 
Figura 10.1: Exemplo de produto obtido da utilização simultânea de ecobatímetro de varredura (Simrad EM 3000) com sistema ecoclassificador do tipo QTC-View. Área proxima à Ilha de Vancouver, Canadá. Fonte: <http://www.questertangent.com>. Acesso: abril/ 2006......

Figura 10.2: Imagem obtida por um sonar de varredura lateral da Marine Sonic $(900 \mathrm{kHz})$, em levantamento executado em área costeira da Nova Zelândia. Destaca-se nesta imagem o nítido contraste entre os dois padrões texturais de fundo identificados: de um lado, sedimentos compostos de areia grossa e fragmentos de conchas; de outro, sedimentos arenosos finos com expressivas marcas onduladas. Ressalta-se, a partir da excelente qualidade desta imagem, a relevante aplicabilidade de sistemas acústicos desta natureza em estudos de processos sedimentares em áreas costeiras. Imagem obtida por Don Wright and Bob Gammisch do Virgínia Institute of Marine Science (VIMS). Disponível em <http://www.marinesonic.com>. Acessso: jan/2006.

Figura 10.3: Desempenho da fonte acústica modelo GeoPulse Pinger $3.5 \mathrm{kHz}$, da Geoacoustics: penetração esperada (em azul) e a variabilidade possível (em vermelho) para a relação penetração do sinal acústico $x$ tipo de fundo. Fonte: <http://www.geocoustics.com>. Acesso: abril/2006

Figura 10.4: Corpos sedimentares arenosos progradacionais de mais de $30 \mathrm{~m}$ de espessura, identificados nos excelentes registros sísmicos obtidos por meio de fonte sísmica do tipo boomer. a) registro original; b) registro interpretado. Modificado de Garcia-Garcia et al. (2005)

Figura 10.5: Refletores sísmicos e estruturas acanaladas, interpretadas como paleocanais, identificados na plataforma continental do Rio Grande do Sul, em perfis sísmicos executados com fonte acústica do tipo sparker : a) registro de campo; b) registro interpretado. Modificado de Abreu \& Calliari (2005).

Figura 10.6: Fotos ilustrando condições operacionais básicas para garantia de controle de qualidade no processo de aquisição de dados: a) sistemas de molas usadas para amortecer cabos de tração de fontes mergulhadas, no exemplo, sonar de varredura lateral em operação na Antártica. Foto do autor; b) equipe de perfilagem sísmica contínua em operação em lago da região de Brotas, SP, de águas tranquilas com geometria do arranjo fonte acústica/sensores embarcação, privilegiando uma boa relação sinal ruído (no caso distanciados de 13 m). Foto: Ricardo S. Xavier.

Figura 10.7: Parâmetros de comparação entre os meios de transportes: hidrovia, ferrovia e rodovia. Fonte: Departamento Hidroviário da Secretaria de Transportes do Governo do Estado de São Paulo.

Figura 10.8: Evolução das cargas transportadas (em toneladas) na Hidrovia Tietê-Paraná entre 1995 e 2004. Fonte Departamento Hidroviário da Secretaria de Transportes do Governo do Estado de São Paulo. 


\section{TABELAS}

Tabela 8-1: Exemplo de conjunto de especificações de fontes acústicas do tipo chirp, fabricados pela empresa americana Edgetec. Modificado de 〈http://www.edgetech.com〉. Acesso: dez/2005.

Tabela 8-2: Exemplo de conjunto de especificações de fontes do tipo chirp com multitransdutores para instalação direta no casco das embarcações, fabricados pela empresa americana Edgetec. Modificado de <http://www.edgetech.com>. Acesso: dez/2005.

Tabela 8-3: Desempenho de quatro fontes acústicas ressonantes de alta resolução $(3.5 ; 14 ; 20$ e 2-16 $\mathrm{kHz}$ ) em testes sistemáticos realizados em projeto de estudos de processos erosivos de instabilidade de pilares de ponte em rio nos EUA. Observa-se nesta tabela a melhor resolução das fontes de maior freqüencia em contrapartida com a melhor penetração das fontes que emitem sinas de frequiências mais baixas, no contexto dos sedimentos fluviais, neste caso, basicamente composto de sedimentos finos (areias siltes e argilas). Placzek \& Haeni, 1994.

Tabela 8-4: Valores de resistividade de materiais comuns na natureza. Fonte: Vogelsang (1995) e Gallas (2000)

Tabela 9-1: Exemplos de resolução vertical teórica obtidos a partir dos espectros de frequiências emitidos pelas fontes acústicas de emprego comum na investigação geofísica rasa, baseado no princípio das interferências entre os sinais refletidos.

Tabela 9-2: Planilha ilustrando simulação comparativa entre leituras de diferença de potencial em levantamentos em água salgada e em água doce, em quatro situações distintas de injeção de corrente. Estão fixos nesta simulação a resistividade da água do mar $(0,2 \mathrm{ohm} . \mathrm{m})$ e da água doce (100 ohm.m) além do tipo de arranjo adotado (dipolo-dipolo).

Tabela 10-1: Composição de conjuntos de equipamentos geofísicos com desempenho mínimo, bom e excelente segundo os objetivos da investigação $x$ custo correspondente (valores de equipamentos geofísicos resultantes de consulta realizada aos principais fabricantes de equipamentos geofísicos no mundo).

Tabela 10-2: Resultados de consulta nacional sobre o potencial (infra-estrutura geofísica) das entidades brasileiras (universidades, institutos de pesquisa e empresas privadas) para execução de levantamentos geofísicos em áreas submersas rasas.

\section{ANEXO}

ANEXO A: Aplicabilidade dos métodos geofísicos na investigação de áreas 


\section{LISTA DE SÍMBOLOS / UNIDADES}

ohm (Georg Simon Ohm, 1787-1854) físico alemão. Unidade de medida de resistência elétrica, no Sistema Internacional, que é a resistência elétrica de um elemento passivo dum circuito no qual circula uma corrente elétrica invariável de um ampère quando existe uma diferença de potencial constante de um volt entre seus terminais. Ohm.m = resistência elétrica $\mathrm{x}$ distância $=$ resistividade elétrica.

$\gamma \quad$ gama. Unidade de medida de intensidade de campo magnético equivalente a 1 nanotesla, ou 10 microgaus, ou seja: 1 gama $(\gamma)=10-3$ gauss $(\mathrm{Gs})=10-9$ tesla (T).

$\mathrm{Hz}$ hertz. Unidade de medida de freqüência de um fenômeno periódico, igual à freqüência de um evento por segundo; um ciclo por segundo [símb.: $\mathrm{Hz}$ ]. $\mathrm{kHz}$ $=$ kilohertz $=1000 \mathrm{~Hz}=$ mil hertz

J Joule. Unidade para medida de energia, trabalho, quantidade de energia térmica. Como unidade de medida de trabalho mecânico é o trabalho realizado por uma força constante de 1 newton, que desloca seu ponto de aplicação de 1 metro na sua direção.

kn nó. Unidade de velocidade, igual a uma milha náutica por hora (milha náutica = unidade de distância usada em navegação pela Comunidade Britânica, igual ao comprimento de um minuto de meridiano terrestre, equivalente a 6.080 pés ou aproximadamente $1.853,18$ metros. Definição adotada pela International Hydrographic Conference em 1929).

$\mathrm{m}$ metro. Unidade fundamental de medida de comprimento no Sistema Internacional, igual ao comprimento do trajeto percorrido pela luz no vácuo durante um intervalo de tempo de 1/299 792458 de segundo.

V Volt. No Sistema Internacional, unidade de medida de diferença de potencial elétrico, igual à diferença de potencial existente entre duas seções transversais de um condutor percorrido por uma corrente elétrica variável de um ampère, quando a potência dissipada entre as duas seções é igual a um watt.

$\mathrm{v}$ (c) o símbolo "v" corresponde à notação geral para velocidade enquanto o símbolo "c" é usado para velocidade de propagação de ondas eletromagnéticas em um meio qualquer ("c $\mathrm{c}_{\mathrm{o}}$ ", quando o meio for o vácuo).

W watt (James Watt, 1736-1819, físico escocês). No Sistema Internacional, unidade de medida de potência igual à potência duma fonte capaz de fornecer, contínua e uniformemente, um joule por segundo. $\mathrm{kW}=$ kilowatts $=1000 \mathrm{~W}$ $=$ mil watts.

S siemens (Wilhelm Siemens, 1823-1883; Werner von Siemens, 1816-1892, inventores alemães). Unidade de condutância elétrica equivalente ao inverso do ohm.

dB decibel (Alexandre Grahan Bell, 1847-1922, inventor norte americano). Unidade relativa de medida de energia ondulatória. Unidade adimensional para exprimir a razão de duas potências; igual a 1/10 do bel, correspondendo, pois, a 10 vezes o logaritmo decimal da razão das potências.

L comprimento (length)

W largura (width)

$\mathrm{H} \quad$ altura (height)

ms milsegundo

ns nanosegundo

s segundo

$\mathrm{kg} \quad$ quilograma 


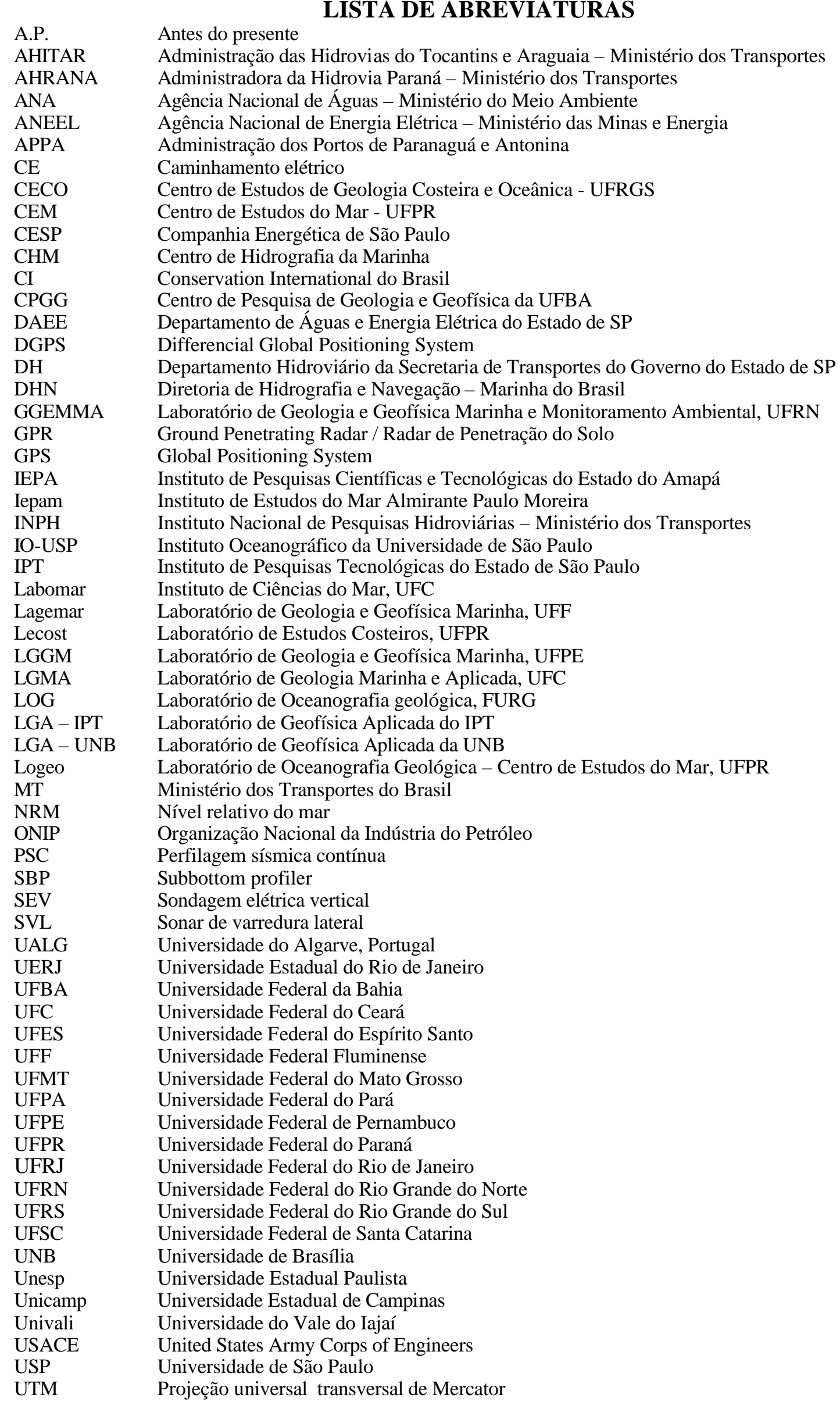




\section{AGRADECIMENTOS}

Expresso meus agradecimentos às pessoas e instituições que contribuíram para os resultados deste estudo.

Ao Prof. Dr. Moysés Gonsalez Tessler, por ter aceitado o desafio de me orientar neste tema, pelas fundamentais e oportunas discussões e sugestões ocorridas no desenvolvimento deste estudo, pelas incansáveis revisões do texto final, e especialmente pelo carinho, paciência e compreensão demonstrados em todos os momentos, que culminaram em me proporcionar oportunidade inestimável de aprendizado e crescimento profissional.

Ao Prof. Dr. Michel Michaelovitch de Mahiques, pelo constante estímulo, pelas várias oportunidades de participação em cruzeiros geofísicos do IO-USP (em especial dos levantamentos geofísicos na Antártica), pelas discussões sobre aplicabilidade de métodos geofísicos e pela cortesia em ceder registros sísmicos que ilustram muitos dos conceitos e exemplos de aplicação apresentados neste estudo.

À Banca de Qualificação, composta pelos Prof. Dr. Moysés G. Tessler, Prof. Dr. Michel M. Mahiques (IO-USP) e Prof. Dr. Renato Luiz Prado (IAG-USP) que apresentaram valiosas e essenciais sugestões ao texto do Exame de Qualificação.

Ao Instituto Oceanográfico da Universidade de São Paulo - IO-USP e ao Instituto de Pesquisas Tecnológicas do Estado de São Paulo - IPT, pelo apoio.

Pela pronta resposta à consulta realizada sobre a capacitação nacional (equipamentos) para execução de levantamentos geofísicos em águas rasas e/ou pelas proveitosas discussões sobre aplicabilidade dos métodos geofísicos, aos professores doutores Valdir V. Manso (UFPE, PE), Helenice Vital (UFRN, RN), Gilberto T. de Macedo Dias, Alberto Figueiredo Jr., Cleverson G. Silva e Adalberto da Silva (UFF, RJ), Susana B. Vizon (UFRJ, RJ), Jose M. Landim Dominguez (UFBA, BA), José G.N. de Abreu (Univali, SC), Augustinho Rigoti (UFPR, PR), Elírio E. Toldo Jr. (UFRS, RS), Valdenir V. Furtado (USP, SP), J. M. Alveirinho Dias (UALG, Portugal), Odete F.M. Silveira (IEPA, AP), Roberto Vizeu e Maamar El-Robrini (UFPA, PA), Shozo Shiraiwa (UFMT, MT), Paulo B. Guimarães (ONIP, DF), Luiz Parente (UFC, CE), Marcelo Sperle Dias (UERJ, RJ), Augusto C. B. Pires e Roberto A.V. Morais (UNB, DF), Jarbas Bonetti (UFSC, SC), João Carlos Dourado (Unesp, SP), Álvaro P. Crosta (Unicamp, SP), Lucia Artusi (IEAPM, RJ) e à Comandante Izabel King Jeck (CHM, RJ), aos geólogos, Marcelo Blunk (Fulgro, RJ), Roberto Bianco (INPH, RJ) e Cláudio G. Gallea (Tethys, RJ) e ao oceanógrafo Diogo de O. Marques (Geoambient).

Aos engenheiros das empresas fabricantes de equipamentos geofísicos e aos pesquisadores de instituições de outros países, pelas profícuas discussões sobre as aplicabilidades e limitações destes equipamentos/métodos e/ou pela gentileza de cederem fotos e registros geofísicos, alguns dos quais ilustram discussões desenvolvidas neste estudo: Kim Ola e Tom Ola, da Meridata (Finlândia); John Spruance, Rob Morris, Simon Reeves e Patrício Grimaud, da EdgeTech (EUA/BR); Allen Hundley, da DPS Technology (USA); Russel Philibert, da Ocean Data/SyQwest (EUA); Gavin Willoughby, Nadine Pearce e Adam Darling, da Applied Acoustics Engineering (UK); Erik Groenendijk, da ART Engineering LLC (EUA), Nadine Mueller, da Innomar Technologie (Alemanha), Alasdair Murrie, da SonaVision (UK), Chris Elliotti, da Quester Tangent (Canadá), Dr. Gary Kozac e Juarez H. Pessoa, da Klein (EUA/BR); Prof. Dr. Jonathan S. Stark, do Australian Antartic Division; e Dra. Pauline P. 
Kruiver, da CSO Adviesbureau voor Milieuonderzoek (Holanda) e ao Rijkswaterstaat Directie Oost Nederland (Holanda).

Ao Prof. Dr. Evert Slob da Universidade de Delft (Holanda) pela oportunidade das breves, mas muito proveitosas conversas sobre aplicabilidade de GPR na investigação de áreas submersas, e pela indicação de referências bibliográficas específicas sobre este tema.

Aos geólogos Roberto Bianco (INPH, RJ) e Cláudio G. Gallea (Tethys, RJ), dois entre os maiores entendedores das variáveis relacionadas com a aplicação da geofísica de alta resolução na investigação de áreas submersas rasas no Brasil, pelas interessantes discussões sobre o tema desta tese, ocorridas em várias oportunidades nos últimos anos, bem como pelos registros geofísicos e fotos cedidas, que ilustram, nesta tese, alguns conceitos e/ou aplicações dos métodos geofísicos.

Aos geólogos Carlos Augusto Esteves e Dr. Yasumasa Kinoshita, por me introduzirem, nos idos anos 80, ao mundo "maravilhoso" da investigação geofísica de alta resolução de áreas submersas rasas; ao Prof. Kinoshita, pelas imagens que ilustram alguns temas abordados nesta tese e pela gentileza do envio de cópias de relatórios com excelentes resultados de levantamentos sísmicos executados no delta do rio Chao Phraya, no golfo da Tailândia.

Aos colegas da pós-graduação do IO-USP, Dra. Andréa Lima, Msc. Fabíola M. Antoneli, Dr. Roberto L. Barcellos, Dr. Luis A. Conti e Dra. Cristina C. Martins pelo companheirismo e incentivo. À Dra. Cristina, agradeço ainda pela gentileza de terminar sua tese meia hora antes do término da minha, conforme combinado!

Aos companheiros do IO-USP, Marcelo Rodrigues, Edílson de O. Faria e Clodoaldo V. Tolentino, pela amizade, incentivo e pelas várias oportunidades de participação em levantamentos geofísicos, em especial, pelo inesquecível levantamento da Enseada Martel, na Antártica, em 2002, com o sonar de varredura lateral.

Ao Dr. Newton de Oliveira Carvalho, pelas profícuas discussões sobre assoreamento de reservatórios e pelas oportunidades de abordagem sobre a relevância da geofísica no estudo do assoreamento de reservatórios.

Ao Tecnólogo Msc. Gerson Salviano de Almeida, pelas oportunidades criadas nos últimos anos no contexto da ratificação da importância dos métodos geofísicos no estudo do assoreamento de reservatórios.

Ao Engenheiro Naval Dr. Carlos Daher Padovezi, pelas profícuas discussões sobre as hidrovias brasileiras.

Ao geofísico Otávio C.B. Gandolfo, pela especial contribuição nas discussões sobre a aplicabilidade do GPR e dos métodos geoelétricos na investigação de áreas submersas e pela revisão "geofísica" do texto desta tese.

Ao Prof. Dr. Jandyr Travassos, do Observatório Nacional (ON), pelas várias discussões ao longo dos últimos anos sobre a aplicabilidade do GPR na investigação de áreas submersas.

Às empresas e órgão públicos, Geo-radar, Microars, Tethys, Engevix, Ambienge, Alta Resolução, DTA, CNEC, CESP, Eletronorte, Eletrosul, CHESF, Ahrana, Sabesp, DAEE Secretaria do Meio Ambiente do Estado de SP, Prefeitura Municipal de Santo André e Diretoria de Hidrovias da Secretaria dos Transportes do Estado de SP e às ONG's, Conservation International e Instituto Ecoplan, pelas oportunidades de trabalho conjunto e/ou pela gentileza em ceder dos dados de levantamentos geofísicos, utilizados nesta tese para ilustrar alguns conceitos ou aplicações dos métodos geofísicos. 
À empresa Art Engineering LLC, Tampa, Flórida, EUA, pela cortesia das fotografias e dos registros do sistema GPR-AquaScan e pela permissão de consulta ao relatório interno PNBC Reserve Basin Aquascan-GPR Survey, sobre levantamento GPR em áreas submersas rasas.

Aos colegas do Laboratório de Geofísica Aplicada do IPT, Rubens P Cordeiro, Vicente L. Galli, Regis G. Blanco, Carlos A. Birelli e Otávio C.B. Gandolfo, pelo apoio e principalmente pelo compartilhamento da responsabilidade pelo Laboratório de Geofísica Aplicada do IPT no período.

Aos geólogos, Dr. Wilson S. Iyomasa, Msc. Antonio Marrano, Dr. Omar Y. Bitar, Dr. José Luiz Albuquerque e Dr. Eduardo S. Macedo, pelo incentivo, mas também por tornarem possível a ocupação de parte da carga horária profissional com atividades relacionadas com a elaboração desta tese.

Ao oceanógrafo (quase) Fernando S. Paolo, pela gentileza de ceder excelentes registros digitais de sonar de varredura lateral e do chirp obtidos em 2005 na região de Cananéia, SP.

Aos arqueólogos Dr. Gilson Rambelli, Paulo Fernando Bava de Camargo e Leandro Duran, pelos períodos de trabalho conjunto, pelas discussões sobre arqueologia submarina e/ou pelas indicações de bibliografias sobre o tema.

Aos Engenheiros Antonio Gotti e José Figueiredo, da Diretoria de Hidrovias da Secretaria de Transportes do Estado de São Paulo, pelas informações atualizadas sobre o sistema de hidrovias do Estado de São Paulo.

Aos colegas Aroldo R. da Silva, Ricardo S. Xavier, Mauro M. Ferreira, Luis Celso C. da Silva, Aluízio de S. Frota, Maria Lucia F. Gonçalves, Valter D. da Silva e João F. Martini, pela contribuição de várias formas e em várias oportunidades no período de desenvolvimento deste trabalho. Ao Aroldo, também pela especial contribuição na edição e impressão da planilha do Anexo A.

Ao Dr. Antonio Manoel dos Santos Oliveira, pela energia compartilhada quando das discussões filosóficas sobre a ciência e o papel do homem, e da geofísica, na lapidação deste planeta.

À Marlene Santana e à Paula Kaori Yamamura Ielo, pela árdua tarefa de revisão deste texto e das referências bibliográficas, respectivamente.

Aos colegas Marsis Cabral Jr. e Genis G. Pereira Jr. pelo especial apoio ao final desta jornada, tornando viável a impressão desta tese em alta qualidade.

Pelo incentivo, em especial, de alguns amigos: Affonso Novello, Paulo Brito, Rosilda Mendes, Sergio Robles, Antônio Marrano e Ivan Mello.

À Equipe Catraca, pelos momentos de descontração ao pedal, que em muito contribuíram para tornar menos estressante a finalização desta tese.

À minha mulher, Ligia Ferrari Torella di Romagnano, pelo diuturno incentivo, pela cuidadosa e meticulosa revisão final do texto, e principalmente pela paciência, carinho, atenção e dedicação com que administrou nossa relação nesse período. 


\section{RESUMO}

Os métodos geofísicos constituem um conjunto de várias ferramentas de investigação, com características específicas e com aplicação, em especial, no estudo de áreas submersas, tendo em vista a inacessibilidade as estes ambientes pelos métodos convencionais. Entretanto, sua aplicação nem sempre traz os resultados esperados e assim, o objetivo principal deste estudo é discutir e avaliar a aplicabilidade dos métodos geofísicos, com ênfase nos métodos sísmicos, em estudos de áreas submersas rasas: plataforma continental interna, áreas costeiras, rios, lagos e reservatórios. O estabelecimento de critérios que auxiliem a escolha do método geofísico mais adequado para a melhor solução ao problema geológico ou geotécnico colocado, visa, entre outros aspectos, contribuir para a mitigação dos problemas, principalmente ambientais, causados pela atividade antrópica concentrada nestes ambientes e ampliar o conhecimento geológico básico, propiciando deste modo intervenções sustentadas nestes complexos ambientes. Este estudo tem como base, ampla consulta bibliográfica e diversos projetos desenvolvidos pelo Instituto de Pesquisas Tecnológicas do Estado de São Paulo - IPT e pelo Instituto Oceanográfico da USP - IOUSP, além de projetos em parceria com empresas privadas nacionais e outros institutos de pesquisa que atuam nesta área do conhecimento. $\mathrm{O}$ foco do estudo em águas rasas é motivado pela ausência de dados sistemáticos e pela decorrente demanda de conhecimento geológico e geotécnico destas áreas, em conseqüência da concentração, nestes setores, das principais atividades econômicas da sociedade nos dias atuais: projetos de construção ou redimensionamento de portos, instalação de molhes, dutos, marinas, pontes, túneis, atividades pesqueiras, regeneração de praias, prospecção mineral, hidrovias, operações de dragagens, instalação de reservatórios para armazenamento de água, ou para contenção de cheias, assoreamento de reservatórios. Em qualquer destes temas o conhecimento geológico básico da superfície de fundo e do subfundo das áreas submersas é essencial para garantir o sucesso do empreendimento. Deste ponto de vista, os métodos geofísicos, notadamente os sísmicos, constituem instrumentos de investigação que contribuem de maneira efetiva para o fomento de novas informações, além de constituírem o único conjunto de instrumentos capaz de rápida e objetivamente oferecer um volume de dados que torne viável o melhor entendimento geológico da área de estudo. O produto final deste estudo contempla ainda uma discussão sobre a viabilidade da aplicação dos métodos geofísicos recomendados, tendo como base ampla consulta realizada em 2005/2006, sobre a disponibilidade de equipamentos geofísicos nas instituições de pesquisa e empresas privadas nacionais.

Palavras-chave: oceanografia geológica; estratigrafia rasa; investigação de áreas submersas rasas; geofísica aplicada; geofísica rasa; sísmica; sonar de varredura lateral; perfilagem sísmica contínua; batimetria; fontes acústicas. 


\begin{abstract}
Geophysical methods consist of a series of investigation tools with specific features that are critical to the study of water-covered areas, since these environments cannot be reached with conventional methods. However, sometimes these applications fail to provide the expected results. The objective of this study is to discuss and assess the applicability of geophysical methods by focusing on seismic methods in studies conducted in shallow water-covered areas: inner continental shelves, coastal areas, rivers, lakes and reservoirs. Criteria to help to select the most appropriate geophysical method to solve geological or geotechnical issues must be established to minimize problems, particularly environmental problems caused by concentrated anthropic activity, and to expand basic geological knowledge to allow for sustained interventions in these complex environments. This study is based on extensive bibliographic research and on several projects developed by IPT (Institute for Technological Research of São Paulo State) and by IOUSP (Oceanography Institute of the University of São Paulo), in addition to partnerships with private companies and other institutes in Brazil that address this field of knowledge. The focus on shallow waters was driven by the lack of systematic data and the demand for geological and geotechnical knowledge in these areas, due to the concentration, in these sectors, of the main economic activities of our current society: projects to build or reassess port dimensions, installation of moles, ducts, marinas, bridges, tunnels, fishing activities, beach regeneration, mineral prospecting, waterways, dredging, installation of reservoirs for water storage or flood containment, and reservoir silting. In any of these topics, basic geological knowledge of the bottom and subbottom of water-covered areas is essential to ensure the venture's success. Considering this, geophysical methods, particularly seismic ones, are investigation tools that effectively contribute to generate new information, and are the only set of tools available to quickly and objectively provide enough data to improve the geological understanding of the area under investigation. The result of this study includes a discussion on the feasibility of the methodologies recommended, based on an extensive survey conducted in 2005/2006 on the availability of geophysical equipment in research institutes and private companies in Brazil.
\end{abstract}

Keywords: geological oceanography; shallow stratigraphy; shallow investigation; applied geophysics; shallow seismic surveys; side scan sonar; bathymetry; continuous seismic profiling; acoustic sources; sedimentary structures. 


\section{INTRODUÇÃO}

A caracterização das superfícies e subsuperfícies rasas das áreas submersas (rios, reservatórios, lagos, áreas costeiras e plataforma continental interna) é extremamente importante, pois contribui tecnicamente para o planejamento das atividades humanas, cada vez mais intensas e concentradas nestes complexos e sensíveis ambientes, que contêm muito dos recursos naturais demandados pelo desenvolvimento econômico da sociedade moderna. Algumas destas atividades podem ser destacadas: o estabelecimento de obras civis (barragens, túneis, pontes, portos), de plataformas exploratórias, a instalação de cabos e dutos, de hidrovias, a prospecção de recursos minerais (petróleo, minerais, material de construção), a exploração de recursos pesqueiros e a caracterização de áreas favoráveis à instalação de depósitos de resíduos, entre outras. Oliveira \& Brito (1998) discutem detalhadamente aspectos geológicos e geotécnicos relacionados com vários tipos de projetos desenvolvidos em ambientes submersos. A caracterização da cobertura sedimentar nestes ambientes auxilia também estudos sobre a origem dos sedimentos que a constituem (Santos \& Dominguez, 2005).

\section{1 Áreas Costeiras e Plataforma Continental}

As áreas costeiras constituem ambientes altamente complexos, pois representam fisicamente uma interface tripla: atmosfera, continente e oceano. Ventos, ondas, marés e correntes são alguns dos agentes da natureza que atuam nestes ambientes promovendo transformações em escalas de tempo das mais variadas, até mesmo durante o próprio período de observação (do levantamento). Investigar este ambiente não é simplesmente transferir de forma direta os princípios dos métodos de investigação empregados nas áreas emersas, tampouco nas áreas submersas profundas. A possibilidade de alterações do equilíbrio dinâmico que reina nestes ambientes, em períodos de horas, dias ou semanas, exige adaptações nos métodos de investigação convencionais, com a finalidade de se caracterizar devidamente estes ambientes geológicos (USACE, 2004).

A erosão costeira, como processo natural, é um fenômeno comum e previsível num contexto de evolução dos sistemas costeiros (Bastos \& Silva, 1996). Variações do nível do mar, instabilidades tectônicas, subsidência ou soerguimento isostático e mudanças climáticas são alguns dos fenômenos naturais responsáveis por este processo (Souza \& Suguio, 1996). Tomazelli et al. (1996) atribuem exclusivamente a estes 
fatores o caráter generalizado da erosão costeira do estado do Rio Grande do Sul, já que constataram sua ocorrência em locais não urbanizados e portanto afastados da influência humana direta, não tendo relação com eventuais desequilíbrios localizados do balanço sedimentar. Mendes (1996) também atribui causas exclusivamente naturais para os processos erosivos que atuam na costa do Amapá e que causam efeitos preocupantes, uma vez que destroem manguezais, certamente de importância vital à dinâmica costeira da região.

Por outro lado, inúmeros são os exemplos na literatura onde se constatam que, aos processos erosivos naturais somam-se comumente aqueles de origem antrópica.

O processo de erosão costeira torna-se uma ameaça ao homem e, em alguns casos, um desastre natural, a partir da interferência ou da ocupação inadequada das faixas costeiras. Tal fato leva geralmente as alterações morfológicas na linha de costa com graves consequiências para a sociedade.

A diminuição de aporte sedimentar às faixas costeiras, como conseqüência dos desvios de curso de rios, construção de barragens e dragagens, constitui um dos inúmeros exemplos de ação do homem que traz drásticas conseqüências ao meio ambiente (Bastos \& Silva, 1996).

A remobilização indevida de areias de praias, não raramente ilegais, constitui também outra forma de interferência do homem nos sistemas costeiros com impacto ambientais negativos à linha de costa (Cazzoli \& Amarante, 1996).

O interesse na investigação de áreas costeiras e da plataforma continental interna ocorre devido à concentração do crescimento populacional, da urbanização e das atividades industriais, turismo e lazer, nas regiões litorâneas. Tal fato contribui diretamente para transformações da paisagem costeira e, portanto, da linha de costa, que se tornaram preocupação permanente, não somente da comunidade, das autoridades públicas, mas também dos inúmeros interesses econômicos instalados neste setor, relacionados com projetos de condomínios, marinas, dutos submarinos, emissários, cabos, portos, plataformas exploratórias, túneis, pontes, ilhas artificiais, áreas para disposição de resíduos etc.

Consequiência imediata destes processos de ocupação é o aumento expressivo de dejetos de toda sorte lançados ao mar, segundo técnicas nem sempre criteriosas, criando obstáculos à circulação oceânica e alterando sensivelmente os regimes de 
deposição e erosão de uma determinada região. Trainini (1994) e Mansor (1994) apresentam bons exemplos de diagnóstico ambiental de área costeira, no caso, litoral norte do Rio Grande do Sul, onde uma série de problemas (manejo impróprio de terrenos, disposição de lixo, poluição de águas, assoreamento de lagos, mineração, extração de madeira, entre outros) oriundos do aumento da demanda por materiais e serviços diversos (material de construção, obras de infra-estrutura etc.), conseqüência do crescente desenvolvimento de núcleos urbanos naquela região, imprimem drásticas transformações na paisagem, colocando em risco todo aquele setor costeiro.

Dantas et al. (1996) discutem também as grandes alterações em desenvolvimento no ambiente costeiro no setor oriental do estado do Rio Grande do Norte como conseqüência do cenário previsto de aumento da ocupação das áreas costeiras em prol do turismo e lazer. A construção de estradas na orla costeira, o estabelecimento de planos estaduais de incentivo à construção de grandes hotéis, centros de negócios e de grandes condomínios de veraneio, nem sempre obedecendo aos limites naturais impostos pelas características geológicas do meio físico, são alguns dos elementos que acabam por exacerbar os problemas naturais de erosão que afetam aquela região. Claudino-Sales \& Maia (2002) também ressaltam os efeitos negativos e o conseqüente impacto ambiental desta política desenvolvimentista estabelecida pelos governos federal e estadual para o nordeste do Brasil que, com as justificativas das mais diversas, implantam mega-projetos freqüentemente sem a realização de estudos básicos.

Outro aspecto natural da linha de costa que é profundamente alterado, como conseqüência dos processos de urbanização e industrialização, são as dunas, que, localizadas à retaguarda, constituem proteções naturais, como dissipadores da energia das ondas, além também de servirem de depósitos de areia, capazes de fornecer material de reposição para as praias. Quaisquer destes casos citados constituem estimulantes e, em muitos casos, agentes forçantes para a instalação de interferências, visando à contenção, à proteção ou ao saneamento costeiro, já que, como resultado das ações antrópicas anteriores, o desequilíbrio dos processos dinâmicos costeiros foi instalado.

Como conseqüência do processo de avanço de ocupação da sociedade, inexoravelmente em direção do mar (áreas costeiras e plataforma continental interna, principalmente), obras de contenção ou proteção tornam-se indispensáveis. Muros, molhes, quebra-mares, guia-correntes, regeneração de praias erodidas, emissários 
submarinos são alguns exemplos de intervenções na tentativa de recuperação do equilíbrio e, portanto, da proteção desejada.

Em qualquer destas intervenções, com ou sem obras de engenharia, haverá sempre necessidade da realização de um estudo oceanográfico e geológico abrangente acerca dos processos atuantes.

Uma solução para determinada interferência em uma zona costeira não é facilmente encontrada, tendo em vista que os processos atuantes neste setor não são lineares e apresentam grande variabilidade no espaço e no tempo. Não raramente, vultosos investimentos em obras de engenharia se fazem prementes para tornar-se viável a ocupação destes setores, ou mesmo a manutenção da ocupação já efetivada sem os essenciais estudos prévios. São comuns, na literatura nacional e internacional, modelos de projetos de estruturas de proteção suportadas por estudos pouco abrangentes, tendo resultados catastróficos, no próprio local focado ou nas áreas contíguas (Trainini, 1994; Mansor, 1994; Morais et al.,1996; Castilhos \& Gré, 1996; Tessler \& Mahiques, 1996; Pereira et al. 1996; Lopes et al., 1996; Neumann et al., 1996; Lima et al., 2002; Maia et al., 2002 e Abreu et al., 2005).

Um item relevante a se destacar na ocupação de áreas costeiras são os portos. Os primeiros no Brasil foram construídos em áreas abrigadas e com boas condições de acesso (ex. portos de Santos, SP e do Rio de Janeiro, RJ). Naquele momento, estas obras, relativamente precárias, davam conta das necessidades sem causar grandes problemas, ou sem conseqüências danosas evidentes às áreas circunvizinhas. Todavia, com a intensificação de seu uso, resultado principalmente do incremento do comércio exterior, novas carências foram surgindo. As obras, no princípio modestas, foram completamente transformadas, ou estão em transformação até hoje, como é o caso de vários importantes portos do Brasil, como por exemplo, os portos de Santos, SP, de Paranaguá, PR e de Fortaleza, CE.

Navios de maior porte exigem aprofundamento dos canais de navegação, com a conseqüente necessidade de remoção de sedimentos de fundo, freqüentemente constituídos de elementos ambientalmente comprometidos (p.ex. metais pesados). O aumento das áreas de manobras e das áreas de armazéns é também alteração oriunda destas transformações. 


\section{2 ÁREAS SUBMERSAS INTERIORES}

No caso das áreas submersas interiores, como rios, lagos naturais ou artificiais (reservatórios ou represas), vários são os aspectos que despertam o interesse da sociedade nos dias atuais, contudo, enfoque especial tem sido dado à questão da água e da energia (Klessig, 2001).

A questão energética tem enorme relevância, principalmente no Brasil, já que grande parte da energia gerada e consumida tem origem hídrica.

A água, por outro lado, tem papel não menos fundamental, já que são muitas as limitações colocadas por diversos autores com relação à sua disponibilidade como bem mineral, com perspectivas bastante preocupantes no que tange ao futuro próximo.

Ambos os tópicos acima conduzem à necessidade premente de maior conhecimento dos cursos d'água e dos reservatórios, quanto ao potencial energético e armazenador de água, bem como dos processos sedimentares atuantes que, em última instância, serão os responsáveis pelo controle da vida útil do empreendimento.

\subsection{A GEOFíSICA NA INVESTIGAÇÃo DE ÁREAS SUBMERSAS}

O uso de métodos geofísicos na investigação geológica e geotécnica, de maneira geral, tanto em terra quanto em água, tem aumentado muito nas últimas duas décadas. Engenheiros, geólogos, oceanógrafos, geógrafos, hidrólogos são alguns dos profissionais que, ao implementarem estudos em terrenos submersos para fins acadêmicos (estudos de ambientes geológicos) ou para aplicação imediata do conhecimento adquirido (construção de portos, condomínios, marinas, hidrovias, pesquisa mineral etc.), têm requerido, para a caracterização devida e segura da área, mais informações de subsuperfície que aquelas geradas pelos métodos convencionais de investigação, que incluem, sondagens, testemunhagens ou amostragens, que possuem baixa representatividade em área, pela própria natureza dos dados coletados (de origem pontual).

São muitas as razões que conduzem à necessidade de obtenção de dados adicionais sobre as áreas cobertas por água: a) em estudos geológicos básicos, destacase a necessidade de se extrapolar, para as áreas submersas, o conhecimento geológico acumulado nas áreas continentais; b) na pesquisa mineral, a própria necessidade de busca de recursos adicionais para suprir as carências da sociedade, já que muitos dos 
depósitos continentais encontram-se em fase de esgotamento; c) a necessidade de estudar rios e reservatórios do ponto de vista da navegação, já que muitos desses se constituem hoje em importantes rotas de transporte de cargas, e, do ponto de vista da água potável, já que grande parte da água que se bebe origina-se de rios e reservatórios; d) a necessidade de estudar os ambientes submersos para dar suporte a projetos de engenharia (dutos e cabos submersos, pontes, barragens, túneis e plataformas exploratórias etc.); e) eventuais interesses arqueológicos.

Em todos estes aspectos, as observações geofísicas têm muito a contribuir, já que constituem um conjunto de ensaios que possibilitam visão mais ampla e contínua da subsuperfície investigada. Além disso, trata-se de ensaios não-destrutivos ou nãoinvasivos, pois as informações são obtidas a partir da superfície, sem a necessidade da penetração física no meio investigado, propriedade, aliás, que tem relevante significância, quando se trata da investigação de terrenos onde a penetração através de sondagens pode comprometer de alguma forma a área estudada (áreas urbanas) ou a operação em si, quando se trata das complexas operações de sondagem em áreas submersas.

São vários os exemplos na literatura que ilustram as diversas vantagens de utilização de métodos geofísicos na investigação de áreas submersas. Tóth et al. (1997) apresentam uma série de modelos de aplicação da sísmica nos temas acima referidos, ratificando, ao final, a excelente relação custo-benefício quando da aplicação de métodos sísmicos na investigação de áreas submersas.

A possibilidade de visualização contínua, em duas ou três dimensões, das superfícies e subsuperfícies submersas por meio de ensaios geofísicos permite uma análise ampla de uma área de estudo, o que seria praticamente impossível, se reunidos apenas dados pontuais obtidos pelos métodos convencionais de investigação, mesmo que estes fossem aplicados em grids com nós muito próximos, o que comumente é inviável, ante principalmente os custos operacionais envolvidos.

A investigação geológica desenvolvida na superfície terrestre é relativamente simples, pelo menos operacionalmente, quando comparada àquela desenvolvida em áreas submersas.

Nas áreas emersas, muitas das características geológicas ou geotécnicas de uma determinada área podem ser determinadas a partir do emprego de métodos diretos de investigação. Nestas áreas, estas observações podem ser executadas pela utilização das 
ferramentas observacionais convencionais (fotografia aérea, imagens de satélite etc.), com uma visita ao terreno, objeto da investigação, para análise da paisagem geológica propriamente dita, com a observação de afloramentos naturais e a realização de medidas de diversos parâmetros, tais como direção e mergulho de feições estruturais, que, ao final, fornecem subsídios para a devida caracterização da área investigada.

Quando dos estudos de terrenos emersos, o exame da área de interesse, a partir de fotografias aéreas e imagens de satélites, hoje com alto poder de resolução, constitui poderosa ferramenta de análise. Informações de subsuperfície se fazem também indispensáveis para o estabelecimento de um modelo geológico-geotécnico da área investigada, e para esta finalidade, são coletadas amostras de superfície e de subsuperfície, por meio de sondagens, testemunhagens ou amostragens. Muito comumente, ensaios geofísicos são também realizados na superfície dos terrenos com vistas à obtenção de dados sobre a variabilidade de algumas propriedades físicas do meio, tais como velocidade de propagação do som e resistividade elétrica, que, entre outras, constituem parâmetros físicos intimamente relacionados com o tipo de material e estruturas geológicas presentes na área investigada.

Na investigação de áreas submersas, por outro lado, os métodos de observação direta não são, na maioria das vezes, aplicáveis, considerando-se basicamente as dificuldades inerentes de acesso do observador ao local de interesse por meio das ferramentas convencionais.

Fotografias aéreas e imagens de satélite dependem da luz, portanto têm penetração extremamente limitada nestes ambientes geológicos, tornando-se ferramentas praticamente inoperantes nos estudos de áreas submersas. A coleta de amostras e a execução de sondagens ou de testemunhagens em áreas submersas são viáveis, entretanto envolvem sempre procedimentos operacionais complexos e de alta risco.

Assim, na investigação de áreas submersas, os métodos geofísicos têm especial relevância, ante suas propriedades inerentes, principalmente ao se considerar que o seu emprego permite a obtenção, a partir da superfície, de dados detalhados sobre a morfologia da superfície e da subsuperfície de fundo. O emprego destes métodos de investigação possibilita, assim, a identificação da espessura das camadas sedimentares e da profundidade do embasamento rochoso, além da identificação e da caracterização de 
estruturas geológicas em subsuperfície, parâmetros fundamentais, em especial, quando do estudo de áreas submersas, com interesses na instalação de obras civis ou mineiras.

A aplicação dos métodos geofísicos na investigação de áreas submersas implica a realização de observações, bem como o controle de equipamentos eletrônicos a partir da superfície, ou seja, remotamente, permanecendo o observador a dezenas ou mesmo a centenas de metros da área examinada, o que torna a operação ainda mais complexa.

Os avanços no campo da investigação de áreas submersas, talvez mais que em qualquer outro campo das ciências da terra, têm profunda relação de dependência com o desenvolvimento da tecnologia, principalmente a elétrica e a eletrônica.

As técnicas de investigação geofísica de áreas profundas têm recebido, desde há muito, grande atenção e enormes investimentos, tanto na questão da aquisição como da interpretação e do processamento dos dados, tendo em vista, é claro, a resposta ou a recuperação quase imediata dos recursos investidos, por se tratar, comumente, de pesquisas relacionadas com a prospecção de hidrocarbonetos.

Por outro lado, somente nestas últimas duas décadas, reconhecida atenção tem sido dispensada às técnicas utilizadas na investigação de áreas rasas ou muito rasas, pois foi neste período que cresceu de forma notável a ocupação, em especial, das regiões costeiras, gerando, conseqüentemente, as demandas inerentes da sociedade.

A investigação de áreas submersas pode ser abordada de vários pontos de vista, que, fundamentalmente, estão sempre relacionados com dois focos de investigação: a superfície e a subsuperfície de fundo. Em ambos,\vários são os métodos disponíveis, sejam diretos (amostragens, testemunhagens e sondagens) ou indiretos (geofísicas).

A discussão desenvolvida neste estudo concentra-se na avaliação da aplicabilidade dos métodos geofísicos na investigação das áreas submersas rasas, a despeito da relevância das análises de materiais diversos oriundos do emprego dos métodos diretos convencionais de investigação.

No âmbito dos métodos geofísicos, destacam-se, neste estudo, os sísmicos, tendo em vista sua consagrada aplicação na investigação destes ambientes, não obstante o crescente emprego de outros métodos geofísicos com a mesma finalidade (métodos elétricos e magnetométricos, p. ex.). 
Desta forma, discute-se o conjunto de métodos sísmicos que utilizam fontes acústicas que emitem espectros contendo altas freqüências (> $30 \mathrm{kHz}$ ) e que são empregados essencialmente na investigação da topografia de fundo ou da profundidade da coluna d'água e no imageamento da superfície de fundo e, o conjunto de métodos sísmicos que utilizam fontes acústicas que emitem espectros contendo baixas freqüências $(<20 \mathrm{kHz})$, e que são empregados na perfilagem de subsuperfície. Esta proposta de abordagem está ilustrada na Figura 1.1.

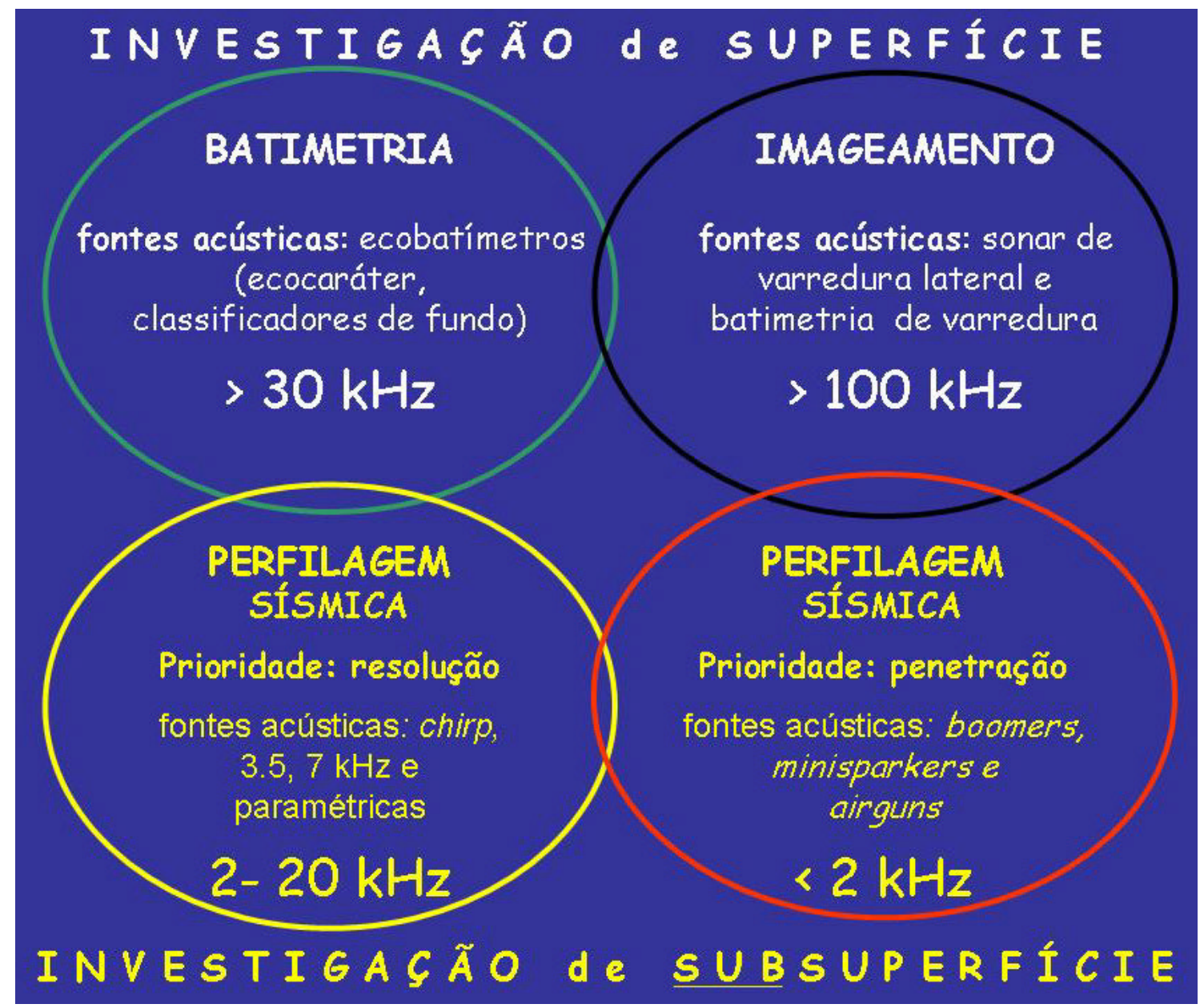

Figura 1.1: Proposta de abordagem da investigação de áreas submersas rasas: a) investigação da superfície por meio da ecobatimetria, que utiliza equipamentos com fontes acústicas que emitem freqüencias a partir de $30 \mathrm{kHz}$; b) investigação da superfície por meio do imageamento de fundo utilizando-se de equipamentos com fontes acústicas que emitem freqüencias geralmente superiores a 100 $\mathrm{kHz}$; c).investigação de subsuperfície (perfilagem) utilizando-se de equipamentos com fontes acústicas que emitem freqüencias geralmente inferiores a $20 \mathrm{kHz}$, e que no âmbito desta discussão foram subdivididos em dois grupos: aqueles métodos que priorizam a resolução e aqueles que priorizam a penetração. 


\section{OBJETIVOS}

O presente trabalho visa contribuir para o aprimoramento da aplicabilidade dos métodos geofísicos utilizados na investigação de áreas submersas rasas no Brasil.

O foco principal da abordagem proposta é discutir a aplicabilidade dos métodos geofísicos, com destaque para os métodos sísmicos, em estudos geológicos e oceanográficos, básicos e aplicados, de ambientes submersos rasos. Nos estudos aplicados discute-se, em especial, a utilização destas ferramentas de investigação como subsídio a projetos de obras civis, como portos, pontes, túneis e barragens, e aos que não necessariamente envolvam tais de obras, como hidrovias, assoreamento de reservatórios, erosão costeira, prospecção mineral, dentre outros. Assim, com esta finalidade, três objetivos básicos são estabelecidos:

- proceder a uma revisão crítica da aplicabilidade dos métodos geofísicos, especialmente dos métodos sísmicos, nos estudos de áreas submersas rasas, entendendo-se como tal, rios, lagos, reservatórios, áreas costeiras e plataforma continental interna, concluindo sobre o potencial dos métodos sísmicos na investigação de áreas submersas rasas, continentais (interiores) e marinhas (plataforma continental interna), para fins geológicos e geotécnicos;

- analisar vantagens, desvantagens, restrições, limitações operacionais dos ensaios sísmicos aplicados a levantamento de áreas submersas rasas, continentais e marinhas, e então orientar procedimentos operacionais para aquisição, tratamento, e interpretação de dados geofísicos de forma a se obter o melhor aproveitamento, a melhor qualidade e o melhor produto final da investigação de áreas submersas rasas por meio dos métodos geofísicos;

- propor critérios de escolha do método geofísico mais adequado para a solução mais apropriada das questões geológicas e geotécnicas envolvidas na investigação de áreas submersas rasas, de forma que os resultados 
obtidos contribuam efetivamente para o aprimoramento dos modelos evolutivos estabelecidos para a costa brasileira e para a melhor compreensão dos processos sedimentares que atuam nas bacias interiores (rios e reservatórios).

Adicionalmente, a análise crítica desenvolvida neste trabalho tem também como objetivo sensibilizar as instâncias decisórias (em especial, o poder público) para a necessidade de considerar as ferramentas geofísicas instrumentos de investigação, não só de fundamental importância, mas também de uso compulsório, na investigação de áreas submersas rasas. Em particular, neste contexto, buscar atenção especial para a relevância da utilização de métodos geofísicos quando da execução de projetos de interesse público, tais como, hidrovias, dutovias, portos, entre outros, bem como nas questões também de interesse público, relativas ao controle de erosão e assoreamento de bacias hidrográficas ou de sistemas costeiros, entre outros temas de vital importância para a sociedade nos dias atuais.

Finalmente, constitui também objetivo deste trabalho analisar tendências no contexto do emprego de métodos geofísicos na investigação de áreas submersas (novas técnicas, novos equipamentos, novos procedimentos), bem como fazer um levantamento da disponibilidade atual do parque de equipamentos do País, em universidades, em institutos de pesquisa e em empresas privadas, com vistas em avaliar o potencial das entidades brasileiras para efetivamente adotarem procedimentos com base nas discussões e sugestões oriundas deste trabalho. 


\section{JUSTIFICATIVAS}

O desenvolvimento do trabalho proposto está embasado em, no mínimo, três demandas detectadas no meio científico e tecnológico nacional:

- demanda de aprimoramento do conhecimento geológico e geotécnico de áreas costeiras e da plataforma continental interna, devido principalmente à rápida evolução do nível de uso e/ou ocupação destas áreas; dutos, portos, emissários submarinos, plataformas de exploração, rotas de navegação, depósitos de resíduos, praias são alguns exemplos de usos múltiplos de áreas costeiras e da plataforma continental interna, que exigem melhor e maior conhecimento deste ambiente geológico para garantia de sucesso na execução dos projetos;

- demanda de conhecimento geológico e geotécnico de áreas submersas continentais (rios e reservatórios), como conseqüência do aumento da população e, portanto, do aumento não só da ocupação propriamente dita, mas também das necessidades básicas decorrentes: armazenamento de água potável, geração de energia elétrica, transportes (hidrovias), controle de vazão dos rios (controle de enchentes), recreação, controle de processos de erosão e assoreamento, prospecção de material de construção, entre outros aspectos;

- demanda denominada neste trabalho de "metodológica", devido à ausência de literatura específica no País, sobre normas ou critérios de orientação que direcionem os trabalhos de investigação de ambientes submersos de águas rasas (terrestres ou marinhos), para a utilização do adequado método geofísico para obtenção do melhor resultado. Não são raros exemplos na literatura nacional do emprego equivocado de métodos geofísicos, na tentativa de resolver questões no contexto da investigação de áreas submersas rasas. A título de exemplo, pode ser citada a utilização de métodos sísmicos de alta freqüência (ecobatímetros, perfiladores $3.5 \mathrm{kHz}$ ) na busca da profundidade do embasamento rochoso, em ambientes desfavoráveis à aplicação desses métodos. Perfiladores acústicos que utilizam fontes de baixa frequiência e maior potência, tipo boomers ou 
sparkers, são geralmente mais eficientes em investigações desta natureza. Ao contrário, em projetos de rotas de navegação, caso em que os métodos geofísicos contribuem por meio da batimetria, a utilização de sistemas com fontes acústicas que emitem freqüências inferiores a $30 \mathrm{kHz}$, pode gerar dados que comprometem a qualidade do produto final, já que em algumas situações o sinal acústico emitido pode penetrar nas camadas lamosas superficiais, e desta forma identificar erroneamente a espessura da coluna d'água.

\subsection{Por QUe Águas Rasas?}

O tema "investigação de áreas submersas" pode ser abordado pelo menos em dois pontos de vista: águas rasas e águas profundas.

Do primeiro ponto de vista, são incluídas áreas costeiras, plataforma continental interna, rios, lagos naturais ou artificiais.

Em qualquer destes ambientes, a coluna d'água a ser ultrapassada, para se obterem informações da superfície e subsuperfície de fundo, raramente alcança algumas dezenas de metros. Neste trabalho optou-se por limitar a coluna d'água a 50 metros de espessura, equivalente a isóbata que aproximadamente delimita a plataforma continental interna no Brasil.

Do segundo ponto de vista, estão as áreas oceânicas (plataforma continental externa, talude continental e bacias oceânicas), setores comumente com coluna d'água de centenas ou milhares de metros.

A divisão apresentada acima leva fundamentalmente em consideração as limitações tecnológicas envolvidas na investigação de cada um destes ambientes. Em ambos os casos, os princípios dos métodos de investigação utilizados são semelhantes, todavia, o porte dos equipamentos, e dos meios de transporte, em cada um dos casos, é distintos.

A abordagem discutida neste trabalho concentra-se na investigação de águas rasas que constituem setores da superfície terrestre mais próximos da sociedade e, de uma forma ou de outra, mais afetados, ou pelo menos, primeiramente afetados pelo crescimento da população e o conseqüente avanço da ocupação do homem. A investigação, destes setores, portanto, está diretamente relacionada a temas como 
geologia costeira, engenharia costeira, geotecnia constituindo tema de grande relevância nos dias atuais.

O conhecimento da superfície e subsuperfície de fundo dos ambientes de águas rasas tem importância vital como subsídio ao desenvolvimento de inúmeras atividades, das quais se podem destacar: navegação (marítima, rios, canais artificiais, reservatórios), gerenciamento de lagos naturais e reservatórios, mapeamento ambiental, prospecção mineral, arqueologia subaquática, obras civis em áreas submersas, lançamento de cabos e dutos subaquáticos, entre vários outros. Grande parte destes estudos desenvolve-se em ambientes com coluna d'água menor que 50 metros, freqüentemente até mesmo menores que 20 metros (Geoacoustics, 2004). Nestes ambientes, e com aqueles objetivos, exige-se comumente a obtenção de dados com alta resolução, alta precisão e com completa cobertura, de forma que seja evidenciada toda e qualquer característica relevante ou significante do ambiente estudado. Ressalta-se ainda que, da necessidade do desenvolvimento da investigação geológica nestes ambientes, decorre o desenvolvimento de instrumentos de investigação (equipamentos de sondagem e equipamentos geofísicos) de pequeno porte e de embarcações apropriadas para navegação nestes ambientes rasos.

\subsection{POR QUE MÉtodos GeOfísICOS?}

Os métodos geofísicos constituem um conjunto de métodos indiretos de investigação que tem especial relevância quando da investigação de áreas submersas e que se destacam dos métodos convencionais basicamente por que:

- possibilitam fácil acesso aos locais de interesse, principalmente quando se trata de investigação de áreas submersas, onde os procedimentos de acesso à superfície de fundo, ou à subsuperfície, são sempre mais complexos, quando comparados às atividades de investigação na superfície terrestre;

- permitem a observação contínua da superfície e subsuperfície de fundo (a depender do método utilizado), ao longo de um perfil, ao contrário de sondagens, amostragens, testemunhagens, que constituem métodos de investigação comumente pontuais;

- tornam viável a rápida observação de grandes áreas, já que a aquisição de dados é realizada a partir de uma embarcação que desliza sobre a superfície 
d'água em velocidades a partir de $6 \mathrm{~km} / \mathrm{h}$, a depender do equipamento utilizado;

- constituem métodos não-destrutivos, ou seja, as observações realizadas por meio de métodos geofísicos não causam qualquer dano ao ambiente investigado;

- permitem a caracterização da superfície e também da subsuperfície de fundo.

Talvez a única propriedade desvantajosa da utilização dos métodos geofísicos refira-se aos custos operacionais, comumente elevados, mas que são, em geral, sobrepujados pela facilidade da cobertura de grandes áreas, tornado viável a relação custo/beneficio.

Dentre os métodos geofísicos, destaca-se o sísmico, pois que os dados obtidos por este método oferecem adicionalmente grande precisão, resolução e penetração. Além disso, os perfis contínuos apresentados são facilmente associados a perfis geológicos, tendo em vista a semelhança visual entre uma seção sísmica e uma seção geológica, tirante a escala e a conseqüente sobrelevação.

À parte destas propriedades, os métodos sísmicos utilizados na investigação de áreas submersas rasas têm ainda como vantagem a facilidade de geração de ondas acústicas na superfície da água, bem como a facilidade de propagação das ondas acústicas na coluna de água. Manuseiam ainda fontes acústicas não-explosivas que são de fácil manuseio.

\section{MATERIAL E MÉTODOS}

A análise realizada neste estudo tem como base principal ampla consulta bibliográfica e de material oriundo do desenvolvimento de vários projetos de investigação de áreas submersas rasas ao longo dos últimos 25 anos, executados principalmente pelo Instituto de Pesquisas Tecnológicas do Estado de São Paulo - IPT e pelo Instituto Oceanográfico da Universidade de São Paulo - IO-USP, mas também desenvolvidos por outras universidades brasileiras e empresas privadas nacionais e estrangeiras. 


\section{SEDIMENTOS INCONSOLIDADOS}

O objeto de estudo deste trabalho é apresentar uma proposta metodológica para investigação e, portanto, quantificação, das coberturas sedimentares inconsolidadas depositadas em áreas submersas.

São estes sedimentos, de origem marinha ou continental, que cobrem grandes extensões da plataforma continental interna, das áreas costeiras, dos canais de rios e da superfície de fundo dos lagos naturais e reservatórios.

O termo "sedimentos inconsolidados" será aqui utilizado como termo genérico para designar camadas ou estratos submersos constituídos por sedimentos recentes, nãocompactados, ou muito pouco, que não possuem composição mineralógica ou granulométrica predeterminada (em geral, composto de material na granulometria da areia, cascalho, silte e da argila), portanto com aparência das mais diversas, oriundos de processos sedimentares de denudação atuantes nas áreas costeiras, na plataforma continental interna e nas áreas submersas interiores, como rios, lagos e canais naturais ou artificiais.

O foco de estudo sobre sedimentos inconsolidados ocorre neste trabalho devido à necessidade de dimensionamento das extensões e das espessuras destes corpos sedimentares, bem como, do conhecimento dos processos de evolução destas coberturas, pois se entende que estes aspectos são de suma importância para a evolução da sociedade moderna. Os métodos geofísicos descritos e analisados aqui constituem ferramentas adequadas para investigações desta natureza.

\subsection{Histórico}

Os sedimentos inconsolidados cobrem boa parte da superfície da Terra e, desde o início da civilização, constituem elementos fundamentais para a evolução do homem (Winterwerp \& Kesteren, 2004). Grande parte destes sedimentos, talvez a maior, é atualmente gerada a partir da atividade antrópica (Wilkinson, 2005).

As coberturas sedimentares geradas por processos naturais ou artificiais de erosão e assoreamento representam duplo papel para a sociedade: ora causam enormes prejuízos econômicos e sociais, ora constituem dádivas da natureza, e neste aspecto consideradas elementos de extrema importância para a própria evolução do homem. 
Bons exemplos da importância das coberturas sedimentares no processo de evolução da sociedade são, nos tempos remotos, as terras férteis das planícies de inundação dos rios Nilo, no Egito, Eufrates e Tigres, na Mesopotâmia, e do rio Amarelo na China, e, nos tempos atuais, as áreas produtivas dos deltas dos rios Yangtze, na China, Reno, na Europa e Mississipi, nos Estados Unidos.

Depósitos sedimentares, principalmente finos, cumprem também papel essencial no desenvolvimento da fauna e da flora nos ecossistemas estuarinos, seja como sedimentos de fundo, seja ocupando as planícies de inundação dos rios.

Sedimentos são também essenciais para a construção civil, possibilitando, no caso de finos, a fabricação de tijolos, ladrilhos, telhas etc., ou, no caso de grossos, cascalhos, por exemplo, a construção de estradas, enrocamentos de barragens, aterros e edificações diversas. Importantes recursos minerais podem também ser extraídos de corpos sedimentares inconsolidados, como ferro, ouro, diamante, entre outros.

Do ponto de vista ambiental, os sedimentos têm papel relevante, ora positivo ora negativo. Quando em suspensão, podem atuar como redutor de poluentes, melhorando, de certa forma, a qualidade da água, mas podem também afetar desfavoravelmente os peixes e sua fauna e flora alimentar, se se considerar que o aumento da turbidez da água impede o desenvolvimento de ovos e larvas e reduz a disponibilidade de alimentos. Em alguns casos, sedimentos poluídos por metais pesados, por exemplo, podem contaminar até mesmo a cadeia alimentar, ante a facilidade com que aderem às partículas de argilas ou à matéria orgânica associada aos sedimentos (Rukavina, 2001) .

Por conta dos processos que governam seu transporte e destino em sistemas abertos, os sedimentos, principalmente os finos, têm tendência em se acumularem em áreas de águas mais tranqüilas, como bacias portuárias e canais de navegação, podendo em muitos casos prejudicar a navegação. São inúmeros os exemplos, no Brasil e no mundo, de portos onde, para se garantirem as condições mínimas de navegação, são removidos anualmente milhões de toneladas de sedimentos, não raramente contaminados, o que torna as operações portuárias cada dia mais caras.

Grandes espessuras de estratos de sedimentos inconsolidados são também encontradas nos instáveis taludes da plataforma continental. A natural instabilidade destas camadas é comumente acelerada pela ação do homem, quando da instalação de dutos, cabos submarinos, plataformas exploratórias ou por distúrbios naturais originados 
de terremotos, tsunamis, liberação de gases, etc., causando enormes prejuízos ao homem. Fenômenos análogos ocorrem no continente, em áreas montanhosas, e a remobilização destas camadas instáveis, pela ação natural ou não, causa também prejuízos devastadores.

\subsection{IMPORTÂNCIA DOS SEDIMENTOS}

O desenvolvimento de uma determinada região pode ser, de certo modo, diretamente relacionado com o planejamento de sua ocupação que, por sua vez, se relaciona também com o controle preciso dos processos sedimentares, erosivos e acumulativos.

São inúmeros os exemplos, na literatura, de problemas e conseqüentes danos às comunidades, no Brasil e no mundo, resultado de alterações indesejáveis às paisagens, seja com o acúmulo indevido de sedimentos, seja pela atuação extensiva dos processos erosivos, em consequiência da condução dos processos de urbanização, sem critérios mínimos e, não raramente, ignorando e desrespeitando os sítios naturais de erosão e deposição (Giannini \& Riccomini, 2000).

Em reservatórios, por exemplo, o processo de assoreamento pode ser responsabilizado por grandes perdas econômicas e ambientais, pois afeta diretamente o abastecimento público de água, com a diminuição do volume disponível do reservatório (volume útil) para o acúmulo de água, com conseqüente prejuízo na geração de energia elétrica.

O acúmulo de sedimentos em cursos d'água interiores e costeiros dificulta ou até mesmo interrompe a navegação fluvial e portuária, não só causando os prejuízos econômicos inerentes, mas também provocando inundações de áreas circunvizinhas economicamente produtivas ou habitadas (Paiva et al., 1998). Os sedimentos ainda provocam aumento da turbidez da água, o que compromete a manutenção de ecossistemas aquáticos, não só afastando turistas de balneários, mas ampliando os custos de tratamento da água para consumo humano.

Evitar ou prevenir problemas oriundos do acúmulo de sedimentos, seja em áreas continentais (rios, reservatórios) ou em áreas costeiras (principalmente em áreas portuárias), passa, por um lado, pelo estabelecimento de uma estratégia de análise dos processos sedimentares atuantes, para prevenção e, por outro, pela estratégia de recuperação da área e, assim, pela necessidade da quantificação dos depósitos. Neste 
último, as ferramentas geofísicas disponíveis, em especial as sísmicas, cumprem papel preponderante, pois possibilitam de forma rápida e eficiente uma avaliação espacial de grandes áreas permitindo ampla cobertura num intervalo curto de tempo, subsidiando, desta maneira, importantes tomadas de decisões do poder público.

\subsection{MEDIDAS EM SEDIMENTOS}

O profundo conhecimento dos processos sedimentares atuantes numa determinada área passa pela execução de medidas de diversos parâmetros, em intervalos de tempo específicos, durante muitos anos. Estas medidas serão úteis para a estimativa da produção de sedimentos das áreas contribuintes, para o conhecimento da distribuição dos sedimentos na área de interesse, para avaliação dos efeitos de eventuais sistemas de proteção já instalados (proteção aos processos de erosão e assoreamento), e para, finalmente, auxiliar estudos sobre as perspectivas da área em estudo com relação ao acúmulo de sedimentos. No caso de estudos de áreas portuárias ou de reservatórios, estas medidas permitirão prever a vida útil dos empreendimentos.

Dentre as inúmeras possibilidades de medidas a serem realizadas, visando ao maior conhecimento de uma área de estudo, destaca-se a necessidade do conhecimento do volume dos corpos sedimentares, ou seja, a espessura dos estratos ou camadas sedimentares.

Em se tratando da investigação de áreas rasas, não são muitas as técnicas disponíveis para tal finalidade. A mais tradicional constitui a execução de sondagens. Apesar de pontuais, ou seja, relativamente pobres no quesito representatividade geográfica, possibilitam contato direto com o material subjacente e, portanto, uma análise substancial sobre a natureza do material depositado, além da possibilidade da avaliação, pelo menos localmente, da espessura do pacote sedimentar.

Outra forma, ou método, para avaliar e quantificar o volume da cobertura sedimentar de uma determinada área se dá por meio da comparação entre curvas topobatimétricas obtidas de um mesmo perfil realizado em datas diferentes. As empresas administradoras de portos, ou de reservatórios, normalmente executam levantamentos batimétricos sistemáticos e periódicos, o que possibilita o monitoramento contínuo da evolução da cobertura sedimentar. 


\section{6 ÁREAS COSTEIRAS E PLATAFORMA CONTINENTAL INTERNA}

Juntamente com o incremento das atividades exploratórias do homem no mar, na busca de recursos para atender o aumento da demanda, conseqüências naturais do crescimento populacional, ampliaram-se também os riscos de degradação ambiental destes complexos ambientes de transição.

Grande parte da população do planeta vive nas regiões litorâneas onde se concentra a maior parte das atividades econômicas. Decorre disto o inerente acúmulo de intervenções antrópicas nesta zona de interface terra-mar, ou zona costeira (Figura 6.1a).

Geologicamente, o substrato que compõe o ambiente costeiro brasileiro e a plataforma continental interna se originou a partir das oscilações do nível do mar no Quaternário. Como resultado, tem-se uma complexa interdigitação de camadas de sedimentos argilosos e arenosos, o que por si só exige investigações detalhadas quando da necessidade de ocupação destes setores por meio da instalação de estruturas de qualquer natureza.

A dinâmica dos processos geológicos que atuam nesta faixa intermediária terra-mar, é influenciada por diversos agentes da natureza, tais como direção dos ventos, correntes, ondas e marés. Entretanto, a atividade antrópica representa relevante papel nos últimos tempos.

A grande quantidade de material (rochas e sedimentos) remobilizada pelo homem em suas atividades construtivas é indiscutível. Wilkinson (2005) afirma que, atualmente, o homem é o mais importante agente de denudação da superfície, superando, em uma ordem de magnitude, a soma de todos os processos naturais atuantes na superfície terrestre. Os estudos comparativos desenvolvidos mostram que o homem passa a ocupar papel de destaque já no final do primeiro milênio desta era (Wilkinson op. cit).

À parte de eventual exagero nestes cálculos, o fato é que intervenções antrópicas, se realizadas sem estudos investigativos prévios, em particular quando se trata de áreas submersas, contribuem efetivamente para o incremento dos processos de denudação com os conseqüentes prejuízos ambientais. 
As intervenções antrópicas geralmente são realizadas sem os devidos estudos e, como tal, tendem a modificar a dinâmica dos processos atuantes, trazendo sempre conseqüências desastrosas ao ambiente (Figura 6.1b,c). Em áreas continentais, constituem exemplos (ante-exemplos) a remoção da cobertura vegetal em áreas interiores com fins agroindustriais. Em áreas submersas, a execução de obras em faixas costeiras (molhes, portos, emissários, muros, vias, calçadões ou obras de proteção de forma geral), e as atividades de mineração, prospecção de petróleo ou de minérios, construção de plataformas de exploração, dutos, a escolha de locais apropriados para disposição de resíduos na plataforma continental interna constituem expressivos exemplos de ocupação humana neste sensível ambiente, com conseqüências desastrosas ao meio ambiente.

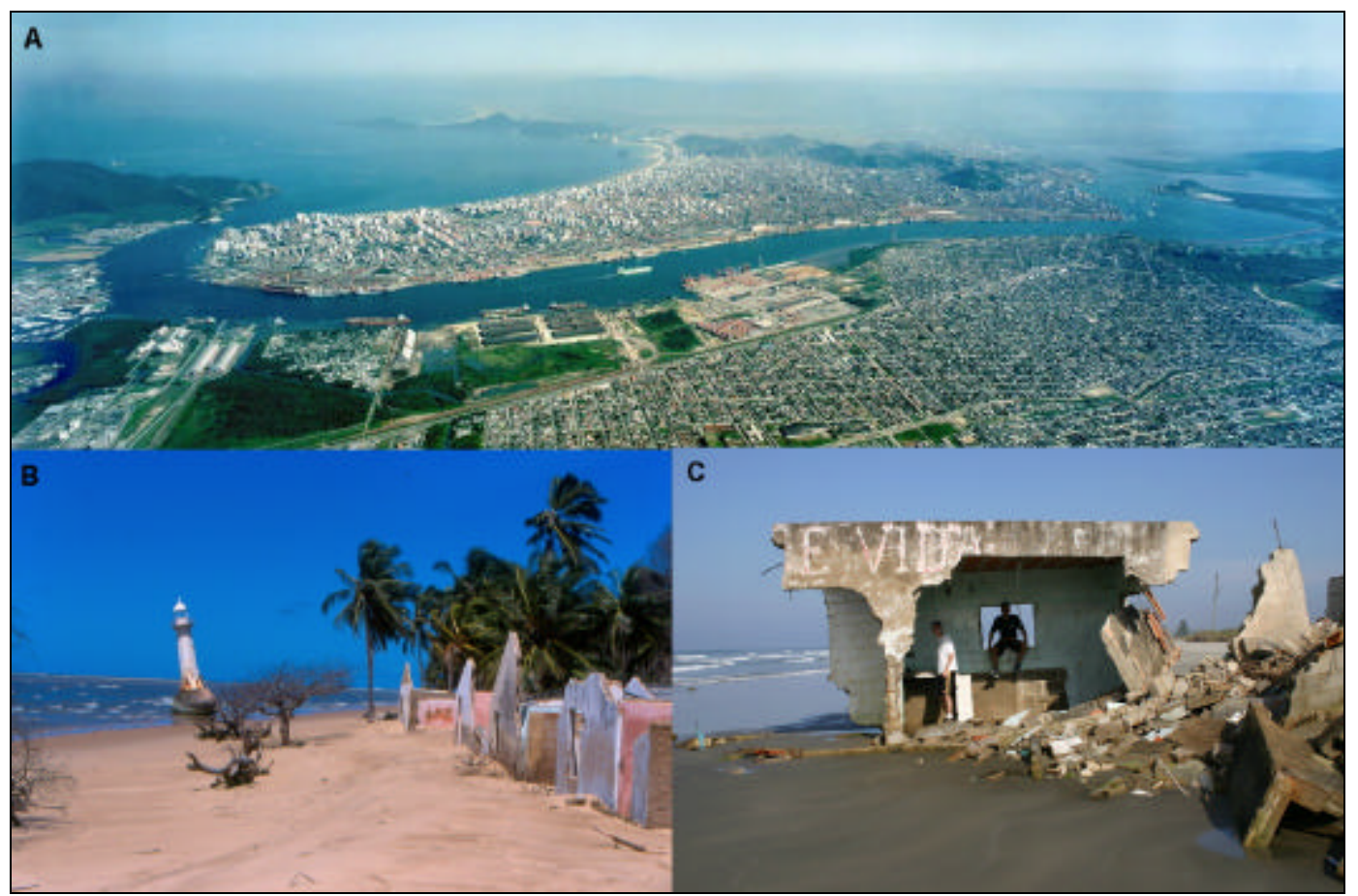

Figura 6.1: a) exemplo de intensa ocupação em área costeira: Santos-SP (foto: Flávio R. Berger disponível em <http://www.portodesantos.com.br/> - acesso: abril/2006); b) Vila de Cabeço, foz do rio São Francisco (SE), destruída em consequência da retenção de sedimentos decorrente da construção de grandes barragens ao longo do rio (foto: Prof. Dr. J.M Landim Dominguez-UFBA); c) casa destruída pela ação do mar em consequência da ocupação indevida de setores instáveis da costa $\mathrm{N}$ da Ilha Comprida,SP (foto: Prof. Dr. P. C. F. Giannini-USP).

Neste contexto, os métodos geofísicos, em particular os sísmicos, representam papel essencial, pois possibilitam o mapeamento de superfícies de fundo identificando possíveis locais de riscos não só ambientais, mas também para a própria estrutura a ser edificada. Feições topográficas de pequena escala, sedimentos ricos em gás (Orange et al., 2005), canais de erosão, instabilidade de taludes, rotas preferenciais (estáveis) para a instalação de dutos (IPT 2002b, 2005b) são algumas das características identificadas 
com detalhe na superfície e subsuperfície de fundo por meio dos métodos geofísicos e que contribuem efetivamente para a melhor solução da questão em pauta. Excelente revisão, do ponto de vista da aplicabilidade e da relevância dos métodos geofísicos no monitoramento dos ambientes costeiros, encontra-se em Morang et al. (1997)

Outro tópico que cresce em relevância acentuada a cada dia é a exploração de placeres marinhos. Esta atividade de mineração já se constitui, em muitos países, como fonte principal e expressiva de recursos minerais (Silva, 2000). Com o inevitável esgotamento das reservas continentais, é incondicional e estratégico para o País envidar esforços na busca de bens minerais na plataforma continental. Os métodos geofísicos contribuem efetivamente neste tema, pois possibilitam mapear ocorrências minerais, avaliar espessuras dos depósitos sedimentares de interesse (cubagem de jazidas), entre outros aspectos.

No Brasil, estes métodos de investigação carecem de revisão crítica com relação às formas, possibilidades e potencialidades de aplicação. Particularmente nas áreas costeiras, onde a ocupação humana avança a cada dia, e num ritmo intenso, é premente a necessidade da configuração de um conjunto de métodos de investigação que evidencie as principais características geológicas e geotécnicas da superfície de fundo e dos estratos sedimentares rasos.

Exemplos de condução equivocada de procedimentos de investigação de áreas costeiras, com a finalidade de execução de projetos de obras civis (portos, muros, molhes etc.), são inúmeros ao longo da costa do Brasil, causando grandes prejuízos econômicos e principalmente ambientais. Raciocínio análogo pode ser desenvolvido para os casos de investigação de áreas submersas continentais (rios e lagos naturais ou artificiais).

Em ambos os casos, para poupar investimentos na fase inicial de um projeto de obras civis, o empreendedor acaba por correr riscos desnecessários, não executando devidamente os procedimentos básicos de investigação, que passam pela utilização e aplicação de métodos indiretos de investigação (métodos geofísicos). De forma rápida e a custos relativamente baixos, a utilização de métodos geofísicos garante ampla cobertura da área de interesse, o que permite, associando os resultados geofísicos aos dados de investigação direta (sondagens, amostragens, etc.), a confecção de um modelo geológico-geotécnico mais próximo do real, que irá contribuir diretamente para a melhor condução do projeto de ocupação. 


\section{7 ÁREAS SUBMERSAS INTERIORES: LAGOS, RESERVATÓRIOS E RIOS}

Reservatórios têm por finalidade básica acumular águas disponíveis na natureza, principalmente as oriundas de períodos chuvosos, para compensar as deficiências nos períodos de estiagem, exercendo também papel fundamental na regularização das vazões naturais. Comumente, os reservatórios se estabelecem a partir de barragens que são construídas em cursos d'água (rios).

Todos os rios transportam certa quantidade de matéria sólida, seja em suspensão, seja pelo arraste, rolamento ou saltação de partículas sólidas junto às paredes do leito ou no fluxo aquoso. A construção de uma barragem para armazenamento de água de um rio altera as condições naturais de transporte de partículas sólidas, agindo como meio artificial de retenção de sedimentos. A deposição contínua ou gradual do material carreado pelos cursos d'água, no interior do reservatório, também chamado de assoreamento, decorre da diminuição de velocidade e da turbulência das águas, que causa sua perda de capacidade de transporte.

Uma das características principais de um reservatório é o volume, ou sua capacidade de armazenamento, que depende diretamente das características físicas (topográficas, fundamentalmente) da área de sua instalação. A variação da capacidade de armazenamento de um reservatório ao longo de sua existência constitui tema de suma importância, particularmente nos dias atuais, em que a água se torna, a cada dia mais escassa, em quantidade e qualidade.

Fatores adversos, não considerados quando da construção de um reservatório, tais como, a indevida ocupação das áreas ribeirinhas, o desmatamento de matas nativas, o desenvolvimento de atividades agrícolas e mineradoras nas áreas circunvizinhas, representam relevante papel na vida útil de um reservatório. A represa Billings, por exemplo, localizada na Região Metropolitana de São Paulo, é responsável pelo abastecimento de 5 milhões de pessoas e tem sua capacidade de armazenamento profundamente comprometida nos dias atuais, decorrente da ação de diversos agentes, sendo o principal o avanço, a passos largos, do assoreamento de vários braços do reservatório. Este processo se tornou mais intenso com o aumento da ocupação ilegal das áreas ribeirinhas ocorrido, em particular, nos últimos 20 anos. A Figura 7.1a ilustra uma situação crítica atual de um trecho deste importante reservatório da área 
metropolitana de São Paulo que, segundo alguns autores, pode, num prazo não superior a 50 anos, se reduzir a apenas e tão somente ao leito do rio Jurubatuba, que ali existia antes da criação do reservatório. Raciocínio análogo pode ser desenvolvido para o caso da Represa Guarapiranga, localizada também na Região Metropolitana de São Paulo (Figura 7.1b).

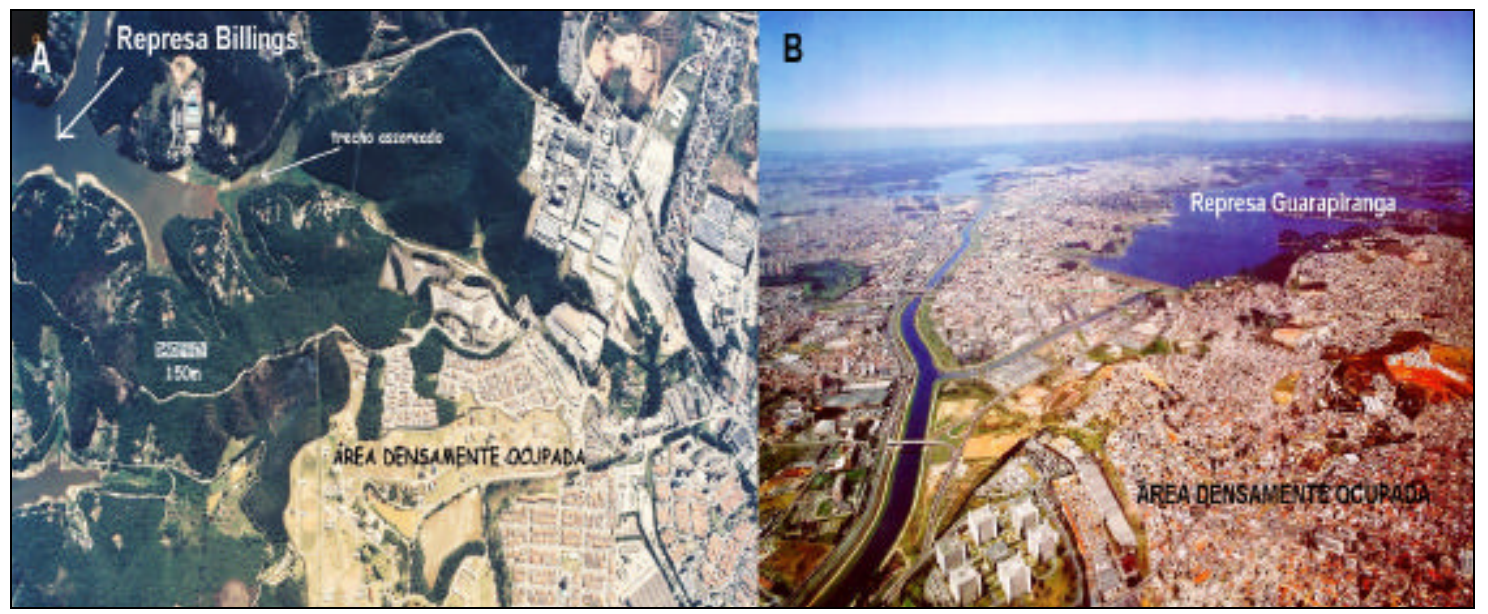

Figura 7.1: Fotografias aéreas ilustrando exemplos da densa ocupação atual ao derredor de importantes reservatórios de água, no caso, as principais represas que abastecem a cidade de São Paulo: a) Represa Billings; b) Represa Guarapiranga. Imagens cedidas por Renato H. Frazão.

O assoreamento de um reservatório ocorre como consequiência da deposição de material proveniente da erosão dos solos de seu entorno, transporte dos sedimentos e pela própria existência do reservatório que, por si só, é uma armadilha para os sedimentos, que tem seu fluxo natural impelido pela barragem. O processo de assoreamento propriamente dito é influenciado por vários fatores locais, a destacar, clima, hidrologia, composição química das águas e dos sedimentos, cobertura vegetal, uso do solo, hoje, fator preponderante, como será mais bem esclarecido adiante. O assoreamento de um reservatório compromete diretamente seu volume útil e é, ao fim, o resultado da ocupação não só ilegal, das áreas ribeirinhas, mas também desordenada e desorientada.

Além do comprometimento do volume útil do reservatório, conseqüência do grande aporte de sedimentos remobilizados pela ocupação das áreas ribeirinhas, grandes quantidades de matéria orgânica, também carreada para o reservatório, levam à proliferação de algas microscópicas que se reproduzem em ritmos intensos. Esta população de algas prejudica, devido à liberação de substâncias tóxicas, a qualidade da água ao consumo humano, exigindo, assim, gastos públicos adicionais no tratamento da água. 
Outro fator importantíssimo, também diretamente relacionado com a diminuição da água disponível no reservatório, é a perda das nascentes, comumente obstruída, como consequiência da ação antrópica, fazendo com que o lençol freático seja rebaixado.

A utilização dos recursos hídricos em geral se intensificou nas últimas décadas, em decorrência não só do aumento do número de usuários (consumidores), mas também do desenvolvimento econômico que, à parte de causar, efetivamente, aumento na quantidade demandada para um determinado uso, ocasionou também o aumento da variedade da utilização destes recursos, a destacar: abastecimento urbano e agrícola (irrigação), controle de cheias, prevenção de inundação, geração de energia, esportes e lazer, piscicultura e aqüicultura e navegação.

O Brasil possui inúmeros reservatórios parcial ou totalmente assoreados, muitos dos quais ainda em operação, mas com problemas sérios com relação ao excesso de sedimentos. Carvalho (1994) apresenta amplo estudo sobre hidrossedimentologia focando em particular a questão do assoreamento dos reservatórios, inclusive com exemplos brasileiros, e as conseqüências para a sociedade, os prejuízos econômicos e sociais.

Exemplos de reservatórios assoreados são freqüentes na literatura internacional. Chanson \& James (1998), Chanson (1998), e Chanson \& James (1999) fazem interessantes retrospectivas sobre as questões deste gênero ocorridas na Austrália no começo do século passado. Destacam, nestes artigos, o estudo de quatro reservatórios que tiveram sua vida útil reduzida a menos de 25 anos, como conseqüência de vários fatores, que vão desde o próprio desconhecimento, naquela época, dos fundamentos dos processos sedimentares, do clima da região (com verões com altíssimos índices pluviométricos) até os próprios erros construtivos das barragens, que não permitiam o escoamento dos sedimentos em excesso.

\subsection{ESTUdOS DE LAgOS, RESERVATÓRIOS E RIOS NO BRASIL E A INVESTIGAÇÃO GEOFÍSICA}

Com o objetivo de promover o estudo e a definição de diretrizes necessárias ao conhecimento e controle de problemas relacionados com sedimentos, foi criada em 1989, na Associação Brasileira de Recursos Hídricos, a Comissão de Engenharia de Sedimentos. 
Cinco importantes eventos foram realizados no período, abordando temas como o impacto sedimentar causado pelos empreendimentos mineradores, produção sedimentar nas bacias fluviais, assoreamento de reservatórios e os processos erosivos à jusante, e a avaliação qualitativa e quantitativa da produção de sedimentos.

O último, ocorrido em 2004, na cidade de Vitória, ES, teve como foco principal os impactos dos sedimentos no desenvolvimento regional (VI ENES Encontro Nacional de Engenharia de Sedimentos). Ao se observar o conjunto de artigos publicados nestes eventos, chama a atenção a ausência de uma discussão mais ampla sobre a aplicabilidade das ferramentas geofísicas na avaliação quantitativa da espessura dos pacotes de sedimentos inconsolidados. Mais de uma centena de artigos foram apresentados e em nenhum deles se discute a aplicação destas ferramentas na investigação destes ambientes geológicos.

As análises da evolução da cobertura sedimentar são, naquele contexto, baseadas principalmente em comparações entre seções topobatimétricas temporais, realizadas em determinados intervalos de tempos, como é o caso de Machado \& Menezes (2004) que avaliam o assoreamento no reservatório da Usina de Três Marias entre 1975 e 2003, fazendo comparações entre curvas topobatimétricas obtidas em diferentes momentos. Estes mesmos autores alegam a freqüente indisponibilidade de recursos por parte das autoridades competentes, para o desenvolvimento dos levantamentos necessários, mesmo para a simples intensificação dos levantamentos topobatimétricos. Afirmam ainda que a eventual negligência das autoridades está diretamente relacionada com a comum lentidão na ação dos processos sedimentares, o que levaria os dirigentes a certa insensibilidade nas tomadas de decisões estratégicas.

Almeida Filho \& Campagnoli (1998) avaliam o processo de sedimentação da Lagoa Primavera, no município de Bauru, SP, medindo o volume de sedimentos exclusivamente por meio da realização de amostragens do tipo Piston Corer e Van Veen, distribuídas ao largo da lagoa. Com base nestes dados, estimam a vida útil da lagoa em 30 anos.

Ottoni (1998) avalia zonas críticas de assoreamento no Reservatório Soledade, MG, com base exclusivamente no confronto de curvas isobatimétricas antigas e atuais. Com o resultado destas análises, conclui sobre a crítica situação do reservatório, particularmente com relação à perda de volume útil desde sua constituição. 
São diversos os exemplos na literatura de danos à sociedade originados pelo acúmulo indesejado de sedimentos ou pela ação erosiva intensa. O rio Taquari, no Pantanal Matogrossense, MS, por exemplo, não tem capacidade de transportar os sedimentos oriundos dos processos erosivos da alta bacia, intensificados desde os anos 70 pela crescente expansão agropecuária, causando inundações em grandes áreas e impactos negativos à pecuária, fauna e flora locais. Fundamental, neste caso, conhecer em detalhe os processos de sedimentação atuantes, sua origem, seus impactos, e as intervenções possíveis com objetivo da mitigação dos prejuízos à jusante. Padovani et al. (1998) executaram uma série de medidas de vazão de seções de amostragem de sedimentos de fundo e em suspensão, em períodos de seca e de cheia. Todas as medidas efetuadas evidenciaram a diminuição da concentração, vazão, e descarga sólida de sedimentos de montante para jusante, corroborando a hipótese da deposição, em processo contínuo, de sedimentos na calha do rio.

Os exemplos citados acima, e muitos outros, a se destacarem Campagnoli (1998), Lastoria et al. (1998) e Paiva et al. (1998), têm em comum o tema focado nos estudos desenvolvidos: sedimentos, assoreamento de rios e reservatórios no Brasil. Interessante, notar que nenhum dos autores exemplificados ou citados, tampouco qualquer outro autor, nos mais de 120 artigos analisados no âmbito dos Encontros Nacionais de Engenharia de Sedimentos, sequer citam a possibilidade de avaliação da espessura dos sedimentos utilizando-se de ferramentas indiretas de investigação, como métodos geofísicos.

Exceção se faz a Campagnoli (1998) que, apesar de não utilizar no artigo dados geofísicos, cita em seu texto que sonar de varredura lateral e perfilagem sísmica contínua foram empregados na investigação de vários reservatórios da Região Metropolitana de São Paulo. Mesmo no caso dos artigos cujo foco é justamente a estimativa de assoreamento de reservatórios, como em Lastoria et al. (1998), que desenvolveram amplo estudo do reservatório de Guarirova, em Campo Grande, MS, nenhum levantamento geofísico foi executado ou planejado, visando à definição da espessura dos pacotes de sedimentos resultantes dos processos de assoreamento que assolavam um reservatório desde sua formação.

É indiscutível a relevância da avaliação adequada dos níveis de assoreamento dos reservatórios, até mesmo em virtude da prevista carência de água para os próximos tempos. A expectativa da utilização do assoreamento como geoindicador ambiental tem- 
se mostrado fundamental e, portanto, uma análise periódica dos níveis de assoreamento de um reservatório deve ser encarada como regra, pois estes níveis, quando devidamente avaliados e medidos, fornecem parâmetros essenciais que viabilizam a mensuração da eficiência das ações preventivas e corretivas dos processos de erosão e degradação do solo e da água instituídas pelo poder público para determinadas bacias hidrográficas.

Paiva et al. (2000) destacam a necessidade e a importância de se ampliar a quantidade de informações de campo com vistas no aprimoramento dos modelos estabelecidos para o transporte de sedimentos em reservatórios. Estes mesmos autores analisam o caso do reservatório de Vacacaí Mirim, RS, que reduziu seu volume útil em $23 \%$ ao longo de 25 anos de operação.

Mais uma vez a utilização de métodos geofísicos, destacando-se entre estes, os métodos sísmicos de alta resolução, tornam-se ferramentas fundamentais, pois permitem, independentemente do histórico do reservatório em foco, avaliar a atual situação, definindo, além do volume atual de água do reservatório, o volume atual de sedimentos, ou seja, dos sedimentos acumulados ou assoreados. Estes dados possibilitam ao poder público planejar um monitoramento efetivo não só do reservatório propriamente dito, como das áreas circunvizinhas, elaborando planos de ocupação e desocupação (se for o caso) de áreas protegidas.

Assim, sugere-se que os métodos geofísicos de alta resolução, a se destacar a perfilagem sísmica contínua e a sonografia, façam parte do conjunto de métodos de investigação de reservatórios. A utilização de métodos geofísicos para a medição das espessuras das camadas de sedimentos, juntamente com os métodos convencionais (medição de descargas sólidas, granulometria dos sedimentos transportados, vazões naturais, topobatimetria), vai sem dúvida aprimorar os resultados finais, permitindo, com maior precisão, conhecer o real volume do aporte e retenção sedimentar e, portanto, prever a vida útil de um reservatório.

O emprego de ferramentas geofísicas de investigação nos estudos do assoreamento de reservatórios torna-se a cada dia mais e mais essencial, pois, com os resultados obtidos, lacunas do conhecimento sobre os processos sedimentares atuantes neste tipo de ambiente poderão ser preenchidas. O estudo realizado por Paiva et al. (1998) constitui um exemplo de que os métodos convencionais utilizados para cálculos volumétricos em reservatórios carecem de ferramentas adicionais. Estes autores concluíram que os métodos de investigação convencionais (amostras de fundo, 
comparação entre as curvas topobatimétricas), utilizados nos estudos efetuados no reservatório de Santa Maria, RS, não se mostraram adequados ou precisos para o desenvolvimento dos cálculos dos volumes envolvidos. Ao fim dos estudos, avaliaram que as medidas volumétricas efetuadas resultaram no dobro daquelas calculadas. Eventos não-registrados e, portanto, não-quantificados durante o período analisado (de 1972 a 1998), como por exemplo, aterros de locais de risco ou para execução de obras, extração de material para construção de rodovias, contribuíram efetivamente para os erros de cálculo observados. Em situações como esta, mais uma vez as ferramentas geofísicas poderiam ter em muito contribuído, permitindo a avaliação direta e atual da espessura do pacote sedimentar.

De maneira geral, os métodos geofísicos não fazem parte do conjunto de instrumentos de medição utilizados rotineiramente na avaliação do assoreamento de reservatórios. Nem mesmo o "Guia de avaliação de Assoreamento de Reservatórios", editado pela ANEEL (2000), avalia como essencial a realização de ensaios geofísicos para a medição do volume de sedimentos acumulados no fundo dos reservatórios. São raros, na literatura nacional, mesmo nos casos mais recentes, modelos de estudos de processos de sedimentação em áreas submersas interiores, subsidiados por informações oriundas da aplicação de métodos geofísicos. Alguns exemplos, contudo podem ser destacados e considerados importantes iniciativas neste sentido.

Sauniti et al. (2004) utilizaram dados do sonar de varredura lateral, na caracterização do assoreamento do reservatório de Passaúna, em Curitiba, PR. Com base nos dados do sonar, os autores puderam planejar a melhor distribuição dos pontos para coleta de amostras de fundo e para localização das sondagens. Esses autores associaram os resultados do sonar de varredura lateral com os dados de sondagens e amostragem de superfície de fundo, para mapear as áreas de ocorrência de assoreamento no lago, a caracterização da variação granulométrica dos sedimentos e da espessura dos estratos sedimentares depositados na fase pós-preenchimento do lago. Puderam, assim, estudar as áreas-fonte potenciais dos sedimentos depositados na bacia e concluir que o desenvolvimento da região, baseado no uso indiscriminado do solo e, portanto, na erradicação das florestas da região, foi um dos principais fatores que contribuíram para o processo de assoreamento do reservatório Passaúna.

Com base nos dados obtidos, os autores indicaram providências imediatas para viabilizar o reservatório, evitando num futuro próximo seu abandono como manancial e 
fonte de recursos hídricos. Dentre as diversas recomendações listadas, basicamente relacionadas com o correto manuseio e uso do solo, os autores insistem na necessidade do monitoramento do lago, que é, ao final, o testemunho dos processos atuantes. Estes mesmos autores ratificaram ainda que, o emprego, de forma sistemática, de métodos geofísicos nos levantamentos do reservatório teria muito a contribuir para o monitoramento do sucesso ou não das providências indicadas quanto ao correto manuseio e uso do solo da bacia de captação.

Por levantamentos geofísicos, entende-se a aplicação não só da batimetria convencional, visando ao controle contínuo do volume útil do reservatório, mas também da batimetria de dupla frequiência e da perfilagem sísmica contínua (ferramentas não utilizadas por estes autores neste trabalho), que propiciariam a determinação do volume de sedimentos acumulados no período analisado.

Outro exemplo de utilização de métodos geofísicos para o estudo de reservatórios foi o projeto desenvolvido no reservatório Capivara (IPT, 1990a,b). Neste estudo, com objetivo de subsidiar tecnicamente projeto de aproveitamento hidroelétrico do rio Paranapanema, além da coleta de dezenas de amostras de sedimento de fundo, foram realizados cerca de $300 \mathrm{~km}$ lineares de perfis geofísicos (sonar de varredura lateral e perfilagem sísmica contínua). O produto final da análise dos dados geofísicos coletados possibilitou o mapeamento da superfície de fundo do reservatório, identificando até mesmo feições de fundo preservadas desde o enchimento (curvas de nível, estradas etc.), características estas intimamente relacionadas com a evolução dos processos de assoreamento do reservatório desde sua criação. Permitiu ainda a identificação, em trechos do reservatório e do rio Paranapanema, de ocorrência de sedimentos arenosos, possível fonte de material de construção para as barragens planejadas. 


\section{INVESTIGAÇÃO DE ÁREAS SUBMERSAS}

\subsection{ASPECTOS GERAIS}

Um dos primeiros e mais expressivos aspectos a ser tratado na investigação de áreas submersas é a capacidade de localização precisa da informação obtida, que pode ser dividida em duas questões: localização da embarcação na superfície da água, durante a execução das observações, e a localização do ponto de amostragem, ou da origem da informação geofísica na superfície de fundo. Estas duas posições podem ser consideravelmente distintas quando da execução de levantamentos geofísicos onde equipamentos (fontes e sensores) são comumente rebocados a certa distância da embarcação, ou mesmo rebocados submersos. Uma abordagem completa de temas relativos à navegação e ao posicionamento é realizada por Langeraar (1984) e Robertson (1990).

Em terra, é relativamente simples tornar concreta a localização de um ponto onde se efetuam observações geológicas diversas. Fotografias aéreas, imagens de satélites e mapas são alguns dos instrumentos existentes que, associados aos sistemas eletrônicos de posicionamento via satélite, como o GPS (Global Positioning System), facilitam em muito esta operação.

Em água, seja no mar ou em áreas submersas continentais, a maior parte das ferramentas convencionais utilizadas na materialização do ponto de observação, não são aplicáveis, e assim entram em cena outras formas de posicionamento. Atualmente, os sistemas de posicionamento via satélite são as ferramentas mais importantes e precisas disponíveis. O GPS é sem dúvida o instrumento que resolve esta questão com a melhor precisão (comumente centimétrica), aspecto especialmente relevante, no caso de levantamentos relacionados com a instalação de obras civis, quando o posicionamento, com precisão das características observadas, se faz obrigatório, já que irão subsidiar projetos de estruturas na superfície de fundo.

O GPS consiste numa constelação de satélites posicionados numa altitude de $20.000 \mathrm{~km}$ que, referenciados ou controlados por estações fixas distribuídas na superfície da terra, possibilitam o posicionamento com precisão de um observador em qualquer ponto da superfície da terra e do mar em qualquer hora do dia. A melhor posição para um determinado ponto de observação vai ser sempre aquela obtida da 
combinação das várias técnicas de navegação, que incluem não só os modernos sistemas de posicionamento via satélite, mas também bússolas, sensores de velocidade e outros sistemas de posicionamento por satélite, que não o GPS (transit, radar, microondas ou sistemas acústicos). Uma introdução sobre este método de posicionamento pode ser encontrada em Beraldo \& Soares (1995) e, discussões sobre o potencial de aplicação do GPS em levantamentos geofísicos, em Santos (2005).

A correta localização das observações efetuadas, das amostras coletadas, dos perfis geofísicos executados, é o que vai garantir o correto posicionamento espacial dos mapas gerados a partir da análise dos dados obtidos. O tipo de equipamento de posicionamento empregado vai ser decidido segundo a escala e a precisão propostas para o estudo. Em áreas restritas, como lagos e portos, o sistema de posicionamento deverá ser de grande precisão, comumente, submétrico. Não são raros os exemplos de variações do perfil da topografia do embasamento cristalino entre 2 e 30 metros de profundidade, em trechos inferiores a 50 metros de extensão. Em casos como este, sistemas de posicionamento de alta precisão (DGPS) se fazem necessários sob pena do comprometimento do modelo geológico ou geotécnico elaborado.

A investigação de áreas submersas, com qualquer que seja a finalidade, pode ser basicamente realizada de forma direta ou indireta.

Por formas diretas entendem-se aquelas que possibilitam ao pesquisador o contato direto (visual ou tátil) com o material que compõe a superfície de fundo ou a subsuperfície. Sondagens, amostragens e testemunhagens são procedimentos que se enquadram nesta categoria, pois permitem, além do contato direto propriamente dito, o desenvolvimento de uma série de ensaios laboratoriais nas amostras coletadas, cujos resultados irão subsidiar uma precisa caracterização do tipo ou da natureza do material coletado. Filmagens, fotografias (inclusive, em estereoscopia) subaquáticas podem também ser consideradas formas diretas de observação de superfícies submersas.

Não está no escopo desta tese discutir as inúmeras possibilidades existentes de investigação direta, tendo em vista a vastidão e a complexidade deste tema. Todavia ressalta-se a importância e a relevância da realização deste tipo de investigação em qualquer estudo de áreas submersas, pois são os resultados obtidos destes procedimentos que, ao fim, ratificam e dão suporte aos modelos geológicos estabelecidos, comumente baseados em meios indiretos de investigação. Alguns 
aspectos relevantes deste tema são discutidos em Souza et al. (1998) e em Figueiredo Jr. \& Brehme (2000).

Por formas indiretas de investigação entende-se aquelas que viabilizam a caracterização dos materiais constituintes do fundo e do subfundo de áreas submersas, a distância e, portanto, não possibilitam o contato direto do pesquisador com o material de fundo.

Os métodos geofísicos (ou simplesmente, a geofísica) enquadram-se nesta categoria, pois se constituem num conjunto de ferramentas (instrumentos/equipamentos elétricos e eletrônicos) que, instalados numa embarcação, viabilizam a observação das características da superfície e subsuperfície de fundo a certa distância definida pela própria espessura da coluna d'água e que pode variar desde poucos metros em áreas continentais e costeiras, até centenas de metros, na plataforma continental externa ou nas bacias oceânicas.

A geofísica está fundamentada nas leis da ciência e estuda a Terra com base nos princípios físicos e nas várias propriedades físicas dos diversos tipos de materiais que compõem os meios geológicos. Identificar propriedades, tais como resistividade e condutividade elétrica, velocidade de propagação de ondas elásticas, radioatividade, aceleração da gravidade, fluxo de calor, magnetismo, entre outras, traz à luz valiosas informações sobre o substrato investigado (composição, estruturas etc.), mesmo porque as propriedades físicas das rochas ou dos sedimentos constituem-se em parâmetros que estão diretamente correlacionados com os tipos de material existentes, bem como com as complexas estruturas que compõem a crosta terrestre.

Ressalta-se ainda que, a interpretação de dados geofísicos é geralmente complexa, pois existem na natureza tipos de materiais distintos, com algumas propriedades físicas semelhantes, o que pode gerar ambigüidades durante a interpretação dos dados coletados. A forma comumente utilizada para sanar tais questões é a associação destes dados com informações oriundas de outras formas de investigação, como amostragens de fundo e sondagens, ou até mesmo oriundas da utilização de métodos geofísicos distintos num mesmo prospecto de investigação.

São vários os métodos geofísicos utilizados na investigação da Terra. Cada método possui características específicas e dedicadas à identificação de determinadas propriedades físicas do meio investigado. Métodos geoelétricos, por exemplo, 
identificam propriedades elétricas dos meios, tais como resistividade e condutividade; métodos sísmicos estudam a propagação das ondas sísmicas; métodos potenciais as propriedades físicas naturais dos meios, tais como, aceleração da gravidade e campo magnético terrestre.

Neste trabalho adotou-se a abordagem do tema "investigação geofísica de áreas submersas rasas" de dois pontos de vista:

- estudo da superfície: morfologia (topografia de fundo) e natureza (dos materiais que compõem a superfície de fundo);

- estudo da subsuperfície: morfologia dos estratos sedimentares (espessura, estruturas presentes, contatos geológicos) e natureza do materiais que constituem os estratos sedimentares;

A decisão por esta abordagem está fundamentada no fato de que estes dois enfoques estão relacionados com métodos distintos de investigação, ou seja, existem alguns métodos geofísicos que são de uso específico para caracterização de superfícies submersas e outros, para caracterização de subsuperfícies submersas.

\subsection{INVESTIGAÇÃO GEOFÍSICA DE ÁREAS SUBMERSAS}

De uma forma ou de outra, os métodos geofísicos são aplicados na investigação de áreas submersas desde há muitos anos, todavia, atualmente sua utilização tem-se ampliada sobremaneira, não só em projetos de pesquisa de recursos naturais (petróleo etc.), mas também com vistas em subsidiar investigações de cunho ambiental originadas das mais recentes necessidades da sociedade.

Um dos fatores que muito contribuíram para o desenvolvimento dos métodos geofísicos foi a Segunda Guerra Mundial. Por conta de interesses militares, equipes especializadas foram constituídas e equipamentos básicos de medição foram desenvolvidos que possibilitaram a observação geofísica em condições operacionalmente mais complexas, pelo menos até aquela data, como por exemplo, levantamentos geofísicos marinhos. Técnicas, primeiramente acústicas e magnéticas, de localização de submarinos, ou de instrumentos no fundo do mar foram, por necessidades estratégicas, rapidamente desenvolvidas nos tempos de guerra. A base teórica e instrumental para o desenvolvimento dos métodos geofísicos e de suas aplicações foi, por razões táticas, estabelecidas também neste período (Jones, 1999).

Vultosos investimentos, tendo como suporte o interesse militar, possibilitaram também grandes avanços na geofísica marinha no período da Guerra Fria. Instrumentos 
especiais e navios de grande porte e muito bem equipados foram construídos neste período com objetivo de conhecer melhor a natureza e a origem da superfície e subsuperfície do mar para se traçar rotas alternativas para navios e submarinos (Jones, 1999).

Outro aspecto a se considerar quando se analisa a evolução da investigação geofísica nestes últimos anos é a própria evolução tecnológica. O desenvolvimento de novos materiais, novas ligas, cabos e fibras ópticas, cerâmicas, plásticos e vidros especiais, a miniaturização de componentes eletrônicos, o surgimento de computadores de alto desempenho, de satélites orbitais são alguns exemplos dos avanços tecnológicos destes últimos tempos que efetivamente contribuíram para o progresso da geofísica aplicada na investigação de áreas submersas. Objetivamente, estes avanços viabilizaram maior capacidade de armazenamento, tratamento e novas formas de apresentação de dados.

A enorme capacidade computacional atual permite que grandes quantidades de dados possam ser analisadas praticamente em tempo real, à medida que são adquiridos, possibilitando controle imediato de qualidade do processo de aquisição de dados. Além disso, os avanços da tecnologia contribuíram ainda para uma portabilidade dos equipamentos geofísicos, possibilitando o desenvolvimento de estudos em áreas restritas, no princípio, inacessíveis a grandes embarcações.

A escala de abordagem dos estudos também evoluiu como consequiência dos avanços tecnológicos tendo em vista que o poder de resolução dos métodos geofísicos foi profundamente melhorado. Levantamentos originalmente realizados em caráter de reconhecimento regional passaram a ser viáveis de realização em escalas locais, possibilitando uma abordagem dos problemas geológicos numa escala mais apropriada.

Os métodos geofísicos utilizados na investigação de áreas submersas rasas são oriundos daqueles utilizados originalmente na investigação profunda, voltada essencialmente para o reconhecimento das estruturas do interior da Terra e à prospecção de petróleo. O desenvolvimento dos métodos geofísicos de investigação profunda se fez possível, se auto-sustentou e se autoviabilizou, principalmente como conseqüência dos interesses econômicos voltados ao petróleo.

Com a crescente demanda de conhecimentos mais detalhados dos terrenos submersos, a partir da necessidade do estabelecimento, com segurança, de grandes obras 
civis em áreas costeiras e em áreas submersas continentais (dutos, pontes, hidrovias, grandes barragens), a geofísica aplicada nas investigações em águas rasas apropriou-se, de certa forma, dos conceitos e princípios estabelecidos originalmente para os métodos geofísicos utilizados para a investigação profunda. Certas adaptações foram necessárias e, esta apropriação possível, devido aos avanços tecnológicos nestes últimos anos no campo da engenharia eletrônica, da informática e da instrumentação.

Basicamente, os ensaios geofísicos empregados na investigação de áreas submersas são desenvolvidos por meio de uma embarcação, que traz no seu interior um sistema para registro e armazenamento de dados e uma fonte de sinais que normalmente é rebocada na superfície da água a certa distância da embarcação (em alguns métodos, imersa na coluna d'água, e em outros, instalada na superfície de fundo). Este arranjo é válido praticamente para todos os métodos utilizados na investigação de áreas submersas.

Serão abordados neste trabalho os principais métodos geofísicos empregados na investigação de áreas submersas rasas, a saber:

- métodos sísmicos: por métodos sísmicos entende-se aqueles que manipulam uma fonte de sinais acústicos. São vários os métodos sísmicos disponíveis e a diferenciação entre eles se faz basicamente pela frequiência e amplitude dos sinais acústicos emitidos. Inclui-se sob esta denominação basicamente a ecobatimetria, sonar de varredura lateral e perfilagem sísmica contínua;

- métodos geoelétricos: destaca-se na investigação de áreas submersas rasas os métodos geoelétricos cujo objetivo é identificar a resistividade elétrica dos meios geológicos.

- magnetometria: medem as variações do campo magnético terrestre que ocorrem devido às influências dos materiais com diferentes suscetibilidades magnéticas existentes na crosta terrestre;

- métodos eletromagnéticos (GPR): medem o comportamento das ondas e dos campos eletromagnéticas no interior da terra. Abordagem especial será dada ao GPR ou radar de penetração do solo, por se tratar de método recente e que tem apresentado boas perspectivas para utilização na investigação de áreas submersas

\subsection{MÉTOdos sísMicos}

Métodos sísmicos de alta resolução têm sido utilizados intensamente nestas últimas duas ou três décadas no mapeamento do Quaternário, na investigação dos processos sedimentares, na engenharia costeira, na exploração mineral e nos estudos de habitats subaquáticos entre outros temas. 
As demandas dos métodos sísmicos de alta resolução para a investigação de áreas submersas rasas são distintas da sísmica de reflexão tradicional voltada à exploração de petróleo. Apesar de ambas as técnicas empregarem os mesmos princípios fundamentais da reflexão sísmica, são diferentes os sistemas de aquisição de dados, as fontes acústicas (comumente de baixa energia), os espectros de freqüências emitidos, os receptores, os sistemas de processamento e até mesmo as formas de apresentação dos dados.

Ao contrário da investigação sísmica convencional, a sísmica de reflexão de alta resolução lida com meios geológicos ou interfaces geológicas que comumente apresentam baixos contrastes de impedância acústica, baixa relação sinal ruído, além de se constituírem em fortes atenuadores de sinais de alta frequiência. Comumente a investigação destes meios exige a utilização de fontes acústicas que emitem sinais com espectros de frequiência mais altos, o que torna a rugosidade das superfícies, ou das interfaces, propriedades físicas relevantes, pois que representam papel importante na análise do espalhamento do sinal acústico (scattering).

No estudo de áreas submersas, os métodos acústicos ou sísmicos se destacam quando comparados com outros métodos geofísicos. Este destaque tem como base algumas características especiais, dentre as quais podem ser ressaltadas:

- a grande precisão, resolução e penetração dos sinais sísmicos;

- o produto obtido em campo, em tempo real, é um perfil contínuo onde se identificam os refletores (contatos geológicos) em subsuperfície, à medida da evolução dos levantamentos, sem a necessidade de complexos processamentos dos dados, que comumente são feitos a posteriori com objetivo de obtenção de detalhes adicionais;

- os perfis obtidos em campo, em tempo real, podem ser interpretados praticamente como uma seção geológica sobrelevada, possibilitando que decisões estratégicas possam ser tomadas durante a própria aquisição de dados (Figura 8.1);

- os levantamentos podem ser conduzidos em embarcações de pequeno e médio porte que se movem a velocidades comumente superiores a $6 \mathrm{~km} / \mathrm{h}$, o que possibilita rápida e ampla cobertura da área investigada;

- fontes acústicas não-explosivas podem ser utilizadas (boomers, sparkers, air-guns) sem prejuízos ou restrições ambientais;

- a geração de ondas acústicas na superfície da água é relativamente fácil, bem como a propagação das ondas acústicas no meio, já que sofrem pouca absorção na coluna d’água. 


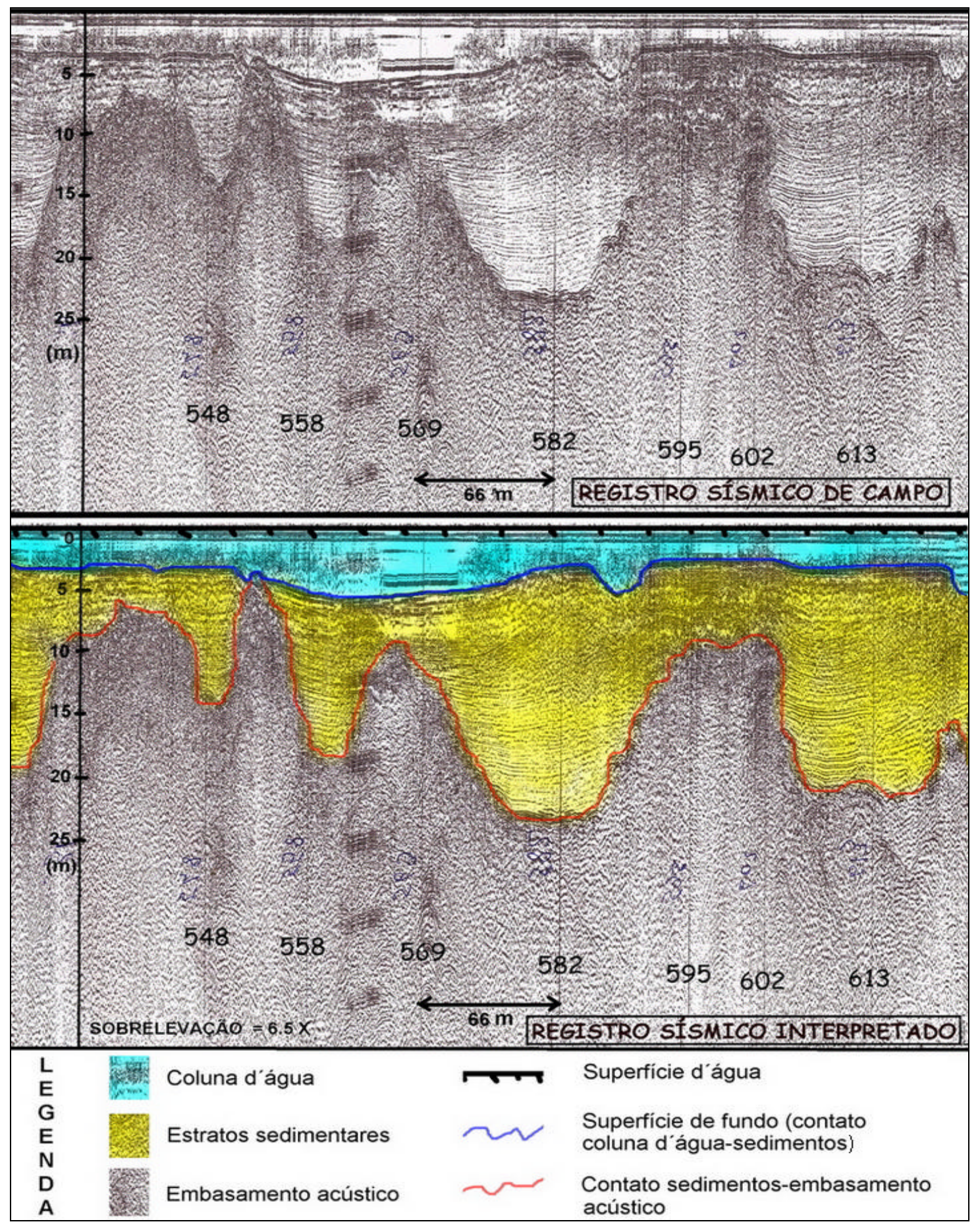

Figura 8.1: Registro sísmico (de expressiva qualidade) obtido no lago Guaraciaba, município de Santo André, SP, ilustrando uma das principais propriedades dos métodos sísmicos que é a possibilidade da correlação praticamente direta, entre um perfil sísmico obtido em campo (parte superior da figura) e um perfil geológico (parte inferior da figura). Modificado de IPT (2004) e Souza et al. (2003).

O produto final de uma investigação geofísica é geralmente um mapa de distribuição de uma determinada, ou de várias, propriedade física, ou não raramente um mapa ilustrando os resultados da interpretação dos parâmetros geofísicos observados. Este mapa por si só não é, necessariamente, a solução da questão inicialmente proposta, mas, sim, mais um instrumento de análise do problema exposto. 
O sucesso na aplicação de métodos geofísicos, para a solução de questões geológicas e geotécnicas, e a obtenção de dados com a melhor qualidade possível, passam pela execução dos ensaios por profissionais competentes, pelo claro estabelecimento dos objetivos da investigação, bem como pela análise preliminar da aplicabilidade de determinados métodos na investigação. Resolução e penetração constituem-se em alguns dos itens que devem ser analisados cuidadosamente e confrontados com os objetivos do projeto, para finalmente se optar pelo método de investigação a ser utilizado.

\subsubsection{FUNDAMENTOS}

Os fundamentos dos métodos sísmicos estão baseados nos princípios de propagação das ondas acústicas. Na investigação de áreas submersas, estes princípios são aplicados diretamente para a compreensão dos fenômenos referentes à propagação das ondas acústicas na água e nos estratos subjacentes (Urick, 1983).

A sísmica de reflexão lida com o fenômeno da reflexão do som nas interfaces entre os meios com distintas propriedades físicas, ou seja, com contrastes de impedância acústica.

Impedância acústica (i) constitui-se em fundamental propriedade do meio geológico quando se trata da investigação sísmica. É matematicamente representada pelo produto da velocidade de propagação do som num meio $\left(\mathrm{v}_{1}\right)$ pela densidade $\left(\mathrm{d}_{1}\right)$, ou seja, a impedância (i) de um meio 1 é igual a: $\mathrm{i}_{1}=\left(\mathrm{v}_{1}\right) \times\left(\mathrm{d}_{1}\right)$. O fenômeno físico da reflexão das ondas acústicas só ocorre quando existem contrastes representativos entre os meios atravessados pelo sinal acústico emitido.

Teoricamente, corpos extremamente homogêneos não refletem as ondas acústicas, até que estas encontrem obstáculos ou interfaces acústicas (outro tipo de rocha, por exemplo).

Da mesma forma, a quantidade de energia que é refletida, quando o sinal acústico atinge uma superfície ou uma interface, é função direta do contraste de impedância existente entre os dois meios. A superfície que delineia o contato entre dois meios acusticamente distintos, e que numa seção sísmica é representada por uma linha contínua (eventualmente não), é denominada de refletor sísmico ou simplesmente refletor. A Figura 8.2 :mostra um registro sísmico de excelente qualidade obtido na Baía 
de Paranaguá, PR, onde se observa nítidos refletores sísmicos representando os contatos entre os estratos sedimentares e com o embasamento rochoso.

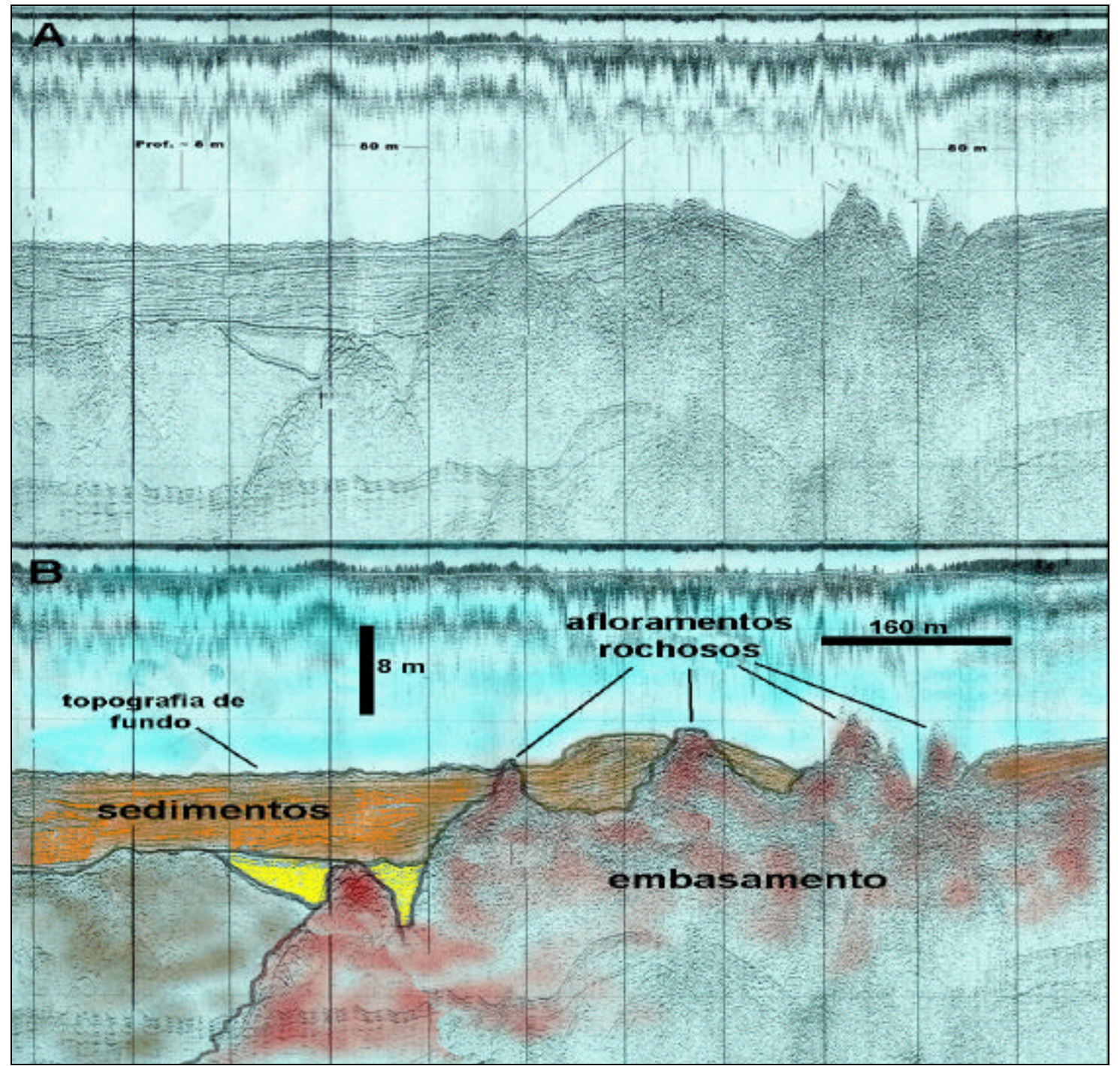

Figura 8.2 : Exemplo de perfil sísmico de excelente qualidade obtido com uma fonte acústica do tipo boomer em levantamento executado na Baía de Paranaguá, PR: a) registro de campo; b) registro interpretado. Registro cedido pela empresa Microars, RJ.

Outro importante conceito na investigação sísmica é o coeficiente de reflexão $(\mathbf{R})$, dado pelo quociente entre a diferença de impedância acústica de dois meios (meio 1 e meio 2), pela soma, ou seja, $R=\left(v_{2} \times d_{2}-v 1 \times d_{1}\right) /\left(v_{2} x_{2}+v_{1} \times d_{1}\right)$.

A título de exemplo, supõe-se uma situação na qual uma camada de sedimentos com velocidade de propagação do som de $1550 \mathrm{~m} / \mathrm{s}$ e densidade de $1.9 \mathrm{~g} / \mathrm{cm}^{3}$ se sobrepõe a uma outra camada de sedimentos com velocidade de propagação de 1750 $\mathrm{m} / \mathrm{s}$ e densidade de $2.1 \mathrm{~g} / \mathrm{cm}^{3}$. Neste caso, o coeficiente de reflexão da interface entre esses dois meios é dado por $(1750 \times 2.1-1550 \times 1.9) /(1750 \times 2.1+1550 \times 1.9)=$ 0.11 , significando que uma interface com estas características reflete $11 \%$ do sinal 
incidente. Refletores comuns possuem valores de coeficiente de reflexão entre $0.1 \mathrm{e}$ 0.01 , enquanto que os excelentes, $R=0.3$.

Basicamente, a utilização dos métodos sísmicos de reflexão se dá a partir da emissão de pulsos sonoros por meio de fontes acústicas rebocadas na superfície da água, ou muito próximos dela. Em alguns métodos a fonte sísmica é posicionada na coluna d'água, a certa distância da superfície de fundo.

As frentes de ondas emitidas pela fonte acústica se propagam através da água e dos estratos sedimentares subjacentes em velocidades que variam de acordo com as características físicas de cada um dos meios geológicos atravessados pelo sinal.

Quando da ocorrência de contrastes de velocidade de propagação e de densidade, ou seja, contrastes de impedância acústica entre dois estratos, uma parte da energia das frentes de onda é refletida na interface entre os meios e retorna à superfície e a outra, penetra nas camadas sedimentares, retornado aos sensores (hidrofones) subseqüentemente. Os sinais recebidos pelos sensores são conduzidos ao sistema de processamento e gravação, para finalmente serem impressos na forma de uma seção, em papel eletrossensível, ou, no caso dos equipamentos mais modernos, gravada digitalmente.

O primeiro sinal que retorna aos sensores é normalmente oriundo da superfície de fundo e, portanto, sua interpretação possibilita identificar a espessura da coluna d'água; os sinais que atingem o sensor subsequentemente, são aqueles que penetraram na coluna sedimentar e, portanto, possibilitam a identificação da espessura dos estratos sedimentares. Em ambos os casos, as medidas efetuadas têm como base os tempos de percurso de ida e volta dos sinais acústicos, ou seja, o tempo duplo de percurso, termo conhecido no meio geofísico como TWT (two way time).

A energia refletida nas interfaces entre os meios com distintas impedâncias acústicas é proporcional à amplitude do sinal emitido pela fonte e a magnitude do contraste propriamente dito entre os meios. A detecção do sinal refletido depende também da geometria do arranjo fonte-sensor.

A Figura 8.3 exibe de forma esquemática a geometria do arranjo de campo entre fonte, receptores e a embarcação. 


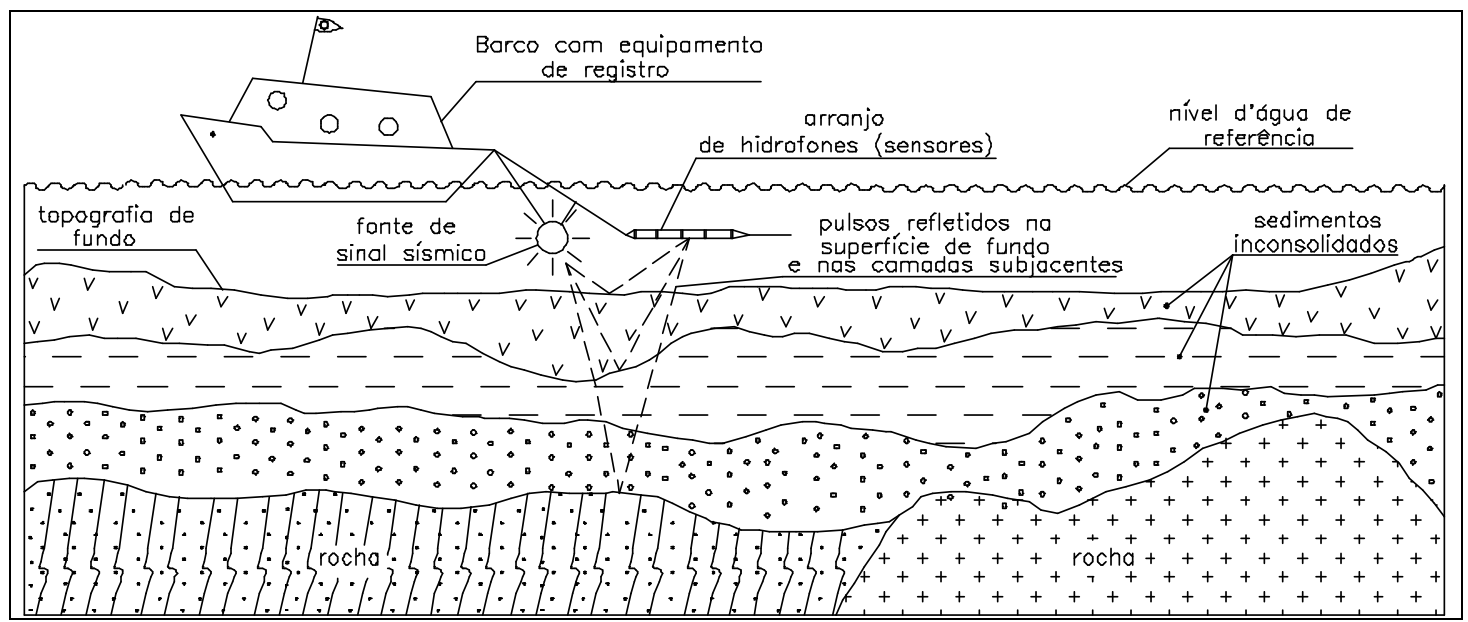

Figura 8.3: Perfilagem Sísmica Contínua: geometria do arranjo para aquisição de dados: fonte acústicasensores-embarcação (Souza, 1988).

\subsubsection{FONTES SÍSMICAS}

No planejamento de um levantamento geofísico de áreas submersas rasas por meio da sísmica de reflexão, o tipo de fonte acústica constitui-se no principal item a ser discutido.

Uma fonte sísmica ideal é aquela que produz um pulso num tempo mínimo, com amplo espectro de freqüências (todas) com alta energia. Como fisicamente esta configuração não é possível, já que a energia armazenada numa fonte acústica não pode ser transferida de maneira instantânea para o meio geológico, a maioria das fontes acústicas é basicamente de dois tipos: aquelas que tentam se aproximar do ideal, emitindo um amplo espectro de freqüências num menor tempo possível (p.ex. sparkers, air-guns), e aquelas que emitem um determinado espectro de freqüências ao longo de um intervalo de tempo pré-definido (p.ex. chirp, vibradores).

A escolha do tipo de fonte acústica apropriada aos objetivos de um determinado estudo resultará sempre de um raciocínio ponderado entre as necessidades de maior penetração, que demanda fontes que emitem baixas freqüências, e de maior resolução, o que demanda fontes acústicas que emitem largas bandas de freqüências (inclusive altas frequiências). Reynolds (1990) discute amplamente este tema apresentando resultados comparativos que permitem avaliar o desempenho de algumas fontes acústicas com relação à resolução e à penetração.

Qualquer fonte acústica utilizada na investigação sísmica de áreas submersas tem por objetivo converter/transmitir a energia acumulada em um capacitor, em movimento da massa de água ao redor da fonte (McGee 1995a; Mosher \& Simpkin 1999). Este movimento da massa d'água se manifesta na forma de variações de pressão 
e se propaga na coluna d'água a partir da fonte, obedecendo às leis físicas da reflexão, absorção, difração, refração e espalhamento (scattering).

São vários os tipos de fontes acústicas desenvolvidos para atuar na água e, como tal, podem ser classificadas de várias maneiras.

McGee (1995a) classifica as diferentes fontes de energia usadas na investigação de áreas submersas basicamente em dois tipos: ressonantes e impulsivas.

\subsubsection{Fontes ressonantes}

Sob a classificação de fontes ressonantes, tanto McGee (1995a) quanto Mosher \& Simpkin (1999) incluem desde fontes usadas na batimetria convencional (ecobatímetros) até fontes mais modernas que possuem capacidade de penetração, ou seja, agem como perfiladores propriamente ditos (chirp p.ex.). Este tipo de fonte produz um sinal acústico com forma conhecida, altamente repetitivo, e origina-se a partir da frequiência de ressonância de pastilhas (cristais) piezelétricas. A Figura 8.4 ilustra as formas de onda originadas deste tipo de fonte acústica.

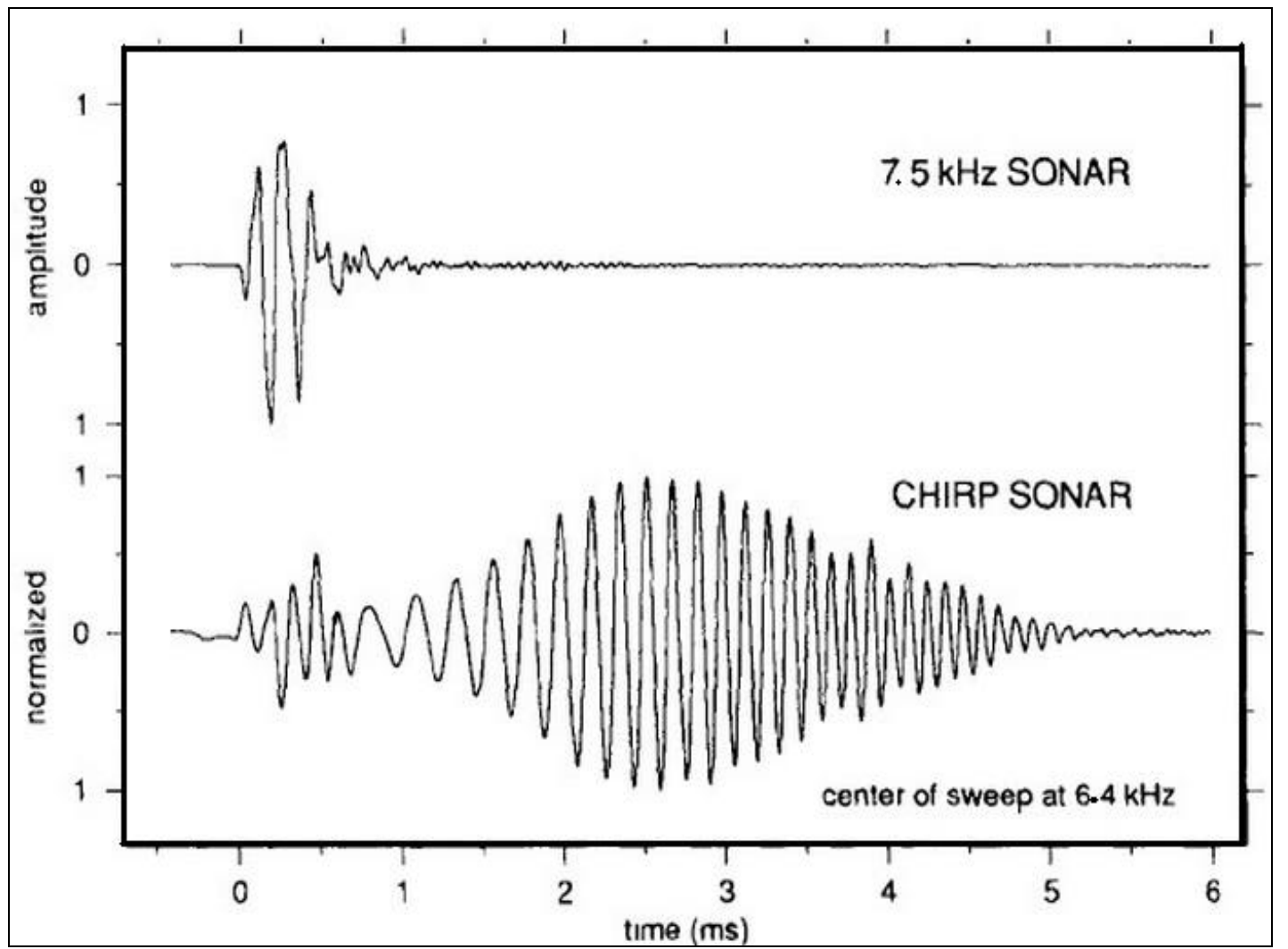

Figura 8.4: Exemplos de forma dos sinais emitidos por fontes acústicas ressonantes ou de forma de onda controlada (McGee, 1995a).

Este tipo de fonte acústica é a mais comumente empregada na investigação de áreas submersas. Utilizam este sistema desde ecobatímetros de alta freqüência, que 
emitem freqüências específicas em intervalos de tempo mínimos (p.ex. $50 \mathrm{kHz}, 200$ $\mathrm{kHz}$ ), até as modernas fontes denominadas chirp, que emitem amplos espectros de freqüências num determinado intervalo de tempo (p.ex. 2 a 8 kHz em 5-6 ms).

Além dos exemplos ilustrados na Figura 8.5 e na Figura 8.6, algumas empresas fabricam também modelos acopláveis ao casco das embarcações. Estes modelos são muito interessantes em algumas situações, como por exemplo, em levantamentos em ambientes ruidosos ou com grande coluna d'água, quando certamente a atuação conjunta, sincronizada e simultânea, de mais de uma fonte acústica, resulta em relevante melhoria da relação sinal/ruído.

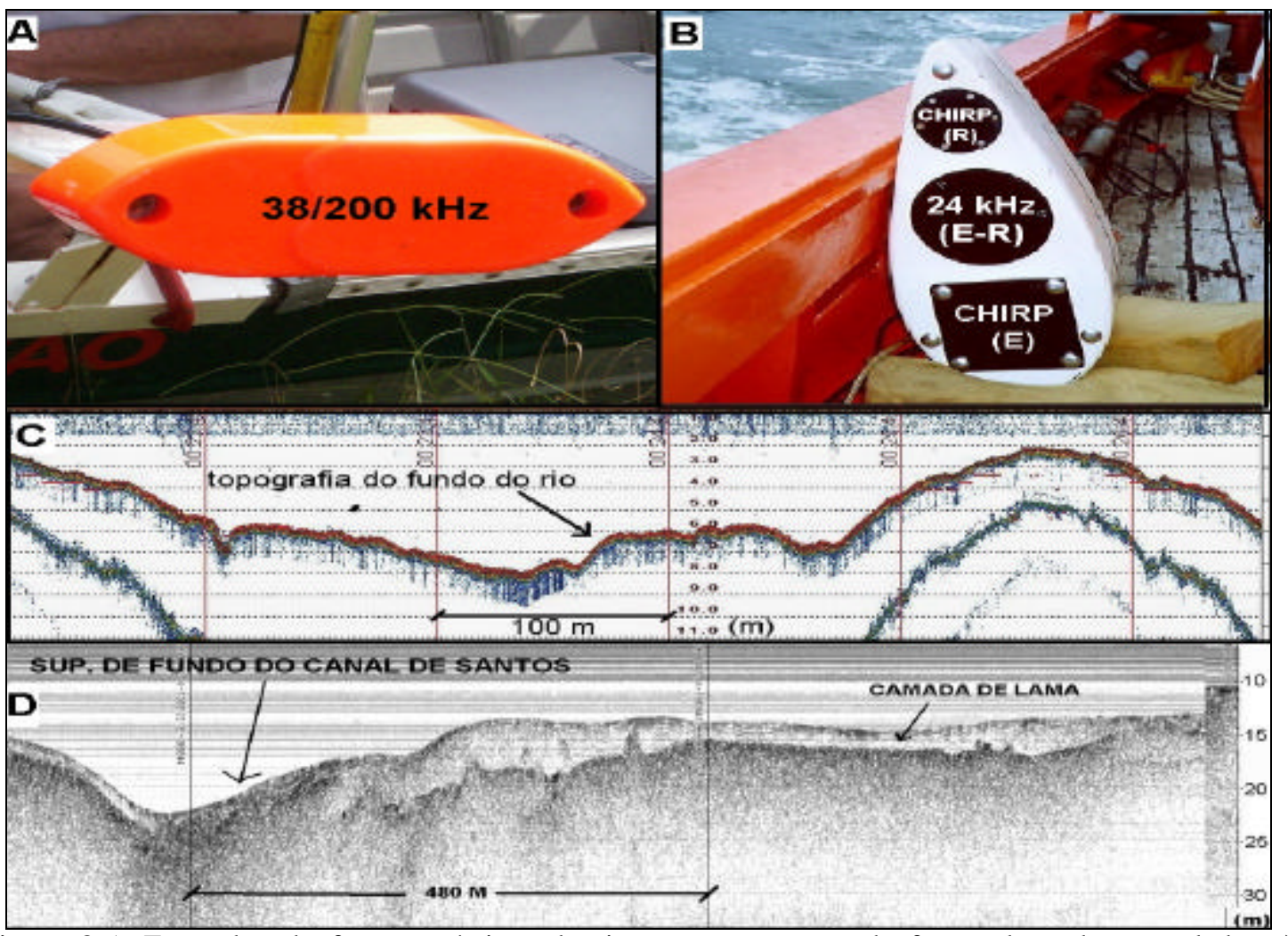

Figura 8.5: Exemplos de fontes acústicas do tipo ressonantes ou de forma de onda controlada: a) transdutor de ecobatímetro de dupla freqüência $(38 / 200 \mathrm{kHz})$ da Kongsberg/Simrad (Noruega) pertencente ao Instituto de Pesquisas Tecnológicas do Estado de São Paulo; b) transdutor composto: chirp + Pinger (24 kHz) da Meridata System (Finlândia), pertencente ao Instituto Oceanográfico da USP. (E = transdutor emissor de sinais acústicos; $\mathrm{R}=$ transdutor sensor/receptor) - Fotos: autor; c) exemplo de perfil batimétrico obtido no rio São Francisco (AL/SE) com o eco 38/200 kHz (Registro cedido pela Georadar); d) exemplo de registro obtido com fonte do tipo chirp no canal de Santos, SP (Registro cedido pelo Prof. Dr. Michel M. de Mahiques).

Qualquer destes sistemas opera com base no princípio de que um campo elétrico aplicado sobre uma pastilha piezelétrica resulta na produção de um trabalho mecânico proporcional à intensidade do campo elétrico aplicado. Se a freqüência do campo elétrico aplicado é próxima da frequiência de ressonância do material do transdutor, a energia elétrica é facilmente convertida em energia mecânica e, por 
conseguinte, em movimento de vibração da pastilha, que é facilmente transmitido à massa de água existente ao redor da fonte. Este processo é reversível, ou seja, a pressão da água sobre o transdutor gera um sinal elétrico que no receptor indica o retorno do sinal emitido. Os perfiladores do tipo $3.5 \mathrm{kHz}$ são bons exemplos deste tipo de fonte.

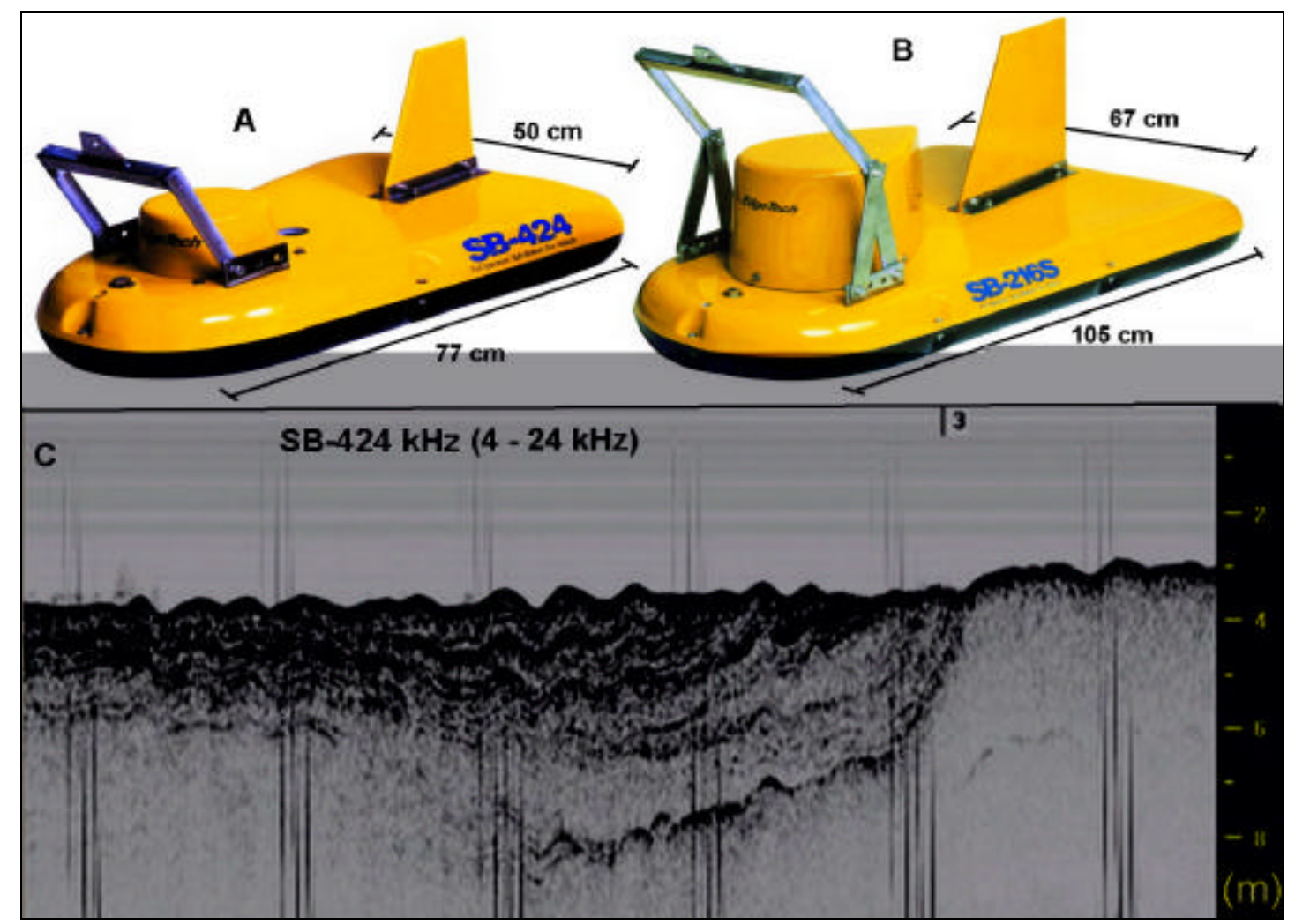

Figura 8.6: Dois modelos de fontes acústicas do tipo chirp da Edgetech: a) SB216S (2-16 kHz); b) SB$424(4-24 \mathrm{kHz}) ;$ c) exemplo de registro sísmico obtido com o chirp modelo SB 424. Fonte: <http://www.edgetech.com>.

Fontes ressonantes, entretanto, possuem limitações físicas com relação à absorção da energia, ou seja, não é ilimitada a capacidade ou a potência de emissão de sinais acústicos. Efeitos do tipo cavitação (vaporização da água no contato com o transdutor devido à rápida contração dos transdutores) surgem com o aumento da energia aplicada sobre estes transdutores, gerando ruídos indesejáveis e inviabilizando o aumento da potência de transmissão para este tipo de fonte.

Uma solução, pelo menos parcial, deste problema foi encontrada com o desenvolvimento recente de uma fonte ressonante denominada de chirp. Por meio da alteração do número de ciclos (freqüência), esta fonte acústica torna o pulso emitido mais longo, ou seja, gera um espectro de freqüências mais amplo, possibilitando relativo aumento da potência do sinal transmitido, aumentando conseqüentemente a penetração do sinal emitido, a despeito da perda parcial da resolução (McGee, 1995a). 
Este tipo de fonte constitui-se num único módulo que contém o sistema emissor (fonte) e o receptor (hidrofone). O tipo de sinal emitido por esta fonte está ilustrado na Figura 8.4. Alguns modelos disponíveis atualmente no mercado estão exibidos na Figura 8.5b, na Figura 8.6 e na Figura 8.7.

Os sistemas sísmicos com fontes acústicas do tipo chirp hoje disponíveis são digitais e disponibilizam várias alternativas operacionais que permitem, por exemplo, o controle total do espectro de frequiências e das características dos pulsos emitidos, propriedades estas que estão diretamente relacionadas com a resolução e penetração do sistema. A título de exemplo, a Tabela 8-1 mostra um conjunto de características de três modelos de fontes do tipo chirp fabricados pela empresa americana Edgetech.

\begin{tabular}{|c|c|c|c|}
\hline modelo da fonte & SB $512 i$ & SB-216S & SB-424 \\
\hline espectro de freqüências & $500 \mathrm{~Hz}-12 \mathrm{kHz}$ & $2.16 \mathrm{kHz}$ & $4 \cdot 24 \mathrm{kHz}$ \\
\hline $\begin{array}{l}\text { pulsos (selecionado pelo } \\
\text { operador) }\end{array}$ & $\begin{array}{c}2-12 \mathrm{kHz}, 2.8 \mathrm{kHz} \\
1.5 .7 .5 \mathrm{kHz}, 1.6 \mathrm{kHz} \\
1.5 \mathrm{kHz}, 0.5 .5 \mathrm{kHz}\end{array}$ & $\begin{array}{c}2-16 \mathrm{kHz}, 2-12 \mathrm{kHz} \\
2-10 \mathrm{kHz}\end{array}$ & $\begin{array}{c}4-24 \mathrm{kHz}, 4-20 \mathrm{kHz} \\
4-16 \mathrm{kHz}\end{array}$ \\
\hline $\begin{array}{l}\text { resolucăo vertical (dependente } \\
\text { do pulso selecionado) }\end{array}$ & $8 \cdot 20 \mathrm{~cm}$ & $6-10 \mathrm{~cm}$ & $4-8 \mathrm{~cm}$ \\
\hline penetração areia grossa & 20 & 6 & 2 \\
\hline (m) argilas & 200 & 80 & 40 \\
\hline $\begin{array}{l}\text { largura do feixe de sinais } \\
\text { (dependente da frequência) }\end{array}$ & $16^{\circ}-32^{\circ}$ & $17^{\circ} \cdot 24^{\circ}$ & $16^{\circ} \cdot 23^{\circ}$ \\
\hline $\operatorname{tamanho}(\mathrm{cm})$ & $160 \mathrm{~L} \times 124 \mathrm{~W} \times 47 \mathrm{H}$ & $105 \mathrm{~L} \times 67 \mathrm{~W} \times 40 \mathrm{H}$ & $77 \mathrm{~L} \times 50 \mathrm{~W} \times 34 \mathrm{H}$ \\
\hline peso & $190 \mathrm{~kg}$ & $76 \mathrm{~kg}$ & $22 \mathrm{~kg}$ \\
\hline calibraçäo & \multicolumn{3}{|c|}{ sistemas calibráveis para medidas de coef. de reflexāo) } \\
\hline cabos & \multicolumn{3}{|c|}{3 pares de cabos blindados } \\
\hline máxima prof de operaçāo & \multicolumn{3}{|c|}{$300 \mathrm{~m}$} \\
\hline altura ideal do peixe & \multicolumn{3}{|c|}{$3-5$ (metros acima da sup. de fundo ) } \\
\hline velocidade de navegação & \multicolumn{3}{|c|}{$3-4$ nós (ideal) $/ 7$ nós (máxima veloc. com segurança) } \\
\hline opções adicionais & \multicolumn{3}{|c|}{ Integrated Depth Sensor, 4 kW Amplifier, USBL Acoustic Tracking System } \\
\hline
\end{tabular}

Tabela 8-1: Exemplo de conjunto de especificações de fontes acústicas do tipo chirp, fabricados pela empresa americana Edgetec. Modificado de <http://www.edgetech.com>. Acesso: dez/2005.

Conforme pode ser observado na tabela, cada um dos três modelos apresentados possui não só características físicas específicas (tamanho e peso) como também propriedades acústicas distintas, que determinam basicamente a resolução e a penetração de cada um dos sistemas. Depreende-se ainda a partir da análise das características dos exemplos mostrados na tabela que o porte da fonte (tamanho e peso) constitui-se em propriedade íntima e diretamente relacionada com a capacidade de penetração do sistema acústico, pois fontes de maior potência são também de maior porte e emitem espectros menores de freqüências, o que propicia a maior penetração dos sinais emitidos. O modelo SB-512i da Edgetech, por exemplo, possui excelente 
desempenho no quesito penetração, entretanto, tendo em vista suas dimensões, exige arranjos operacionais mais complexos quando da aquisição dos dados (Figura 8.7).

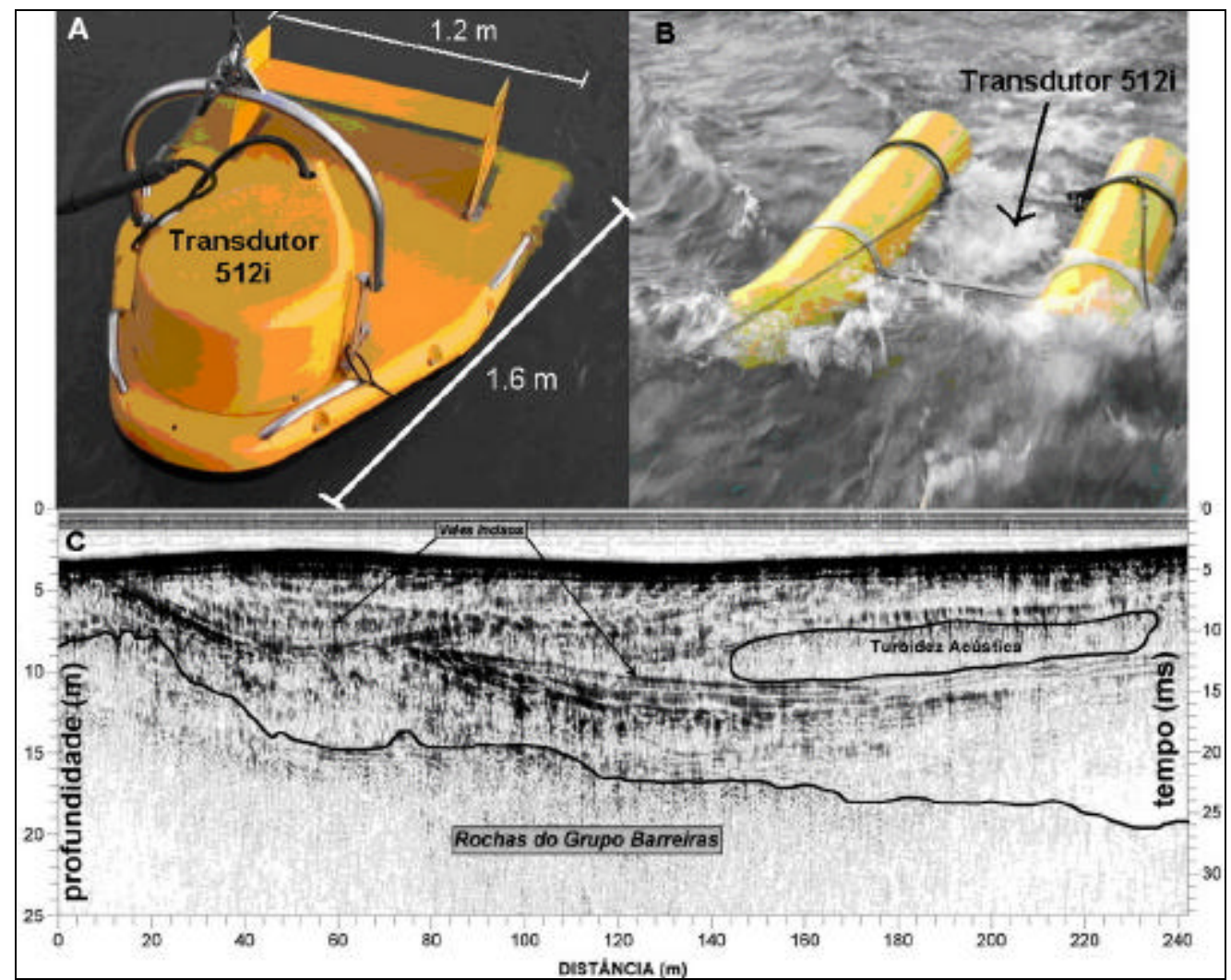

Figura 8.7: a) vista do perfilador EdgeTech modelo SB-512i $(500 \mathrm{~Hz}-12 \mathrm{kHz})$; b) transdutor acoplado em catamarã, em operação no Estuário Potengi (RN); c) registro obtido por este perfilador no Estuário Potengi (Frazão \& Vital, 2006). Fotos: Dra. Helenice Vital.

O uso de fontes ressonantes ou de forma de onda controlada na investigação de áreas submersas tem uma série de vantagens, a saber: a enorme facilidade operacional (grande manobrabilidade devido ao pequeno porte), o baixo custo de manutenção, a alta taxa de repetibilidade, eficiência (alta relação sinal/ruído) e a facilidade de ser utilizada até mesmo em grandes profundidades.

As desvantagens na utilização destas fontes acústicas residem principalmente no fato de que em alguns projetos se faz necessária a penetração na superfície de fundo além de alguns poucos metros e, a depender do tipo de fundo estudado (areia grossa, p.ex.), este tipo de fonte acústica pode não atingir a profundidade desejada.

À exceção do chirp, que tem a característica de lidar com espectros mais amplos de frequiência, conforme mostra Figura 8.4, fontes do tipo ressonantes utilizam comumente estreitos espectros de freqüências, de baixa energia e com limitações em relação ao comprimento dos pulsos emitidos, e assim, constituem sistemas com baixo poder de penetração em sedimentos arenosos, por exemplo. 
Uma opção interessante para obtenção de maior penetração do sinal acústico emitido por fontes do tipo ressonante, é a instalação direta no casco da embarcação de conjuntos de transdutores. A possibilidade de somar os sinais recebidos por cada uma das fontes age diretamente na direção da melhoria da relação sinal/ruído. A quantidade de fontes a serem instaladas é regida basicamente pela espessura da coluna d'água. Em áreas costeiras, por exemplo, arranjos com duas fontes já demonstram notável melhoria do desempenho do sistema. Para áreas mais profundas, quatro ou cinco fontes emitindo simultaneamente o sinal acústico garantem excelente desempenho do sistema. A Tabela 8-2 ilustra um exemplo de configuração de arranjos de fontes do tipo chirp da marca Edgetech. Denota-se nesta tabela, que ao se aumentar o número de transdutores do arranjo, diminui-se a largura do feixe de sinais, o que contribui efetivamente para a melhoria da relação sinal/ruído. Algumas experiências registradas na literatura demonstram de forma inequívoca o relevante aumento no desempenho de fontes do tipo ressonante quando da atuação conjunta e simultânea de uma série de transdutores (Nishimura et al., 1984).

\begin{tabular}{|c|c|c|c|}
\hline espectro de frequências & \multicolumn{3}{|c|}{$2-16 \mathrm{kHz}$} \\
\hline pulso (selecionado pelo operador) & \multicolumn{3}{|c|}{$2-16 \mathrm{kHz}, 2-12 \mathrm{kHz}, 2-10 \mathrm{kHz}$} \\
\hline $\begin{array}{l}\text { resoluçäo vertical (dependente do } \\
\text { pulso selecionado) }\end{array}$ & \multicolumn{3}{|c|}{$6 \cdot 10 \mathrm{~cm}$} \\
\hline \multirow{2}{*}{$\begin{array}{ll}\text { PENETRAÇÃo } & \begin{array}{l}\text { areia grossa } \\
\text { sedimentos finos }\end{array}\end{array}$} & \multicolumn{3}{|c|}{$6 \mathrm{~m}$} \\
\hline & \multicolumn{3}{|c|}{$80 \mathrm{~m}$} \\
\hline \multirow{5}{*}{ largura do feixe de sinais } & $\begin{array}{c}\text { arranjo de } \\
\text { transdutores }\end{array}$ & $\begin{array}{c}4.5 \mathrm{kHz} \\
\text { freqüência central }\end{array}$ & $\begin{array}{c}5 \mathrm{kHz} \\
\text { frequência central }\end{array}$ \\
\hline & $2 \times 2$ & $40^{\circ}$ & $33^{\circ}$ \\
\hline & $3 \times 3$ & $30^{\circ}$ & $25^{\circ}$ \\
\hline & $4 \times 4$ & $24^{\circ}$ & $20^{\circ}$ \\
\hline & $5 \times 5$ & $20^{\circ}$ & $17^{\circ}$ \\
\hline possibilidades com relação à calibração & \multicolumn{3}{|c|}{ o sistema pode ser calibrado para medida do coef. de reflexão } \\
\hline outras opçőes & \multicolumn{3}{|c|}{ Amplificador de $4 \mathrm{Kw} /$ arranjos de freqüências mais baixas } \\
\hline
\end{tabular}

Tabela 8-2: Exemplo de conjunto de especificações de fontes do tipo chirp com multitransdutores para instalação direta no casco das embarcações, fabricados pela empresa americana Edgetec. Modificado de <http://www.edgetech.com>. Acesso: dez/2005.

Algumas fontes acústicas alternativas baseadas no princípio paramétrico de propagação do som foram desenvolvidas com a finalidade de minimizar algumas das desvantagens das fontes ressonantes.

Transdutores acústicos que se utilizam do princípio paramétrico (Grant \& Schreiber, 1990; Wunderlich, 2003) são aqueles que produzem sinais de baixa frequiência a partir da emissão de dois sinais simultâneos de freqüências ligeiramente diferentes. A interferência entre os dois sinais emitidos gera uma freqüência secundária 
igual à diferença entre elas. Este sistema é bastante interessante, pois a partir de dois transdutores de alta freqüência (p.ex. $20 \mathrm{kHz}$ ), normalmente de pequeno porte, gera-se um sinal de baixa freqüência (neste caso, entre 2.5 e $5.5 \mathrm{kHz}$ ), de excelente diretividade e de alta energia e, portanto, com grande poder de penetração (Mosher \& Simpkin, 1999).

A Figura 8.8 ilustra o efeito denominado de paramétrico. No exemplo, observase o baixo poder de penetração do sinal acústico de $18 \mathrm{kHz}$ (perfil A) bastante melhorado (perfil B) quando da emissão simultânea de um sinal acústico de $21.5 \mathrm{kHz}$, resultando na emissão da freqüência de 3.5 kHz (Grant \& Schreiber, 1990).

Hübscher et al. (2003) utilizam-se deste sistema acústico para estudar os padrões sedimentares característicos da porção submersa do delta do rio Amazonas. Reinhardt et al. (2002) utilizam-se também deste método acústico pra investigar sequiências deposicionais de cerca de $30 \mathrm{~m}$ de espessura do quaternário superior da plataforma continental do Peru.

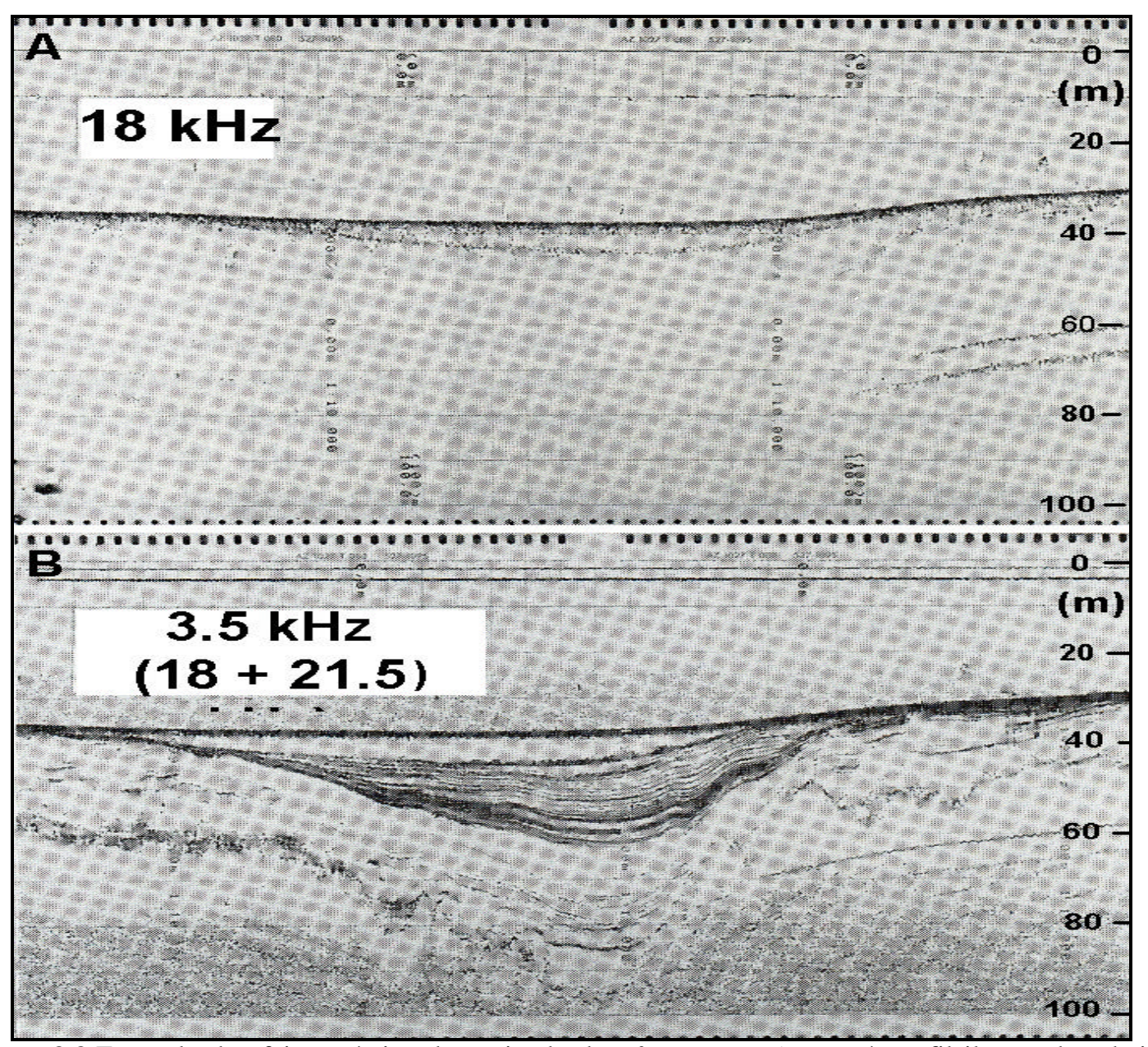

Figura 8.8:Exemplo do efeito acústico denominado de efeito paramétrico. a) perfil ilustrando o baixo poder de penetração do sinal acústico de $18 \mathrm{kHz}$; b) perfil ilustrando a penetração do sinal de $3.5 \mathrm{kHz}$, resultado da emissão simultânea de $18+21.5$ kHz. Modificado de Grant \& Schreiber (1990). 
A emissão de um sinal acústico equivalente a $3.5 \mathrm{kHz}$, por exemplo, a partir de um único transdutor, exigiria um sistema de maior porte, o que evidentemente demandaria maior complexidade operacional. Este tipo de fonte acústica tem sido amplamente utilizado na Europa em questões relacionadas com a batimetria de precisão, a projetos de dragagem, estudos de áreas favoráveis à instalação de dutos e cabos submarinos, à pesquisa mineral e até mesmo em estudos relacionados com a arqueologia subaquática. A Figura 8.9 exibe um sistema alemão (Innomar Technologie) que se utiliza do efeito paramétrico, lidando com freqüências primárias ao redor de 100 $\mathrm{kHz}$.

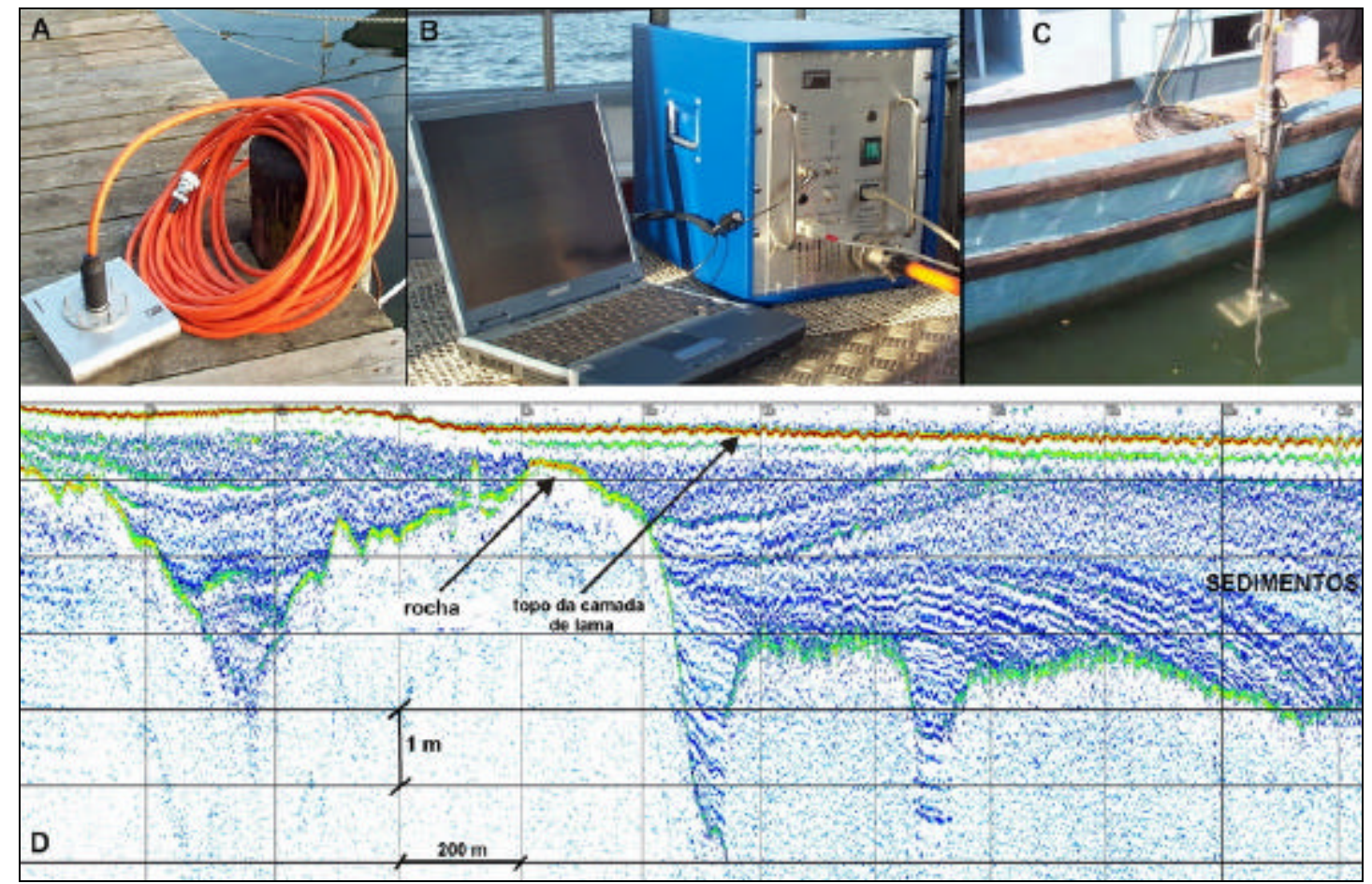

Figura 8.9: a) exemplo de transdutor acústico que utiliza o sistema paramétrico (modelo SES-96/2000Standard fabricado pela Innomar Technologie - Alemanha); b) notebook e equipamento de controle do sinal emitido; c) transdutor SES-96/2000 instalado numa embarcação de pequeno porte em levantamento executado na Índia (Lowag, 2000); c) exemplo de perfil ilustrando os nítidos contatos entre os diferentes estratos geológicos (sedimentos e afloramento rochoso), obtido em levantamento executado em bancos de areia de rios em Gâmbia. Fotos e registro sísmico, cedidos pela Dra. Sabine Mueller (Innomar Technologie / Alemanha).

A evolução da tecnologia tem tornado viável atualmente a construção de fontes ressonantes integradas. Num mesmo corpo, juntam-se fontes acústicas com espectros de freqüência distintos (ecobatímetros, sonar de varredura lateral, chirp) e diversos outros sensores (de pressão, temperatura e de movimentos). Estes modernos equipamentos são de alto custo e de porte relativamente grande, tendo sua maior aplicação nos estudos de áreas submersas profundas, até mesmo pela própria operacionalidade dos sistemas. Os modelos 2400-C (Integrated Deep Sonar System) da Edgetech, o Datasonics SIS-1000 
(Sea Floor Imaging System) da Benthos e o Deep Tow 2000 Telemetry System, da Geoacoustics, são exemplos de sofisticados e modernos sistemas multifunções que reúnem num só equipamento um sonar de varredura lateral (comumente de dupla freqüência) perfiladores do tipo chirp, além de magnetômetros e outros sensores diversos (pressão, temperatura etc.).

Placzek \& Haeni (1994) avaliaram o desempenho, em águas rasas, de fontes acústicas do tipo ressonantes em projeto piloto de avaliação de processos erosivos atuantes em áreas próximas aos pilares de uma ponte sobre o rio Connecticut, nos EUA. Utilizaram para tal finalidade fontes ressonantes de freqüência fixa de 3,5, 14 e $20 \mathrm{kHz}$ e também fontes do tipo chirp que emitem espectros de frequiência mais amplos, no caso entre 2-16 kHz. Conforme a Tabela 8-3 estes autores observaram que estas fontes acústicas são perfeitamente aplicáveis na investigação de áreas rasas, já que todas elas apresentaram resultados satisfatórios nos ensaios realizados em áreas com coluna d'água até mesmo inferiores a $1 \mathrm{~m}$. Destacam ainda que o chirp apresentou excelentes resultados em coluna d'água de até $0,3 \mathrm{~m}$. Quanto à resolução, a fonte fixa de 3,5 kHz e a fonte chirp apresentaram resultados semelhantes permitindo identificar estratos de até $0,8 \mathrm{~cm}$. As fontes de maior freqüência, como era de se esperar, apresentaram melhor resolução permitindo identificar estratos de até $0,3 \mathrm{~cm}$ de espessura. Quanto à penetração, as fontes acústicas com freqüências superiores a $10 \mathrm{kHz}$ alcançaram não mais que poucos metros ( $3 \mathrm{~m}$ para a fonte de $20 \mathrm{kHz} ; 6 \mathrm{~m}$ para a fonte de $14 \mathrm{kHz}$ ). A fonte fixa de $3,5 \mathrm{kHz}$ penetrou cerca de $30 \mathrm{~m}$, e a fonte chirp, $61 \mathrm{~m}$, ratificando a necessidade de utilização de fontes de baixa freqüência quando o projeto indica a necessidade de penetração nas camadas sedimentares rasas.

\begin{tabular}{|c|c|c|c|}
\hline freqüência $(\mathbf{k H z})$ & penetração máx $(\mathbf{m})$ & resolução $(\mathbf{m})$ & coluna d'água $(\mathbf{m})$ \\
\hline fixa 3.5 & 30.5 & 0.8 & 2.1 \\
\hline fixa 14.0 & 6.1 & 0.3 & 1.2 \\
\hline fixa 20.0 & 3.0 & 0.3 & 1.5 \\
\hline varredura 2-16 & 61.0 & 0.9 & 0.3 \\
\hline
\end{tabular}

Tabela 8-3: Desempenho de quatro fontes acústicas ressonantes de alta resolução $(3.5 ; 14 ; 20$ e 2-16 kHz) em testes sistemáticos realizados em projeto de estudos de processos erosivos de instabilidade de pilares de ponte em rio nos EUA. Observa-se nesta tabela a melhor resolução das fontes de maior freqüencia em contrapartida com a melhor penetração das fontes que emitem sinas de freqüências mais baixas, no contexto dos sedimentos fluviais, neste caso, basicamente composto de sedimentos finos (areias siltes e argilas). Placzek \& Haeni, 1994.

Ainda com relação às fontes ressonantes, é importante ressaltar que a freqüência do sinal emitido determina o tamanho e o peso dos transdutores que geram 
os sinais. De maneira geral, transdutores que geram freqüências mais baixas são maiores e mais pesados, e o feixe principal de sinais tem largura (beam angle) maior que aqueles que geram sinais de freqüências mais altas. Importante lembrar neste contexto que a largura do feixe principal de sinais constitui-se num item essencial na caracterização de uma fonte, pois contém a grande parte da energia emitida. Além disso, quando muito grandes $\left(120^{\circ}\right.$, p.ex.), permitem a reflexão de sinais fora da área de interesse - ecos laterais - possibilitando a geração de ruídos indesejáveis.

Assim, o tamanho da fonte acústica tem influência direta na logística de um levantamento geofísico. $\mathrm{Na}$ execução de estudos em áreas marinhas, são poucas as limitações com relação ao tamanho das fontes acústicas ou ao tamanho dos equipamentos geofísicos de um modo geral, pois comumente são utilizadas embarcações de porte médio a grande para a navegação no mar. Porém, quando do levantamento de áreas restritas (baías, rios etc.), este item torna-se importante aspecto a ser considerado. Os estudos realizados por Placzek \& Haeni (1994), por exemplo, desenvolveram-se em área restrita próxima aos piers de uma ponte, com pequena coluna d'água variando desde $1 \mathrm{~m}$ de profundidade, fatores que oferecem uma série de limitações operacionais.

\subsubsection{Fontes impulsivas}

As fontes acústicas impulsivas classificadas por McGee (1995a) são aquelas que liberam grande quantidade de energia num intervalo de tempo que idealmente é próximo de zero (Figura 8.10). Mosher \& Simpkin (1999) desenvolvem classificação análoga para fontes desta natureza, subdividindo este tipo de fonte de aceleração de massa, implosivas e explosivas.

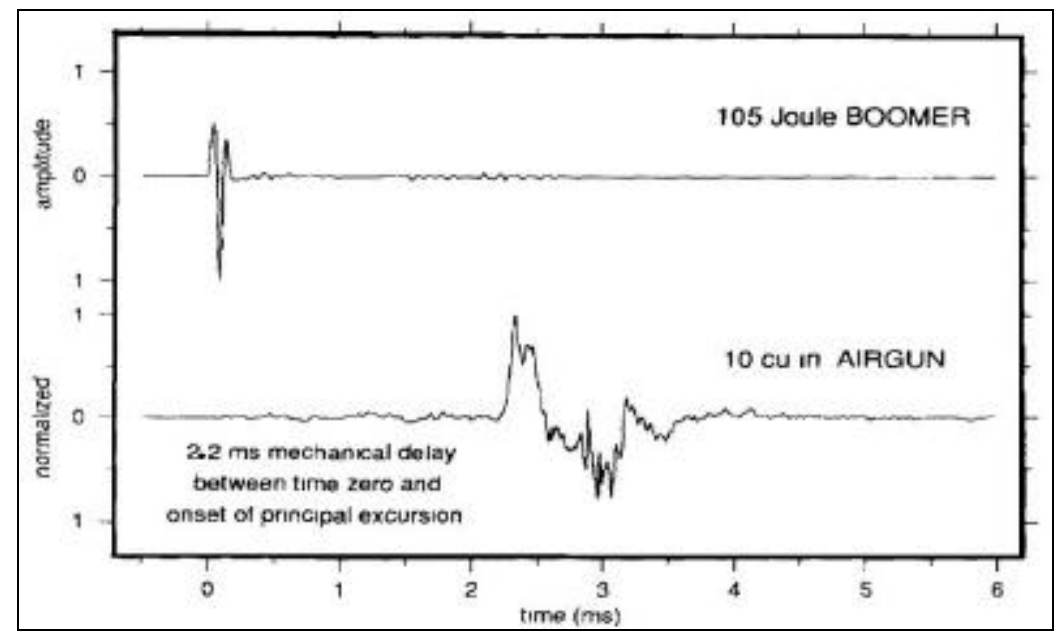

Figura 8.10: Exemplos de fontes impulsivas: boomer e airgun. McGee, 1995a. 
Fontes acústica do tipo aceleração de massa (Mosher \& Simpkin, 1999) são as que provocam rápido deslocamento de massa d'água quando da emissão do sinal acústico e têm sido muito utilizadas atualmente na sísmica de reflexão de alta resolução.

Boomers são os representantes mais comuns deste tipo de fonte. Alguns modelos existentes estão ilustrados na Figura 8.11.

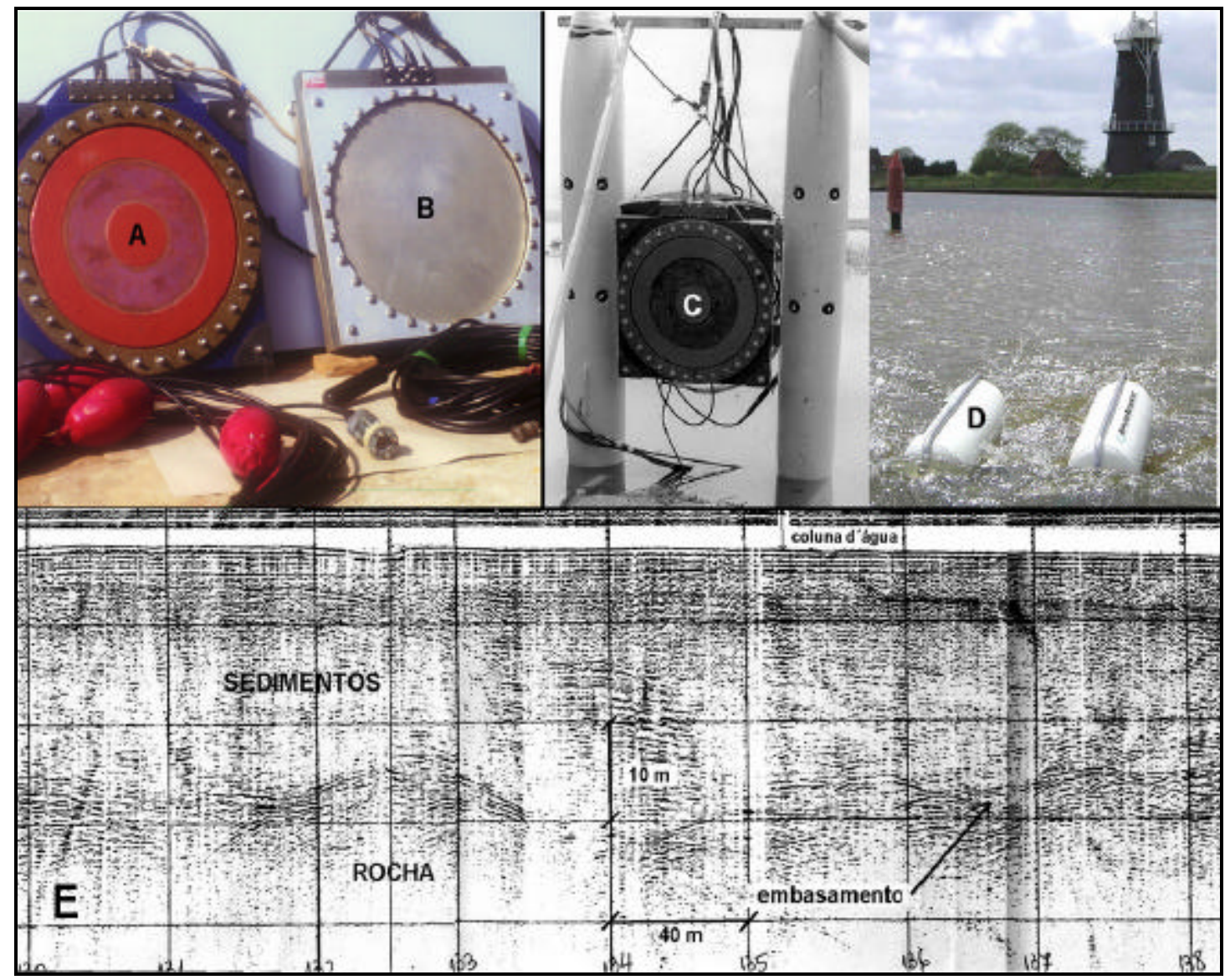

Figura 8.11: Exemplo de fontes acústicas do tipo boomer a) placa do boomer modelo ED-5 (5 kHz); b) placa do boomer modelo ED-10 $(10 \mathrm{kHz})$ c) boomer ED-5 montado em catamarãs, à beira do rio Paranapanema, SP. Ambas, fabricadas pela Huntec (Canadá) e pertencentes ao Instituto de Pesquisas Tecnológicas do Estado de São Paulo - IPT. Fotos: autor; d) boomer da Applied Acoustic (UK) em operação no rio Waveney (UK). Foto cedida pelo Dr. Adam Darling (Applied Acoustic, UK); e) perfil sísmico obtido com a utilização de fonte acústica do tipo boomer, em projeto de prospecção de areias (material de construção) no rio Paranapanema, SP, onde se observa a penetração do sinal a profundidades de cerca de 30 m (IPT, 1990a.).

O princípio deste tipo de fonte está relacionado com o deslocamento da massa d'água quando a energia elétrica armazenada em um capacitor é descarregada sobre uma mola plana conectada a uma placa vibradora. Ao contrário das fontes do tipo "forma de onda controlada", estas fontes podem absorver até $1000 \mathrm{~J}$ de energia e, portanto, tornarem viável a emissão de sinais de um amplo espectro de freqüências (p.ex. 500 a $20.000 \mathrm{~Hz}$ ) com alta potência, possibilitando a obtenção de excelentes registros sísmicos com grande penetração no substrato (Figura 8.11 e Figura 8.12). 
Boomers estão entre as principais fontes acústicas utilizadas na investigação de áreas submersas rasas, pois este tipo de fonte emite amplo espectro de freqüências, possibilitando resolução centimétrica em algumas situações, com alta energia, largos pulsos (75-150 ms - o que possibilita a penetração de até $200 \mathrm{~m}$ em sedimentos arenosos saturados - Simpkin, 2005), alta repetibilidade, além de boa diretividade do sinal, a despeito de algumas restrições com relação ao tamanho da fonte (portabilidade), já que, não raramente, o conjunto completo (fonte/catamarãs/cabos) pesa mais que 100 $\mathrm{kg}$, e o fato de lidar com altas voltagem e corrente, exige, portanto, cuidados operacionais adicionais. Todavia, como qualquer outra fonte sísmica para investigação de áreas com coluna d'água muito rasa, interferências ocorrem no espectro de freqüências que acabam por prejudicar a resolução do sistema (Simpkin, 2005).

Com tais propriedades, este tipo de fonte torna viável a obtenção de excelentes resultados que combinam boa resolução com excelente penetração conforme ilustrado na Figura 8.12.

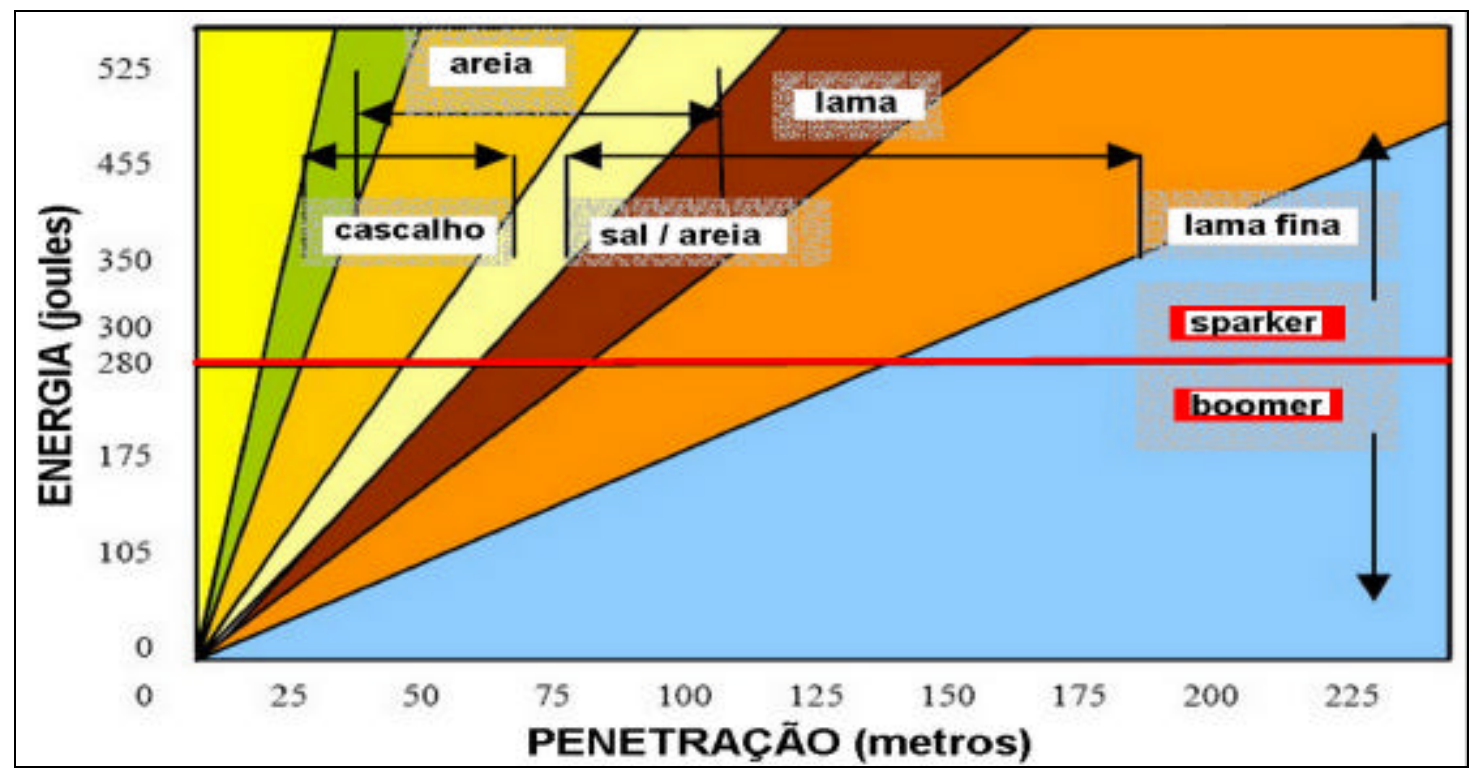

Figura 8.12: Gráfico comparando a penetração esperada da fonte acústica do tipo boomer (modelo GeoPulse da GeoAcoustics) com fonte do tipo sparker. Modificado de <http://www.geoacoustics.com>. Acesso: fev/2006.

São vários os fabricantes no mundo deste tipo de fonte, destacando-se as empresas inglesas AppliedAcoustics e GeoAcoustics, a americana EdgeTech (antiga EG\&G), a francesa SIG-Services et Instruments Géophysique e a canadense Huntec. Certamente, os melhores e mais elucidativos registros sísmicos obtidos na investigação de áreas submersas rasas foram obtidos por meio da utilização de fonte acústica do tipo boomers. 
Ao se escolher este tipo de fonte sísmica, há necessidade da configuração adequada de alguns parâmetros de aquisição de dados, a se destacar o filtro passabanda, pois o espectro de frequiências emitido por este tipo de fonte é comumente bastante largo, muito embora o pico de maior potência esteja concentrado nas freqüências mais baixas $(6.6 \mathrm{kHz})$ conforme exemplos mostrados na Figura 8.13 e na Figura 8.14. Em verdade seria inviável, fisicamente, utilizar um sistema de amostragem sobre um espectro daquela natureza, que evitasse o efeito alias (amostragem incorreta das frequiências dos sinais acústicos), no mínimo, pela enorme quantidade de informação que teria que ser armazenada.

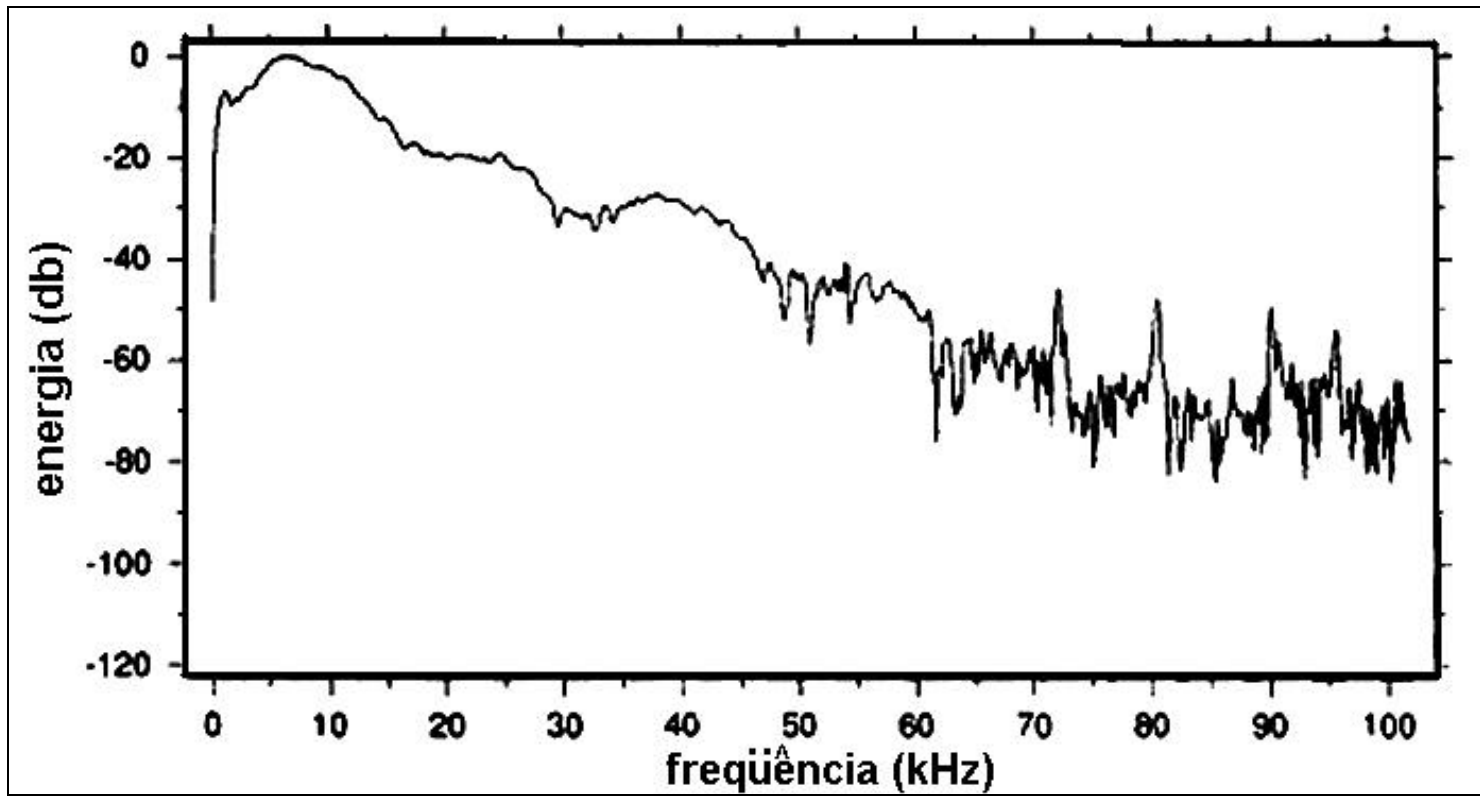

Figura 8.13: Espectro de energia da assinatura do sinal sísmico de uma fonte do tipo boomer de $280 \mathrm{~J}$. Modificado de McGee, 1995b.
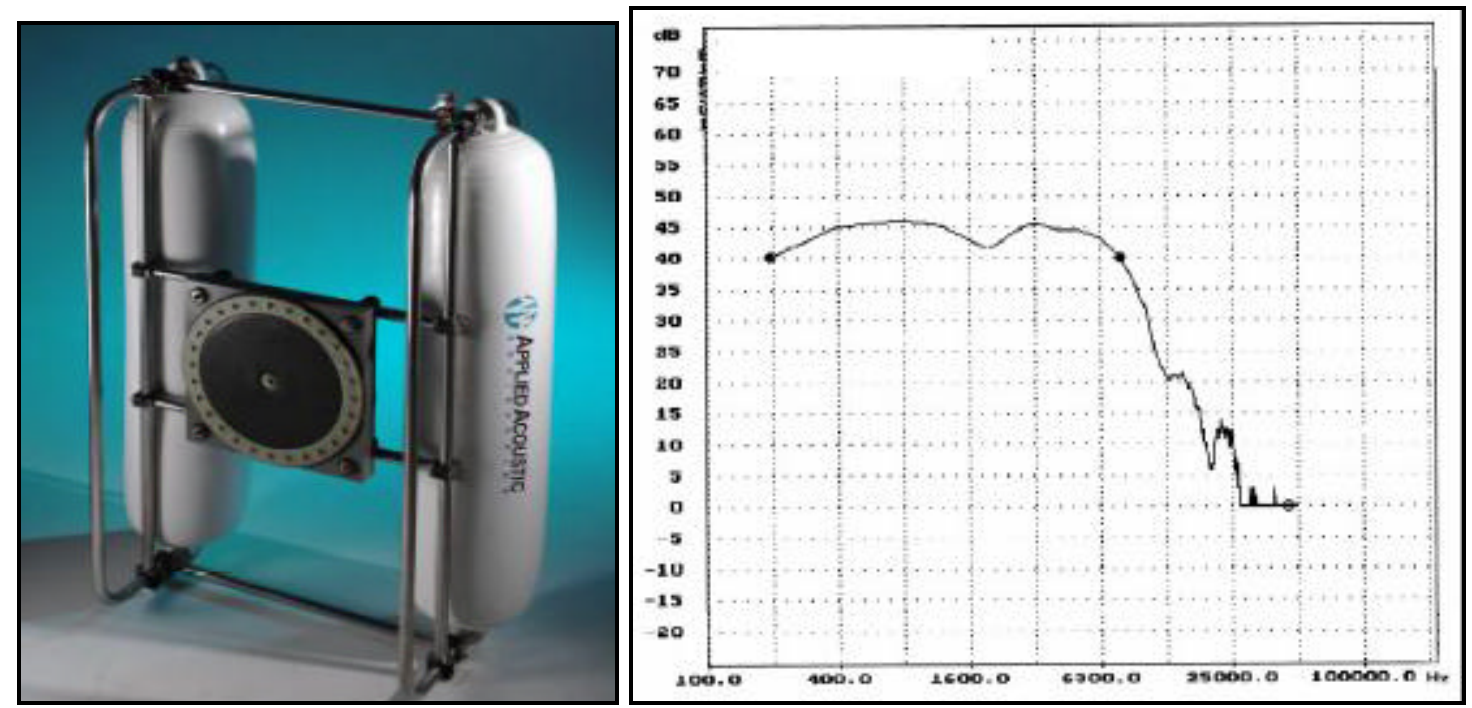

Figura 8.14: à esquerda, foto do boomer modelo AA200 da AppliedAcoustic Engineering, fonte sismica relativamente pequena (dimensões da placa $=38 \times 38 \mathrm{~cm}$ ), leve (peso da placa $=10 \mathrm{~kg}$ na água) e potente, com capacidade de transmissão de energia de até $300 \mathrm{~J}$ com largura de pulso de $150 \mu \mathrm{s}$; à direita, espectro de freqüiências $(\mathrm{Hz})$ x energia $(\mathrm{dB})$ deste modelo. Applied Acoustic Engineering, 2005b. 
Air-guns de pequeno porte são também incluídos neste tipo de fonte, já que tem também por princípio provocar rápido deslocamento de massa d'água quando o ar comprimido contido em recipientes apropriados é subitamente liberado na coluna d'água através de válvulas especiais. Um exemplo de fonte acústica do tipo air-gun de pequeno porte está ilustrada na Figura 8.15.

Apesar de se constituírem em fontes acústicas com grande capacidade de absorção de energia e com poder de emissão de espectros de frequiências mais baixas, tornando viável, maior penetração no substrato, além de maior relação sinal/ruído, quando comparado às demais fontes acústicas, sistemas desta natureza têm limitações com relação ao rebocamento a maiores profundidades, à pouca diretividade dos sinais emitidos, à maior complexidade nas operações de manutenção, mais exigentes e constantes, e finalmente com a maior complexidade operacional (cuidados especiais no manuseio), o que comumente não permite a utilização destes sistemas em águas muito rasas.

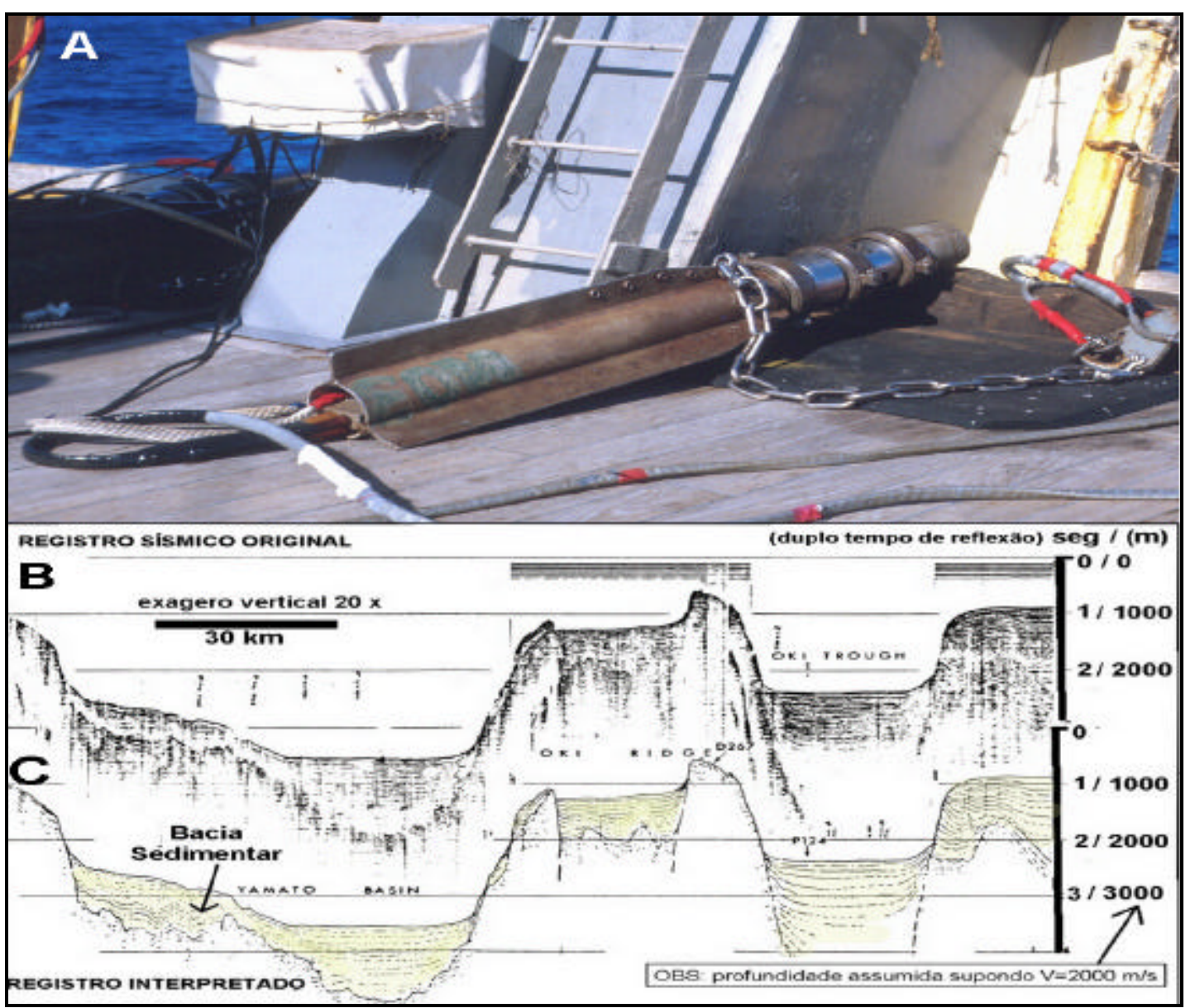

Figura 8.15: a) exemplo de fonte acústica do tipo impulsiva. Air-gun utilizado em levantamento sísmico monocanal no mar do Japão. (Equipametno do Serviço Geológico do Japão - GSJ). Foto: autor; b) registro sísmico de campo obtido com o air-gun (Tamaki et al., 1979). Notar a escala de investigação ilustrada no registro: bacias sedimentares com centenas de metros de espessura; c) registro interpretado. 
Sob a denominação de fontes do tipo implosivas, Mosher \& Simpkin (1999) classificam aquelas fontes impulsivas que utilizam a implosão de uma bolha para criar uma onda de pressão (pressure wave) na coluna d'água. Vaporchoc, flexichoc, waterguns são alguns dos exemplos deste tipo de fonte.

Estes sistemas, de uma forma geral, empregam ar comprimido para deslocar subitamente um pistão encapsulado, que se choca em alta velocidade com a massa de água ao redor, gerando uma cavidade na coluna d'água preenchida pelo vácuo. A imediata implosão desta cavidade gera o sinal sísmico de interesse e com uma assinatura bastante definida que produz resultados muito interessantes na investigação de áreas submersas. Estas fontes acústicas são utilizadas basicamente na investigação profunda, embora muitas delas são, nos dias atuais, fabricadas também em versões de menor porte, o que as tornam viáveis na investigação de águas rasas.

Um último tipo de fonte impulsiva, segundo Mosher \& Simpkin (1999) são as fontes explosivas que, como expressa o próprio nome, utilizam dinamites, espoletas elétricas, gás, entre outros meios, para gerar ondas acústicas na coluna d'água.

Apesar de se constituírem em fontes acústicas de relativo baixo custo, alta potência e grande poder de emissão de amplos espectros de freqüências (inclusive altas frequiências) oferecendo excelente penetração e razoável resolução, este tipo de fonte possui algumas limitações técnicas específicas, a se destacar a pobre repetitividade, e a limitada diretividade, além de restrições ambientais.

A mais comum fonte sísmica explosiva utilizada na investigação de áreas submersas ainda nos dias de hoje é o sparker. Este tipo de fonte tem por princípio a geração de uma descarga elétrica, num eletrodo mergulhado num meio condutor (p.ex. água do mar) conectado a um banco de capacitores instalado e gerenciado na embarcação. A descarga elétrica no meio condutor cria uma bolha de vapor que em rápida expansão gera um impulso positivo que se propaga na coluna d'água gerando o sinal sísmico desejado.

Apesar do excelente desempenho deste tipo de fonte sísmica (penetração e resolução adequadas), a bolha de vapor criada com a descarga elétrica tem limites de expansão e, assim, quando colapsa, acaba por gerar um segundo sinal acústico que comumente causa interferências destrutivas ao espectro de freqüências de interesse. Este problema é minimizado por meio da utilização de arranjos geométricos multifontes 
durante a aquisição de dados ou até mesmo por meio de fontes multieletrodos. Alguns exemplos de fontes desta natureza estão ilustrados na Figura 8.16, Figura 8.17, Figura 8.18 e Figura 8.19.

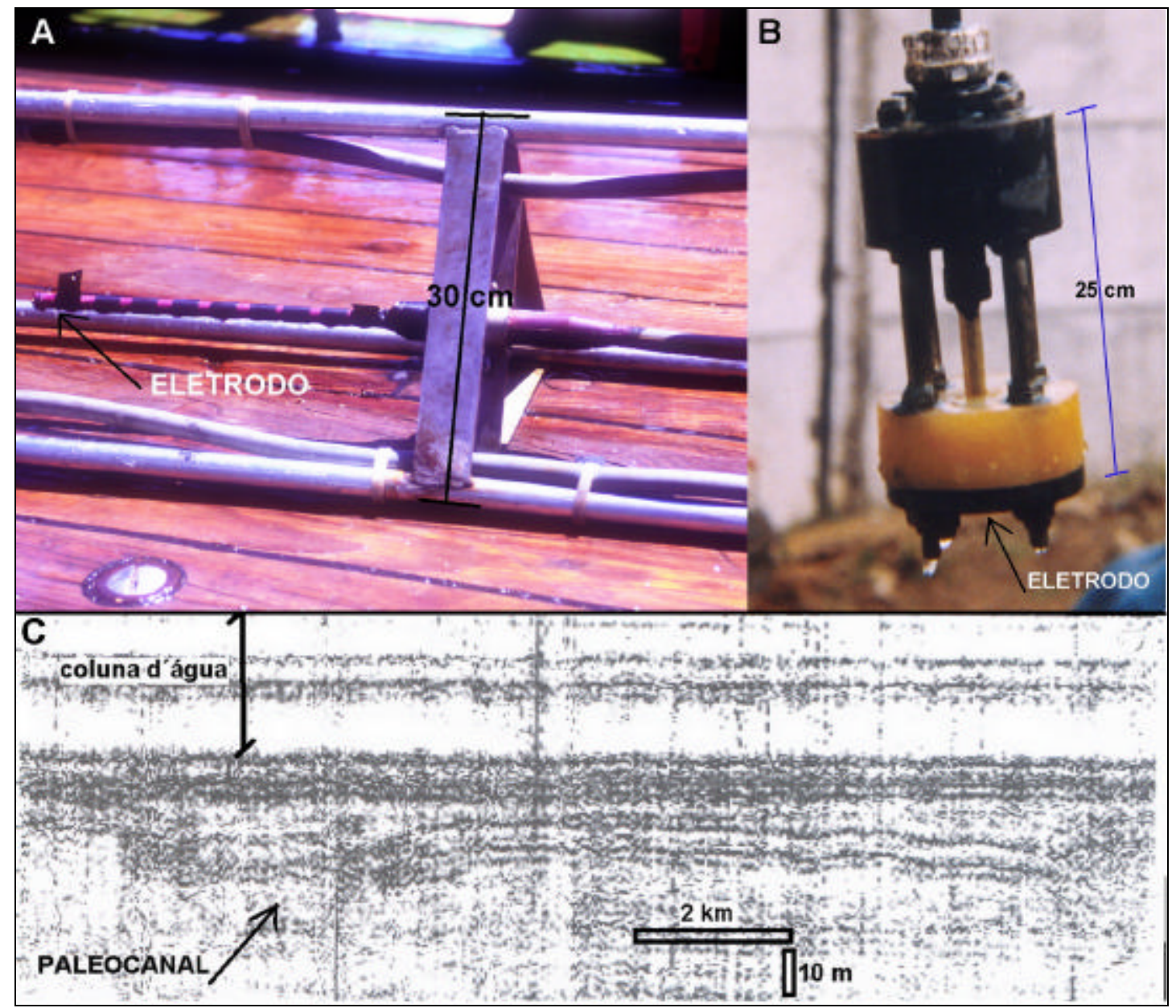

Figura 8.16: Exemplos de fonte acústica do tipo sparkers a) vista parcial de sparker multieletrodo (de alta energia) com arranjo de $5 \mathrm{~m}$ de extensão, pertencente ao navio de pesquisa alemão Victor Hansen; b) sparker de pequeno porte (baixa energia) utilizado para levantamentos de áreas rasas, inclusive água doce, pertencente ao IPT. Neste caso a fonte é envolvida com em uma embalabem plástica contendo uma solução condutora. Fotos do autor; c) exemplo de um registro sísmico obtido com um sparker que identificam a ocorrência de paleocanais na plataforma continental riograndense (Abreu \& Calliari, 2005).
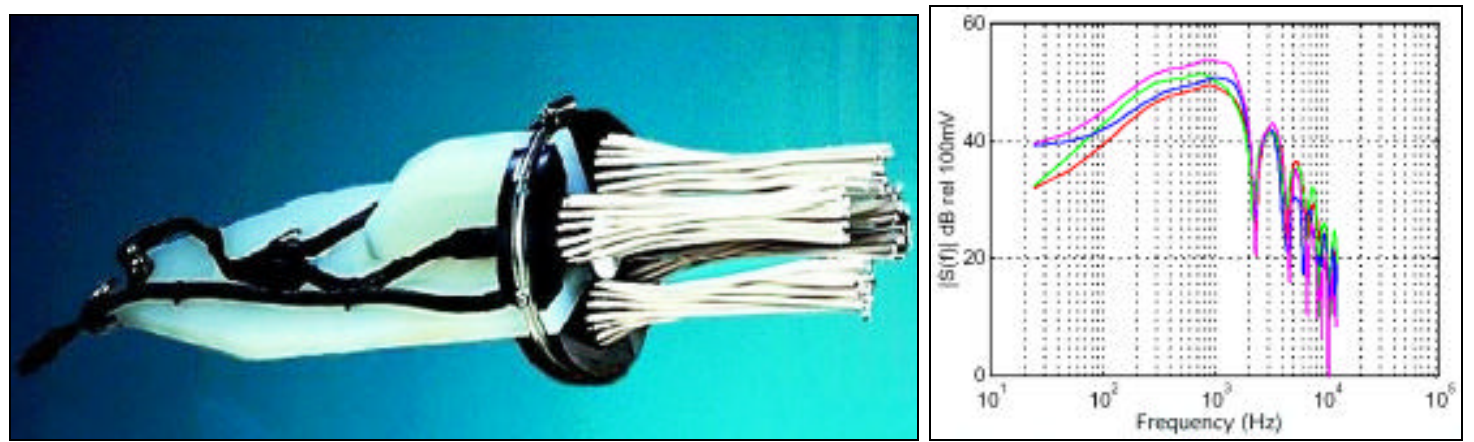

Figura 8.17: Sparker modelo Squid 500, da Applied Acoustic. Pesa apenas $3 \mathrm{~kg}$, lida com energia entre 200 e $600 \mathrm{~J}$. O gráfico da direita mostra o espectro de potência desta fonte: cor magenta = fonte de $1550 \mathrm{~J}$, 8 eletrodos; cor azul $=$ fonte de $1000 \mathrm{~J}, 8$ eletrodos; cor verde $=$ fonte de $1000 \mathrm{~J}, 4$ eletrodos; cor vermelha = fonte de $600 \mathrm{~J}, 4$ eletrodos. Applied Acoustic Engineering, 2005a. 


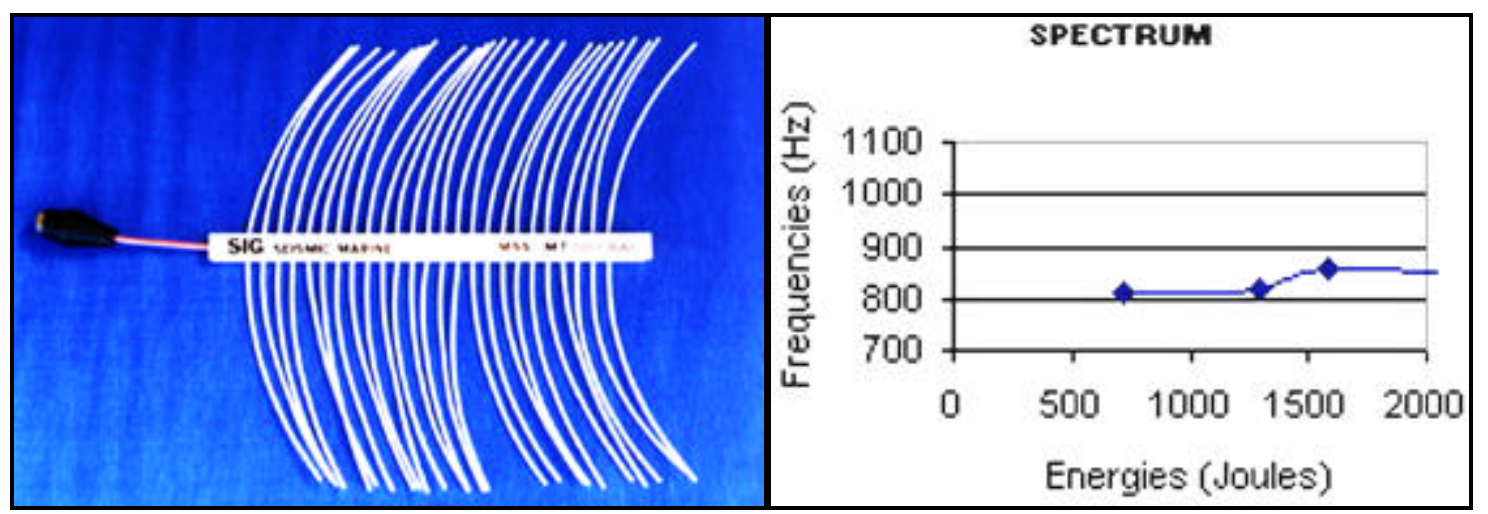

Figura 8.18: Sparker modelo ELC820 da SIG. Pesa pouco mais de $1 \mathrm{~kg}$, tem $1 \mathrm{~m}$ de extensão e lida com energia entre 100 e $1000 \mathrm{~J}$ e espectro de freqüencias entre 800-850 Hz. Fonte: http://perso. wanadoo.fr /sigfrance/ . Acesso: dez/2005.

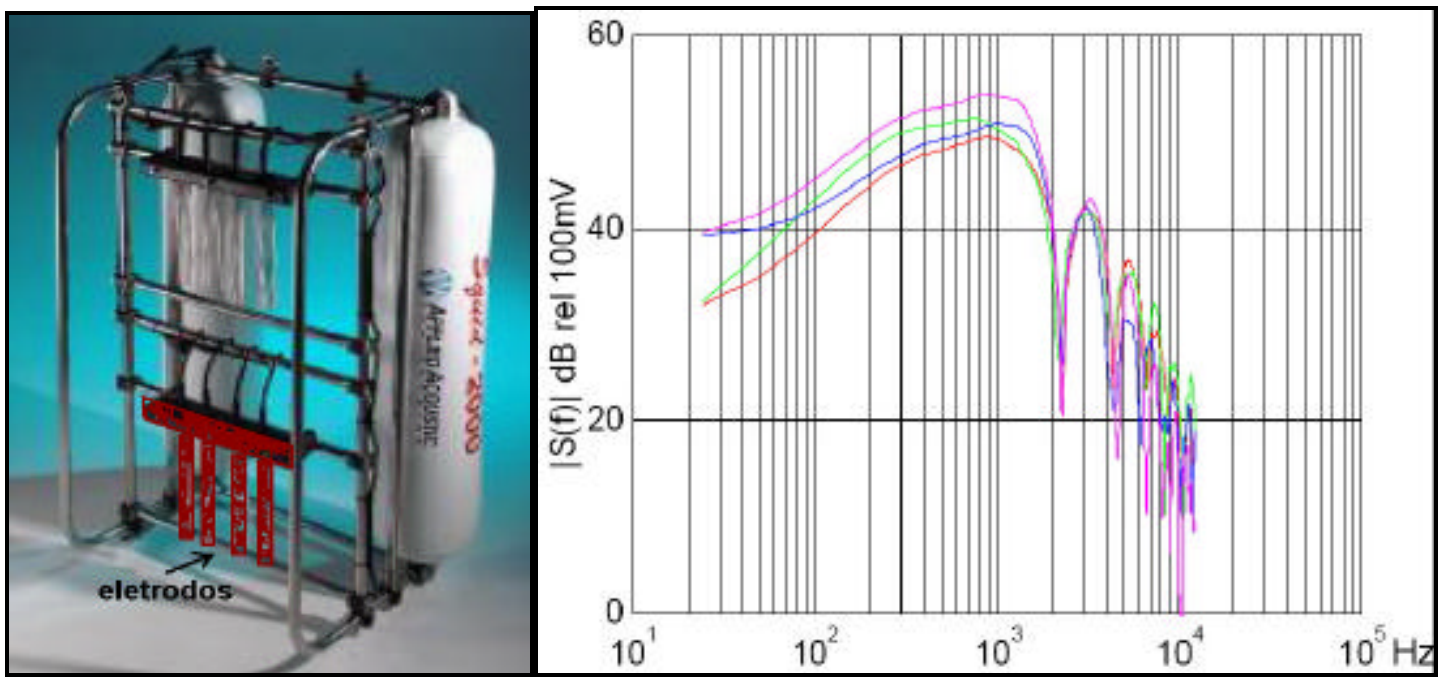

Figura 8.19: Espectro de potência do sparker Squid 2000, da Applied Acoustics. Cor magenta = fonte de $1550 \mathrm{~J}, 8$ eletrodos; cor azul = fonte de $1000 \mathrm{~J}, 8$ eletrodos; cor verde $=$ fonte de $1000 \mathrm{~J}$, 4 eletrodos; cor vermelha $=$ fonte de $600 \mathrm{~J}, 4$ eletrodos. Applied Acoustics Engineering, 2005a.

A Figura 8.20 representa uma tentativa de ilustrar de forma ampla, as relações existentes entre os diferentes tipos de fontes acústicas com suas principais propriedades específicas (energia x espectro de freqüências emitidas) e o alcance em profundidade da investigação. Desta figura, denota-se que a energia da fonte acústica se relaciona de forma inversa com o espectro de freqüências emitido pela fonte e de forma direta com a profundidade de investigação, ou seja, fontes de maior potência emitem frequiência mais baixas e possibilitam maior penetração. Observa-se ainda que a profundidade de investigação representada na parte inferior desta figura não é linear, já que são muitas as variáveis que compõem a equação que define o poder de penetração de uma fonte acústica. Não estão representadas nesta figura, por exemplo, aspectos relacionados com a natureza geológica do substrato e as especificações construtivas das fontes acústicas, variáveis intimamente relacionadas com a maior ou menor penetração do sinal acústico emitido. 


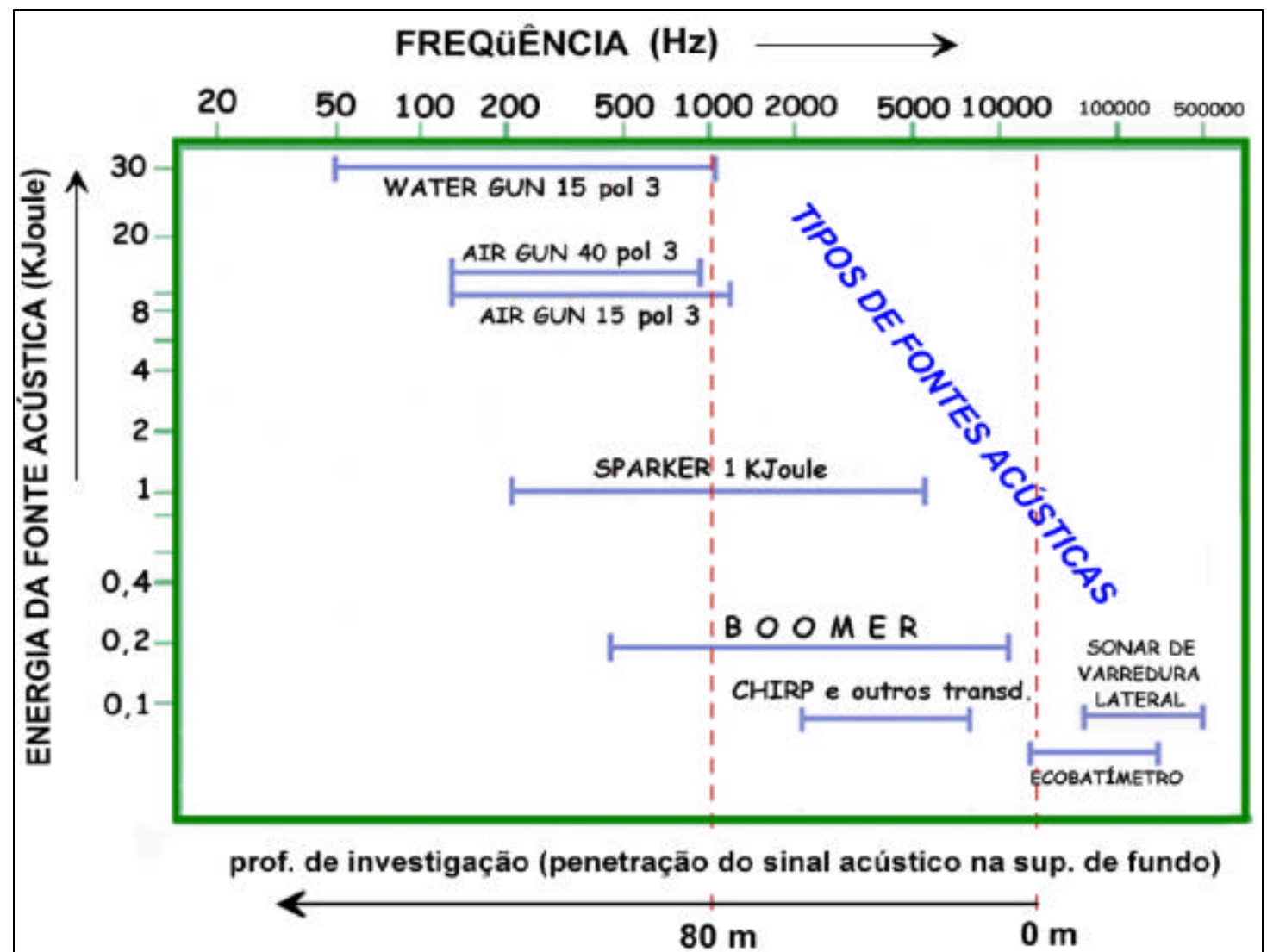

Figura 8.20: Ilustração confrontando tipo de fontes sísmicas $\mathrm{x}$ espectro de freqüências emitido $\mathrm{x}$ energia da fonte acústica (quilojoules = kJ) x profundidade de investigação. Modificado de Trabant (1984).

\subsubsection{RECEPTORES ACÚSTICOS}

Por receptores acústicos, entendem-se os sensores que captam o retorno dos sinais sísmicos emitidos e os transferem para o setor de armazenamento. São basicamente de dois tipos, se considerada a natureza das fontes sísmicas discutidas no item anterior.

Um primeiro tipo de receptor é aquele em que a própria fonte piezelétrica age simultaneamente como emissora e receptora do sinal emitido. Este modelo é aquele que compõe a maioria dos modelos de fonte acústicas que utilizam o sistema de forma de onda controlada. Incluem-se nesta categoria inúmeros ecobatímetros, sonar de varredura lateral entre outros.

Nos outros tipos de fontes sísmicas (explosivas, impulsivas e de aceleração de massa), os sensores são corpos separados da fonte, basicamente compostos de conjuntos de partículas piezelétricas que são sensíveis a variações de pressão, denominados de hidrofones. Estes receptores têm a função de identificar as variações de pressão na massa de água ao redor dos sensores e converter estas variações numa voltagem proporcional às amplitudes das variações da pressão (Urick, 1983). Estes sensores 
piezelétricos, comumente distribuídos no interior de tubos plásticos (mangueiras), são rebocados a certa distância da embarcação de forma a se evitar a captura de ruídos indesejáveis oriundos de motor do barco, de geradores etc. A Figura 8.21 ilustra dois modelos de hidrofones: um de pequeno porte $(6 \mathrm{~m}$ de extensão com 10 elementos piezelétricos), utilizado na investigação rasa; e outro de grande porte, na investigação profunda, que utiliza arranjos longos de sensores (centenas de metros).

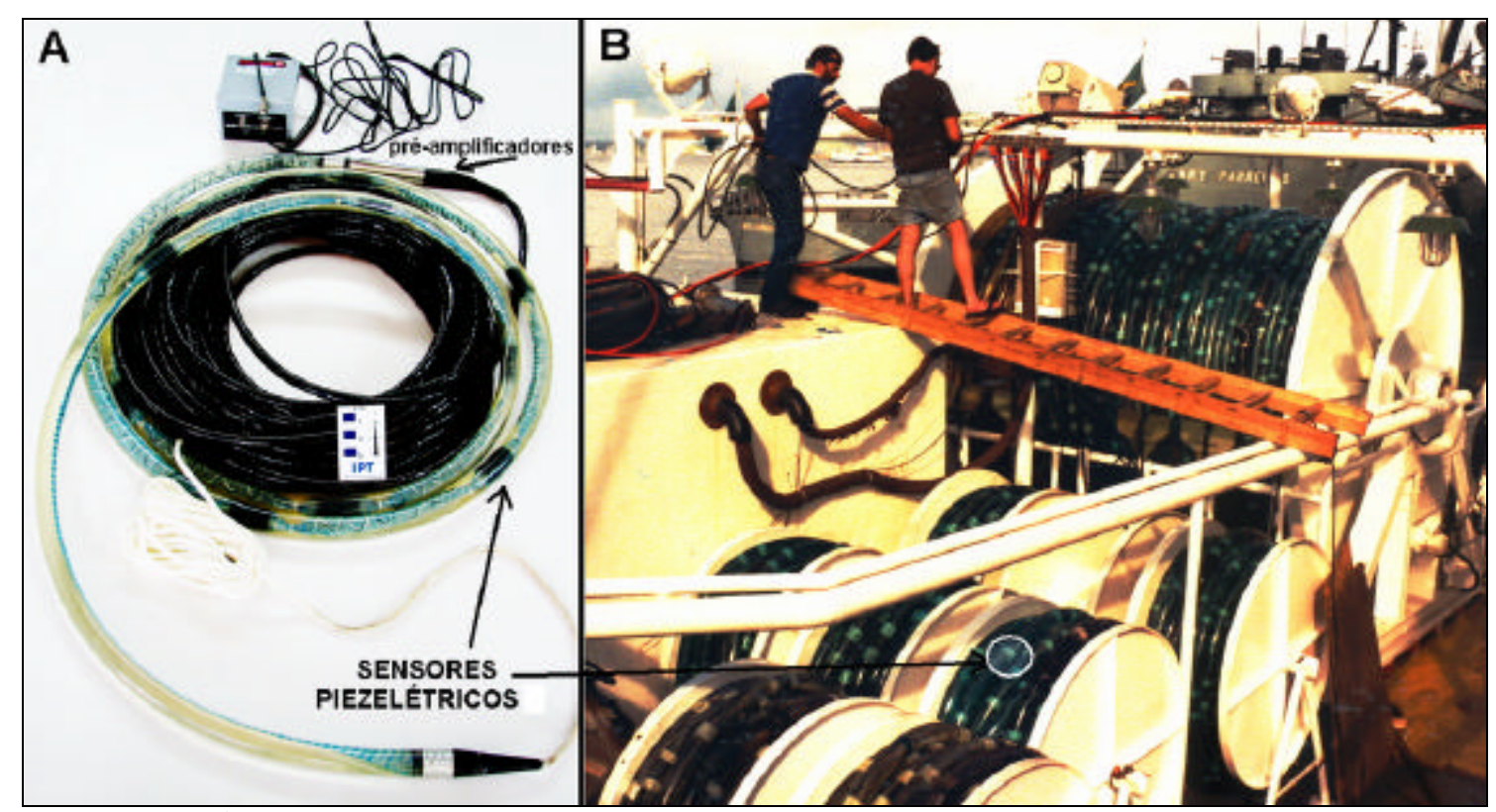

Figura 8.21: a) hidrofone do tipo monocanal, com $6 \mathrm{~m}$ de extensão e 10 sensores piezelétricos, utilizado na investigação rasa (foto: Ricardo S. Xavier); b) conjunto de hidrofones do tipo multicanal, instalados no Navio Oceanográfico Almirante Câmara, utilizado na investigação sísmica profunda. Foto: autor.

Além dos ruídos oriundos da embarcação que traciona o sistema de sensores, muitos outros agentes ruidosos agem sobre os sinais registrados pelos sensores à medida que a embarcação avança na execução de um determinado perfil sísmico, que vão desde a própria onda direta (aquela que se origina na própria fonte sísmica e viaja diretamente pelo caminho mais curto, até o sensor), até ondas, ventos, tráfego de navios ou mesmo outras fontes acústicas em operação simultânea na mesma embarcação ou não.

Umas das formas de minimização do efeito destes indesejáveis ruídos é a constituição de arranjos geométricos de sensores dentro destes tubos. Sensores adequadamente espaçados dentro dos hidrofones promovem uma soma dos sinais recebidos. Para os ruídos que são comumente sinais randômicos e incoerentes, esta soma tende a anular o efeito final. Para os sinais sísmicos propriamente ditos, que são coerentes, esta traz aumento da amplitude do sinal de interesse e, portanto, melhorias na razão sinal/ruído. 
Outra forma de minimização de ruídos é a construção de hidrofones com certa diretividade de recepção do sinal. Como os hidrofones são geralmente rebocados na horizontal, sinais que chegam à fonte no plano horizontal (ruídos diversos) tendem a ser cancelados.

A melhor concepção de um arranjo de sensores é aquela que leva em consideração a distância entre os sensores, que é função do comprimento de onda dos principais sinais sísmicos, da profundidade dos sensores na coluna d'água, do comprimento do arranjo (que tem relação direta com a espessura da coluna d'água a ser investigada) e, finalmente com a geometria fonte - receptor (Mosher \& Simpkin 1999). A Figura 8.22 ilustra a relação das distâncias fonte-receptor (X), espessura da coluna d'água (D) e extensão do arranjo de receptores (L).

A partir da análise da Figura 8.22, observa-se que arranjos curtos se fazem necessários quando se lida com altas freqüências que é o caso da investigação rasa. Outro fator também preponderante no controle de qualidade dos dados na aquisição da sísmica rasa é a profundidade dos sensores (do hidrofone) na coluna d'água. Os sinais que retornam da superfície de fundo atingem não só os sensores (hidrofones), mas também a interface água-ar, retornando novamente ao hidrofone, o que pode causar interferências destrutivas entre os sinais de interesse se a profundidade do hidrofone for igual a $1 / 4$ do comprimento de onda da maior freqüência de interesse (Mosher \& Simpkin, 1999). A solução para esta questão é rebocar o hidrofone a profundidades que não permitam estas indesejáveis interferências. Os recentes desenvolvimentos tecnológicos no campo da sísmica de alta resolução possibilitaram a construção de receptores bastante versáteis e que, portanto, podem ser utilizados em levantamentos sísmicos com coluna d'água bastante variáveis e também com fontes acústicas distintas.

Estes avanços tecnológicos permitem, por exemplo, que alguns hidrofones sejam compostos por conjuntos de sensores com arranjos distintos (distância entre os sensores) e independentes entre si, e assim sendo permitem que dados oriundos de cada um destes arranjos sejam gravados independentemente, para serem somados posteriormente durante $\mathrm{o}$ processamento dos dados. A gravação de dados separadamente permite que se utilizem, por exemplo, arranjos curtos, privilegiando a alta resolução, e arranjos mais longos, que privilegiam a penetração do sinal nas camadas subjacentes, conseqüentemente atuando na melhoria da razão sinal/ruído. 


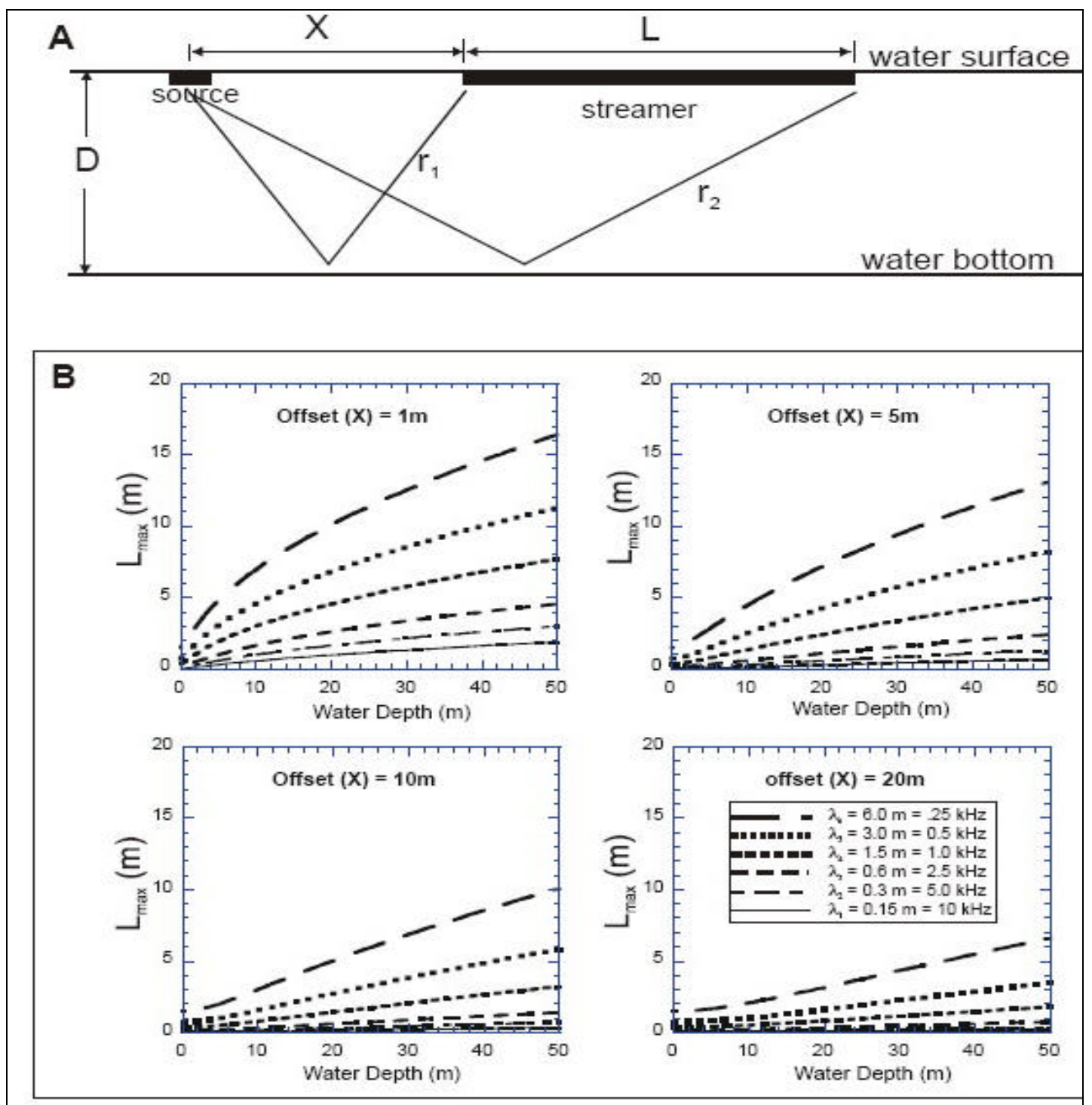

Figura 8.22: (A) geometria fonte-recepetor comumente utilizada em levantamentos sísmicos de áreas submersas; (B) relação entre profundidade da coluna d'água (D), distância fonte - receptor (X = offset), mínimo comprimento de onda (?) ou maior frequiência de interesse e máximo comprimento do arranjo $\left(\mathrm{L}_{\max }\right)$ para a geometria fonte - receptor. (Mosher \& Simpkin, 1999)

\subsubsection{AQUISIÇÃO DIGITAL DE DADOS}

Como conseqüência dos avanços tecnológicos destas últimas duas ou três décadas, que permitiram a construção de computadores mais rápidos a custos mais acessíveis, a aquisição de dados sísmicos na forma digital passou a ser relativamente comum. Praticamente todos os sistemas atualmente disponíveis no mercado são digitais.

No entanto, conforme destacado por Mosher \& Simpkin (1999), geralmente se dá prioridade, nos estudos da questão digital, ao armazenamento dos dados em relação à amostragem do sinal sísmico propriamente dita. A digitalização de um dado sísmico, por princípio, é uma amostragem discreta destes dados ao longo do tempo, de forma tal a permitir que o sinal sísmico digitalizado possa ser recuperado integralmente sem qualquer perda de detalhes. 
Não é objetivo deste trabalho discutir este tema em profundidade, todavia alguns aspectos relevantes devem ser destacados, sob pena de comprometimento da qualidade dos dados adquiridos pelos sistemas sísmicos atuais.

Um primeiro aspecto a ser destacado é a resolução digital, e, como tal, entendese o número de bits que compõe cada amostra digital. Este parâmetro afeta diretamente a precisão da medição da amplitude do sinal sísmico (dynamic range do sistema). Um sistema digital deve permitir que toda a gama de variações possíveis das amplitudes de um sinal sísmico possa ser registrada. Ao se optar por um sistema de 16 bits, em vez de 8 bits, se ganha qualidade, mas no caso de levantamentos longos, em grandes projetos, a quantidade de dados acumulados vai ser enorme, assim como o tempo a ser gasto no processamento, incrementado em muitas vezes.

Um segundo aspecto relevante na digitalização de um sinal sísmico é a razão de amostragem. A amostragem de um sinal sísmico está baseada no princípio de Nyquist (Nyquist, 1928 e Hannon, 1949, apud Moscher \& Simpkin, 1999) que indica que uma forma de onda pode ser descrita por no mínimo duas amostras coletadas por período. Esta freqüência de amostragem é conhecida por freqüência de Nyquist e significa que, por exemplo, se uma razão de amostragem de $4 \mathrm{~ms}$ for utilizada, a freqüência de Nyquist é $125 \mathrm{~Hz}$. No exemplo apresentado por estes autores, se um sinal de $150 \mathrm{~Hz}$ é amostrado com esta freqüência de amostragem (4 ms), o sinal sofrerá amostragem incorreta, sendo registrado apenas $100 \mathrm{~Hz}$, ocorrendo assim o fenômeno descrito como alias.

O estabelecimento de uma ou de outra razão de amostragem está diretamente relacionado com a capacidade do equipamento sísmico, não só de armazenamento de dados (razão de amostragem menor significa grandes volumes de dados), mas também das próprias limitações físicas do equipamento para a efetivação das amostragens (capacidade dos conversores analógico-digitais).

\subsection{INVESTIGANDO A MORFOLOGIA E A NATUREZA DA SUPERFÍCIE DE FUNDO}

A partir do trabalho pioneiro de Colladon \& Sturm (1827, apud Grant \& Schreiber, 1990), que determinou em estudo experimental a velocidade do som na água, foram estabelecidos os fundamentos dos sistemas hoje conhecidos como sondagens acústicas, que tornaram viável a constituição dos métodos de investigação que vieram a 
substituir, muitos anos depois, as tradicionais medidas pontuais da espessura de coluna d'água.

A partir destes estudos pioneiros e com a evolução da engenharia acústica, da eletrônica, e da informática, o estudo das formas das superfícies submersas, no mar ou áreas continentais, está baseado principalmente nos métodos que envolvem sondagens acústicas, representados pela ecobatimetria e pela sonografia ou sonar de varredura lateral.

Considerando os grandes avanços da tecnologia nos últimos dez anos, estas ferramentas têm-se desenvolvido de forma notável: novos tipos de material cerâmico possibilitaram a construção de poderosos transdutores; como também a de transdutores com estreitos ângulos de emissão, ao contrário dos antigos modelos, que possuíam ângulos maiores, e, portanto, atingiam áreas maiores da superfície de fundo (quanto maior a profundidade, maior a área amostrada) possibilitando a ocorrência de erros de interpretação dos dados.

Adiciona-se a estes desenvolvimentos o advento da tecnologia digital que possibilita incrementos notáveis na relação sinal/ruído e nas técnicas de processamento e tratamento dos dados, trazendo melhorias indiscutíveis na qualidade do sinal acústico oriundo da superfície de fundo.

Ainda, com o avanço da tecnologia, surgiu a possibilidade da amostragem ou do imageamento de grandes áreas da superfície de fundo, utilizando-se da técnica acústica denominada de sonografia ou sonar de varredura lateral. Este técnica, da mesma forma que a ecobatimetria, se beneficiou também dos avanços tecnológicos da eletrônica e da informática, constituindo-se hoje em poderosa ferramenta de investigação de áreas submersas, e de grande precisão, possibilitando até mesmo a caracterização da natureza da superfície de fundo, tomando como base a determinação dos níveis de energia dos sinais acústicos de retorno.

\subsubsection{A MORFOLOGIA DA SUPERFÍCIE DE FUNDO}

A medida da coluna d'água constitui-se numa das observações fundamentais quando se investigam áreas submersas, sejam rasas ou profundas. Em muitos estudos, básicos ou aplicados, a caracterização da batimetria da área definindo-se a morfologia da superfície de fundo já permite a constituição de um conjunto de dados suficientes 
para se atingirem os objetivos da investigação proposta, não havendo, obrigatoriamente, a necessidade da busca de informações sobre o substrato da área.

Existe uma relação muito próxima entre a batimetria de uma determinada área e suas características geológicas e geomorfológicas, já que a topografia de fundo é gerada a partir da evolução geológica da área que, por sua vez, condiciona os processos sedimentares que ocorrem na coluna d'água.

Considerando-se que nos dias atuais têm-se concentrado esforços em levantamentos em escalas locais, em substituição aos levantamentos de reconhecimento, em escalas regionais, a investigação de detalhe das superfícies submersas passa então a representar relevante papel no estudo de áreas submersas. Neste contexto, os métodos acústicos constituem-se em importantes ferramentas de investigação, principalmente pela facilidade de propagação das ondas acústicas na água. Sinais acústicos de potência menores que $1 \mathrm{~kW}$ percorrem distâncias da ordem de quilômetros na coluna d'água e ainda retornam aos transdutores/receptores para a definição da espessura da coluna d'água. Radiações eletromagnéticas também são utilizadas com esta finalidade, entretanto possuem limitações com relação ao alcance tendo em vista a forte atenuação destes sinais na coluna d'água, tendo aplicações restritas em estudos de áreas submersas rasas.

Com a finalidade de se investigar a superfície de fundo, equipamentos específicos são designados, comumente sistemas acústicos que lidam com espectros de freqüências mais altas e, portanto, com grande poder de resolução.

Muitos são os exemplos na literatura de casos de estudos em que tão somente os conhecimentos das características da superfície de fundo (batimetria) já são suficientes para atingir as respostas aos problemas colocados. O mapeamento batimétrico cumpre papel fundamental quando da análise de processos sedimentares recentes, continentais (rios e reservatórios) ou costeiros, em especial aqueles que ocorrem em curtos períodos de tempo (meses ou dezenas anos), tornando-se ferramenta essencial no estudo de processos nesta escala de tempo.

Lamour et al. (2005) analisaram mapas batimétricos obtidos em períodos distintos, no complexo estuarino de Paranaguá, e chegaram a conclusões substanciais sobre as variações da morfologia de fundo, principalmente nas áreas rasas (bancos de areia), desenvolvidas em conseqüência das intensas atividades portuárias na área. Os 
dados analisados constituíram-se em importantes subsídios à melhor compreensão dos processos costeiros na área. Ressaltaram ainda os autores neste artigo a necessidade da realização freqüente de levantamentos batimétricos sistemáticos para garantir o monitoramento da topografia de fundo na melhor escala possível.

Manso et al. (2003) estudaram a morfologia e a sedimentologia de um trecho da plataforma continental interna do litoral sul do estado de Pernambuco, tendo como base mapas batimétricos traçados a partir de dados da DHN - Diretoria de Hidrografia e Navegação (Carta Náutica e folhas de bordo) e amostras de sedimentos de fundo. A partir dos resultados das análises sedimentológicas das amostras coletadas, e da observação das formas das curvas batimétricas (isóbatas) identificaram dois setores com propriedades distintas, níveis de terraço, bancos arenosos, evidenciando, inclusive, a presença de falhas estruturais no setor mais ao sul, em direção concordante com as feições mapeadas no continente.

Veiga (2005) associou informações batimétricas com dados sedimentológicos de dezenas de amostras de sedimentos de fundo para analisar as características morfodinâmicas da plataforma continental interna rasa (até $10 \mathrm{~m}$ de profundidade) do litoral do Paraná, no trecho entre Pontal do Sul e Matinhos.

Na tentativa de melhor compreender a dinâmica sedimentar (processos de erosão e assoreamento) do estuário do rio Potengi (RN), Frazão \& Vital (2002) utilizaram-se de dados de batimetria e de sonografia para caracterizar em detalhe a morfologia de fundo do rio, na área que abriga a principal zona portuária do Estado.

\subsubsection{A NATUREZA DA SUPERFÍCIE DE FUNDO}

No mapeamento geológico básico, quando o objetivo é a identificação de estruturas sedimentares, lineamentos, falhas, contatos geológicos, entre outras feições geológicas na superfície de fundo, o sonar de varredura lateral, juntamente com a ecobatimetria convencional se constituem em poderosas ferramentas de investigação.

Mckinney et al. (1974) associaram imagens de sonar de varredura lateral com imagens de submersíveis e também com análises de sedimentos de fundo, para obter mapa detalhado da superfície de fundo da plataforma continental ocidental dos EUA, na região de Nova Jersei. Com base nestes dados mapearam a distribuição de sedimentos na superfície de fundo e identificaram várias formas de fundo, como afloramentos rochosos e proeminentes lineamentos, formados por faixas alongadas de sedimentos 
grossos alternados por faixas de sedimentos arenosos finos, ricos em marcas onduladas de pequeno porte.

Suguio et al. (1987) comprovaram pela primeira vez, por meio do sonar de varredura lateral, a existência da Laje do Argolão, proeminente afloramento rochoso no fundo do canal lagunar que interliga os maciços alcalinos de Morro de São João (Ilha de Cananéia, SP) e Morrete, Ilha Comprida, SP. Observando também as estruturas sedimentares (marcas onduladas: forma, tamanho e orientação) identificadas nas imagens do sonar, puderam ainda tecer considerações sobre os complexos processos hidrodinâmicos da área, que controlam a migração dos bancos arenosos existentes na barra de Cananéia.

Calliari et al. (1994) utilizaram o sonar de varredura lateral para definir padrões sonográficos e sedimentológicos, na plataforma interna do Rio Grande do Sul, relacionados com depósitos sedimentares com concentrações variáveis de calcário biodetrítico, associados a parcéis de beachrock (Parcel do Carpinteiro). Excelentes contrastes texturais foram observados nas imagens obtidas do sonar de varredura o que permitiu mapear com precisão a distribuição geográfica dos depósitos, a partir dos mosaicos constituídos pelas imagens e, assim, avaliar a importância econômica dos depósitos identificados. Calliari \& Abreu (1984) utilizaram-se também deste mesmo método de investigação para mapear a cobertura sedimentar da plataforma continental interna adjacente à cidade de Rio Grande, RS, com vistas a, entre outros, fornecer subsídios técnicos à indústria pesqueira local.

Souza (1995) e Tessler \& Souza $(1996,1998)$ utilizaram-se do sonar de varredura lateral para mapear o canal do Mar Pequeno, no sul do Estado de São Paulo, identificando na superfície de fundo do canal feições diretamente relacionadas com fluxos bidirecionais, assim como um setor do canal com marcas onduladas assimétricas, o que permitiu concluir que o local representa, no processo hidrodinâmico da área, o ponto de inversão do sentido das marés vazantes, anteriormente atribuído, por outros autores, a outro segmento do canal.

Dias \& Silva (2003) utilizaram sonar de varredura lateral associado a outros métodos geofísicos para investigar um trecho da Baía da Guanabara, visando subsidiar estudos para construção de metrô submarino entre Rio de Janeiro e Niterói. Além de caracterizar a profundidade do embasamento rochoso por meio da perfilagem sísmica contínua, utilizaram as imagens do sonar de varredura lateral para definir os padrões 
texturais superficiais, correspondentes à distribuição dos sedimentos na Baía da Guanabara no trecho estudado.

Antoneli (2004) associou a interpretação de fotografias aéreas, de perfis de praias e de dados das análises de amostras de sedimento de fundo, com dados oriundos da interpretação de perfis batimétricos e sonográficos, para concluir sobre o padrão de distribuição sedimentar e os mecanismos hidrodinâmicos responsáveis por esta distribuição na região marinha rasa d'As Ilhas, litoral norte do Estado de São Paulo.

Rodrigues (1996), em estudo sobre os processos de sedimentação atual nas enseadas de Ubatumirim e Picinguaba e plataforma interna adjacente, em Ubatuba, litoral norte do Estado de São Paulo, utilizou o sonar de varredura lateral para identificar feições de fundo de média e pequena escala, tais como afloramentos rochosos, contatos entre diferentes padrões texturais dos sedimentos superficiais e estruturas sedimentares (marcas onduladas). A análise das imagens do sonar de varredura lateral conjuntamente com os dados das análises das amostras de sedimentos superficiais coletadas na área permitiram ainda revelar a grande variabilidade de feições superficiais, bem como concluir sobre as direções preferenciais (NNW-SSE) dos processos hidrodinâmicos que atuam na área de estudo, responsáveis pelo transporte e seleção do material arenoso, identificados nos registros do sonar na forma de faixas orientadas e em grandes manchas.

Comumente, a identificação das formas das superfícies de fundo (canais), bem como de feições na superfície de fundo (afloramentos de diques, p.ex.), está diretamente relacionada com a gênese de uma determinada área. Furtado et al. (2000) e Klein et al. (2004) tendo como base imagens de sonar de varredura lateral e também de perfis de sísmica de alta resolução, identificaram, dentre várias feições atuais da superfície de fundo do Canal de São Sebastião, SP, testemunhos de antigas linhas de costa (beachrocks) e, portanto da ação dos eventos regressivos e transgressivos do mar, que atuaram no litoral norte do Estado de São Paulo. Identificaram também, na superfície de fundo, estruturas sedimentares, diretamente relacionadas com os processos atuais de sedimentação, cujos agentes (ventos, correntes etc.) são condicionados, pela própria conformação do canal (eixo SW-NE), originado a partir dos eventos tectônicos e magmáticos responsáveis pela elevação da Serra do Mar no Mesozóico Superior e Cenozóico Inferior. 
Paolo \& Mahiques (2005) desenvolveram substanciais considerações sobre a circulação de fundo e sobre os processos de transporte sedimentar que atuam na desembocadura sul do sistema Cananéia-Iguape, litoral sul do estado de São Paulo com base na identificação de formas na superfície de fundo (estruturas sedimentares), em imagens obtidas com o sonar de varredura lateral.

Dias et al. (1982) utilizando sonar de varredura lateral, ecobatimetria e perfilagem sísmica (sparker), identificaram, na Plataforma Continental Sudeste Brasileira ao largo de Macaé, RJ, longas feições retilíneas a profundidades entre 79 e 109 metros, que foram correlacionadas, por estes autores, a antigas formações de praias (beachrocks) que teriam, portanto, se constituído quando do nível do mar na cota -100 $\mathrm{m}$.

Klein (2005) associou imagens de sonar de varredura lateral com perfis de sísmica de alta resolução (pinger $24 \mathrm{kHz}$ ) e observações diretas da superfície de fundo (mergulhos, coleta de amostras e testemunhagens), para mapear a extensão de afloramentos de beachrock que ocorrem a profundidades ao redor de $13 \mathrm{~m}$ na porção norte do Canal de São Sebastião, litoral norte do Estado de São Paulo. A análise conjunta dos dados obtidos permitiu a este autor propor um modelo de evolução sedimentar para a porção do litoral paulista.

Veiga (2005) em estudos de processos morfodinâmicos e sedimentológicos de um trecho do litoral paranaense, detectou em imagens de sonar de varredura lateral, conspícuos contrastes texturais que foram correlacionados diretamente com os distintos padrões sedimentares da superfície de fundo na área. As informações extraídas das imagens do sonar (contatos entre os corpos sedimentares, afloramentos rochosos, estruturas sedimentares etc.) foram associadas com dados batimétricos pré-existentes e com dados sedimentológicos oriundos das diversas amostras de fundo coletadas com objetivo da caracterização da superfície de fundo da plataforma continental interna rasa da área estudada.

Belo et al. (2002) e Belo (2002) executaram cerca de $160 \mathrm{~km}$ de perfis com o sonar de varredura lateral $(100 \mathrm{kHz})$ e com um perfilador sísmico de baixa potência (7 $\mathrm{kHz}$ ) e coletaram dezenas de amostras de fundo, com objetivo de caracterizar o relevo de fundo e os processos de sedimentação atual da Baía da Ilha Grande, RJ. A análise conjunta destes dados possibilitou aos autores identificar oito padrões acústicos sedimentares superficiais, além de mapear com detalhes a morfologia da superfície de 
fundo, e as áreas de ocorrências de afloramentos rochosos, estruturas sedimentares e terraços marinhos, dados que contribuíram efetivamente para a análise dos processos sedimentares atuantes na área estudada. Estes autores relacionaram ainda as formas de fundo identificadas nos registros de sonar de varredura lateral com parâmetros sedimentológicos (diâmetro médio dos grãos), profundidade e tipo de estrutura, para estimar as velocidades de fluxos associados à ação de correntes de fundo e ondas, concluindo sobre a ação combinada destes agentes no canal central da Baía da Ilha Grande.

Em estudos hidroviários para estabelecimento de rotas de navegação, ou em estudos de áreas portuárias, os objetivos são comumente alcançados apenas com a utilização da batimetria convencional ou do sonar de varredura lateral, já que estes equipamentos geofísicos tornam possível a identificação da espessura da coluna d'água, o que permite a construção de mapas batimétricos, além do mapeamento de obstáculos à navegação (afloramentos rochosos etc.), informações estas que subsidiam decisões sobre as melhores opções para rotas segundo o tipo de embarcação a ser utilizada.

Dezenas de quilômetros de ecobatimetria e sonar de varredura lateral foram executados simultaneamente em projeto de redimensionamento da Hidrovia TietêParaná, em trecho crítico próximo da cidade de Icaraíma, PR (IPT, 1999b). Com objetivos semelhantes, IPT (2000, 2003) utilizou-se destas mesmas técnicas acústicas de investigação para mapear obstáculos à navegação em trechos da Hidrovia Tietê -Paraná próximos de Guairá, PR, trechos próximos de Promissão, SP, e trechos do rio Tietê próximos da cidade de Barra Bonita, SP (IPT, 1998e, 2006). Ainda com foco na questão hidroviária, Souza \& Moura (2005a) utilizam o sonar de varredura lateral para estudos de viabilidade para implantação de hidrovia em parque marinho na região de Abrolhos, sul do Estado da Bahia.

Ressalta-se que, em alguns projetos relacionados com hidrovias, todavia, quando da necessidade da realização de escavações para aprofundamento de canais de navegação, outros ensaios geofísicos apresentam melhor desempenho, já que, neste caso, prever o tipo de material, bem como o volume a ser removido, passa a ser fundamental, dado que só poderá ser obtido por métodos que informem, adicionalmente, a espessura das camadas sedimentares subjacentes à superfície de fundo.

Ayres Neto (2000) e Dias (2000) apresentaram bons exemplos de aplicação de métodos geofísicos de alta resolução (sonar, boomer e sbp-3.5 kHz) para caracterização 
de superfícies de fundo, em estudos de avaliação de potencial mineral de áreas submersas. Nos registros geofísicos obtidos por estes autores, são identificadas falhas, gás em sedimentos, paleocanais, banco de corais, áreas de ocorrência de areias e cascalhos carbonáticos.

Informações referentes à topografia, morfologia e à natureza da superfície de fundo constituem-se em relevante conjunto de dados que também muito contribuem para respostas a questões ambientais de diversas naturezas. Parques ecológicos submarinos, por exemplo, utilizam-se destas ferramentas geofísicas para investigação e mapeamento da distribuição de recifes de corais. Souza \& Moura (2005), em subsídio a projeto de delimitação de parque marinho, utilizaram-se do sonar de varredura lateral para mapear áreas de ocorrência de recifes de corais na região de Abrolhos áreas estas de difícil localização pelos meios convencionais de investigação, basicamente mergulhos (IPT, 2005a).

IPT (2002a) utilizou-se desta mesma ferramenta para mapear a distribuição de recifes artificiais na plataforma continental interna do Estado do Paraná, lançados ao mar em projeto de reocupação da fauna e flora de alguns setores da costa desse estado arrasados pela pesca predatória. Analogamente ao exemplo anterior, este método geofísico se mostrou como poderosa ferramenta de investigação ao possibilitar a identificação e a localização, além de ampla visualização, na superfície de fundo, dos conjuntos de agrupamentos de recifes artificiais lançados ao mar pelas embarcações, impossível de se obter pelos procedimentos convencionais (fotografia, mergulho) tendo em vista a baixíssima visibilidade na área.

Nelson \& Jonhson (1984), Nelson et al. (1987) e Bornhold et al. (2005) utilizaram-se do sonar de varredura lateral, para obter imagens da superfície de fundo da costa ocidental do Alaska, onde identificaram formas distintas, arredondadas e côncavas, produto da ação de baleias e morsas sobre a superfície de fundo, em busca dos sedimentos ricos em matéria orgânica. A partir das imagens do sonar, estes autores ainda inferiram sobre a importância destes animais, em determinados períodos do ano, nos processos sedimentares locais, de retrabalhamento, remobilização e homogeneização dos sedimentos bem como na destruição das estruturas sedimentares. Concluíram também sobre a importância dos sedimentos no ciclo alimentar destes mamíferos, pois realizaram, inclusive, análises sedimentológicas de material extraído dos estômagos destes animais. 
Figueiredo Jr. \& Kowsman (1976) realizaram levantamentos geofísicos na costa sul do Brasil, com objetivo de mapear depósitos conchíferos, com vistas em subsidiar estudos de avaliação de potencial econômico destes sedimentos, como matéria prima para fabricação de cimento e corretivo de solos. Os dados obtidos destes estudos possibilitaram mapeamento litológico detalhado da área, e assim subsidiaram a indústria pesqueira, pois a natureza dos sedimentos de fundo está diretamente relacionada com a fertilidade piscosa da área, bem como com as facilidades de arrasto de redes de pesca.

O sonar de varredura lateral associado à ecobatimetria contribui também efetivamente para projetos de obras em áreas submersas. Em projetos de instalação de dutos, por exemplo, o planejamento de suas rotas se faz por meio do prévio reconhecimento da superfície de fundo, identificando eventuais obstáculos (recifes de corais, afloramentos rochosos).

IPT (2002b) utilizou-se destas ferramentas geofísicas ao longo do Porto de Suape, em subsídio a projeto de rotas de dutos submarinos na costa sul do Estado de Pernambuco. Gorini et al. (1982) utilizaram-se do sonar de varredura lateral e da batimetria para estudar as formas de fundo e seu caráter móvel na região costeira de Guamaré, RN, para concluir sobre a melhor rota para instalação de gasoduto submarino.

Os métodos geofísicos que investigam exclusivamente as propriedades da superfície de fundo representam papel relevante também na arqueologia subaquática, em especial, quando se trata da localização de embarcações naufragadas em tempos pretéritos ou de outros objetos de valor histórico, ou mesmo nas operações de busca e salvamento.

Camargo (2002) utilizou-se do sonar de varredura lateral para mapeamento das fortificações da planície costeira Cananéia-Iguape, litoral sul do Estado do São Paulo, com vistas na localização de testemunhos da Fortificação da Trincheira construída no pontal Norte da Barra de Cananéia, na Ilha Comprida, em meados do século XIX. Rambelli (2003) utilizou-se da mesma ferramenta geofísica, para investigar o Sítio Arqueológico Cananéia I, local do naufrágio em 1858 do navio a vapor Conde D'Áquila. As operações de campo, bem como os resultados obtidos encontram-se descritos em detalhe em IPT (2001). 


\subsubsection{B ATIMETRIA}

A batimetria constitui-se no primeiro e mais tradicional método acústico de investigação de áreas submersas.

Originalmente a medida da espessura da coluna d'água era tomada pontualmente por meio do lançamento de um fio com um peso de chumbo.

A utilização de fontes acústicas, com a finalidade de medir a espessura da coluna d'água, ocorreu apenas durante a Segunda Guerra Mundial, quando transdutores acústicos eram fixados no casco dos navios e equipamentos de registro de grande porte, instalados a bordo da embarcação, mediam o tempo de ida e volta do sinal acústico até a superfície de fundo. Naquele período, linhas de investigação eram posicionadas em paralelo de forma a permitir, no tratamento dos dados, a interpolação de informações possibilitando finalmente a construção de mapas de contorno, ou mapas batimétricos, com precisão, naquele período, apenas razoável.

A técnica acústica da batimetria muito evoluiu a partir de então, mas continua tendo por objetivo básico a determinação da espessura da coluna d'água e, com este propósito, utiliza-se das propriedades relativas à propagação das ondas acústicas através da água.

Atualmente, os ecobatímetros possuem sua capacidade original em muito ampliada, pois, como conseqüência da evolução tecnológica da engenharia acústica e da informática, modernos sistemas de registro, periféricos com grande capacidade de armazenamento e de processamento dos dados, possibilitam também, além da medição com alta precisão da espessura da coluna d'água propriamente dita, a coleta simultânea de informações que efetiva e diretamente contribuem para a definição da natureza da superfície de fundo, tais como os níveis de energia dos sinais de retorno.

As ondas acústicas emitidas pelos ecobatímetros são constituídas de sinais de altas freqüências (normalmente superiores a $30 \mathrm{kHz}$ ) e emitidas a partir de uma fonte rebocada na superfície da água ou instalada no próprio casco da embarcação. Estas ondas viajam na coluna d'água a velocidades que variam conforme a temperatura, salinidade e pressão.

A influência das variações destes parâmetros sobre a velocidade de propagação do som na água é tema de estudo de vários autores. A Figura 8.23 ilustra ensaios realizados no Pacífico Central $\left(39^{\circ} \mathrm{N}, 146^{\circ} \mathrm{W}\right)$ mostrando como as variações de 
temperatura e de salinidade afetam a velocidade de propagação do som (Jones, 1999). Nota-se nesta figura que a velocidade do som na área estudada alcança um valor mínimo à profundidade de $650 \mathrm{~m}$.

Telford et al. (1976) também desenvolveram estudos neste tema e avaliaram que a velocidade de propagação do som na água varia entre $1440 \mathrm{~m} / \mathrm{s}$ e $1520 \mathrm{~m} / \mathrm{s} \mathrm{em}$ águas salgadas rasas e atingem valores mais baixos, ao redor de $1430 \mathrm{~m} / \mathrm{s}$, em águas doces rasas.

Os sinais acústicos emitidos pelos ecobatímetros são refletidos nas superfícies de fundo como se estas fossem espelhos. Entretanto, os sinais emitidos perdem energia ao longo da coluna d'água na razão aproximada de $4 \times 2$, ou seja, ao se duplicar a distância percorrida pelo sinal acústico, quadruplica-se a energia perdida na coluna d'água. A perda de energia emitida é muito maior quando se trabalha no mar e sempre maior quanto maiores forem as frequiências emitidas pela fonte acústica. Por exemplo, um sinal de frequiência $200 \mathrm{kHz}$ tem absorção de $10 \mathrm{~dB} / \mathrm{km}$ ao percorrer uma coluna de água doce e $50 \mathrm{~dB} / \mathrm{km}$ quando se desloca em coluna de água salgada; um sinal de 38 $\mathrm{kHz}$ tem absorção de $0.5 \mathrm{~dB} / \mathrm{km}$ em água doce e $10 \mathrm{~dB} / \mathrm{km}$ em água salgada (EA-400, Kongsberg-Sinrad, 2004). Relembra-se que "dB" é uma unidade comum na Física e representa o logaritmo da razão entre duas grandezas, no caso em questão, o logaritmo da razão entre energia emitida / energia recebida.

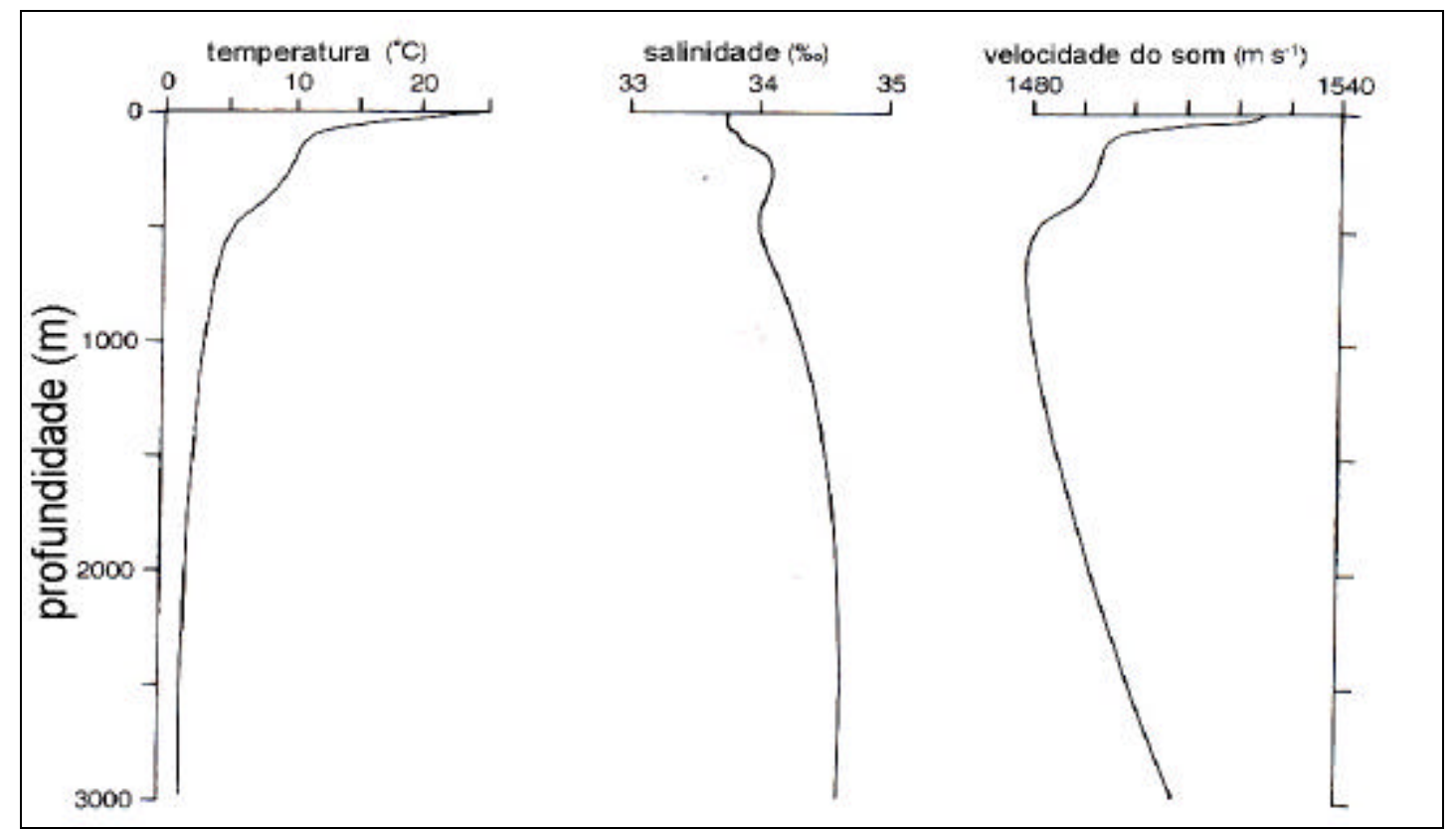

Figura 8.23: Variações de temperatura, salinidade e velocidade de propagação do som no Pacífico Central $-39^{\circ} \mathrm{N}, 146^{\circ} \mathrm{W}$ (Jones, 1999). 
Com o avanço da tecnologia e da eletrônica, os atuais sistemas de emissão e recepção de sinais acústicos se tornaram muito diferentes daqueles do começo do século passado, quando os resultados eram impressos em papel. As possibilidades são muitas, e as variações operacionais nos sistemas disponíveis, amplas. Os equipamentos hoje são digitais e, não raramente, emitem dupla freqüência, ampliando desta forma o campo de ação deste método, que originalmente foi criado apenas para informar sobre, ou medir, a espessura da coluna d'água. Ecobatímetros com frequiências de 38 e $200 \mathrm{kHz}$, por exemplo, possibilitam trabalhar tanto em águas profundas (da ordem de centenas de metros), quando as frequiências menores oferecem melhor resposta, quanto em águas rasas (até mesmo menores que $5 \mathrm{~m}$ ) onde freqüências maiores fornecem resultados mais precisos. A Figura 8.24 ilustra um registro de campo de um ecobatímetro de dupla freqüência $(38 / 200 \mathrm{kHz})$.

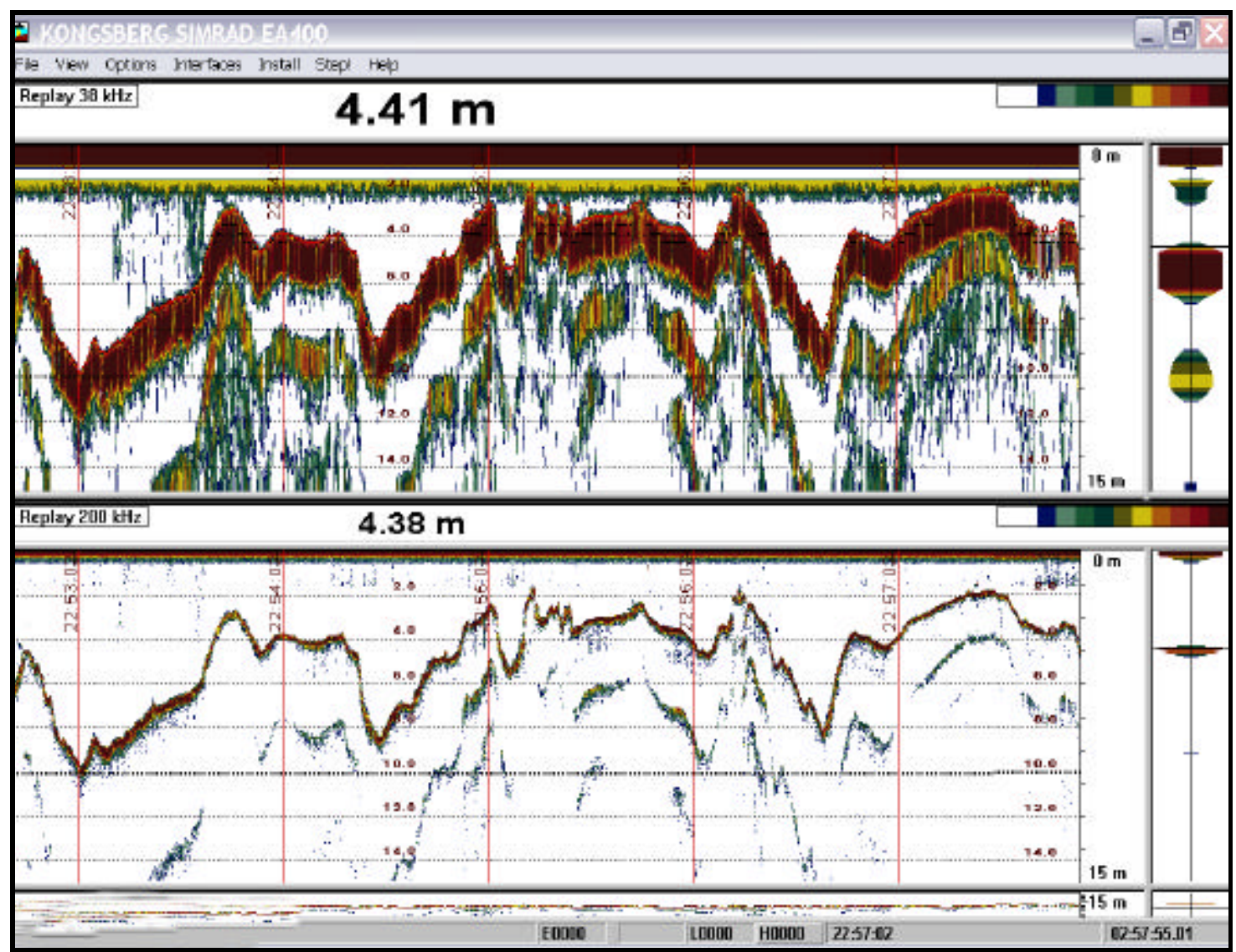

Figura 8.24: Tela de notebook acoplado a ecobatímetro de dupla freqüência $(38 / 200 \mathrm{kHz})$ marca Kongsberg-Simrad modelo EA-400. Cada uma das freqüências emitidas produz um perfil correspondente, como resultado: na parte superior da figura, observa-se o perfil obtido com a frequiência de $38 \mathrm{Khz}$; na parte inferior, o perfil obtido com a emissão de $200 \mathrm{kHz}$. Ambos os sinais são digitalizados automatica e simultaneamente, e o sistema gera uma planilha do tipo X, Y, Z1, Z2 (coordenadas X,Y e profundidades Z1 e Z2, fornecidas por cada uma das freqüências). Perfil obtido em trecho do rio Ribeira de Iguape. As diferenças entres os dados obtidos de ambas as freqüências para um mesmo ponto podem significar justamente a penetração do sinal de mais baixa freqüência no substrato sedimentar.Fonte: IPT (dados inéditos). 
A depender da natureza do substrato, ecobatímetros de frequiências baixas (inferiores a $50 \mathrm{kHz}$ ) podem ainda, em situações favoráveis, possibilitar a penetração do sinal acústico através das camadas superficiais de sedimentos, permitindo, assim, eventual análise de assoreamento na área investigada.

A menor ou maior penetração do sinal na superfície de fundo dependerá ainda da energia do sinal emitido, que de forma direta está relacionada com o porte dos equipamentos envolvidos. Potentes transdutores (emissores de sinais acústicos) podem até mesmo possibilitar a penetração do sinal de alta freqüência, contudo são normalmente de grandes formatos (tamanho e peso grandes) e necessitam do acoplamento de geradores de energia de grande porte, o que nem sempre torna viável sua utilização em estudos de áreas restritas. Ao contrário, os sistemas mais comuns, de menor porte, portanto menos potentes, empregam como fonte de energia baterias comuns e são portáteis, possibilitando sua instalação em embarcações de pequeno porte, viabilizando, assim, o estudo de áreas restritas, como rios, lagos, ou áreas portuárias.

A opção por determinado equipamento, quando da elaboração de um projeto de estudos de uma área específica, vai depender dos objetivos do projeto.

O sistema convencional de batimetria de precisão, entretanto, mede a coluna d'água imediatamente abaixo da embarcação, na vertical, ao longo da linha de investigação, o que significa que, para obter um mapa batimétrico preciso, um grande número de perfis paralelos entre si, e o mais próximo possível um do outro, é necessário. A distância entre estes perfis vai depender da escala desejada para o mapa final, o que está intimamente relacionado com o objetivo do levantamento, de maior ou menor detalhamento. Mesmo no caso da execução de linhas muito próximas uma da outra, eventualmente importantes informações sobre a superfície de fundo podem não ser identificadas, o que pode causar sérios problemas, principalmente se a investigação em andamento tiver alguma relação com projetos de rotas de navegação (hidrovias).

Para a solução deste problema e graças ao avanço da tecnologia a partir dos anos 70, ecobatímetros de varredura lateral foram criados e aplicados com sucesso em vários estudos de águas profundas. Estes equipamentos compõem-se de um conjunto de transdutores, fixado no casco da embarcação, ou numa estrutura própria de forma a se constituir em múltiplas fontes de sinais acústicos (Figura 8.25) que, emitindo sinais, para ambos os lados da rota de navegação, e em ângulos próximos, mas diferentes, praticamente amostram $100 \%$ da área investigada, quando linhas paralelas são planejadas. 


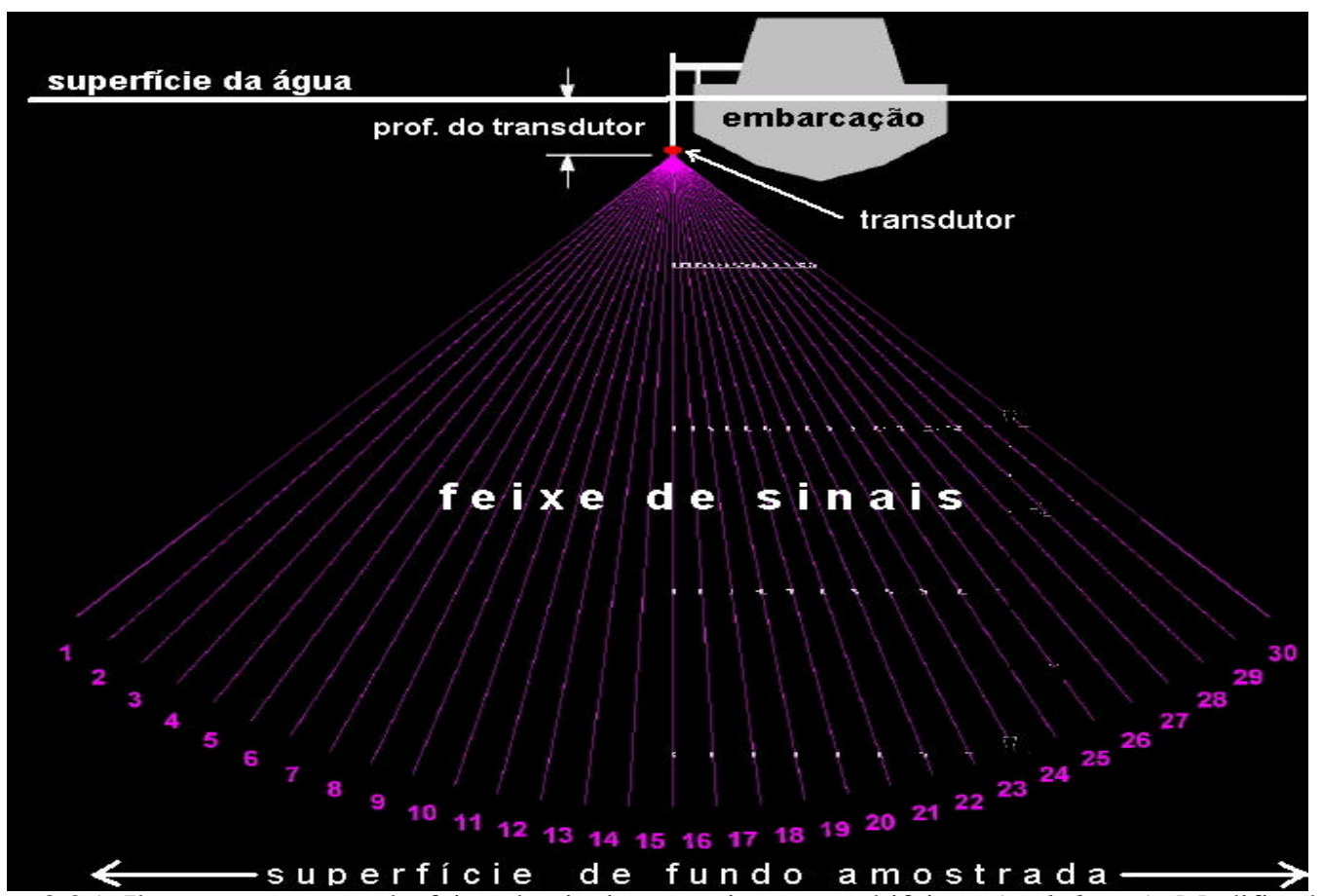

Figura 8.25: Ilustração mostrando feixe de sinais num sistema multifeixes (multibeam). Modificado de USACE (2004)

Os primeiros sistemas com base no princípio de multifontes foram criados nos anos 60, entretanto, somente a partir de 1975, estavam disponíveis os primeiros sistemas comerciais. Apesar de sua alta sofisticação no dias atuais, possibilitando a confecção de mapas batimétricos de alta precisão, estes sistemas, contudo, não fornecem dados quanto à natureza da superfície de fundo ou mesmo relativos à espessura das camadas sedimentares. Fornecendo dados detalhados da topografia da superfície de fundo e com ampla cobertura da área investigada, alguns aspectos da natureza da superfície de fundo podem ser indiretamente evidenciados.

Marlow et al. (2000) constitui-se em um bom exemplo de aplicação deste sistema. Estes autores utilizaram sistema batimétrico de varredura de alta resolução para identificar feições lineares na superfície de fundo (rupturas) relacionadas ao complexo de falhas holocênicas (sistema Palos Verdes), em área offshore no sul da Califórnia (EUA). Os altos estruturais identificados nos mapas gerados pelo sistema batimétrico de varredura multifeixe foram ainda ratificados por meio da execução de perfis sísmicos de alta resolução. Neste artigo, estes autores ainda ressaltaram a importância da utilização destes sistemas para a identificação de feições estruturais regionais (falhas, sistemas de drenagens etc.), na superfície de fundo, o que não ocorreria com a realização simplesmente de um grid de perfis, longitudinais e/ou transversais na área de interesse. Em áreas sujeitas a terremotos, a identificação de lineamentos (forma e extensão) na 
superfície de fundo, relacionados com falhas, em muito contribui para as análises de riscos relacionados com a instalação de projetos de plataformas exploratórias, por exemplo.

Uma das grandes vantagens dos sistemas batimétricos de varredura (multifeixes) é a possibilidade que oferecem da geração em tempo real de mapa topográfico da área coberta pelo perfil em execução, o que outrora, por meio dos ecobatímetros convencionais (de transdutor único), só era possível após o processamento conjunto de todos os perfis executados. A única desvantagem deste sistema é o fato de que os múltiplos canais utilizados simultaneamente na aquisição de dados permitem ampla cobertura da área investigada, consequentemente gerando enorme volume de dados, do que decorre a necessidade de armazenadores de dados de grande porte, bem como, computadores de grande desempenho para processamento dos dados. A Figura 8.26 ilustra de forma esquemática o produto gerado em campo em um levantamento por meio deste sistema.

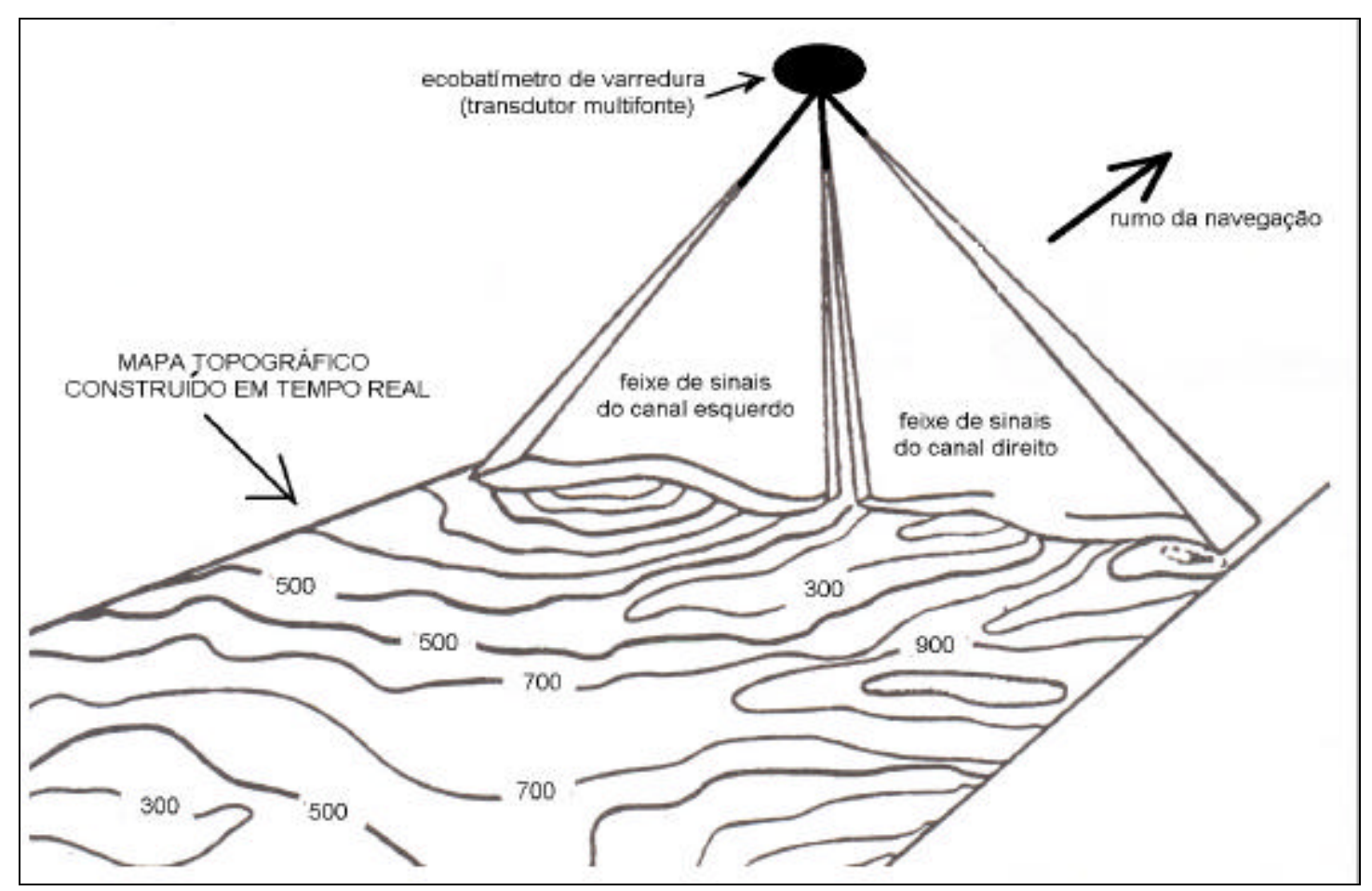

Figura 8.26: Ilustração mostrando o produto obtido em tempo real quando da execução de levantamentos batimétricos utilizando-se ecobatímetros de varredura. Modificado de Hussong \& Fryer (1983).

A utilização de sistemas batimétricos desta natureza tem especial aplicação nos estudos geológicos básicos, pois a análise dos mapas oriundos destes levantamentos permite a observação de características morfológicas da área investigada, tais como canais, afloramentos rochosos, estruturas na superfície de fundo, entre outras, que auxiliam o subseqüente planejamento otimizado de levantamentos adicionais e de mais 
alta resolução, como por exemplo, a sísmica e a sonografia, ensaios geofísicos com custos operacionais mais elevados. Gardner et al. (1998) utilizaram-se deste sistema para mapeamento em grande escala da plataforma continental leste do EUA, obtendo imagens de alta resolução onde observaram detalhes na morfologia da superfície de fundo comparáveis àqueles observados em fotografias aéreas, detectando inclusive, feições na topografia de fundo diretamente correlacionáveis com a atividade humana (plataformas exploratórias, dutos etc.).

Uma alternativa a este sistema que tem sido empregada, por exemplo, nos estudos de portos e hidrovias na Europa e EUA, são sistemas de ecobatímetros multicanais, com transdutores instalados lateral e equidistantemente em suportes posicionados transversalmente à rota de navegação, rebocados ou empurrados fora da embarcação (Figura 8.27).

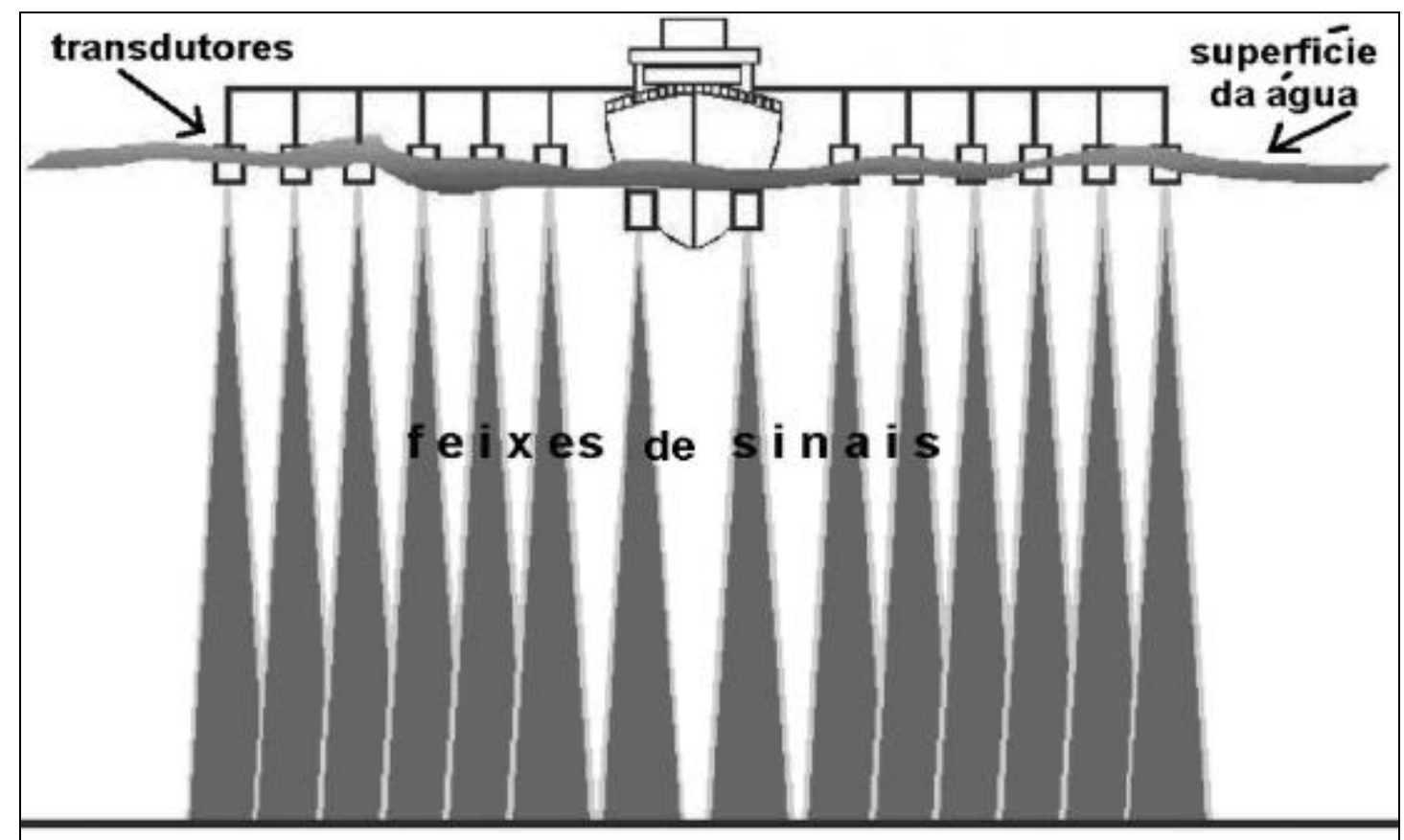

Figura 8.27: Arranjo de transdutores posicionados paralelamente à rota de navegação. Modificado de USACE (2004).

A Figura 8.28 ilustra um sistema desta natureza utilizado pelo Serviço Geológico da Finlândia. Estes sistemas oferecem uma série de vantagens em relação aos convencionais, monocanais, ou mesmo em relação aos sistemas de varredura lateral, a saber:

- numa só linha de navegação, amostram-se simultânea e verticalmente vários pontos da superfície de fundo;

- o sinal é emitido e recebido verticalmente, o que imprime maior precisão na medição já que, neste caso, minimizam-se os eventuais efeitos de distorção 
do sinal, causados quando da propagação do sinal acústico lateralmente num certo ângulo de inclinação;

- dados são coletados num mesmo intervalo de tempo, garantindo maior precisão na geração dos mapas batimétricos, particularmente em locais com grandes variações do nível do mar (marés);

- com este procedimento, poupa-se a necessidade de realização de perfis adicionais para se recobrir totalmente a área de interesse, já que de fato vários perfis são executados paralelamente numa mesma linha de pesquisa ou de navegação.

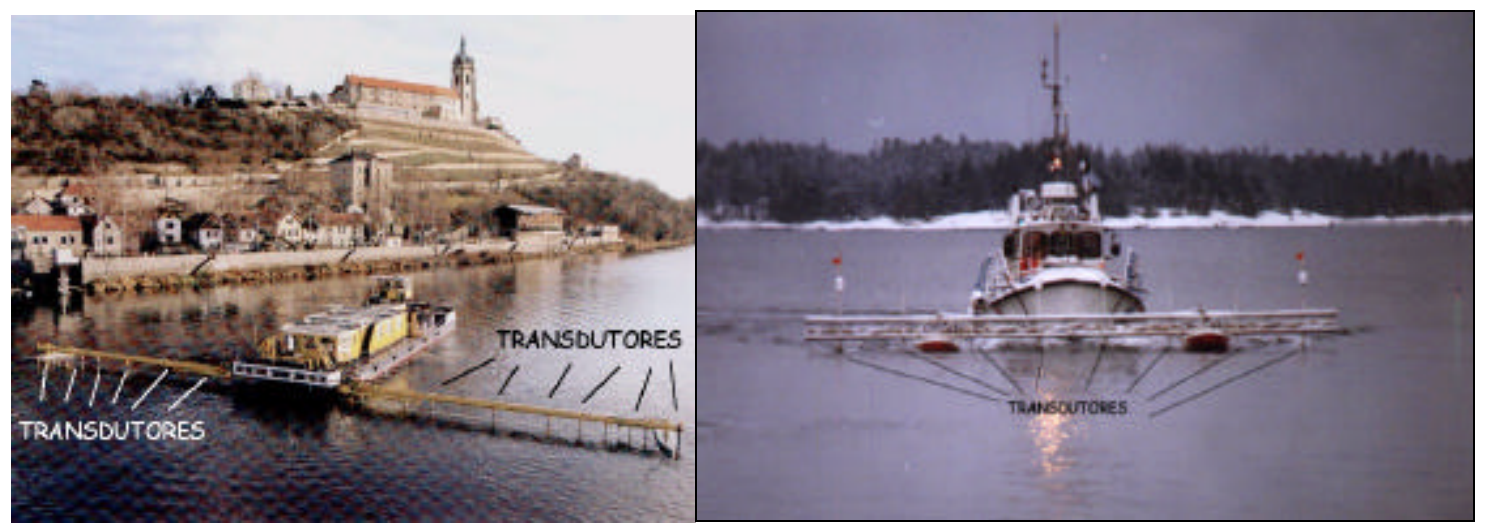

Figura 8.28: Exemplos de sistemas batimétricos multicanais utilizados pelo Serviço Geológico Finlandês, para levantamentos de detalhe de canais de navegação. Fotos: cortesia da Meridata (Finlância).

Para aprimorar a qualidade e o conteúdo dos mapas gerados a partir dos dados coletados por ecobatímetros, que comumente não permitem a caracterização do tipo de material que compõe a superfície de fundo, outros sistemas acústicos foram criados.

O sonar de varredura é um destes sistemas que muito tem contribuído para a efetiva caracterização da superfície de fundo de áreas submersas. Lida também com freqüências altas (geralmente superiores a $100 \mathrm{kHz}$ ) que permitem o imageamento da superfície de fundo, possibilitando uma análise praticamente geológica da superfície, já que viabilizam a identificação, não só da topografia da superfície de fundo, mas também das principais feições geológicas estruturais e dos tipos de fundo, permitindo ainda a análise da sua distribuição em área.

Os novos equipamentos acústicos destinados à investigação de superfícies submersas têm sido construídos de forma a acoplar ambos os sistemas: ecobatímetros de varredura e sonar de varredura lateral. Os produtos originados de levantamentos com estes sistemas deixam distantes os estudos pioneiros que utilizaram o som como fonte de sinais. Com estes sistemas, mapas são obtidos em tempo real mostrando a batimetria (curvas de nível) associada às imagens da superfície, produto que pode ser diretamente correlacionado com as características geológicas e geomorfológicas da superfície investigada. 


\subsubsection{ECOCARÁter}

Vários estudos têm demonstrado que, dos registros contínuos de ecobatímetro de alta freqüência, não se extraem somente dados de espessura da coluna d'água, mas também informações adicionais relativas ao tipo de eco recebido (intensidade e forma), extremamente importantes para a caracterização geológica da superfície de fundo, constituindo-se assim, em instrumento fundamental no estudo de processos e ambientes sedimentares em área submersas.

Combinando-se a análise detalhada do tipo de eco registrado com informações oriundas de amostragens de fundo, de fotografias submarinas, e demais dados hidrográficos, é possível muito se avançar no estudo da caracterização geológica da superfície de fundo e dos processos sedimentares atuantes numa determinada área.

São vários os exemplos na literatura de estudos sobre a superfície de fundo com base no tipo do sinal acústico que retorna ao ecobatímetro (Toldo Jr. et al., 1994; Toldo Jr. et al., 2000; Dias et al., 2005; Lima, 2003; Gasperini, 2005). Um conjunto de características do sinal de retorno ao eco constitui-se no denominado caráter do eco. Basicamente, para determinação do tipo de caráter do eco, observa-se, no registro obtido, a linha que identifica a superfície de fundo. Sobre esta linha, analisam-se: sua espessura, sua rugosidade, sua continuidade, presença de hipérboles de difração, de refletores em subsuperfície, sua duplicidade. Cada tipo distinto de caráter do eco, ou simplesmente tipo de eco, correlaciona-se com um tipo distinto de superfície de fundo, que de forma direta ou indireta está relacionado com os processos sedimentares atuantes. Alguns exemplos de tipo de caráter de eco estão ilustrados na Figura 8.29.

Dunsiger et al. (1981) teceram considerações específicas e detalhadas sobre as relações físicas, entre a natureza da superfície de fundo, sua variabilidade espacial e as propriedades ou as características físicas dos sinais acústicos emitidos em levantamentos acústicos de alta resolução em águas rasas.

Damuth \& Hayes (1977) desenvolveram, como base em registros acústicos de $3.5 \mathrm{kHz}$, importante análise regional dos processos sedimentares atuantes na margem continental leste do Brasil. Nestes estudos os autores mapeiam dez tipos diferentes de eco ou de caráter de eco, que são correlacionados diretamente com padrões de distribuição dos sedimentos ao longo de toda a área. A Figura 8.29 ilustra alguns tipos de ecos identificados nos estudos realizados por estes autores. 
Damuth (1978) analisando dados coletados com um sistema de $3.5 \mathrm{kHz}$, no mar da Noruéga, encontrou importantes relações entre a sedimentação quaternária e os padrões observados nas análises dos tipos de sinais de retorno do eco. Neste mesmo trabalho, ainda destacou que, à parte dos oito padrões e ecos identificados, similares a padrões anteriormente identificados em outras regiões do planeta, dois padrões bastantes distintos foram detectados e correlacionados com superfícies criadas em processos glaciais de erosão e deposição.

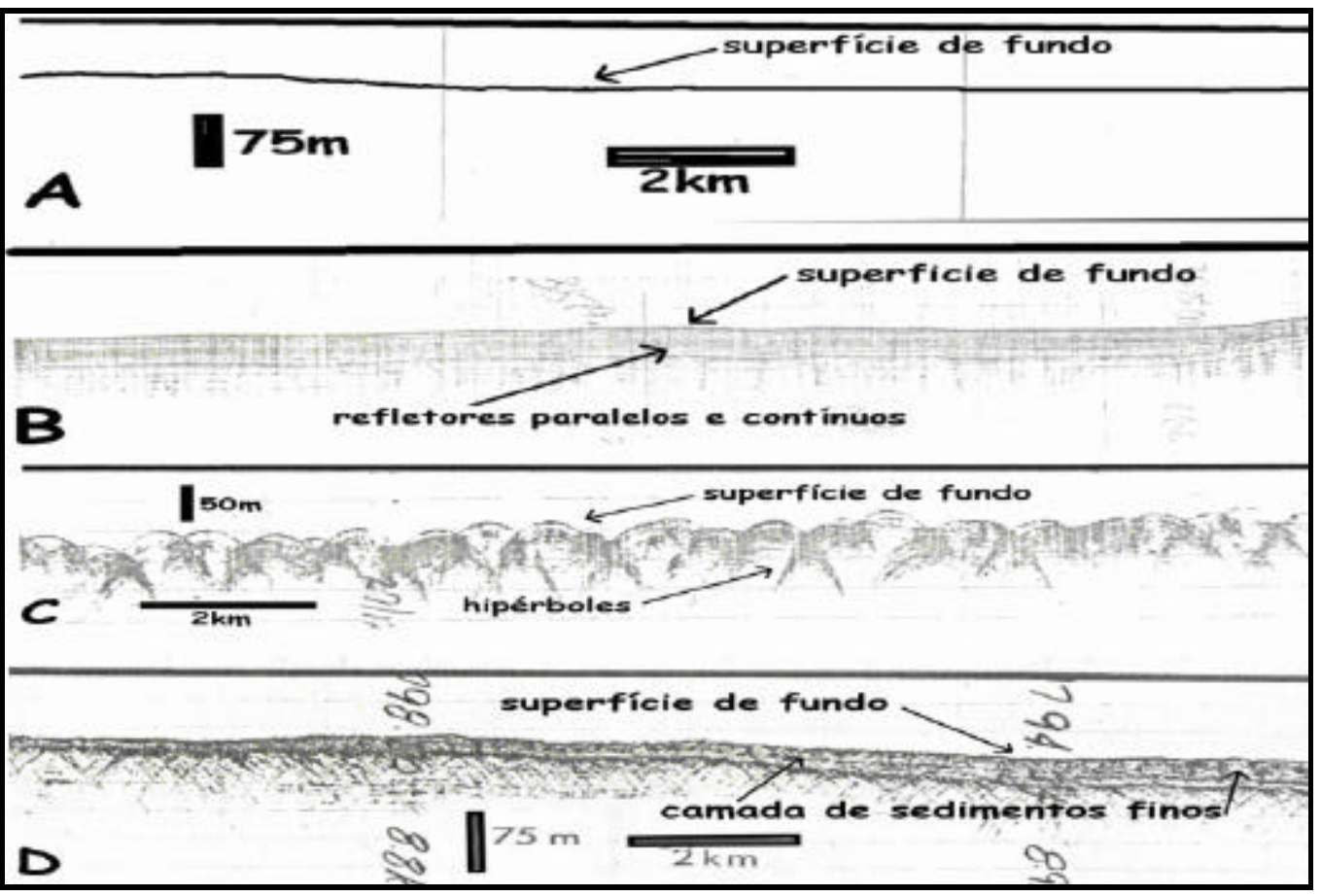

Figura 8.29 - Exemplos de tipo de caráter do eco: a) eco contínuo, homogêneo, com a linha que representa a superfície de fundo muito bem definida, sem refletores subjacentes, típico de plataforma continental com sedimentos consolidados, eventualmente com sedimentos inconsolidados, o que torna a superfície de fundo excelente refletor e, portanto, com raríssima penetração do sinal acústico; b) eco continuo, homogêneo, com a linha da superfície de fundo bem definida e com refletores subjacentes também bem definidos que, segundo os autores, podem representar a distribuição em área dos caminhos de dispersão dos sedimentos terrígenos da Bacia do Brasil, pelo menos nos tempos mais recentes; c) eco com linha irregular da superfície de fundo, presença de hipérboles, inclusive nos refletores referentes ao substrato, típicos das áreas mais acidentadas e mais profundas (plataforma continental externa, talude continental, cadeia mesoatlântica, canions e vales submarinos, morros submarinos); d) eco com linhas da superfície mais espessas, presença de hipérboles, relacionadas, provavelmente, com processos sedimentares gerados nas correntes de contorno. Damuth \& Hayes (1977).

Damuth (1980) fez uma excelente revisão sobre este tema, demonstrando e ilustrando claramente como o tipo de sinal de retorno (o caráter do eco), dos sinais acústicos emitidos pelos ecobatímetros de alta precisão contribuem para o estudo dos processos sedimentares atuantes na superfícies de fundo. Analisou dados de perfiladores que emitem freqüências entre 3.5 e $12 \mathrm{kHz}$, freqüências comumente utilizadas na investigação profunda. Neste artigo, o autor mostrou exemplos de mapas de caráter do eco que possibilitam análises regionais de bacias sedimentares quanto à distribuição 
relativa dos tipos de sedimentos de fundo (argilas, siltes e areias), destacando, até mesmo, setores de algumas regiões onde se observam padrões de sinais de eco com penetração do sinal nas camadas superficiais dos sedimentos finos.

Forsgren et al. (1993) analisaram sinais acústicos de alta freqüência (200 kHz) oriundos de levantamentos executados no Estuário Ore, no Golfo da Bothnia, norte da Suécia, concluindo que os dados oriundos da utilização de ecobatímetros de alta frequiência têm grande aplicação, com resultados altamente confiáveis, na determinação da extensão espacial dos diferentes tipos de superfície de fundo (sedimentos finos, grossos, afloramentos rochosos).

Tendo como base também o método de análise do caráter do eco utilizado por Damuth (1980), mas estudando uma área costeira rasa no Brasil, Rocha (2003) desenvolveu estudo semelhante, em levantamento executado na baía de Santos, no Estado de São Paulo. Utilizando sistema acústico de $24 \mathrm{kHz}$ (pinger) identificou, nos registros do eco, seis padrões de fundo que representam seis distintas respostas da superfície de fundo, ao sinal acústico emitido. Conforme a Figura 8.30 e a Figura 8.31, cada uma das respostas sísmicas foi obtida para distintos tipos de fundo na área da baía de Santos. Ressaltou a autora que a classificação aplicada aos registros obtidos foi desenvolvida exclusivamente para os sedimentos da superfície de fundo da baía de Santos e teve como base conceitual as discussões abordadas em Damuth $(1975,1978$, 1980) e Damuth \& Hayes (1977).

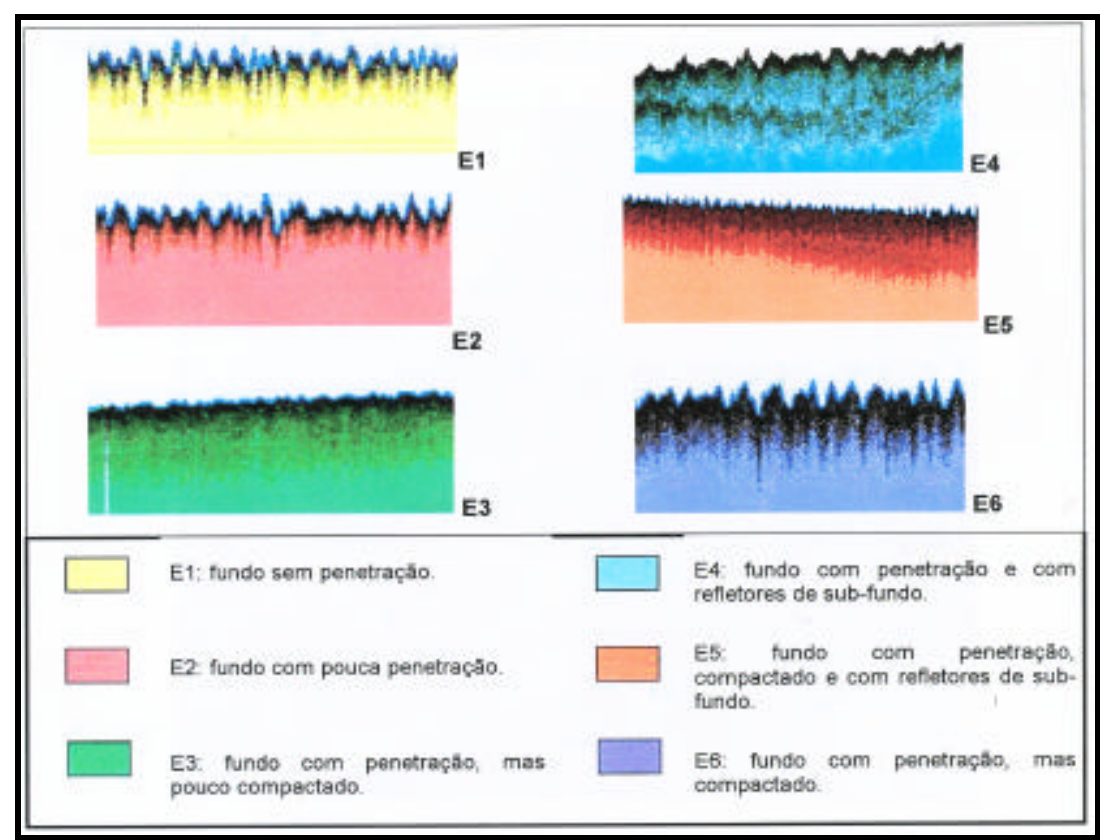

Figura 8.30: Tipos de caráteres de eco identificados na classificação dos sedimentos de fundo da baía de Santos a partir de registros de uma fonte acústica do tipo pinger - 24kHz (Rocha, 2003). 


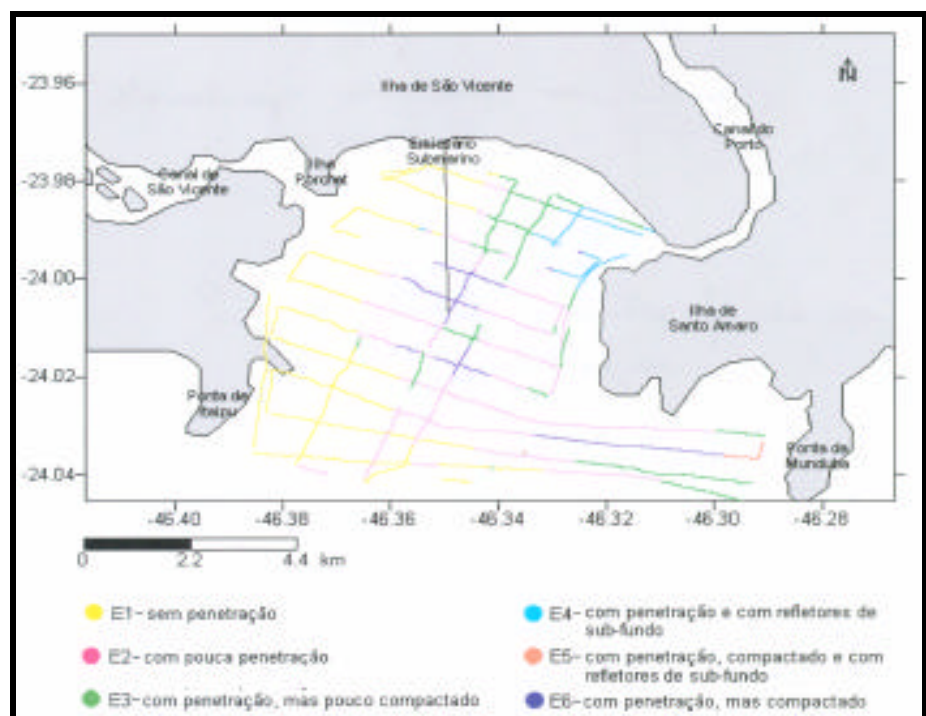

Figura 8.31: Mapa da baía de Santos ilustrando rotas executadas e classificadas por meio da análise do caráter do eco (vide legenda de cores) oriundo de levantamento executado com um ecobatímetro do tipo pinger $-24 \mathrm{kHz}$ (Rocha, 2003).

Lima (2003) utilizou-se também das características do sinal acústico de retorno (caráter do eco), tendo como base perfis obtidos com perfiladores do tipo $3.5 \mathrm{kHz}$, para tecer considerações sobre os processos sedimentares atuantes em sistemas de águas profundas, relacionando os tipos de caráter do eco identificados com tipos de processos sedimentares, e assim, diferenciando corpos sedimentares oriundos de correntes de contorno, movimentos de massa e correntes de turbidez na margem continental sudestesul do Brasil e bacia oceânica adjacente. Conforme ilustrado na Figura 8.32, padrões de eco bastante distintos foram identificados nos perfis, o que permitiu caracterização extremamente objetiva, deste ponto de vista, dos três corpos sedimentares estudados por esta autora (Columbia, São Tomé e Vema).

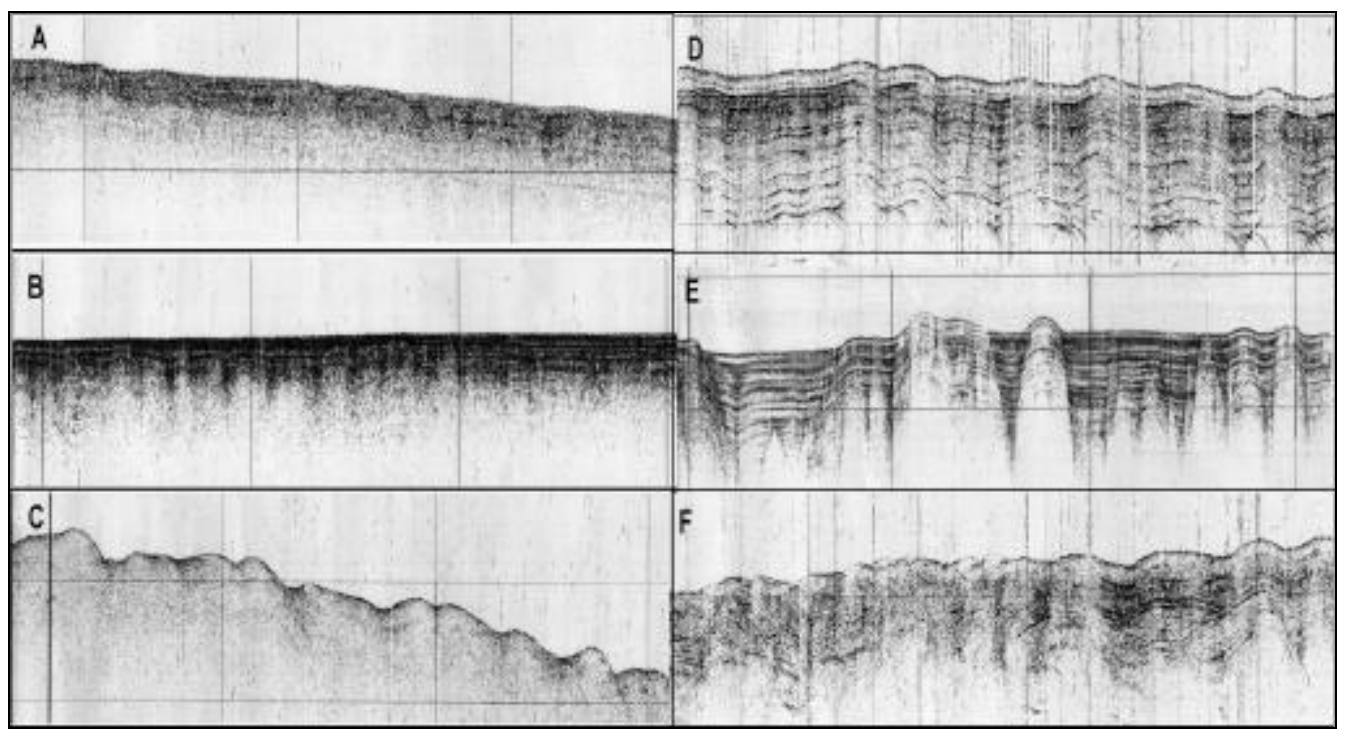

Figura 8.32: Exemplos de registros de levantamentos sísmicos com perfilador $3.5 \mathrm{kHz}$ obtidos no estudo padrões de eco identificados nos estudos dos corpos sedimentares Columbia, São Tomé e Vema, na margem continental Sudeste-Sul e bacia continental adjacente. Modificado de Lima (2003). 
São vários os aspectos a serem levados em conta quando se analisa o sinal acústico que retorna ao eco. Este sinal varia com a profundidade da coluna d'água na área investigada, com a amplitude do sinal e com o comprimento de onda do sinal acústico emitido pelo transdutor e, assim, para cada área de estudo deve ser feita uma modelagem prévia, estabelecendo-se um padrão de correlação entre a morfologia sedimentar da superfície de fundo com os possíveis padrões do eco (Flood, 1980). Assim, uma simples correlação direta entre caráteres de ecos obtidos em áreas distintas pode não fornecer resultados satisfatórios. Neste caso, uma normalização dos dados obtidos se faz necessária.

\subsubsection{Classificadores de FUNDO OU AGDS (ACOUSTIC GROUND DISCRIMINATION SYSTEMS)}

Desde há muitos anos que pesquisadores envolvidos com o estudo de áreas submersas interpretam dados oriundos de ecobatímetros com objetivo de classificar geologicamente as superfícies de fundo. Esta classificação ocorreu fundamentada na observação visual, das propriedades do sinal de retorno (intensidade e forma), nos registros analógicos, o que tornava os resultados fortemente dependentes do "olhar" do intérprete e, portanto, portadores de relativa subjetividade.

Sabe-se que as propriedades dos sinais acústicos que retornam aos transdutores (eco) contêm uma série de informações (espectro de frequiências, amplitudes etc.) que são diretamente correlacionáveis às características da superfície de fundo. A classificação acústica da superfície de fundo constitui-se justamente no processo de organização automática, de uma superfície de fundo, em classes ou em tipos geológicos distintos, tendo como base as respostas acústicas oferecidas por cada um destes tipos de fundo.

Ecobatímetros modernos, conhecidos como sistemas acústicos de classificação de fundo, ou AGDC (Acoustic Ground Discrimination Systems), possuem módulos de controles especiais com algoritmos dedicados (softwares) acoplados ao sistema de recepção dos sinais, que permitem automaticamente processar, em paralelo, o sinal acústico recebido e assim, classificar o tipo de sedimento de fundo, de acordo com a energia ou a forma do pulso refletido e, a partir de um padrão preestabelecido para cada área.

A forma como um sinal acústico é refletido ou absorvido depende das propriedades elásticas e da densidade dos materiais que constituem a superfície de 
fundo. Superfícies duras ou densas, como fundos rochosos, produzem fortes reflexões do sinal acústico (ecos), enquanto superfícies macias, como aquelas constituídas por sedimentos inconsolidados, produzem ecos ou reflexões de baixa amplitude, pois parte do sinal emitido não regressa ao transdutor, penetrando nos sedimentos.

Além do sinal refletido principal (primeiro eco), ou seja, o sinal que parte do transdutor atinge a superfície de fundo e regressa ao transdutor, múltiplos ecos também podem ocorrer, pois, a depender do tipo de fundo, os sinais acústicos refletem duas, três ou mais vezes na superfície. O significado geológico dos ecos subseqüentes ao principal é discutível, todavia, a maioria dos autores relaciona diretamente a existência destes ecos com a dureza do fundo.

Estes sistemas partem do princípio de que a quantidade de energia acústica e a forma do sinal acústico, que retornam ao sensor após refletir na superfície de fundo, está diretamente relacionada com as características físicas da superfície. Uma cobertura sedimentar homogênea, por exemplo, possibilita o retorno, ao transdutor, de grande parte da energia emitida, resultando num sinal acústico de forma bastante definida (traço sísmico relativamente estreito); uma superfície de fundo rugosa, composta de sedimentos grossos (areias e cascalhos), por outro lado, exibem alto grau de espalhamento da energia emitida e, assim, o sinal acústico de retorno ao transdutor apresenta forma bastante distinta (traço sísmico largo). A Figura 8.33 ilustra o princípio de funcionamento dos sistemas classificadores de fundo.
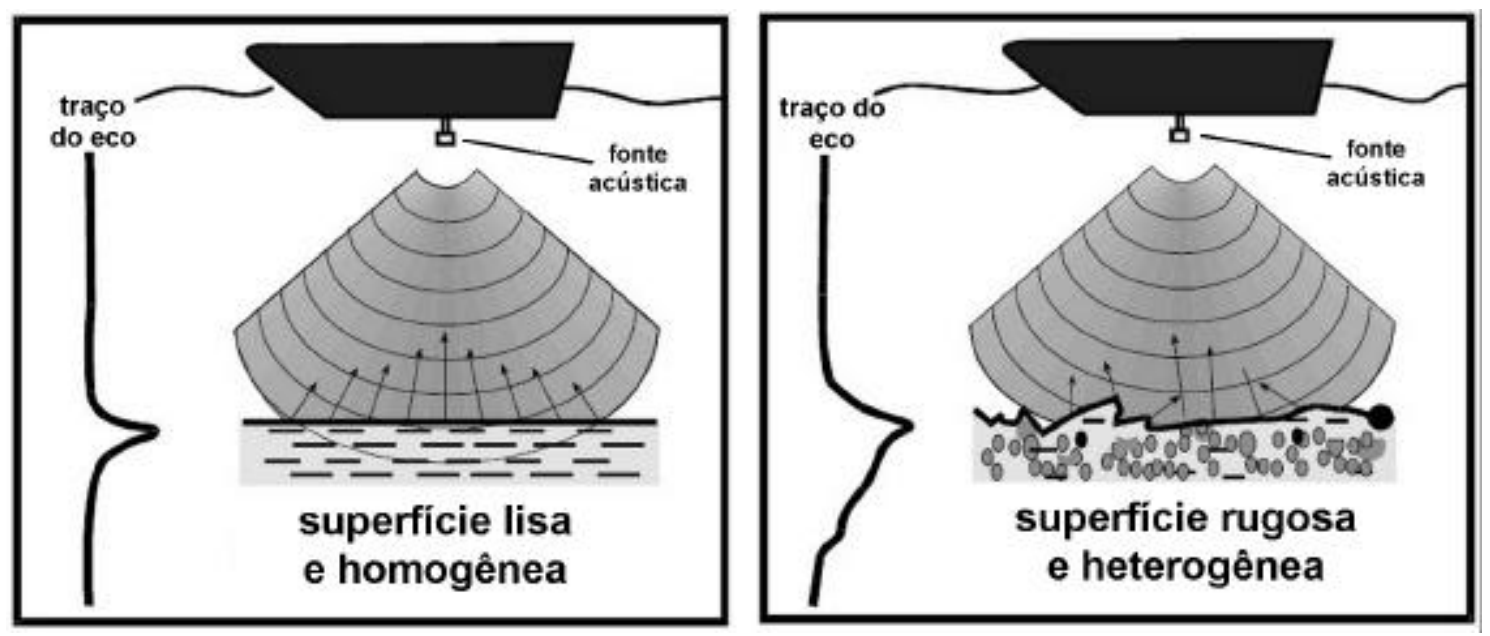

Figura 8.33: Ilustração mostrando o princípio da análise dos sinais acústicos que retornam ao transdutor, fundamento dos sistemas de classificação automática de fundo (AGDS). Modificado de <http://www.questertangent.com/m papers.html>. Acesso: março 2006.

$\mathrm{Na}$ análise da energia de retorno, a classificação de fundo é feita com base no decaimento da energia do sinal acústico em função do tempo. Desta forma, quanto mais 
heterogênea a superfície de fundo, maior a perda de energia do sinal de retorno; raciocínio contrário se faz no caso de superfícies de fundo homogêneas. A Figura 8.34 mostra um perfil, resultado da utilização de um sistema classificador de fundo do tipo RoxAnn, executado sobre uma área onde parte da superfície de fundo compõe-se de afloramentos rochosos. Nesta figura, observam-se as alterações nos perfis E1 e E2 quando da passagem sobre os afloramentos rochosos.

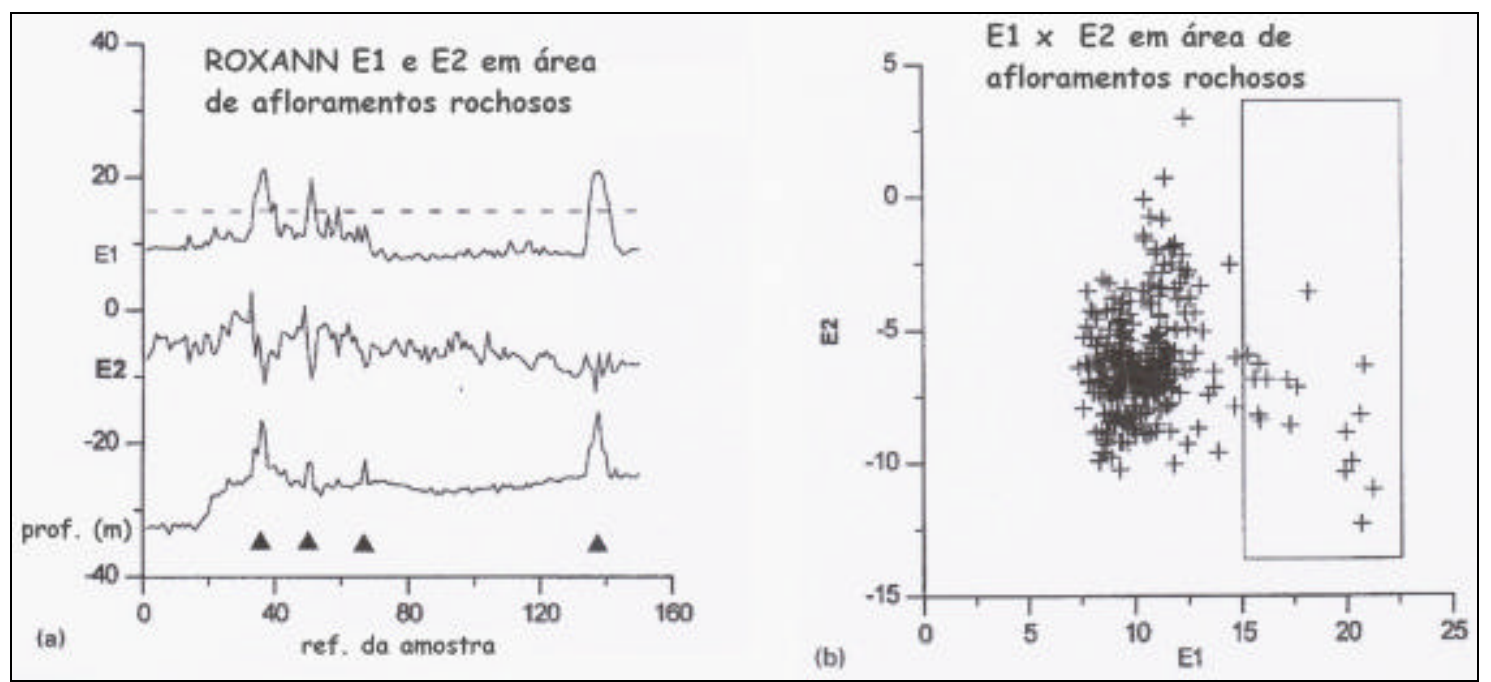

Figura 8.34: Exemplos das variações dos parâmetros do sistema Classificador de Fundo RoxAnn E2 (dureza) e E1 (rugosidade) em área de ocorrência de afloramentos rochosos submersos. Os triângulos pretos na base da figura "a" indicam a localização dos afloramentos rochosos. Observa-se que em (a) o perfil de E1 alcança um máximo sobre o afloramento rochoso, o contrário ocorrendo (um mínimo) com o perfil de $\mathrm{E} 2$, indicando que o segundo eco, na verdade, não chega totalmente ao receptor. $\mathrm{O}$ gráfico $\mathrm{E} 1 \mathrm{x}$ E2 da figura "b" mostra a distribuição anômala dos dados (ocorrem fora da tendência) obtidos sobre o afloramento rochosos. Modificado de Hamilton et al. (1999).

Softwares dedicados são acoplados a estes ecobatímetros de modo que seja realizada a análise dos sinais de retorno quanto ao conteúdo em energia ou à forma, a depender do sistema utilizado. Cores são atribuídas às diferentes quantidades de energias dos sinais que retornam, o que possibilita a geração de mapas coloridos a partir destas análises. Nestes mapas, cores semelhantes correlacionam-se com um mesmo tipo de fundo. A Figura 8.35 ilustra um mapa construído com dados de eco desta natureza oriundos de um sistema RoxAnn. Neste exemplo, as cores utilizadas e as atribuições geológicas de cada uma delas não foram padronizadas para a área previamente, o que pode ocasionar erros, se a interpretação dos dados for realizada em tempo real, ou seja, durante a navegação. Neste caso específico, a cor avermelhada no mapa, indicando a ocorrência de corais, pode significar, de fato, a ocorrência de sedimentos carbonáticos, ou uma eventual concentração de conchas, por exemplo, já que sabidamente não ocorrem feições daquela natureza no trecho investigado (Rocha, 2003). 


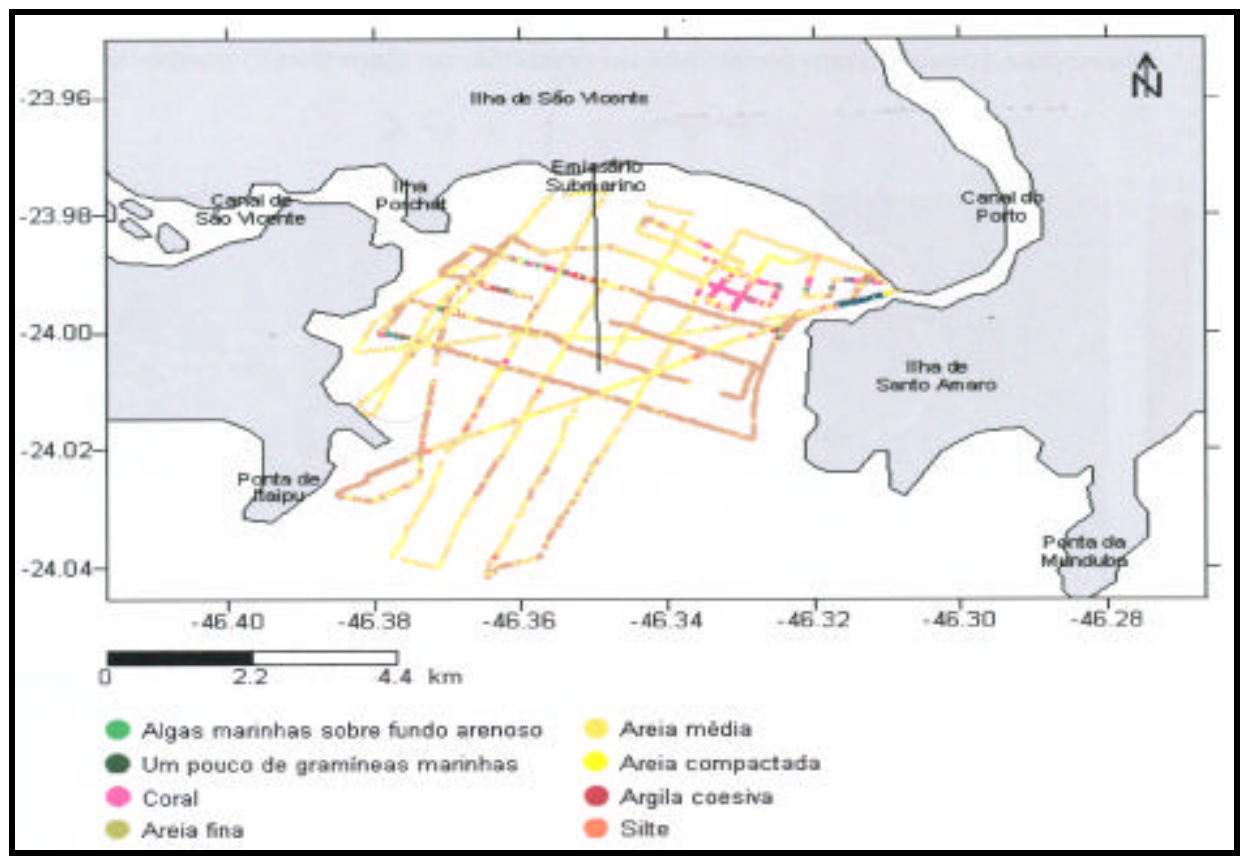

Figura 8.35: Mapa da baía de Santos ilustrando rotas executadas e classificadas com relação às características de fundo, por um ecobatímetro do tipo classificador de fundo (RoxAnn - Marine Micro Systems Ltd, Irlanda), que emite sinais acústicos na faixa de 50kHz (Rocha, 2003).

Outra forma de representação gráfica dos dados obtidos de classificadores de fundo está ilustrada na Figura 8.36 e na Figura 8.37. Nestas figuras, Mac-Dougall \& Black (1999), com base em mapa de isovalores de E1 e E2, caracterizaram a superfície de fundo de uma área na Grécia, subsidiando estudos de impactos ambientais causados pela ocupação da superfície de fundo por empreendimentos de mariculturas.

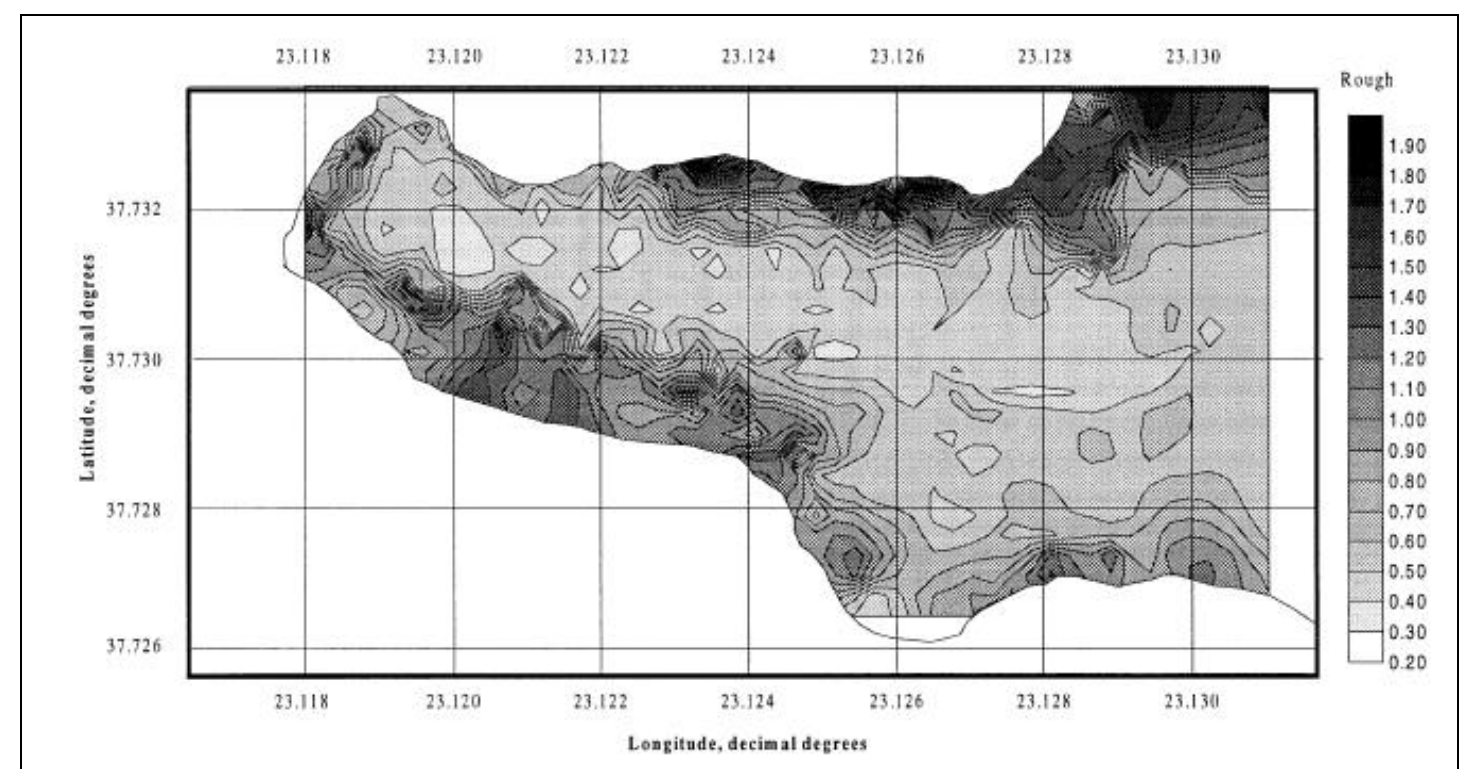

Figura 8.36: Mapa com curvas de isovalores do parâmetro E1, oriundos de levantamento com classificador de fundo do tipo RoxAnn na Baía de Selonda, na Grécia, em estudos de impactos causados por ocupação da superfície marinha por empreendimentos de maricultura. Nesta figura observa-se que a superfície de fundo da área investigada é relativamente rugosa em toda sua extensão, sendo menos rugosa na porção central, mais profunda. Esta rugosidade foi posteriormente correlacionada, por meio de observações diretas, com sedimentos grossos. Mac-Dougall \& Black (1999). 


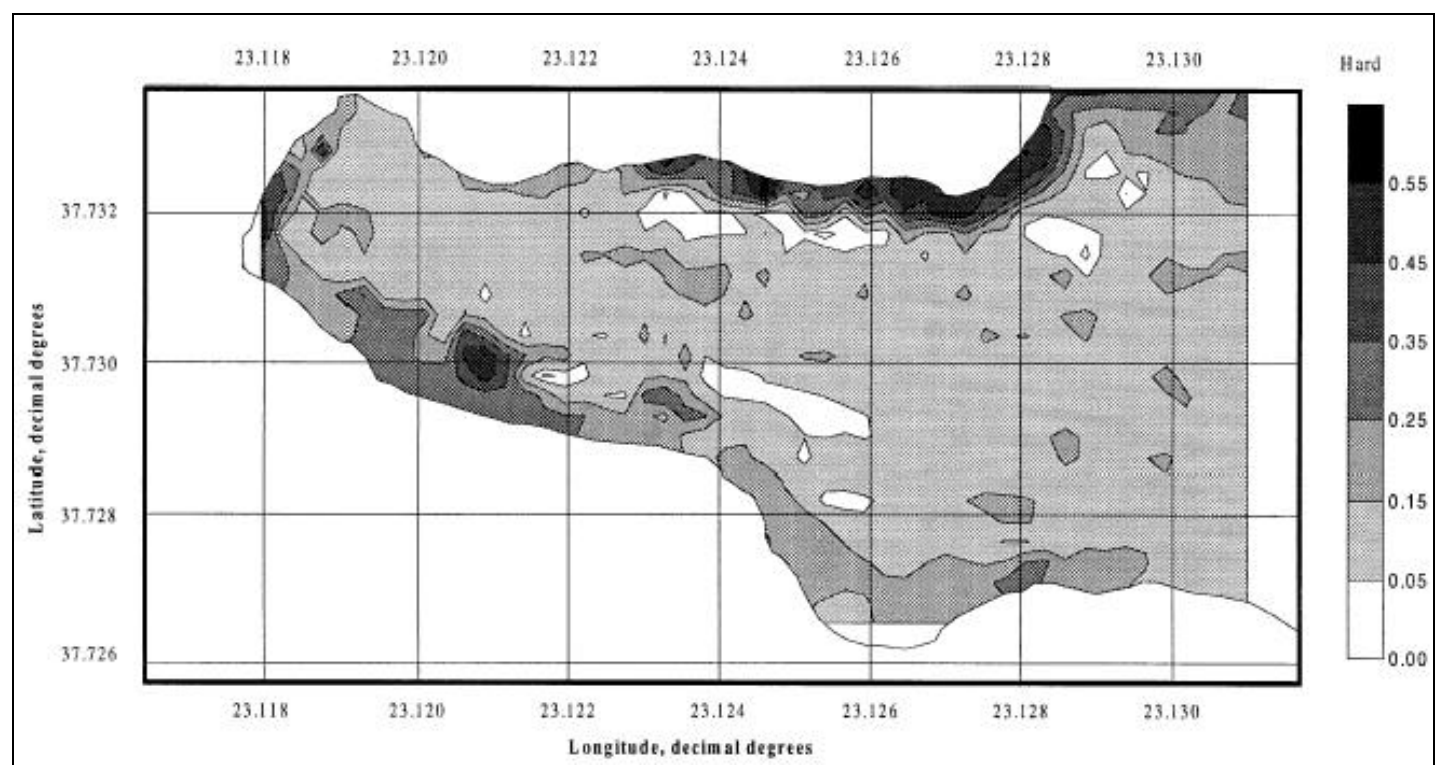

Figura 8.37: Mapa com curvas de isovalores do parâmetro E2, oriundos de levantamento com classificador de fundo do tipo RoxAnn na Baía de Selonda, na Grécia, em estudos de impactos causados por ocupação da superfície marinha por empreendimentos de maricultura. Nesta figura nota-se que, embora a superfície de fundo da área investigada seja relativamente dura em toda sua extensão, em especial nas porções marginais, detectaram-se por meio do parâmetro E2, algumas áreas cobertas por sedimentos mais inconsolidados (menos duros). Mac-Dougall \& Black (1999).

Existem três tipos básicos de sistemas ecoclassificadores de fundo disponíveis atualmente são o sistema RoxAnn, fabricado pela SonaVision Ltd. que utiliza um sistema processador do sinal analógico que seleciona dois elementos do sinal acústico de retorno do fundo e mede a variação da intensidade do sinal (em milivolts) no tempo: um primeiro elemento denominado Eco 1 ou simplesmente E1, que é correlacionado com a rugosidade do fundo; um segundo, Eco 2, denominado E2, oriundo da primeira reflexão múltipla, que é correlacionado com a dureza da superfície de fundo. Estas duas variáveis são representadas num gráfico cartesiano E1 x E2 sobre o qual é realizada a análise da área, o que pode ser feito, inclusive, em tempo real, ao longo da linha de navegação, à medida que o levantamento evolui; o sistema $\mathbf{Q T C}$-View, fabricado pela Quester Tangent Corporation, que tem base operacional distinta do RoxAnn, pois se fundamenta na análise, por meio de vários algoritmos, da forma do primeiro eco, que é convertido durante o processo, de analógico para digital (Foster-Smith et al., 1999). Diferentemente do sistema RoxAnn, o QTC-View não utiliza a energia do segundo eco oriundo da primeira reflexão múltipla. Analogamente ao RoxAnn, o QTC-View apresenta uma classificação automática de fundo com base nos parâmetros medidos $(Q$ values); e, um terceiro sistema, modelo Echo Plus, fabricado pela SEA Ltd, um sistema digital de dupla freqüência com princípios de funcionamento similares ao sistema RoxAnn. 
Hamilton et al. (1999) compararam os dois sistemas classificadores de fundo mais utilizados (RoxAnn e QTC-View) demonstrando os principais fatores que afetam cada um dos sistemas. Destacaram a forte dependência do sistema RoxAnn da velocidade da embarcação durante a aquisição dos dados, ao contrário do sistema QTCView, concluindo, contudo, que ambos os sistemas apresentam dificuldades de calibração quando utilizados sobre superfícies de fundos com texturas muito rugosas, como fundos rochosos ou recifes de corais. As comparações efetuadas por estes autores permitiram ainda concluir que nenhum destes sistemas se constituem em ferramentas absolutas ou únicas para a caracterização geológica de superfícies submersas e que, portanto, para a confecção de um mapa final de caracterização de fundo, a partir destas ferramentas geofísicas, se faz necessária a coleta de informações diretas, como amostras da superfície de fundo (grabs, boxcore), vídeo-filmagens, fotografias submarinas, observações por meio de mergulhadores ou submersíveis. De posse destas informações padrões da refletividade de fundo da área de estudo, podem ser estabelecidos, de forma a subsidiar a interpretação dos dados oriundos dos classificadores de fundo, para finalmente se confeccionar o mapa de caracterização da superfície investigada.

Analogamente ao procedimento de análise do caráter do eco, o processo de classificação da superfície de fundo, com base neste método, carece de estabelecimento prévio de um padrão ou uma calibração, para cada área de investigação, pois intensidades de energia ou formas dos sinais acústicos de retorno semelhantes podem não significar, em locais distintos, o mesmo tipo de fundo. Assim, amostras de fundo devem ser coletadas em pontos representativamente distribuídos, de modo a possibilitar a correlação entre as cores nomeadas para cada padrão acústico identificado pelo sistema e a geologia da superfície de fundo.

A calibração do sistema pode também ser executada por meio do levantamento de um perfil experimental em área, com características geológicas conhecidas em detalhe, ajustando-se as cores designadas automaticamente pelo sistema às reais características da superfície de fundo daquele local de calibração. Humborstad et al. (2004) utilizaram-se deste expediente para estudar áreas impactadas por intensa atividade pesqueira, no mar de Barents, na Noruéga. Dados de amostras de fundo, imagens de sonar de varredura lateral, além de imagens de vídeo somaram-se para compor o produto final dos estudos efetuados. 
Os mapas gerados a partir destes sistemas, analisados em conjunto com os dados oriundos do sonar de varredura lateral, associados às análises sedimentares das amostras coletadas e, quando possível, comparadas às imagens de vídeo ou de fotografia submarina, possibilitam a caracterização contínua e, com bastante detalhe, da superfície de fundo da área investigada.

Assim, por meio desta técnica, um ecobatímetro permite também a caracterização ou classificação geológica da superfície de fundo, informação esta fundamental para estudos de áreas submersas e com aplicação em diversos setores, e particularmente em questões ambientais.

Rocha (2003) apresentou uma tentativa de classificação de superfície de fundo a partir de dados desta natureza obtidos na baía de Santos, com um ecobatímetro acoplado a um classificador de fundo do tipo RoxAnn. Neste trabalho, apesar de a autora identificar alguns problemas para uma correlação direta entre os dados gerados pelo sistema de classificação automática e as características sedimentológicas da superfície de fundo da baía, forte correlação foi verificada entre a distribuição dos carbonatos biodetríticos na área e os padrões identificados pelo ecobatímetro classificador de fundo de $50 \mathrm{kHz}$, e pelos padrões dos caráteres de eco oriundos da interpretação dos perfis obtidos do pinger de $24 \mathrm{kHz}$ (Figura 8.30 e Figura 8.31).

Greenstreet et al. (1997), por meio deste método de caracterização de superfícies submersas, e utilizando-se de um sistema classificador de fundo com transdutor de $38 \mathrm{kHz}$, realizaram importante estudo sobre habitats submarinos, na Inglaterra, como subsídio a estudos da diversidade marinha local. Ressaltaram os autores neste artigo a importância do conhecimento detalhado dos habitats submarinos para a avaliação ecológica de uma determinada região, com respeito a eventuais procedimentos legais para a preservação de determinadas espécies. Observaram ainda que uma avaliação, utilizando-se destas ferramentas de investigação, possibilita a obtenção rápida de informações detalhadas da superfície de fundo, que só seriam possíveis a partir da execução de um programa de coleta de amostras de fundo numa densa malha de amostragem, o que tornaria o projeto mais caro e de execução mais demorada. É também realizada uma interessante comparação entre dados batimétricos classificados e amostragens de fundo, coletados num mesmo local e em períodos distintos, e também com mapas sedimentológicos da área construídos pelo Serviço Geológico Britânico, concluindo serem os dados essencialmente similares e, assim, 
mostrando a grande aplicabilidade deste sistema em estudos ecológicos, biológicos e geológicos.

Collier \& Brown (2005) encontraram forte correlação, principalmente no item rugosidade (E1), quando da comparação entre dados obtidos numa mesma área, oriundos de um ecobatímetro do tipo classificador de fundo $(200 \mathrm{kHz})$ e de um sonar de varredura lateral de dupla freqüência $(100$ e $400 \mathrm{kHz})$. Os resultados destes levantamentos, associados a resultados das análises de várias amostras coletadas e com base em imagens de vídeos subaquáticos e observações de mergulhos, levaram os autores a concluir sobre a extrema importância destas duas ferramentas na caracterização detalhada da superfície de fundo de áreas submersas. Mesmo considerando que as imagens oriundas do sonar de varredura lateral cobrem, na execução de uma linha, uma área maior e, portanto, possibilitam uma cobertura ampla e rápida da área de estudo, os autores destacaram a positiva correlação entre os dados do eco e do sonar, sugerindo que ambas as ferramentas utilizadas em estudos de caracterização da superfície de fundo de uma determinada área oferecem resultados de tal detalhes que, com certeza, reduzem em muito o número de amostragens de fundo necessárias para a devida e detalhada caracterização da área de estudo.

Uma avaliação crítica dos sistemas acústicos utilizados no mapeamento de superfícies submersas, com atenção para o mapeamento de habitats submarinos em áreas protegidas, é desenvolvida por Brown et al. (2005). Neste artigo os autores resumem a interessante experiência do desenvolvimento de levantamentos geofísicos por quatro diferentes equipes de pesquisadores atuando numa mesma área de estudo, cada grupo utilizando os parâmetros que julgavam adequados e estratégicos para o estudo daquela mesma área.

Com objetivo de avaliar a resolução e a aplicação de sistemas classificadores de fundo, como ferramentas para mapeamento de habitats submarinos, em áreas de preservação/conservação, foram executados levantamentos sísmicos bastante detalhados em uma área geologicamente heterogênea de apenas $1 \mathrm{~km}^{2}$, na costa oeste da Escócia. Foram utilizados classificadores de fundo do tipo RoxAnn acoplados a ecobatímetros operando na frequiência de $200 \mathrm{kHz}$, e um sonar de varredura lateral (100 kHz), além de extensiva campanha de vídeo-filmagens com amostragens da superfície de fundo. Sobre a área de interesse, visando comparar a eficiência dos sistemas classificadores de fundo, foram executados levantamentos com distintos sistemas RoxAnn, utilizando-se de 
parâmetros também distintos, em cada um dos levantamentos, variando-se, distância entre as linhas, a grade de dados para análise, a velocidade da embarcação, e até mesmo o tipo de embarcação. A partir das análises das imagens de vídeo, Brown et al. (2005) identificaram seis tipos de fundo. O mosaico criado com as imagens do sonar ofereceu resolução que permitiu subdividir a área estudada em apenas três setores acusticamente distintos.

A partir da análise detalhada dos dados obtidos de cada um dos levantamentos acústicos realizados, bem como de cada um dos conjuntos de parâmetros utilizados em cada levantamento, os autores concluem que os sistemas classificadores de fundo (ou $A G D S)$ permitem uma caracterização ampla da superfície de fundo, bem como da definição dos habitats submarinos. Entretanto, ressaltam que a precisão do levantamento pode estar comprometida no caso da necessidade de detalhada discriminação espacial dos tipos de fundo, o que ocorre devido ao fato de que os sistemas classificadores de fundo utilizam, comumente, a tecnologia de pulsos simples, ou seja, no espaço entre os perfis, nenhum dado existirá entre as linhas de investigação, e, portanto, uma interpolação deverá ser realizada no processo de interpretação dos dados, o que pode comprometer a qualidade e a resolução do mapa final. Nestes casos, talvez sistemas de varredura lateral (sistemas multifeixes ou swathe acoustic systems) podem oferecer resultados mais interessantes e detalhados.

Mesmo considerando a semelhança entre os mapas acústicos finais, obtidos a partir da experiência destes levantamentos multiparametrizados, os autores ainda ressaltam a importância da escolha do equipamento adequado às condições topográficas da área a ser estudada. Grandes variações no perfil topográfico (p.ex, 20-100 m) exigem a escolha de transdutores com frequiências e ângulos de emissão adequados para garantir que a área atingida na superfície de fundo por cada pulso emitido seja a menor possível, com resolução compatível com o objetivo do levantamento.

\subsubsection{Outras Aplicações}

À parte dos cuidados básicos, mas fundamentais, na execução dos ensaios de campo (questões operacionais), bem como na interpretação dos dados, destacados no item anterior, os sistemas acústicos classificadores de fundo constituem-se em importantes ferramentas, com aplicações das mais diversas, seja na caracterização de habitats subaquáticos, subsidiando, desta forma, estudos de comunidades bentônicas na oceanografia biológica, nas questões ambientais, mapeando tipos de sedimentos que de 
algum modo se associam a contaminantes, ou mapeando os impactos na superfície de fundo dos instrumentos utilizados amplamente na pesca.

Não é novidade o constante crescimento, nestas últimas décadas, das atividades pesqueiras no Brasil e no mundo, e seu conseqüente impacto ambiental acarretando não só a diminuição do estoque de peixes, como também afetando direta e fisicamente a superfície de fundo, destruindo os habitats naturais, e dramaticamente, a cadeia primária de alimentação da comunidade marinha. Existem vários exemplos de setores da costa brasileira onde o desenvolvimento da pesca, sem o devido controle, causou prejuízos, talvez irreparáveis, à comunidade bentônica, liquidando comunidades que dela dependiam. A costa do Estado do Paraná é um exemplo desta situação, até certo ponto, de calamidade. Esforços das autoridades governamentais estão sendo realizados na tentativa de recuperação da comunidade marinha destruída, ao mesmo tempo em que normas estão sendo criadas para regulamentar os períodos adequados às atividades pesqueiras de determinadas espécies. No caso do Estado do Paraná, a solução encontrada para a recuperação da comunidade faunística foi o lançamento de recifes artificiais em locais pré-definidos (IPT, 2002a).

A pesca é uma das atividades antropogênicas mais tradicionais no ambiente marinho, contudo, apenas nas últimas décadas atenção especial foi dada aos aspectos negativos ou impactantes desta atividade. Os impactos no ambiente marinho, observados a partir das alterações físicas da superfícies de fundo, bem como nas perturbações biológicas das comunidades bentônicas, causadas por esta atividade antropogênica são, atualmente, amplamente conhecidos. Rosenberg et al. (2003) discutiram impactos significantes em comunidades bentônicas observados na Suécia, em experimentos realizados em área de coluna d'água inferior a $100 \mathrm{~m}$, sob intensa atividade pesqueira, que utilizam, em especial, sistemas de pesca do tipo redes de arrasto. Muitos outros registros existem na literatura internacional mostrando o impacto desta atividade de pesca na superfície e subsuperfície de fundo, alterando consideravelmente as estruturas e as condições geoquímicas da coluna sedimentar, o que em muitos casos tem como conseqüência imediata dramáticas reduções na biomassa da infauna e da epifauna (Rosenberg et al., 2003). Ao se considerar que estes sistemas de pesca podem perturbar vários centímetros da coluna de sedimentos finos, comunidades inteiras, principalmente da infauna bentônica, podem ser destruídas em regiões onde esta atividade é intensa, causando efeitos significantes nos ambientes 
perturbados, já que várias propriedades dos sedimentos são profundamente alteradas nestas condições.

Da necessidade das empresas pesqueiras de avançar com as atividades rumo a mares mais profundos, tendo em vista a própria escassez de peixes na regiões mais rasas, surgem a cada dia equipamentos de grande porte e, conseqüentemente, causadores de maiores impactos na superfície de fundo e, portanto, nas comunidades bentônicas, já que, com instrumentos deste porte, estas técnicas convencionais de pesca praticamente varrem (sensu strictu) 100\% da superfície fundo.

Humborstad et al. (2004) utilizaram o sistema RoxAnn (38 kHz), juntamente com o sonar de varredura lateral $(120 \mathrm{kHz})$, e sistema de vídeo subaquático para o mapeamento do impacto na superfície de fundo, causado pelos sistemas para pesca do tipo redes de arrasto no mar de Barents, na Noruéga. Perfis distanciados entre si de cerca de 300-400m, distribuídos transversal e longitudinalmente à área de interesse (aprox. 7x5 km), identificaram padrões de cores (previamente calibrados) diretamente correlacionáveis com areias, lamas e cascalhos, concluindo ser a área relativamente homogênea. Todavia, levantamento complementar com o sonar de varredura lateral, cobrindo $100 \%$ da área de interesse, mostrou que a área investigada não era tão homogênea como demonstrado pelo classificador de fundo.

Importante conclusão a se destacar destes autores é que sempre se faz necessária a utilização de um conjunto de ferramentas de investigação, e não uma única, para obter uma classificação detalhada e confiável da superfície de fundo. Neste estudo, o classificador de fundo RoxAnn foi fundamental para a classificação ou caracterização geral da superfície de fundo da área, entretanto, a utilização do sonar de varredura garantiu o mapeamento de detalhe da superfície de fundo, pois possibilitou a identificação e a distribuição espacial dos cordões de materiais grossos orientados NE/SW, conforme ilustrado na Figura 8.38, não caracterizados nos dados do RoxAnn.

Ressaltaram ainda estes autores a importância do emprego de ferramentas de observação convencional ou diretas (amostragem de fundo, fotografia, vídeo), para caracterizar efetivamente a natureza ou a composição da superfície de fundo. Neste caso, o material grosso dos cordões observados nos registros do sonar de varredura lateral foi caracterizado por meio das imagens de vídeo e amostragens, como cascalhos e fragmentos de rochas. Estes autores ressaltaram também neste artigo a importância da utilização de multiferramentas na investigação de superfícies submersas. Observaram 
ainda que as conclusões obtidas neste estudo sobre o impacto na superfície de fundo das atividades pesqueiras se basearam em relevantes informações oriundas de cada uma das ferramentas, e não de uma única, já que cada uma tem propriedades específicas quanto à resolução e cobertura (escala), e erros de interpretação poderiam ser cometidos caso a conclusão estivesse fundamentada em dados de uma única ferramenta.

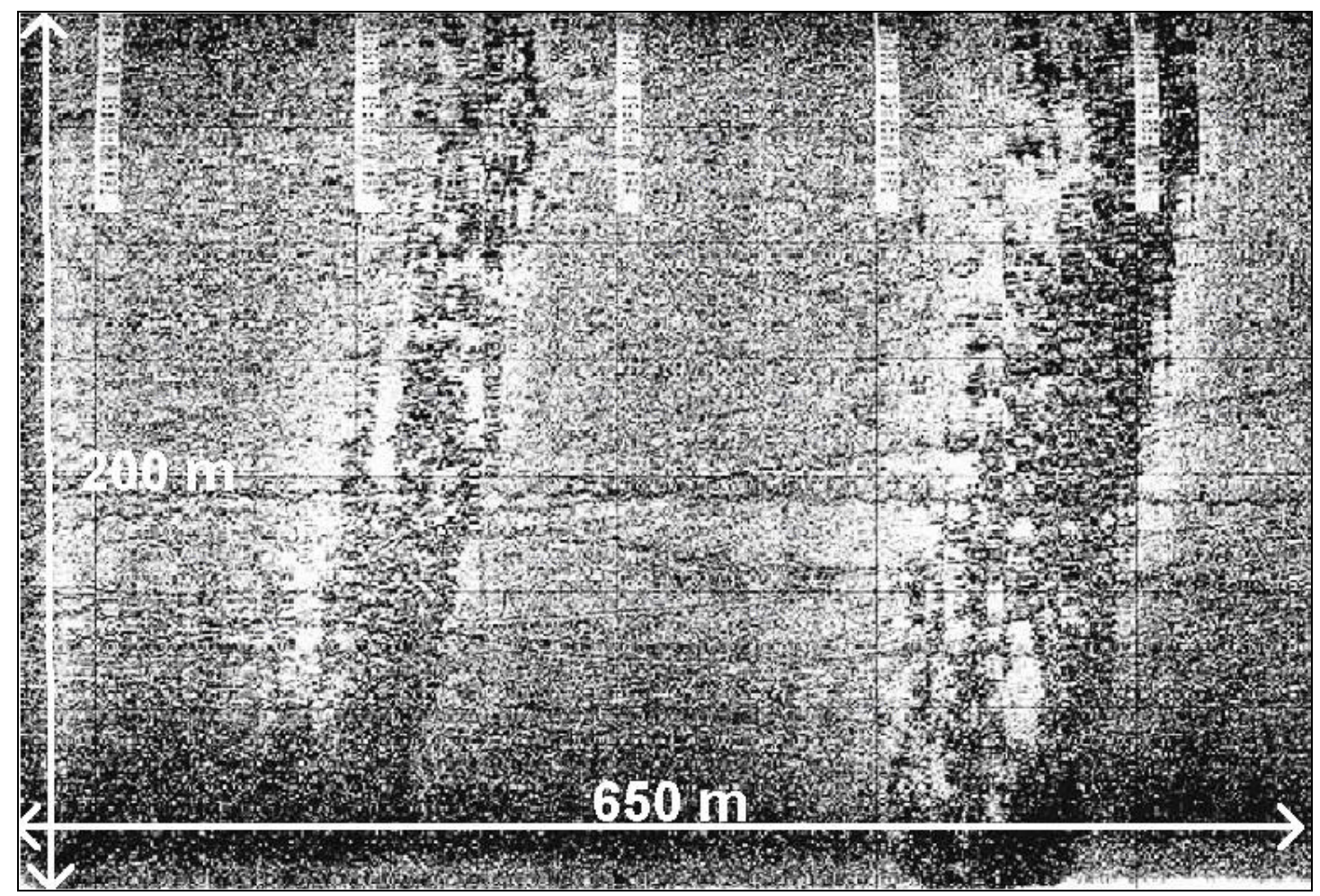

Figura 8.38: Imagem do sonar de varredura lateral $(120 \mathrm{kHz})$ mostrando elevações na superfície de fundo orientadas SW-NE, não identificadas nos dados do classificador de fundo RoxAnn e compostas de material grosso (cascalhos e fragmentos de rocha), identificado por meio de amostragens de fundo. Humborstad et al. (2004).

Mac Dougall \& Black (1999) também utilizaram o sistema classificador de fundo RoxAnn $(50 \mathrm{kHz})$ para avaliar impactos ambientais causados pelo intenso aumento das atividades de maricultura na Grécia. Analisaram, por meio do RoxAnn, apoiado na coleta de amostras de fundo, na fotografia submarina e nas medidas oceanográficas (correntes etc.), as alterações na superfície de fundo, consequiência dos processos de disposição dos resíduos alimentares e fezes, resultado das atividades inerentes à cultura submarina na forma de fazendas. Concluíram ainda que levantamentos acústicos se constituem em poderosos instrumentos para a caracterização da superfície de fundo e de habitats e, portanto, em fundamental método de investigação para a avaliação do impacto sofrido pelas superfícies submersas quando submetidas a atividades antrópicas, como a pesca, principalmente aquela feita por arrasto, e as fazendas submarinas, que implicam a ocupação da superfície de fundo com 
construções apropriadas. Acrescentam que, de forma rápida e com grande cobertura espacial, os métodos acústicos permitem a análise da área da atividade de cultivo submarino (fazendas) sob um contexto sedimentológico amplo, ao contrário do tradicional sistema de amostragens pontuais, comumente exclusivas das áreas de estabelecimento das obras.

Rukavina (2001) destacou a aplicação desta ferramenta acústica de investigação no mapeamento e no monitoramento de sedimentos contaminados nos Grandes Lagos e canais adjacentes, no Canadá. Por meio deste sistema, mapeou os tipos de sedimentos de fundo localizando depósitos de sedimentos finos, com os quais, geralmente, os elementos contaminantes têm natural relação e associação, demonstrando, assim, claramente a vasta aplicação desta técnica de investigação em projetos de monitoramento e remediação de áreas submersas.

Freitas et al. (2003) utilizaram o sistema classificador de fundo QTC-View (50 $\mathrm{kHz}$ ) para mapear habitats bentônicos em extensa faixa costeira rasa do litoral ocidental de Portugal (Aveiro). Destaca-se neste estudo uma particular e relevante característica, pois estes autores, a partir da experiência descrita, validaram a utilização de sistemas de classificação acústica de fundo também para estudos de áreas extremamente homogêneas, corroborando, portanto, com os conceitos básicos sobre os sistemas de classificação acústicos de superfícies de fundo, nos quais as propriedades granulométricas e texturais dos sedimentos de fundo são, direta ou indiretamente, responsáveis pela energia contida nos sinais acústicos que retornam aos transdutores após atingir a superfície.

Mesmo sendo área extremamente homogênea, pois nenhuma proeminente heterogeneidade foi identificada, a utilização desta ferramenta possibilitou o mapeamento de três áreas acusticamente distintas, variando desde sedimentos arenosos muito finos e finos a sedimentos arenosos grossos com cascalhos. Além disso, definiu claramente dois habitats bastante contrastantes: uma comunidade localizada mais próxima da costa (inshore) relacionada com uma superfície de fundo de sedimentos arenosos finos a muito finos, e uma mais distante da costa (offshore) vivendo sobre uma superfície composta de sedimentos arenosos grossos com cascalhos.

Estes autores observaram ainda consistente correlação entre as feições acústicas e os tipos de sedimentos identificados e analisados. Análoga observação foi também realizada com relação aos dados biológicos coletados. A primeira conclusão 
destes autores foi sobre a importância da realização prévia de levantamentos geofísicos desta natureza, quando do estudo de grandes áreas, pois que permitem num tempo relativamente rápido produzir mapas sedimentológicos ou mapas de habitats, poupando, num primeiro momento, maior esforço em programas de amostragens, e análises laboratoriais que, em qualquer caso, serão sempre necessários. A Figura 8.39 ilustra o mapa de classificação, produto final da investigação realizada.

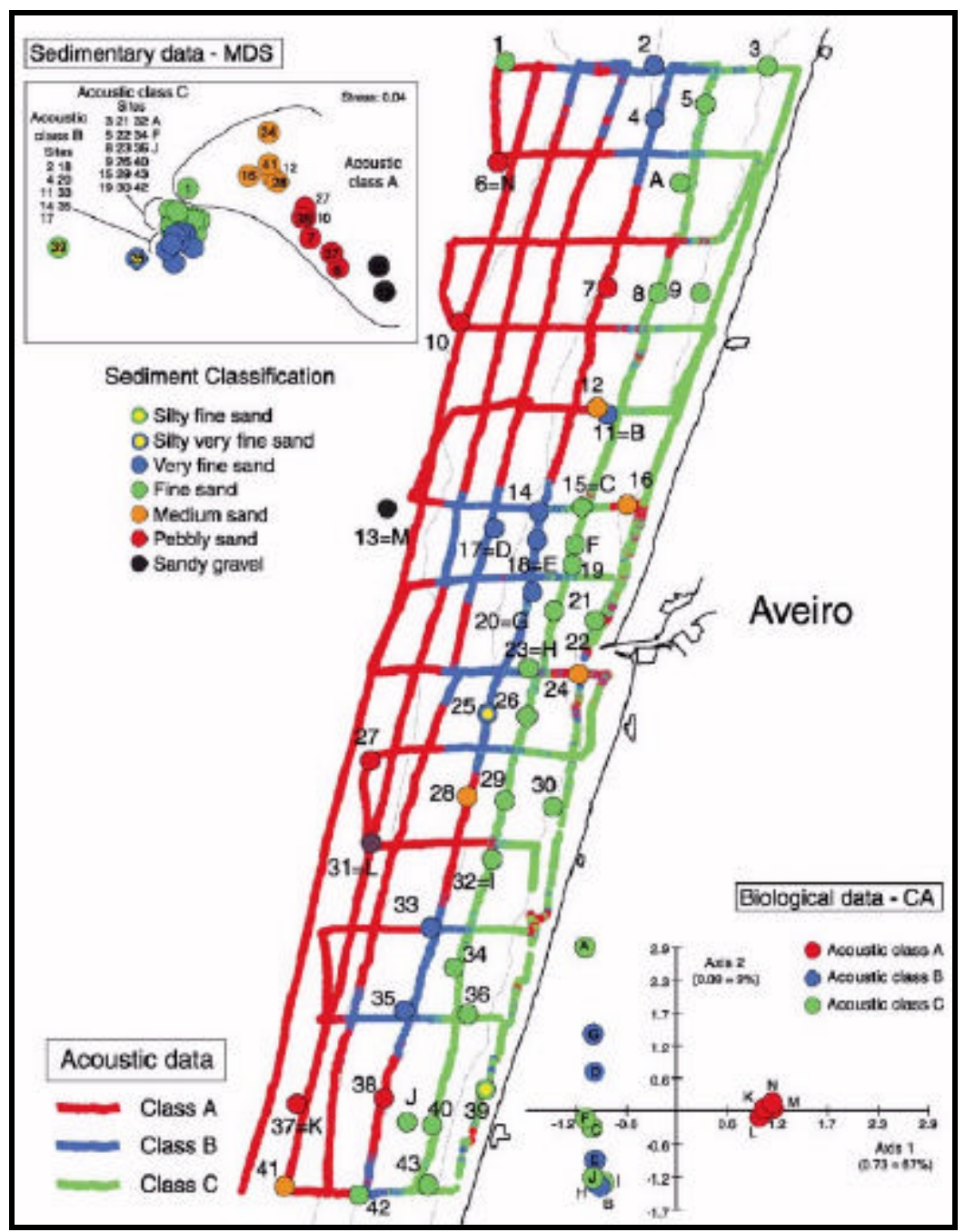

Figura 8.39: Mapa de classificação de fundo resultado da utilização do sistema acústico QTC-View na costa Ocidental de Portugal. Nota-se neste mapa a distribuição espacial das trê classes acústicas identificadas pelo sistema $(\mathrm{A}=$ areias grossas, inclusive com cascalhos; $\mathrm{B}=$ areais muitos finas; $\mathrm{C}=$ areia fina). Freitas et al. (2003).

\subsubsection{SONAR DE VARREDURA LATERAL (SVL)}

O sonar de varredura lateral - SVL ou a sonografia constitui-se também num método acústico de investigação de áreas submersas e baseia-se, portanto, nos princípios da propagação do som na água.

Originalmente sonares eram equipamentos acoplados ao casco dos navios e utilizados com dois objetivos básicos: medir a coluna d'água imediatamente abaixo da 
embarcação e/ou localizar grandes obstáculos à navegação como icebergs e submarinos. Somente a partir dos anos 60, os sonares passaram a emitir vários pulsos acústicos simultaneamente, ao contrário dos primeiros modelos que emitiam um único pulso e numa direção específica. Passaram também, nesta mesma época, a apontar lateralmente em relação à rota de navegação, e não verticalmente para baixo, como até então, permitindo desta forma a construção de uma imagem da superfície de fundo a partir de uma série de sucessivas varreduras (scans) laterais. O processo de construção da imagem do assoalho marinho por meio deste método de investigação está ilustrado na Figura 8.40.

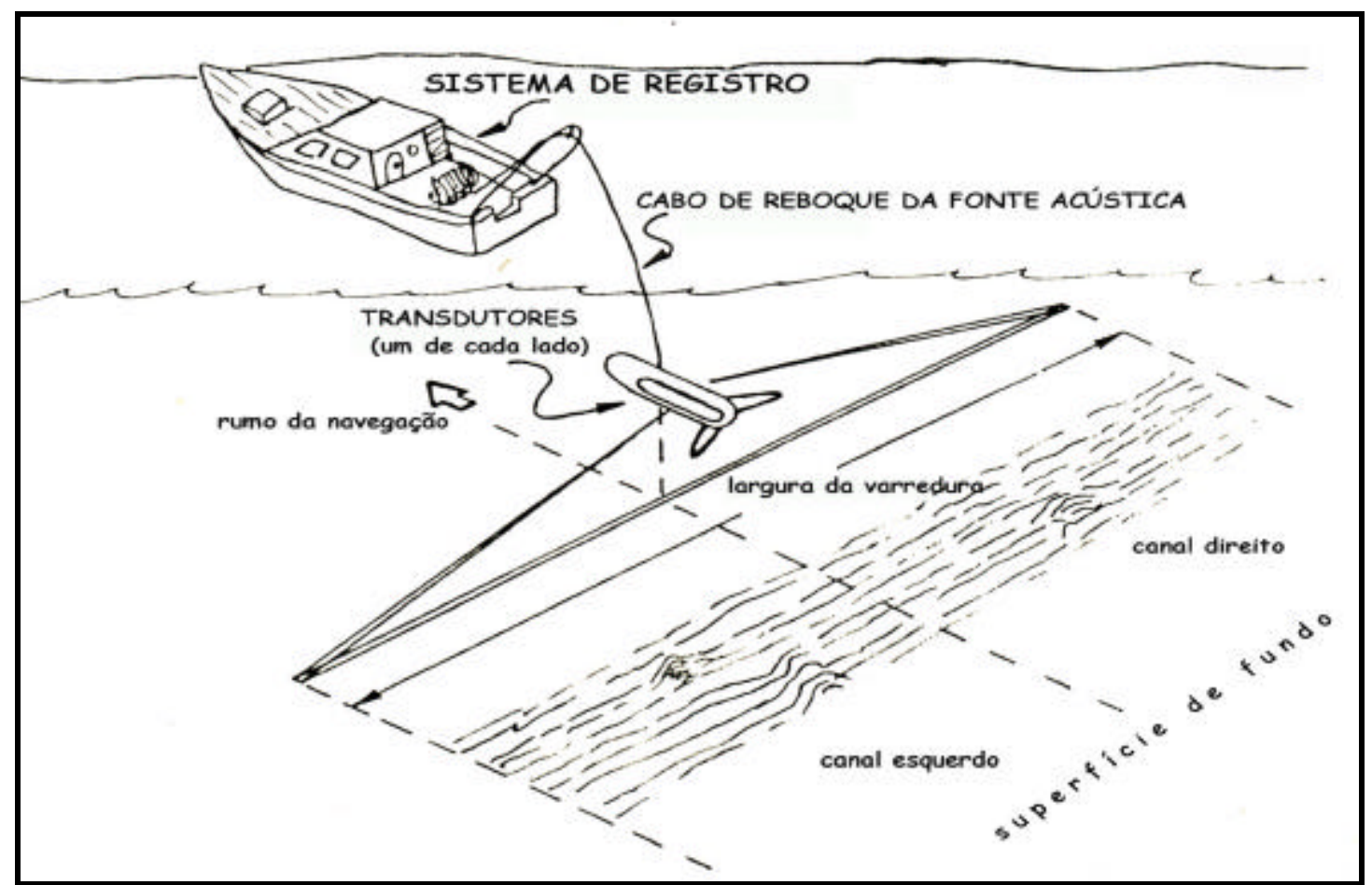

Figura 8.40: Ilustração mostrando como é construída a imagem do sonar de varredura lateral à medida que a embarcação se locomove ao longo da perfil. Modificado de Mazel (1985).

Com a evolução dos sistemas de aquisição de dados, estes equipamentos passaram ainda a ser rebocados a certa distância da embarcação e mergulhados na coluna d'água, o que em muito melhorou o desempenho do sistema e a qualidade dos sinais registrados, pois assim o sistema ficou à parte dos ruídos e das movimentações inerentes da embarcação, bem como passou a existir a possibilidade de posicionar a fonte acústica abaixo da termoclina, evitando-se deste modo a interferência de outros fenômenos acústicos sobre o sinal emitido (refração etc.).

Se comparado com os demais sistemas acústicos de investigação de áreas submersas observar-se-á, que a sonografia se utiliza de espectros de freqüências superiores, normalmente entre 100 e $500 \mathrm{kHz}$. Existem, porém, sistemas que utilizam 
frequiências menores (entre 8 e $20 \mathrm{kHz}$ ), mas com aplicação restrita em mapeamentos de grande escala, pois se trata de sistemas de longo alcance relacionados com mapeamentos de áreas marítimas profundas, quando da necessidade de ampla cobertura (alcances laterais de dezenas de quilômetros), não tendo aplicação em estudos de áreas rasas, como reservatórios, rios ou plataforma continental interna.

Um dos sistemas de longo alcance mais conhecidos, o GLORIA (Geologic Longrange Inclined ASDIC), desenvolvido em 1977 pelo Reino Unido, constitui-se num sistema de grande porte, com fontes acústicas laterais que emitem sinais com freqüências baixas $(6-7 \mathrm{kHz})$ que são rebocadas próximas da superfície e com capacidade de varredura lateral de algumas dezenas de quilômetros (14-60 km).

Outros sistemas de longo alcance surgiram após o GLORIA, dentre os quais se destaca o SEA-MARC II, criado em 1982, que, de menor porte, mais versátil, utilizando freqüências um pouco mais altas (11-12 kHz), oferece resolução superior ao GLORIA, e a possibilidade de melhor e mais detalhada caracterização da superfície de fundo, mesmo considerando seu menor desempenho quanto ao alcance lateral $(1-10 \mathrm{~km})$, quando comparado ao sistema predecessor.

Alguns sistemas modernos permitem ainda, além do imageamento da superfície de fundo, a perfilagem rasa, já que possibilitam o acoplamento de fontes sísmicas de baixas freqüências (comumente abaixo de $7 \mathrm{kHz}$ ) do tipo subbottom profilers.

\subsubsection{Histórico}

Wood et al. (1935, apud Flemming, 1976) desenvolveram as primeiras experiências utilizando-se do fenômeno da propagação do som, mas foi somente a partir de 1958 (Chesterman et al., 1958) que se desenvolveu o mapeamento geológico, propriamente dito, de superfícies submersas, a partir dos fenômenos relativos à propagação do som.

Tucker \& Stubbs (1961, apud Flemming, 1976) construíram, na Inglaterra, o primeiro sistema acústico de varredura lateral. Embora os primeiros levantamentos sistemáticos tenham ocorrido apenas a partir de 1964 (Clay et al., 1964), somente a partir da década de 70 é que levantamentos desta natureza se tornaram rotina. Rusby (1970), Rusby et al. (1973), Wong et al. (1970) e Chesterman (1974) discutiram amplamente a utilização do sonar de varredura lateral como ferramenta acústica na 
investigação de áreas submersas. Belderson et al. (1972) compilaram interessantes registros obtidos da utilização do sonar de varredura lateral de grande alcance.

No Brasil, atualmente, o sonar de varredura lateral é utilizado pela Petrobras em estudos detalhados de áreas para instalação de plataformas exploratórias (IPT, 1985a,b). Algumas universidades (USP, UERJ, UFF, UFBA, UFPA, UFPE, UFRN, UFRS, Univali) empregam também este sistema, associado a outros sistemas acústicos, para investigação de ambientes de sedimentação, preferencialmente em estudos da plataforma continental interna, tendo em vista as próprias limitações dos equipamentos existentes no Brasil, que são configurados preferencialmente para utilização na investigação de águas rasas. Existem também exemplos na literatura nacional de aplicação do sonar de varredura lateral na pesquisa e na prospecção de recursos minerais não só em áreas da plataforma continental interna (IPT, 1985c,d), mas também em áreas submersas interiores e continentais. A prospecção de material de construção (areias e cascalhos) em áreas costeiras, visando reconstituição de praias ou em rios, em subsídio a projetos de obras civis (portos, pontes, barragens etc.), constitui-se alguns dos exemplos na literatura nacional desta aplicação do sonar de varredura lateral IPT (1985c,d; 1990a,b; 1996 e 2002c); Souza (1988 e 1998); Souza et al. (1997, 1998 e 1999).

\subsubsection{Princípios}

A sonografia tem por objetivo o imageamento da superfície de fundo de áreas submersas, em substituição às técnicas usualmente empregadas no mapeamento em terra, como a fotografia aérea, imagens de satélite e de radar, que não são aplicáveis no mapeamento de superfícies submersas, tendo em vista as limitações quanto à penetração da luz, que sofre forte atenuação na coluna d'água (McQuillin \& Ardus, 1977).

O princípio da sonografia está baseado na emissão de um sinal acústico de alta frequiência, em intervalos de tempo regulares, por dois transdutores (emissores e receptores) submersos, que apontam para ambos os lados da superfície de fundo em relação ao rumo da navegação. Em contraste à forma padrão cônico do feixe de sinais emitidos pelos ecobatímetros, o feixe principal de sinais emitidos pelo sonar de varredura lateral é bastante estreito, na direção paralela à navegação (raramente ultrapassando $2^{\circ}$ ) e largo na direção perpendicular à rota de navegação (comumente da ordem de $\left.40-50^{\circ}\right)$. A Figura 8.41 ilustra a geometria deste método de investigação. 


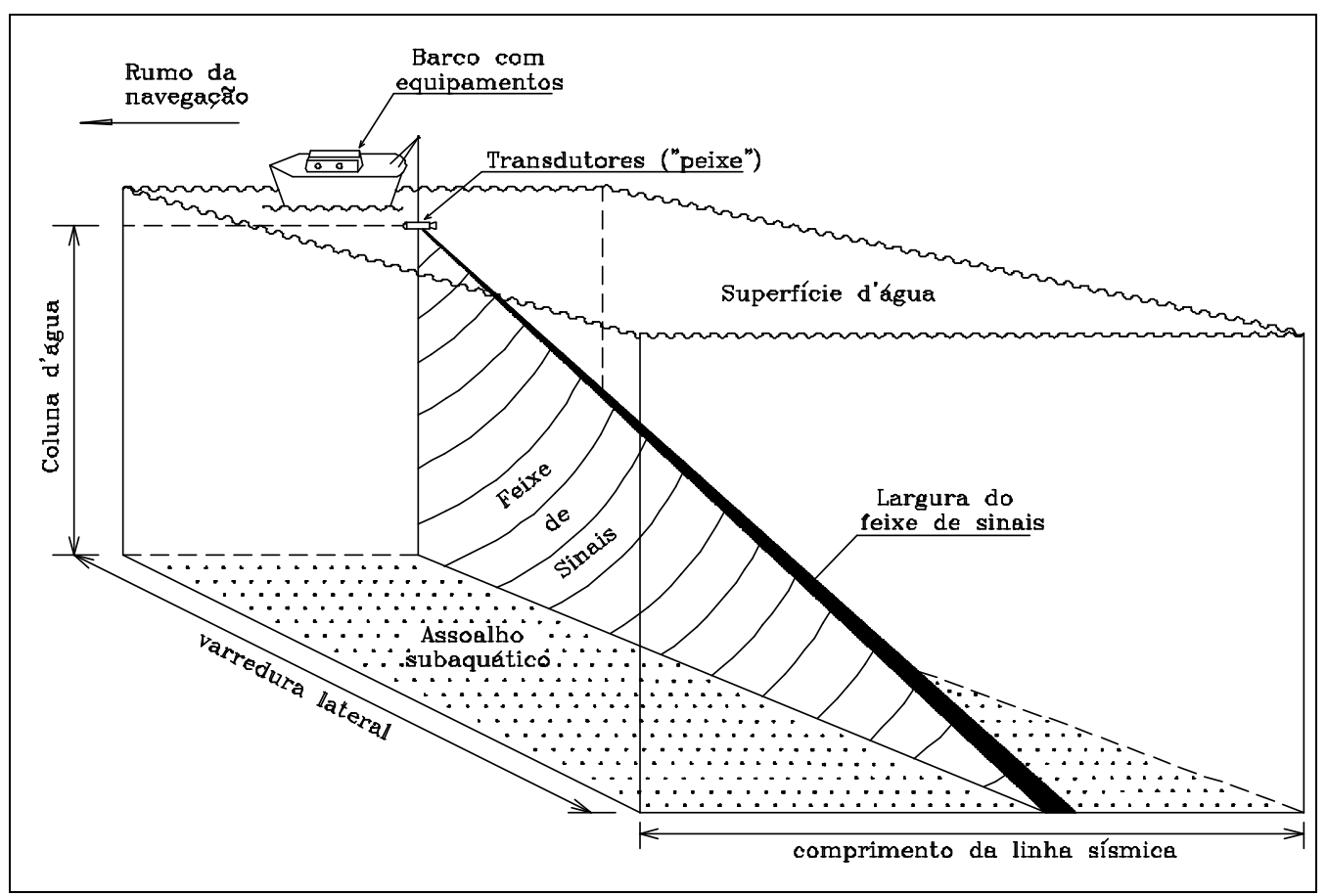

Figura 8.41: Geometria do sistema de aquisição de dados do sonar de varredura lateral. Vista do canal lateral esquerdo (Souza, 1988).

Os mesmos transdutores de emissão do sinal acústico são também responsáveis pela recepção do sinal, oriundos da reflexão ou do backscattering na superfície de fundo, e atuam independentemente um do outro. Os transdutores, geralmente constituídos por conjuntos de pastilhas piezelétricas, formam a parte principal do sistema, já que são os responsáveis pela conversão da energia elétrica original em energia mecânica (vibrações) que irá se propagar na coluna d'água, e vice-versa, quando do retorno do sinal, na forma de energia mecânica, ao transdutor, após refletir na superfície de fundo.

Os sinais acústicos emitidos pelo sistema possuem propriedades, como largura, vertical e horizontal, do feixe e inclinação em relação ao plano da superfície da água conforme ilustrado na Figura 8.42. As pastilhas piezelétricas que compõem os sonares de varredura lateral operam com freqüências comumente superiores a $100 \mathrm{kHz}$. Existem entretanto sistemas de longo alcance que lidam com freqüências mais baixas.

O sinal acústico de alta frequiência emitido pelo sonar não penetra através dos estratos sedimentares, levando-se em conta a alta frequiência emitida, porém permite, por outro lado, ao retornar ao transdutor, a obtenção de informações detalhadas da subsuperfície de fundo que possibilita a identificação, com grande precisão, de feições na superfície de fundo, como estruturas sedimentares, contatos litológicos ou objetos diversos (naufrágios, dutos etc.). 


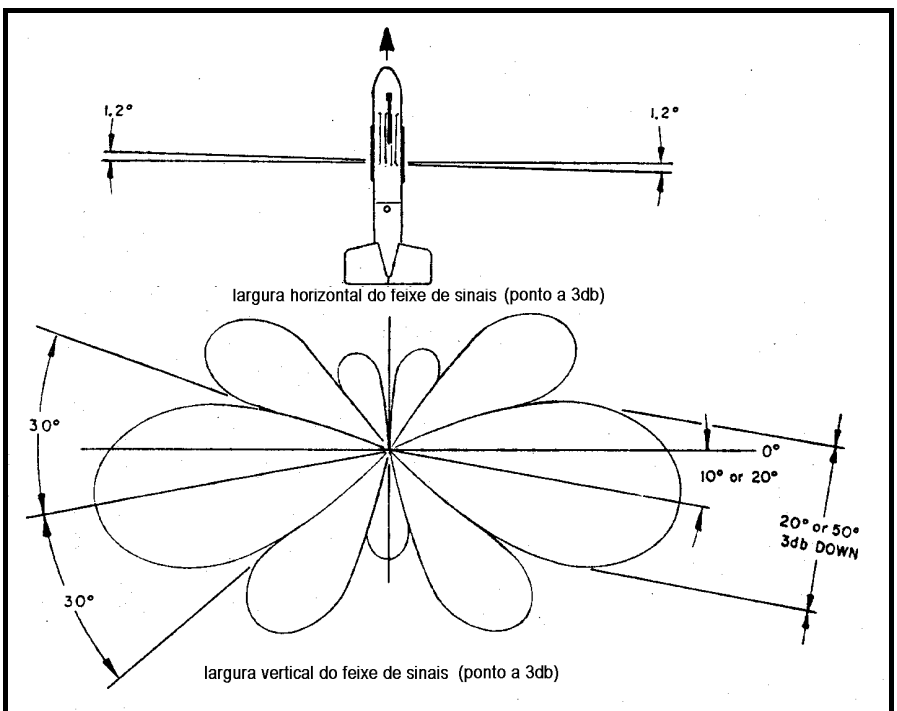

Figura 8.42: Principais características do sinal acústico emitido pelo sonar de varredura lateral: largura do feixe de sinais paralelamente à rota de navegação comumente inferior a $2^{\circ}$; inclinação do lóbulo principal de sinais, em relação à horizontal, comumente entre 10 e $20^{\circ}$; largura do feixe de sinais no plano perpendicular à rota de navegação, variando comumente entre 20 e 50. Modificado de Mazel (1985).

Os sinais provindos da superfície de fundo são gravados à medida que chegam ao registrador, de modo que os sinais oriundos de pontos mais próximos são gravados primeiro, e os de pontos mais distantes, posteriormente, compondo desta forma uma imagem do fundo da área investigada. A geometria dos registros de campo obtidos por meio da sonografia, denominados de sonogramas, está ilustrada na Figura 8.43.

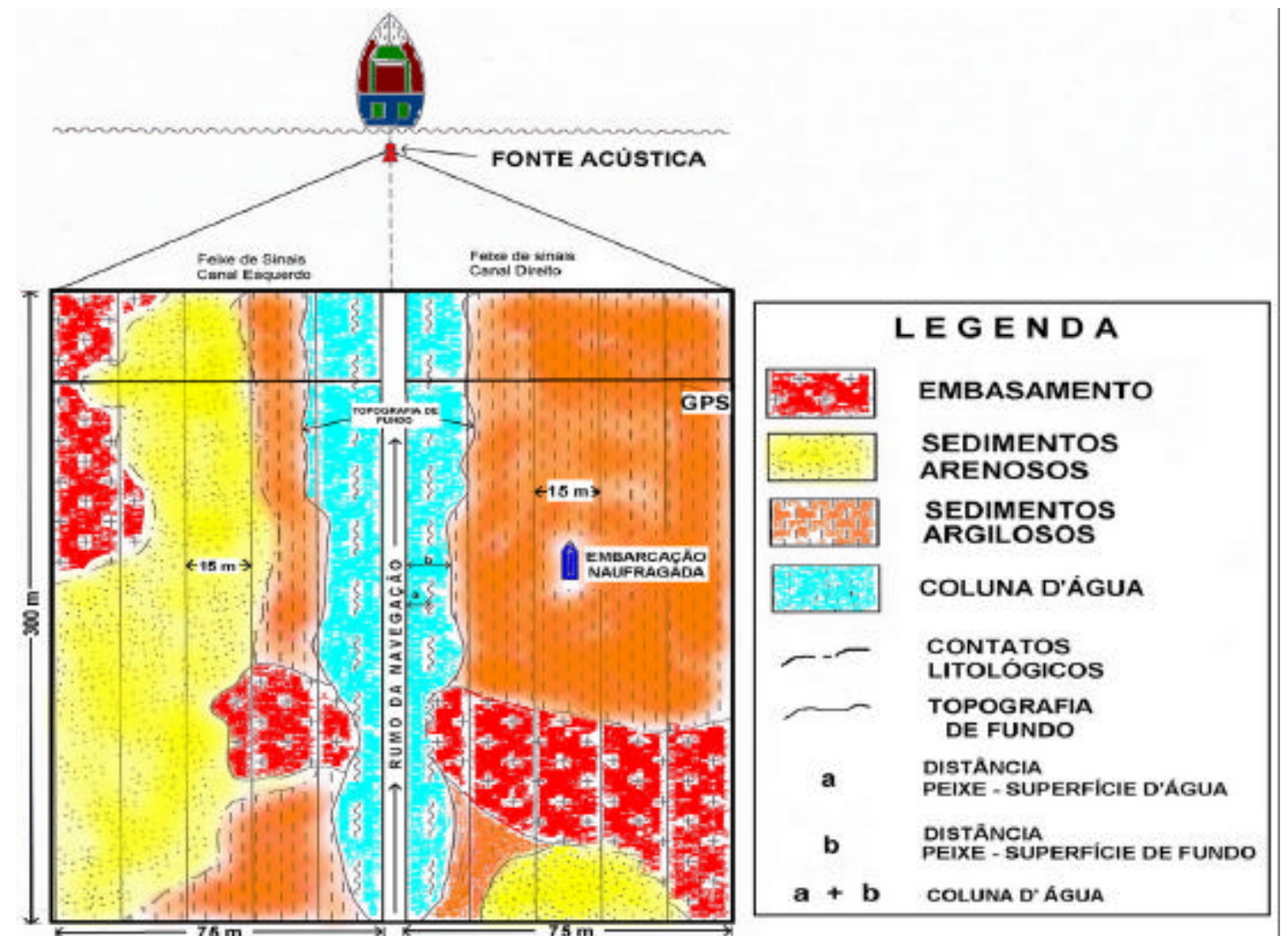

Figura 8.43: Características geométricas do registro de campo obtido por meio da sonografia (Souza, 1988). 
São basicamente dois os mecanismos primários que permitem que o som emitido pelo sonar retorne ao transdutor: reflexão e backscattering.

A reflexão está relacionada com o sinal que atinge a superfície de fundo e retorna diretamente ao transdutor, numa reflexão total; o backscattering está relacionado com a interação entre a energia do som e a textura do material da superfície de fundo. A quantidade de energia que retorna ao transdutor, seja por qualquer um destes fenômenos, está diretamente relacionada, em primeiro lugar, com o tipo de pulso acústico emitido (cada equipamento possui propriedades especificas), e em segundo lugar, com o tipo de fundo e suas propriedades acústicas (impedância acústica etc.). Superfícies extremamente homogêneas favorecerão um baixo retorno dos sinais; superfícies heterogêneas, rugosas, propiciarão retorno do sinal com maior energia, pois neste caso, pelo menos estatisticamente, maior será a probabilidade da existência, na superfície de fundo, de micro áreas ou rugosidades, com faces voltadas para o transdutor, o que evidentemente contribui diretamente para o aumento das reflexões totais do sinal emitido na direção do transdutor.

De fato, se se admitir uma superfície de fundo plana e lisa, os sinais sísmicos não retornariam ao transdutor, conforme ilustrado na Figura 8.44. A existência de rugosidades na superfície de fundo, seja devido à granulometria ou à micro e macrotopografia de fundo, é que proporcionará o espalhamento (scattering) do sinal incidente, e parte deste sinal atingirá os transdutores (backscattering). A intensidade do sinal oriundo da superfície de fundo é função também do ângulo de incidência do sinal emitido. Quanto mais rugosa a superfície de fundo e menor o ângulo de incidência, maior intensidade terá o sinal de retorno a ser registrado.

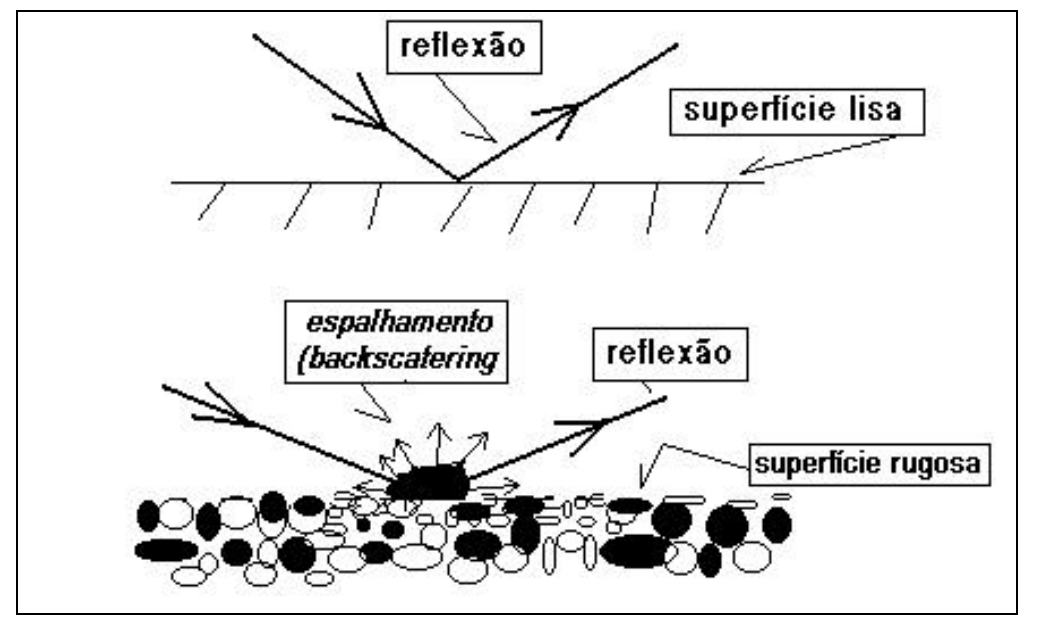

Figura 8.44: Reflexão e espalhamento (backscattering) do sinal acústico emitido pelo sonar. Modificado de Mazel (1985). 


\subsubsection{Aquisição de dados}

A aquisição de dados por meio da sonografia é feita através de transdutores que podem ser afixados no casco de uma embarcação, ou rebocados na superfície ou próximo dela, quando da execução de levantamentos em áreas muito rasas. O mais comum, porém é rebocar os transdutores por meio de cabos com dupla função (tração e condução dos sinais), o que permite que estes se posicionem numa parte intermediária da coluna d'água e, portanto, distante da embarcação, garantindo desta forma uma melhor relação sinal/ruído, proporcionando a obtenção de registros de melhor qualidade. Nestes casos, os transdutores são montados em estruturas de aço, com formas hidrodinâmicas, denominadas de "peixe". A Figura 8.45 ilustra um sistema de sonar de varredura lateral em operação na região de Abrolhos, em projeto de mapeamento de recifes de corais.

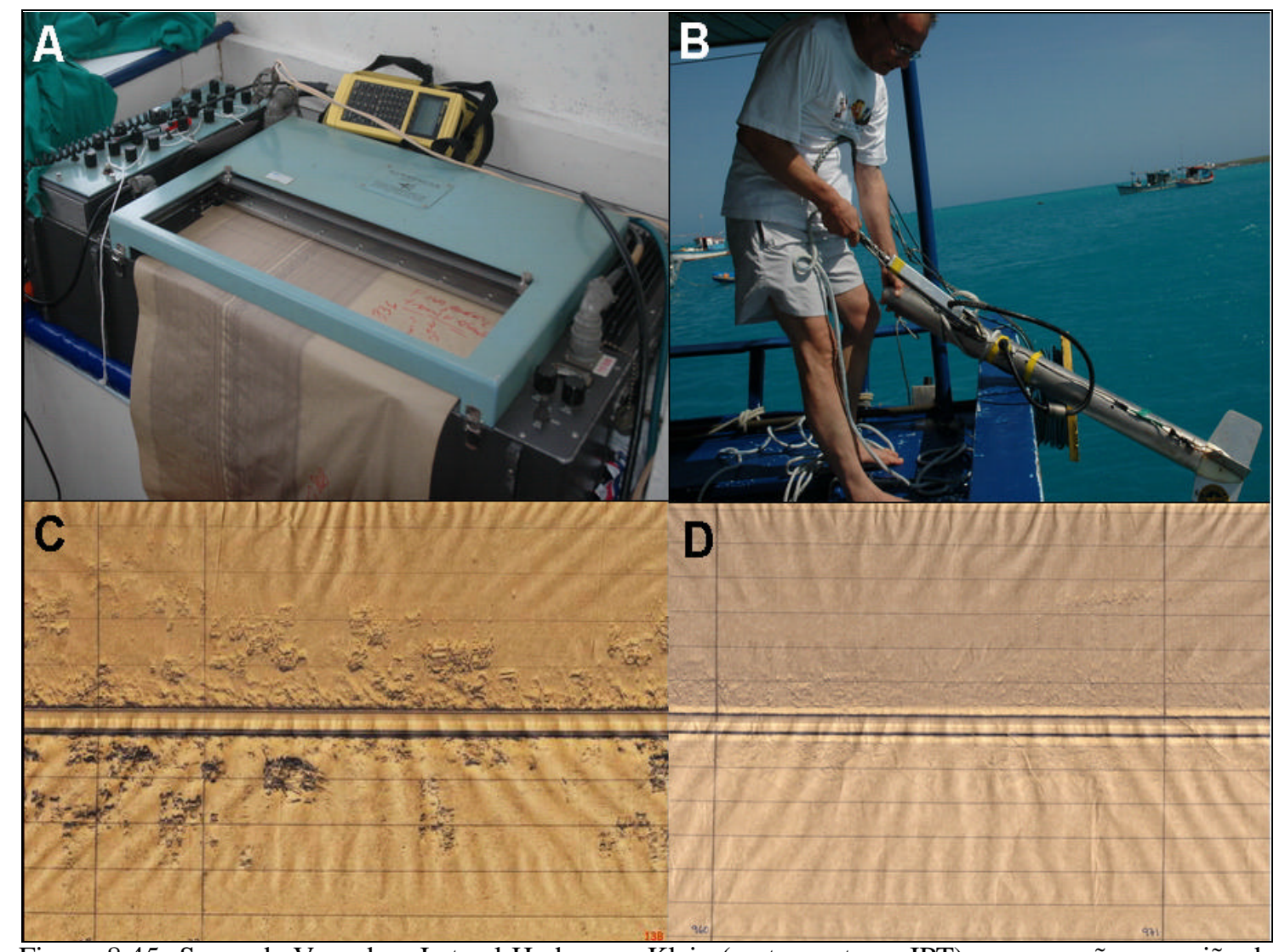

Figura 8.45: Sonar de Varredura Lateral Hydroscan Klein (pertencente ao IPT) em operação na região de Abrolhos (Bahia) em novembro de 2004: a) registrador analógico; b) fonte de sinais acústicos ("peixe"); c) registro do sonar mostrando textura rugosa, indicando a presença de recifes de corais; d) registro do sonar mostrando textura lisa e homogênea indicando a ausência de recifes de corais. (IPT, 2005a; Souza \& Moura, 2005).

Observa-se que, no caso da opção por rebocamento da fonte acústica na coluna d'água, deve ser obedecida um geometria que favoreça a projeção do sinal emitido na porção central do alcance lateral escolhido. Para que isto ocorra, durante o levantamento 
os transdutores devem ser mantidos a uma distância do fundo equivalente a $10 \%$ do alcance lateral escolhido, ou seja, em levantamentos de áreas rasas, onde tipicamente se utilizam alcances laterais de 100-200 m, os melhores resultados vão ser colhidos com os transdutores posicionados a uma altura de 10-20 metros em relação à superfície de fundo.

Normalmente transdutores do sonar de varredura lateral operam com uma única frequiência e com único emissor de sinais instalado em cada lado do "peixe". Sistemas modernos têm utilizado com sucesso transdutores de dupla freqüência, que permitem, ao mesmo tempo, a utilização de alcances laterais maiores, devido às baixas frequiências (ao redor de $100 \mathrm{kHz}$ ), e a obtenção de grande resolução, devido às altas freqüências (entre 300 e 500 kHz). Sistemas de altíssima resolução estão hoje também disponíveis. Alguns destes modelos são mostrados na Figura 8.46a,b,c. Existem ainda disponíveis no mercado sistemas de altíssima resolução. Alguns fabricantes produzem sistemas com transdutores que emitem sinais com frequiências, desde 600 até $1200 \mathrm{kHz}$, em alguns casos até $2400 \mathrm{kHz}$, que possuem aplicação mais restrita, comumente relacionada com operações de busca e salvamento.

Uma tendência de evolução dos SVL que se constata atualmente é a construção de sistemas com mais de uma fonte acústica (sistemas multifeixes) de cada lado do “peixe”. Os modelos 4300 MPX da EdgeTech e o System 5000 da Klein são bons exemplares desta tendência evolutiva do sonar de varredura lateral.

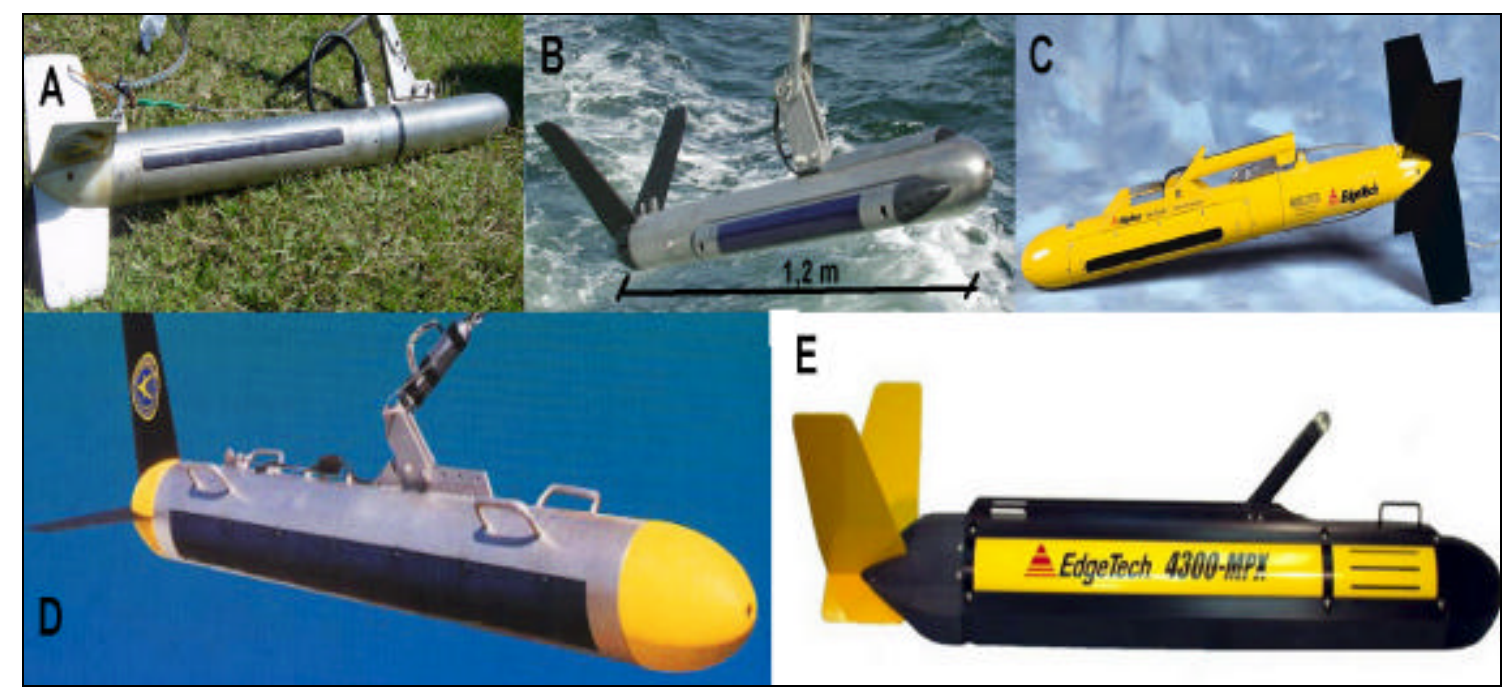

Figura 8.46: Exemplos de cinco modelos de "peixes" existentes no mercado a) modelo antigo Klein Hydroscan 530 (100 kHz -pertecente ao IPT); b) sistema 3000 digital da Klein (132-445 kHz)c) modelo 272 TD digital da Edgetech (100-500 kHz); d) sistema de ultra-resolução multifeixe (4 5 ou 8 feixes de cada lado) modelo 5000 - $455 \mathrm{kHz}$ da Klein; e) sistema de ultra-resolução multifeixe modelo 4300 MPX - $410 \mathrm{kHz}$ da Edgetech. 
Com a emissão de sinais multifeixes laterais (dois, quatro ou oito emissores de cada lado), estes sistemas possibilitam a aquisição de dados com cobertura total da superfície, com a embarcação navegando em velocidades muito superiores àquelas convencionais, permitindo, deste modo, a obtenção de grande cobertura em área, num intervalo de tempo muito menor que o convencional, altíssima resolução e longo alcance lateral, contribuindo efetivamente para diminuição dos custos operacionais quando da investigação de grandes áreas. A Figura 8.47 mostra um exemplo da altíssima resolução obtida com a utilização destes sistemas. Neste exemplo, com uma embarcação navegando a uma velocidade superior a $14 \mathrm{~km} / \mathrm{h}$ e com um alcance lateral de $75 \mathrm{~m}$, foi possível a detecção de detalhes centimétricos da superfície de fundo da área investigada.

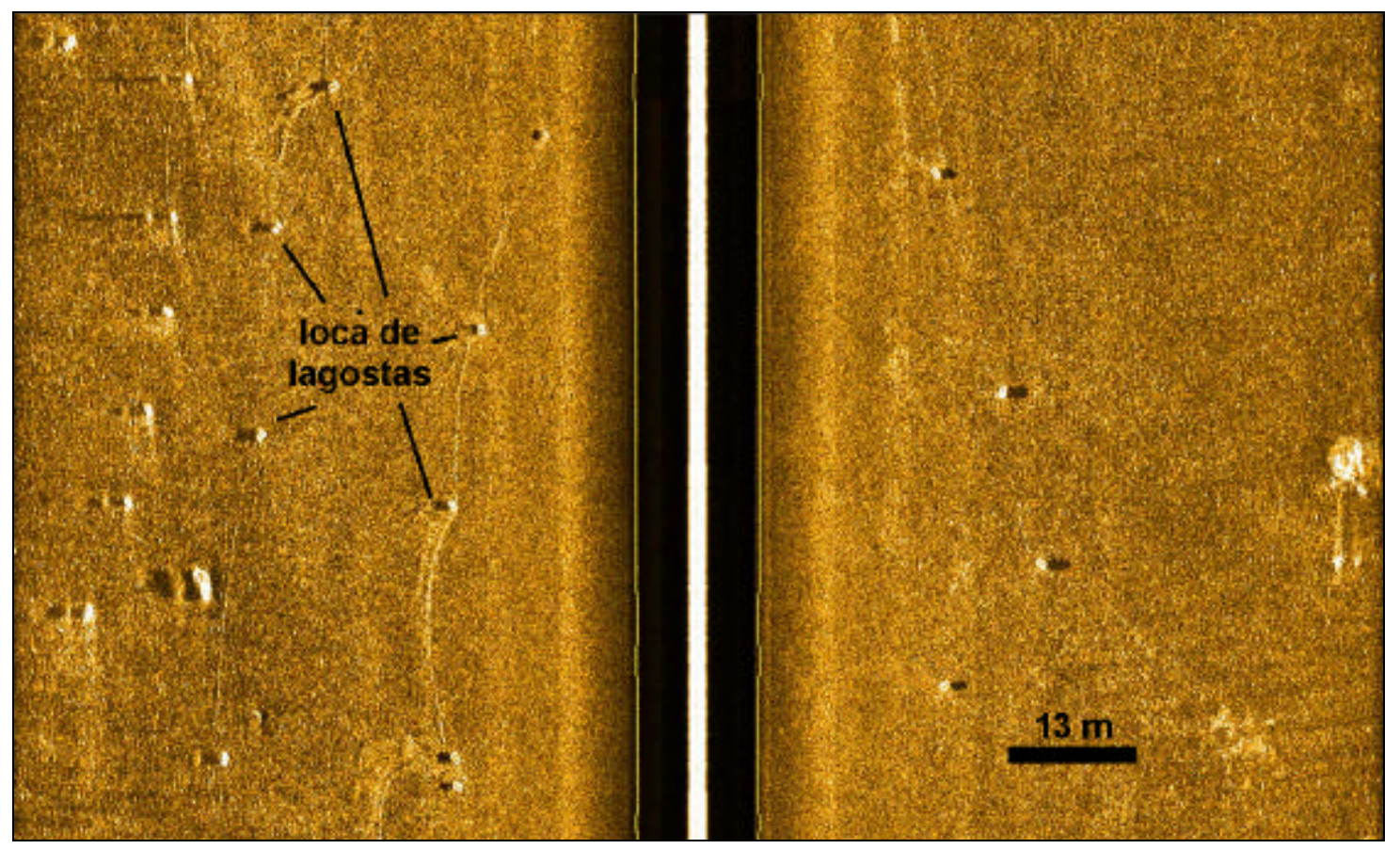

Figura 8.47: Imagem de altíssima resolução obtida por meio do sonar Klein System 5000 ilustrando detalhes centimétricos da superfície de fundo. Locas de lagostas de dimensões submétricas e as trilhas que as interligam são visualizadas em detalhe nesta imagem. Fonte: <http://www.l-3klein.com>. Acesso: $\operatorname{dez} / 2005$.

\subsubsection{Aplicações}

O sonar de varredura lateral - SVL tem vasta aplicação na investigação de áreas submersas, contribuindo para a solução de várias questões relacionadas com projetos de investigação geológica, geotécnica e oceanográfica. A aplicação deste método de investigação possibilita a análise e caracterização de terrenos submersos, visando, por exemplo, em demandas ambientais, a escolha e monitoramento de áreas para depósito de materiais dragados, monitoramento de populações de peixes, mapeamento de recifes 
naturais ou artificiais. Na construção civil, a inspeção ou o fornecimento de subsídios técnicos para projetos de obras submersas, tais como, pontes, píers, dutos entre outras. Tem ainda grande aplicação em questões não necessariamente relacionadas à investigação geológica, tais como, operações de busca e salvamento de pessoas afogadas, veículos, barcos, aeronaves e equipamentos naufragados, e até mesmo em questões militares, de segurança nacional de áreas portuárias, quando das operações de busca de armas (minas etc.).

Em estudos geológicos e oceanográficos, o SVL tem aplicação sem precedentes, pois possibilita o mapeamento detalhado (a depender da freqüência empregada) das superfícies submersas, identificando estruturas sedimentares (Tessler \& Souza, 1996,1998; Souza, 1984,1988,1995; Lopes et al., 2003; Lancker et al., 2004), afloramentos rochosos, beachrocks, recifes de corais (IPT, 2002a, 2005a e Dias, 1982, 2000), bancos arenosos, estruturas geológicas (falhas, lineamentos etc.) e a distribuição de sedimentos de fundo (Woodruff et al. 2001), características geológicas que muito contribuem para a compreensão da evolução geológica da área investigada e dos processos sedimentares atuantes. A Figura 8.48 ilustra exemplos de registros que identificam estruturas sedimentares, e a Figura 8.49, registros exibindo afloramentos rochosos e contatos geológicos.

Este método de investigação de áreas submersas constitui-se assim em um poderoso instrumento, não só em estudos geológicos básicos, mas também nos estudos que envolvam a delimitação de áreas de riscos à integridade de estruturas instaladas, ou por instalar, tais como, plataformas exploratórias de petróleo, dutos de gás e petróleo, cabos de telecomunicações etc. Por áreas de riscos, entendem-se superfícies submersas com afloramentos rochosos, beachrocks, recifes de corais, taludes instáveis, canions submarinos, evidências de depósitos de gás subsuperficiais, características estas identificáveis nas imagens do sonar de varredura lateral. 


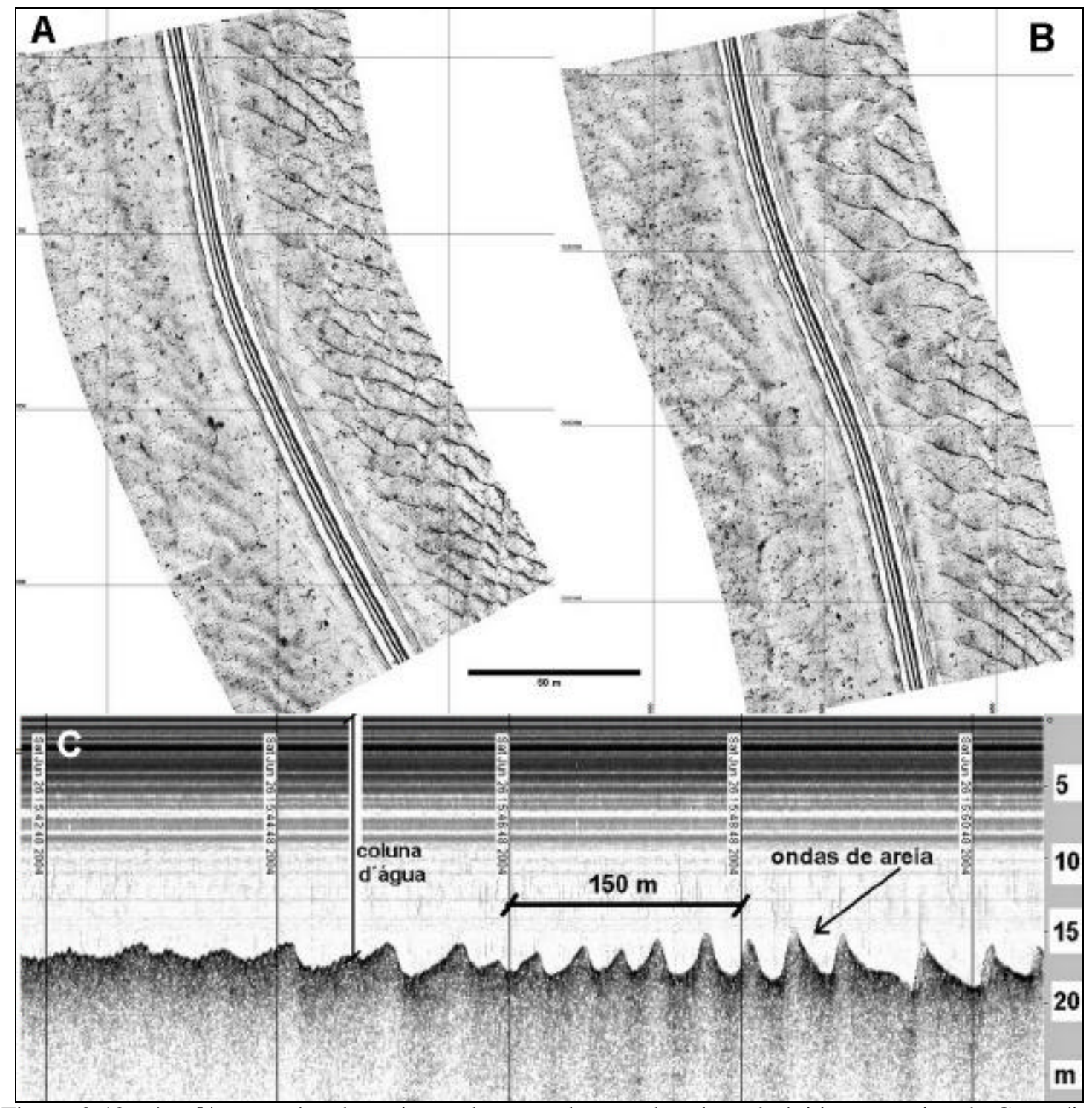

Figura 8.48: a) e b) exemplos de registros de sonar de varredura lateral obtidos na região de Cananéia, litoral sul de São Paulo, mostrando de forma clara a ocorrência de estruturas sedimentares do tipo marcas onduladas; c) registro sísmico (fonte acústica do tipo chirp) obtido na mesma região, mostrando, em perfil, ondas de areia de grande porte. Importante notar nestas figuras a significância da visualização em planta das referidas feições sedimentares, o que só é possível por meio do sonar de varredura lateral. Paolo \& Mahiques (2005).

A Figura 8.50, por exemplo, mostra uma imagem obtida por meio do sonar de varredura lateral, na plataforma continental interna de Ilhéus (Bahia), em área com coluna d'água de espessura ao redor de $30 \mathrm{~m}$. Neste caso específico, o SVL foi utilizado para o mapeamento detalhado das anomalias topográficas para definição de rota segura de aproximação e de manobras para embarcações que rebocavam plataforma exploratória de grande porte para uma posição predeterminada. Nesta imagem, identificam-se anomalias na topografia de fundo que foram correlacionadas à ocorrência de beachrocks, feições de fundo que geram alterações no perfil topográfico que podem colocar em risco operações de manobras das embarcações quando da fixação de plataformas exploratórias de petróleo. A opção pelo emprego do SVL decorreu da 
necessidade objetiva de cobertura de $100 \%$ da área de interesse, o que não poderia ser obtida se executados apenas perfis batimétricos convencionais. Por mais próximos que estes fossem posicionados, não se conseguiria tal nível de cobertura.

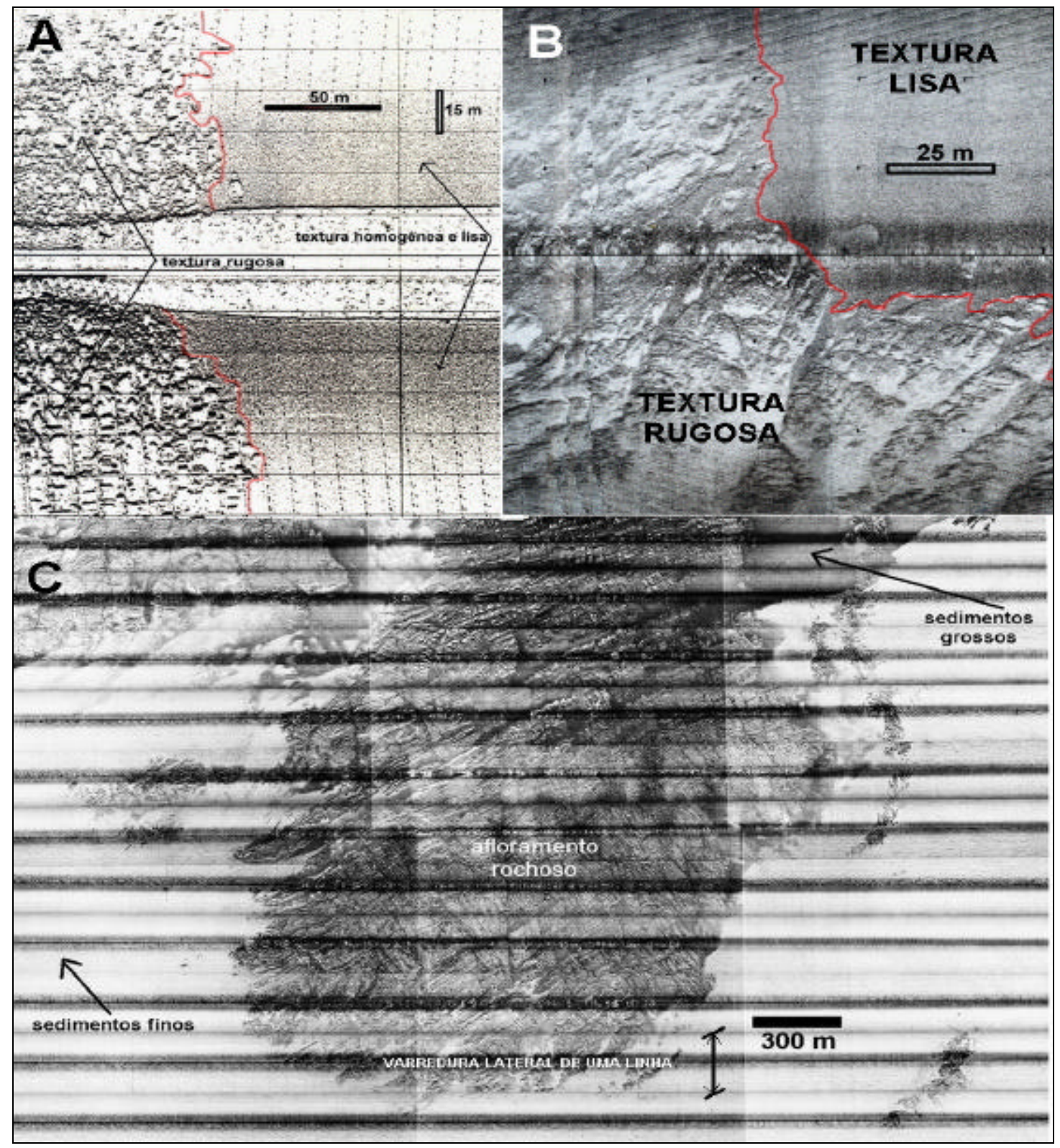

Figura 8.49: Exemplos de registros de sonar de varredura lateral mostrando nítidos contatos geológicos além de estruturas: a) registro com dois padrões texturais muito distintos, sendo o mais rugoso relacionado com a ocorrência de beachrocks na superficie de fundo, e o padrão liso e homogêneo, com a cobertura sedimentar (a linha vermelha delineia este contato geológico). Registro obtido no canal de São Sebastião, SP (Furtado et al., 2000); b) analogamente, dois padrões texturais distintos são evidenciados neste registro: o padrão rugoso está relacionado com afloramento rochoso; o padrão liso e homogêneo, com a cobertura sedimentar. Registros obtidos na costa sul do Japão (Souza, 1984); c) imagem do tipo mosaico, composta a partir da justaposição lateral de várias seções de sonar de varredura lateral, ilustrando pelo menos três padrões texturais distintos: um primeiro, claro e homogêneo, representando uma cobertura de sedimentos finos; um segundo, de ocorrência na porção superior da figura, constitui um padrão liso, homogêneo e escuro, relacionado com a cobertura de sedimentos grossos (em ambos os padrões foram coletadas amostras e procedidas as devidas análises sedimentológicas); e um terceiro padrão, na porção central da figura, representa um enorme afloramento rochoso. Uma cuidadosa análise desta imagem permite inclusive identificar falhas geológicas na porção central da imagem. Registro obtido na costa leste do Japão. Registro cedido pelo Dr. Y. Kinoshita do Serviço Geológico do Japão. 


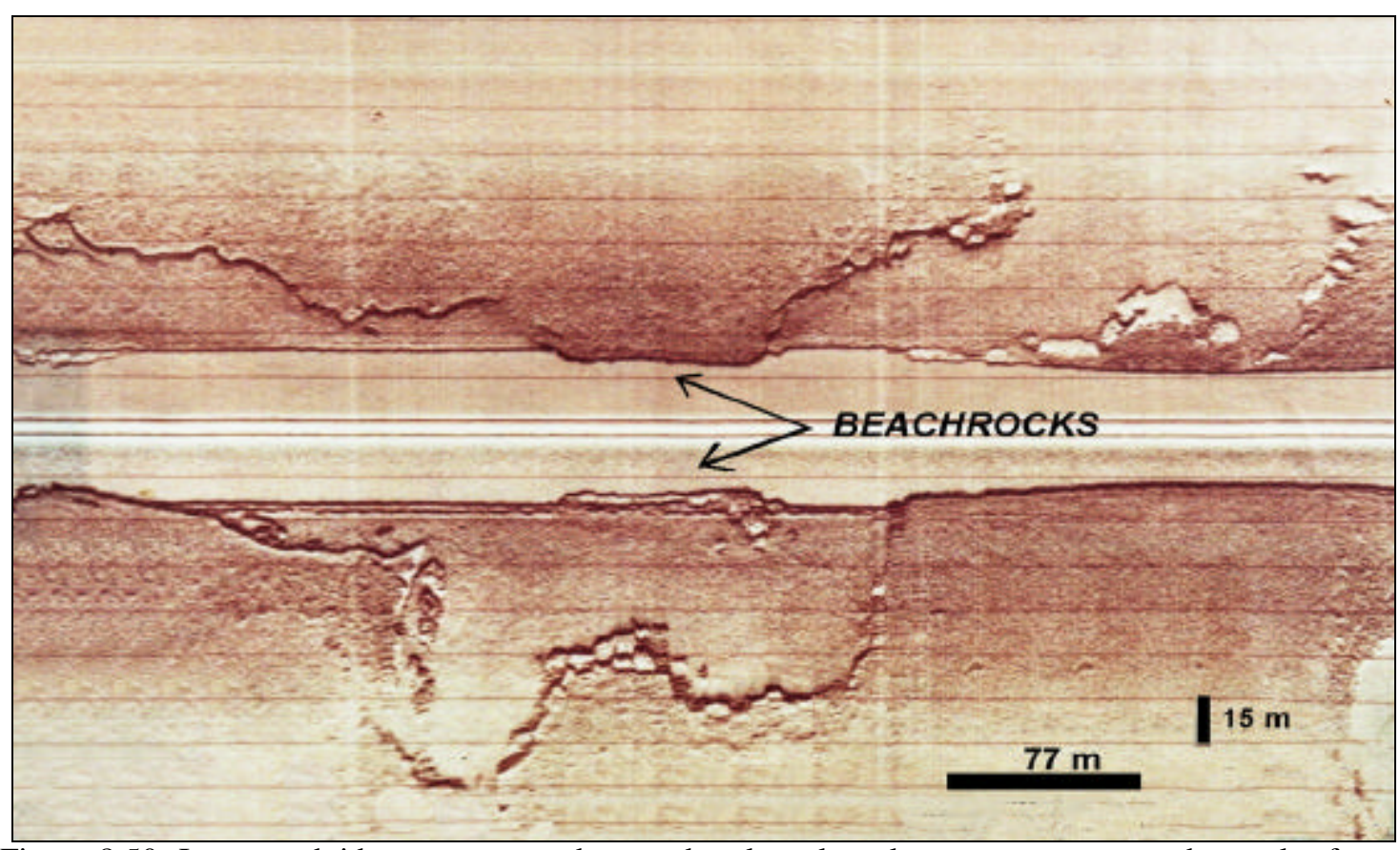

Figura 8.50: Imagem obtida com o sonar de varredura lateral em levantamento executado na plataforma continental interna do Estado da Bahia (Ilhéus) para subsidiar projeto de instalação de plataforma exploratória de petróleo. IPT (1985a).

Definidos como rochas formadas a partir da cimentação carbonática de sedimentos de praia em regiões de intermarés, os beachrocks tem forte correlação com antigos níveis marinhos, tornando-se assim importantes elementos em estudos de variações relativas do mar. Como pode ser observado na Figura 8.50, os beachrocks constituem-se em feições facilmente identificáveis nas imagens do sonar de varredura lateral, o que atribui papel muito especial a esta ferramenta geofísica em estudos desta natureza. Furtado et al. (2000), Vital et al. (2002), Klein et al. (2004) e Veiga et al. (2004) constituem exemplos recentes de utilização do sonar com esta finalidade.

$\mathrm{Na}$ prospecção de materiais de construção (areias e cascalhos) em áreas submersas, esta técnica de investigação tem papel muito especial, não só na investigação da plataforma continental interna, como também das áreas costeiras, dos rios e dos reservatórios, já que é premente o esgotamento dos depósitos continentais destes materiais, ante o aumento da demanda, conseqüência do aumento da população e das necessidades inerentes referentes à construção civil.

As imagens obtidas do SVL em projetos com este objetivo propiciam, de forma rápida e a um custo viável, o mapeamento detalhado da superfície de fundo. Os contrastes texturais identificados em imagens de sonar possibilitam identificar as áreas de ocorrência dos depósitos sedimentares, tornando viável a otimização do planejamento dos ensaios adicionais para avaliação do volume das jazidas mapeadas. A 
Figura 8.51 ilustra exemplo de imagens obtidas em projeto desenvolvido com este objetivo no rio Paranapanema (SP).

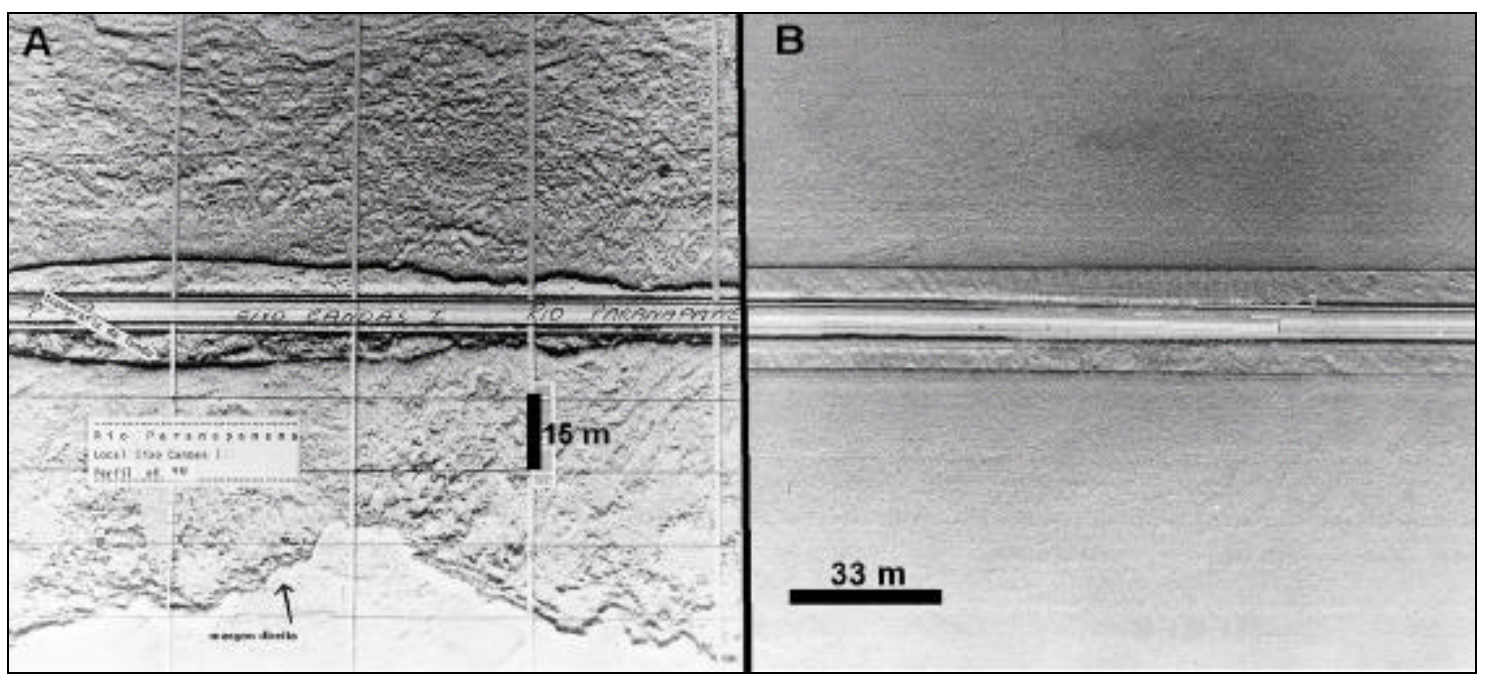

Figura 8.51: Registros obtidos de sonar de varredura lateral utilizado na prospecção de material de construção (areias) no rio Paranapanema (SP/PR) em subsídio a projeto de construção de barragem: a) registro com textura rugosa característica de fundos rochosos; b) registro com textura lisa e homogênea, característico de fundos com cobertura sedimentar arenosa. IPT (1990a,b).

Depósitos do tipo placer ricos em minerais pesados (cassiterita, ilmenita etc.) estão sempre associados a depósitos de sedimentos grossos, que por sua vez possuem características acústicas como um forte "backscattering”, que tornam o sonar de varredura uma excelente ferramenta de prospecção. Mosaicos de imagens do sonar realizadas em áreas com interesses econômicos desta natureza possibilitam o planejamento de ensaios sísmicos de perfilagem, para avaliação do volume disponível, bem como de coleta de amostras de fundo, para avaliação do conteúdo mineral dos placeres.

Outra aplicação de destaque do SVL se dá nos estudos relativos a hidrovias, seja na fase de execução do projeto, seja nas fases posteriores de aperfeiçoamento de rotas de navegação, quando se precisa avaliar os dinâmicos processos sedimentares atuantes nos rios (IPT, 1998b; IPT, 2006).

As imagens obtidas com este equipamento permitem identificar obstáculos à navegação de toda ordem, desde embarcações naufragadas, afloramentos rochosos, bancos de areia, árvores (comuns em reservatórios), características de fundamental importância, quando da necessidade do remodelamento ou redimensionamento de vias navegáveis, o que comumente implica a remoção de materiais (Figura 8.52).

IPT (2001b) utilizou-se também do sonar de varredura lateral para monitoramento de processos de erosão e assoreamento atuantes no rio Paraná, 
decorrentes da abertura das comportas da barragem de Porto Primavera, tais como fortes erosões das margens e das ilhas, deslocamento de bancos de areia, entre outros aspectos.

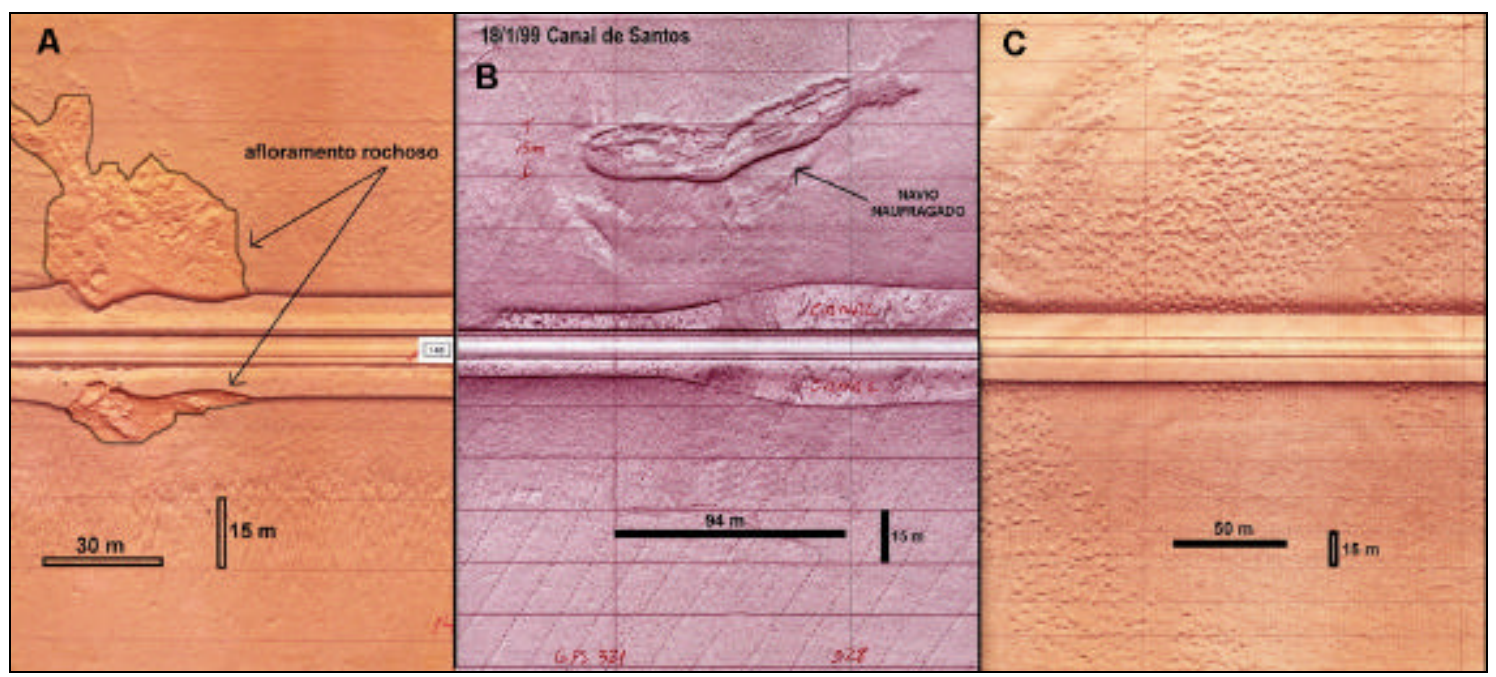

Figura 8.52: Três exemplos ilustrando potenciais obstáculos à navegação em hidrovias: a) afloramento rochoso no canal da Ilha Comprida-SP (Suguio et al., 1987); b) navio naufragado no canal de Santos-SP (IPT, 1999a); c) textura indicativa de presença de árvores na fundo do rio Tietê, a montante da Barragem de Barra Bonita - SP (IPT, 1998e).

O sonar de varredura lateral tem também vasta aplicação em questões ambientais. O monitoramente de áreas de deposição de material dragado constitui-se num dos exemplos desta aplicação. Apesar do rígido controle existente quanto à rota de navegação e, portanto, da posição da embarcação no processo de transporte e descarga de sedimentos dragados em áreas predeterminadas, levantamentos com o sonar de varredura lateral permitem o monitoramento de detalhe das transformações que ocorrem na superfície de fundo da área de descarte, quando do lançamento do material dragado. Permitem ainda, principalmente quando associados com imagens de vídeo, observar se o material lançado se depositou efetivamente na posição esperada ou planejada.

O potencial de monitorar a superfície de fundo é, hoje em dia, ainda mais eficaz, pois a maioria dos SVL é atualmente digital possibilitando não só a interpretação dos registros ou das imagens, em tempo real, como a geração dos próprios mosaicos, também em tempo real, o que propicia uma ampla visualização da área estudada. As alterações texturais nas imagens seqüenciais do SVL, oriundas de levantamentos sistemáticos em áreas submetidas a este tipo de atividade, permitirão certamente o monitoramento em detalhe da evolução dos processos atuantes nestas superfícies submersas. Excelentes exemplos de aplicação desta ferramenta no monitoramento ambiental estão ilustrados em Mosher \& Currie (1997), que se utilizaram desta para monitorar uma das mais ativas áreas de descarga de material de dragagem na costa 
Oeste do Canadá e, em Garcia-Garcia et al. (1999) e Garcia-Garcia et al. (2002), que identificaram nas imagens de sonar de varredura lateral, obtidas na costa noroeste da Espanha (Vigo), marcas na superfície de fundo correlacionadas a pontos de exsudação de gás (gas-seep pockmarks), fenômeno relativamente comum em ambientes costeiros (Figura 8.53).

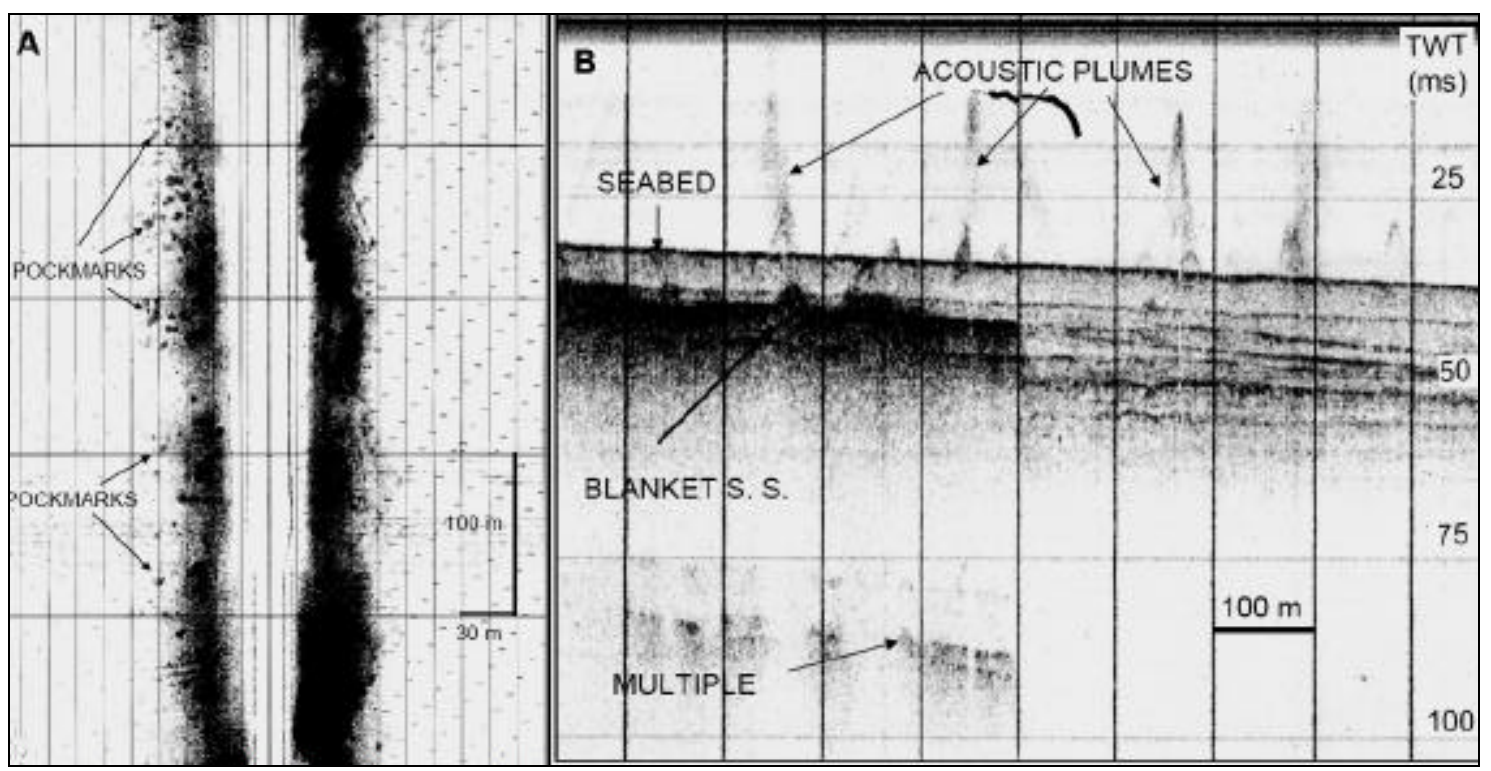

Figura 8.53: a) imagem obtida com o sonar de varredura lateral mostrando marcas na superfície de fundo de dimensões médias de $6,5 \times 4.5 \mathrm{~m}$, que foram correlacionadas pelos autores com áreas de exsudação de gases; b) perfil sísmico $(3.5 \mathrm{kHz})$ mostrando plumas geradas pela exsudação destes gases. Garcia-Garcia et al. (2202).

Ainda no contexto de questões ambientais, o SVL tem ainda larga aplicação no mapeamento de recifes de corais naturais, de recifes artificiais, e de afloramentos rochosos, principalmente em áreas cuja visibilidade é comprometida a partir de certa profundidade, tornando os métodos visuais convencionais inoperantes (observação visual, fotografia ou vídeo). Apesar da ocorrência em área ser praticamente desprezível, se comparada com a enorme área que corresponde às superfícies submersas sedimentares, as superfícies duras (afloramentos rochosos, recifes de corais etc.) têm papel de suma importância na biodiversidade submarina e, portanto a delimitação das áreas de ocorrência destas feições cumpre papel relevante na investigação biológica (Bianchi et al., 2004).

As imagens ilustradas na Figura 8.54 constituem-se em excelentes exemplos de aplicação deste método na identificação das ocorrências de recifes submersos. Na Figura 8.54a, observam-se recifes de corais na região de Abrolhos. A precisa localização destas feições submersas permitiu aos pesquisadores da Conservation 
International do Brasil executar mergulhos precisos nos pontos de interesse do projeto, obtendo desta forma maior rendimento operacional.

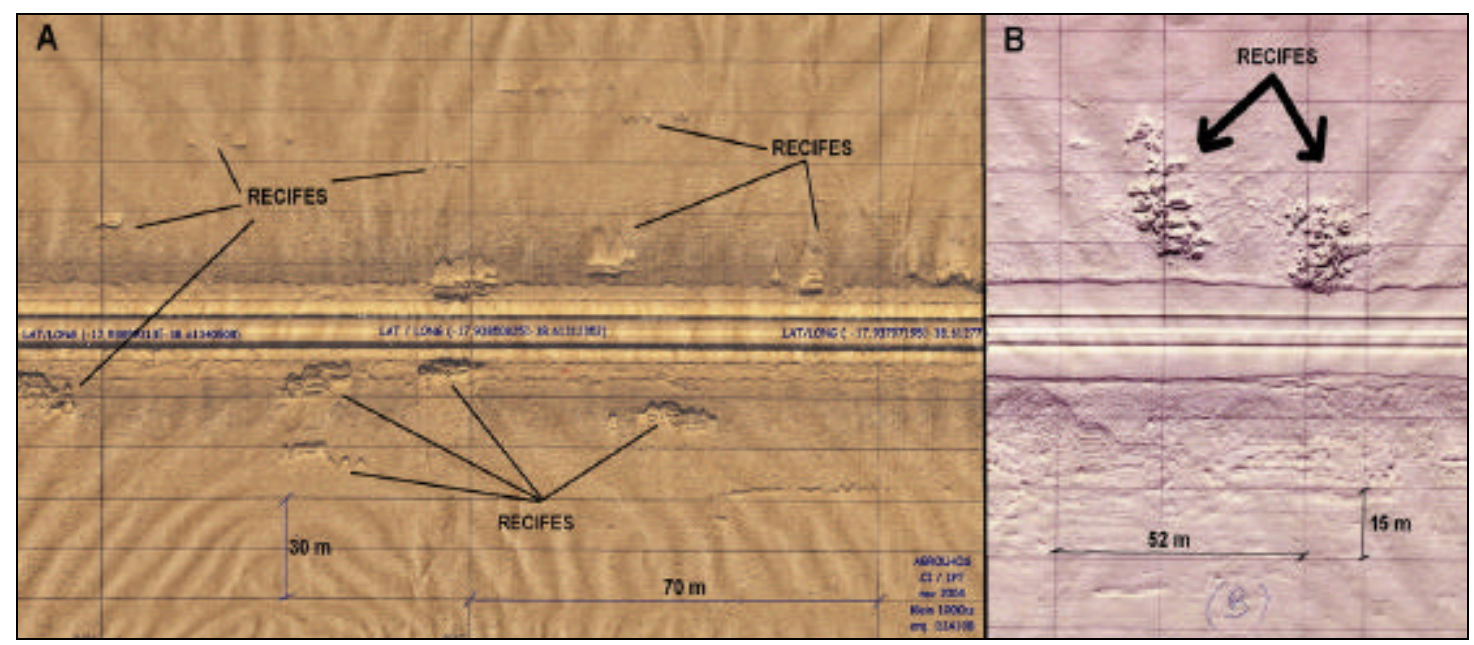

Figura 8.54: Exemplos de registros obtidos em áreas de recifes: a) recifes de corais em Abrolhos (BA), IPT (2005a), Souza \& Moura, (2005); b) recifes artificiais na costa do Estado do Paraná, IPT (2002a).

$\mathrm{Na}$ Figura 8.54b, trabalho análogo foi desenvolvido pelo Instituto Ecoplan, que encontrou no SVL a única via para obtenção de imagens do assoalho marinho da costa do Estado do Paraná que possibilitassem visualização ampla do arranjo final dos recifes artificiais lançados ao mar, em projeto de recuperação da fauna e flora do litoral do estado. Observa-se que, nesta área de estudo, as vias convencionais de investigação (fotografia, vídeo, observação direta) foram inoperantes tendo em vista as críticas condições de visibilidade da área.

À parte do excelente desempenho na investigação geológica de superfícies submersas, o SVL tem também grande aplicação nas investigações relacionadas com a arqueologia subaquática e a operações de busca e salvamento.

$\mathrm{Na}$ arqueologia subaquática, as imagens obtidas com o SVL subsidiam efetivamente não só a localização, mas também o mapeamento detalhado de embarcações naufragadas de interesse arqueológico, conforme exemplo na Figura 8.55a.

Em operações de busca ou salvamento, as aplicações do SVL são as mais variadas e vão desde localização de naufrágios recentes, de embarcações e aeronaves (Figura $8.55 b$ ) até utilização militar no auxílio a projetos de mapeamento de detalhe de áreas costeiras para localização de minas enterradas. Os mais recentes exemplos de uso não-geológico do SVL têm sido dados por companhias seguradoras, que se utilizam deste sistema para localização de carros, barcos etc., desaparecidos em operações tidas, em princípio, como fraudulentas. Dezenas de veículos já foram encontrados em 
operações desta natureza no EUA e na Austrália. Excelentes imagens obtidas com estes objetivos podem ser visualizadas em http://marinesonic.com/applications.

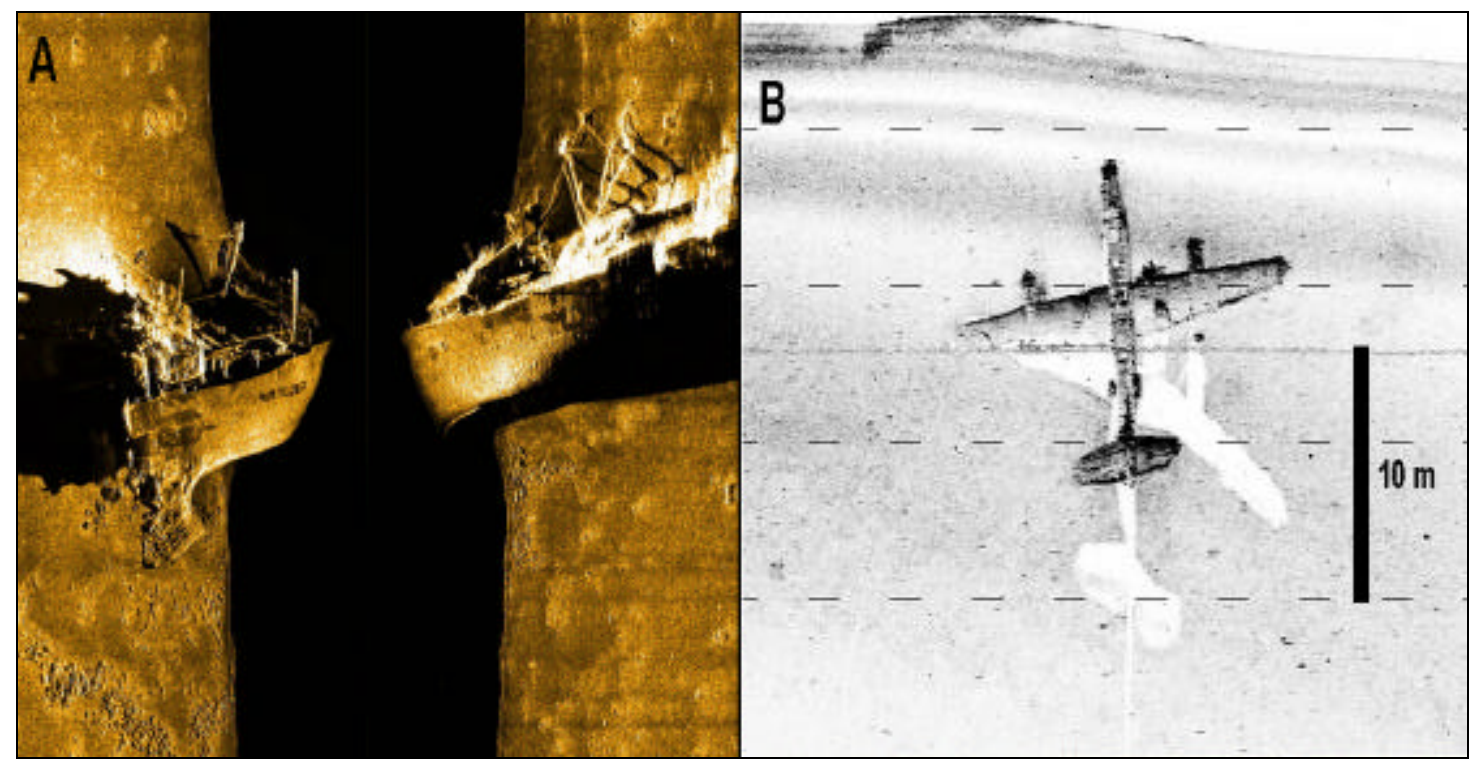

Figura 8.55: a) imagem obtida com um sonar de $500 \mathrm{kHz}$ (Klein System 3000) mostrando detalhes do navio Empire Knight. Fonte: <http://www.l-3klein.com>; b) imagem obtida com o sonar MarineSonic $600 \mathrm{kHz}$, mostrando a evidente aplicação do SVL na investigação de acidentes aéreos (Lago Washington, EUA). Fonte: 〈http://www.marinesonic.com>.

Em projetos de busca com objetivos muito específicos, o sonar de varredura lateral pode até mesmo ser utilizado de modo múltiplo. Um dos clássicos exemplos deste modo de operação ocorreu em 1987, quando a Sociedade Internacional de Criptozoologia, coordenou o projeto denominado "Operação Sondagem Profunda”, em que 24 embarcações executaram simultânea e paralelamente perfis com sonar de varredura lateral no lago Ness, na Escócia (Figura 8.56).

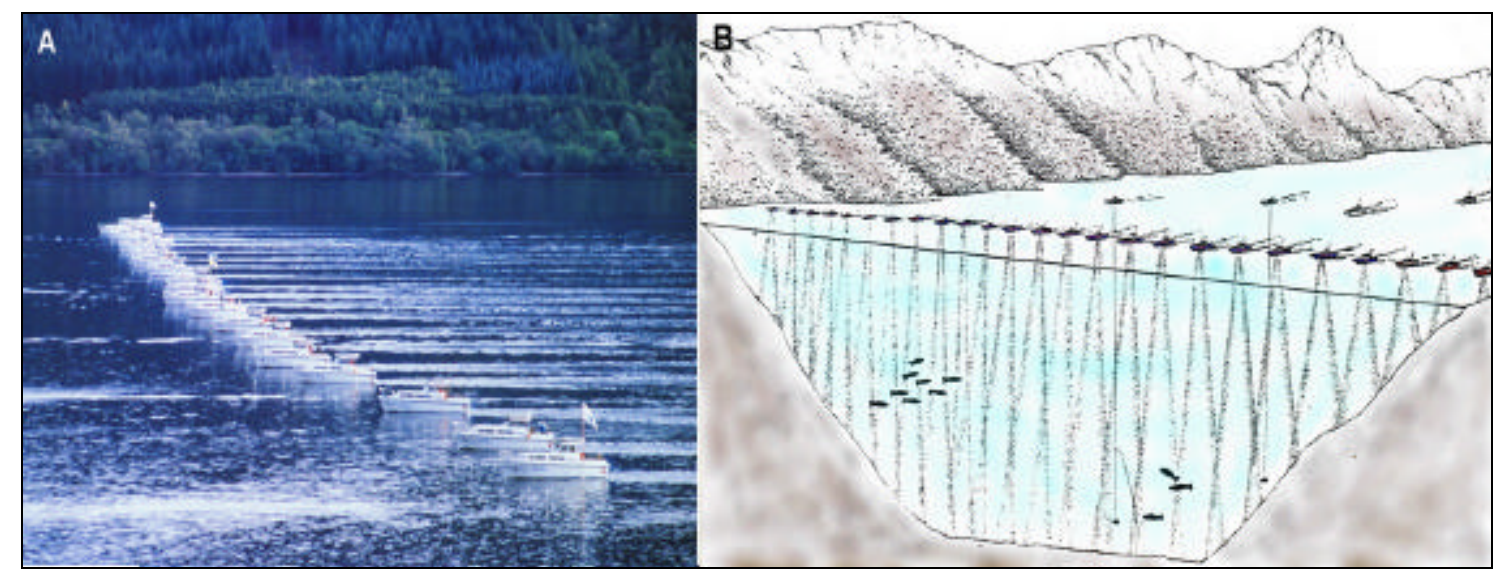

Figura 8.56: Exemplo do emprego de múltiplos sistemas de sonar de varredura lateral, visando a cobertura total $(100 \%)$, e em tempo real, da largura $(1.5 \mathrm{~km})$ do lago Ness, Escócia: a) vista das 24 embarcações navegando paralela e simultaneamente; b) geometria (cobertura) do arranjo de sonares. Modificado de Abril Coleções (1996). 


\subsubsection{Os registros do sonar de varredura lateral}

\subsection{Escala}

Como em grande parte dos métodos acústicos utilizados na investigação de áreas submersas, a medida principal realizada pelos sistemas é o tempo de percurso das ondas acústicas para realizarem o trajeto transdutor-fundo-transdutor. No caso específico do sonar de varredura lateral, em que se sabe previamente que o sinal vai percorrer um meio com velocidade de propagação conhecida (no caso, a água), o registro obtido, ou seja, o produto final gerado pelo sonar, comumente se apresenta em escala métrica, já que a conversão do tempo de percurso em distância pode ser feita automaticamente utilizando-se da clássica equação, velocidade $=$ espaço $/$ tempo, em que a única incógnita é o espaço. Desta forma, as dimensões das feições identificadas nos registros podem ser diretamente medidas no próprio registro, utilizando-se apenas de uma escala.

À parte de que a escala dos registros da sonografia, ao longo da linha perpendicular à rota de navegação ser definida a partir da velocidade de propagação das ondas acústicas no meio, ressalta-se que a escala do registro ao longo do perfil em execução depende exclusivamente da velocidade da embarcação.

Os sistemas modernos e digitais tornam o processo de dimensionamento dos registros extremamente fáceis, pois, ao contrário dos sistemas analógicos antigos que produziam registros com escalas diferenciadas em direções perpendiculares (Figura 8.57), possibilitam o controle total, automático e em tempo real, destas duas variáveis que influenciam diretamente as escalas dos registros nas duas direções.

Desde que conhecidas a velocidade de propagação das ondas acústicas na água no ambiente investigado e a velocidade de deslocamento da embarcação, registros isométricos são produzidos (Figura 8.57). Neste caso, torna-se ainda mais fácil medir as dimensões das feições identificadas nos registro, pois a escala do registro é única e idêntica em qualquer direção.

\subsection{Alcance Lateral}

No imageamento de superfícies submersas com o sonar de varredura lateral, o alcance lateral ou a varredura lateral representa o ponto máximo de amostragem da 
superfície ao longo de uma linha perpendicular à rota de navegação, de ambos os lados da embarcação, conforme já apresentado na Figura 8.41 e na Figura 8.43.

Os equipamentos disponíveis atualmente permitem optar por alcances laterais variáveis, normalmente, no caso da investigação rasa, entre 25 e 600 metros. Os sonares de grande alcance podem atingir até mesmo mais de $50 \mathrm{~km}$ de varredura lateral, mas não se adequam a levantamentos de áreas rasas.
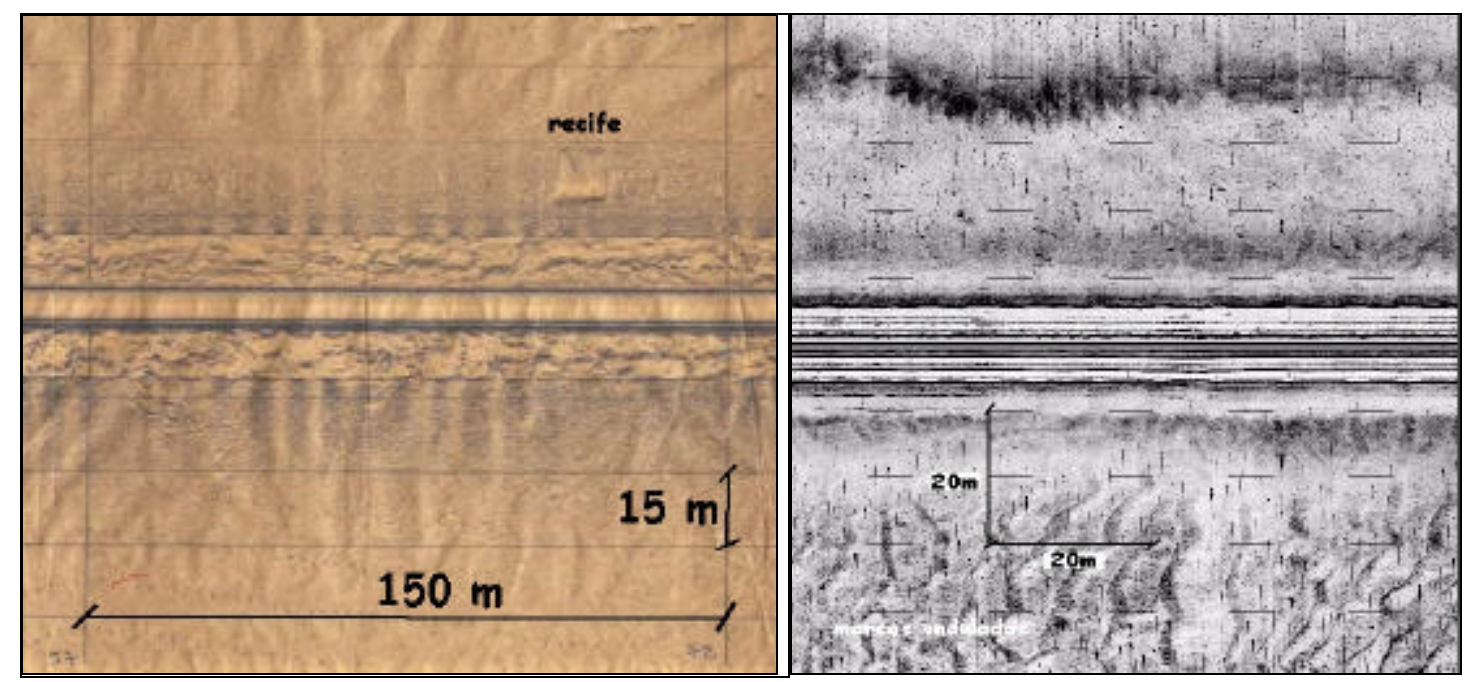

Figura 8.57: Escalas diferenciadas nos registros do sonar de varredura lateral: à esquerda, registro analógico obtido na região de Abrolhos, BA, mostrando escalas diferenciadas em direções ortogonais; à direita, registro digital obtido na região da Ilha Comprida, SP, mostrando escalas idênticas (isométricas) em qualquer direção no registro.

A escolha do alcance lateral é função direta, em primeiro lugar, da escala do levantamento ou, ainda, do nível de detalhamento exigido no estudo. Comumente um levantamento com o sonar de varredura lateral se desenvolve numa fase inicial, de reconhecimento geral, quando se utilizam alcances laterais maiores, mais longos.

No caso da investigação de águas rasas, alcances laterais a partir de 250 metros já podem ser considerados grandes ou de longo alcance. Nesta fase de reconhecimento geral, os setores de interesse da área investigada ou objetos (ou pontos) da busca são localizados na superfície de fundo.

Uma segunda fase refere-se ao imageamento de detalhe, planejado com a utilização de alcances laterais curtos, inferiores a 100 metros. Operações de busca e salvamentos são bons exemplos de situações operacionais em que inicialmente se utilizam grandes varreduras laterais para a localização do objeto da busca, seguido de varreduras curtas para o imageamento de detalhe do ponto ou do objeto de interesse. 
A Figura 8.58 mostra dois registros obtidos com o sonar de varredura configurado para distintos alcances laterais, utilizados em fases subseqüentes, de localização e de aproximação ou detalhamento do objeto da busca, neste caso, uma investigação arqueológica do navio a vapor Conde d'Áquila, naufragado na canal da Ilha Comprida, SP, em 1858 (IPT, 2001 e Rambelli, 2003).
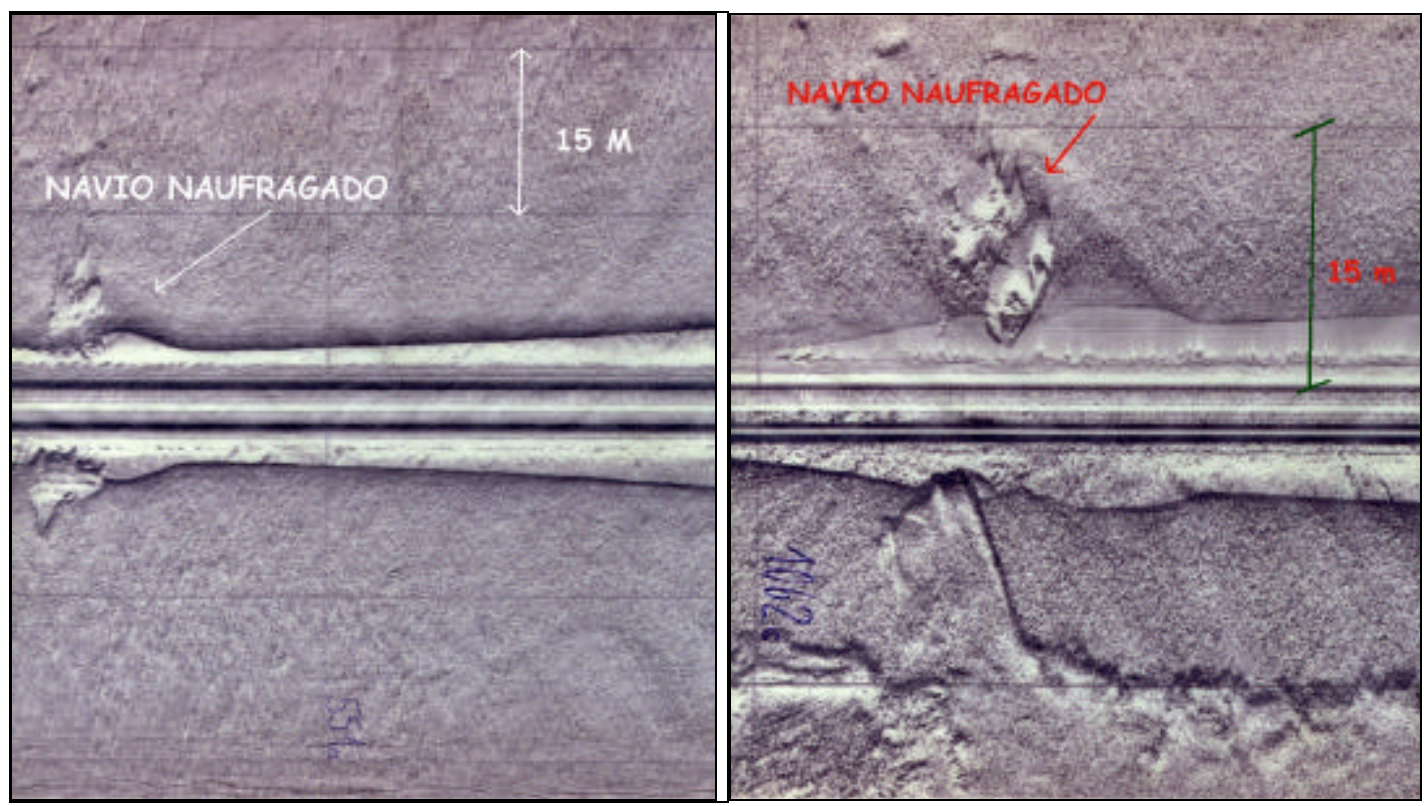

Figura 8.58: Registros analógicos do sonar de varredura utilizando alcances laterais distintos: à esquerda, alcance lateral de $100 \mathrm{~m}$ para localização do objeto de busca (ver escala); à direita, alcance lateral de 25 m utilizado para aproximação do objeto da busca para obtenção de detalhes. Equipamento utilizado: Klein 530. Hydroscan Side Scan Sonar 100kHz. (IPT, 2001a e Rambelli, 2003).

A utilização de alcances laterais curtos (inferiores a $100 \mathrm{~m}$ ) significa elevado custo operacional do levantamento, pois grande número de perfis será necessário para o recobrimento total ou parcial da área de interesse, que, por sua vez, implica a coleta de maior quantidade de dados e conseqüentemente na necessidade de enorme memória para armazenamento e maior tempo para processamento dos dados. Alcances laterais maiores que 200-300 m normalmente estão relacionados com levantamentos de reconhecimento de grandes áreas que privilegiam o reconhecimento amplo da área a um menor custo.

Outra característica preponderante dos sistemas acústicos de varredura lateral, que interfere diretamente na definição do alcance lateral, refere-se à freqüência do sinal emitido. Os sistemas de grande alcance, como o GLORIA, o SEAMARCII, geralmente rebocados na superfície da água, ou próximo dela, utilizam freqüências abaixo de 12 $\mathrm{kHz}$ e, com este espectro de freqüências, permitem que o sistema seja configurado para longos alcances laterais, da ordem de dezenas de quilômetros. 
Estes sistemas são empregados para levantamentos marinhos em grandes escalas e não tem aplicação no estudo de áreas rasas como rios, lagos e plataforma continental interior, pois se trata de equipamentos de grande porte que exigem complexa mobilização operacional. Sistemas como estes têm a capacidade de mapear áreas de milhares de quilômetros quadrados em um único dia, utilizando alcances laterais de algumas dezenas de quilômetros de cada lado (50-60 km). Experiências brasileiras com sonar deste porte são quase que exclusivas da Petrobras.

Piauilino et al. (2002) destacaram a experiência com um novo sonar de varredura lateral de águas profundas, rebocado, próximo da superfície de fundo, o que poupou o sistema de várias interferências ou ruídos, quando do sistema tracionado na superfície, ou próximo dela que, aliás, é o mais comum. Na Figura 8.59 pode-se notar, em escala, a robustez de equipamentos deste porte, principalmente quando comparado ao ilustrado na Figura 8.60, que mostra um sonar de varredura lateral de pequeno porte, para levantamentos de águas rasas.

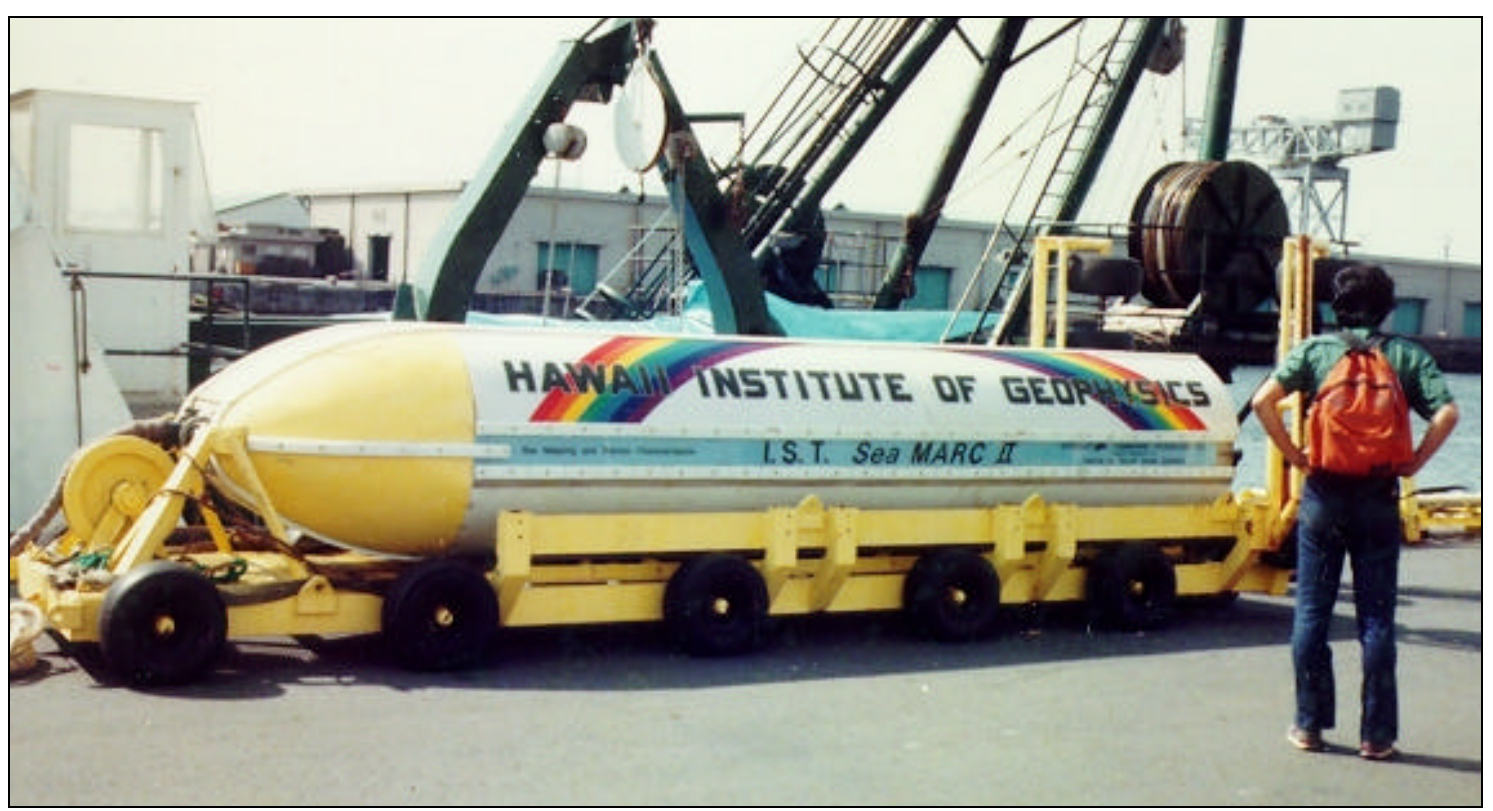

Figura 8.59: Sonar de varredura lateral de longo alcance: Sea Marc II (11/12kHz) em operação na costa oriental do Japão. Foto: cortesia do Dr. Y. Kinoshita do Serviço Geológico do Japão.

Os sistemas acústicos de varredura lateral de uso mais comum utilizam freqüências ao redor de $100 \mathrm{kHz}$. Com este espectro de freqüências, estes sistemas podem ser configurados para alcances laterais desde algumas dezenas de metros até algumas centenas de metros, comumente inferiores a $1000 \mathrm{~m}$.

Existem também sonares que emitem freqüências ainda maiores (300, 500, 900 e até $1200 \mathrm{kHz}$ ), constituindo-se em equipamentos de grande desempenho do ponto de vista da resolução, com prejuízo do alcance lateral, que raramente é superior a $250 \mathrm{~m}$. 
Estes equipamentos produzem imagens da superfície de fundo extremamente detalhadas e têm aplicação em especial nas operações de busca e salvamento.

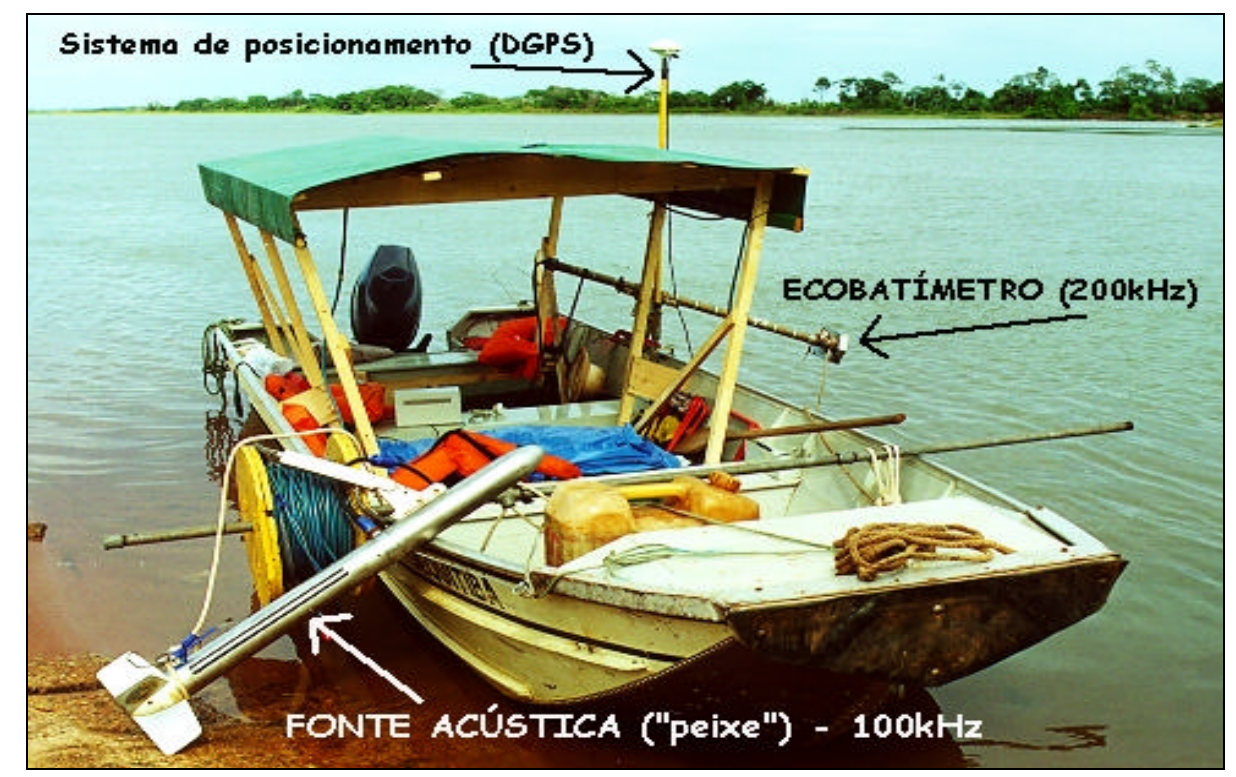

Figura 8.60: Sonar de varredura lateral de curto alcance modelo Klein Hydroscan Side Scan Sonar (100 $\mathrm{kHz})$, em operação no rio Paraná. Foto: autor

Os modelos mais recentes de sonares de varredura lateral permitem operação com dupla freqüência, o que torna o sistema bastante interessante, pois, assim, se obtêm simultaneamente grande resolução e grande alcance lateral. Os sistemas mais comuns oferecem a possibilidade de operação simultânea ou não, com freqüências mais baixas da ordem de $100 \mathrm{kHz}$ e as mais altas, entre 300 e $500 \mathrm{kHz}$.

\subsection{Geometria dos registros analógicos e digitais}

Os registros analógicos oriundos dos sistemas sonográficos mais antigos apresentam uma série de distorções geométricas, e assim cuidados especiais devem ser tomados ao manuseá-los com a finalidade de análise e interpretação.

Normalmente as imagens obtidas pelos sonares analógicos são criadas a partir de sistemas de recepção que mostram uma pobre relação sinal/ruído e são impressas em papel eletrossensível úmido ou seco, o que, por si só, gera severas distorções geométricas na imagem. Nestes registros, por exemplo, não é corrigida a relação DI/DH (distância inclinada / distância horizontal), tampouco são computadas as variações de velocidade da embarcação durante a aquisição dos dados, nem mesmo as eventuais variações na velocidade de propagação do som na coluna d'água, o que provoca, nos registros, sensíveis diferenças nas escalas longitudinais e transversais em relação à navegação. 
A relação DI/DH constitui-se num importante fator de correção, principalmente nos casos onde a fonte de sinais ("peixe") é rebocada muito próxima da superfície da água. Nestes casos, a distância real (DH), medida na superfície de fundo, torna-se muito diferente da distância medida no registro analógico (DI), já que esta se origina do tempo de deslocamento do sinal acústico, desde a fonte acústica até o ponto na superfície, ao longo de uma linha inclinada entre a fonte acústica e o ponto observado. A Figura 8.61 ilustra as relações geométricas entre a distância real ou distância horizontal (DH) e a distância medida no registro.

Conforme a Figura 8.62, os registros do sonar de varredura lateral sofrem severa deformação geométrica devido a alterações da velocidade da embarcação. Levantamentos executados com sistemas desta natureza serão tão mais precisos quanto mais constante a velocidade da embarcação durante a aquisição dos dados. Ainda nesta figura, velocidades baixas, ao redor de 2 ou 3 nós, produzirão registros com pouca ou nenhuma deformação, o que em muito facilitará o trabalho do intérprete na análise das imagens obtidas com vistas na construção de mosaicos.

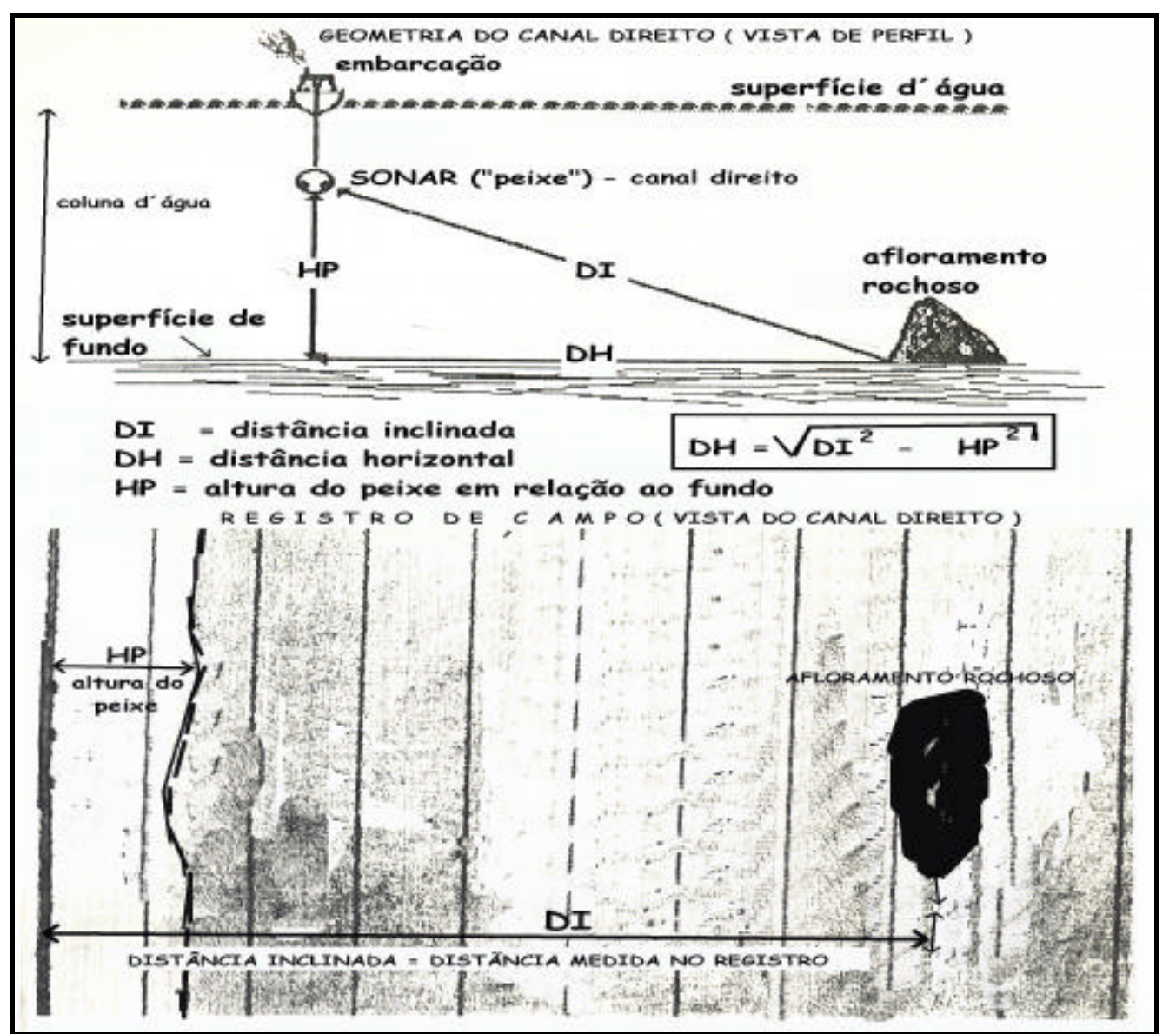

Figura 8.61: Ilustração mostrando a diferença entre a distância de dois pontos na superfície, medidas ao longo da distância inclinada (DI = distância inclinada, medida no registro) e ao longo da distância horizontal (DH = distância verdadeira). Modificado de Mazel (1985). 


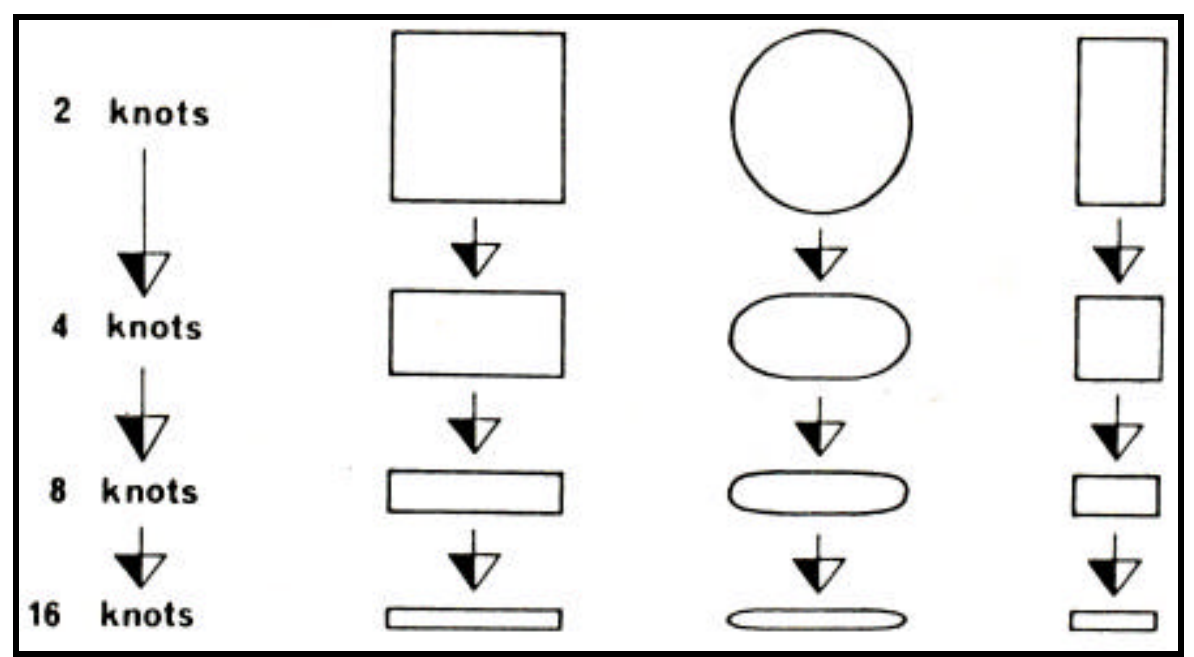

Figura 8.62: Ilustração que mostra, por meio de deformações em figuras geométricas regulares, o efeito da variação de velocidade de navegação sobre os registro do sonar de varredura lateral. Mazel (1985).

Os sistemas modernos com aquisição de dados digitais permitem que as informações de posicionamento da embarcação, obtidas dos sistemas baseados em satélites (DGPS), sejam inseridas, em tempo real, no sistema operacional, de forma a propiciar a eliminação das deformações causadas pelas alterações da velocidade da embarcação ao longo de um levantamento. Deste modo, os dados obtidos em campo podem ser observados sem distorções, ou seja, as imagens se apresentam, em tempo real, de forma isométrica: as escalas na imagem são idênticas em qualquer direção. Tal possibilidade muito facilita a criação de mosaicos com os registros de campo justapostos lateralmente, de modo análogo ao tratamento de fotografias aéreas, proporcionando maior precisão e conforto no manuseio e na interpretação dos registros obtidos.

Outro produto do avanço tecnológico da eletrônica e da acústica é o aprimoramento da relação sinal/ruído nos sistemas de aquisição de dados, o que possibilita a aquisição de imagens com maior resolução. Os sistemas atuais são totalmente digitais tornando o processamento e a análise das informações obtidas extremamente práticas, precisas e rápidas, ao contrário dos sistemas analógicos, que geram enorme volume de registros em papel, dificultando o manuseio dos dados.

Berkson \& Clay (1973), Chesterman (1974), Flemming (1976, 1982), Denbigh \& Flemming (1982) e Searle et al. (1990), Luyendyk et al. (1983) discutiram ampla e detalhadamente as distorções causadas nos registros do sonar de varredura lateral e apresentam técnicas para as devidas correções.

Outro fator a se considerar na análise das imagens obtidas com o sonar de varredura lateral consiste na variação da velocidade de propagação das ondas acústicas 
emitidas na coluna d'água. Os equipamentos mais modernos possibilitam que os valores destas velocidades sejam também inseridos no sistema operacional para isentar a imagem final de deformações causadas por este fator.

A determinação das variações da velocidade de propagação do som na coluna d'água é extremamente importante ao se desenvolver trabalhos em águas profundas, onde a coluna d'água pode apresentar-se estratificada, com relação à temperatura, salinidade, turbidez, entre outras propriedades. Esta estratificação atua diretamente no desvio do trajeto original das ondas acústicas emitidas pelo sonar, que desta maneira atingem a superfície de fundo por vias "alternativas", alterando assim o tempo de percurso normal. Em levantamentos de áreas rasas, estes fatores são praticamente desprezíveis. Alguns aspectos da propagação do som na coluna d'água são discutidos em detalhe por Chesterman (1974) e Mazel (1985).

\subsection{Resolucão}

Por resolução, entende-se a capacidade do sistema de distinguir dois pontos distintos na superfície de fundo, o que depende fortemente das características do equipamento utilizado, principalmente da largura do feixe de sinais, e da duração do pulso e freqüência do sinal emitido. A natureza da superfície de fundo, a velocidade da embarcação e a distância do ponto observado até os transdutores constituem-se também em fatores que influenciam a resolução de uma imagem do sonar ao longo da linha de navegação, conforme ilustrado na Figura 8.63. Feixe de sinais estreitos (menores que $1.2^{\circ}$ ), de curta duração (menores que 0.1 milissegundo) e com fonte acústica de alta freqüência (500 kHz, p.ex.), apresenta resolução centimétrica.

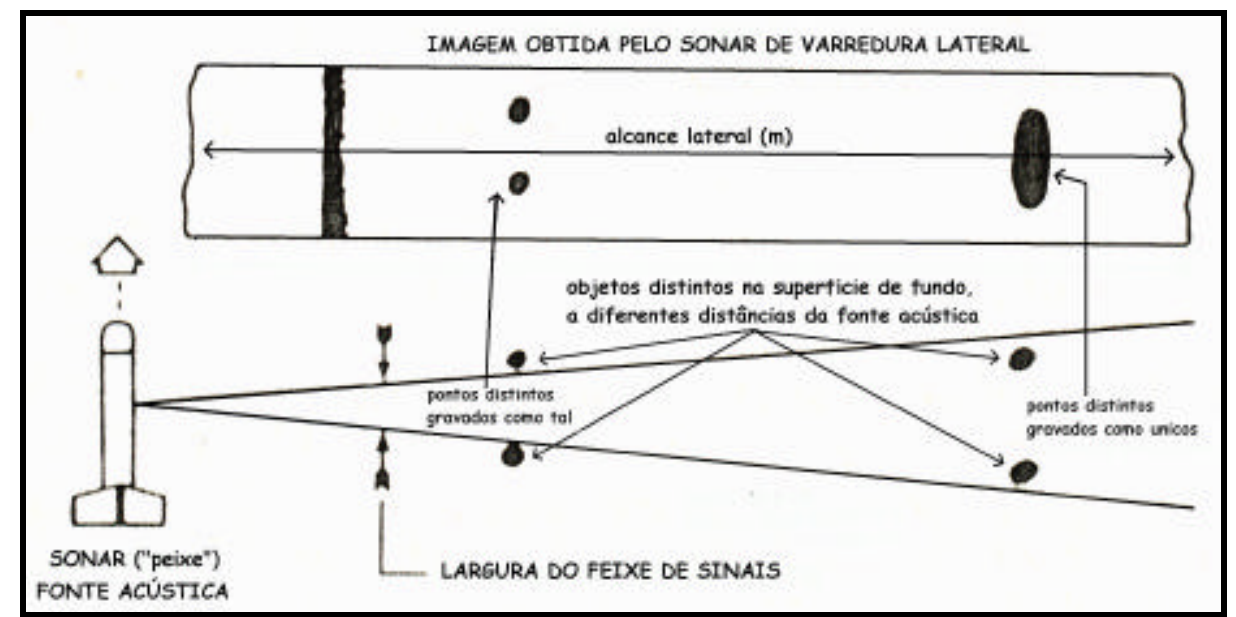

Figura 8.63: Resolução das imagens do sonar de varredura lateral ao longo da linha de navegação. Observa-se, neste exemplo, que objetos distintos podem ser gravados, no registro do sonar, como um único objeto, se localizados a distâncias da fonte acústica que permitam ser englobados pelo feixe de sinais. Modificado de Mazel (1985). 
Estes sistemas de alta resolução têm grande aplicação no mapeamento em pequena escala de áreas submersas rasas e em operações de busca e salvamento, considerando a riqueza de detalhes observáveis nos registros obtidos. As altas freqüências emitidas por estes sistemas se dissipam mais facilmente ao longo da coluna d'água e, portanto, perdem para o sistema anterior quando se compara o potencial de alcance lateral de ambos.

A Figura 8.64 aponta de maneira bastante clara a diferença básica entres estes dois sistemas. As duas imagens (a e b) mostradas nesta figura foram obtidas em levantamentos simultâneos na Enseada do Flamengo em Ubatuba, SP, durante o verão de 2005, utilizando-se distintos equipamentos. Na parte superior (a) desta figura observam-se detalhes na imagem que ratificam o grande desempenho, no quesito resolução, de um sistema de alta frequiência (no exemplo, $300 \mathrm{kHz}$ ), quando comparado com um sistema de baixa frequiência, no exemplo, $100 \mathrm{kHz}$ (parte inferior da figura). No registro obtido do sistema de alta freqüência (a), observa-se na superfície de fundo, nitidamente, e com riqueza de detalhes, uma estrutura artesanal de pesca. Ao contrário, no registro obtido com o sistema de menor frequiência (b), observam-se apenas feições lineares, não suficientemente claras para a definição da forma do instrumento de pesca observado no registro superior.

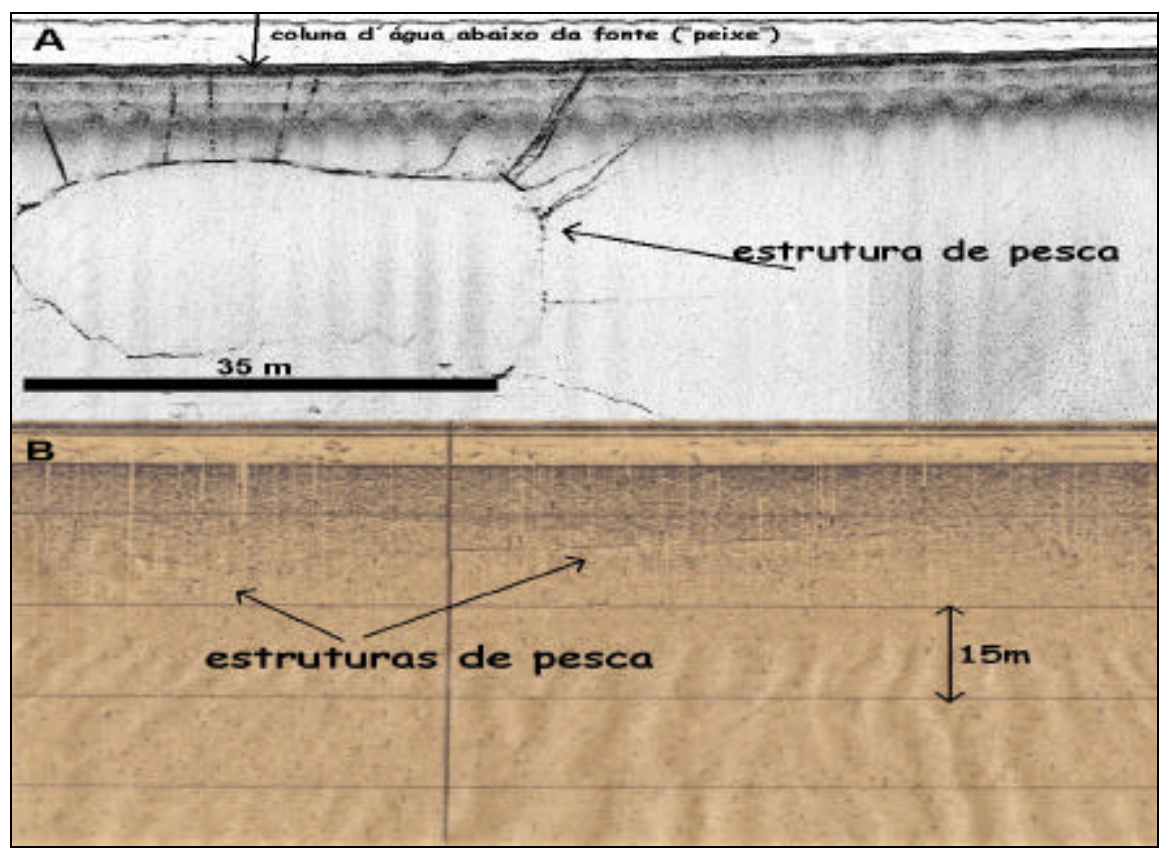

Figura 8.64: Registros originais de campo de SVL obtido num mesmo local, mostrando resoluções distintas para freqüências distintas: a) a imagem mostra registro obtido com um sonar digital de alta resolução $(300 \mathrm{kHz})$ na Enseada do Flamengo, SP, onde se observam-se, com detalhes, feições na superfície de fundo interpretadas como estruturas de pesca locais; b) imagem ilustrando um registro analógico de baixa resolução $(100 \mathrm{kHz})$ onde, todavia, não se observam os detalhes identificados na imagem superior. Nesta, apenas alguns traços evidenciam elementos que poderiam ser correlacionados a estruturas de pesca. Registros cedidos pelo Prof Dr. Michel M. de Mahiques - IO-USP. 
Com progresso tecnológico, a geofísica aplicada obtém, mais uma vez, vantagens muito apropriadas, pois os SVL mais recentes possuem propriedades adicionais que permitem a escolha do espectro de freqüência a ser emitido e, assim, num mesmo equipamento, pode-se optar, segundo o objetivo do estudo, por maior resolução, quando do levantamento de detalhe, ou maior alcance lateral, quando do levantamento de reconhecimento geológico.

Em levantamentos cujo objetivo é cobrir grandes faixas do assoalho submerso (p. ex. levantamentos da plataforma continental externa), o tempo disponível para a execução dos levantamentos constitui-se em forte fator de restrição, que está diretamente relacionado com a verba disponível. Nestes casos, portanto, são empregados sistemas com características que favorecem a utilização de grandes alcances laterais, com evidente prejuízo da resolução ao longo da linha de navegação, que, em alguns sistemas, podem chegar a 20-30 m. Belderson et al. (1972), Damuth \& Kumar (1975), Somers et al. (1978), Laughton (1981), Damuth et al. (1983), Hussong \& Fryer (1983), Scalon (1984) e Kastens \& Shor (1985) discutiram amplamente a geometria de imagens do sonar de varredura lateral de longo alcance.

Outros fatores contribuem, em maior ou menor grau, para a definição da qualidade dos registros obtidos em campo, dentre os quais, podem-se destacar a altura do transdutor em relação à superfície de fundo e os ruídos em geral ocasionados por turbulências, ondas, correntezas, redes de alta tensão ou por outros equipamentos geofísicos operando simultaneamente.

\subsubsection{Interpretação dos registros do sonar}

A interpretação dos dados oriundos do sonar de varredura lateral está baseada na análise dos contrastes texturais apresentados pelas imagens obtidas, sejam digitais ou analógicas. A forte correlação existente entre os contrastes texturais observados nas imagens e as características dos materiais que compõem a superfície de fundo constituise também em importante premissa para a interpretação das imagens obtidas com o sonar de varredura lateral (Urick, 1983; Wever et al. 1997; Golf et al. 2000).

A análise visual da imagem acústica contínua gerada pelo sonar permite reconhecer as principais características da superfície de fundo (contatos entre diferentes materiais, relevo etc.), tendo como base os padrões texturais observados nas imagens, a geometria das feições identificadas e a refletividade acústica da superfície. As sombras 
acústicas projetadas no registro, decorrência da incidência inclinada do sinal, permitem determinar a altura das feições identificadas na superfície de fundo. Texturas rugosas são comumente interpretadas como afloramentos rochosos, recifes de corais, arenitos de praia ou sedimentos grossos (cascalhos). Texturas lisas e homogêneas são interpretadas como sedimentos finos (lamas ou areias finas). Comumente, a análise de uma forma global das imagens de sonar é precedida pelo estabelecimento de um padrão de referência textural, indicativo do tipo de fundo, criado para cada projeto, em função dos objetivos dos estudos.

A Figura 8.65 ilustra padrão textural utilizado como referência para interpretar imagens do sonar obtidas em projeto de investigação desenvolvido ao longo do rio Paranapanema, para prospecção de material de construção (areias e cascalhos), em subsídio a projeto de construção de duas barragens na região de Ourinhos, Estado de São Paulo (IPT, 1990a,b). Neste caso, apenas dois padrões básicos para interpretação foram estabelecidos, o que possibilitou a identificação de setores do rio onde ocorriam afloramentos rochosos e os setores onde ocorriam coberturas sedimentares, objeto do interesse em um rápido (três dias) mapeamento de mais de $200 \mathrm{~km}$ do leito do rio. Trabalhos mais detalhados foram posteriormente desenvolvidos (sondagens e levantamentos geofísicos com perfilagem sísmica) para a avaliação das espessuras das coberturas sedimentares identificadas.
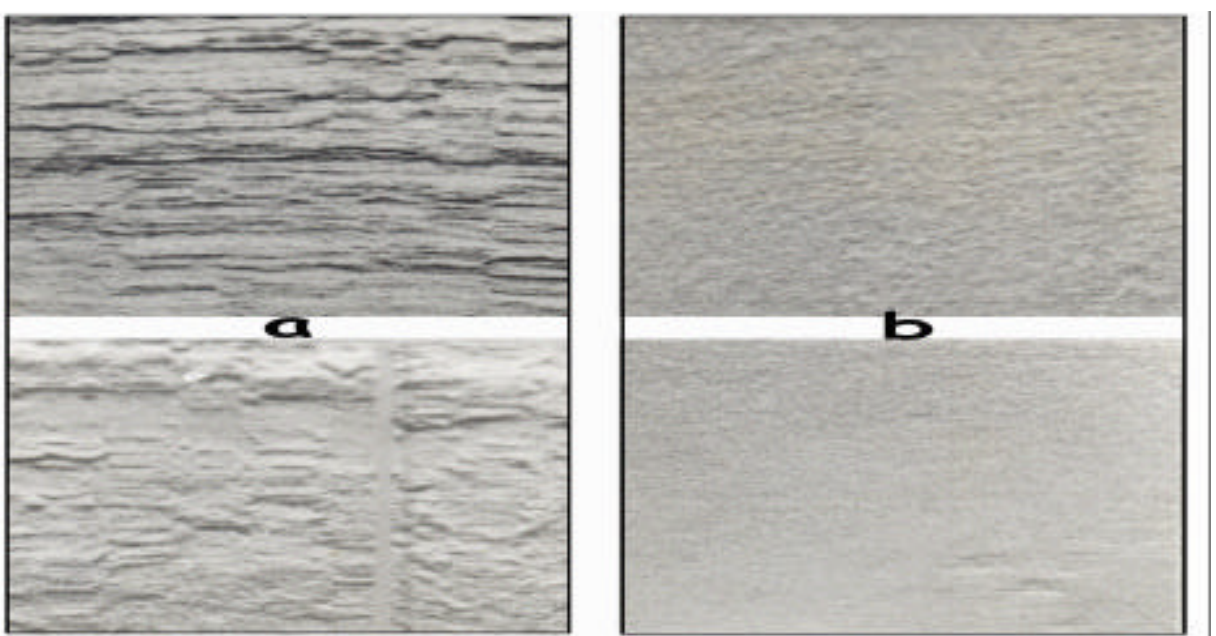

Figura 8.65: Padrão de referência utilizado para análise e interpretação da imagens de sonar de varredura lateral obtidas no rio Paranapanema, com objetivo de prospecção de material de construção: a) padrão de textura rugosa correlacionável com superfícies de fundo rochosas; b) padrão de textura lisa e homogênea característica de superfícies de fundo cobertas por sedimentos. IPT (1990a).

Em projetos com objetivos mais detalhados, maior número de padrões podem ser estabelecidos. Brown et al. (2002) discutiram a aplicação de métodos acústicos de investigação utilizados em conjunto com técnicas de amostragem biológica, no 
mapeamento da distribuição de habitats submarinos associados a comunidades bentônicas. Os autores utilizaram o sonar de varredura lateral para o mapeamento detalhado (cobertura 100\%) da superfície de fundo e para a interpretação das imagens do sonar, e estabeleceram oito padrões de referência distintos de fundo, conforme ilustrado na Figura 8.66. Com base nestes padrões, mapearam os contatos entre os tipos de fundos geologicamente distintos, propiciando no momento seguinte, o planejamento de coletas biológicas discretas, em pontos estratégicos, de forma a amostrar assembléias específicas no assoalho marinho.

Trabalho análogo foi desenvolvido por Mcrea Jr. et al. (1997) que, utilizando sonar de varredura lateral de alta resolução $(150 \mathrm{kHz})$, mapeou habitats marinhos na plataforma continental próximo da ilha Kruzof, no Alaska, com objetivo de fornecer subsídios à atividade pesqueira na região.

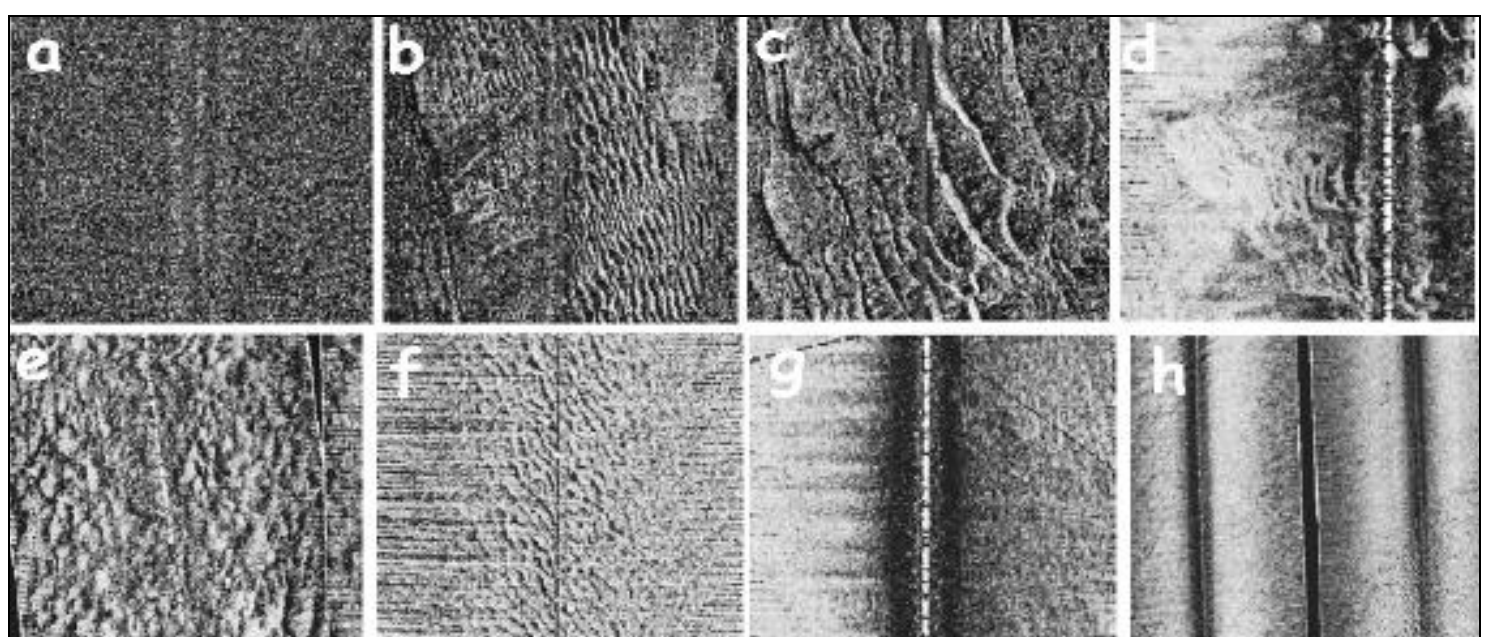

Figura 8.66: Exemplos de imagens do sonar de varredura lateral obtidas em setores acusticamente distintos: a) fundo arenoso homogêneo; b) fundo arenoso homogêneo com ripple marks; c) fundo arenoso com marcas onduladas de grande porte; d) fundo com sedimentos heterogêneos; e) fundo heterogêneo e irregular com seixos; f) porção interna da área com sedimentos arenosos e ripple marks; g) fundo homogêneo, mas com maior refletividade, típico de fundos com sedimentos de maior granulometria areais grossas e seixos; h) região de transição: areais grossas e cascalhos. Modificado de Brown et al. (2002).

Ayres Neto \& Aguiar (1993) com base em vários levantamentos com o sonar de varredura lateral na plataforma continental na bacia de Campos, RJ, apresentaram uma proposta tentativa de estabelecimento de uma nomenclatura básica e, portanto, padronização para interpretação de imagens de sonar naquela região. Analisaram dezenas de quilômetros de registros obtidos na área durante anos e associaram imagens com texturas homogêneas e pouco reflexivas a sedimentos pouco selecionados, ricos em lama carbonática, de ocorrência no talude continental. Desta forma, estes autores, correlacionaram as imagens homogêneas com textura rugosa, de ocorrência na plataforma continental interna, a sedimentos arenosos grossos e/ou biodetríticos; as 
imagens com feições circulares (manchas), próximo de campos de exploração de petróleo, a depósitos sedimentares superficiais e locais; imagens com fortes reflexões pontuais, de ocorrência nas áreas mais profundas, a material rolado da parte superior do talude continental; imagens com padrões irregulares, com textura rugosa, de forte reflexão, ocorrendo em faixas alongadas, aproximadamente paralelas à linha de costa, foram associadas, por estes autores, a beachrocks. Finalmente, aos padrões com reflexões orientadas foram correlacionadas diretamente com marcas onduladas e padrões texturais com feições não-naturais, correlacionados com estruturas artificiais, tais como, linhas de dutos, arrasto de âncoras, poitas de bóias etc.

Fundamentados também na análise dos padrões texturais observados em imagens de sonar de varredura lateral, integrada a dados de sísmica de alta resolução, Quaresma et al. (2000) apresentaram mapas de caracterização da superfície de fundo da baía de Guanabara (porção sul) em estudo que muito contribuiu para o entendimento dos processos sedimentares atuantes na região.

Outros exemplos de imagens obtidas por meio do sonar de varredura lateral, podem ser vistos na Figura 8.67 e na Figura 8.68 onde se evidenciam na superfície de fundo, características texturais distintas, correspondentes a diversos ambientes geológicos (IPT, 1986, 1992a,b e Suguio et al., 1987).

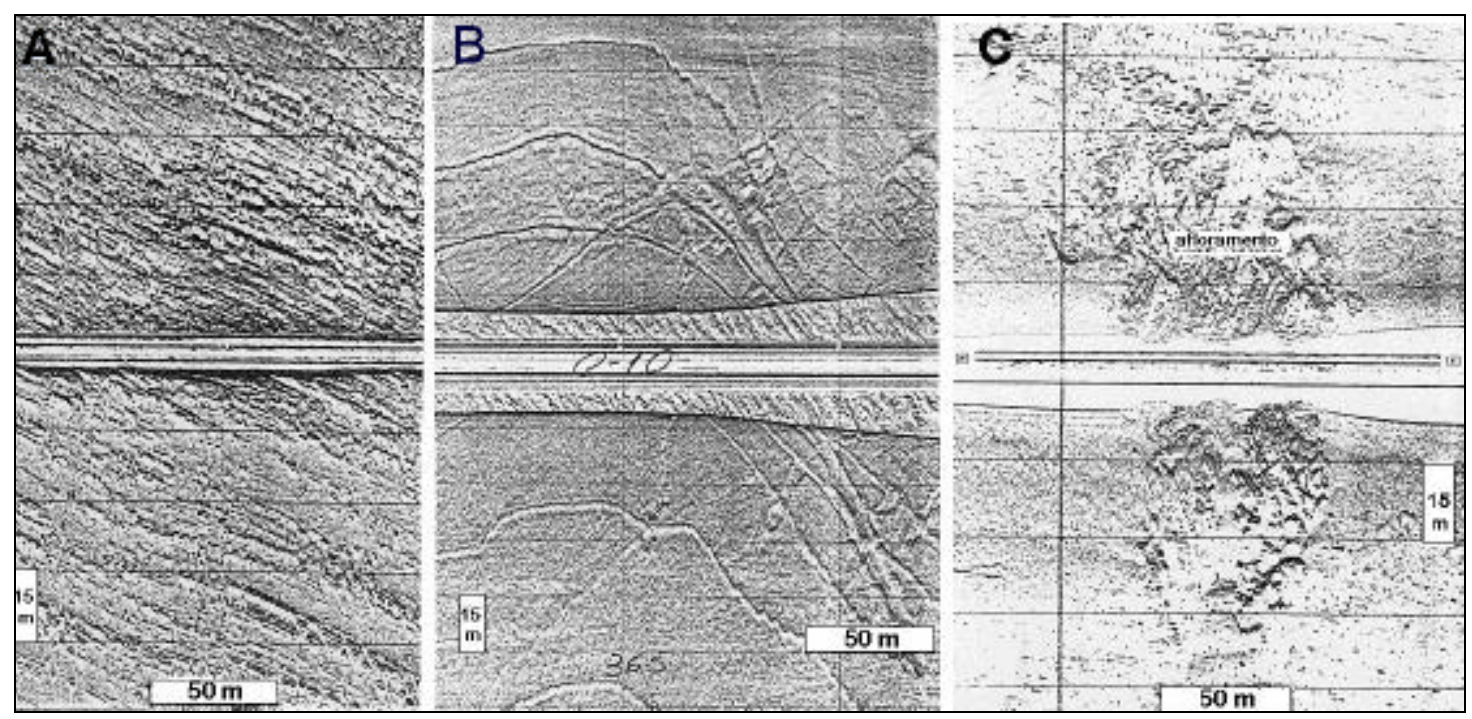

Figura 8.67: Registros obtidos através da sonografia ilustrando distintos padrões texturais de superfícies de fundo: a) textura rugosa representando o fundo rochoso (basalto) do reservatório Itaipu, PR (IPT, $1986 a)$; b) textura lisa e homogênea mostrando detalhes de feições interpretadas como antigas curvas de nível utilizadas nas plantações de algodão da região hoje coberta pelas águas do Reservatório Capivara, SP (IPT, 1992a,b); c) textura mista: na porção central a textura rugosa representa um afloramento de rocha alcalina no canal da Ilha Comprida, SP; a textura lisa e homogênea nas porções adjacentes ao afloramento rochoso é resultado da baixa refletividade dos sedimentos arenosos característicos do canal. (Suguio et al., 1987). 


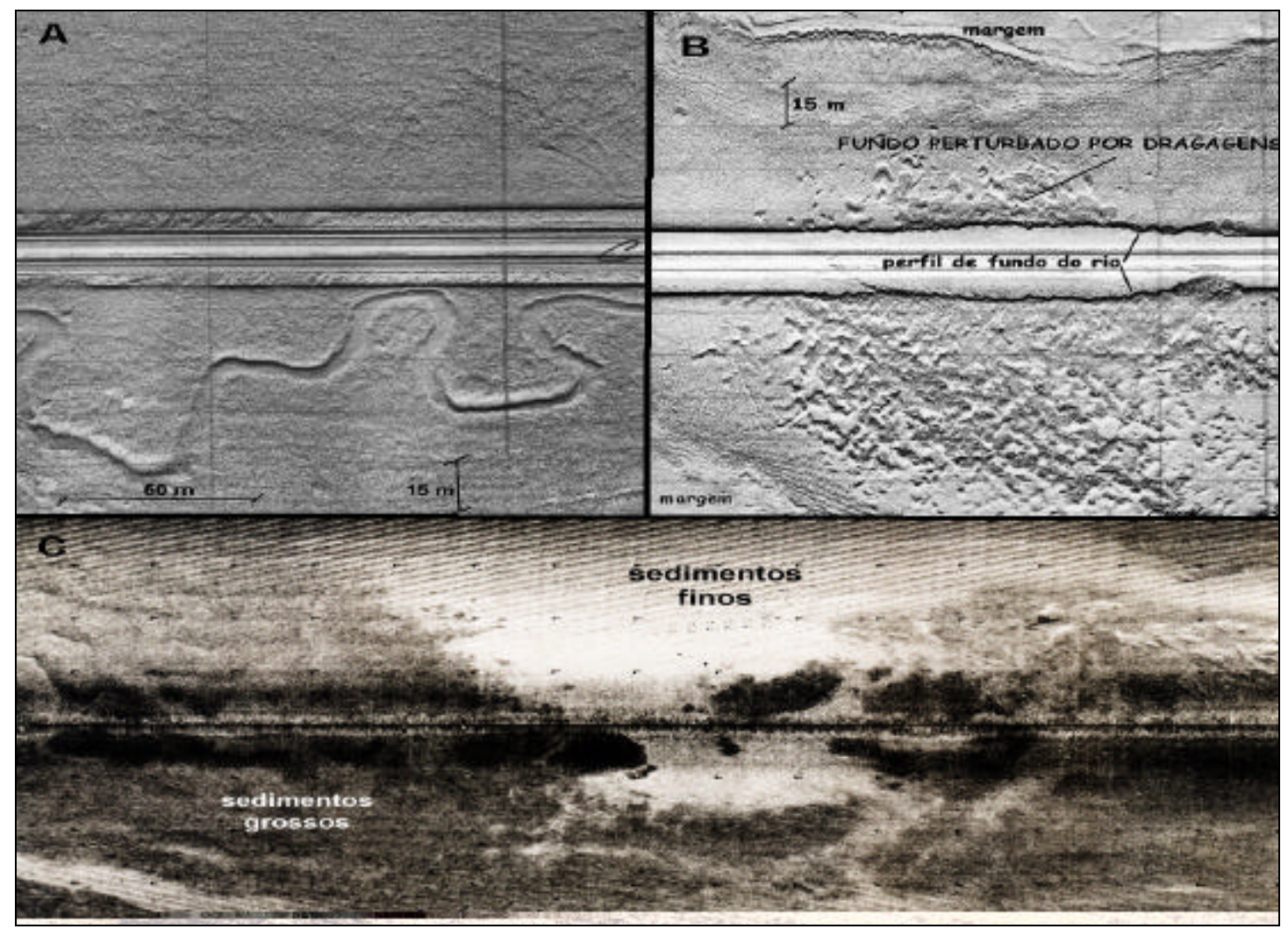

Figura 8.68: Imagens obtidas por meio do SVL ilustrando distintos padrões texturais de superfícies de fundo: a) superfície de fundo com textura lisa e homogênea mostrando canal antigo de rio, Reservatório Capivara, PR/SP (IPT, 1992a,b); b) registro obtido no rio Tietê, SP, mostrando contrastes texturais entre uma superfície lisa e homogênea (sedimentos) e uma superfície rugosa, neste caso correlacionada com superfície gerada a partir de atividades de dragagem do rio (IPT, 1998e); c) .texturas lisas e homogêneas, todavia diferenciadas em áreas claras e escuras, sendo as claras correlacionadas à ocorrência de sedimentos finos, as escuras, a sedimentos grossos (areias e cascalhos). A ratificação do padrão textural mostrado neste registro foi embasado também em fotografias submarinas e amostragens de sedimentos de fundos, com as análises sedimentológicas correspondentes (Souza, 1984).

Recentes avanços na tecnologia de interpretação de imagens obtidas com o sonar de varredura lateral apontam para o desenvolvimento de softwares para análise automática dos contrastes texturais (Preston et al. 2004).

A possibilidade da classificação automática dos contrastes texturais existentes nas imagens do sonar traz uma série de vantagens sobre o método convencional baseado na análise direta do observador (intérprete). Em levantamentos de larga escala, principalmente, quando grande quantidade de imagens é obtida, o árduo trabalho do intérprete, inevitavelmente com certa subjetividade, é substituído pela objetiva e consistente análise automática das imagens desenvolvida por softwares dedicados a esta tarefa.

Softwares devidamente calibrados detectam variações texturais que não seriam observadas pelo olho humano numa simples análise visual direta da imagem obtida. A Figura 8.69 mostra um exemplo de classificação automática de uma imagem de sonar 
onde cores são atribuídas a padrões texturais distintos durante a calibração do sistema o que permite a obtenção de mapas de caracterização de superfícies submersas com muito mais detalhe que aqueles gerados pelo método convencional da observação visual.

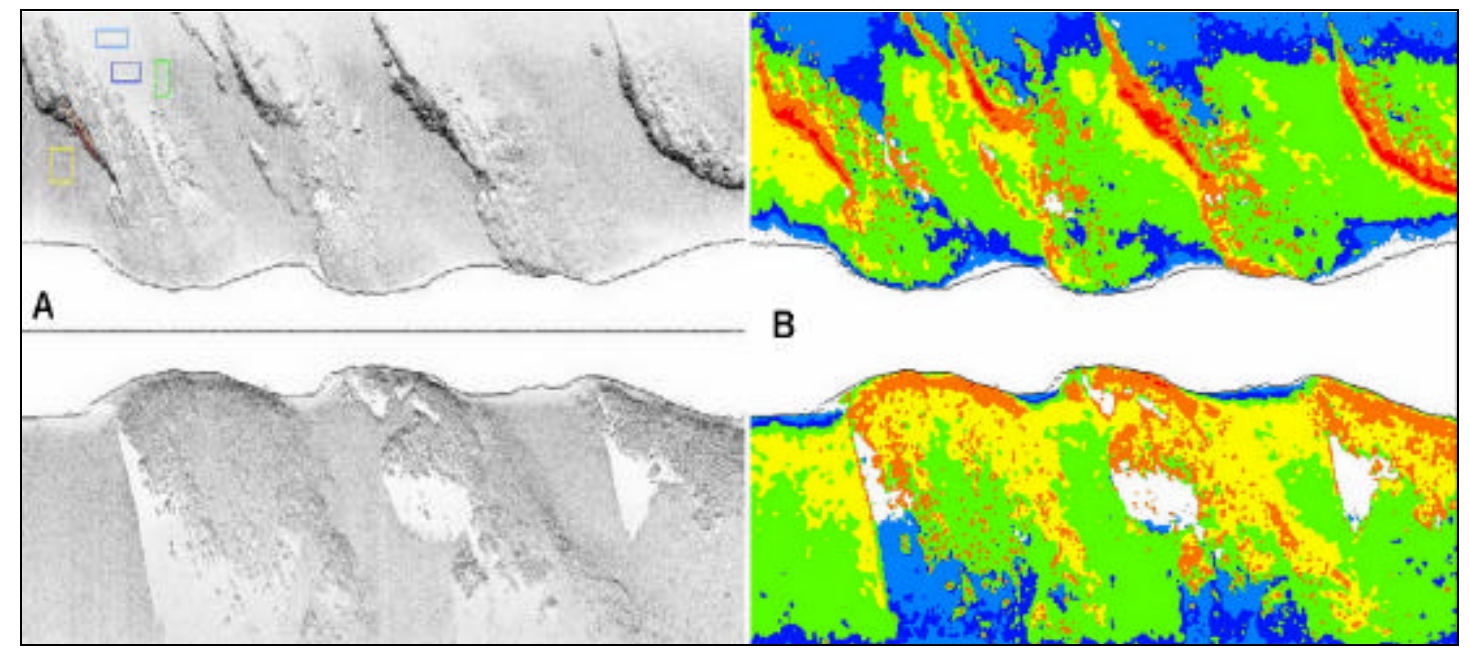

Figura 8.69: Exemplo de classificação automática de uma imagem de sonar onde cores são atribuídas a padrões texturais distintos o que permite a obtenção de mapas detalhados de caracterização de superfícies submersas: a) registro (imagem) original; b) imagem interpretada automaticamente. Geoacoustics (2001).

Outro aspecto extremamente relevante no processo de análise dos dados oriundos do sonar de varredura lateral é a possibilidade da justaposição lateral das imagens obtidas, criando-se, desta forma, um mosaico, analogamente ao processo de análise de fotografias aéreas. A geração destes mosaicos, hoje, totalmente automática, (por meio de softwares) permite uma visualização ampla do conjunto de dados obtidos, possibilitando a observação da consistência lateral das feições geológicas ou geotécnicas detectadas nas imagens analisadas individualmente (Figura 8.70). Souza (1984) e Lancker et al. (2004) mostram exemplos da importância da visualização ampla e conjunta das imagens obtidas a partir destes sistemas acústicos. Softwares desenvolvidos recentemente permitem, inclusive, a criação de mosaicos em tempo real, o que muito contribui para o incremento do desempenho deste método de investigação no estudo de áreas submersas.

Levando-se em conta que os sinais acústicos do sonar de varredura lateral não são emitidos verticalmente para baixo, mas, sim, com certo ângulo em relação ao plano horizontal da superfície, conforme mostrado na Figura 8.41, dados precisos de batimetria, ou seja, da espessura da coluna d'água, não podem ser obtidos diretamente dos registros. Assim, levantamentos com o sonar de varredura lateral são freqüentemente acompanhados por levantamentos simultâneos com ecobatímetros de precisão. 


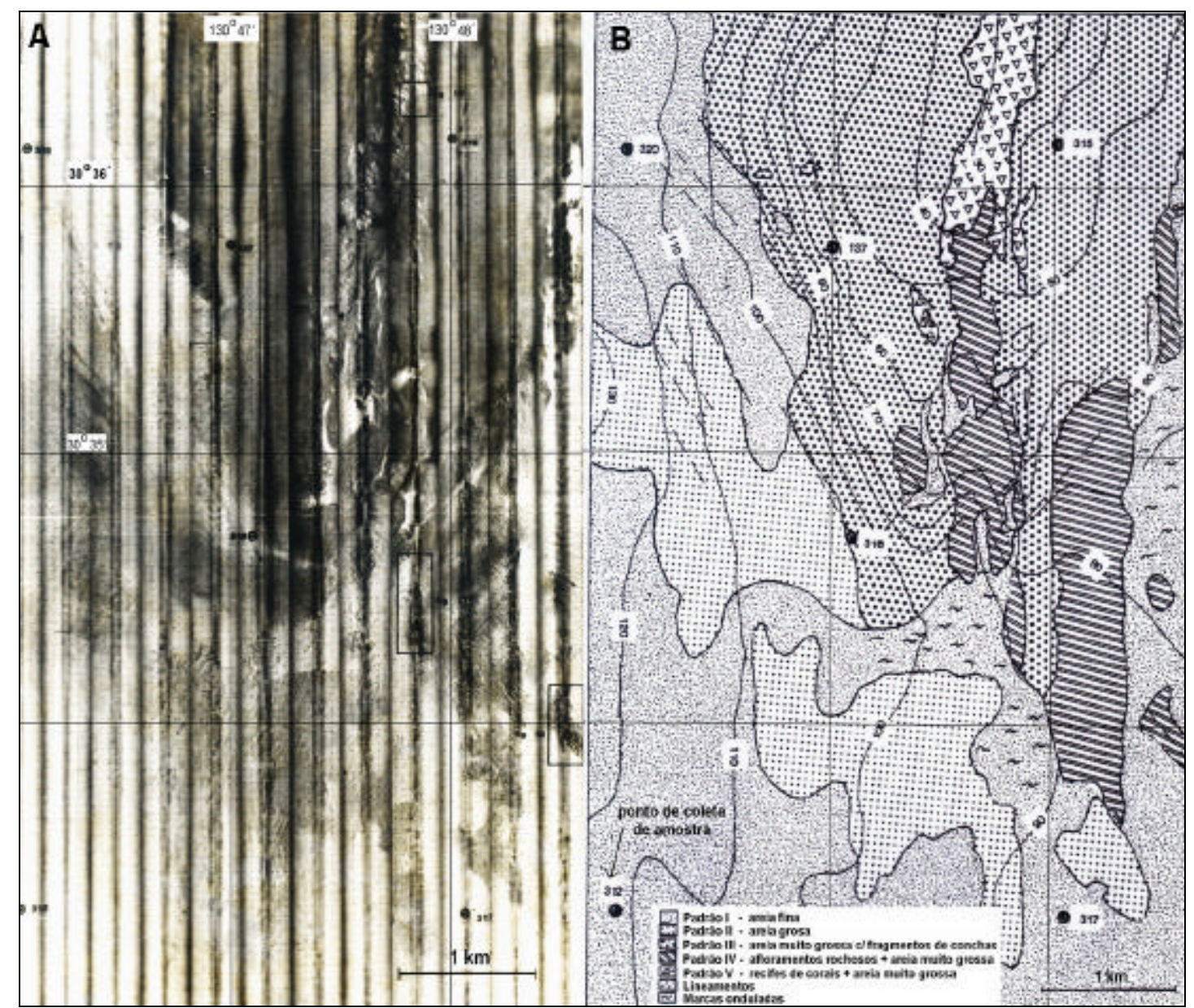

Figura 8.70: Exemplo de mosaico construído a partir da justaposição lateral de 12 perfis de sonar de varredura lateral obtidos na costa leste da Ilha de Tanegashima (sul do Japão) em área de aprox. de 7x3 km: a) images do sonar justapostas lateralmente compondo um mosaico; b) mapa de caracterização do fundo construído com base na interpretação do mosaico e dos resultados das análises sedimentológicas das amostras coletadas. Souza, 1984.

Uma opção muito apropriada para a obtenção simultânea de imagens da superfície de fundo com dados precisos da espessura da coluna d'água são os sistemas de varredura laterais compostos. Estes sofisticados equipamentos emitem simultaneamente, a partir de um arranjo de transdutores, vários feixes muito estreitos de sinais acústicos, em ângulos distintos, em relação à vertical. Cada feixe de sinais informa, separadamente e com precisão, a profundidade da coluna d'água em vários pontos ao longo de uma linha perpendicular à rota de navegação, com alcance lateral determinado pelo operador do sistema, e dependente de uma série de propriedades de cada sistema. Estes dados digitais são compilados e, em tempo real, obtém-se, uma imagem do sonar de varredura lateral e um mapa de contorno topográfico da superfície investigada. Trata-se de equipamentos de grande porte, altos preços e comumente utilizados na investigação de áreas profundas, que fogem, portanto, do escopo da abordagem deste trabalho. 


\subsubsection{A natureza da superfície de fundo}

Mesmo considerando a forma indireta, ou remota, de atuação dos métodos geofísicos para obtenção de informações da superfície de fundo, a batimetria e a sonografia têm muito a contribuir para a definição, não só da forma, mas também da natureza da superfície de fundo.

Algumas características observadas nos perfis acústicos oriundos de ecobatímetros, analisados em conjunto com os contrastes texturais observados nas imagens acústicas do sonar de varredura lateral, fornecem dados que permitem a caracterização da natureza da superfície de fundo principalmente quando correlacionados com outros dados, obtidos da observação direta (amostragens, sondagens, observações a partir de submersíveis, fotografias ou filmagens submarinas), executadas em segmentos da área de estudo, posicionados de forma estatisticamente representativa.

Este conjunto de informações fornecem subsídios ao desenvolvimento de análises que permitem concluir sobre a evolução dos processos geológicos, ou não, de atuação recente na superfície investigada, conseqüentemente contribuindo para o estabelecimento de um modelo de evolução geológica para a área investigada. As informações obtidas permitirão a elaboração de mapas de caracterização da superfície de fundo em escalas variáveis conforme interesses específicos.

\subsection{INVESTIGANDO A NATUREZA E A GEOMETRIA DOS ESTRATOS SEDIMENTARES}

Em determinados projetos de investigação, a morfologia e a natureza da superfície de fundo constituem-se em características que encerram em si próprias um volume de dados, necessários e suficientes, para alcançar os objetivos propostos, não havendo obrigatoriamente a necessidade do conhecimento da subsuperfície. Entretanto, não são raros os estudos de áreas submersas, em que informações de subsuperfície são fundamentais, ou seja, a identificação da natureza e da forma ou das dimensões (espessura, extensão, etc.) das camadas sedimentares e das estruturas geológicas subjacentes.

Existem vários métodos de obter informações sobre as camadas subjacentes à superfície de fundo em estudos de áreas submersas. Pelos métodos diretos, destaca-se basicamente a testemunhagem (coring), que permite observar as camadas mais 
superficiais, comumente da ordem de apenas alguns metros, e as sondagens (drilling), propriamente ditas, que são aquelas que possibilitam a investigação mais profunda, relacionadas com pesquisa de petróleo ou projetos de investigação marinha de grande porte.

Dados coletados por meio da testemunhagem representam pontualmente determinadas características de um meio geológico, contudo, trazem informações essenciais sobre o substrato próximo da superfície. Mesmo com a realização de diversas testemunhagens numa área de estudo, visando à ampla cobertura em área e, portanto, uma valorização da representatividade estatística dos dados, este método de coleta de dados possui limitações quanto ao alcance, já que comumente investigam profundidades de até entre 3 e $6 \mathrm{~m}$. Em condições muito favoráveis (sedimentos finos, lamosos), podem atingir 10-12 $\mathrm{m}$ de profundidade.

A sondagem profunda (drilling), por outro lado, resolve parcialmente esta questão, pois traz à luz informações das porções mais profundas. Todavia, considerando-se as dificuldades operacionais inerentes a este método de investigação (dificuldade de realizar sondagens em número estatisticamente representativo), o produto final da utilização deste instrumento de investigação constitui-se em informações pontuais que não possuem, naturalmente, a representatividade em área, desejada.

Os métodos geofísicos, em especial, os acústicos, cumprem importante papel na investigação de áreas submersas, pois, entre outras vantagens, tornam possível a correlação entre os dados, comumente pouco representativos em área, coletados por métodos diretos (testemunhagens e/ou sondagens), tornando-os, de certa forma, estatisticamente mais representativos. A partir da interpretação de dados geofísicos, é possível ainda o planejamento de forma otimizada, de novas operações de testemunhagens e/ou sondagens, agora com o foco mais dirigido.

São muitos os exemplos na literatura mostrando a grande aplicabilidade de métodos geofísicos na investigação das camadas sedimentares subjacentes às superfícies de fundo de áreas submersas.

Souza (1988), IPT (1979, 1986b, 1987, 1988) são exemplos de utilização de métodos geofísicos na investigação de áreas submersas, aplicados tanto na investigação geológica básica como aplicada, com ênfase neste último tema, tendo em vista a 
relevância das ferramentas geofísicas no subsídio de projetos de obras civis em áreas submersas, quando comumente a principal questão em pauta é "qual a profundidade do embasamento rochoso", pois é a partir da definição deste parâmetro que se dimensionam os principais parâmetros de um projeto.

Com estes mesmos objetivos, Gallea et al. (1989); e Orcioli \& Santarelli (1978), Sperle et al. (2003) e Dias \& Silva (2003) constituem-se em exemplos que ilustram a importância do uso de sistemas acústicos que penetram na superfície de fundo e possibilitam identificar a espessura e a morfologia das camadas sedimentares subjacentes, subsidiando, assim, soluções em várias questões de engenharia ou de mapeamento geológico básico.

Estes autores apresentaram exemplos de uso destas ferramentas de investigação em estudos de áreas submersas rasas, para caracterização da estratigrafia rasa, determinação de níveis de assoreamento, prospecção de material de construção (jazidas de areia), e também como auxílio para projetos de instalação de obras civis, como pontes, barragens, marinas, metrô submarino e operações de dragagem. Apontaram ainda modelos de aplicação destas ferramentas de investigação em águas mais profundas, neste caso, no estudo da estabilidade das camadas de sedimentos na plataforma continental externa e talude continental, visando basicamente subsidiar estudos para a instalação de estruturas de prospecção e produção de petróleo.

$\mathrm{Na}$ investigação de assoreamento de reservatórios, analisaram dados geofísicos obtidos nos ensaios de perfilagem sísmica contínua, utilizados no reservatório Guarapiranga, na cidade de São Paulo, e concluíram pelo descarte da possibilidade do aproveitamento econômico dos sedimentos arenosos e argilosos, por meio da mineração, diante da pequena espessura dos depósitos sedimentares identificados (IPT, 1996; Mello et al., 1996 e Souza et al. (1997)).

Ainda no contexto da investigação de reservatórios em áreas urbanas, com vistas nos estudos de processos de assoreamento, bons modelos de aplicação de perfilagem sísmica, com excelentes resultados, são encontrados em Augusto Filho (1992), Souza et al. (2004), IPT (2003) e IPT (2004).

$\mathrm{Na}$ investigação geológica básica, são também muitos os exemplos em que a investigação das camadas sedimentares subjacentes, por meio de métodos geofísicos, contribuíram para a reconstituição da história geológica recente. Lessa et al. (2000), 
com base na análise de vários perfis sísmicos obtidos com um perfilador do tipo ELAC (Eletric Acoustic Profiler - $18 \mathrm{kHz}$ ), que permitiu a obtenção de dados de até $40 \mathrm{~m}$ de profundidade, analisaram a geologia de subsuperfície da Baía de Todos os Santos (BA) reavaliando todo o processo de sedimentação quaternária na área.

Kinoshita (1998, 1999, 2000) utiliza sísmica de reflexão de alta resolução (boomer) para mapear as seqüências sedimentares do quaternário superior da região do delta do rio Chao Phraya (Golfo da Tailândia). Os excelentes registros sísmicos obtidos por este autor permitiram a classificação e caracterização detalhada das unidades que compõem a coluna sedimentar rasa quaternária da área.

Mahiques \& Souza (1999), com base em perfis sísmicos obtidos de sistemas acústicos de perfilagem que utilizam fonte acústica do tipo boomer, estabeleceram uma relação entre unidades sísmicas rasas e variações do nível do mar no Quaternário, na região de Ubatuba, litoral norte do Estado de São Paulo. Na correlação dos dados de um testemunho de sondagem com a interpretação dos perfis sísmicos, estes autores identificaram quatro unidades sísmicas e as associaram diretamente a seqüências sedimentares de expressão regional, correspondentes a depósitos sedimentares do Pleistoceno Superior e Holoceno.

A intercalação de depósitos arenosos e argilosos é mapeada com detalhes por Carter \& Carter (1986), que utilizaram métodos sísmicos para estudar a evolução holocênica da plataforma continental oriental sul da Nova Zelândia. Os excelentes perfis sísmicos obtidos por meio do sistema Uniboom (boomer), associados a dados de amostras da superfície de fundo, a algumas sondagens do tipo piston-cores e também a perfis adicionais executados por perfiladores $3.5 \mathrm{kHz}$, permitiram a estes autores discutir em detalhe a evolução holocênica da plataforma continental interna daquela região, desde os últimos 10.000 anos.

Lima (2003) utilizou-se de informações de centenas de quilômetros de perfis batimétricos e de dados sísmicos de alta resolução obtidos por meio de perfiladores dos tipos $S B P-3.5 \mathrm{kHz}$ e perfiladores do tipo airgun, para estudar os mecanismos de formação de corpos sedimentares profundos e suas inter-relações, na margem continental Sudeste-Sul do Brasil, e bacia oceânica adjacente, para reconstruir a história da sedimentação na bacia durante o Cenozóico. 
A partir da análise destes dados, a autora mapeou a coluna sedimentar cenozóica identificando contatos concordantes e discordantes entre as formações e localizando os depocentros das formações identificadas. Com os mesmos objetivos, a autora ainda analisou dados obtidos de sonar de varredura lateral nos quais identificou alinhamentos de corais de águas profundas $(550-800 \mathrm{~m})$ ao longo de mais de $40 \mathrm{~km}$ de extensão. Tais dados contribuíram para a melhor compreensão dos processos sedimentares atuantes na área investigada.

Silva et al. (2000) utilizou sísmica de alta resolução para mapear depósitos litoclásticos marinhos de origem continental, relacionados com episódios de nível do mar mais baixo, retrabalhados pela ação conjunta das ondas e de correntes marinhas, durante eventos de elevação do nível do mar, na plataforma continental dos Estados Unidos. Os registros sísmicos obtidos por estes autores identificaram contatos erosivos discordantes entre as camadas de sedimentos e paleocanais preenchidos por areias modernas, que se constituíram em importantes subsídios técnicos a estudos de fontes de materiais para insumos industriais e também para projetos de engenharia costeira, principalmente projetos de regeneração de praias erodidas.

Silva (2000) ressaltou também a relevância dos métodos geofísicos na determinação da espessura dos estratos sedimentares e para a visualização dos contatos entre as superfícies de discordância e das irregularidades do fundo e subfundo marinho com vistas na exploração mineral. Este autor ressaltou ainda a necessidade de investimento do país na investigação de placeres marinhos, tendo em vista que em muitos países estes depósitos já se constituem em fonte principal de alguns recursos minerais (ilmenita, rutilo, zircão, cassiterita, ouro e diamantes), ante o inevitável esgotamento das reservas continentais.

Lowag (2000), por meio da perfilagem sísmica contínua, utilizando fonte acústica do tipo paramétrica, mapeou, em baía próxima à costa na Índia (Mar da Arábia), áreas de empréstimo obtendo, com a aplicação deste método, excelentes seções sísmicas que permitiram identificar os contatos entre os estratos sedimentares e os contatos com o embasamento cristalino na área, propiciando o desenvolvimento dos cálculos necessários à determinação dos volumes dos depósitos arenosos disponíveis na área.

Outros exemplos de utilização deste mesmo sistema sísmico (fontes paramétricas) com objetivo de penetrar através de camadas sedimentares para 
basicamente subsidiar cálculos de volume de sedimentos em projetos de dragagem ou em projetos de prospecção de materiais (comumente areias), podem ser vistos em Wunderlich \& Muller (2003); Wunderlich et al. (2004); Wunderlich \& Went (2004) e Wunderlich et al. (2005);

Gokasan et al. (2005) executaram uma série de perfis sísmicos, utilizando o sistema Uniboom, no estreito de Istambul na Turquia, canal que liga o mar Mediterrâneo ao mar Negro, obtendo registros de excelente qualidade, que permitiram aos autores reconstituir toda a história geológica recente do canal.

A partir da identificação, nos registros sísmicos, de diferentes unidades estratigráficas, separadas por contatos discordantes, que representam os diferentes estágios evolutivos da região desde o começo do Holoceno, foi possível aos autores reconstituir a história dos processos sedimentares atuantes no canal, como conseqüência das variações diferenciais do nível do mar para ambos os mares, inicialmente não conectados. Além da perfilagem sísmica por meio do boomer, estes autores ainda utilizaram um sistema batimétrico multifeixe que permitiu o modelamento, em três dimensões, da complexa morfologia da superfície de fundo do canal.

Lobo et al. (2002) interpretaram dezenas de quilômetros de perfis sísmicos de alta resolução (sistema Uniboom, da Geopulse) realizados no golfo de Cádiz, na plataforma continental de Portugal, identificando seqüências estratigráficas (unidades sísmicas), de mais de $100 \mathrm{~m}$ de espessura, e feições de escavação e preenchimento, entre outras estruturas sedimentares, que permitiram aos autores melhor compreenderem a evolução dos processos sedimentares atuantes durante o Quaternário daquela região, no contexto das variações locais do nível do mar neste período.

Perfilador sísmico com fonte acústica do tipo minisparker $(300 \mathrm{~J} / 500-1500 \mathrm{~Hz})$ foi utilizado por Barnhart et al. (2005), para estudar as relações entre as variações do nível mar e o desenvolvimento dos extensos bancos de recifes de corais na região das principais ilhas havaianas. Além de ratificarem a grande aplicação deste método geofísico em investigações desta natureza, os excelentes registros sísmicos obtidos permitiram ainda que estes autores tecessem considerações sobre a evolução dos processos geológicos na área durante o Quaternário, pois, além de mapearem a distribuição superficial das feições recifais, identificaram também estruturas internas dos corpos recifais antigos, sobrepostas por uma coluna sedimentar de mais de $20 \mathrm{~m}$ de espessura. 
Murakami et al. (2004) utilizaram perfilagem sísmica contínua (sparker e boomer) para investigar sedimentos pleistocênicos e holocênicos ao longo dos canais principais do delta do rio Mekong, Vietnam. Centenas de quilômetros de perfis sísmicos foram realizados, o que permitiu mapear a espessura dos pacotes sedimentares, bem como identificar a profundidade do embasamento rochoso na área.

Garcia-Garcia et al. (2005) executaram dezenas de quilômetros de perfis sísmicos de alta resolução (boomer / monocanal) para mapear, em detalhe, o quaternário costeiro do noroeste da Espanha (Ría de Vigo). Associando os resultados da interpretação dos excelentes registros sísmicos obtidos, com dados de sondagens (análises sedimentológicas e datações) e com imagens de sonar de varredura lateral, estes autores identificaram a profundidade do embasamento rochoso, e cinco unidades sedimentares, constituindo desta forma um conjunto de dados que contribuíram para a elaboração do modelo sismo-estratigráfico para a área, diretamente correlacionado às variações do nível do mar nos últimos 18-20 mil anos.

\subsubsection{ASPECTOS GERAIS DA INVESTIGAÇÃO DE SUBSUPERFÍCIE}

Tendo em vista a importância de se investigar a subsuperfície, seja para auxiliar projetos de geologia básica ou projetos de engenharia, desenvolveram-se vários sistemas acústicos de baixas freqüências, denominados perfiladores acústicos de subsuperfície. Estes sistemas emitem sinais acústicos que penetram através da superfície de fundo e, assim, detectam importantes características do substrato da área investigada. São vários os sistemas existentes, cada qual com funções específicas, para cada objeto de estudo: sistemas de baixa frequiência e alta energia são usados para investigação profunda; sistemas de alta frequiência e baixa energia, para investigação rasa.

São muitas as técnicas de perfilagem acústica e muitos os equipamentos disponíveis, entretanto, fontes acústicas de alta energia (sparkers, air-guns, waterguns) constituem-se em equipamentos de grande porte, utilizados na investigação profunda, relacionada geralmente com a prospecção de petróleo. A esse tipo de investigação estão comumente associados sistemas de recepção de sinais (hidrofones) multicanais, compostos de centenas de sensores distribuídos na superfície da água ao longo de vários quilômetros. O porte do conjunto de equipamentos envolvidos em investigações desta natureza exige embarcações de grande porte, característica que por si só limita sua utilização na investigação de águas rasas. 
Os sistemas de perfilagem sísmica na investigação de águas rasas são de pequeno porte, utilizam fontes acústicas de baixa energia, sensores (hidrofones) de apenas alguns metros e, portanto constituem um conjunto de instrumentos viáveis de ser transportados em embarcações de pequeno porte, possibilitando assim a execução de levantamentos em áreas com coluna d'água de espessura a partir de 2-3 metros.

\subsubsection{Perfilagem Sísmica Contínua}

O termo perfilagem sísmica contínua - PSC tem significado amplo no contexto da investigação acústica de áreas submersas. Sob esta nomenclatura, podem ser reunidos vários métodos sísmicos que tenham como objetivo penetrar na superfície de fundo, podendo ser incluídos sob esta denominação métodos que utilizam fontes acústicas de grande potência, como sparkers, air-guns e water-guns, de potências intermediárias, como minisparkers e boomers, como também perfiladores de baixa potência, do tipo SBP (Subbottom Profilers), chirp e sistemas paramétricos (Parasound Systems), entre outros.

Qualquer destes métodos têm base conceitual comum, pois se tratam de métodos indiretos de investigação que se utilizam do princípio da propagação das ondas acústicas na água, explorando a existência de contrastes de impedância acústica entre os diferentes meios físicos subjacentes à superfície de fundo.

Ressalta-se que, por investigação rasa, entendem-se estudos cujos objetivos sejam a análise das primeiras dezenas de metros da coluna sedimentar, com profundidades de investigação comumente inferiores a $100 \mathrm{~m}$. Estudos profundos de bacias oceânicas, seja para subsidiar projetos de geologia básica (estratigrafia de bacias) ou para prospecção de hidrocarbonetos, utilizam equipamentos de maior porte que manipulam espectros de freqüências mais baixos.

\subsubsection{Aquisição de dados}

O levantamento geofísico de áreas submersas tem, entre outras propriedades, a vantagem de poder ser executado a partir de uma embarcação que se desloca de forma contínua e livre sobre a superfície da água, ao contrário da investigação geofísica em terra, onde é inerente a existência de obstáculos, naturais ou não, ao progresso contínuo da aquisição de dados.

Assim, a depender dos interesses específicos de cada projeto de estudos, uma velocidade de navegação para aquisição de dados deve ser estabelecida para garantir 
que a área de estudo possa ser coberta devida e rapidamente, assegurando a qualidade dos dados (a velocidade de navegação influi na qualidade dos dados), bem como o nível de detalhamento compatível com a escala desejada. Em áreas restritas, como plataforma continental interna, lagos, reservatórios e rios, comumente se desenvolvem levantamentos geofísicos de forma a cobrir $100 \%$ da superfície de interesse. Entretanto, quando o interesse é mais amplo, a distribuição dos perfis é realizada para privilegiar uma caracterização geral, em sacrifício de detalhamento local.

A Figura 8.71 ilustra, a título de exemplo, a distribuição de perfis em áreas de estudo com escalas de abordagem distintas e com objetivos específicos, aspectos que sempre deverá ser levado em consideração quando do planejamento de levantamentos. Uma essencial discussão sobre planejamento e distribuição de perfis sísmicos sobre uma área de investigação é desenvolvida em USACE (2004).

No caso de estudos detalhados de áreas restritas, pode ser muito interessante que vários perfis sejam realizados paralela e proximamente, pois as tecnologias atuais de tratamento e interpretação de dados permitem análises tridimensionais da área investigada, muito contribuindo para a melhor compreensão da geologia e dos processos sedimentares atuantes na área de estudo.

Observa-se ainda que, atualmente, sistemas digitais de aquisição de dados possibilitam a coleta e armazenamento de grandes volumes de dados, procedimento que favorece e facilita o manuseio dos dados, não só no seu posterior processamento (aplicação de filtros, ganhos do sinal etc.), mas também na utilização de diversas formas de apresentação dos resultados (mapas, visualização 3D, blocos-diagramas etc.).

O conjunto de equipamentos que compõe o sistema de aquisição de dados da perfilagem sísmica contínua (PSC) é composto basicamente de uma fonte repetitiva de sinais acústicos com características específicas para atuar na água (boomers, sparker, air-guns etc.) e de um sistema de recepção do sinal sísmico (hidrofones), ambos rebocados na superfície da água, conforme ilustrado na Figura 8.72 ou, em algumas situações, a depender do tipo de fonte acústica, mergulhados na coluna d'água a profundidades variáveis. Fazem parte também deste sistema equipamentos para gravação, armazenamento (quando do sinal digital), processamento e impressão dos dados, conjunto este que é instalado no interior da embarcação. 


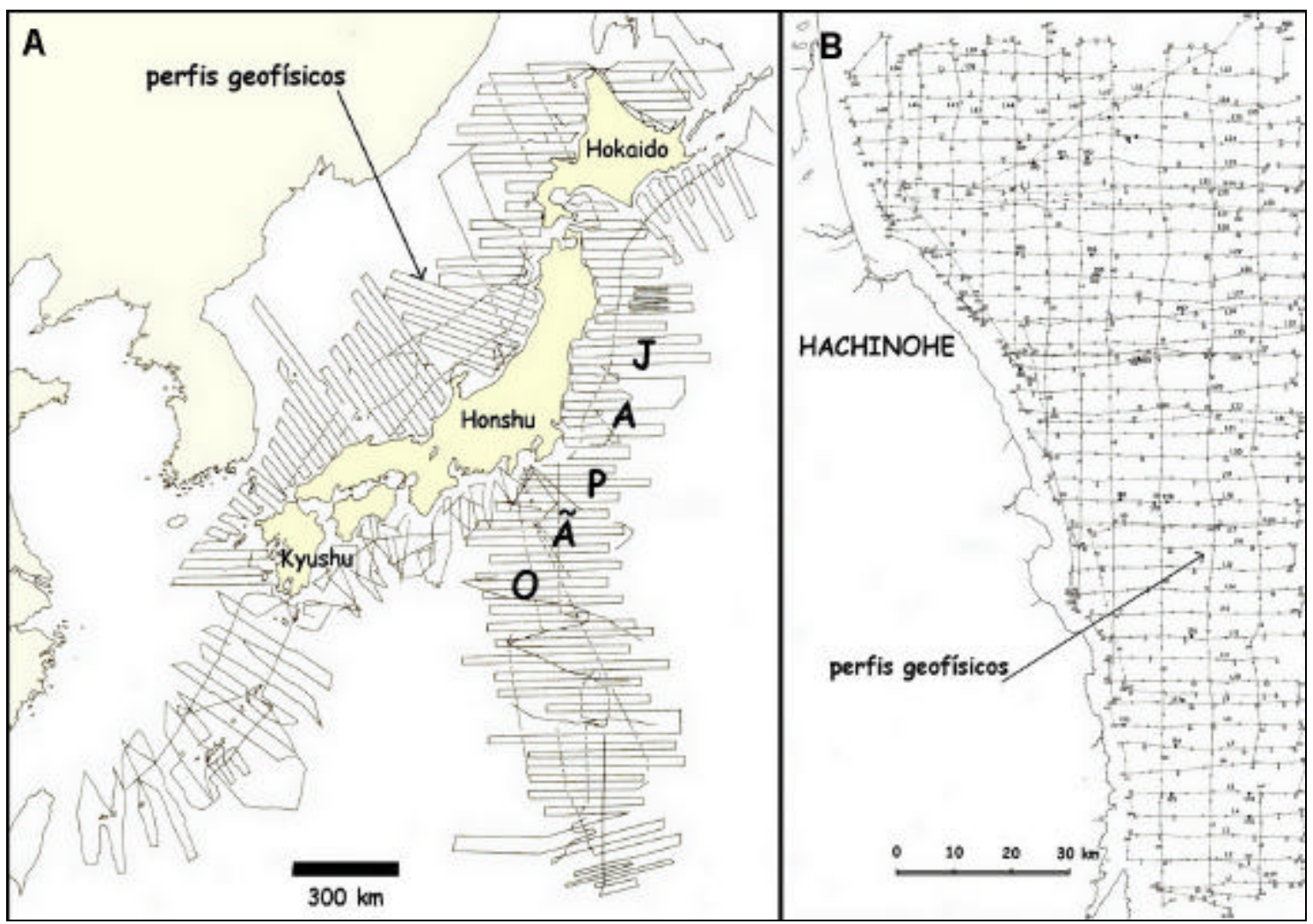

Figura 8.71: Exemplos de utilização da investigação geofísica em escalas distintas: a) distribuição de perfis sísmicos em grande escala - de reconhecimento - em estudo amplo das ilhas do Japão. Neste caso, milhares de quilômetros quadrados foram cobertos por levantamentos sísmicos (Unoue \& Honza, 1982); b) distribuição de perfis sísmicos em estudo de trecho restrito da costa Norte do Japão, no caso, a plataforma continental interna na região de Hachinohe (Tamaki, 1978).

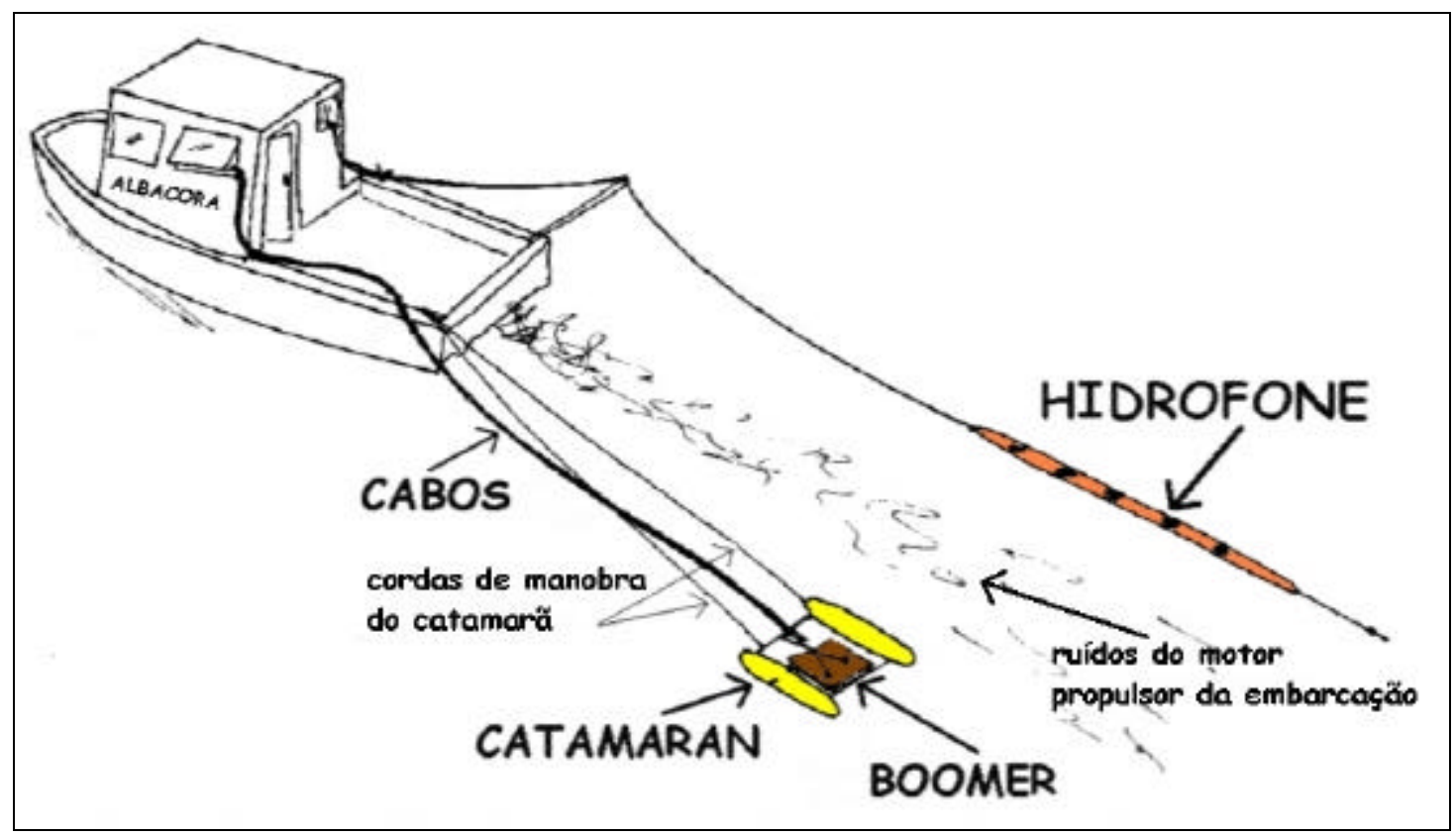

Figura 8.72: Ilustração mostrando uma das formas de rebocamento do sistema fonte-sensor na perfilagem sísmica contínua. Fonte acústica (boomer) e sensores (hidrofones) tracionados lateralmente à embarcação propiciam a obtenção de sinais de melhor qualidade, pois evitam-se desta forma os ruídos gerados pelo motor propulsor da embarcação. Modificado de Applied Acoustic Engineering (2005a). 


\subsubsection{O registro de campo e sua interpretação}

Uma importante vantagem na utilização de métodos sísmicos, em relação a outros métodos de investigação de áreas submersas, está associada à possibilidade da obtenção, em tempo real, no campo, de um registro sísmico que em muito se assemelha a uma seção geológica.

O registro obtido em campo apresenta-se na forma de uma seção em duas dimensões, que pode ser interpretada simplesmente traçando-se linhas sobre os principais refletores identificados. Refletores sísmicos são os elementos numa seção sísmica que simbolizam os fortes contrastes de impedância acústica detectados pelas ondas ao se propagarem através do meio, representando, portanto, os contatos entre meios geológicos com propriedades acústicas distintas. Quanto maior o contraste de impedância, ou seja, quanto maior o coeficiente de reflexão, maior será a nitidez com que será detectada a interface (o refletor) na seção obtida. Um exemplo bastante claro desta definição pode ser observado na seção sísmica ilustrada na Figura 8.73.

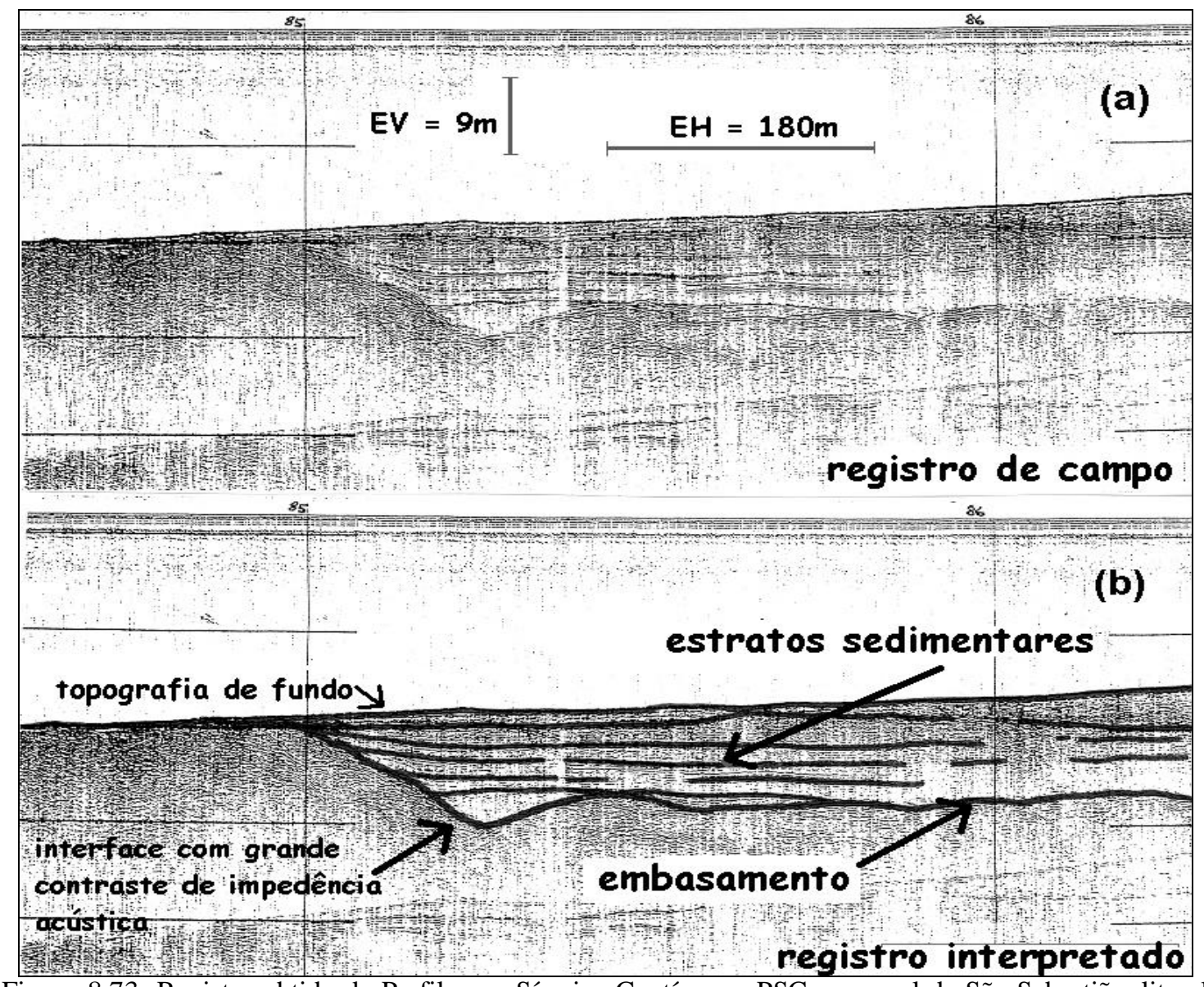

Figura 8.73: Registro obtido da Perfilagem Sísmica Contínua - PSC, no canal de São Sebastião, litoral norte do Estado de SP, utilizando fonte acústica do tipo boomer. Notar o forte contraste de impedância acústica representado pelo refletor, que evidencia de forma clara e inequívoca a interface embasamento estratos sedimentares: a) registro original de campo; b) registro interpretado. Modificado de Furtado et al. (2000). 
Quando da necessidade da definição dos contatos entre as camadas sedimentares sobre o embasamento, como no caso de estudos de seqüências estratigráficas, cuidados adicionais deverão ser tomados na análise do registro obtido, em especial, no traçado das linhas que representam os refletores ou as interfaces. Além do simples contato entre dois meios, estas interfaces ou refletores acústicos podem, em muitos casos, apresentar também propriedades correlacionáveis com a gênese dos estratos, pois registram de alguma maneira a história geológica da área, permitindo assim a reconstituição dos eventos geológicos ou dos processos sedimentares que determinaram aquela conformação, ou aquela geometria do pacote sedimentar.

No registro obtido em campo por meio da PSC, observam-se basicamente, as camadas atravessadas pelo sinal acústico, a saber, a coluna d'água, os estratos sedimentares inconsolidados e o embasamento acústico, que pode ser entendido como o limite de penetração do sinal sísmico. Este limite é devido ao tipo de sinal emitido (espectro de frequiências e energia) e ao tipo de material que compõe o substrato da área investigada. Sinais de baixa frequiência contribuirão para maior penetração do sinal, em detrimento da resolução. O contrário ocorre quando da emissão de sinais de alta freqüência, que possibilitam maior resolução e melhor definição dos estratos sedimentares de pequena espessura (centimétricos), com prejuízo da penetrabilidade do sinal.

Na Figura 8.74, observam-se nos registros obtidos em campo, refletores sísmicos, objeto principal da investigação, e linhas horizontais e verticais que estão relacionadas com o sistema de posicionamento utilizado e que permitirão, na etapa seguinte, de interpretação dos registros, a compreensão das escalas (vertical e horizontal), bem como da localização dos perfis em mapas.

Por mais claros e evidentes que estejam identificados os refletores sísmicos, e portanto as camadas sedimentares, sempre se farão necessárias sondagens ao longo de um perfil sísmico, para viabilizar a correlação direta entre as informações detectadas no perfil com as descrições das sondagens, o que possibilitará, na interpretação final dos dados, a correlação espacial e temporal entre os refletores. Eventuais detalhes identificados em algum nível nos materiais recuperados das sondagens, como microfósseis, concentração de minerais pesados etc., podem ainda permitir a correlação direta de um determinado refletor com algum importante evento geológico na área, 
tornando este refletor um marcador, ou seja, uma espécie de cronorefletor, o que contribui efetivamente em estudos de reconstituição paleoambiental.

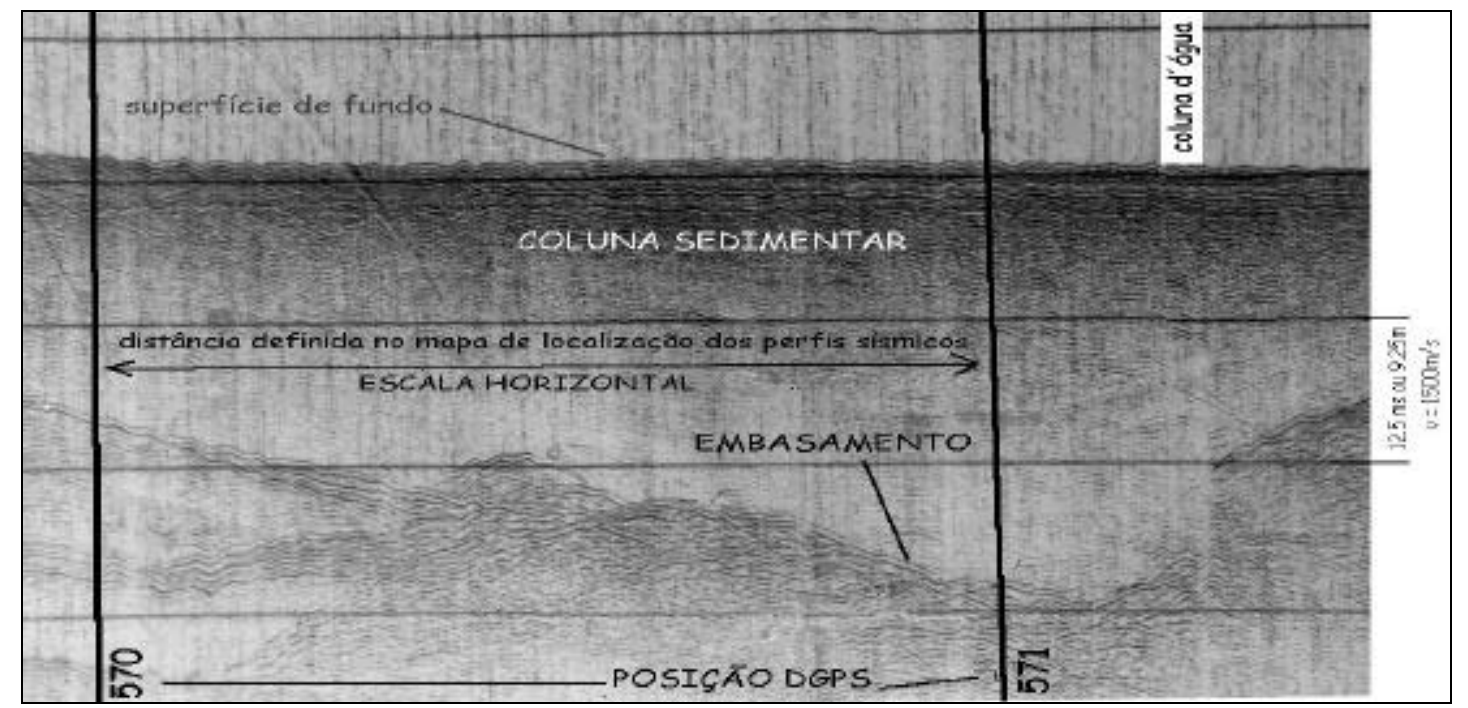

Figura 8.74: Registro analógico obtido da perfilagem sísmica contínua no canal da Ilha Anchieta, SP, com o perfilador modelo Hidrosonde M2A-Huntec utilizando fonte do tipo boomer $(5 \mathrm{KHz})$. Mahiques e Souza (1999).

\subsection{Escala Vertical - EV}

Ao se observarem os registros sísmicos, sempre se depara com perfis sobrelevados, ou seja, escalas diferentes medem a extensão do perfil e a profundidade investigada. O nível de sobrelevação de um perfil sísmico é dependente de vários fatores, a se destacar: a profundidade de investigação, a extensão do perfil, a velocidade da embarcação quando da aquisição dos dados, do tipo de fonte acústica (tipo de sinal) e do sistema de registro utilizado, entre outros. De qualquer forma, alguns aspectos relacionados com as escalas horizontais e verticais devem ser considerados.

$\mathrm{Na}$ investigação sísmica, a unidade de medida da espessura dos estratos sedimentares, ou da profundidade do topo do embasamento, é sempre o tempo: $\underline{\text { milissegundos, }}$ quando se trata da investigação rasa; segundos, no caso da investigação profunda.

O tempo medido ou lido num registro sísmico representa o intervalo de tempo do percurso do sinal acústico entre a fonte, que comumente está na superfície da água, até cada um dos estratos sedimentares, e seu retorno ao sensor (hidrofone), que também está na superfície d'água. Este tempo de ida e retorno do sinal acústico é conhecido como tempo duplo de reflexão. Uma vez conhecida a velocidade de propagação das ondas acústicas nos diversos meios geológicos atravessados pelo sinal acústico, e o tempo gasto no percurso da propagação, obtém-se a distância percorrida pelo sinal, 
utilizando-se a equação básica de propagação do som: espaço $=$ velocidade $x$ tempo e, conseqüentemente, a profundidade ou espessura de cada um dos estratos observados nos registros sísmicos.

A velocidade de propagação das ondas acústicas em cada meio é relativamente complexa, na medida em que está condicionada por uma série de parâmetros, entre os quais se destacam: porosidade, cimentação, teor em água e matéria orgânica e tensão de confinamento (Sjogren, 1984). A presença de gás nos sedimentos também atua de modo a alterar, no caso para baixo, a velocidade das ondas acústicas nos sedimentos. Nesse caso, sendo o gás um fluido com módulo de compressão menor que o da água, sua presença, mesmo que em quantidades pequenas, torna-o importante elemento no cálculo dos parâmetros dos estratos sedimentares físicos (módulo de compressão etc.) fazendo com que a velocidade do som diminua.

Desta maneira, a variabilidade da velocidade de propagação do som, aumentando no sentido dos estratos mais profundos, faz com que a escala vertical, ou seja, a escala de profundidade no perfil sísmico, não seja linear, daí o motivo de uma seção sísmica ser comumente apresentada com sua escala vertical em tempo.

São várias as causas do aumento da velocidade de propagação da velocidade do som com a profundidade, destacando-se algumas: redução da porosidade dos sedimentos com a profundidade, devido ao aumento da pressão intragranular, aumento da temperatura com a profundidade e aumento da pressão hidrostática expulsando a água dos poros com conseqüente aumento da rigidez dos sedimentos, ou seja, aumento da coesão entre os grãos (Hamilton, 1979).

A determinação precisa da velocidade de propagação do som nas camadas sedimentares rasas pode ser feita a partir de ensaios sísmicos de refração, ou de transmissão direta entre furos de sondagem, ou ainda pela comparação direta entre dados de perfilagem sísmica contínua e dados de sondagens mecânicas ou de testemunhagens. Em levantamentos geofísicos de águas profundas, utilizando-se métodos sísmicos multicanal, a velocidade dos pacotes sedimentares é subproduto do processamento dos dados.

Macedo et al. (2005) desenvolveram método de medição de velocidade de propagação das ondas acústicas em testemunhos de sondagem comparando os 
resultados com os parâmetros sedimentológicos oriundos da análise do próprio testemunho, encontrando valores muito similares aos descritos na literatura.

Hamilton $(1979,1980)$ fez relevante revisão sobre este tema, ressaltando a importância de conhecer em detalhe os fenômenos relativos à propagação do som através da coluna sedimentar, pois a velocidade de propagação das ondas acústicas nos sedimentos constitui-se num dos parâmetros principais responsáveis pela elaboração do modelo geológico da área em estudo, pois é a partir dela que se determina a espessura dos pacotes sedimentares.

Tendo em vista a comum dificuldade em desenvolver ensaios apropriados e exclusivos, em cada área de estudo, para a determinação da velocidade de propagação do som nos sedimentos, ocorre que, ao estabelecer os modelos para uma determinada área, se extrapolam os valores encontrados em outras áreas com propriedades físicas (sedimentares) semelhantes. No caso de estudos de áreas rasas (camadas sedimentares de poucas dezenas de metros de espessura), o interesse está em determinar o comportamento das ondas acústicas de alta freqüência. Ao contrário, o comportamento de baixas freqüências está relacionado com a investigação das profundas (centenas de metros) camadas sedimentares, inclusive da velocidade de propagação das ondas acústicas nas rochas consolidadas, que é muito maior que nas primeiras camadas sedimentares.

Comumente, na prática da investigação das camadas superficiais de sedimentos, assumem-se valores entre 1450 e $1550 \mathrm{~m} / \mathrm{s}$ para a velocidade do som na água (variáveis principalmente em função da pressão, temperatura e salinidade) e entre 1400 e $1700 \mathrm{~m} / \mathrm{s}$ (variáveis conforme descrito acima) para velocidade de propagação nos sedimentos rasos inconsolidados. Estes valores são assumidos levando-se em consideração informações da literatura (Houtz, 1973, 1977, 1981; Gibbs, 1974 e Hamilton, 1979, 1980) e também experiências do autor em projetos em que ocorreram oportunidades de se efetuar correlações diretas de dados sísmicos com sondagens mecânicas de um mesmo local de estudo.

\subsection{Escala Horizontal - EH}

A escala horizontal do registro sísmico depende basicamente da velocidade da embarcação durante a aquisição de dados. Quanto mais rápido esta se move, maior será o trecho do fundo representado num mesmo intervalo horizontal do registro e, portanto, 
menor a escala de levantamento. Durante a execução de um perfil sísmico, procura-se manter a embarcação em velocidade constante, para se evitar maior complexidade na determinação da escala horizontal.

Os sistemas analógicos mais modernos já permitem que o sistema de posicionamento tenha controle total da velocidade dos mecanismos de impressão do registrador, fazendo com que a escala do registro impresso seja homogênea ao longo de um perfil. Atualmente, os sistemas digitais de aquisição de dados são ainda mais sofisticados, pois, diretamente conectados aos equipamentos de posicionamento da embarcação, tornam viável o controle total das escalas das imagens, tanto na direção paralela quanto perpendicular à rota de navegação.

\subsection{OUTROS MÉTODOS GEOFÍSICOS EMPREGADOS NO ESTUDO DE ÁREAS SUBMERSAS}

Apesar do excelente desempenho, já consagrado na literatura, do uso dos métodos sísmicos (principalmente reflexão) na investigação de áreas submersas, outros métodos geofísicos são também empregados na investigação de ambientes subaquáticos.

As propriedades magnéticas dos diversos materiais que compõem a crosta terrestre alteram localmente o campo magnético terrestre, e as variações decorrentes são identificadas pelo método geofísico denominado magnetometria. Este método geofísico, quando utilizado na investigação de áreas submersas, constitui-se num excelente instrumento que, medindo na superfície as variações do campo magnético da Terra, conseqüência da presença de materiais com distintas propriedades magnéticas, permite mapear as ocorrências de intrusões ígneas, placeres de minerais metálicos, estruturas geológicas (falhas, lineamentos), além de subsidiar operações para localização de tubulações metálicas enterradas, de naufrágios etc.

A medição das propriedades geoelétricas (a se destacar a resistividade), das rochas e dos sedimentos constitui-se também num método geofísico de investigação de áreas submersas, com resultados muito expressivos, principalmente com relação à caracterização qualitativa dos meios geológicos subjacentes. Os contrastes identificados nas medidas desta importante propriedade elétrica dos materiais terrestres possibilitam a identificação de contatos entre os estratos e destes com o embasamento rochoso, da presença de estruturas geológicas, de corpos condutivos, entre várias outras características geológicas de interesse no estudo de áreas submersas. 
Mais recentemente, o método eletromagnético denominado GPR (ground penetrating radar ou radar de penetração do solo ou radar penetrante no solo), que utiliza ondas eletromagnéticas e que foi criado originalmente para a investigação em terra, tem sido também aplicado com sucesso na investigação de lagos e rios.

\subsubsection{ELETRORRESISTIVIDADE}

\subsubsection{Fundamentos}

Os contrastes existentes entre as várias propriedades geoelétricas das rochas, do solo, dos sedimentos e dos minerais tornam viável a utilização dos métodos geoelétricos como ferramenta de investigação geológica, com vasta aplicação em estudos envolvendo os temas mais variados.

Prospecção de águas subterrâneas, prospecção mineral, estudos de áreas cársticas, subsídios a projetos de engenharia na execução de grandes obras civis, estudo de áreas de risco, estudo de áreas para disposição de resíduos e mapeamento do contato entre água doce e água do mar nas áreas costeiras constituem alguns dos inúmeros temas para os quais muito contribui a identificação dos contrastes entre as propriedades elétricas dos meios geológicos envolvidos. São muitos os exemplos na literatura de aplicação de métodos elétricos na busca de soluções para questões relacionadas com estes temas: Ogilvy \& Bogoslovsky (1977), Gallas (1998), Gallas \& Augusto Filho (1999), Elis (1998), IPT (1993; 1998d,f; 1999c,d), Lima \& Porsani (1994), Cardarelli \& Filippo (2004) e Gallas et al., (2005).

A investigação geofísica por meio dos métodos geoelétricos envolve a detecção, na superfície dos terrenos, dos efeitos produzidos pelo fluxo de corrente elétrica em subsuperfície.

Dentre as principais propriedades elétricas empregadas na investigação geoelétrica, destaca-se a resistividade elétrica, que representa a dificuldade encontrada pela corrente elétrica para se propagar em um meio qualquer. Sua unidade de medida é ohm $\times m$.

Nas rochas, os mecanismos de propagação de corrente elétrica podem ser eletrônicos ou iônicos. No primeiro, ocorre transporte de elétrons na matriz da rocha e é governado pelo modo de agregação dos minerais e do grau de impurezas. No segundo, ocorre deslocamento de íons existentes na água contida nos poros e fissuras das rochas. Este segundo mecanismo é certamente o mais importante no contexto da investigação geoelétrica, pois a maioria das rochas é mal-condutora e, portanto, estas deveriam apresentar resistividades elétricas extremamente altas, não fosse pelo fato de que 
usualmente exibem poros preenchidos por água, o que faz com que se comportem como condutores eletrolíticos (Telford et al., 1976).

Outro fator que condiciona fortemente a resistividade elétrica de um meio é sua textura. Um arenito bem selecionado apresenta maior volume de espaços vazios para o armazenamento do eletrólito e, conseqüentemente, possui menor resistividade; ao contrário, menor porosidade significa maior resistividade.

A resistividade é uma das propriedades que mais variam para um mesmo material, pois são vários os fatores que a influenciam, a saber: conteúdo em água, em sais, porosidade, permeabilidade, conteúdo em argilas, temperatura (resistividade decresce com o aumento da temperatura) e a própria condutividade dos minerais. Uma aproximação com relação à ordem de grandeza da variação deste parâmetro para alguns materiais mais comuns na natureza pode ser observada na Tabela 8-4.

De maneira geral, materiais de baixa porosidade como, por exemplo, folhelhos maciços, rochas ígneas e metamórficas tenderão a exibir altas resistividades, assim como sedimentos secos, como areias e cascalhos ou materiais com poros preenchidos com água (livre de sais dissolvidos). Por outro lado, sedimentos ou rochas saturadas (com sais dissolvidos), ou com a presença de minerais argilosos, tenderão a possuir resistividade intermediária ou baixa, a depender do conteúdo em argilo-minerais (Gallas, 2000).

\begin{tabular}{|l|c|}
\hline \multicolumn{1}{|c|}{ MATERIAL } & $\begin{array}{c}\text { resistividade } \\
\text { (ohm } \text { x m) }\end{array}$ \\
\hline água do solo & $1-100$ \\
\hline água da chuva & $30-1000$ \\
\hline água do mar & 0.2 \\
\hline gelo & $10^{5}-10^{8}$ \\
\hline granito & $2000-10.000$ \\
\hline gnaisse & $400-6000$ \\
\hline calcário & $500-3500$ \\
\hline arenito & $1000-4000$ \\
\hline Areia e cascalho secos & $800-5000$ \\
\hline Areia e cascalho saturados & $200-400$ \\
\hline areia com argila & $50-300$ \\
\hline camadas salinas / domos salinos & $>10.000$ \\
\hline areia de dunas & $6000-8000$ \\
\hline lixo doméstico & $12-30$ \\
\hline arenito & $1000-4000$ \\
\hline óleo usado & $150-700$ \\
\hline
\end{tabular}

Tabela 8-4: Valores de resistividade de materiais comuns na natureza. Fonte: Vogelsang (1995) e Gallas (2000). 
Os métodos utilizados atualmente para medição de parâmetros relacionados com fluxo de corrente elétrica nos meios podem ser subdivididos em dois grupos: aqueles que usam fontes naturais e os que usam fontes artificiais (induzidas).

O método geofísico da eletrorresistividade de interesse à discussão proposta neste trabalho emprega fonte artificial de corrente contínua (I) a qual é introduzida no solo por intermédio de um par de eletrodos denominados de A e B. A diferença de potencial $(\Delta \mathbf{V})$ que se estabelece em resposta à injeção desta corrente elétrica pode ser medida através de outros dois eletrodos, denominados $\mathbf{M}$ e $\mathbf{N}$, situados nas proximidades (Figura 8.75). Os parâmetros medidos permitem calcular a resistividade aparente $\left(\rho_{a}\right)$ do volume investigado (solo ou rocha) em subsuperfície através da expressão:

$\rho_{a}=K \cdot \frac{\Delta V}{I}$, onde $\mathbf{K}$ é o fator geométrico relacionado com disposição (geometria) dos quatro eletrodos A,B,M e $\mathbf{N}$ no momento da medida. As diferentes possibilidades de disposições geométricas dos eletrodos recebem o nome genérico de "arranjos", muitos destes comumente utilizados nos levantamentos de campo e recebendo denominações especiais: Schlumberger, Wenner, dipolo-dipolo, pólo-dipolo, pólo-pólo etc.

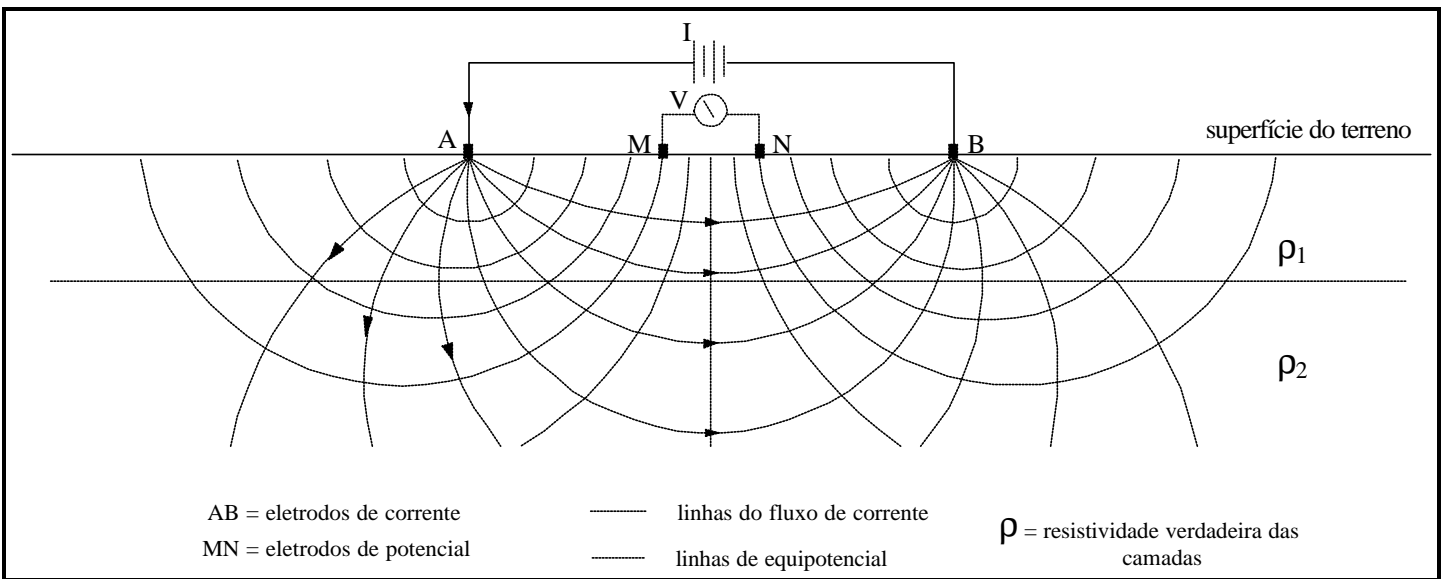

Figura 8.75: Princípio do método da eletrorresistividade. A e B representam pontos de injeção artificial no terreno da corrente elétrica (I); $\mathrm{M} \mathrm{e} \mathrm{N}$, pontos de leitura do potencial criado $(\Delta \mathrm{V})$, parâmetros estes que permitem calcular a resistividade real ou aparente do material (solo ou rocha) em subsuperfície. Fonte: geól. Regis G. Blanco (IPT).

As principais técnicas operacionais de medição do parâmetro resistividade elétrica dos terrenos são a sondagem elétrica vertical (SEV) e o caminhamento elétrico (CE). 


\subsubsection{Sondagem Elétrica Vertical (SEV)}

A aquisição de dados por meio da sondagem elétrica vertical (SEV) é realizada com arranjo de eletrodos, conforme ilustrado na Figura 8.75, e tem como objetivo o estudo da distribuição vertical (com a profundidade) do parâmetro resistividade elétrica. O melhor resultado da aplicação desta técnica sempre ocorrerá em terrenos lateralmente homogêneos compostos de camadas estratificadas plano-paralelas.

A SEV tem ocupado papel de relevância na Geologia de Engenharia, pois tem fornecido subsídios fundamentais em estudos de investigação de áreas para construção de grandes obras civis, como barragens, portos e túneis, já que permite mapear os contatos litológicos, identificar estruturas geológicas, profundidade do nível freático, entre outras características geológicas de interesse a estes projetos. No campo dos problemas ambientais, a SEV desempenha papel preponderante, na medida em que auxilia estudos de monitoramento ambiental em áreas contaminadas, por exemplo, na escolha de locais para instalação de aterros sanitários.

A SEV mede o parâmetro resistividade elétrica a partir de uma corrente I, que é enviada entre os eletrodos $\mathbf{A B}$ fixados na superfície do terreno (Figura 8.75). Entre os eletrodos $\mathbf{M N}$, é medida a diferença de potencial resultante $(\Delta \mathbf{V})$. A resistividade elétrica medida é denominada resistividade aparente ( $\rho \mathbf{a})$ porque representa a resistividade de todo o volume de material, entre a superfície e o ponto investigado, e é dada por $\rho \mathbf{a}=\mathbf{K} \Delta \mathbf{V} / \mathbf{I}$ (onde $\boldsymbol{K}$ é um fator geométrico relacionado com o espaçamento entre os eletrodos).

Aumentando-se a distância entre os eletrodos de corrente (AB), o volume total da subsuperfície incluída na medida também aumenta, permitindo alcançar camadas cada vez mais profundas.

\subsubsection{Caminhamento Elétrico (CE)}

Outra forma de se medir o parâmetro resistividade elétrica de um meio é através do caminhamento elétrico (CE), que, analogamente à SEV, também mede este parâmetro a partir de uma corrente $\mathbf{I}$ que é injetada entre os eletrodos $\mathbf{A B}$ na superfície do terreno, gerando uma diferença de potencial $(\Delta \mathbf{V})$ que é lido entre os eletrodos $\mathbf{M N}$. A diferença básica entre estas duas técnicas de medição do parâmetro resistividade está no arranjo dos eletrodos (Figura 8.76) e na forma como estes se deslocam ao longo do perfil. 


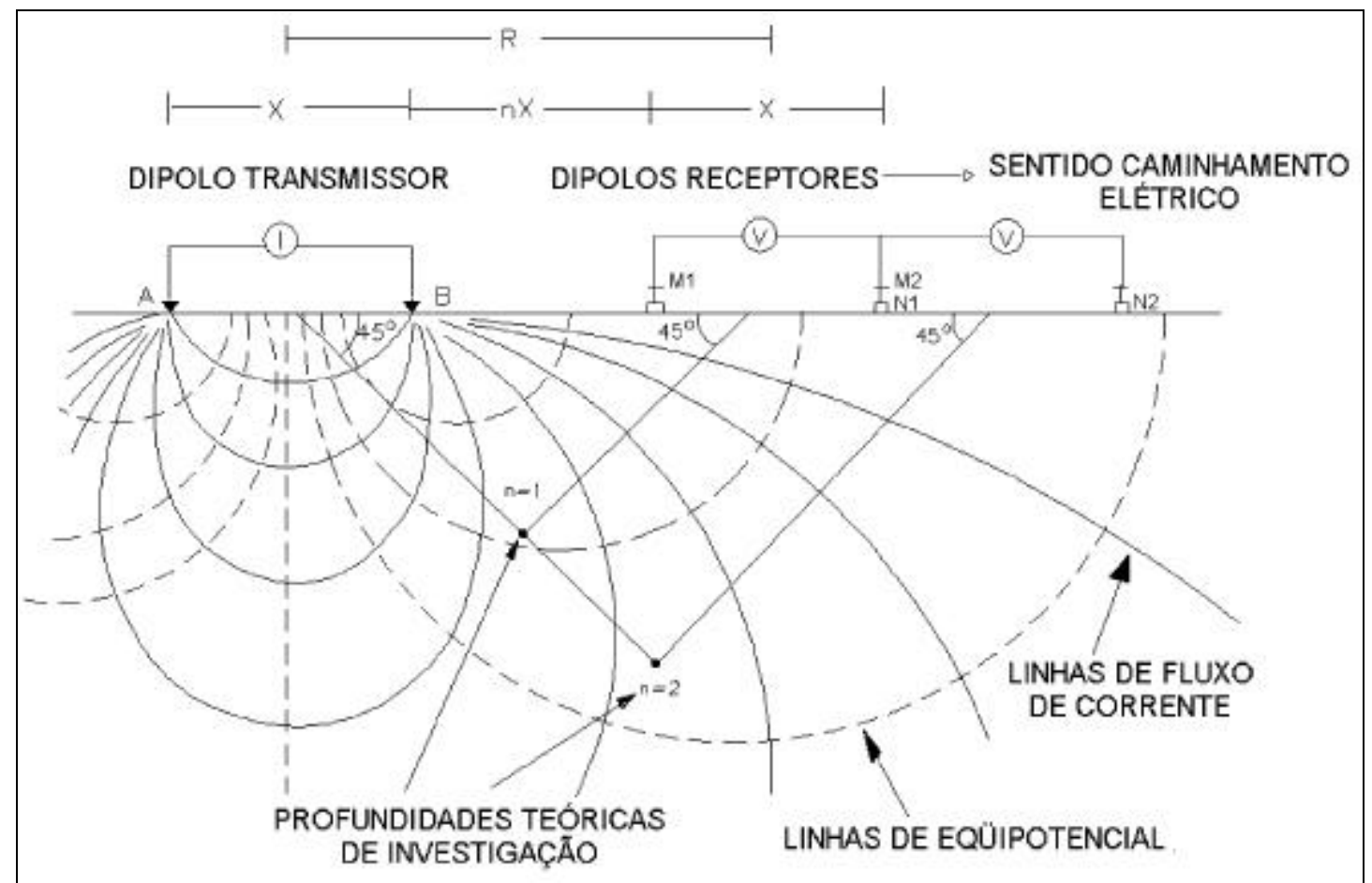

Figura 8.76: Geometria do arranjo de eletrodos para aquisição de dados no caminhamento elétrico. $\mathrm{AB}$ pontos de injeção de corrente; M1N1, M2N2... pontos de leitura da diferença de potencial gerada. Fonte: geól. Regis G. Blanco (IPT).

No caso do caminhamento elétrico, a aquisição de dados ocorre a partir do avanço lateral de todo o arranjo de eletrodos A-MN-B, ao longo do perfil. Desta forma, investiga-se uma ou mais profundidades, aproximadamente constantes, privilegiando a análise das variações laterais de resistividade aparente, diferentemente da variação vertical a partir de um mesmo ponto na superfície, analisada por meio da SEV, cuja aquisição de dados é feita apenas a partir do afastamento entre os eletrodos $\mathbf{A B}$, de injeção de corrente, mantendo-se fixa, até determinados limites, as posições dos eletrodos MN de leitura.

As variações da resistividade, observadas a partir do caminhamento elétrico, representam principalmente características geológicas de subsuperfície que se apresentem com heterogeneidades laterais ao longo do perfil investigado, tais como, contatos geológicos verticais ou inclinados, mineralizações, diques, fraturamentos, falhamentos, plumas de contaminação.

\subsubsection{Eletrorresistividade em áreas submersas}

Da mesma forma que em terra, medidas de parâmetros geoelétricos em áreas submersas trazem também à luz importantes informações sobre a geologia da área, pois muitos tipos de materiais que constituem a superfície e subsuperfície de fundo de áreas 
cobertas por água apresentam propriedades elétricas contrastantes o suficiente para que sejam detectados pelos métodos geofísicos denominados de geoelétricos.

No mar, por exemplo, zonas com fluidos hidrotermais, sulfetos polimetálicos ou depósitos de placeres oferecem baixa resistência ao fluxo de correntes elétricas e, a depender das características geoelétricas dos meios adjacentes, anomalias elétricas são geradas e, portanto, estes ambientes são identificáveis por meio dos métodos geofísicos que exploram justamente as propriedades elétricas dos meios geológicos, a se destacar, a resistividade.

A utilização dos métodos elétricos tem particular relevância na investigação de áreas submersas, quando se investigam corpos de pequeno volume, profundos ou com contrastes desprezíveis de densidade, de velocidade sísmica ou de magnetização, condições em que levantamentos sísmicos ou magnetométricos efetivamente não trazem soluções adequadas (Jones, 1999). Em regiões com coluna d'água inferior a 3 m (rios, plataforma continental interna), ou com a presença de sedimentos ricos em gás, a penetração dos sinais acústicos é também comprometida e, nestas situações, os métodos geoelétricos têm aplicação especial, pois comumente apontam informações de interesse, a despeito da complexa relação resistividade do sedimento $\mathrm{x}$ tipo de sedimento (Lavoie et al., 1987).

Lavoie et al. (1987) utilizaram com sucesso este método de investigação em estudos sedimentológicos e estratigráficos em área costeira do EUA. Associaram dados geoelétricos com informações de várias sondagens mecânicas realizadas na área, e com dados de perfilagem sísmica de alta resolução, obtendo alto grau de correlação entre estes dados, concluindo ser de valiosa importância os resultados obtidos, principalmente quando utilizado em áreas com âmina d'água menores que $3 \mathrm{~m}$, quando entram em cena as limitações dos métodos sísmicos.

Nebrija et al. (1976) utilizaram este método de investigação com objetivos de exploração mineral subaquática em ambiente de águas rasas no Lago Superior (EUA). Tomaram como base o fato de que depósitos de placeres metálicos geralmente têm menor resistividade elétrica que os materiais adjacentes (rochas ou sedimentos) e geram anomalias geoelétricas detectáveis em levantamentos geofísicos do tipo caminhamento elétrico. Assim, tracionando arranjos de eletrodos na superfície de fundo em áreas rasas do lago, mapearam com alta resolução as ocorrências de depósitos de minerais pesados, veios ricos em cobre e contatos litológicos. 
Baumgartner (1996) propôs um novo método para determinação da resistividade aparente das camadas sedimentares em áreas submersas. Baseado nos mesmos princípios discutidos nos itens anteriores, propôs arranjo de eletrodos na coluna d'água na posição vertical, ressaltando a especial vantagem deste arranjo sobre o convencional (na superfície) quando do estudo de áreas com coluna d'água maiores.

Souza \& Sampaio (2001) utilizaram métodos geoelétricos para avaliar a condutividade elétrica e parâmetros de polarização induzida na água do mar e nos sedimentos de fundo, estudando um ambiente de águas calmas e rasas (=10 $\mathrm{m}$ de profundidade) localizado próximo à Base Naval de Aratu, em Salvador, BA. Concluíram, a partir deste trabalho, sobre a grande aplicabilidade dos métodos geoelétricos em estudos de ambientes marinhos de águas rasas, principalmente para subsidiar projetos de engenharia costeira e os relacionados com questões ambientais.

\subsubsection{Aquisição de dados}

Os levantamentos de eletrorresistividade em água utilizam, de maneira geral, um cabo composto por um conjunto de eletrodos e um resistivímetro, equipamento que lê e registra os dados coletados.

Um par de eletrodos envia a corrente (I), enquanto os outros pares medem o potencial gerado pela passagem da corrente pelo meio.

Os resistivímetros utilizados na investigação de áreas submersas deverão possuir grande sensibilidade para leitura de diferenças de potencial, principalmente no caso de levantamentos no mar, já que neste ambiente a condutividade elétrica (água e sedimentos de fundo) é extremamente elevada, ou seja, a resistividade ( $\rho$ ) é muito baixa, o que requer uma capacidade do instrumento de registro de efetuar leituras de valores de diferença de potencial $(\Delta \mathbf{V})$ extremamente pequenos, da ordem de $\boldsymbol{\mu} \mathbf{V}$, o que significa pelo menos duas ordens de grandeza inferiores àqueles oriundos de levantamentos em água doce ou em terra.

Basicamente são duas formas de execução de um levantamento em água: com o cabo rebocado pela embarcação na superfície da água (ou próximo da), ou na superfície de fundo, em contado direto com os sedimentos de fundo.

A Figura 8.77 ilustra uma aquisição de forma contínua (caminhamento) com o cabo de eletrodos posicionado na superfície da água. Neste caso, o par de eletrodos (A e B) emite a corrente e o potencial é medido em um conjunto de nove eletrodos (P1 a P9) 
posicionados na superfície, configurando um arranjo do tipo dipolo-dipolo com oito níveis de investigação. O cabo é conectado ao sistema de aquisição (resistivímetro) que se encontra na embarcação. À medida que a embarcação avança, reboca um cabo com os eletrodos (comumente 9 ou 10), sempre totalmente submersos, responsáveis pela leitura dos potenciais. Dois eletrodos próximos da embarcação são usados para injeção de correntes, que ocorre comumente a intervalos pré-definidos (alguns segundos: 2 - 4 s). Os potenciais lidos, simultaneamente, nos eletrodos rebocados geram dados que vão sendo coletados e gravados num receptor central. A profundidade de penetração depende do comprimento do cabo e do tipo de arranjo, ou seja, da distância entre os dois eletrodos emissores (de corrente) e cada um dos eletrodos de leitura ao longo do cabo.

Geralmente, em águas rasas, um arranjo de eletrodos do tipo apresentado na Figura 8.77 permite penetrar na coluna d'água e nos sedimentos, o equivalente a $25 \%$ da extensão total do arranjo. Assim, utilizando-se, por exemplo, um cabo de 11 eletrodos espaçados de $3 \mathrm{~m}$, ou seja, um arranjo de extensão total de $30 \mathrm{~m}$, a máxima penetração esperada é 7,5 m (incluindo a coluna d'água e os sedimentos). Arranjos curtos como esse evidentemente não têm aplicação em situações onde a coluna d'água é superior a 34 m (AGI - Advanced Geosciences, 2003). Cabos mais longos são necessários quando da coluna d'água maior. Neste tipo de arranjo, quando os eletrodos são rebocados na superfície da água, a utilização simultânea de um ecobatímetro se faz necessária para garantir o registro preciso da espessura da coluna d'água, item importante no momento da modelagem (processamento/inversão) dos dados geoelétricos obtidos. Observa-se ainda que, em qualquer caso, a utilização de um sistema preciso de posicionamento (tipo DGPS) é fundamental.

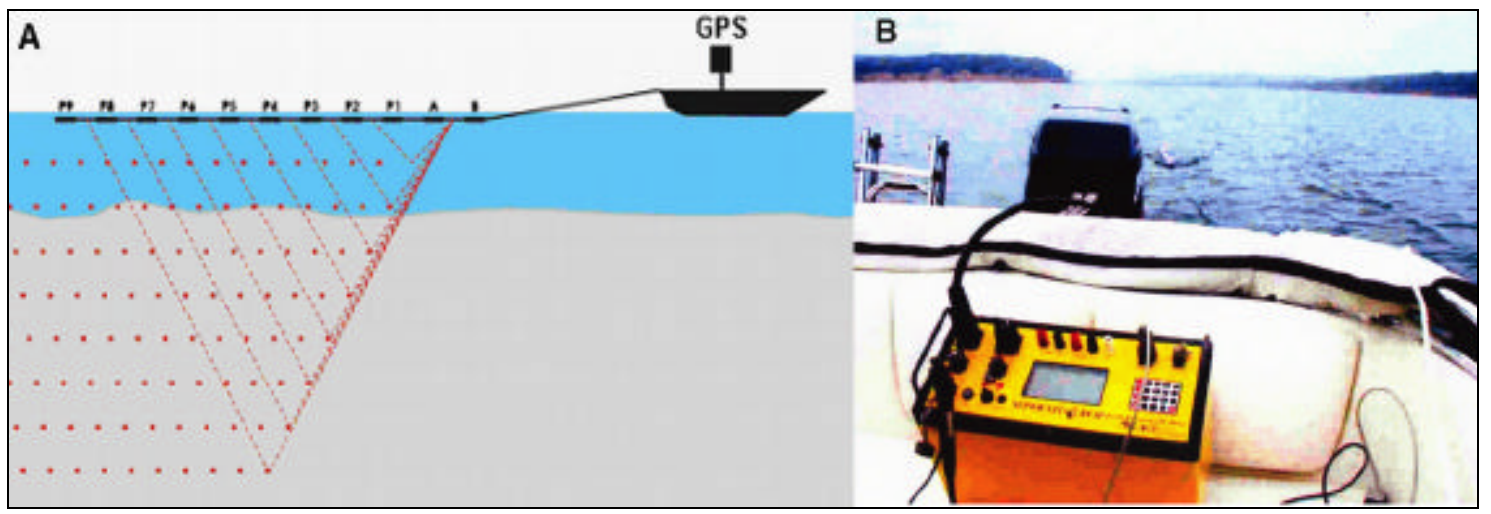

Figura 8.77: Ensaio de eletrorresistividade em água: a) ilustração esquemática da geometria do arranjo de eletrodos quando tracionados na superfície da água; b) vista parcial do sistema de aquisição de dados, modelo SuperSting, da AGI (USA), com arranjo de eletrodos de 8 canais e GPS. Modificado de $<$ http://www.agiusa.com>. Acesso: fev/2006. 
Outra forma de execução de levantamentos de eletrorresistividade na água é a constituição de arranjos com o cabo de eletrodos de potencial e de injeção de corrente, próximos, ou na superfície de fundo, em contato direto com os sedimentos. Um exemplo de arranjo de eletrodos deste tipo (no exemplo, arranjo Wenner) está ilustrado na Figura 8.78.

Quanto à qualidade de dados (resolução e penetração) esta é a melhor opção, pois as medidas são efetuadas por meio do contato direto dos eletrodos com a superfície de fundo. Além disso, a eliminação, de certo modo, da coluna d'água, já na aquisição dos dados, contribui em muito no processamento e modelamento dos dados. Diz-se "de certo modo" porque, mesmo no caso da utilização do sistema de eletrodos na superfície de fundo, não é desprezível a influência, em especial no caso de levantamentos marinhos, da coluna d'água, extremamente condutora, acima dos eletrodos.

Uma desvantagem a se destacar, quando da opção pelo posicionamento dos eletrodos na superfície de fundo, é o fato de que o cabo arrastado pode encontrar obstáculos tornando complexa e arriscada a operação de aquisição de dados.

Sistemas de longos cabos multieletrodos automatizados são utilizados atualmente como forma de se evitar este tipo de problema, e neste caso, o cabo lançado na superfície de fundo permanece estacionado durante toda, ou quase toda, aquisição dos dados, pois a alternância entre os pares de eletrodos de leitura é feita eletronicamente e remotamente, a partir da embarcação, sem necessidade de deslocamento físico dos eletrodos.

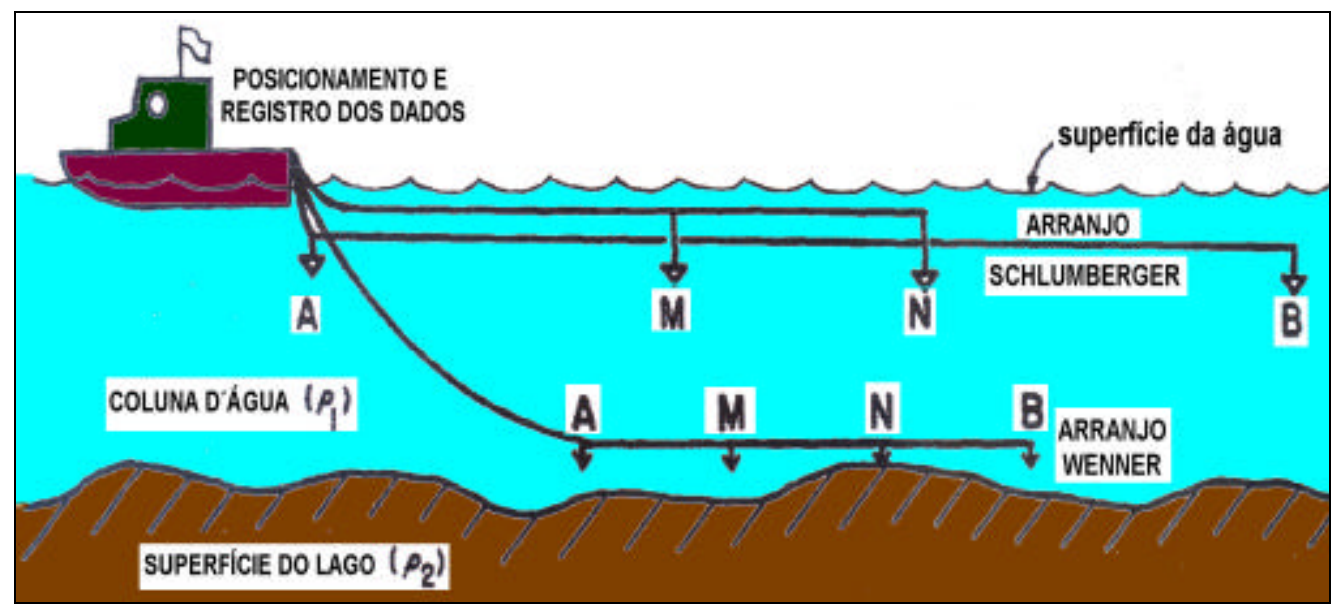

Figura 8.78: Exemplos de arranjos de eletrodos para levantamentos geoelétricos de áreas submersas. Modificado de Nebrija et al. (1976). 
Os eletrodos utilizados podem ser em forma de disco ou barra (Souza \& Sampaio, 2001). O eletrodo em forma de barra ilustrado na Figura 8.79 é constituído de grafite, minimizando os efeitos inerentes de corrosão, principalmente quando utilizados em ambientes marinhos.

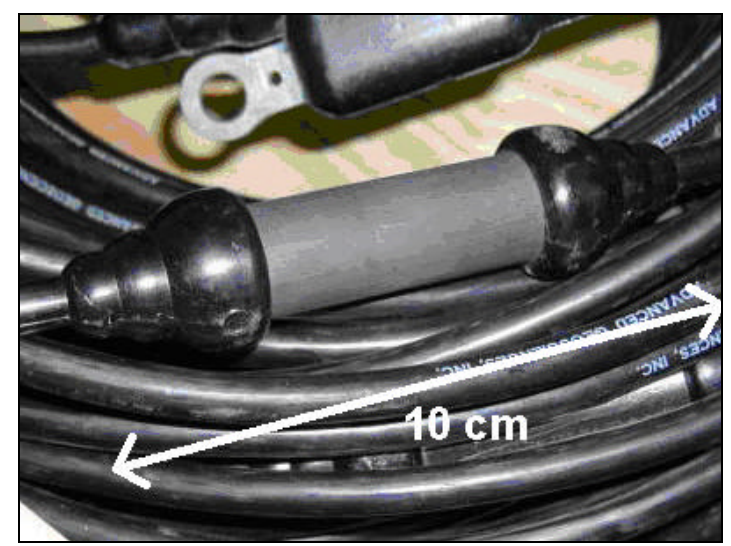

Figura 8.79: Eletrodos utilizados em levantamentos geoelétricos em água fabricados em grafite, não sofrendo, portanto, o efeito da corrosão com a passagem da corrente elétrica. Os cabos são de kevlar e à prova d'água. Fonte: <http://www.agiusa.com>. Acesso: dez/2005.

A Figura 8.80 apresenta uma seção modelada de resistividade, obtida através da inversão dos dados de campo com este tipo de aquisição em um lago de água doce.

A Figura 8.81 ilustra um exemplo de utilização da eletrorresistividade no rio São Francisco com um equipamento multieletrodos que possibilita a aquisição automática dos dados, sem a necessidade de deslocamento dos eletrodos na superfície de fundo. Este levantamento teve por objetivo subsidiar estudos da superfície de fundo do rio para escolha de melhor local para instalação de dutos. Um cabo de $200 \mathrm{~m}$ de extensão, com eletrodos espaçados de $5 \mathrm{~m}$, foi lançado sobre o fundo do rio gerando a pseudo-seção de resistividade aparente também ilustrada na Figura 8.81.

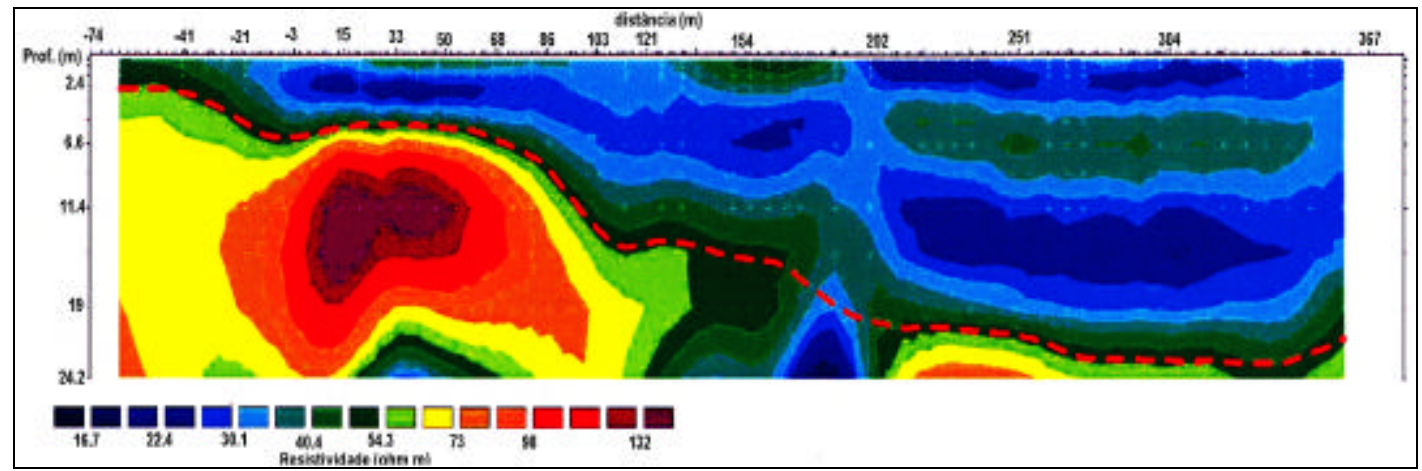

Figura 8.80: Seção de eletrorresistividade modelada obtida em um lago de água doce. A camada superior com tonalidades predominantemente azuis corresponde à lâmina d'água, que apresenta excelente correlação com os dados batimétricos (linha vermelha hachurada representa a superfície de fundo do lago obtida através da batimetria). AGI - Advanced Geoscience (2002). Disponível em $<$ http://www.agiusa.com. Acesso em fev/2006. 


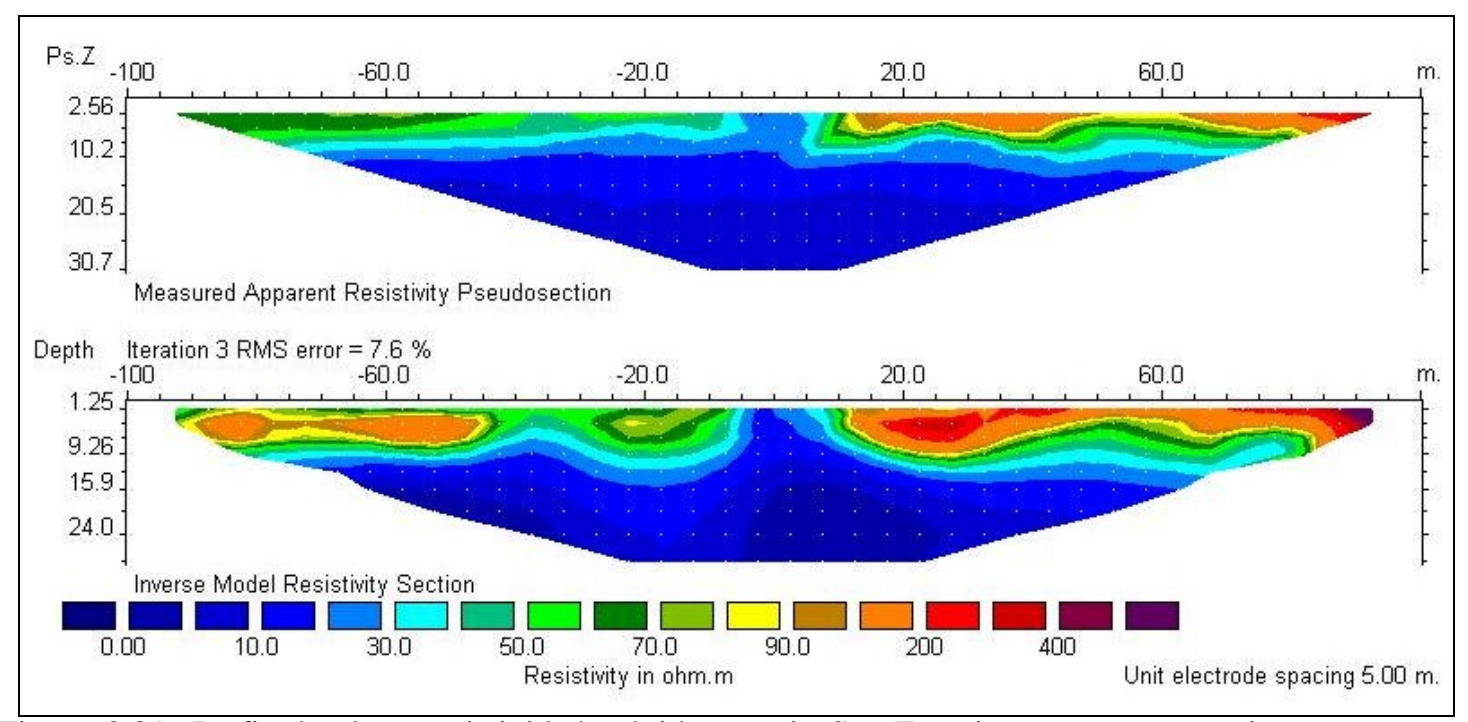

Figura 8.81: Perfis de eletrorresistividade obtidos no rio São Francisco: a seção superior apresenta os dados de campo (pseudo-seção); a seção na porção inferior da figura corresponde ao modelo geoelétrico obtido pela inversão (modelamento) dos dados no processamento. Dados: cortesia da Geo-radar Levantamentos Geofísicos, MG.

\subsubsection{MAgnetometria}

O estudo do magnetismo terrestre constitui-se num dos ramos mais antigos da investigação geofísica. Há alguns séculos já se sabia que a Terra se comporta aproximadamente como um grande ímã e de alguma forma esta característica já era utilizada pelos antigos para a navegação (Jones, 1999).

As propriedades do campo magnético terrestre tem sido há muito estudado, e as variações nas suas medidas tiveram suas primeiras aplicações na detecção de corpos mineralizados de grande interesse econômico.

Muitos avanços ocorreram neste campo de pesquisa nos últimos anos, não só nos aspectos relativos à instrumentação, resultante da própria evolução das tecnologias eletrônicas, mas também com relação à interpretação dos dados coletados, com o surgimento de softwares com poder de manipulação de grande quantidade de dados. Ambos os fatores contribuíram diretamente para o aumento da aplicabilidade deste método geofísico na solução de diversas questões geológicas em distintas escalas. Numa abordagem em maior escala, este método geofísico representa hoje um papel importante na prospecção de hidrocarbonetos, pois possibilita a identificação de corpos intrusivos, estruturas (falhas, lineamentos etc.), contatos entre as formações ou entre as bacias sedimentares, que são características geológicas comumente associadas a depósitos de interesse econômico, em especial, hidrocarbonetos. Em escala menor permite, por exemplo, mapeamentos detalhados da ocorrência de diques de diabásio (Souza \& 
Tessler, 1992; Souza et al., 1996; Ferreira et al. 1981; Ferreira, 1982) e de estruturas ou dutos enterrados (Mello et al., 1988).

A despeito da complexidade relativa ao tratamento dos dados de campo, a magnetometria constitui-se num método de investigação cujas operações de aquisição de dados em campo são relativamente simples, rápidas e de baixo custo, quando comparadas a qualquer outro método geofísico. Devido a estas facilidades operacionais, levantamentos magnetométricos são comumente utilizados, nos dias de hoje, pelo menos na fase de reconhecimento regional em diversos projetos de investigação, já que anomalias identificadas por meio deste método geralmente tem relação direta com estruturas regionais que freqüentemente representam condições favoráveis à ocorrência de depósitos minerais de interesse.

\subsubsection{Fundamentos}

A magnetometria constitui-se num método geofísico que mede o campo magnético total da Terra em qualquer ponto de observação na sua superfície, no ar (aerolevantamentos) ou no mar. Fosse a Terra um corpo extremamente homogêneo, as medições do campo magnético terrestre representariam tão somente as variações naturais ocasionadas pela distância entre o equador (onde o campo magnético terrestre é de aproximadamente $23000 \gamma$ ) e os pólos (onde o campo magnético terrestre é de aproximadamente $60000 \gamma$ ). Todavia os corpos rochosos que compõem a estrutura da Terra são heterogêneos e, possuem diferentes suscetibilidades magnéticas (propriedade dos materiais que identifica a maior ou menor capacidade de magnetização), que por sua vez influenciam de maneiras distintas os valores medidos do campo magnético da Terra em cada ponto de observação. Os princípios deste método de investigação são amplamente discutidos em Telford et al. (1976).

\subsubsection{Aplicação da magnetometria na investigação de áreas submersas rasas}

À parte da vasta aplicação da magnetometria em questões geológicas, relacionadas com mapeamentos geológicos e estruturais, com objetivos principalmente associados à prospecção mineral, este método tem sido amplamente utilizado associado aos métodos sísmicos de alta resolução, na investigação de áreas submersas rasas, como subsídio a projetos de investigação com vistas em instalação de estruturas fixas ou móveis (dutos, cabos, plataformas etc.) e em operações de busca de objetos metálicos submersos ou soterrados (embarcações, dutos, cabos etc.). 


\subsubsection{Aquisição de dados}

O levantamento magnetométrico em água é relativamente simples, pois o sensor é mergulhado na água e, através de cabos, mantido a certa distância para evitar ruídos magnéticos da embarcação sobre as leituras sucessivas do campo magnético terrestre ao longo de um perfil.

O campo magnético total é composto essencialmente por fontes internas e externas. As internas correlacionam-se com as propriedades magnéticas dos meios propriamente ditos, como rochas, sedimentos, depósitos minerais, ou estruturas geológicas (falhas etc.). Podem também estar relacionadas com materiais artificiais, eventualmente o próprio objeto da busca (dutos ou estruturas metálicas, embarcações etc.). As fontes externas, responsáveis pela introdução de erros de leitura das anomalias magnéticas, são representadas pelas variações temporais do campo magnético terrestre relacionadas com a atividade solar (Dobrin, 1976), destacando-se entre elas a quietude solar, as tempestades magnéticas e as micropulsações, que juntas podem eventualmente atingir valores superiores às próprias anomalias causadas por algumas interferências do tipo cabos ou dutos. Estas anomalias são eliminadas durante o processamento quando são correlacionada com os dados obtidos em campo com aqueles coletados simultaneamente em uma estação de observação fixa em algum ponto de referência próximo da área do levantamento.

Um sistema básico para a execução de levantamentos magnetométricos em áreas submersas compõe-se de:

- um sensor, que é tracionado na superfície da água a certa distância da embarcação (pode também ser tracionado próximo à superfície de fundo) Alguns exemplos estão ilustrados na Figura 8.82;

- um registrador, instalado no interior da embarcação onde os dados são acumulados para posterior interpretação;

- $\quad$ cabos de conexão;

- uma estação base que é instalada em um ponto fixo de referência e que registra as variações do campo magnético terrestre durante o mesmo período da aquisição dos dados da estação itinerante.

A aquisição de dados propriamente dita se desenvolve na forma de navegação em perfis, a velocidades normalmente inferiores a 5 nós. Os perfis são posicionados perpendicularmente às principais estruturas da área, ou sobre a área (ou objeto) de interesse da investigação, no caso de uma operação de busca específica. 


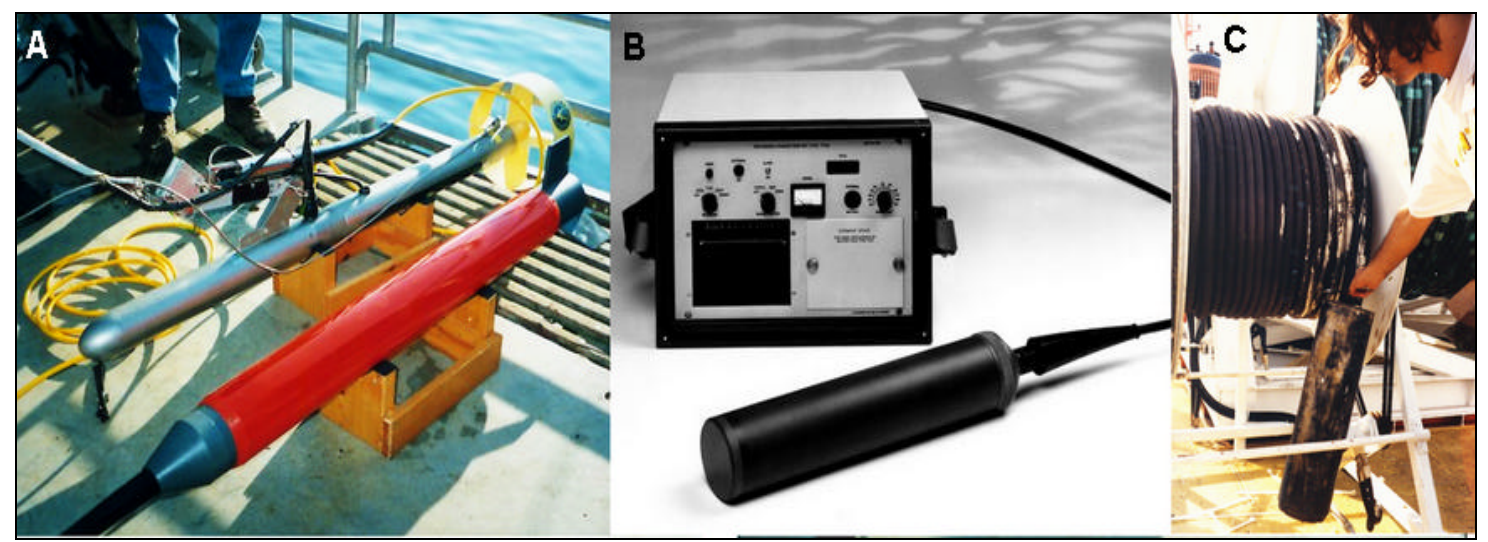

Figura 8.82: Exemplos de magnetômetros de utilização na investigação de áreas submersas: a) e b) magnetômetros de pequeno porte utilizados na investigação rasa. Fotos cedidas pelo geól. Cláudio G. Gallea; c) magnetômetro de grande porte utilizado na investigação de bacias sedimentares. Sistema instalado no Navio Oceanográfico Almirante Câmara em 1986. Foto do autor.

A unidade sensora (magnetômetro) é rebocada na coluna d'água a uma distância da embarcação que é definida em testes in situ para evitar que as medidas efetuadas sofram interferências indevidas, conseqüência da proximidade de objetos metálicos ou da própria embarcação. A Figura 8.83 ilustra um arranjo embarcação-sensor adequado para este tipo de levantamento segundo Mello et al. 1988.

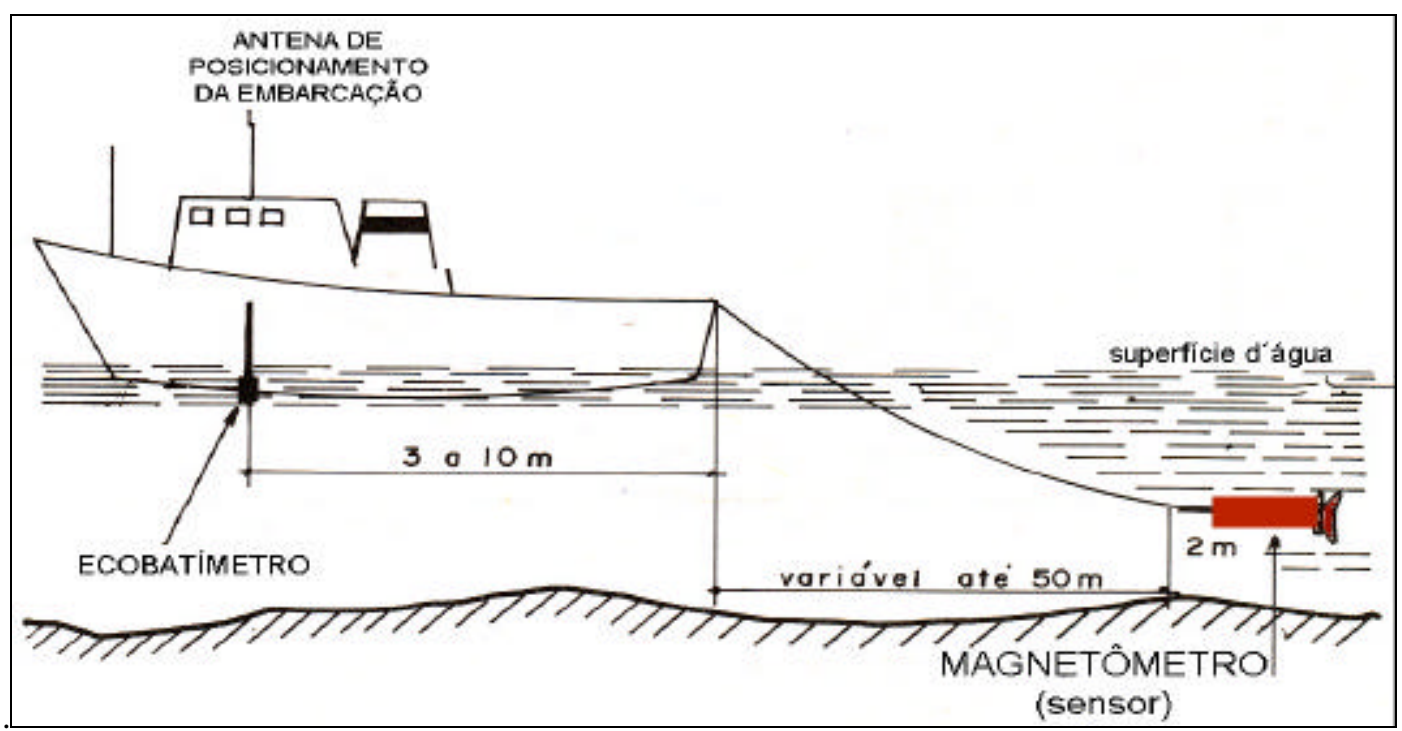

Figura 8.83: Magnetometria em áreas submersas: geometria do arranjo sensor-embarcação. Modificado de Mello et al. (1988).

No caso do mapeamento de dutos, enterrados ou dispostos na superfície, que normalmente possuem diâmetros entre 6 e 32 polegadas, os cuidados operacionais mencionados são particularmente relevantes, pois as anomalias que são somadas ao campo magnético terrestre devido à presença destes dutos são relativamente pequenas, da ordem de 300 gamas (Mello et al., 1988). A Figura 8.84 ilustra um perfil obtido em 
levantamento executado no litoral do Estado do Rio Grande do Norte que teve por objetivo o mapeamento de dutos enterrados próximo à praia.

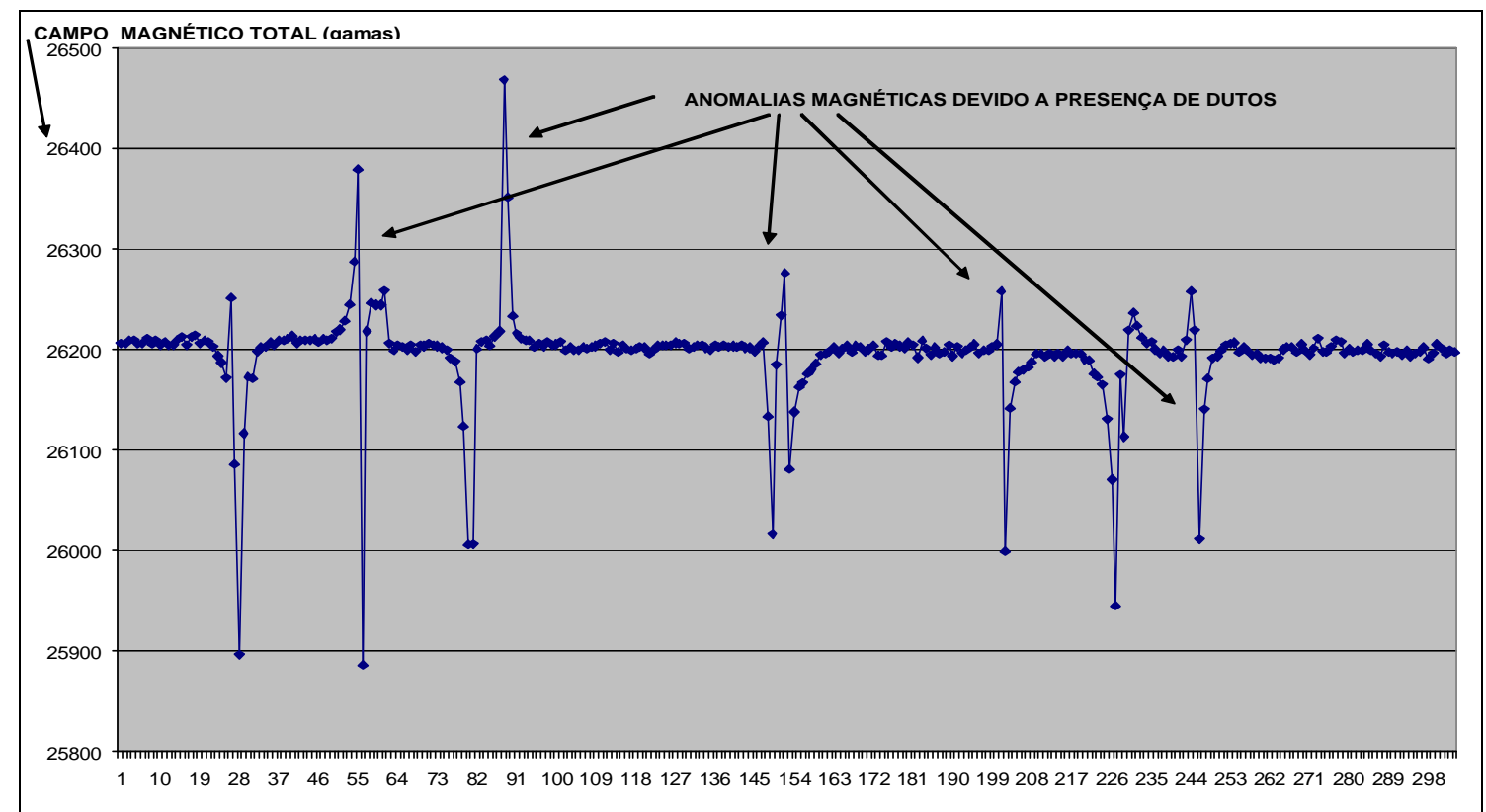

Figura 8.84: Perfil de magnetometria obtido próximo à praia, no litoral do Rio Grande do Norte mostrando as anomalias geradas pela presença de dutos enterrados no local. Dados cortesia do geól. Claudio G. Gallea (Tethys).

Outro aspecto operacional importante de ser observado é que, quanto maior a proximidade do sensor da superfície de fundo, mais precisa será a medida efetuada e, portanto, mais facilmente será identificada a anomalia correspondente ao objeto da busca, conforme ilustrado na Figura 8.85 .

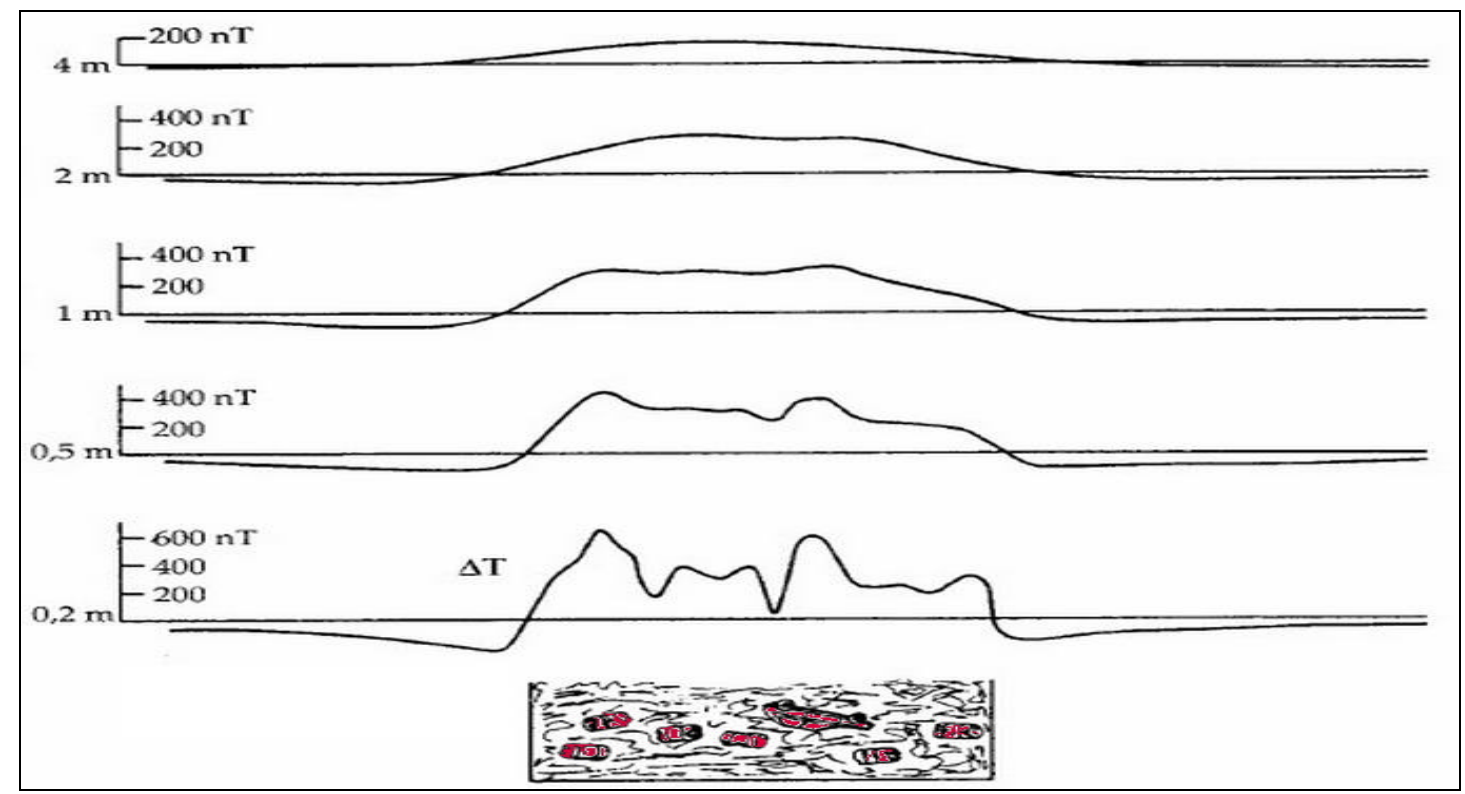

Figura 8.85: Ilustração mostrando como varia a forma de uma anomalia magnética em função da altura do sensor, neste exemplo variando de 0.2 a 4 metros de altura. Pode-se observar que, à medida em que o sensor se aproxima da superfície, as características magnéticas de cada um dos objetos enterrados influenciam diretamente na forma final da anomalia detectada. À medida em que se distancia, a influência diminui e a curva vai se aplainando e se aproximando da curva representativa do campo gravitacional global. Vogelsang (1995). 


\subsubsection{RAdAR DE PENETRAÇÃo do Solo (GPR)}

\subsubsection{Fundamentos}

O GPR (Ground Penetrating Radar) ou radar de penetração do solo ou ainda radar penetrante do solo, constitui-se num método geofísico que utiliza ondas eletromagnéticas de alta frequiência (10-2500 MHz). Baseia-se na emissão de um pulso de energia eletromagnética para o subsolo através de uma antena transmissora (Tx).

Durante a propagação, o sinal emitido sofre reflexões, refrações e difrações nas descontinuidades existentes no meio, ou nas interfaces entre as camadas com distintas propriedades elétricas, ou seja, distintos valores de velocidade de propagação da onda eletromagnética (que guarda relação com a permissividade dielétrica - $\varepsilon$-, ou constante dielétrica - k -, do meio), retornando à superfície onde é captado por uma antena receptora $(\mathrm{Rx})$.

A amplitude do sinal refletido será mais intensa quanto maior for o contraste existente entre as propriedades elétricas dos meios atravessados pelo sinal (constante dielétrica). Por constante dielética (k) entende-se a grandeza definida pela relação da capacidade dielétrica, ou permissividade dielétrica, de um material ( $(\varepsilon)$ pela capacidade dielétrica do vácuo $\left(\varepsilon_{0}\right)$.

O sistema é composto por um par de antenas de transmissão e recepção, por uma central de controle e por um notebook que armazena os dados coletados (Figura $8.86 \mathrm{e}$ Figura 8.87).

Este método de investigação foi disponibilizado comercialmente nos anos 80, mas somente a partir da metade dos anos 90 passou a ser utilizada amplamente na investigação geológica (Neal, 2004).

Os perfis obtidos do GPR trazem à luz informações geológicas sobre a superfície de fundo, sobre as camadas subsuperficiais e sobre objetos ou estruturas enterradas nas camadas de sedimentos subsuperficiais. Analogamente aos métodos sísmicos, as medidas são apresentadas nos perfis na forma de "tempo de percurso do sinal" (ida e volta), e assim, para a transformação do tempo (ns) em profundidade real (m) dos níves estratigráficos investigados, são necessários dados adicionais, com relação à velocidade de propagação das ondas eletromagnéticas no meio geológico, parâmetro que pode ser obtido a partir de sondagens mecânicas ou de ensaios geofísicos específicos. 

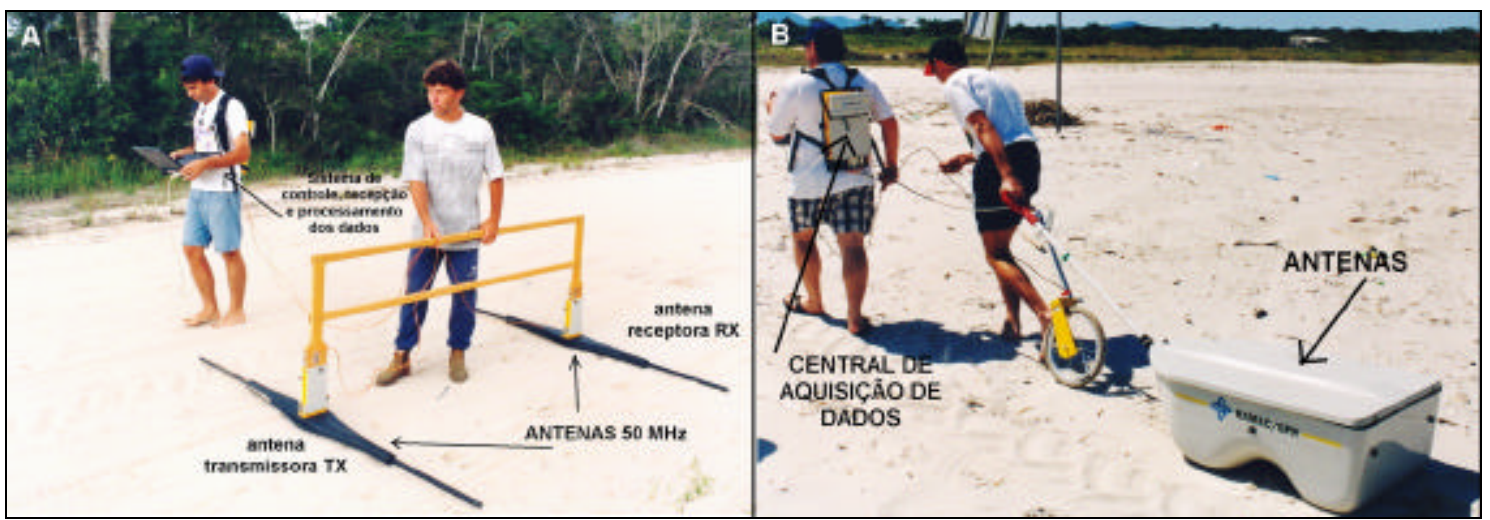

Figura 8.86: GPR em operação na Ilha Comprida, litoral sul do ESP, ilustrando algumas das diferentes formas de tracionamento do sistema de antenas sobre a superfície investigada: a) GPR com antena de 50 $\mathrm{MHz}$ ( $\mathrm{Tx}$ = antena de transmissão $\mathrm{Rx}=$ antena de recepção) com dados sendo adquiridos passo a passo; b) GPR com antena de $200 \mathrm{MHz}$ com dados sendo adquiridos de forma de rebocamento contínuo. Gandolfo et al., 2001. Fotos do autor.

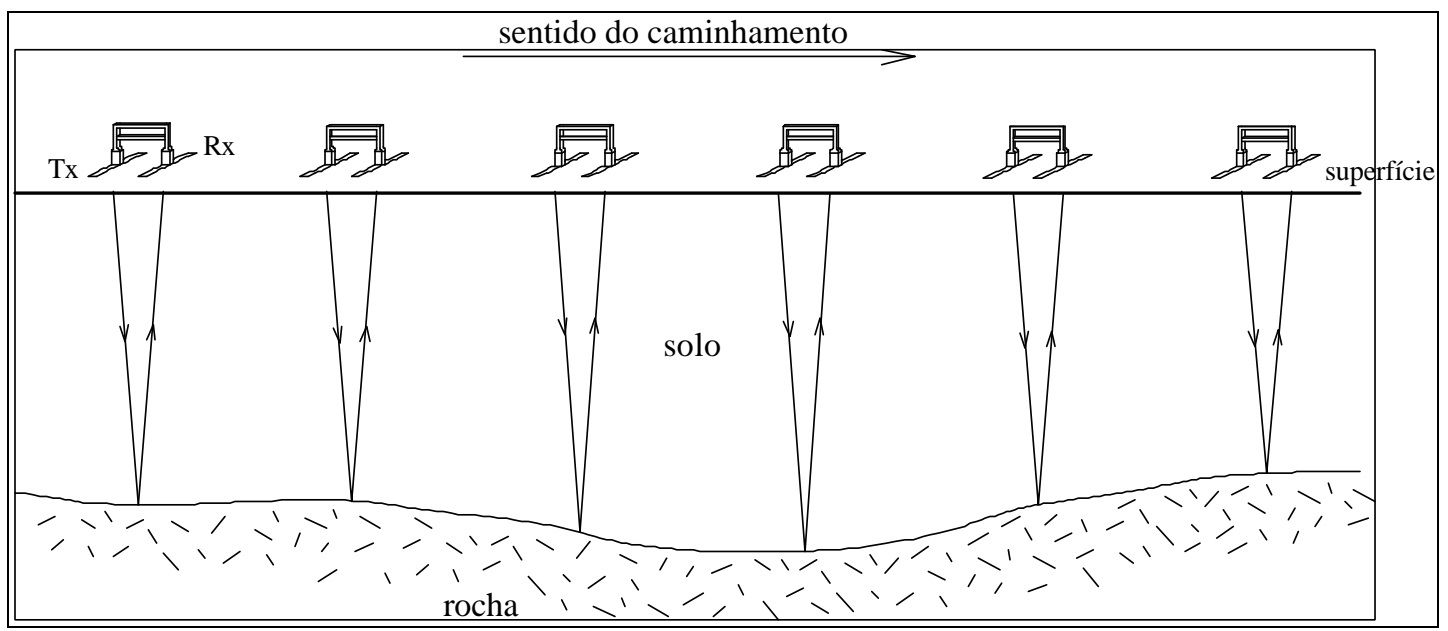

Figura 8.87: Diagrama ilustrando as diversas posições do par de antenas (Rx e Tx) no procedimento de aquisição de dados com o sistema GPR ao longo de um perfil. Modificado de Davis \& Annan (1989).

\subsubsection{Aplicações do GPR}

Por constituir-se num método geofísico relativamente recente, o potencial de aplicação do GPR encontra-se ainda em franca expansão. Algumas aplicações atuais podem ser destacadas.

O GPR tem na identificação de interferências em áreas urbanas uma das suas principais aplicações. Detectando a localização de cabos e dutos enterrados, galerias etc. auxilia projetos de construção de túneis, rodovias, entre outras obras que exigem o conhecimento detalhado da subsuperfície. IPT (1998b), Gandolfo \& Miranda (2002), Galli \& Souza (1999), e Carrasquilla \& Ceia (2005) são exemplos de aplicação do GPR com esta finalidade. A Figura 8.88a mostra exemplo de registro de GPR obtido com este objetivo.

Como ferramenta de investigação em estudos de áreas contaminadas, o GPR detecta de forma bastante clara as profundas alterações das características geoelétricas 
do meio geológico decorrentes de vazamentos ou derrames de materiais poluentes. Lorenzo et al. (2004), por exemplo, obtiveram excelentes resultados utilizando o GPR para mapear manchas de óleo em subsuperfície nas praias da Galícia (Espanha), oriundas de derramamento acidental de mais de 30.000 toneladas de óleo no mar. IPT (1998d) utilizou-se desta mesma ferramenta para avaliar a extensão em subsuperfície de depósitos de sais em área de empresa química em processo de avaliação de passivo ambiental. Outros exemplos de utilização desta ferramenta com aplicação em questões ambientais podem ser observados em (Galli \& Souza, 1999; Aquino et al., 1998a,b; Rodrigues \& Porsani, 1995; Porsani \& Rodrigues, 1998; Machado et al., 2004). A Figura $8.88 \mathrm{~b}$ demonstra exemplo de registro de GPR obtido com esta finalidade;

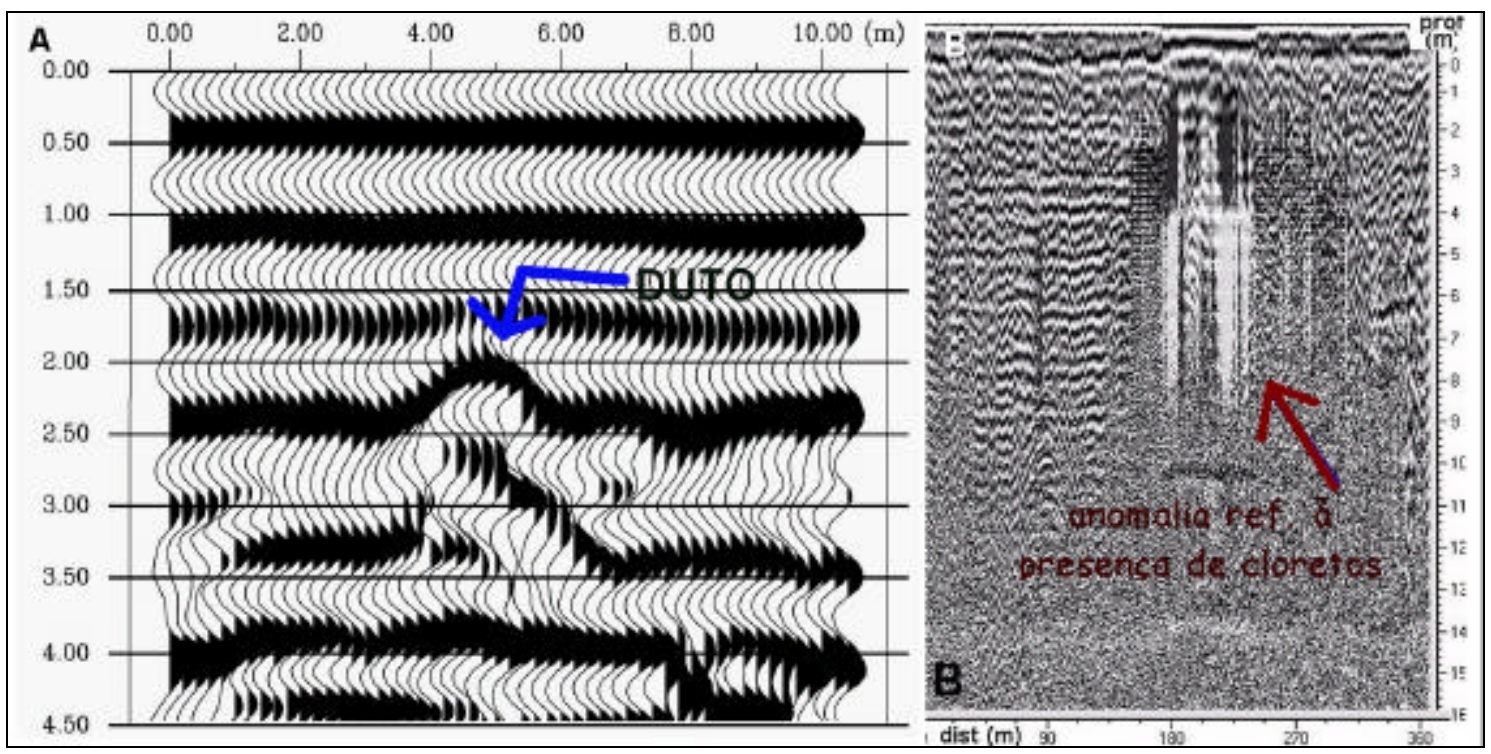

Figura 8.88: a) exemplo de perfil obtido com o GPR ilustrando anomalia relacionada com a presença de um duto enterrado à profundidade de $2 \mathrm{~m}$ (Galli \& Souza, 1999; IPT, 1998b); b) perfil obtido com o GPR onde se observa anomalia gerada pela presença de depósito de sais de cloro em subsuperfície (IPT, 1998d).

$\mathrm{Na}$ investigação estratigráfica rasa o GPR cumpre relevante papel. São muitos os exemplos na literatura de sucessos obtidos com a aplicação desta ferramenta geofísica em estudos estratigráficos (Ceia et al., 2004), em especial, no mapeamento detalhado do Quaternário costeiro, já que estes ambientes se compõem de depósitos sedimentares com alto conteúdo de sedimentos arenosos, meio geológico que proporciona grande facilidade para a propagação das ondas eletromagnéticas, gerando dados de alta qualidade e propiciando a penetração do sinal a profundidades superiores a $10 \mathrm{~m}$. Jol et al. (1996), Jol \& Smith (1991), McGeary et al. (1998), Porsani \& Rodrigues (1998), Gandolfo (1999), Gandolfo et al. (2001a,b), Daly et al. (2002), Figueiredo Jr. et al. (2003), Pereira et al. (2003), Asp et al. (2005) e Angulo et al. (2005) apresentaram 
excelentes exemplos de aplicação do GPR em estudos estratigráficos rasos em áreas costeiras. Em todos estes, a interpretação sismoestratigráfica dos perfis de GPR contribuiu efetivamente para a reconstituição da arquitetura e evolução das feições holocênicas e pleistocênicas, constituindo importantes subsídios para o aperfeiçoamento dos modelos evolutivos das áreas estudadas.

No mapeamento geológico básico e na prospecção mineral resultados expressivos têm sido obtidos por meio do uso de GPR tanto em trabalhos de reconhecimento ou mapeamento geológico, como na identificação da profundidade do embasamento rochoso raso (Rodrigues \& Porsani, 1997; Porsani et al., 2002, 2004), de estruturas geológicas (falhas, lineamentos etc.) em subsuperfície, não raramente relacionados com projetos de prospecção mineral.

Sauck (1998) apresentou exemplos de aplicação desta ferramenta geofísica em levantamentos geológicos onde se identificaram feições em subsuperfície sem qualquer expressão na superfície, tais como, conformação e estruturas do embasamento cristalino raso, paleocanais preenchidos por sedimentos arenosos, deltas afogados, entre outras feições geológicas. A Figura 8.89 expõe um dos didáticos exemplos apresentados pelo autor neste artigo.

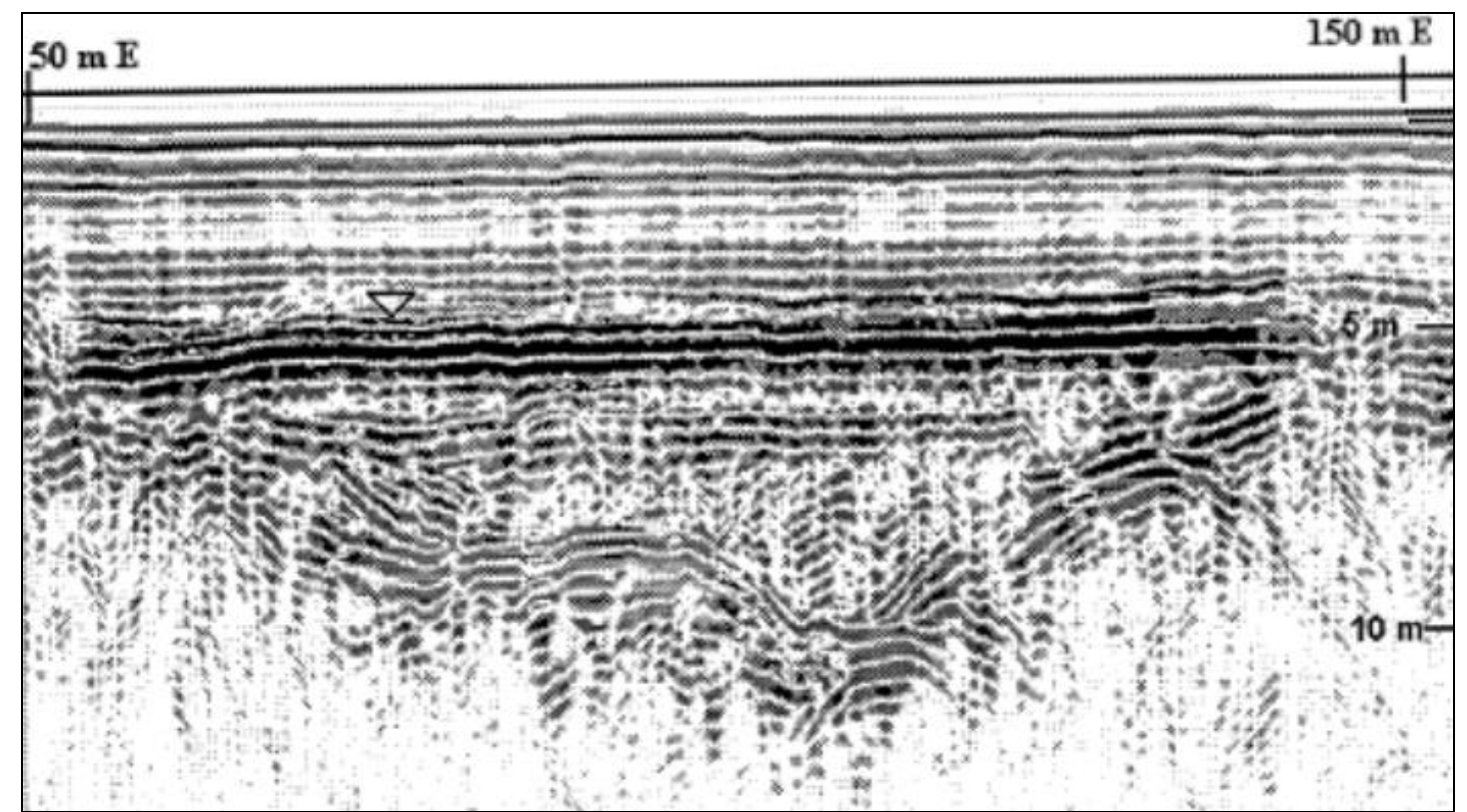

Figura 8.89: Perfil de GPR com antena de $100 \mathrm{MHz}$ obtido na Ilha de Outeiro, Belém (PA) ilustrando o potencial desta ferramenta no mapeamento geológico básico, neste caso, detectando paleocanias preenchidos por sedimentos arenosos (Sauck, 1998).

$\mathrm{Na}$ arqueologia, são muitas as empresas e instituições de pesquisa no Brasil e no mundo que empregam, com sucesso, o GPR em investigações de sítios arqueológicos, tendo sempre como objetivo a investigação rasa, raramente ultrapassando $5 \mathrm{~m}$ de 
profundidade (Faflak, 1998; Gracia, 1998; Lawrence \& Conyers, 1998; Goodman et al., 1998 e Sauck et al., 1998; Hesse, 1999).

Outras aplicações do GPR ainda podem ser destacadas: a detecção da profundidade do nível freático, da integridade de estruturas (IPT, 1998a,c), da presença de espaços vazios subterrâneos, principalmente em estudos de zonas cársticas (IPT 1999c; Nuzzo et al., 2004), e a caracterização de maciços rochosos (mapeamento da distribuição de falhas, juntas e fraturas), visando à exploração de rochas ornamentais (Botelho \& Araújo, 1996; Botelho et al., 1999 e Porsani et al., 2006), são algumas aplicações adicionais do GPR.

\subsubsection{Profundidade de investigação}

A profundidade de investigação por meio do GPR é condicionada pelas propriedades elétricas do meio: condutividade e resistividade. Em condições de baixa condutividade elétrica ou alta resistividade (>50 ohm x m), o sinal emitido pode atingir camadas a profundidades superiores a $20 \mathrm{~m}$. Argilas condutivas, por exemplo, podem reduzir a penetração do sinal eletromagnético a menos de um metro. São raros na literatura exemplos de penetração do sinal do GPR superiores a $50 \mathrm{~m}$.

Gandolfo et al. (2001b) aplicaram o GPR em estudos estratigráficos na Ilha Comprida, litoral sul do Estado de São Paulo. Os resultados obtidos permitiram a identificação de três unidades estratigráficas separadas por contatos bastante conspícuos, que foram diretamente correlacionadas aos modelos evolutivos estabelecidos para a área. As duas unidades superiores identificadas nos registros corresponderiam a depósitos holocênicos formados em eventos transgressivo e regressivo.

A Figura 8.90 ilustra um perfil de GPR obtido na área estudada, utilizando antena de $50 \mathrm{MHz}$ com excelente resolução das camadas sedimentares até a profundidade de $12-15 \mathrm{~m}$, a despeito da limitação de penetração do sinal eletromagnético a partir desta profundidade, devido à existência de meios condutores (água salgada), inibindo completamente a propagação do sinal (vide porção inferior desta figura). Neste perfil, inclusive, é possível observar, na porção superior, cordões arenosos gerados no evento regressivo holocênico descritos no modelo evolutivo da área. 
Resultados semelhantes, com relação à profundidade de investigação do GPR em estudos estratigráficos costeiros, foram obtidos por Pereira et al. (2003) em levantamentos executados na praia de Itaipuaçu (Maricá, RJ) e por Jol et al. (1998), em estudos desenvolvidos na costa noroeste do EUA (Washington/Oregon) para avaliar os processos erosionais e acrescionais atuantes naquela região costeira.

Excelentes resultados têm sido obtidos com a utilização do GPR em ambientes insaturados altamente resistivos (Pestana \& Botelho, 1997).

O exemplo na Figura 8.91 mostra perfis obtidos de levantamento com o GPR executados em área de mineração de dunas no Estado da Paraíba (Gandolfo et al. 2001a). No ambiente estudado, os contrastes entre as propriedades elétricas das litologias presentes (sedimentos argilosos da Formação Barreiras e depósitos arenosos das dunas) foram muito favoráveis à aplicação deste método. Esta característica proporcionou a penetração do sinal eletromagnético a profundidades superiores a $60 \mathrm{~m}$ e, assim, permitiu o alcance da interface que representa o contato entre os depósitos arenosos das dunas e o topo da Fm Barreiras, atingindo o objetivo principal dos ensaios propostos. Neste exemplo, a integração dos resultados dos levantamentos com o GPR com inúmeras sondagens realizadas na área permitiu ainda uma precisa visualização da geometria do topo da Fm Barreiras e conseqüentemente a correta cubagem dos depósitos de areias sobrejacentes.

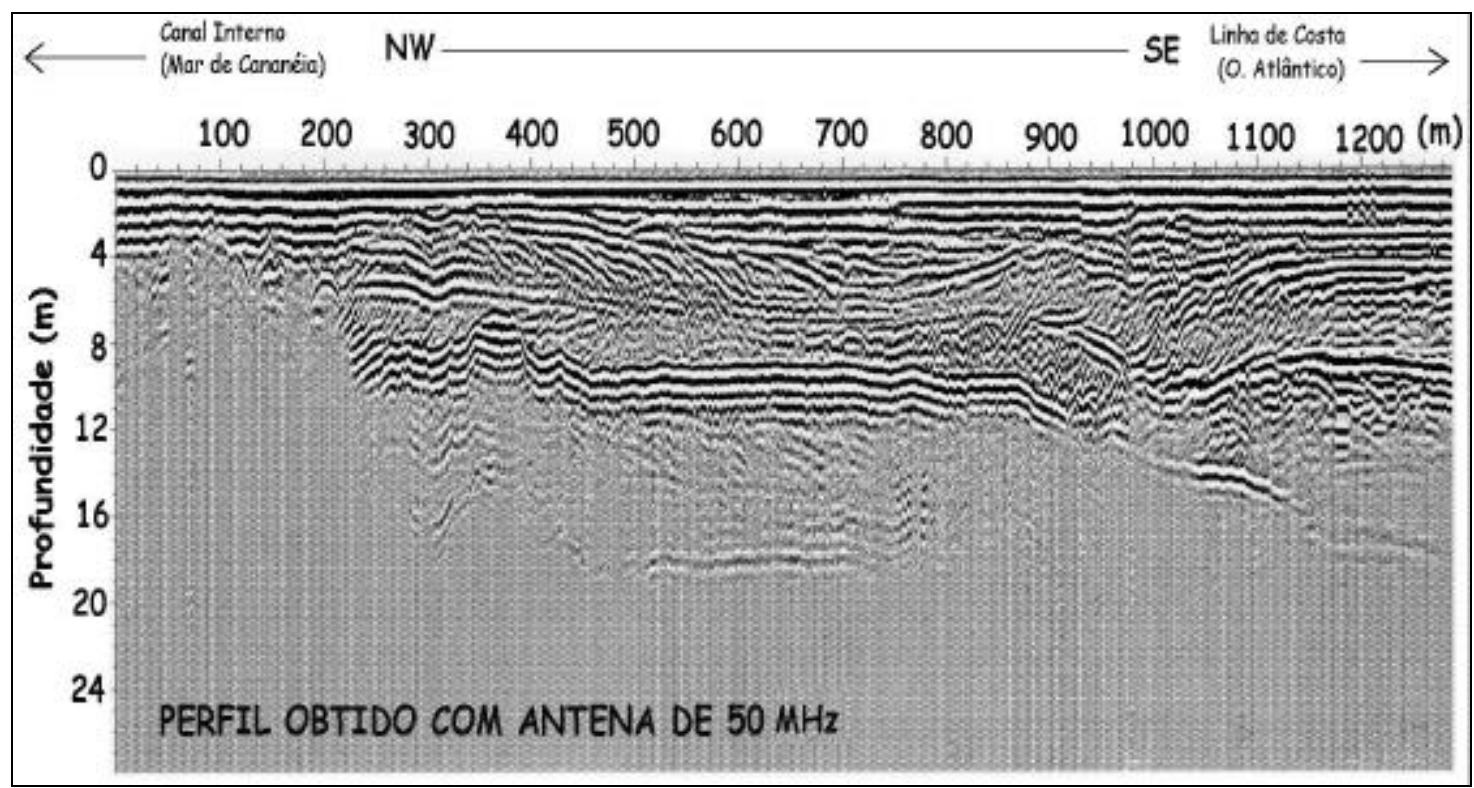

Figura 8.90: Perfil de GPR utilizando antena de $50 \mathrm{MHz}$ obtido na Ilha Comprinda, litoral sul do Estado de São Paulo, ilustrando a limitação de penetração do sinal eletromagnético a partir de $12-15 \mathrm{~m}$ de profundidade, devido à existência de meios condutores (água salgada), a despeito da excelente resolução do método até esta profundidade. Gandolfo et al. (2001b). 


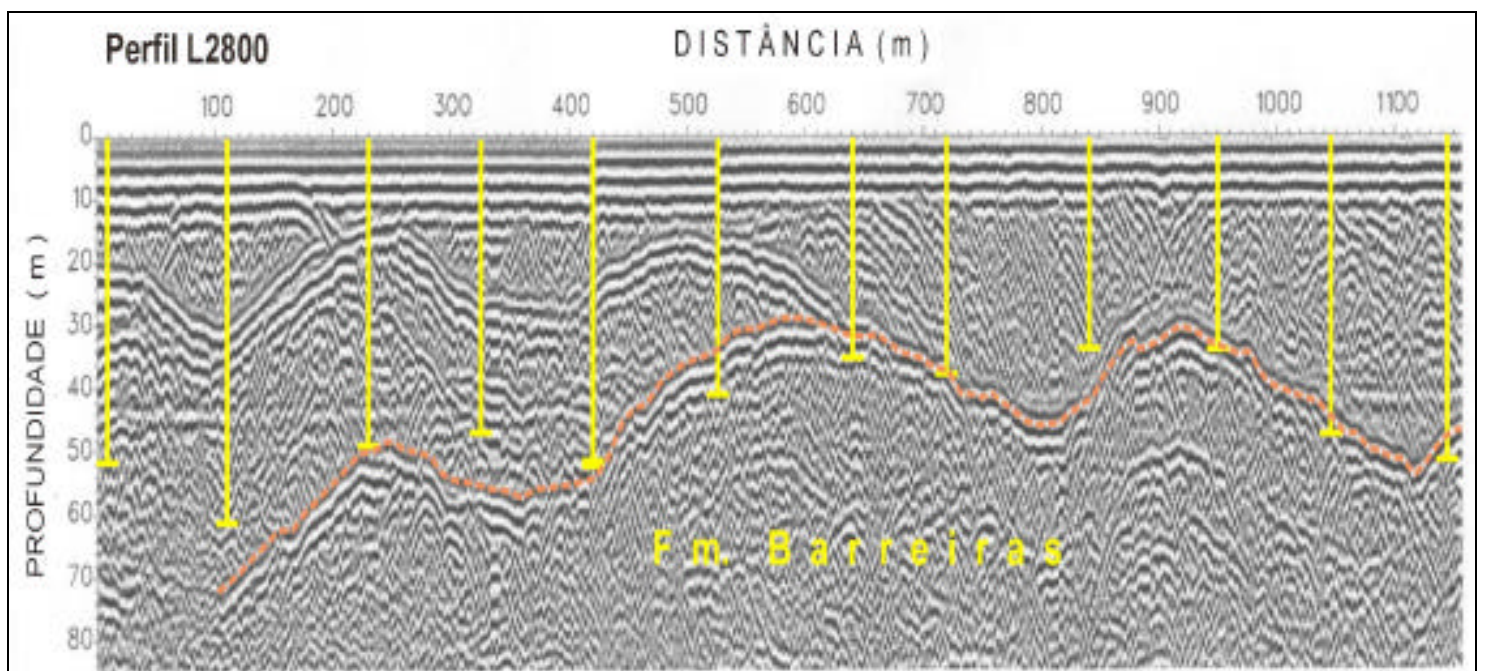

Figura 8.91: Perfil de GPR obtido com antena de $25 \mathrm{MHz}$ com leituras a cada dois metros, ilustrando a excelente penetração do sinal eletromagnético em ambientes resistivos. As linhas verticais em amarelo referem-se às sondages efetuadas ao longo do perfil, a maioria delas atingindo o topo da Fm. Barreiras. Gandolfo et al. (2001a).

\subsubsection{A utilização do GPR na investigação de áreas submersas}

As dificuldades de propagação das ondas eletromagnéticas em meios condutivos tornam praticamente inviáveis a utilização deste método na investigação de áreas submersas costeiras ou na plataforma continental interna, tendo em vista as propriedades inerentes de alta condutividade elétrica das águas salgadas ou salobras destes ambientes (Placzek \& Haeni, 1994; Olhoeft, 1999 e Gandolfo et al., 2001).

Todavia, apesar de ainda raros na literatura nacional e internacional, estudos recentes expõem experiências muito relevantes que mostram enorme potencial de aplicação deste método para investigação de áreas submersas continentais (rios e lagos, naturais ou artificiais), em especial quando da necessidade de investigação de áreas muito rasas, onde a clássica perfilagem sísmica contínua encontra dificuldades operacionais.

Spicer et al. (1997) utilizaram GPR com antenas de baixa freqüência (100 $\mathrm{MHz}$ ) para estudo de canais de rios e lagos, em ambientes de baixa condutividade elétrica (<400 S/cm), obtendo bons resultados, com resolução da ordem de $10 \mathrm{~cm}$, em locais com coluna d'água de até $10 \mathrm{~m}$.

Por meio da comparação entre informações extraídas das seções de GPR e dados das medições convencionais da espessura da coluna d'água, estes autores mostram a grande confiabilidade do GPR para estudos de áreas submersas, no caso, para determinação da forma dos canais de rios, com vistas em estudos de fluxos. Mostram ainda o excelente desempenho do sistema GPR para levantamentos realizados 
em períodos de cheias, ou seja, em situações operacionalmente críticas quando posicionar qualquer instrumento de medição na coluna d'água torna-se operação extremamente complexa. Neste caso, a antena do GPR foi posicionada acima da superfície d'água $(0,5 \mathrm{~m})$.

No Brasil, as primeiras experiências de utilização do GPR em ambientes submersos estão registradas em Aquino et al. (1998a), Galli \& Souza (1999), Souza et al. (2001, 2002), Ussami et al. (2000), Travassos \& Adepelumi (2001), que aplicaram este método de investigação no reservatório Billings, SP, Rio Taquari, MS, Rio Paraná, SP/PR e rio Jacui, RS. Em todas estas experiências, o objetivo foi estudar os processos sedimentares recentes atuantes nos respectivos ambientes e com este objetivo identificar as espessuras das camadas sedimentares recentes.

Nos últimos anos, outras iniciativas pioneiras também ocorreram visando avaliar o potencial desta ferramenta na investigação de áreas submersas continentais (água doce), a saber, os levantamentos executados no rio Tietê, pelo Prof. Dr. Jandyr Travassos, do Observatório Nacional, RJ (dados inéditos), e no rio Pomba, MG, pelo Prof. Dr. Marcos A. B. Botelho, da Universidade Federal da Bahia (dados inéditos).

Recentemente, algumas empresas nacionais (Geo-radar, Alta Resolução, entre outras) têm utilizado o GPR como ferramenta auxiliar na investigação de rios e reservatórios para identificação da espessura das camadas rasas de sedimentos e identificação de interferências (dutos ou cabos enterrados).

Porsani et al. (2005) e Moutinho et al. (2005) apresentaram não só exemplos mais recentes da utilização de GPR, como também novas perspectivas com relação ao processamento de dados de radar oriundos de levantamentos executados em áreas submersas, como por exemplo, procedimentos no tratamento dos dados para eliminação das reflexões múltiplas.

O GPR foi utilizado com sucesso por Placzek \& Haeni (1994) na investigação do rio Connecticut, nos EUA, em substituição à clássica perfilagem sísmica contínua, tendo em vista as limitações operacionais da área com relação à espessura da coluna d'água. A baixa condutividade da água do rio no trecho estudado contribuiu também como fator estimulante para a aplicação deste método de investigação.

Para a viabilização dos ensaios na superfície d'água, estes autores adaptaram os sistemas de aquisição de dados a pequenas embarcações de fibra de vidro e 
desenvolveram proteções específicas à prova d'água para garantir a flutuabilidade das antenas. Utilizaram antenas de 80, 100 e $300 \mathrm{MHz}$. Os melhores resultados foram obtidos com as antenas de 80 e $100 \mathrm{MHz}$, nos quais observaram penetração do sinal eletromagnético de até $11 \mathrm{~m}$. Um exemplo de registro obtido por estes autores está ilustrado na Figura 8.92.

Na Figura 8.93 pode também ser observado exemplo de registro de radar de excelente qualidade, obtido com antena de $200 \mathrm{MHz}$ em lago na Suécia. Neste perfil é possível identificar claramente a topografia de fundo e a estratigrafia rasa do lago.

Aquino et al. (1998a) realizaram ensaios pioneiros com radar em reservatórios na tentativa de classificar os sedimentos de fundo do reservatório Billings. Apesar da alta condutividade das águas do reservatório, propriedade que inibe a propagação do sinal eletromagnético, registros de qualidade razoável foram obtidos o que permitiu uma classificação tentativa do material de fundo da represa. Um dos perfis obtidos está apresentado na Figura 8.94.

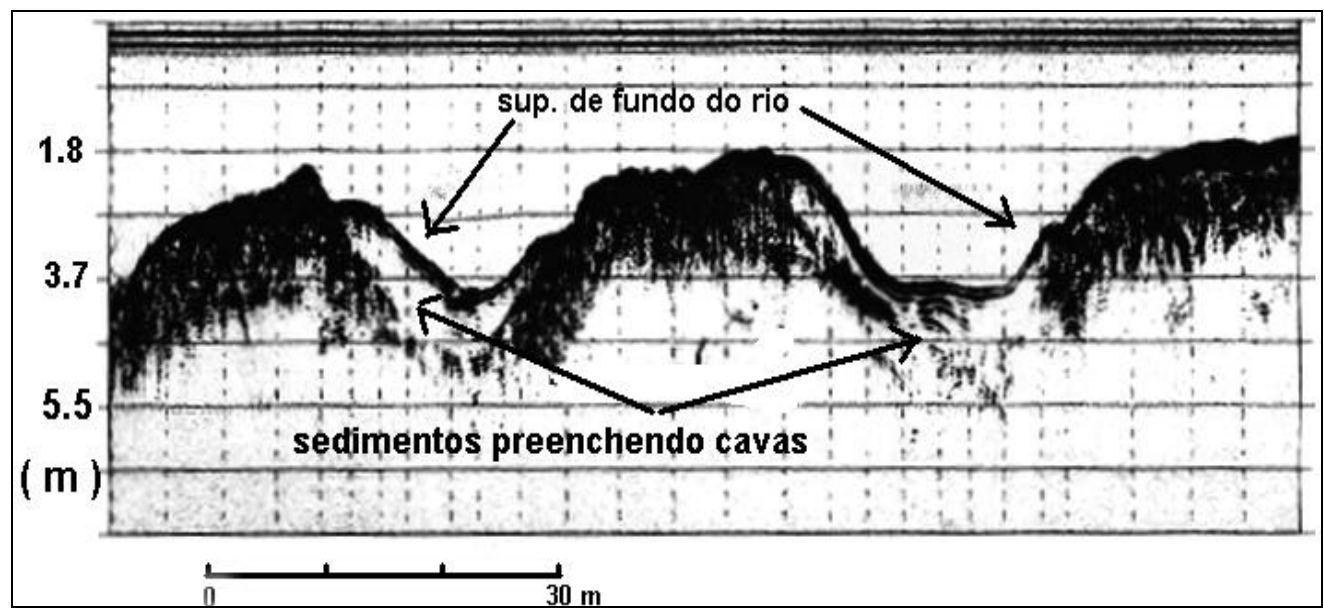

Figura 8.92: Imagem de radar obtida em rio dos EUA (Connecticut), com antema de $100 \mathrm{MHz}$, mostrando vales preenchidos por sedimentos. Placzek \& Haeni, 1994.

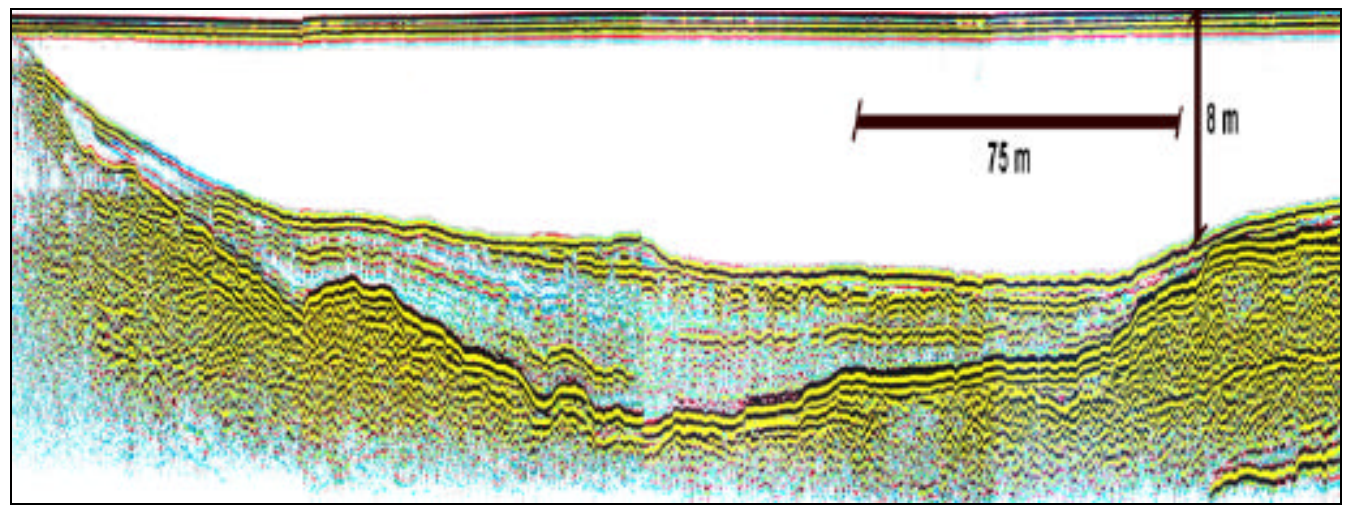

Figura 8.93: Perfil de GPR com cerca de 300m de extensão obtido em um lago na Suécia (antena de $200 \mathrm{MHz}$ ). Neste perfil observam-se claramente a topografia de fundo do lago, bem como refletores subjacentes, sendo possível portanto caracterizar a estratigrafia rasa do lago. Registro cortesia da Mala Geosciense. 
IPT (dados inéditos) utilizou também o GPR em estudo de avaliação dos processos de erosão e assoreamento atuantes no rio Paraná, alterados e intensificados em conseqüência da instalação da Barragem de Porto Primavera. A Figura 8.95 mostra um dos perfis obtidos neste estudo.

Ainda no contexto da aplicação do GPR na investigação dos processos sedimentares de erosão e assoreamento, Souza et al. (2002), Porsani et al. (2005) e Moutinho et al. (2005) utilizaram-se desta ferramenta geofísica para investigar as causas do estado crítico que se encontra atualmente o rio Taquari, MS, com relação ao assoreamento. Alguns exemplos de registros do GPR obtidos neste estudo estão ilustrados na Figura 8.96 e na Figura 8.97.

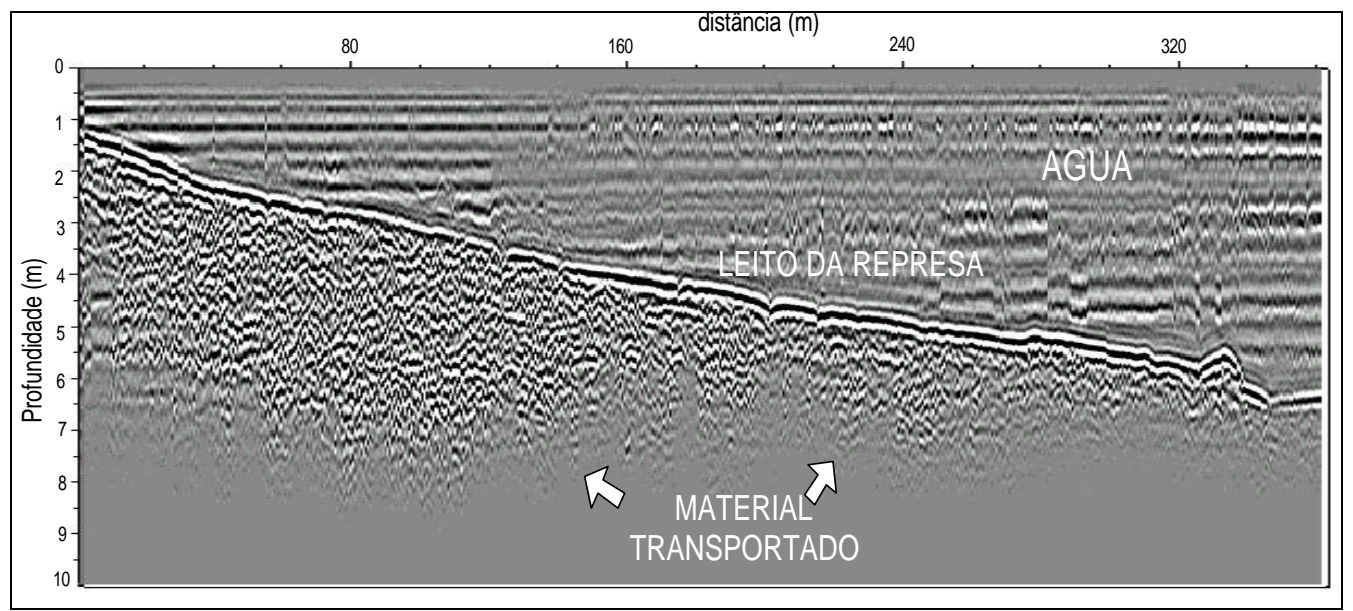

Figura 8.94: Seção de GPR obtida na Represa Billings, SP, em estudo de assoreamento de reservatórios (Aquino et al., 1998a).

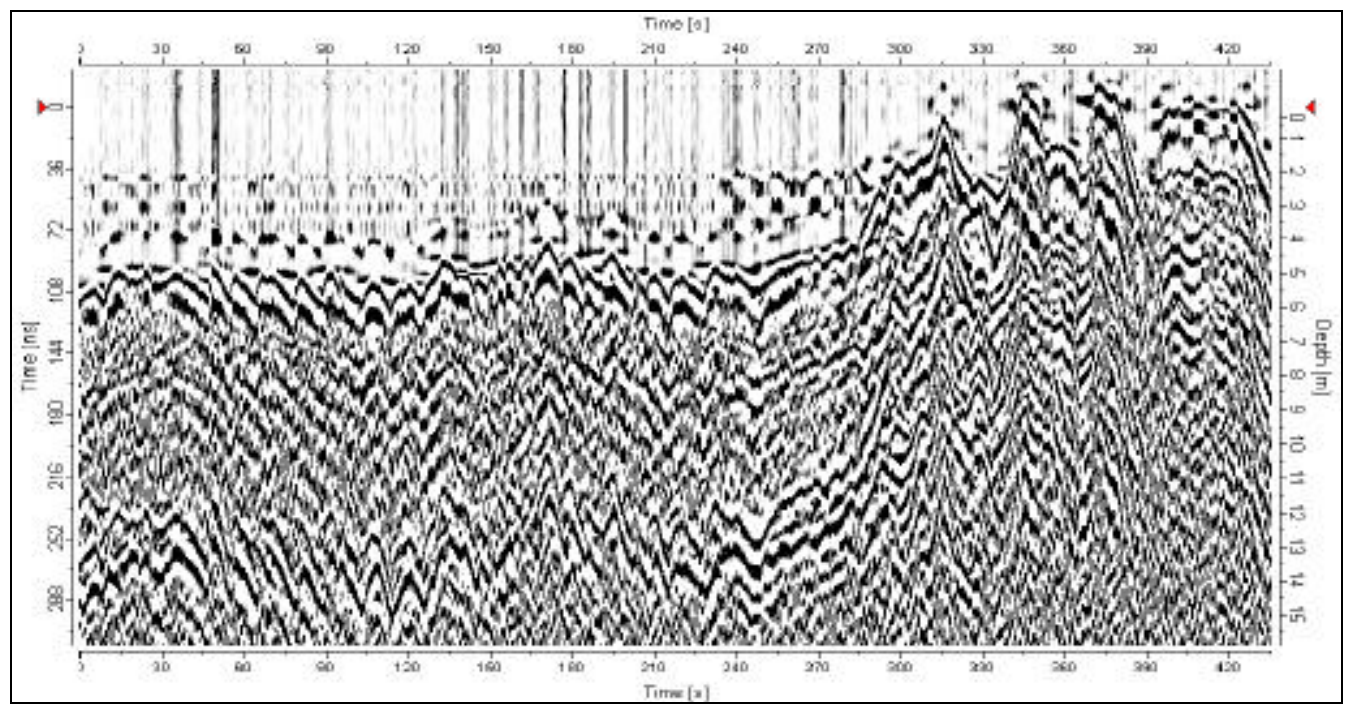

Figura 8.95: Perfil de GPR obtido no rio Paraná em trecho a jusante da Barragem de Porto Primavera, em projeto de estudo de processos de erosão e assoreamento causados pela instalação da Barragem. Neste perfil observa-se a topografia irregular do fundo do rio, resultado da grande mobilidade dos depósitos arenosos que formam a superfície de fundo na área. Registros cedidos pelo IPT (dados inéditos). 


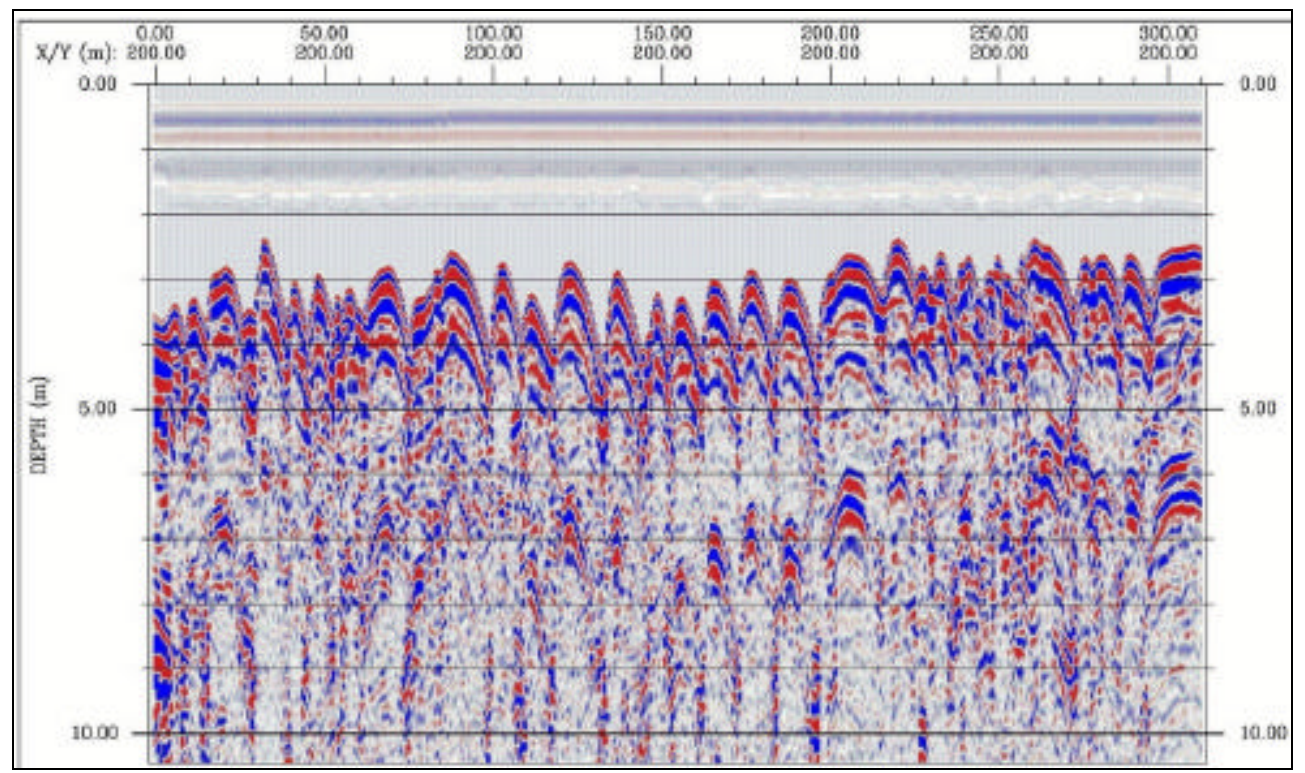

Figura 8.96: Perfil de GPR obtido no rio Taquari, MS, mostrando estruturas sedimentares (ondas de areia) definindo a conformação da superfície de fundo do rio em trecho de intensa dinâmica sedimentar (Souza et al., 2002).

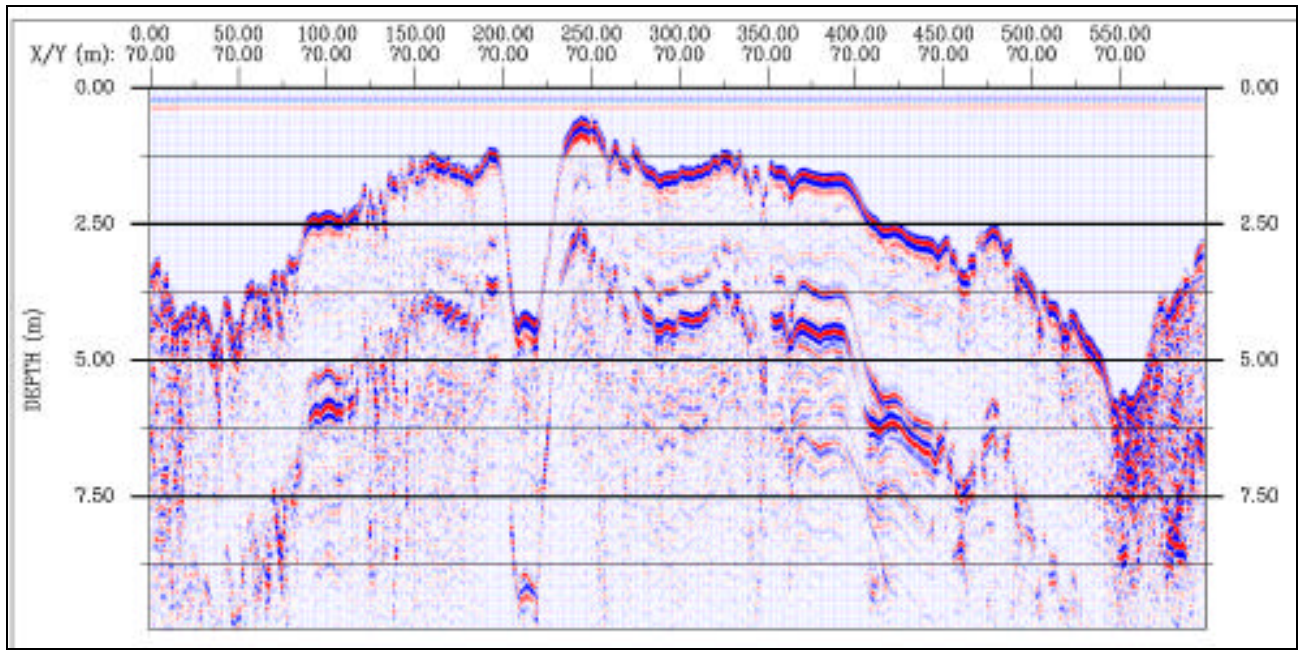

Figura 8.97: Perfil de GPR, obtido no rio Taquari, MS, definindo a conformação irregular da superfície de fundo do rio em trecho de intensa dinâmica sedimentar (Souza et al., 2002).

\subsection{Equipamentos}

O sistema GPR foi originalmente desenvolvido para atuar em terra, sua utilização sobre uma lâmina d'água está ainda em desenvolvimento, e as primeiras experiências realizadas exigiram adaptações e improvisações com relação à flutuabilidade das antenas.

Nos primeiros levantamentos executados em rios e reservatórios, as antenas foram utilizadas de forma improvisada em embarcações de madeira ou em botes infláveis que eram tracionados ou empurrados por uma embarcação principal (Figura 8.98). 


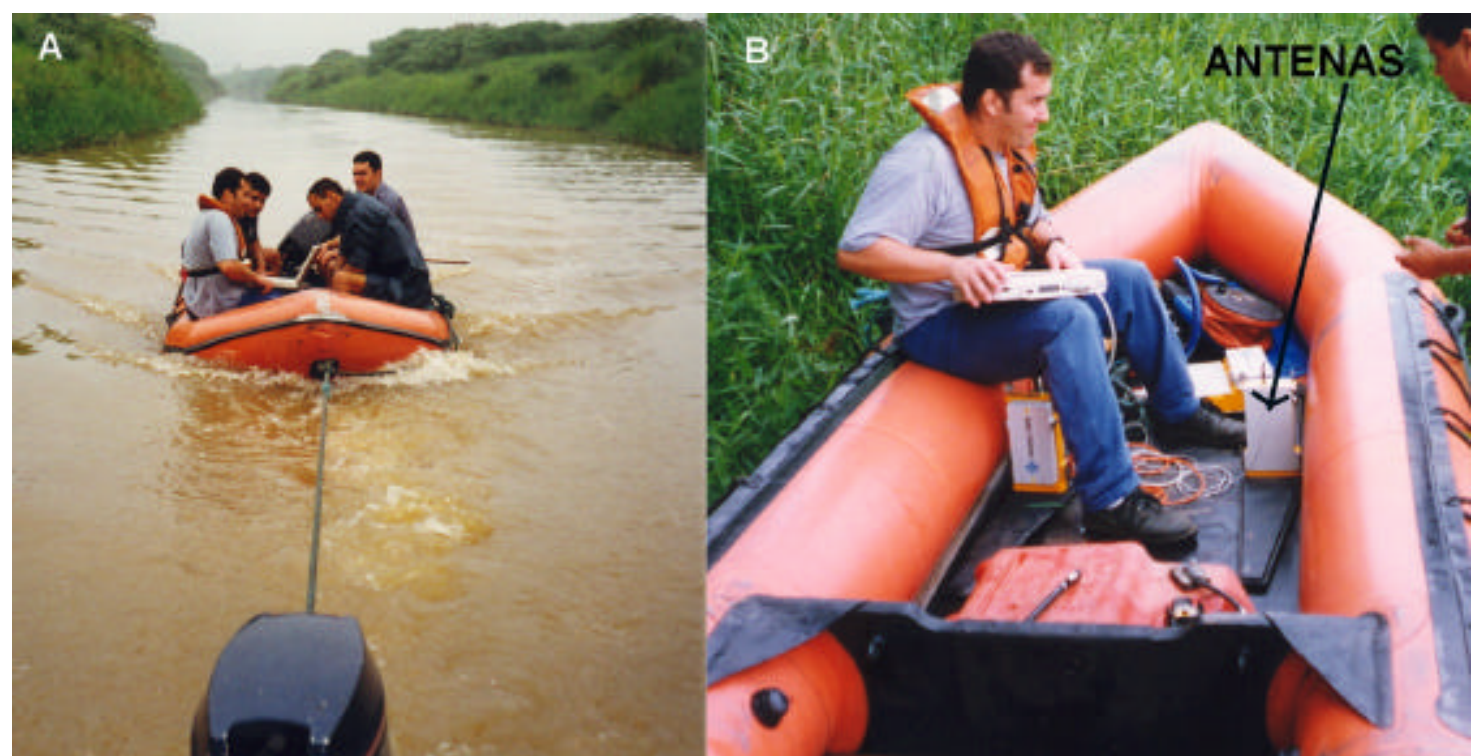

Figura 8.98: Levantamento GPR de áreas submersas: a) sistema instalado em um bote inflável, rebocado por outra embarcação, em operação na represa Billings pela equipe IPT/Cetesb/UFBA; b) vista de detalhe da disposição das antenas no interior do bote. Fotos do autor.

Num segundo momento, o IPT (Instituto de Pesquisas Tecnológicas do Estado de São Paulo) desenvolveu catamarãs especiais construídos com fibra de vidro, num formato adequado ao porte e transporte das antenas do GPR (Figura 8.99), o que proporcionou um avanço não só com relação à maior facilidade operacional na aquisição dos dados, como também na qualidade destes, conseqüência do melhor acoplamento das antenas com a superfície da água.

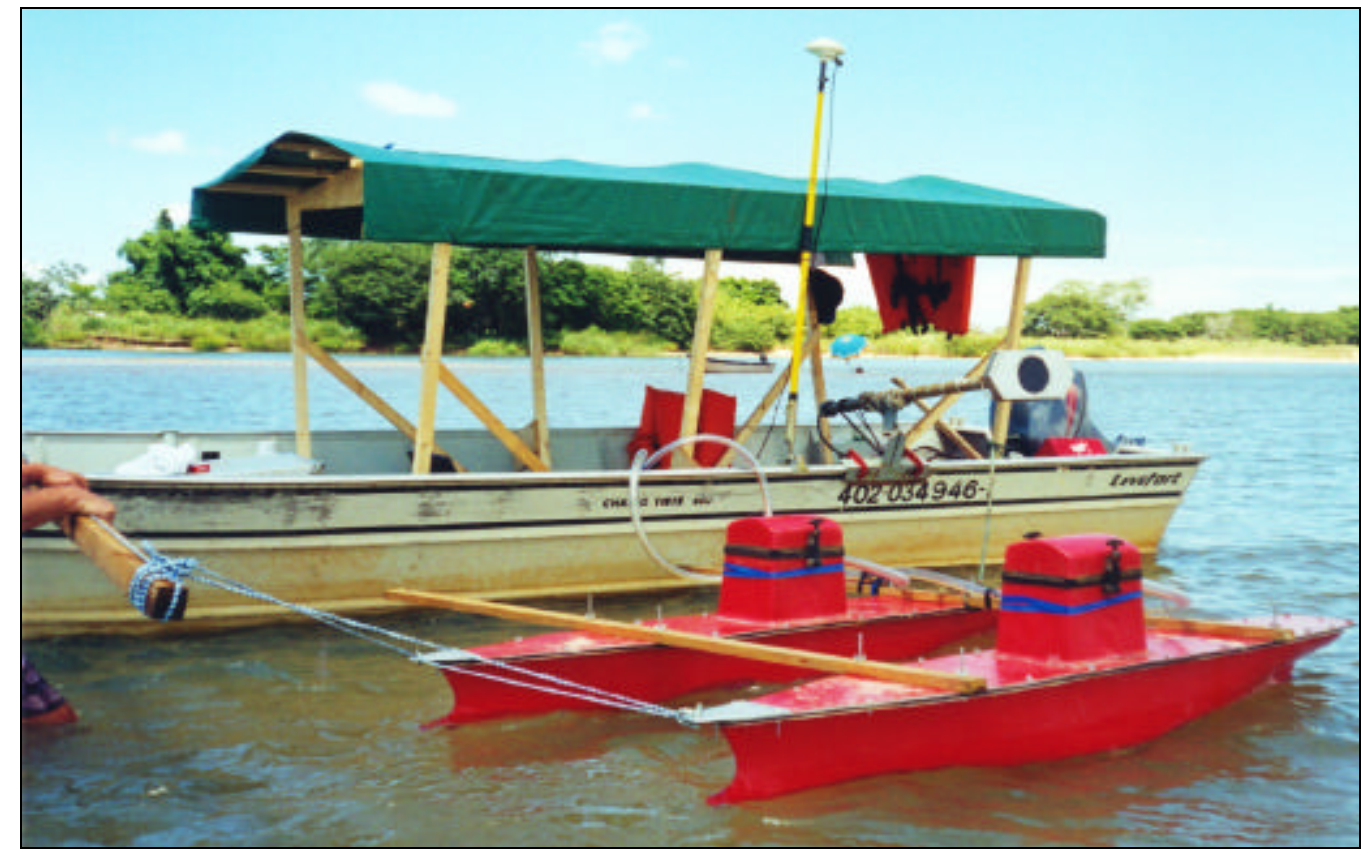

Figura 8.99: Catamarã desenvolvido pelo IPT para utilização do GPR em levantamentos de áreas submersas. Sistema em operação no rio Paraná (SP). Foto do autor. 
A empresa americana ART Engineering LLC executou em julho de 2005 levantamentos com o GPR em água em zona portuária da Filadélfia, EUA no PNBC (Philadelphia Naval Business Center Reserve Basin).

Os levantamentos executados tiveram por objetivo dar suporte técnico a projeto de dragagem em desenvolvimento pela Marinha dos EUA naquela região e, assim, mapear as litologias da subsuperfície de fundo dos canais de navegação, identificando a espessura das camadas de sedimentos finos (siltes/argilas), que jazem sobre as camadas de areia e cascalho que compõem a base sedimentar dos canais estudados. O produto final visou subsidiar cálculos do projeto de dragagem principalmente relacionados com o volume de material a ser dragado.

Com estes objetivos, a ART Engineering desenvolveu um sistema próprio de antenas de GPR submersíveis a até $10 \mathrm{~m}$ de profundidade, acopláveis lateralmente à embarcação, analogamente aos sistemas convencionais de acoplamento de transdutores de ecobatímetros (Figura 8.100).

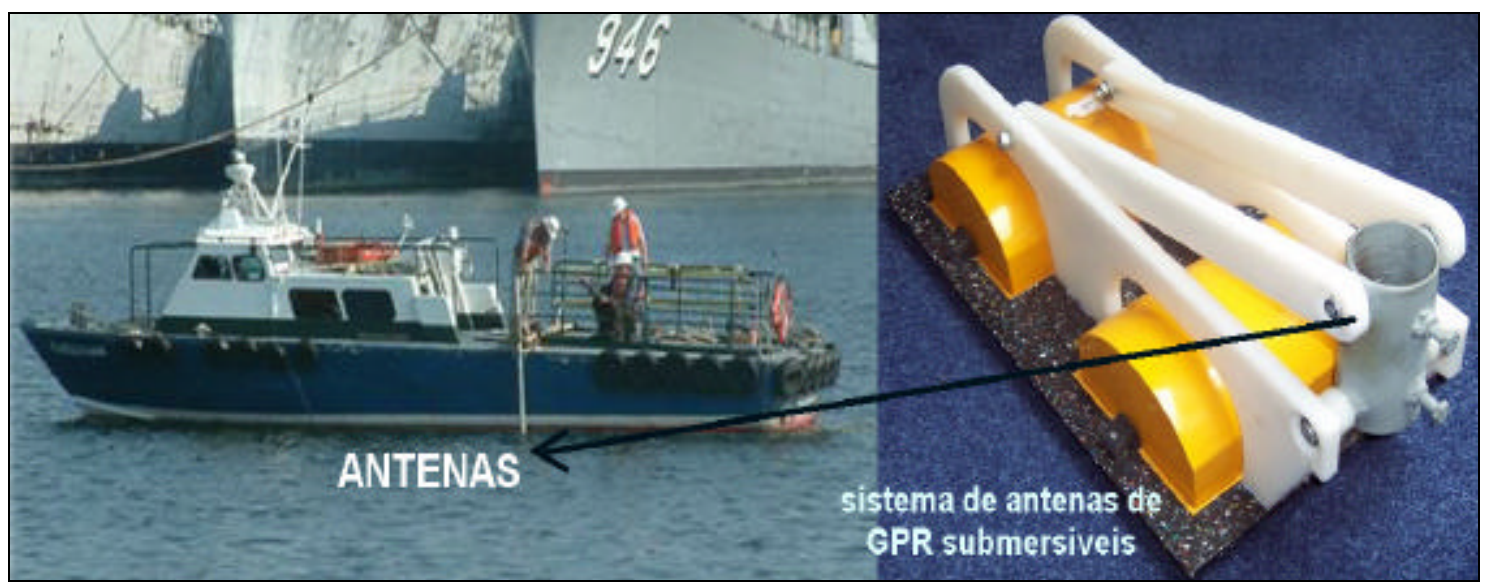

Figura 8.100: Sistema de antenas de GPR submersíveis utilizadas pela empresa americana ArtEngineering LCC. Fotos cedidas por Erik Groenendijk (Art-Engineering LLC, EUA)).

$\mathrm{Na}$ área estudada, a coluna d'água variou entre 3 e 13 m, e a antena do GPR foi submergida a profundidades de até $8.6 \mathrm{~m}$, procedimentos estes que permitiram que o sinal do GPR atravessasse cerca de 3 metros de camadas de sedimentos finos, identificando a posição do topo da camada de sedimentos arenosos (Figura 8.101). A correlação dos dados de GPR com os das sondagens efetuadas na área permitiu a conversão dos dados de tempo de percurso do sinal (nanossegundos) para a real profundidade em metros de cada uma das camadas subjacentes. (Art-Engineering LLC, 2005).

A empresa sueca Mala Geoscience, fabricantes do sistema Ramac, um dos mais populares sistemas de radar, também tem feito experiências com o uso do radar em 
água, em ambientes de baixa condutividade (rios e lagos) e já disponibiliza para aquisição um sistema (RAMAC X3M) com antena de $250 \mathrm{MHz}$.

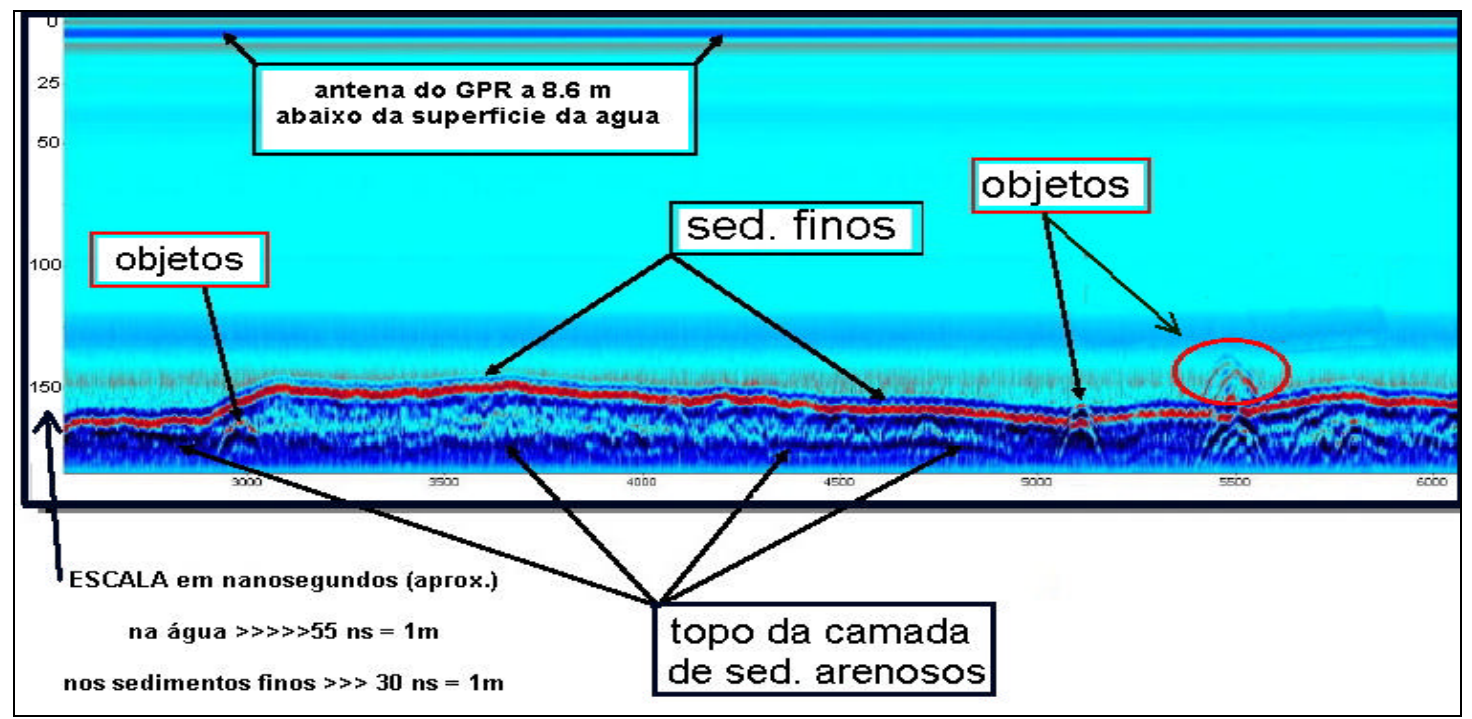

Figura 8.101: Interpretação de um registro de radar obtido em zona portuária da Filadélfia (EUA) onde se identifica uma camada superior de sedimentos finos e destacam-se três pontos com feições que sugerem objetos/estruturas enterradas. Modificado de ART Engineering (2005).

A aquisição de dados é feita com a acomodação das antenas no interior da embarcação (no piso) para garantir a menor distância possível entre a superfície da água e a superfície da antena. Neste caso, inclusive, é importante que o barco não tenha casco duplo, evitando-se desta forma reverberações internas no casco e perda de energia do sinal emitido. Um exemplo de perfil obtido com este sistema está ilustrado na Figura 8.102.

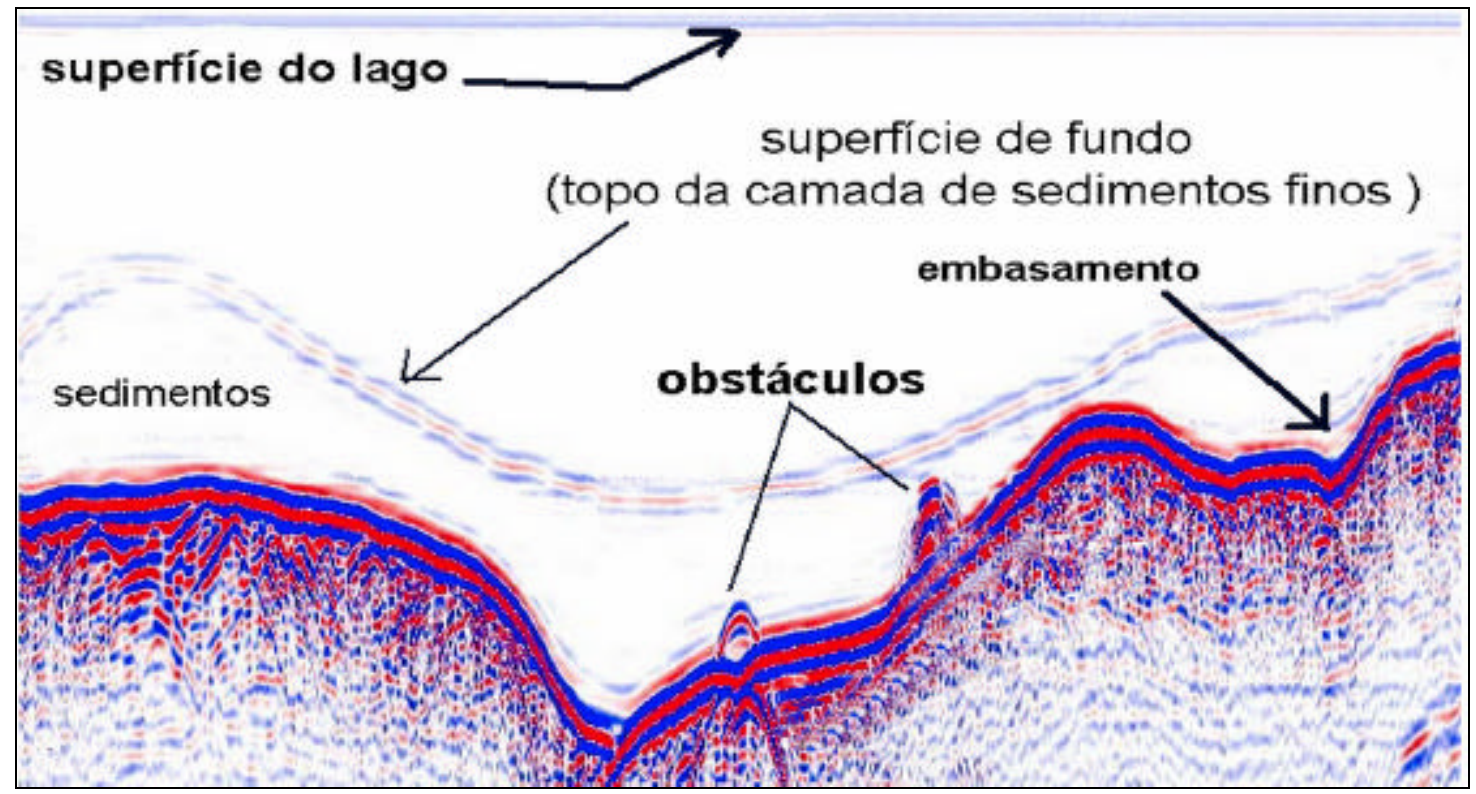

Figura 8.102: Pefil de GPR obtido com o sistema Ramac X3M com antena de $250 \mathrm{MHz}$ ilustrando claramente a superficie de fundo (topo da camada de sedimentos finos) e uma superfície inferior referente ao topo do embasamento (localmente relacionada com tilitos) além de dois pontos anômalos referentes a obstáculos ou objetos enterrados na fina camada de sedimmentos finos ou a afloramentos rochosos. Modificado de Mala Geoscience (2004). 
A impossibilidade da detecção de cabos subaquáticos enterrados no leito do rio Waal, na Holanda, por meio da sísmica, tendo em vista a pequena dimensão dos mesmos, e também por meio da magnetometria, devido ao baixo magnetismo dos cabos elétricos e de telecomunicações, a empresa Holandesa CSO Adviesbureau, desenvolveu juntamente com o Instituto Rijkswaterstaat (instituto governamental responsável pelos rios da Holanda) um sistema GPR dedicado à investigação de áreas submersas rasas.

O sistema criado consiste numa caixa à prova d'água contendo as antenas transmissora e receptora, fixada lateralmente à embarcação por meio de uma haste, que durante a aquisição de dados, é colocada na posição vertical, para garantir o posicionamento das antenas o mais próximo possível da superfície de fundo (Figura 8.103).

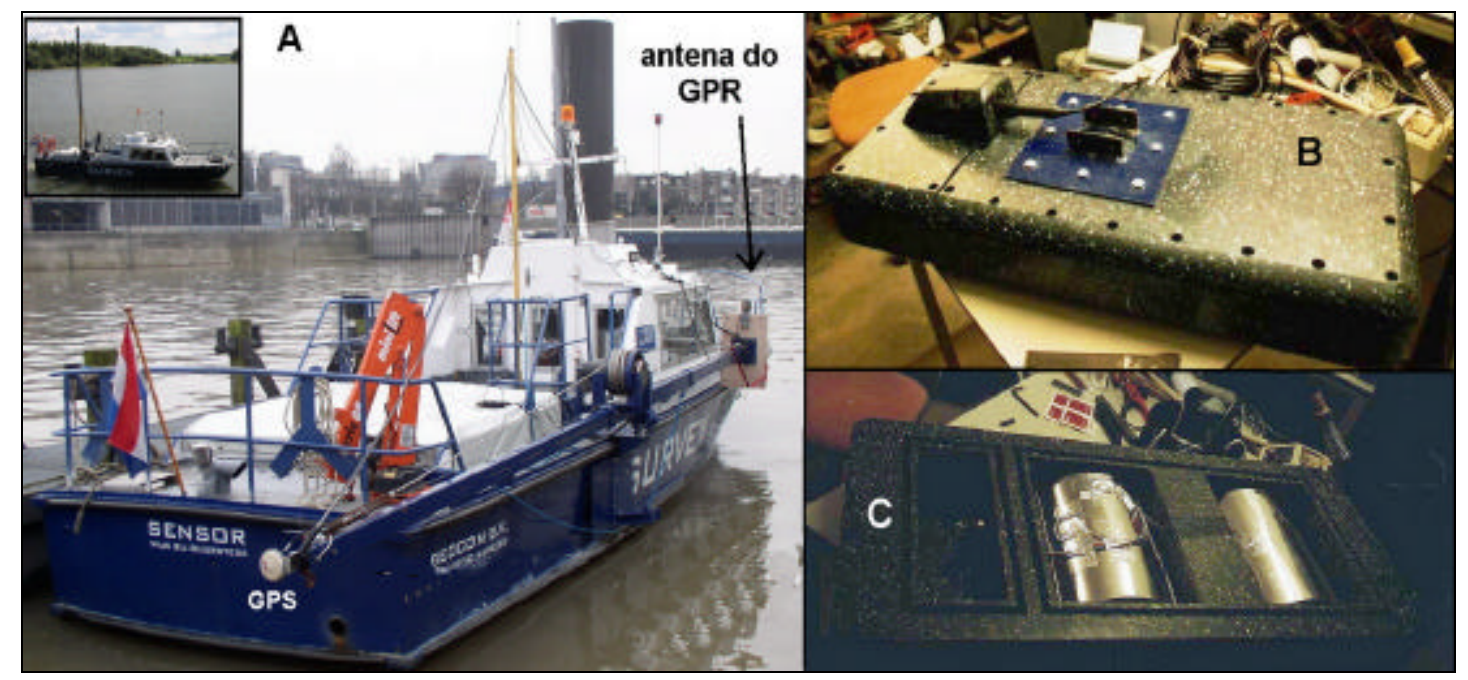

Figura 8.103: Sistema GPR desenvolvido pela CSO Adviesbureau com apoio do Instituto Rijkswaterstaat (Holanda) para emprego na investigação de áreas submersas rasas: a) embarcação adaptada ao sistema GPR. As hastes de suporte das antenas do GPR, bem como do sistema de posicionamento (GPS) são posicionadas na vertical durante a aquisição de dados; b) e c) vistas, com detalhe, da antena, nas posições posterior e inferior, respectivamente. Fotos: cortesia da Dra. Pauline P. Kruiver (CSO Adviesbureau voor Milieuonderzoek)

O registro ilustrado na Figura 8.104 foi obtido no rio Waal, próximo à cidade de Nijmegen, na Holanda. Neste levantamento, as antenas do GPR foram mantidas a cerca de um metro da superfície de fundo, de modo a evitar choque com eventuais anomalias topográficas do leito do rio. Neste registro, observam-se nitidamente hipérboles geradas pelos cabos, objeto da busca, enterrados a cerca de dois metros de profundidade.

Todavia, apesar do excelente desempenho para objetivos desta natureza, o sistema se mostrou ineficiente para detecção de cabos a profundidades superiores a 2,5$3 \mathrm{~m}$, tendo em vista as limitações quanto à penetração dos sinais eletromagnéticos 
emitidos, conforme destacado pela Dra. Pauline P. Kruiver, da CSO Adviesbureau, Holanda (comunicação oral).

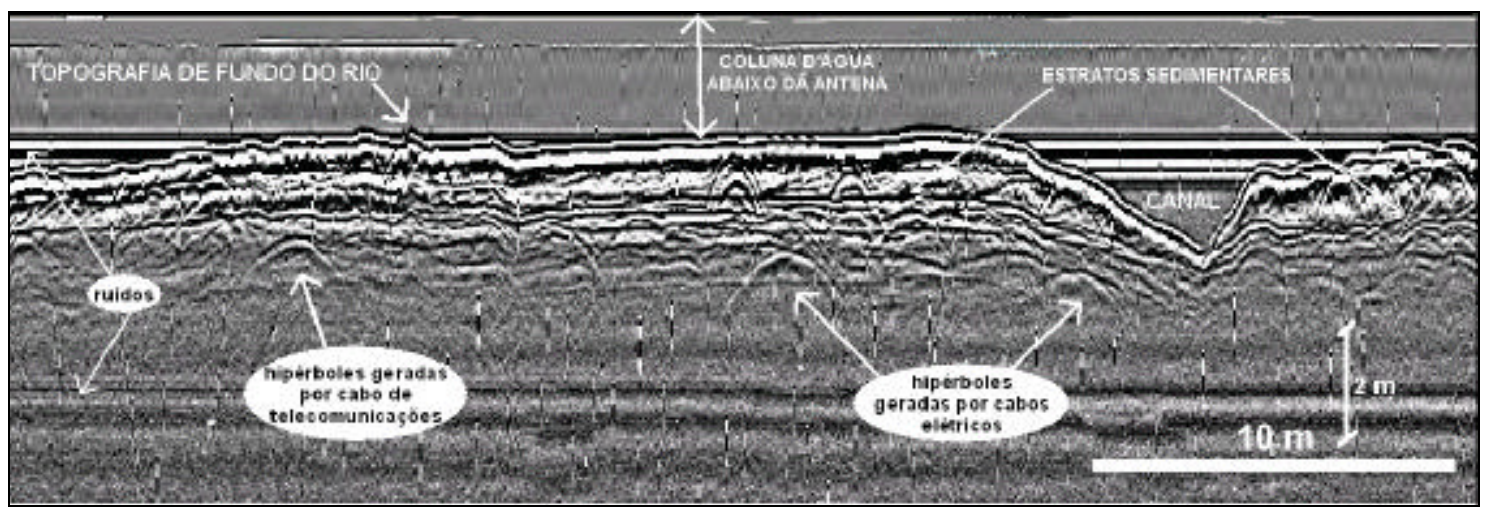

Figura 8.104: Registro de GPR (antena de $500 \mathrm{MHz}$ ) de excelente qualidade, obtido no rio Waal, Holanda, mostrando as principais feições geológicas do substrado do rio (topografia de fundo e estratos sedimentares rasos) além da localização de dutos enterrados, objetivo principal do levantamento executado. Registro cedido pela Dra. P.P. Kruiver, da CSO Adviesbureau voor Milieuonderzoek e pelo Instituto Rijkswaterstaat (Holanda). 


\section{CONSIDERAÇÕES SOBRE A APLICABILIDADE DOS MÉTODOS GEOFÍSICOS NA INVESTIGAÇÃO DE ÁREAS SUBMERSAS RASAS}

O uso de métodos geofísicos, em especial, dos sísmicos, tem crescido de forma notável nos últimos 20 anos, principalmente aqueles dedicados à aplicação na investigação de alvos rasos, na busca de soluções de questões básicas das geociências, relacionadas com os estudos de processos sedimentares atuais e pretéritos, atuantes nas áreas costeiras, plataforma continental interna e em áreas submersas continentais. A utilização de métodos geofísicos tem também crescido de forma relevante visando subsidiar questões geológicas aplicadas, na solução de problemas hidrogeológicos, de engenharia ambiental, de arqueologia e problemas geotécnicos em geral, tanto na investigação em terra como em áreas submersas. Considerações adequadas, quanto às limitações e aplicabilidades, devem ser levadas em conta ao se decidir, diante dos objetivos colocados, por um ou outro método de investigação.

Fontes de energia, arranjos de sensores, geometria do sistema de aquisição de dados e o próprio processamento dos dados são alguns dos parâmetros que devem ser escolhidos cuidadosamente no planejamento de uma determinada investigação. Para cada situação, para cada objetivo traçado, um determinado método geofísico oferecerá a melhor solução. Não são raros na literatura aplicada, exemplos de condução equivocada de projetos que se utilizam de métodos inadequados na busca da solução para determinadas questões. Tal fato ocorre não só devido ao eventual desconhecimento do usuário das reais potencialidades de um determinado método, mas também, e não raramente, pela indisponibilidade de equipamentos adequados para a devida condução de um projeto de investigação.

São muitas as possibilidades operacionais quando se lida com métodos geofísicos. No caso dos métodos sísmicos, por exemplo, a escolha do tipo de fonte acústica, que por sua vez está relacionada com a técnica a ser empregada, constitui-se na principal ação a ser analisada e decidida no planejamento dos ensaios. Cada tipo de fonte acústica, ou seja, cada espectro de freqüências emitido pelas fontes acústicas oferece resultados específicos e tem aplicações específicas na resolução de questões distintas. Em algumas situações, inclusive, não muito raras, o melhor procedimento a ser adotado passa pela utilização simultânea de mais de uma fonte sísmica, de modo a se 
obter uma abordagem mais ampla do problema investigado, minimizando-se assim eventuais ambigüidades na interpretação dos resultados.

\subsection{Alguns CONCEITOS GEOFÍSICOS}

Ao se utilizarem métodos geofísicos para a investigação de uma determinada área, é fundamental que se compreendam alguns aspectos conceituais, em especial aqueles relacionados com suas limitações.

Um dos aspectos fundamentais na geofísica aplicada está relacionado com a compreensão da detectabilidade de um determinado método.

A detecção das variações das propriedades físicas dos meios geológicos requer contrastes fortes e evidentes.

Cada método geofísico tem seu próprio poder de detecção para cada propriedade física específica do meio investigado. No caso da investigação de áreas submersas através da sísmica, os parâmetros físicos analisados estão diretamente relacionados com as propriedades elásticas e a densidade (D) do meio que, por sua vez, caracterizam a velocidade de propagação das ondas acústicas (V) definindo a impedância acústica do meio $(\mathrm{I}=\mathrm{V}$ x D). Para que as interfaces entre as camadas sejam detectadas por meio da sísmica, há necessidade da ocorrência de fortes contrastes de impedância acústica entre os meios.

O som se propaga nas camadas rasas de sedimentos inconsolidados no fundo do mar, dos reservatórios ou rios, em velocidades que variam entre 1450 e $1600 \mathrm{~m} / \mathrm{s}$. Nas rochas, esta velocidade pode atingir $6000 \mathrm{~m} / \mathrm{s}$, como é o caso das rochas calcárias. Contrastes desta ordem de grandeza, ou seja, sedimentos depositados sobre um embasamento rochoso, geram interfaces sísmicas que representam alto contraste de impedância acústica, sendo facilmente identificadas numa seção sísmica. Por outro lado, o contato, por exemplo, entre camadas de sedimentos arenosos inconsolidados pode não ser identificado ou detectado por meio de métodos sísmicos, já que representa interface entre camadas com propriedades físicas muito semelhantes, que podem não apresentar contrastes de impedância acústica detectáveis pelos métodos sísmicos. Alternâncias entre sedimentos finos, areias e cascalhos, por outro lado, proporcionam um perfil geológico com contatos entre as camadas comumente detectáveis por este método. 
Este raciocínio sobre a detectabilidade pode ser extrapolado para outros métodos geofísicos aplicáveis na investigação de áreas submersas. Analogamente, na magnetometria, por exemplo, há necessidade da existência de contrastes conspícuos entre as propriedades magnéticas dos materiais para que anomalias sejam detectadas por meio deste método de investigação. Uma tubulação metálica, por exemplo, encravada em sedimentos arenosos, certamente proporcionará contrastes magnéticos evidentes, o que propiciará sua identificação por meio da magnetometria. Uma tubulação de material plástico, ao contrário, não seria detectada por este método de geofísico.

A resolução e a penetração constituem-se em dois outros conceitos que devem ser abordados com cuidado ao se planejar um levantamento geofísico.

Por resolução, entende-se a capacidade de um método geofísico detectar dois objetos distintos na superfície (resolução horizontal) ou em subsuperfície (resolução vertical) e está diretamente relacionada com o espectro de freqüências emitido pela fonte acústica: freqüências altas oferecem boa resolução; freqüências baixas, boa penetração mas, pobre resolução. Optar pela utilização de um ou de outro sistema está diretamente relacionada com os objetivos do projeto de investigação.

A resolução vertical constitui-se num dos principais aspectos a ser considerado em estudos estratigráficos, pois é definida como a capacidade do sistema acústico de identificar ou distinguir estratos sedimentares, e está diretamente relacionada com a duração do pulso emitido: quanto mais curto o pulso emitido, maior a capacidade de discriminação ou maior a resolução vertical do sistema.

A Figura 9.1 ilustra o conceito de resolução vertical mostrando uma camada de sedimentos de espessura $\mathbf{E}$ na qual o som se propaga numa velocidade Vs, sendo ?t o intervalo de tempo entre dois pulsos e Lt o comprimento do pulso. Se se considerar um ângulo de incidência praticamente normal, ?t $=\mathbf{2} \times \mathbf{E} / \mathbf{V s}$, ou seja, dois pulsos serão distinguíveis à medida que a separação, em tempo, entre eles seja maior ou igual ao comprimento do pulso, também em tempo, e, assim, a resolução é inversamente proporcional ao comprimento do pulso.

Este aspecto torna-se ainda mais importante quando da investigação de áreas rasas ou muito rasas, onde se tem a expectativa, a priori, de encontrar estratos sedimentares de espessuras muito finos, devido à própria natureza dos processos que os originam. Em algumas situações, a identificação detalhada da espessura das camadas 
sedimentares superficiais (rasas) é até mesmo mais relevante que a própria penetração do sinal acústico a grandes profundidades. O custo de operações de dragagens em portos, por exemplo, é quantificado em termos de metros cúbicos de lama a serem dragados. Um erro de $10 \mathrm{~cm}$ na determinação da espessura dos estratos finos superficiais a serem dragados, constitui-se num erro de $1 \mathrm{~m}^{3}$ em cada $10 \mathrm{~m}^{2}$ de área dragada, o que significa uma razoável elevação no custo final do projeto (Cobo et al., 2005).

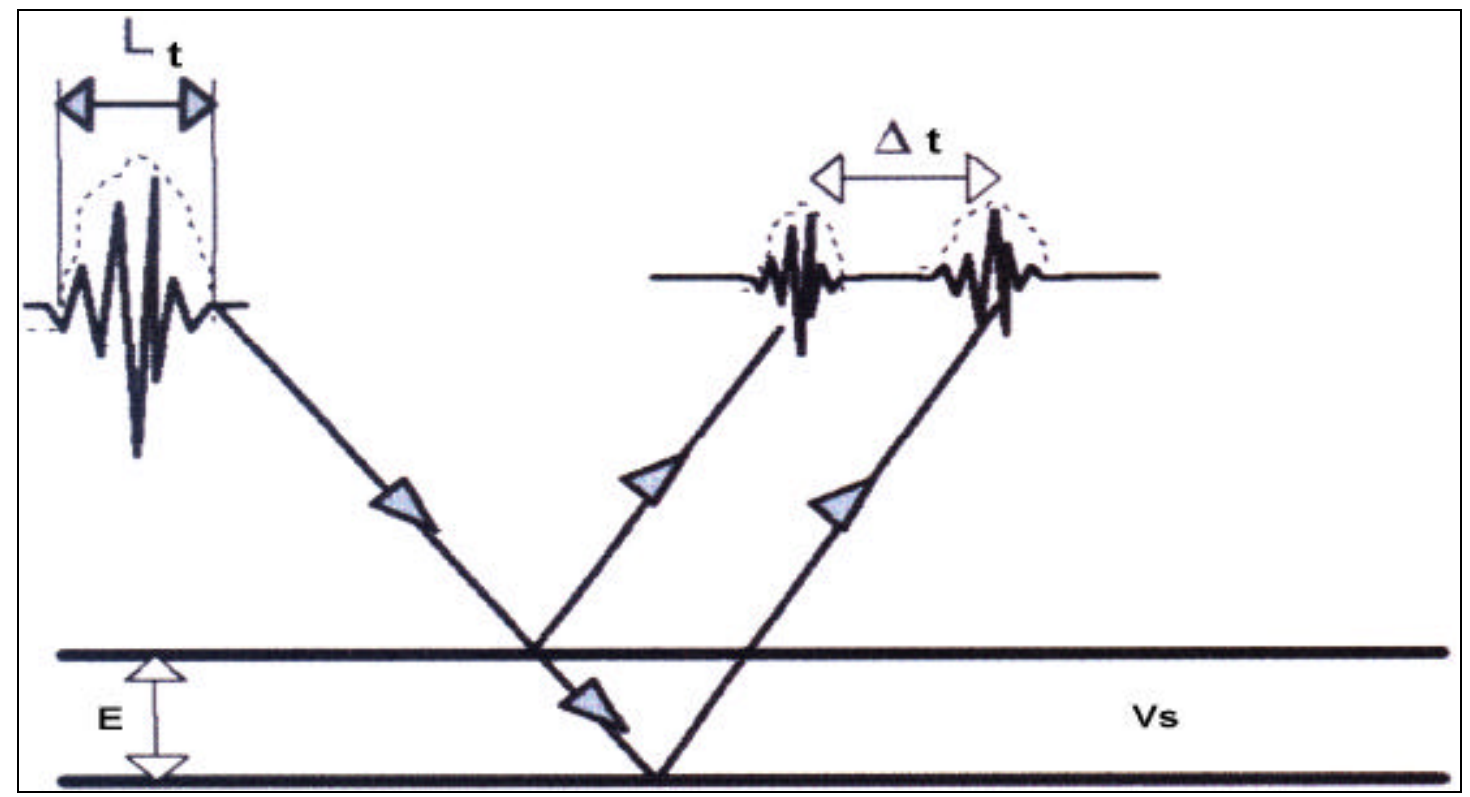

Figura 9.1: Resolução vertical de um pulso sísmico. E é a espessura; ? t é o intervalo de tempo entre dois pulsos e Lt, o comprimento do pulso. Modificado de Cobo et al. (2005).

Outra forma de abordagem do tema resolução vertical é do ponto de vista do conteúdo de frequiências dos sinais emitidos tendo em mente as seguintes questões: a) qual a espessura mínima de um pacote sedimentar para que as reflexões oriundas da base e do topo do estrato não interfiram uma na outra? b) qual a menor espessura de uma camada sedimentar para que possa ser detectada?

A Figura 9.2 mostra que os sinais refletivos no topo e na base de uma camada sedimentar, serão identificados como tal desde que a camada sedimentar tenha espessura maior ou igual à metade do comprimento de onda do sinal emitido, ou seja, topo e base das camadas não serão individualizados (Badley, 1985). Assim, conforme ilustra a tabela contida na figura, que toma como exemplo sinais acústicos com frequiência principal de $50 \mathrm{~Hz}$ (típico de investigação profunda) e $1000 \mathrm{~Hz}$ (típico de investigação rasa), as espessuras mínimas detectadas por estes sistemas, são, 50 m e 1 m, respectivamente. Outros exemplos de espessuras mínimas teóricas, detectáveis por 
sistemas acústicos comumente utilizados na investigação rasa, podem ser observados na tabela Tabela 9-1, construída pelo autor mas baseada em Badley (1985).

Observa-se, entretanto, que os valores de espessuras apresentados nestas planilhas têm a intenção tão somente de mostrar a ordem de grandeza das espessuras mínimas de estratos sedimentares identificáveis a partir dos métodos acústicos, pois, além do conteúdo de frequiência, existem vários outros fatores que afetam a resolução vertical, desde a própria natureza do meio investigado, ao desempenho da fonte acústica (relação sinal/ruído).

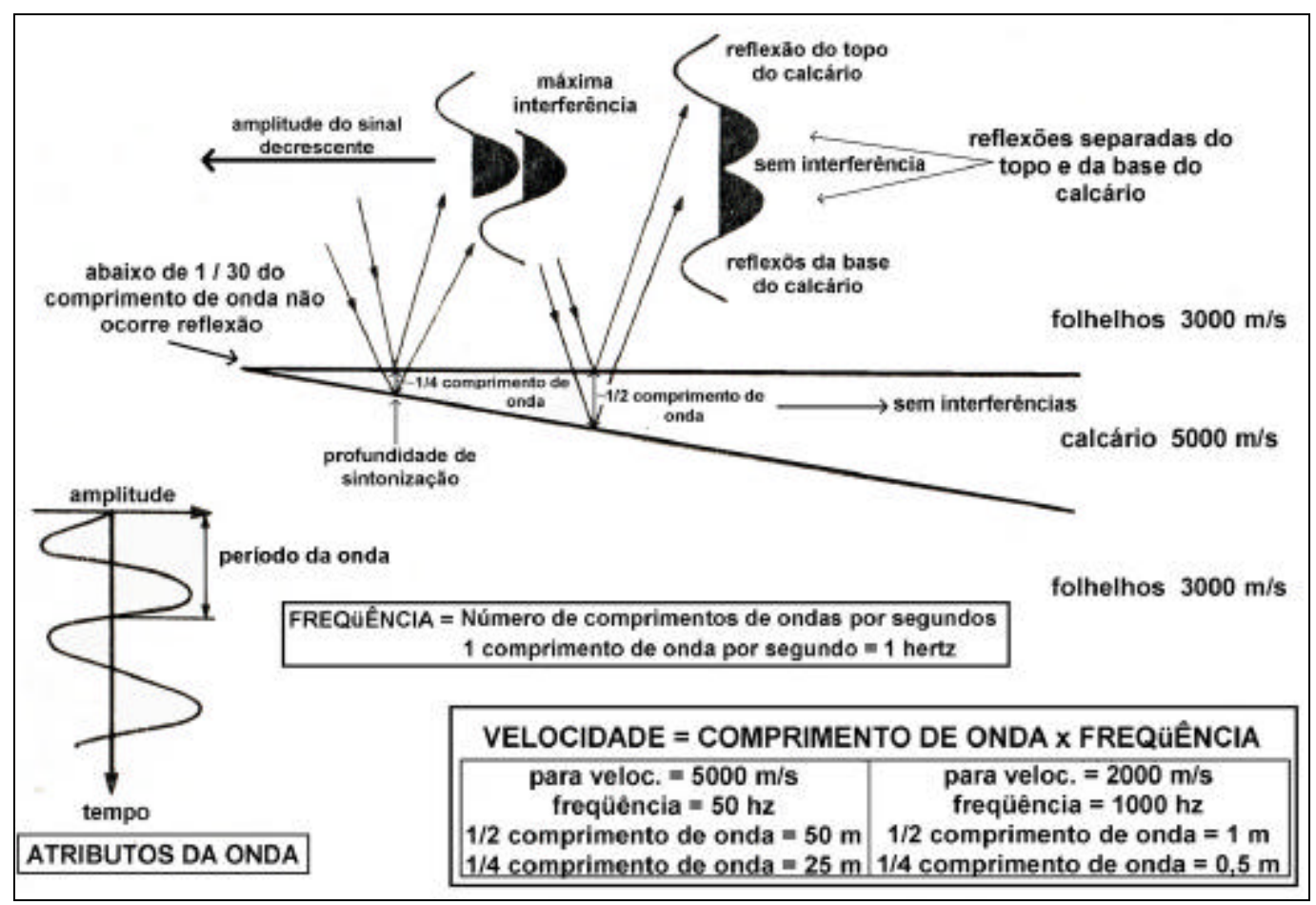

Figura 9.2: Interferências entre os sinais acústicos que condicionam a identificação das espessuras das camadas sedimentares e dos correspondentes, topo e base. Observa-se nesta figura que a espessura de um estrato será identificada se ela for maior que $1 / 4$ do comprimento de onda do sinal acústico emitido; topo e base das camadas só serão identificados se a espessura do pacote sedimentar for maior que $1 / 2$ do comprimento de onda do sinal acústico emitido. Modificado de Badley (1985).

\begin{tabular}{|c|c|c|c|c|c|}
\hline \multicolumn{2}{|c|}{ EXEMPLOS DE FONTES ACÚSTICAS } & \multicolumn{4}{|c|}{ RESOLUÇÃO VERTICAL (Teórica) } \\
\hline \multirow[b]{2}{*}{ fonte acústica } & \multirow{2}{*}{$\begin{array}{c}\text { freqüências } \\
\text { principais } \\
\text { emitidas }(\mathrm{Hz})\end{array}$} & \multicolumn{2}{|c|}{$\begin{array}{c}\text { espessura minima para detecção da } \\
\text { presença da camada }(\mathrm{m})\end{array}$} & \multicolumn{2}{|c|}{$\begin{array}{l}\text { espessura minima para detecção do } \\
\text { topo e da base da camada }(\mathrm{m})\end{array}$} \\
\hline & & $\mathrm{p} / \mathrm{V}=1600 \mathrm{~m} / \mathrm{s}$ * & $\mathrm{p} / \mathrm{V}=2000 \mathrm{~m} / \mathrm{s}^{*}$ & $\mathrm{p} / \mathrm{V}=1600 \mathrm{~m} / \mathrm{s}^{*}$ & $\mathrm{p} / \mathrm{V}=2000 \mathrm{~m} / \mathrm{s}^{*}$ \\
\hline sparker / airgun & 50 & 8.00 & 10.00 & $\begin{array}{l}16.00 \\
\end{array}$ & 20.00 \\
\hline sparker / boomer & 500 & 0.80 & 1.00 & 1.60 & 2.00 \\
\hline boomer/chirp & 1000 & 0.40 & 0.50 & 0.80 & 1.00 \\
\hline chirp / boomer & 2000 & 0.20 & 0.25 & 0.40 & 0.50 \\
\hline chirp / sbp & 3500 & 0.11 & 0.14 & 0.23 & 0.29 \\
\hline$s b p$ & 7000 & 0.06 & 0.07 & 0.11 & 0.14 \\
\hline sbp & 14000 & 0.03 & 0.04 & 0.06 & 0.07 \\
\hline pinger & 24000 & 0.02 & 0.02 & 0.03 & 0.04 \\
\hline
\end{tabular}

Tabela 9-1: Exemplos de resolução vertical teórica obtidos a partir dos espectros de frequiências emitidos pelas fontes acústicas de emprego comum na investigação geofísica rasa, baseado no princípio das interferências entre os sinais refletidos. 
A penetração, por outro lado, relaciona-se com o espectro de freqüências emitidas pela fonte, de maneira inversa, ou seja, com espectro de freqüências mais baixas ocorre maior penetração.

Assim, na investigação para petróleo, por exemplo, cujo objetivo é a investigação profunda, as freqüências dos sinais acústicos utilizados são comumente inferiores a $300 \mathrm{~Hz}$. Emitindo-se espectro de freqüências desta natureza, fontes sísmicas de alta energia são empregadas e grandes profundidades são alcançadas (milhares de metros), com prejuízo da resolução, pois neste caso camadas sedimentares finas (de algumas dezenas de metros) não são identificadas tampouco distinguidas uma das outras.

Ao contrário, quando se utilizam fontes sísmicas que emitem altas freqüências, camadas decimétricas podem ser identificadas, mas com prejuízo da penetração do sinal, que comumente não ultrapassa algumas dezenas de metros. Daí a aplicação distinta para cada tipo de fonte acústica.

Outro conceito que deve ser levado em conta, ao efetuar-se um levantamento geofísico, é a amostragem a ser realizada, ou seja, a densidade de dados a serem coletados.

Perfis transversais e longitudinais, adequadamente espaçados e em quantidades compatíveis com a escala do levantamento, são essenciais para a obtenção dos resultados desejados, sob pena de não serem detectadas importantes características do fundo e subfundo da área investigada.

Em levantamentos de reconhecimento, não se tem a expectativa da caracterização detalhada da superfície de fundo de um setor específico e, portanto, os perfis são executados a distâncias um do outro que não vão permitir a análise detalhada, mas, por outro lado, possibilitarão a abordagem conjunta e global da área investigada, e desta forma o planejamento de ensaios complementares e detalhados nos trechos de maior interesse.

Outro conceito básico que se deve levar em conta ao se lidar com dados geofísicos é o da precisão.

As medidas geofísicas, propriamente ditas, são muito precisas, em particular nos dias de hoje, tendo em vista a evolução dos equipamentos geofísicos em decorrência 
do progresso da tecnologia eletrônica. A mesma afirmação, todavia não pode ser extrapolada para a interpretação dos dados geofísicos.

Os resultados obtidos de levantamentos geofísicos executados para a determinação das propriedades físicas dos meios geológicos, são precisos, entretanto, não são, necessariamente, correlacionáveis direta e univocamente com um tipo específico de material que compõe o meio investigado. Sempre existirá mais de um tipo de material que possuirá semelhantes propriedades físicas e, portanto, mesmos "números" poderão ser obtidos para distintos materiais. Tal fato gera, por si só, inevitáveis ambigüidades na interpretação dos dados. A solução para este impasse, obrigatoriamente, passa pela associação dos dados obtidos, com dados oriundos da utilização de outras ferramentas de investigação. Um único método geofísico raramente fornece informações suficientes sobre as condições de subsuperfície, para serem usados sem dados adicionais oriundos de amostragens, testemunhagens, sondagens, fotografias, vídeos submarinos ou de outros ensaios geofísicos (Morang et al., 1997).

\subsection{CONSIDERAÇÕES SOBRE A BATIMETRIA E CARÁTER DO ECO}

Quando se trata de investigação da superfície de fundo pura e simples, ou seja, o objetivo é a manipulação dos dados obtidos para que se identifique com precisão a espessura da coluna d'água e, portanto, a topografia da superfície de fundo, a ecobatimetria constitui-se no método de investigação ideal, basicamente por sua objetividade, baixo custo e pela rapidez na execução dos levantamentos.

No começo do século passado, a identificação da espessura da coluna d'água era realizada por meio de um peso posicionado na ponta de uma corda. Desde então rápido, progresso tecnológico tem ocorrido e os fenômenos relativos à propagação do som na água passaram a ser utilizados com esta finalidade.

Assim, os equipamentos utilizados atualmente para a medição da espessura da coluna d'água são extremamente portáteis e muito fáceis de ser manipulados e transportados em qualquer tipo de embarcação. Para esta finalidade, as fontes sísmicas empregadas são aquelas que emitem sinais acústicos de altas freqüências (comumente entre 50 e $200 \mathrm{kHz}$ ) possibilitando tomar a medida da coluna d'água com precisão milimétrica.

São várias a aplicações deste método de investigação. Nos estudos relativos à hidrovias, por exemplo, a utilização destas ferramentas possibilita a geração de mapas 
náuticos ou batimétricos que, entre outras funções, subsidiarão os projetos de rotas de navegação.

$\mathrm{Na}$ investigação de áreas dragadas, este método é utilizado com sucesso, pois, por meio da comparação entre curvas batimétricas obtidas antes e depois das operações de dragagens, é possível a avaliação do volume de material (rochas ou sedimentos) retirado da área dragada. Observa-se, todavia, que se houver a necessidade do conhecimento prévio do volume do material a ser dragado, ou seja, a identificação das espessuras da cobertura sedimentar dragável, a ecobatimetria não é o método indicado, já que as altas freqüências emitidas não penetram no substrato e, portanto, os resultados não permitirão a análise desejada. Neste caso, métodos sísmicos com fontes acústicas de maior potência (boomers, sparkers) e que, portanto, emitem espectros com freqüências mais baixas, devem ser utilizadas.

Levantamentos batimétricos são também realizados em reservatórios com objetivo análogo, qual seja, a comparação entre curvas batimétricas de um mesmo perfil, obtidas em épocas diferentes. A análise das diferenças entre estas curvas ao longo do tempo possibilita concluir-se sobre a evolução dos processos de assoreamento do reservatório desde sua construção ou em períodos predeterminados.

A análise de curvas batimétricas obtidas em levantamentos periódicos e sistemáticos permite a constante avaliação do processo evolutivo do reservatório e, por conseguinte, das variações do volume útil ao longo do tempo, que representa um parâmetro fundamental em qualquer análise que se faça de um reservatório. Normalmente ocorre que muitos reservatórios no Brasil não possuem dados históricos que permitam esta retro-análise tendo em vista a inexistência de curvas batimétricas pretéritas e, nestes casos, a análise da evolução de um reservatório com relação à sua vida útil não é possível. Nestas situações, ocorre a necessidade de se determinar a espessura atual da camada de sedimentos, o que não pode ser feito por meio da batimetria, e sim pela perfilagem sísmica utilizando-se de fontes acústicas de maior potência e que lidam com espectros de freqüências mais baixos.

\subsubsection{CARACTERÍSTICAS DA FONTE ACÚSTICA}

A execução de um levantamento ecobatimétrico é operacionalmente simples. Entretanto, alguns cuidados devem ser tomados quando da escolha do tipo de 
equipamento a ser utilizado, ou seja, qual o tipo de fonte acústica ideal para os objetivos traçados.

Equipamentos que emitem espectros de frequiência mais baixos possuem maior energia e alcançam maiores profundidades de investigação. Por outro lado, considerando-se que o feixe principal de sinais emitidos pelo transdutor de um ecobatímetro tem formato de um cone (Figura 9.3), a geometria do sistema constitui-se num fator de extrema relevância no controle da resolução do sistema adotado. Cones de sinais com ângulos mais amplos amostram grandes áreas da superfície de fundo e afetam negativamente a resolução do sistema. O contrário ocorre quando se utilizam sistemas que emitem feixes de sinais estreitos.

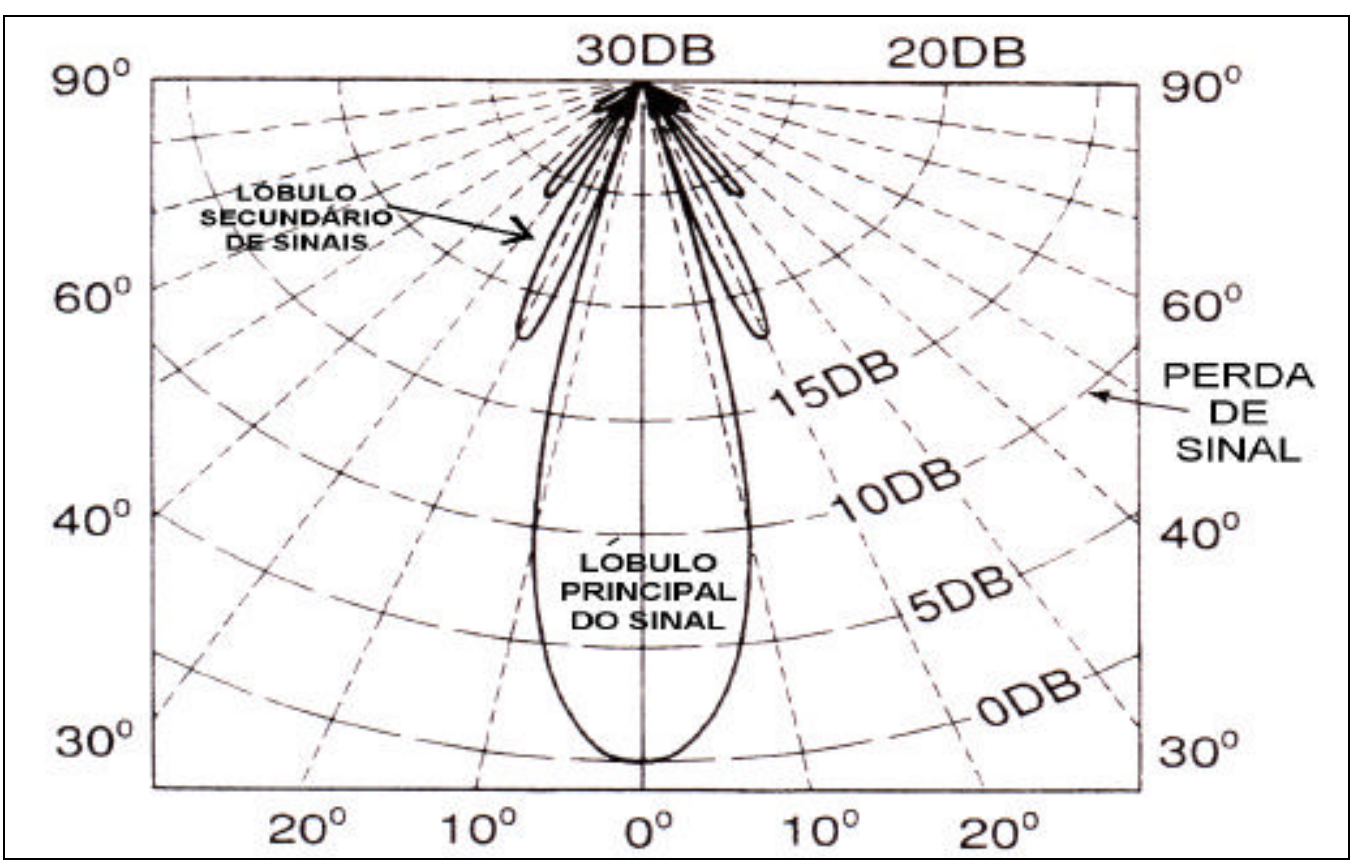

Figura 9.3: Padrão geral da diretividade de um transdutor de um ecobatímetro. Notar a perda de amplitude do sinal com o aumento da distância da fonte acústica. Modificado de Jones (1999).

Numa investigação batimétrica, em uma área com coluna d'água de 5000 m, por exemplo, utilizando-se de um sistema cujo cone principal de sinais tem ângulo de abertura de $40^{\circ}$, a projeção dos sinais emitidos na superfície de fundo atinge uma área de 3,6 km de diâmetro. O sinal que retorna desta enorme área amostrada na superfície de fundo vai ser interpretado pelo sistema como um único ponto e conforme ilustrado na Figura 9.4 e na Figura 9.5, perde-se resolução, pois feições topográficas importantes da superfície de fundo certamente não serão detectadas.

Utilizando, neste mesmo exemplo, um sistema com o cone de sinais de ângulo de abertura de apenas $1^{\circ}$, a projeção do sinal na superfície de fundo vai definir uma área 
com diâmetro de apenas $0,087 \mathrm{~km}$, possibilitando a detecção de detalhes da superfície de fundo e desta forma, maior resolução.

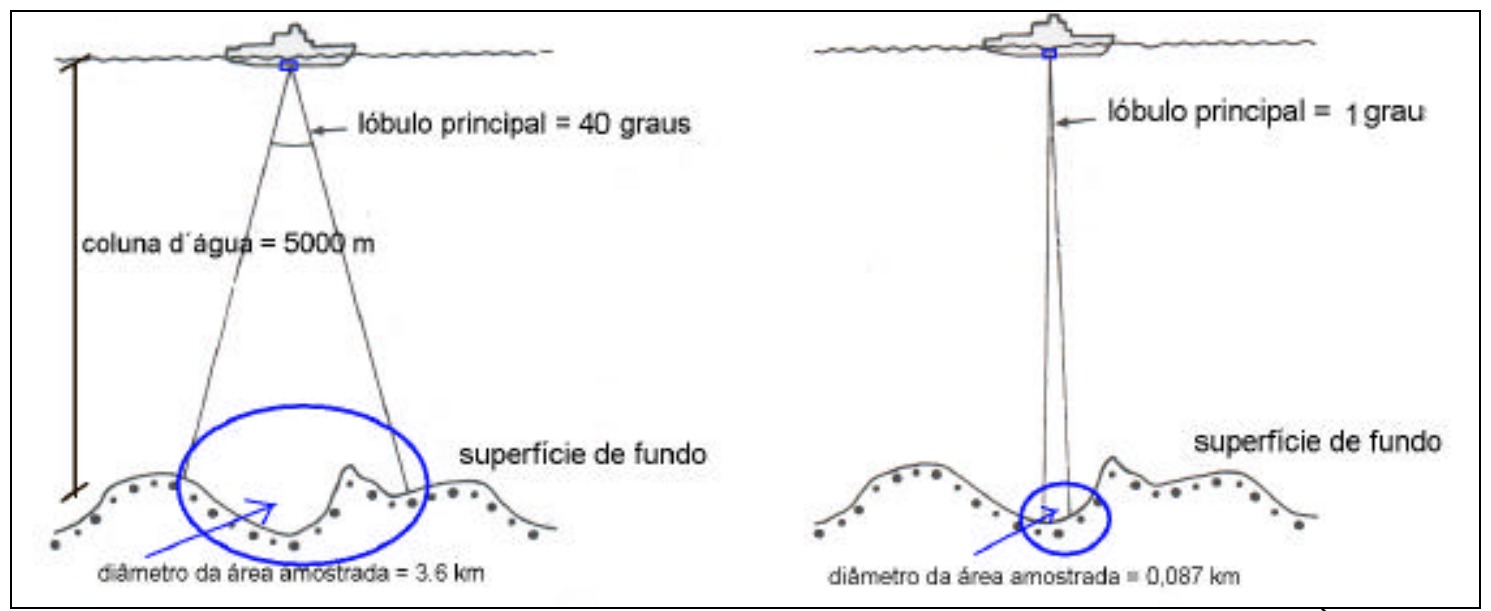

Figura 9.4: Padrões de ângulos de abertura dos feixes de finais emitidos por ecobatímetros. À esquerda, ilustra-se um feixe de sinais de ângulo maior, que projeta o sinal acústico sobre grande área na superfície de fundo, tornando pobre a resolução do sistema; à direita, feixe de sinais com ângulo pequeno, o que possibilita maior resolução na informação adquirida, já que menor área da superfície de fundo é amostrada em cada pulso emitido. Modificado de Jones (1999).

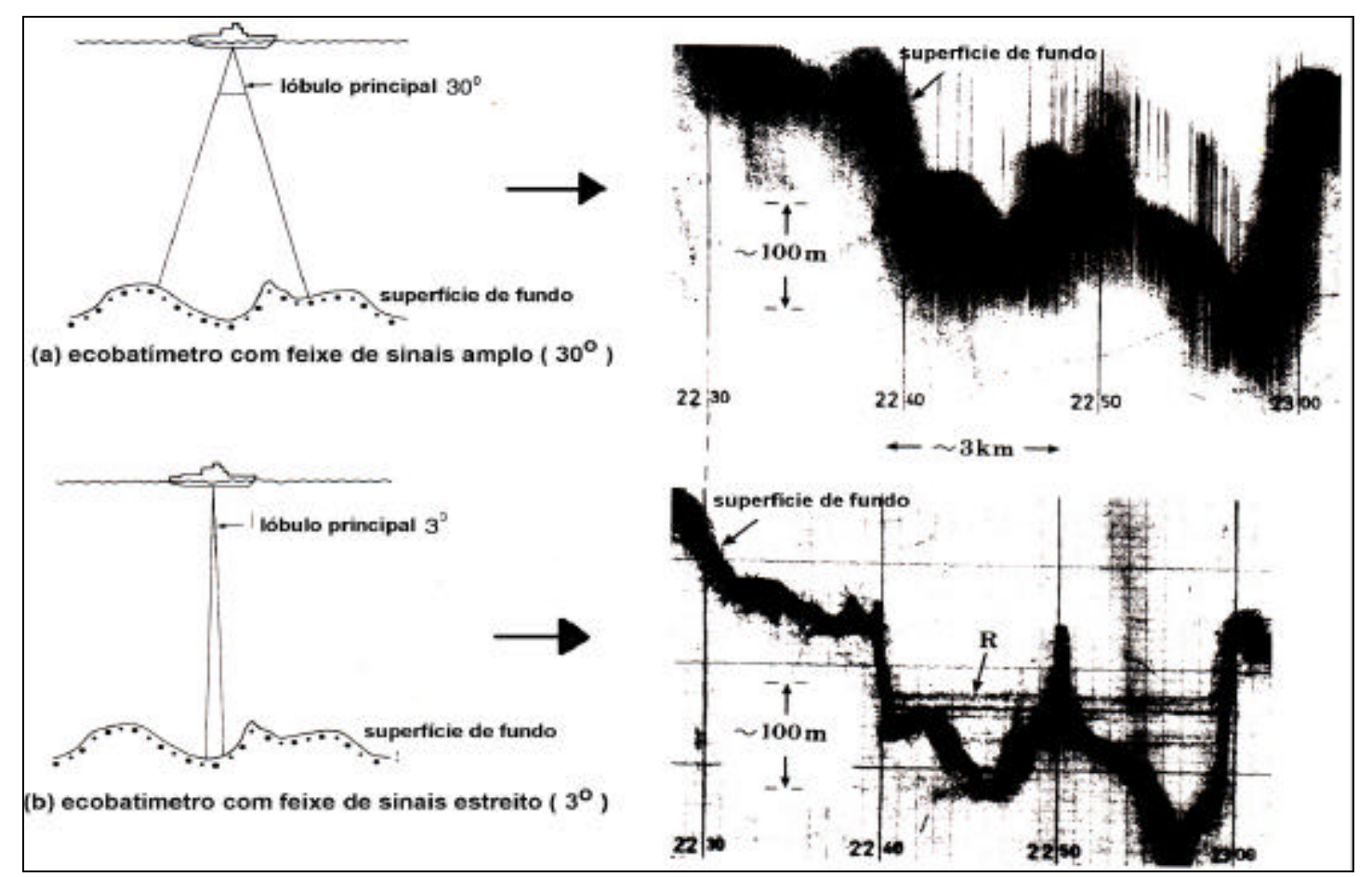

Figura 9.5: a) ecobatímetro com feixe de sinais amplo $\left(18 \mathrm{kHz} / 30^{\circ}\right)$ e, à direita, o perfil obtido; b) ecobatímetro com feixe de sinais estreito $\left(30 \mathrm{kHz} / 1,3^{\circ}\right)$ e à direta o perfil obtido. Notar a melhor definição da superfície de fundo no perfil obtido com o ecobatímetro com feixe de sinais estreito. Neste perfil inclusive identifica-se um zona de reflexão $(\mathrm{R})$ na coluna d'água provavelmente relacionada com a zona de atividade hidrotermal. Modificado de Jones (1999).

A opção por um ou outro sistema não depende apenas do usuário. Restrições mecânicas e eletrônicas são as responsáveis pela configuração de sistemas acústicos desta natureza. Comumente, sistemas que emitem freqüências mais baixas (p. ex. 10-20 $\mathrm{kHz}$ ), possuem maiores alcances em profundidade, possuem ângulos do cone de sinais 
da ordem de $30^{\circ}$, às vezes até mesmo maiores e assim, para investigação de grandes profundidades, oferecem pobre resolução. Sistemas que emitem freqüências da ordem de $200 \mathrm{kHz}$, que por sua vez tem aplicação limitada em estudos de grandes profundidades, possuem cones de sinais com ângulos inferiores a $3^{\circ}$, proporcionando excelente resolução.

\subsubsection{TOPOGRAFIA DA ÁREA ESTUDADA}

Outro aspecto que se deve considerar ao analisar registros de um ecobatímetro está relacionado a levantamentos de áreas com topografia muito irregular ou com superfícies de fundo muito inclinadas.

Geralmente, os ângulos de inclinação das superfícies de fundo mostrados nos registros não correspondem à inclinação real do terreno, sendo sempre menores. Os sinais acústicos que retornam ao transdutor são aqueles que atingem um ponto na superfície de fundo, que não é aquele na vertical da embarcação, pois o sinal emitido percorre sempre um caminho perpendicular à real superfície de fundo. A Figura 9.6 ilustra este aspecto.

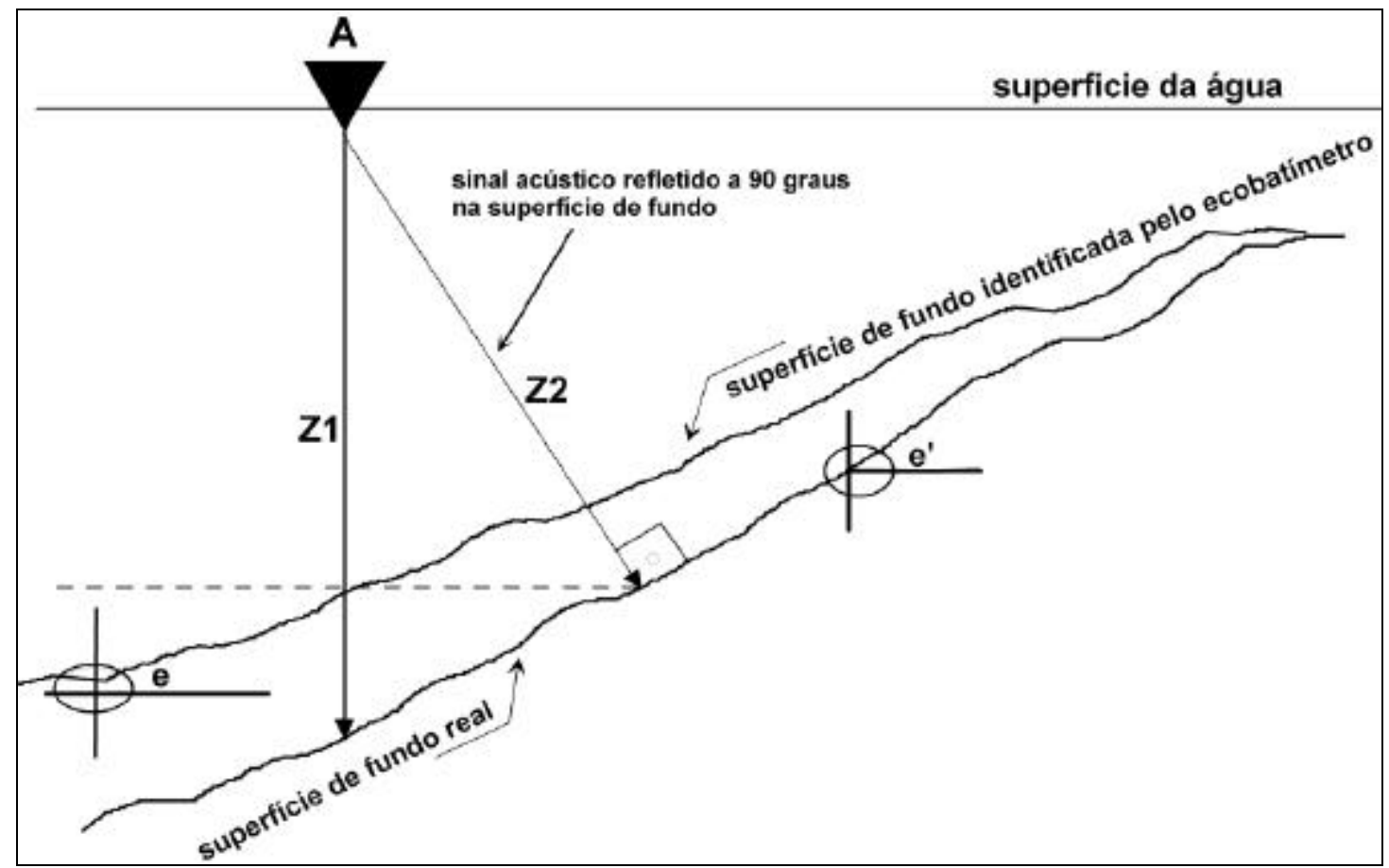

Figura 9.6: Desenho ilustrando a utilização de ecobatímetros em levantamentos de áreas com superfícies de fundo inclinadas. $\underline{Z 1}$ é a espessura real da coluna d'água no ponto $\underline{A} ; \underline{Z 2}$ é a espessura da coluna d'água no ponto $\underline{A}$ medida pelo ecobatímetro; $\underline{e}$, a inclinação real da superfície de fundo; $\underline{e}$, a inclinação detectada pelo ecobatímetro (sempre menor que a real). Modificado de Jones (1999).

Erros de amostragem análogos podem também ser cometidos se cuidados devidos não forem tomados com relação às condições gerais de navegação. Superfície d'água agitada, isto é, condições desfavoráveis à navegação, levam a embarcação e o 
transdutor a movimentos indevidos que têm como conseqüência imediata a amostragem incorreta da superfície de fundo e, portanto, leituras incorretas podem ser registradas (Figura 9.7).

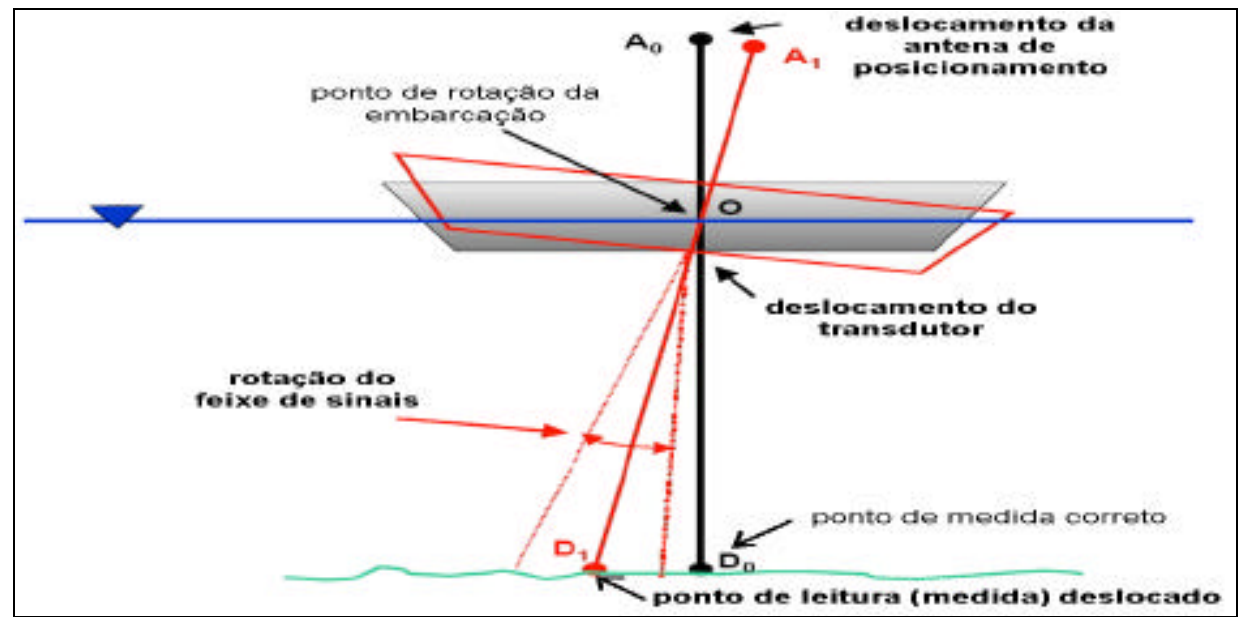

Figura 9.7: Ilustração mostrando o efeito negativo na leitura dos dados batimétricos quando do movimento indevido da embarcação e do transdutor acoplado a ela. Modificado de <http://www.usace.army.mil/inet/usace-docs/eng-manuals/em1110-2-1003/>. Acesso: jan/2006.

\subsubsection{DAdOS DIGITAIS X DAdOS ANALÓgICOS}

Os ecobatímetros modernos constituem-se em excelentes ferramentas geofísicas para a avaliação e medição de acumulação de sedimentos nos reservatórios. Além de totalmente digitais, facilitando a aquisição, o processamento e a análise dos dados, os sistemas modernos possuem transdutores de dupla freqüência, com uma segunda freqüência quatro ou cinco vezes mais baixa que a primeira, o que possibilita, em algumas condições, a penetração do sinal acústico na superfície de fundo, identificando a espessura da cobertura sedimentar superficial, tópico de suma importância na investigação de assoreamento de reservatórios, por exemplo.

Hoje, sistemas de dupla freqüência são relativamente comuns. Além dos sinais com freqüências da ordem de $200 \mathrm{kHz}$, que identificam com grande precisão a espessura da coluna d'água e a topografia de fundo, transdutores de menores frequiências (geralmente entre 25 e $50 \mathrm{kHz}$ ) atuam simultaneamente, proporcionando "certa penetração" no substrato. Termo este utilizado para tentar deixar claro que, mesmo neste caso, emitindo espectros de freqüências menores, é limitada a penetração dos sinais, principalmente devido à baixa potência destes tipos de fontes acústicas.

Por meio destes sistemas de dupla frequiência, pode-se tão somente penetrar nas camadas de sedimentos finos e inconsolidados. É praticamente impossível, utilizando-se 
destes sistemas, atingir o embasamento cristalino e, se for este o objetivo do projeto, a ecobatimetria não é o método de investigação recomendado.

O exemplo na Figura 9.8 mostra um registro de excelente qualidade obtido por meio de um ecobatímetro com transdutores de dupla freqüência, neste caso, 33/210 kHz, em levantamento executado em um lago na Áustria. Nos registros ilustrados nesta figura, é possível observar claramente o resultado obtido por cada uma das duas frequiências emitidas. No perfil inferior, oriundo do transdutor de $210 \mathrm{kHz}$, observa-se apenas uma linha contínua que representa a superfície de fundo do lago (contato águasedimentos de fundo), sem qualquer evidência de penetração do sinal acústico através dos sedimentos lamosos do lago, resultado que corrobora com as expectativas teóricas, co relação ao desempenho destas freqüências no quesito penetração. Por outro lado, no perfil mostrado na parte superior da figura, oriundo do transdutor de $33 \mathrm{kHz}$, é clara e evidente a penetração deste sinal acústico de menor freqüência, sendo possível observar, além da topografia da superfície de fundo, uma camada de lama no fundo do lago com cerca de $6 \mathrm{~m}$ de espessura.

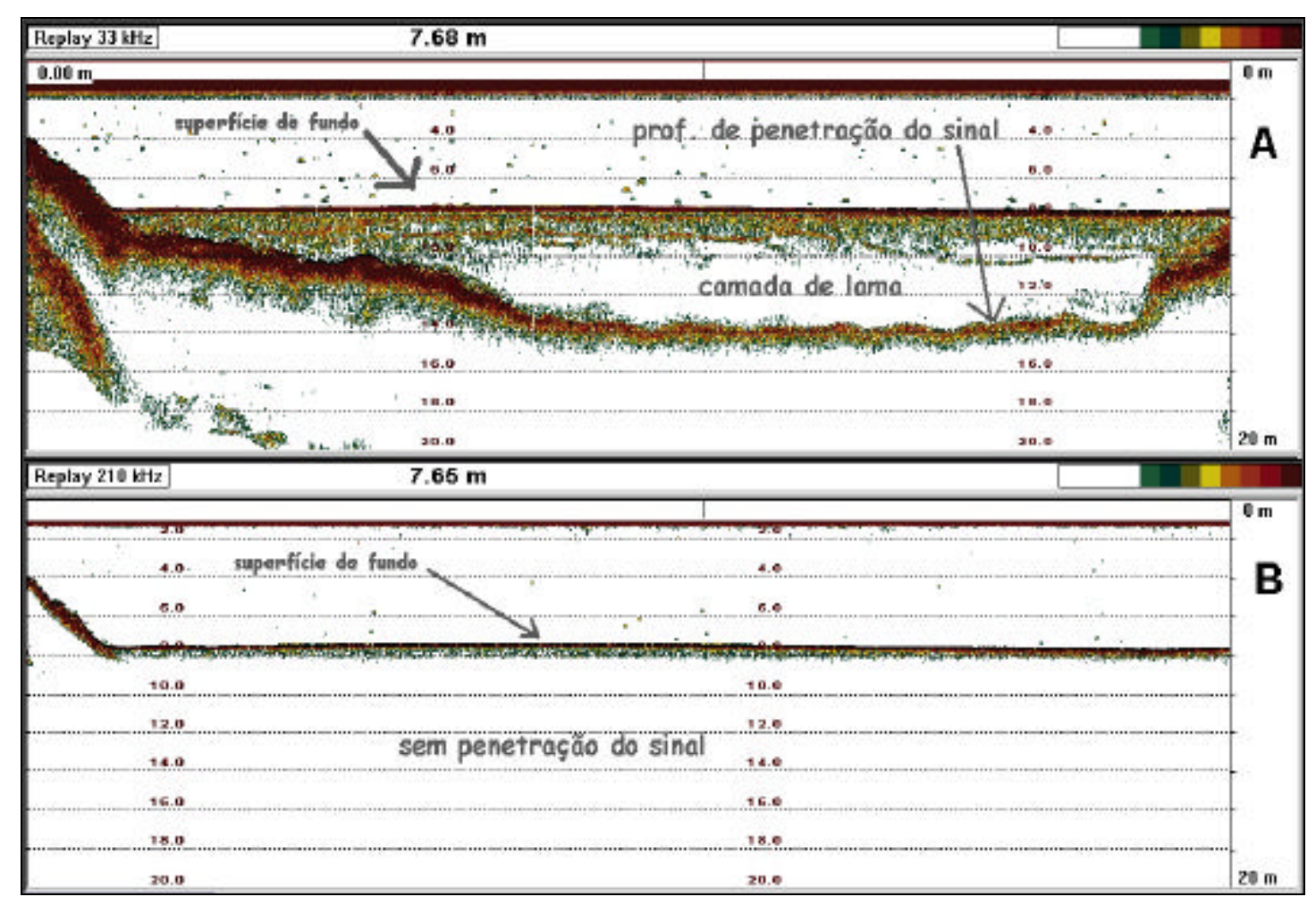

Figura 9.8 - Registro de ecobatímetro EA400A de dupla frequiência (33/210Khz) da Kongsberg-Sinrad obtido de um lago na Áustria: a) perfil obtido com a freqüência de $33 \mathrm{kHz}$ ilustrando a nítida penetração do sinal de menor freqüência no substrato; b) perfil obtido com a freqüência de $210 \mathrm{kHz}$ mostrando a plana superfície de fundo do lago, sem penetrar na coluna de sedimentos. Registro cedido pela Kongsberg-Simrad.

O registro na Figura 9.9 mostra um caso típico em que um ecobatímetro digital com transdutor de $38 \mathrm{kHz}$ apresenta resultados (leituras digitais das profundidades) que 
não representam de fato a espessura da coluna d'água e, assim, não apresentam adequada resolução para definição precisa do contato da coluna d'água com os sedimentos de fundo, se aquisição de dados for efetuada em modo automático.

No exemplo desta figura, o perfil oriundo do transdutor de $38 \mathrm{kHz}$ (Figura 9.9a) detecta e lê a profundidade de um refletor principal a 14.79 m num ponto do perfil. Neste mesmo ponto, o transdutor de $200 \mathrm{kHz}$ identifica um refletor principal a uma profundidade de $12.50 \mathrm{~m}$, conforme Figura 9.9b. A diferença de 2,29 $\mathrm{m}$ entre as medidas detectadas pelos transdutores, para a espessura da coluna d'água num mesmo ponto, representa justamente a espessura da coluna de sedimentos inconsolidados (provavelmente lamas) que cobre uma superfície mais dura. A partir deste exemplo, conclui-se que, quando o interesse do estudo está focado na determinação precisa da coluna d'água, o uso de equipamentos com freqüências altas se faz necessário, sob pena de se cometerem erros de grande amplitude na determinação da espessura da coluna d'água.

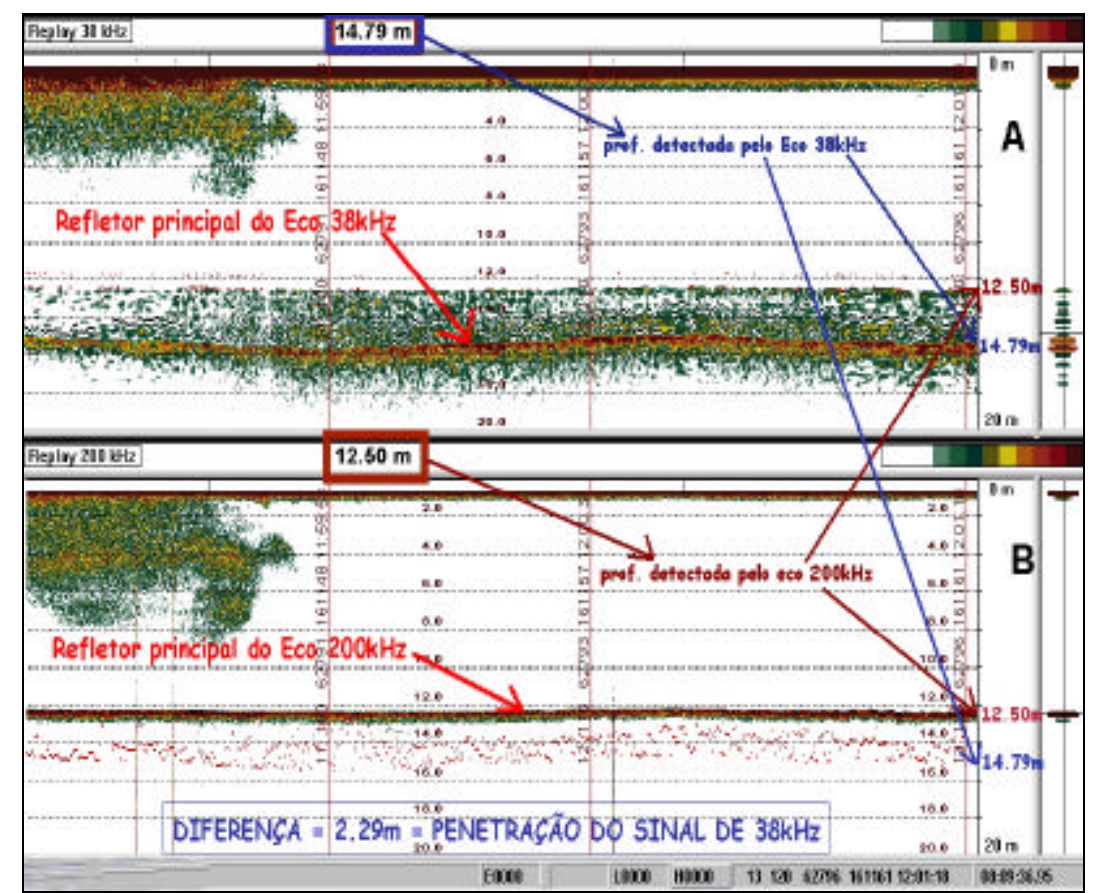

Figura 9.9: Registro de campo obtido com o ecobatímetro de dupla frequiência (38/200 kHz) EA400A da Simrad Kongsber: a) perfil obtido com a freqüência de $38 \mathrm{kHz}$ ilustrando a nítida penetração do sinal de menor freqüência na tênue camada de sedimentos finos; b) perfil obtido com a freqüência de $200 \mathrm{kHz}$ mostrando a plana superfície de fundo, sem evidências de penetração do sinal na coluna de sedimentos. Registro cedido pela Kongsberg-Simrad.

Se procedimento análogo for desenvolvido para o exemplo apresentado na Figura 9.10, denotam-se erros em torno de 6 ou $7 \mathrm{~m}$ em alguns pontos do perfil. Um mapa batimétrico construído apenas com informações oriundas do registro digital de 
dados de um transdutor de $33 \mathrm{kHz}$, conforme ilustrado neste exemplo, conduziria o intérprete a erros que certamente comprometeriam o produto final.

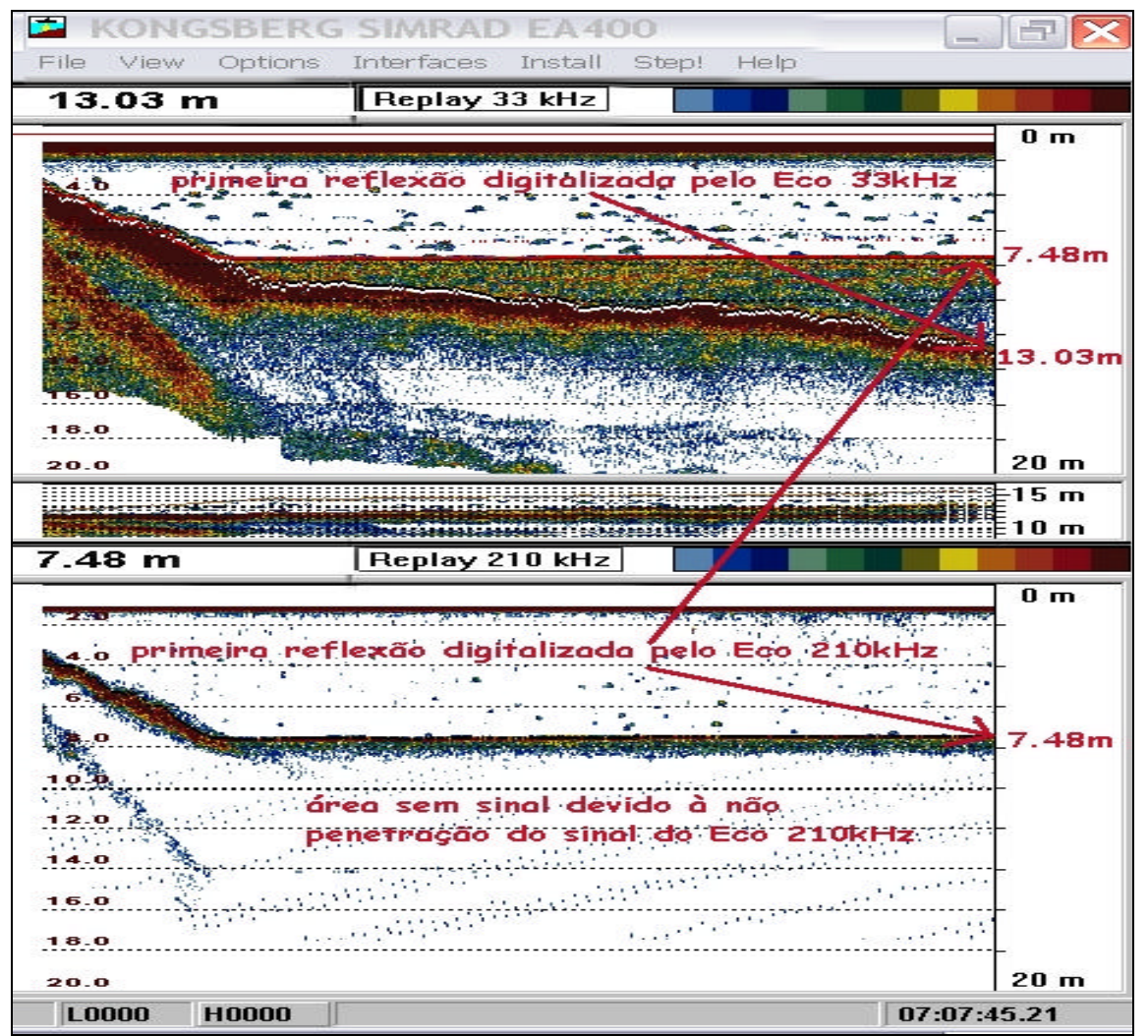

Figura 9.10: Registro de campo obtido com o ecobatímetro de dupla freqüência (33/210kHz) EA400A da Simrad Kongsberg ilustrando perfis construídos por cada uma das freqüências emitidas pelo sistema. Observaram-se nos registros as diferentes espessuras da coluna d'água identificadas por cada uma das freqüências num mesmo ponto do perfil. Registro cedido pela Kongsberg-Simrad.

Dos exemplos apresentados, conclui-se ser de fundamental importância a observação e análise visual dos perfis batimétricos propriamente ditos, impressos, ou na tela do computador.

No caso da utilização de sistemas de aquisição digital de dados empregando-se transdutores que emitem freqüências inferiores a $50 \mathrm{kHz}$, a real superfície de fundo pode não ser detectada, pois sinais acústicos com estas freqüências, não raramente, atravessam as camadas lamosas, levando a erros que comprometem os produtos finais destes levantamentos (mapas batimétricos).

Por outro lado, ao se utilizarem fontes acústicas de altas freqüências (p. ex. 200 $\mathrm{kHz}$ ), o sinal emitido poderá refletir ao encontrar pequenas variações de densidade na coluna de sedimentos, identificando o ponto ou a superfície refletora, como o fundo, o que também pode não ser a realidade. Nestes casos, o dado digital registrado também não é totalmente confiável, já que os modernos equipamentos não têm autonomia para 
decidir se a informação registrada é oriunda do topo, da base ou mesmo de um ponto intermediário na coluna sedimentar.

Quaisquer dos exemplos ilustrados acima reforçam a necessidade do controle total da qualidade dos obtidos. Da análise criteriosa do perfil "desenhado" no papel, ou na tela do computador durante a aquisição dos dados, ou a posteriori, extraem-se também informações que possibilitam não só a identificação com precisão da profundidade da interface coluna d'água - sedimentos de fundo, mas também dados que subsidiarão a identificação da natureza da superfície de fundo.

Discussão detalhada deste ponto de vista é desenvolvida por Gasperini (2005) que, em levantamento batimétrico em lago muito raso na Itália, ressaltou a importância da análise cuidadosa do tipo de material de fundo, pois, alguns sinais acústicos de alta freqüência penetram através das camadas de sedimentos superficiais altamente hidratadas, gerando ambigüidades na interpretação da real superfície de fundo, ou seja, aquela que representa o contato entre a coluna d'água e os sedimentos de fundo, conforme ilustrado na Figura 9.11.

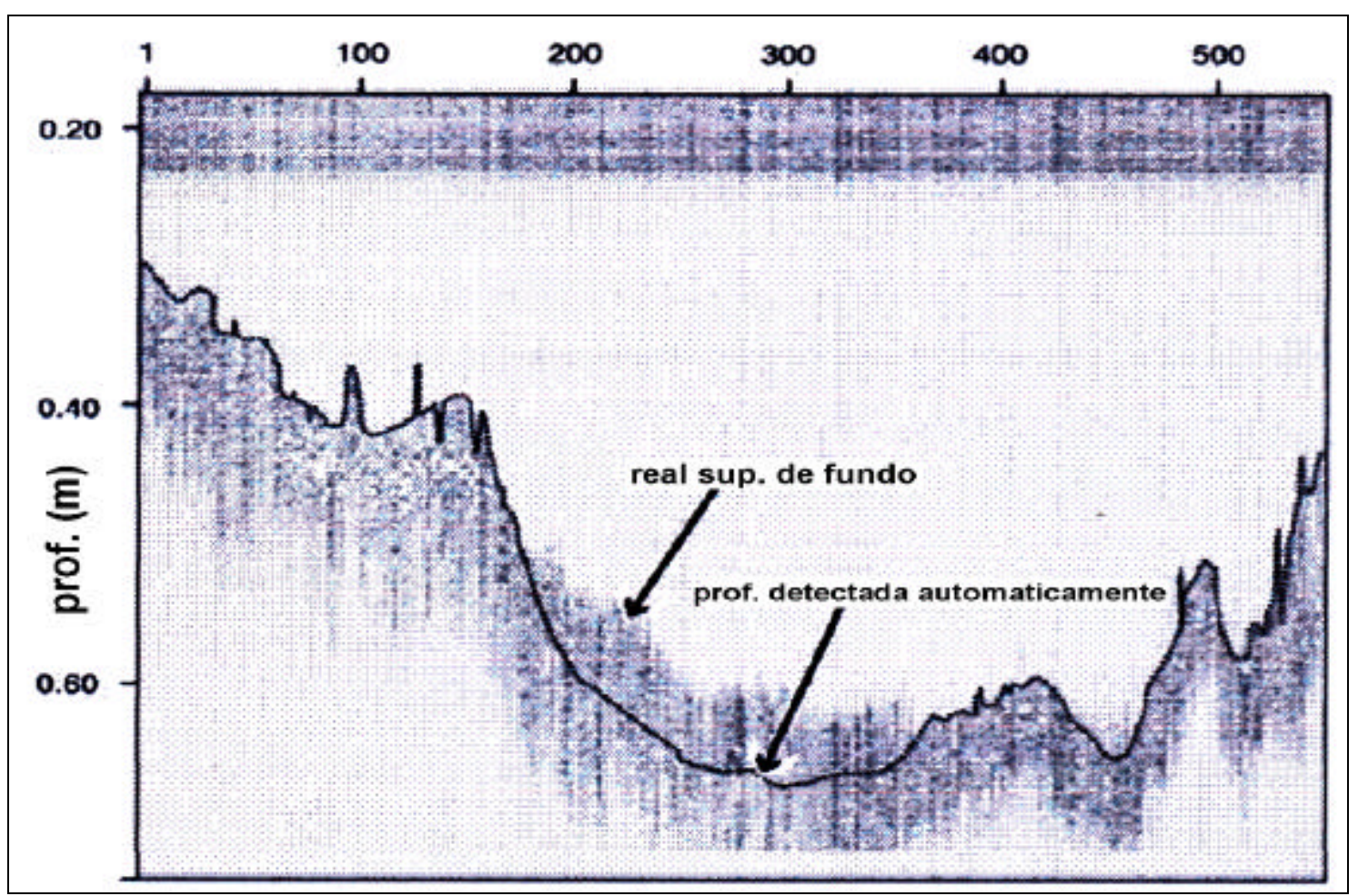

Figura 9.11: Comparação, num perfil de ecobatímetro, entre a detecção automática da superfície de fundo (linha escura contínua) e a real superfície de fundo que representa o contato entre a coluna d'água e os sedimentos de fundo. Modificado de Gasperini (2005). 


\subsection{CONSIDERAÇÕES SOBRE OS CLASSIFICADORES DE FUNDO (AGDS)}

Além de proporcionar o conhecimento da espessura da coluna d'água e, por conseguinte, a topografia detalhada de superfícies submersas, algumas características dos registros acústicos oriundos de ecobatímetros são também indicativas da natureza da superfície de fundo.

Os primeiros estudos, utilizando-se de sinais acústicos como ferramenta de caracterização de superfícies submersas, foram efetuados a partir de análise da intensidade do sinal acústico impresso, sendo, portanto, oriunda da observação visual e comparativa entre registros analógicos. Esta análise dependia de padrões estabelecidos pelo observador e carregava intrinsecamente certa subjetividade e alguma ineficiência.

Recentemente, entretanto, com o desenvolvimento das técnicas de mapeamentos de superfícies submersas, sistemas acústicos, como o sonar de varredura lateral e os sistemas classificadores de fundo, oferecem novo potencial de observação e de monitoramento de superfícies submersas, principalmente quando utilizados em conjunto, ou simultaneamente. Estes procedimentos acoplados permitem ampla e rápida cobertura da área de estudo e são particularmente úteis quando se estudam grandes áreas onde o uso dos métodos convencionais, como amostragens de fundo, mergulhos, fotografias tomariam muito tempo e implicariam alto custo, para se obter uma composição quantitativamente representativa de informações que permitissem caracterização ampla de uma área de levantamento.

Os modernos sistemas de classificação de fundo (AGDS), tais como o RoxAnn e o QTC-View, identificam de forma automática atributos dos sinais acústicos que atingem os transdutores oriundos da superfície de fundo, que são correlacionáveis a algumas propriedades físicas da superfície e dos materiais que a compõe, como por exemplo, granulometria, compactação, rugosidade, presença de estruturas sedimentares, afloramentos rochosos, cobertura de conchas ou algas e tipos de comunidades bentônicas, o que torna estes métodos ferramentas extremamente úteis nos estudos de ambientes de sedimentação subaquáticos.

Os sistemas de classificação de fundo, como qualquer outro método geofísico, identificam, de forma indireta, as propriedades acústicas da superfície de fundo, e não exatamente as propriedades físicas dos sedimentos de fundos, propriamente ditos. Assim, a interpretação final dos dados obtidos de levantamentos com sistemas AGDS 
deverá ser necessariamente auxiliada por informações obtidas por meio de métodos diretos de investigação, como coleta de amostras, fotografias submarinas, vídeofilmagens, observações de mergulhos, entre outras.

A capacidade dos sistemas classificadores de fundo de distinguirem acusticamente dois ou mais padrões distintos de fundo (padrões sedimentares ou habitats) depende da amplitude dos contrastes entre estes meios. Contatos muito distintos entre dois meios serão facilmente delineados; contatos interdigitados e de baixo contraste, dificilmente serão mapeados por estes sistemas acústicos.

Em várias situações, os resultados oriundos dos classificadores de fundo são muito claros e objetivos, principalmente quando é viável a análise conjunta destes dados geofísicos com os oriundos dos métodos convencionais de investigação. Entretanto, ao utilizar-se desta ferramenta geofísica em estudos de caracterização de superfícies submersas, deve-se conhecer profundamente as limitações deste método de investigação e levar em conta cuidados especiais, tanto na operação de aquisição de dados, quanto na interpretação, tendo em vista a necessidade da eliminação, tanto quanto possível, dos ruídos indesejáveis na operação e, assim, as incertezas e imprecisões no tratamento e interpretação dos dados.

Wilding et al. (2003), em seus detalhados experimentos com o sistema RoxAnn acoplado a um transdutor de $200 \mathrm{kHz}$, na Escócia, avaliaram a sensibilidade deste sistema a mudanças do tipo de fundo. A partir destes experimentos, os autores tentaram explicar o porquê das variações dos sinais do eco (E1 e E2) para um mesmo tipo de fundo. Destacaram ainda neste mesmo artigo a enorme variabilidade encontrada entre os padrões texturais identificados por este sistema classificador de fundo, com relação ao tempo (repetibilidade) e à velocidade da embarcação, propondo técnicas para abordagem deste problema. Notaram, ainda, a partir destes ensaios, que levantamentos realizados com a embarcação a uma velocidade superior àquela da calibração do sistema, fazem com que a superfície de fundo torne-se menos rugosa e menos dura. Diminuições bruscas da velocidade durante a aquisição dos dados fazem com que as superfícies se tornem aparentemente mais rugosas e mais duras, ou seja, ambas as situações alteram sensivelmente os valores de E1 e E2, tornando complexa a interpretação dos dados. 
Hamilton et al. (1999), analisando dados de um classificador de fundo do tipo RoxAnn, já tinham concluído também sobre a grande influência da componente velocidade da embarcação, na qualidade dos dados registrados.

Wilding et al. (2003) observaram ainda que a aplicação deste método de investigação em estudos de áreas muito extensas, onde, por motivos diversos, não seja possível empreender um programa de amostragens de fundo com a representatividade necessária, pré-condições terão que ser assumidas, e critérios específicos deverão ser estabelecidos, para garantir alguma representatividade em área dos dados obtidos, a saber:

- que os sedimentos de fundo não tenham sofrido qualquer alteração no período da investigação, sob pena de, ao fim do processo de aquisição de dados numa grande área, os padrões previamente estabelecidos terem sido comprometidos;

- que o processo de amostragem tenha sido estatisticamente representativo do setor estudado de forma a permitir ampla correlação entre os dados das amostragens e os geofísicos;

- que se estabeleça um processo que torne viável o desenvolvimento de compatibilidade da análise de dados eventualmente coletados como a embarcação a diferentes velocidades, e

- deve-se assumir que as variações nas condições do mar não tenham afetado sistematicamente os valores de E1 e E2 identificados pelo sistema.

Wilding et al. (2003) sugeriram finalmente, que é fundamental em estudos desta natureza:

- a realização de amostragens periódicas da superfície de fundo, pelo menos na escala de tempo dos levantamentos executados;

- a repetição periódica, de no mínimo, um dos perfis executados.

Experiências análogas foram desenvolvidas por Greenstreet et al. (1997), que detectaram também variações ao longo do tempo, nos parâmetros medidos por sistema semelhante.

Hamilton et al. (1999) apresentaram pormenorizada comparação entre dois sistemas classificadores de fundo: RoxAnn e QTC-View. Neste artigo, os autores avaliaram o desempenho de cada um destes sistemas em variados ambientes, concluindo que, a despeito das limitações de cada um deles em determinados ambientes ou em determinadas condições operacionais, ambos funcionam tanto melhor quanto maior a quantidade de informações complementares existentes, obtidas preferencialmente pelos 
meios convencionais de investigação. Ou seja, ambos os métodos de investigação são carentes do estabelecimento prévio de modelos ou padrões comparativos para que se efetive a desejada correlação direta entre os parâmetros físicos registrados por estes métodos geofísicos e as características geológicas da superfície de fundo.

As experiências destes autores ainda permitiram concluir que os dados obtidos do sistema classificador de fundo do tipo RoxAnn sofrem forte influência das variações da velocidade da embarcação durante a aquisição dos dados, portanto, seu desempenho será certamente melhorado quando da execução de levantamentos a velocidades constantes.

Neste mesmo artigo, estes autores ainda concluíram que o sistema QTC-View não sofre qualquer influência da velocidade da embarcação, tendo em vista que lida somente com o primeiro eco, ou seja, com a forma do sinal do primeiro retorno. Avaliaram que ambos os sistemas apresentam problemas ou limitações de resolução, podendo fornecer resultados ambíguos ou classificações equivocadas do tipo de fundo, quando utilizados em áreas com superfícies de fundo com texturas rugosas, do tipo afloramentos rochosos, recifes de corais, ou mesmo coberturas sedimentares ricas em estruturas sedimentares do tipo marcas onduladas. Em ambos os casos, o próprio perfil batimétrico, juntamente com uma análise do caráter do eco, irá contribuir para a avaliação da classificação de fundo apresentada pelo sistema utilizado.

Concluíram que ambos os sistemas, o QTC-View, que utiliza apenas a forma do primeiro eco, e o RoxAnn, a energia de dois ecos, classificam de forma equivalente uma mesma superfície de fundo. Destacaram, entretanto, que o sistema RoxAnn está mais susceptível a ruídos indesejados no segundo eco, principalmente em áreas com superfícies de fundo com textura muito rugosa, e também em áreas com mudanças abruptas de profundidades ou de inclinação da superfície, além de, conforme já mencionado, sofrerem forte influência das variações da velocidade da embarcação. Segundo estes autores, as informações oriundas do primeiro eco são mais confiáveis em terrenos com as propriedades descritas acima.

Há ainda de se considerar que a investigação por meio desta técnica, visando à classificação geológica da superfície de fundo de áreas submersas, está sujeita a alguns erros que vão desde problemas relativos à calibração do sistema, a questões operacionais, referentes notadamente ao posicionamento das observações efetuadas. Neste último, aproximações sempre ocorrerão com relação às posições das informações 
coletadas pelo sistema classificador de fundo, quando confrontadas com as oriundas de fundo obtidas por meio de formas diretas (amostras, vídeo-imagens, fotografias etc.).

Raciocínio análogo pode ser desenvolvido quando da análise de imagens do sonar, pois, neste caso, a fonte acústica é rebocada na coluna d'água e numa posição conhecida apenas aproximadamente a partir da medição da extensão do cabo (layback) que conecta a fonte acústica ao sistema registrador, tornando complexa a interpretação e a correlação entre as observações registradas por meio do sonar de varredura lateral e do sistema classificador de fundo com os resultados das observações diretas de fundo (amostras, vídeo-imagens etc.).

Vários autores analisaram também a repetibilidade dos dados oriundos de classificadores de fundo. Além da influência da própria velocidade da embarcação na qualidade e natureza dos dados oriundos dos classificadores de fundo, Hamilton et al. (1999) destacaram ainda a importância do controle na direção dos traçados dos perfis de investigação. Linhas longitudinais e transversais devem ser executadas na área em estudo, para suprimir ou filtrar eventuais efeitos nocivos, relativos à direção de navegação, sobre os dados.

\subsubsection{ASPECTOS OPERACIONAIS}

A qualidade dos dados obtidos a partir dos classificadores de fundo será sempre maior quanto mais cuidadosa forem as operações de aquisição de dados em campo. O controle de alguns parâmetros de campo é fundamental no caso dos levantamentos com os $A G D S$, já que estes sistemas, em geral, são extremamente sensíveis às variações quanto ao tipo de embarcação, velocidade de navegação, interferências oriundas da utilização simultânea de outros equipamentos principalmente acústicos (Foster et al., 1999).

Um bom sistema de posicionamento dos perfis bem como um planejamento da distribuição de perfis em escala adequada e compatível aos objetivos do estudo constituem-se em tópicos fundamentais para a garantia de obtenção de dados representativos e de boa qualidade. A distância entre os perfis está diretamente relacionada com a variabilidade das propriedades da superfície de fundo ao longo do perfil: maior variabilidade, menor deve ser o espaço entre os perfis. A orientação dos perfis deve levar em conta as orientações gerais dos prováveis fenômenos responsáveis pelos processos sedimentares na área de estudo: ventos, marés etc. 
Enfim, a qualidade e a confiabilidade dos dados obtidos por este método de investigação, talvez mais que em qualquer outro método geofísico, serão tão maiores quanto maior a possibilidade do controle direto em campo do processo de aquisição de dados por um profissional experiente.

Uma interessante tentativa de garantir representatividade e qualidade dos dados obtidos pode ser, por exemplo, o retorno da embarcação, ao fim de cada dia, ao perfil efetuado no início do dia. Um procedimento desta natureza permite a comparação entre dados de um mesmo local obtido em condições distintas - começo e fim do dia, o que permite comparações que só enriquecerão a análise posterior do conjunto dos dados coletados.

Levantamentos geofísicos utilizando classificadores de fundo têm sido conduzidos nas escalas mais variadas. Freitas et al. (2003), por exemplo, conduziram estudos ao longo de uma faixa litorânea da costa ocidental de Portugal executando perfis com extensão variando entre 7 e $12 \mathrm{~km}$ e distanciados um do outro cerca de 3,5 km. Pinn \& Robertson (2003) conduziram estudos utilizando classificadores de fundo em área de cerca de $400 \mathrm{~km}^{2}$ ao sul da Ilha de Rhum, na costa oeste da Escócia, executando perfis distanciados um do outro cerca de $1 \mathrm{~km}$. Brown et al. (2005) realizaram ensaios na costa oeste da Escócia, com sistemas classificadores de fundo em área de apenas $1 \mathrm{~km}^{2}$, com perfis distribuídos entre si a distâncias de apenas algumas dezenas de metros.

Levantamentos acústicos desta natureza em grandes áreas muito raramente podem ser realizados com a cobertura ou a densidade de perfis desejados, tendo em vista, é claro, o alto custo operacional envolvido. Assim, as pesquisas desenvolvidas em grandes áreas acabam por interpolar dados obtidos para finalmente gerar um mapa classificatório ou um de distribuição de sedimentos.

Levantamentos acústicos de maneira geral coletam dados ao longo de uma linha de navegação e, portanto, cada ponto ao longo do perfil executado tem consistência, correlação e continuidade, já que cada informação é obtida direta e seqüencialmente, uma após outra. Por outro lado, transversalmente à linha de navegação, o mesmo raciocínio não pode ser aplicado. As informações sobre a superfície de fundo entre dois perfis terão de ser interpoladas. Comumente, os perfis são distribuídos de forma a compor um grid regular e a interpolação entre os dados de cada 
perfil, com objetivo da construção de um mapa, é feita por meio de vários métodos estatísticos.

Pinn \& Robertson (2003) analisaram o efeito de variações no espaçamento entre perfis acústicos sobre a interpretação da distribuição de comunidades bentônicas com base em dados obtidos de um classificador de fundo do tipo RoxAnn (38 kHz). Estes autores concluíram que não necessariamente uma menor distância entre perfis é a melhor solução para o desenvolvimento de determinados estudos. $\mathrm{Na}$ verdade, a decisão sobre a melhor distribuição de perfis numa área de estudo está baseada na complexa relação entre o objetivo do estudo, a escala desejada (detalhe requerido), o tamanho da área, o tempo disponível e finalmente a verba dispensada para a execução dos estudos.

\subsubsection{CONSIDERAÇÕES GERAIS}

Como todo método geofísico, os sistemas acústicos classificadores de fundo (SACF ou $A G D S$ ) são também métodos remotos de investigação e o manuseio e a interpretação dos dados obtidos a partir deste método trazem consigo sempre certas ambigüidades ou incertezas, que serão tão reduzidas quanto mais informações, de outras fontes, existirem sobre a área de estudo.

De maneira geral, estes sistemas são bastante empregados no reconhecimento amplo, em grande escala, de superfícies submersas, principalmente daquelas onde pouco ou nada se conhece. Nestas áreas, estes sistemas permitem o mapeamento de

subáreas de maior interesse sobre as quais levantamentos detalhados devem ser realizados, reduzindo desta forma o esforço e os custos finais do projeto de investigação.

A portabilidade destes equipamentos constitui-se também em propriedade a se destacar, pois a versatilidade operacional, decorrente desta característica, possibilita a repetibilidade dos ensaios e, portanto, o monitoramento de transformações gerais dos terrenos submersos numa escala de tempo bastante reduzida. A relativa facilidade operacional, todavia, não se traduz na complexidade dos cuidados operacionais que se fazem necessários quando da realização dos ensaios.

Para cada área de estudo, limitantes específicos são estabelecidos, tendo como base, os objetivos e a extensão dos levantamentos. Em qualquer caso, alguns cuidados com o levantamento propriamente dito, mas também com o processamento dos dados, devem ser tomados para garantir a consistência dos dados adquiridos, a se destacar: 
- controle e registro preciso dos parâmetros de navegação (velocidade da embarcação, condições de mar etc.), já que variações, por exemplo, na velocidade de navegação, contribuem efetivamente para alterações nos parâmetros medidos nos sistemas $A G D S$ 's, em particular no sistema RoxAnn;

- controle detalhado das condições operacionais bem como dos parâmetros físicos dos equipamentos envolvidos na aquisição dos dados (AGDS e sistema de posicionamento);

- planejamento adequado da localização e disposição dos perfis, levando em conta os objetivos do levantamento e a escala desejada para o produto final;

- conhecimento, no mínimo geral, da topografia de fundo da área a ser investigada, pois características como a declividade do terreno afetam diretamente os parâmetros detectados por estes sistemas;

- controle preciso da localização das amostragens (fotografias de fundo, coletas de amostras, vídeo-filmagens etc.) bem como dos outros ensaios realizados (p.ex. sonar de varredura lateral) que subsidiarão a interpretação dos parâmetros medidos (E1, E2 etc.); e

- controle detalhado dos procedimentos adotados no processamento dos dados (análises estatísticas, fatores de interpolação dos dados etc.), que serão fundamentais na confecção do produto final.

\subsection{CONSIDERAÇÕES SOBRE O SONAR DE VARREDURA LATERAL}

É sempre desejável que, a partir de dados gerados por um levantamento batimétrico, se possam construir mapas altamente confiáveis, especialmente quando se trata da utilização do produto destes levantamentos para o estabelecimento ou planejamento de rotas de navegação em estudos para hidrovias. Nestes casos, em especial, se faz necessário o mapeamento, em detalhe, dos obstáculos à navegação de forma a garantir segurança às vias navegáveis estabelecidas pelo projeto.

Em projetos desta natureza, o sonar de varredura lateral tem papel de destaque, como ferramenta de investigação indireta, pois viabiliza rápida e efetivamente que $100 \%$ da área investigada seja abrangida. Por maior que seja a extensão de perfis batimétricos realizados ao longo de linhas tão próximas quanto possível, nunca irão possibilitar um recobrimento de $100 \%$ da área investigada, tendo em vista a própria geometria do método na coleta dos dados, que representam, tão somente, a topografia de fundo na vertical, imediatamente abaixo da embarcação ao longo da linha de pesquisa.

Assim, um mapa batimétrico construído exclusivamente a partir de dados de ecobatímetros convencionais pode não representar as variações topográficas reais da superfície de fundo da área investigada. Em muitos casos, eventuais anomalias topográficas nas áreas intermediárias entre os perfis não são detectadas, podendo em 
alguns casos estabelecer graves comprometimentos ao projeto da rota de navegação. Situações como a descrita neste exemplo obrigam ao planejamento adequado de uma malha ou uma grade de perfis batimétricos associada a uma grade de perfis sonográficos, pois somente desta forma se pode obter garantia do recobrimento total da área de estudo.

Não são raras as descrições na literatura de ocorrências de acidentes em hidrovias, com grandes prejuízos materiais e pessoais, onde este princípio não foi obedecido, ou seja, procedeu-se à aquisição de dados batimétricos com perfis distribuídos em malhas inadequadas e com a ausência de perfis sonográficos.

Outro aspecto a ser destacado, quando da utilização do sonar de varredura no mapeamento de superfícies submersas é a importância da coleta de dados da superfície investigada por outras vias para possibilitar o estabelecimento de um modelo geológico da superfície investigada o mais próximo do real. A Figura 9.12 exemplifica a importância de, na medida do possível, utilizar-se de ferramentas complementares de investigação. Neste caso, a interpretação das imagens obtidas do sonar de varredura lateral foi complementada pela possibilidade da análises das feições identificadas também nos registros da perfilagem sísmica.

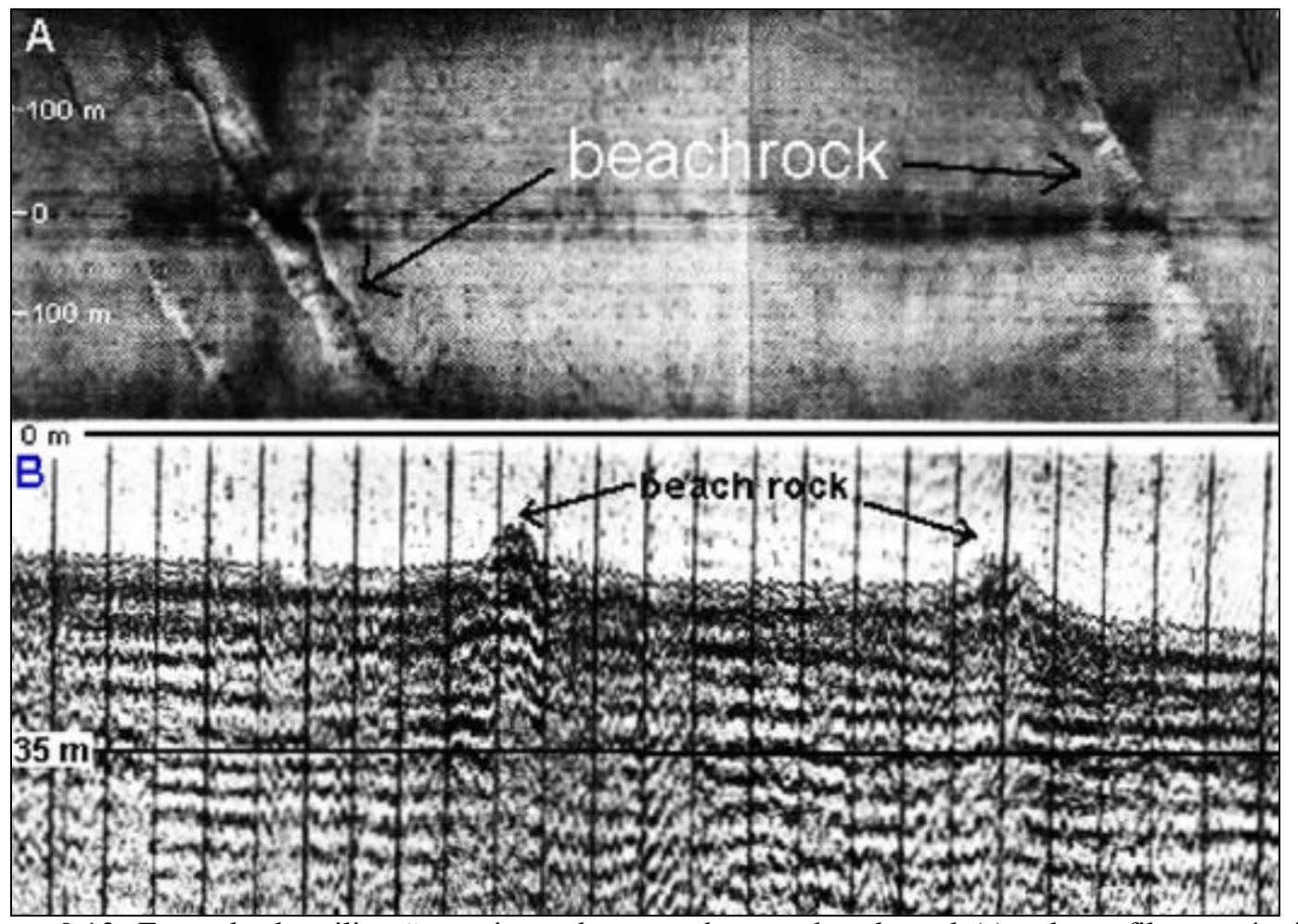

Figura 9.12: Exemplo de utilização conjunta do sonar de varredura lateral (a) e da perfilagem sísmica contínua (b) ilustrando em planta (Sonar) e em perfil (Sísmica) as caracterísiticas correspondentes às feições lineares identificadas no litoral norte do Rio de Janeiro, nas profundidades entre 72 e 109 m, correlacionadas a beachrocks. Dias et al. (1982). 


\subsection{CONSIDERAÇÕES SOBRE A INVESTIGAÇÃO DE SUBSUPERFÍCIE}

Estudos geológicos desenvolvidos em áreas submersas costeiras, na plataforma continental interna e nas áreas submersas continentais, exigem informações não só da superfície de fundo, mas também sobre a subsuperfície.

Dados como espessura dos estratos sedimentares subjacentes, presença de estruturas, contatos geológicos, paleocanais e profundidade do embasamento rochoso são algumas das informações que em muito contribuem, e em muitos casos são fundamentais, para o estabelecimento das bases técnicas para o desenvolvimento de estudos geológicos que irão subsidiar não só a pesquisa básica, mas também projetos de engenharia costeira ou de reservatórios. Em qualquer destes, os métodos geofísicos a serem utilizados deverão propiciar a penetração do sinal emitido através das camadas sedimentares.

No caso dos métodos sísmicos, principal método utilizado na investigação de áreas submersas, a maior ou menor penetração do sinal acústico emitido vai depender do tipo de fonte de sinais acústicos empregada, mas certamente a maior penetração vai ser encontrada quando da utilização de fontes de alta energia que emitem freqüências inferiores a $10 \mathrm{kHz}$.

\subsubsection{FONTES SÍSMICAS}

À parte das características específicas da fonte acústica, ou seja, das propriedades do sinal emitido, que são muito limitantes e oferecem respostas específicas para objetivos específicos, as características geológicas do material que compõe a superfície de fundo das áreas submersas têm fundamental papel sobre a escolha do tipo de fonte ou de equipamento sísmico a ser utilizado na investigação de determinada área submersa.

Se a superfície de fundo constituir-se de material composto por sedimentos lamosos ou argilosos em áreas restritas continentais, como fundos de reservatórios de água, lagoas de decantação, por exemplo, fontes acústicas de baixa energia, com espectros de freqüências intermediárias $(10-30 \mathrm{kHz})$, podem fornecer resultados de interesse ao projeto, desde que o objetivo não seja penetrar além dos primeiros decímetros ou metros na subsuperfície. Nestes casos, o objetivo da investigação é a avaliação da espessura das camadas superficiais de material fino e inconsolidado, 
comumente oriundos de processos sedimentares recentes, como por exemplo assoreamento de reservatórios ou de canais portuários.

O registro mostrado na Figura 9.13 constitui-se num excelente exemplo de utilização de um sistema acústico de baixa energia e alta freqüência (Pinger $24 \mathrm{kHz}$ ) ilustrando a penetração do sinal emitido nas primeiras camadas de sedimentos. A conformação da topografia de fundo bem como as espessuras das camadas lamosas superficiais identificadas nos perfis executados constituem-se em informações suficientes para atingir os objetivos do levantamento, que era justamente a avaliação da espessura destas camadas para o planejamento de coleta de testemunhos de sondagens visando o desenvolvimento de análises ambientais (conteúdo dos sedimentos em agentes poluidores orgânicos, metais pesados etc.) e a cubagem deste material para planejamento de dragagens.

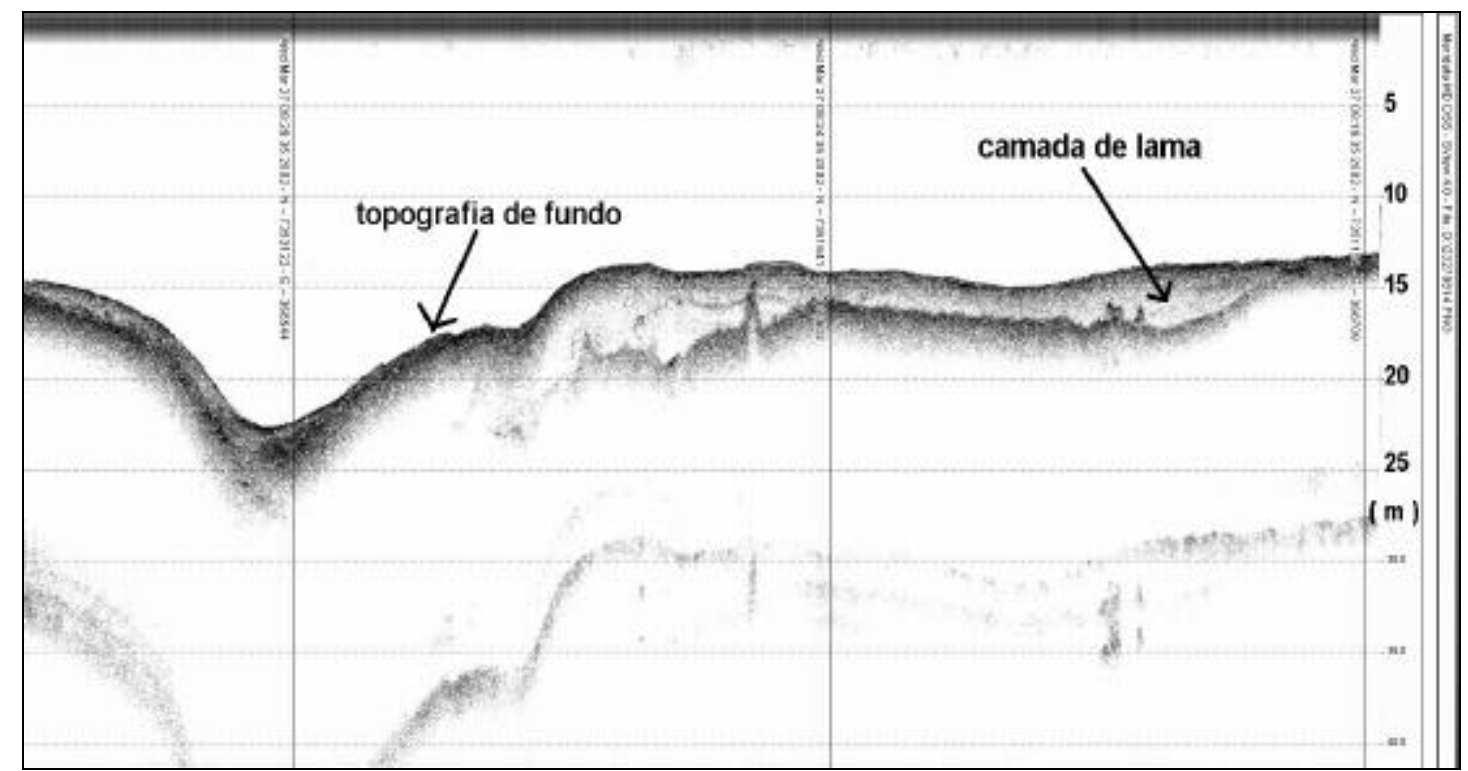

Figura 9.13 : Perfil sísmico obtido no canal de Santos com o sistema Meridata utilizando uma fonte do tipo Pinger de 24kHz. Fonte: cortesia do Prof. Dr. M.M. Mahiques - IO-USP.

Sistemas acústicos de potência intermediária e que emitem espectros de freqüências mais baixas que aqueles apresentados no parágrafo anterior (comumente inferiores a $10 \mathrm{kHz}$ ) são conhecidos de modo genérico como SBP (Subbottom Profilers). Em muitas situações estes sistemas oferecem bons resultados, ou seja, boa resolução, e adequada penetração. Por boa resolução, entende-se a possibilidade de definição de camadas sedimentares com espessuras decimétricas; por adequada penetração, que estes sistemas podem penetrar no substrato inconsolidado, alcançando algumas dezenas de metros. 
Todo Jr. et al. (2000) utilizaram um perfilador sísmico (RTT 1000), que se constitui de duas fontes acústicas $(7$ e $3.5 \mathrm{kHz})$, para estudos sobre a sedimentação holocênica da Lagoa dos Patos (RS). Com base nos princípios estabelecidos por Damuth \& Hayes (1977), estes autores identificaram os tipos de ecocaráter e classificaram a superfície de fundo da área investigada. Com relação à penetração, ambas as fontes acústicas utilizadas não penetraram na superfície de fundo além de 14 m de profundidade e a fonte de $7 \mathrm{kHz}$, como teoricamente esperado, apresentou melhor resolução. Ressalta-se, todavia, que mesmo com este nível de penetração do sinal acústico, os autores identificaram conspícuos refletores que foram correlacionados à base dos depósitos holocênicos na lagoa, dados estes que tornaram viável os cálculos da taxa de sedimentação no período.

São raros os exemplos na literatura de utilização de sistemas acústicos desta natureza com penetração de dezenas ou centenas de metros através das camadas de sedimentos. Bons resultados estão sempre associados a condições muito especiais, não só geológicas (espessas camadas de material fino inconsolidado), mas também à geometria do arranjo dos transdutores de sinais acústicos.

Nishimura et al. (1984), em levantamento sísmico do mar do Japão, utilizaram nove transdutores de $3.5 \mathrm{kHz}$ acoplados ao casco do navio Hakurei Maru, atingindo com este arranjo excelente penetração, para este tipo de fonte, de algumas centenas de metros (Figura 9.14).

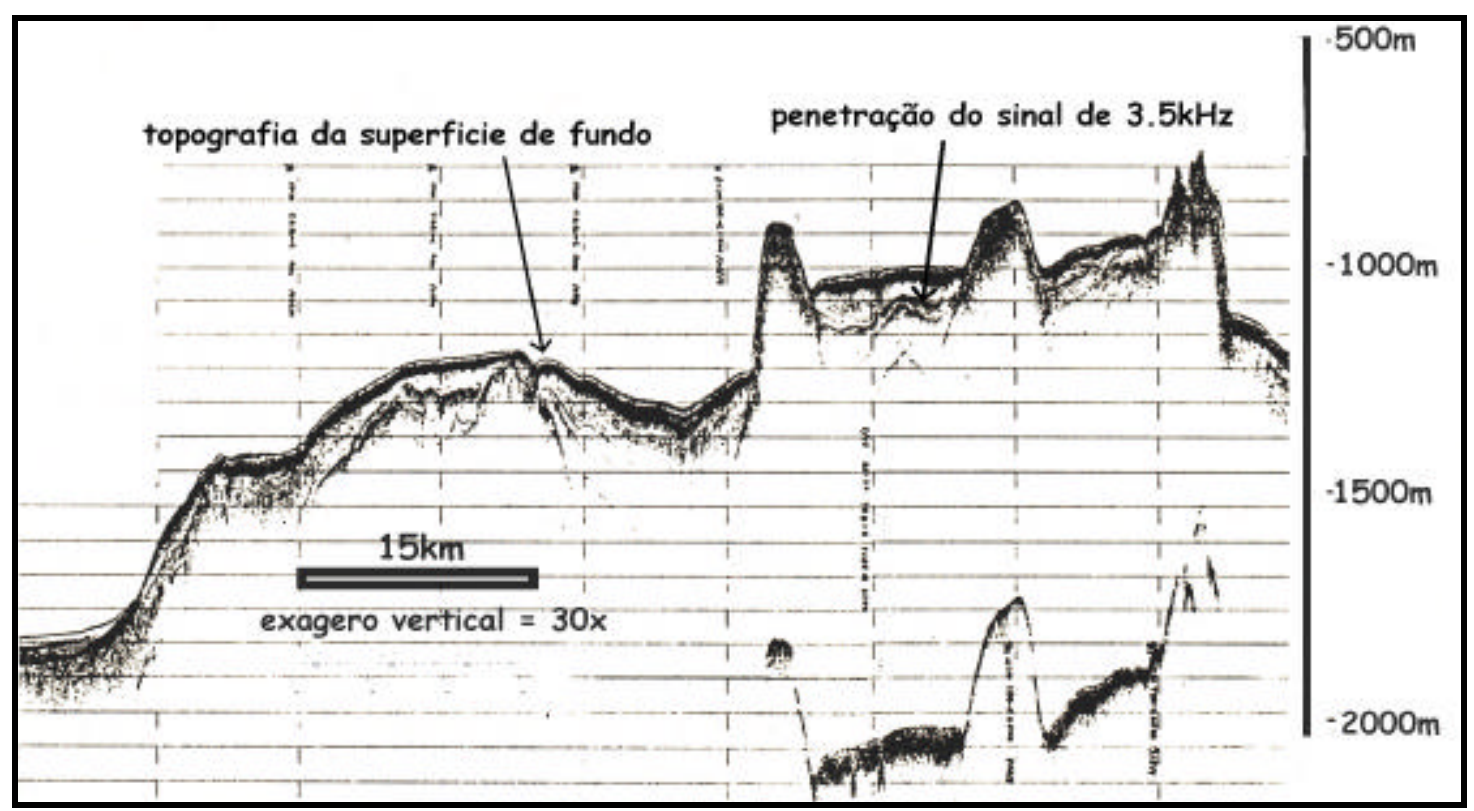

Figura 9.14: Perfil ilustrando a excelente e rara penetração de um sistema $3.5 \mathrm{kHz}$, obtido, neste caso, pelo acoplamento de nove transdutores de $3.5 \mathrm{kHz}$ ao casco do navio Hakurei Maru, do Serviço Geológico do Japão, em levantamento do Mar do Japão. Modificado de Nishimura et al. (1984). 
Ressalta-se que, em todas as discussões sobre levantamentos geofísicos em áreas submersas, entrelaçam-se, inevitavelmente, aspectos ou conceitos que, em princípio são independentes, mas que perdem esta independência quando se trata do planejamento e da execução do complexo ato de investigar áreas submersas.

Quando o objetivo é investigar as camadas inconsolidadas de sedimentos finos, seja para estudos sedimentológicos básicos, seja como subsídio a estudos ambientais, equipamentos que utilizam fontes acústicas que emitem espectros com frequiências mais altas são suficientes para a obtenção das informações necessárias. Equipamentos desta natureza são de menor porte, envidam menor custo operacional, utilizam embarcações de pequeno porte, exigem menor equipe de especialistas a bordo e possibilitam o levantamento de grandes áreas num curto intervalo de tempo e, portanto, envolvem custo operacional menor, quando comparado a levantamentos cujo objetivo é a investigação de estratos sedimentares a grandes profundidades.

A Figura 9.15 ilustra um registro de campo (e sua respectiva interpretação) obtido a partir de um sistema de perfilagem do tipo $S B P$ de $3.5 \mathrm{kHz}$, em levantamento executado no canal de Santos, SP. Neste registro, os refletores sísmicos observados representam o limite da penetração do sinal acústico através das camadas mais superficiais (camadas lamosas) do canal. Nota-se também neste registro a impossibilidade da visualização de refletores correlacionáveis ao embasamento cristalino do canal, demonstrando que a utilização de sistemas de perfilagem acústica desta natureza, não é recomendada, quando o objetivo é a investigação de estratos mais profundos ou a delimitação do contorno do embasamento rochoso. No caso de projetos de investigação para suporte a obras de engenharia, como por exemplo, a instalação de dutos ou cabos submersos, pontes e túneis, sistemas de perfilagem com fontes acústicas mais potentes se fazem necessários, já que é fundamental a identificação da espessura dos estratos sedimentares, bem como da profundidade do embasamento, para o devido planejamento do posicionamento das fundações da obra.

Os perfiladores acústicos de baixa potência do tipo chirp permitem certo controle da fonte acústica, e portanto, com algumas limitações, a escolha do espectro de freqüência a ser emitido (comumente entre 2 e $12 \mathrm{kHz}$ ) e assim, têm especial aplicação na investigação rasa, já que possibilita, durante a aquisição de dados, alterações no padrão do sinal acústico emitido, com vistas à obtenção da melhor relação resolução/penetração. 


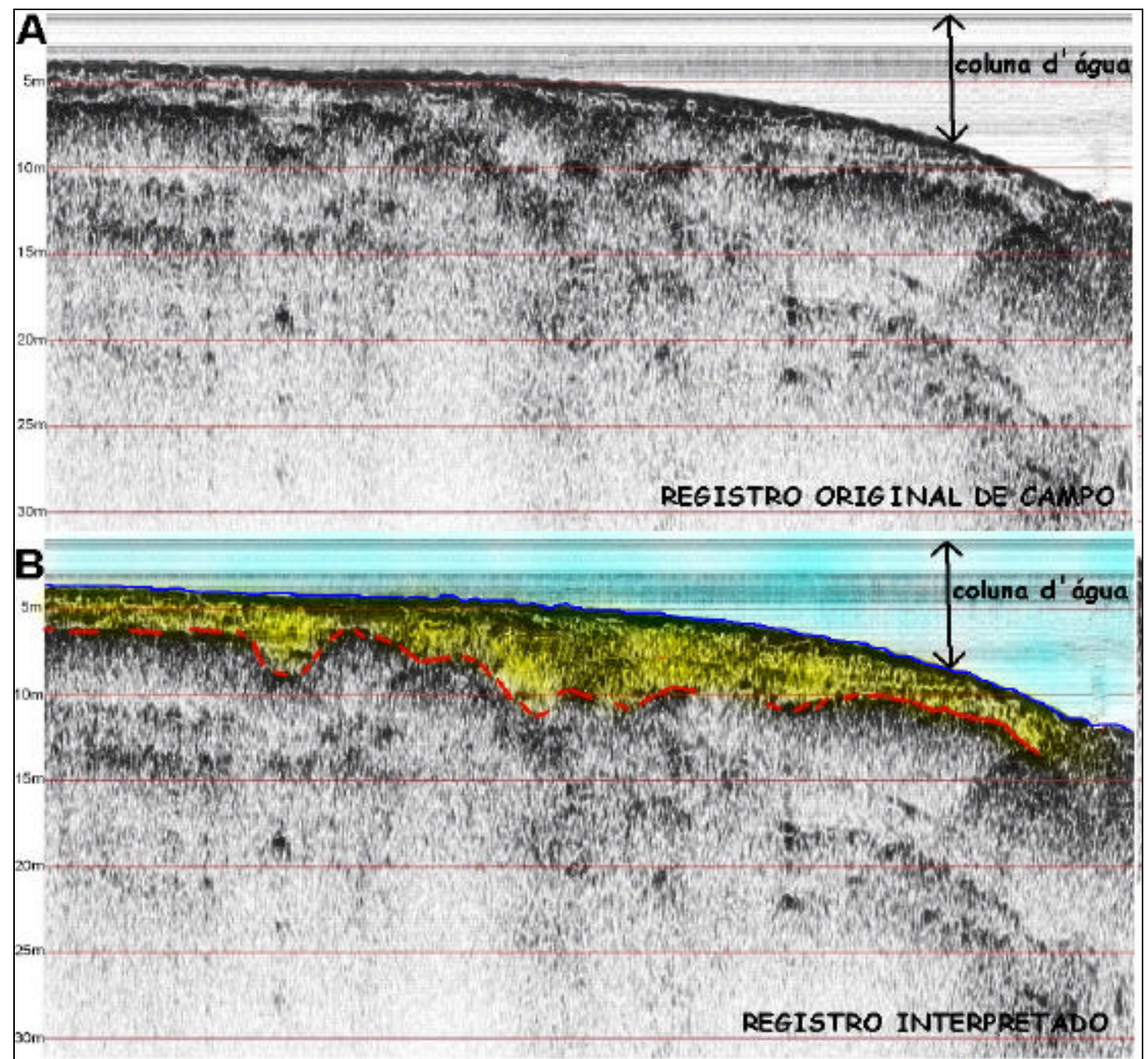

Figura 9.15: Registro obtido em 2005 no canal de Santos, SP com perfilador acústico do tipo SBP $3.5 \mathrm{Khz}$ - Geopulse modelo 5430A. Registro Sísmico cortesia da Microars Consultoria de Projetos.

Mesmo estes modernos equipamentos, que permitem alterações em tempo real dos parâmetros de aquisição dados, em função das propriedades específicas da cobertura sedimentar de uma área específica de estudo, possuem, não raramente, limitações para atingir um refletor sísmico correlacionável ao embasamento. A Figura 9.16 ilustra um exemplo de registro de excelente qualidade obtido no canal de Santos, SP com este tipo de perfilador, cuja interpretação permite apenas visualizar as camadas inconsolidadas superiores de lama.

Quando o objetivo da investigação está relacionado com estudos geológicos básicos ou aplicados, em que o objeto fundamental da busca é a investigação das camadas sedimentares rasas, mas não tão rasas quanto aquelas ilustradas na Figura 9.13, Figura 9.15 e na Figura 9.16, mas, sim, algumas dezenas de metros abaixo da superfície de fundo, equipamentos sísmicos que utilizam fontes acústicas de maior potência se fazem necessários. 


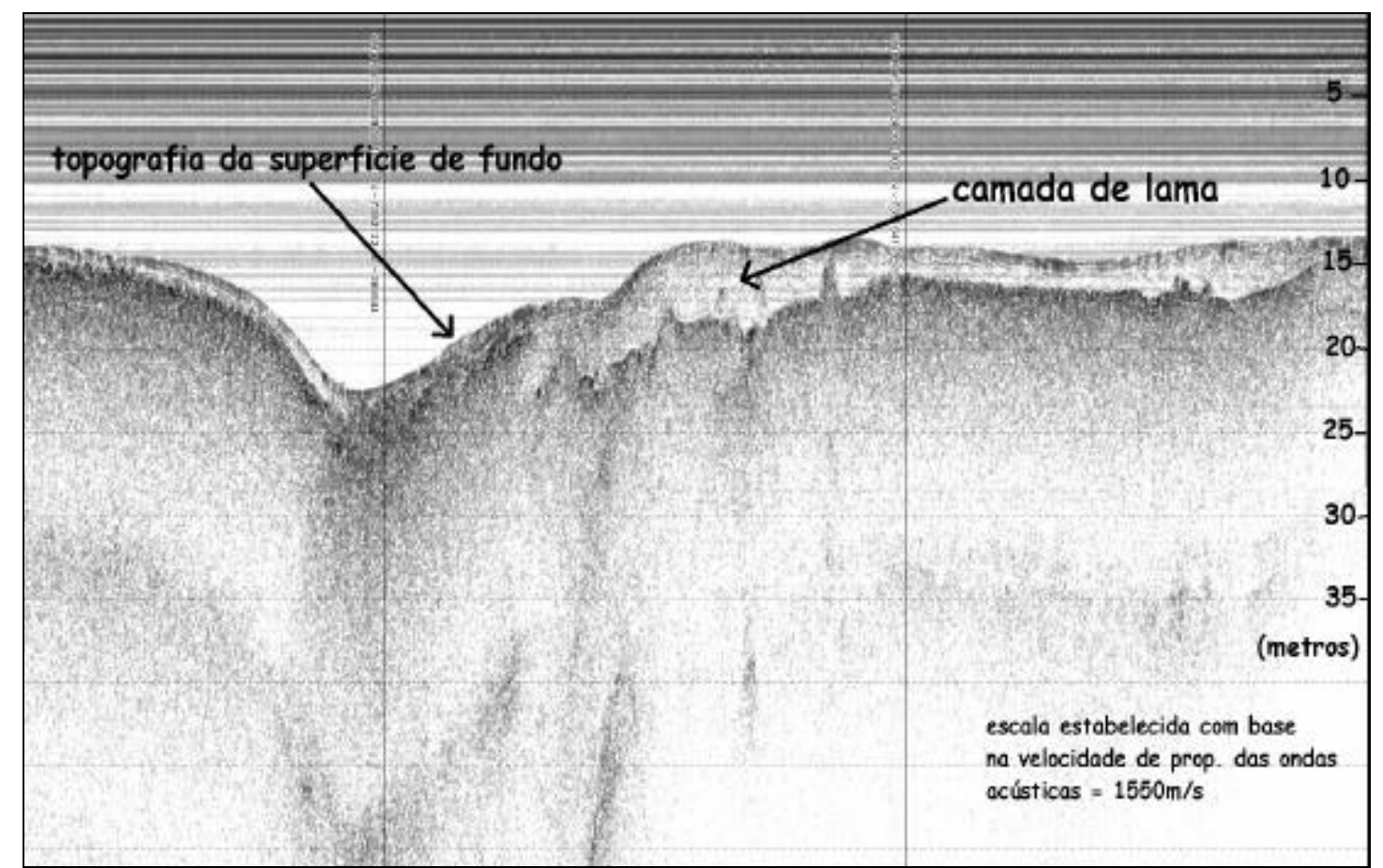

Figura 9.16: Registro obtido no canal de Santos, SP com perfilador acústico do tipo chirp, pertencente ao Instituto Oceanográfico da USP. Observa-se neste figura a nítida interface entre a camada de lama e o substrato do canal, definida pelo sistema acústico utilizado. Registro Sísmico cortesia do Prof. Dr. Michel M. Mahiques - IO-USP.

Para atingir profundidades de algumas dezenas metros, fontes do tipo boomers, minisparkers e air-guns constituem-se nas ferramentas apropriadas, pois tratam-se de fontes acústicas de maior potência e que lidam com espectros com sinais acústicos de menor freqüência, o que potencializa maior poder de penetração do sinal através dos estratos sedimentares. Estas fontes acústicas compõem sistemas sísmicos mais complexos, de maior porte e custo operacional mais elevado, quando comparados aos sistemas discutidos anteriormente.

Embarcações de maior porte, geradores próprios de energia, são alguns dos quesitos necessários para o desenvolvimento da aquisição de dados com sistemas deste porte. Além disso, os equipamentos envolvidos neste tipo de levantamento, são de portabilidade intermediária, carecendo de sistemas de registro, de armazenamento e de processamento de dados, mais complexos, assim como mais complexas são as operações de campo envolvendo o processo de aquisição de dados.

Mesmo considerando-se esta complexidade operacional relativa, equipamentos desta natureza são fundamentais para estudos cujo objetivo principal seja o conhecimento das espessuras das camadas sedimentares subjacentes.

Um passo essencial na investigação de áreas submersas é justamente o estabelecimento do objetivo principal do estudo ou do alvo da investigação. Esta 
decisão vai condicionar toda a infra-estrutura necessária à coleta das informações que irão subsidiar as análises subseqüentes.

Num projeto de instalação de dutos subaquáticos em áreas portuárias, por exemplo, a investigação geofísica principal a ser desenvolvida deverá ser conduzida de modo a fornecer informações sobre os estratos sedimentares depositados sobre o embasamento local, pois estruturas serão instaladas na coluna sedimentar, abaixo da superfície de fundo, e com estes objetivos, há necessidade de se conhecer, em detalhes, o tipo de material que vai ser escavado e/ou removido, e suas espessura e volume. Para projetos com estes objetivos, informações sobre a natureza da superfície de fundo oriundas, por exemplo, de amostragens de fundo, fotografias subaquáticas, imagens do sonar de varredura lateral, auxiliarão de forma apenas secundária os estudos, pois as principais incógnitas envolvidas na equação final de projetos desta natureza estão relacionadas com a espessura da coluna sedimentar, a profundidade do embasamento rochoso e a presença de estruturas geológicas, ou seja, variáveis relativas à subsuperfície.

Informações de subsuperfície são basicamente obtidas de duas maneiras: direta, através de sondagens, ou indireta a partir de ensaios geofísicos, geralmente, sísmicos.

Supondo que o duto, do exemplo citado acima, deva ser instalado a profundidades da ordem de alguns metros, e ainda, com base nos conhecimentos preexistentes sobre a estratigrafia da área, que as investigações terão que atravessar uma camada superficial de lama e camadas de sedimentos arenosos, pode-se concluir que os sistemas acústicos de alta freqüência, do tipo ecobatímetros, ou perfiladores de baixa potência, do tipo $3.5 \mathrm{kHz}$ ou chirp, entre outros, contribuem apenas de maneira secundária às necessidades do projeto. Sistemas de perfilagem de baixa potência e altas freqüências podem, em condições normais, identificar camadas superficiais, decimétricas ou métricas, de lama, mas só em condições muito especiais possibilitarão a identificação da profundidade do embasamento rochoso se este estiver coberto por espessa camada de sedimentos arenosos.

Para atingir o embasamento cristalino, ou no mínimo, para identificar as primeiras dezenas de metros da coluna sedimentar, é essencial a utilização de métodos sísmicos que empregam fontes do porte intermediário do tipo boomers ou sparkers. 
Os perfis exibidos na Figura 9.17 e na Figura 9.18 ilustram de maneira explícita e inequívoca o desempenho, com relação ao poder de penetração, no substrato submerso, de cada uma das três fontes acústicas utilizadas simultaneamente em perfil realizado no litoral norte de São Paulo: pinger (24 kHz), chirp (2-8 kHz) e boomer (0.1$1.5 \mathrm{kHz})$.

O exemplo na Figura 9.17 mostra uma situação onde o perfil obtido com a utilização dos sistemas de alta freqüência (pinger e chirp) identifica anomalia na topografia no fundo que pode ser diretamente correlacionada à ocorrência de afloramentos rochosos na superfície de fundo do canal. O delineamento da extensão em profundidade do corpo rochoso, todavia, só é evidenciado no perfil obtido com a utilização da fonte acústica de maior potência e que emite sinais acústicos com espectro de freqüências mais baixas, no caso, um boomer.

No exemplo da Figura 9.18, por outro lado, a existência do corpo rochoso e suas dimensões em profundidade só é evidenciada de forma completa no perfil obtido com o boomer. No perfil obtido com o pinger, nenhuma evidência da existência de afloramento rochoso é notada. No perfil obtido com o chirp, difrações do sinal acústico identificadas em subsuperfície (vide figura) sugerem a existência de corpos rochosos, sem entretanto permitir qualquer análise quantitativa (profundidade etc.).

Ambos os exemplos mostram claramente o desempenho de cada uma das fontes acústicas empregadas, com relação ao poder de penetração no substrato, estabelecendo-se de maneira explícita o fundamento de que, para o desenvolvimento de projetos de estudos em que informações de subsuperfície, tais como, espessura dos estratos sedimentares e dimensões dos corpos rochosos subjacentes, sejam fundamentais, necessariamente deverão ser utilizados sistemas sísmicos de perfilagem contínua que utilizam fontes acústicas de potência, no mínimo intermediária, e que emitam sinais acústicos com freqüências inferiores a $2 \mathrm{kHz}$, tais como, boomers ou minisparkers, sob pena de não se obter qualquer informação sobre os estratos subjacentes. 


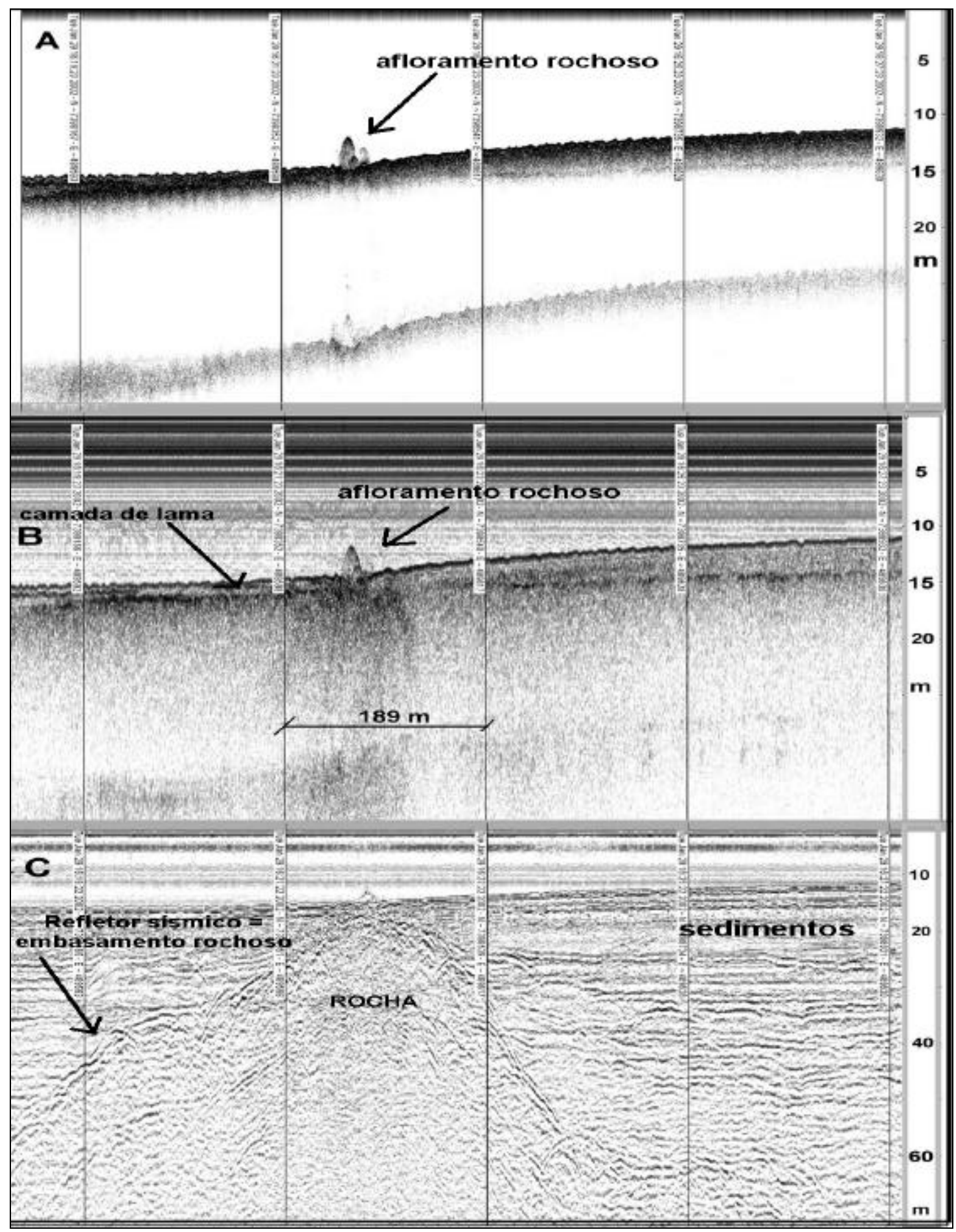

Figura 9.17: Perfil sísmico executado com a utilização simultânea de três fontes acústicas distintas: a) pinger $(24 \mathrm{kHz})$; b) chirp $(2-8 \mathrm{kHz})$; c) boomer $(0.1-1.5 \mathrm{kHz})$. Observa-se nitidamente nestes perfis o desempenho diferenciado das três fontes acústicas utilizadas, com relação à penetração do sinal nos estratos sedimentares subjacentes. No perfil A obtido por meio do pinger $(24 \mathrm{kHz})$, identifica-se uma anomalia na topografia de fundo que pode ser correlacionada à ocorrência de um corpo rochoso aflorante na superfície de fundo. Características similares podem ser observadas no perfil B obtido pelo chirp (2-8 $\mathrm{kHz}$ ). Neste perfil observa-se ainda uma camada de sedimentos finos de espessura variável entre $1 \mathrm{e} 4 \mathrm{~m}$. Em nenhum destes dois perfis (A e B), entretanto, é possível observar o contorno do corpo rochoso em subsuperfície. No perfil C obtido com a utilização de uma fonte acústica do tipo boomer, delineia-se, além das características observadas nos perfis A e B, o contorno do substrato rochoso em subsuperfície, que mergulha até a profundidade de 60 metros. Registros obtido na enseada do Flamengo, litoral norte de São Paulo. Registros cedidos pelo Prof. Dr. Michel M. Mahiques - IO-USP. 

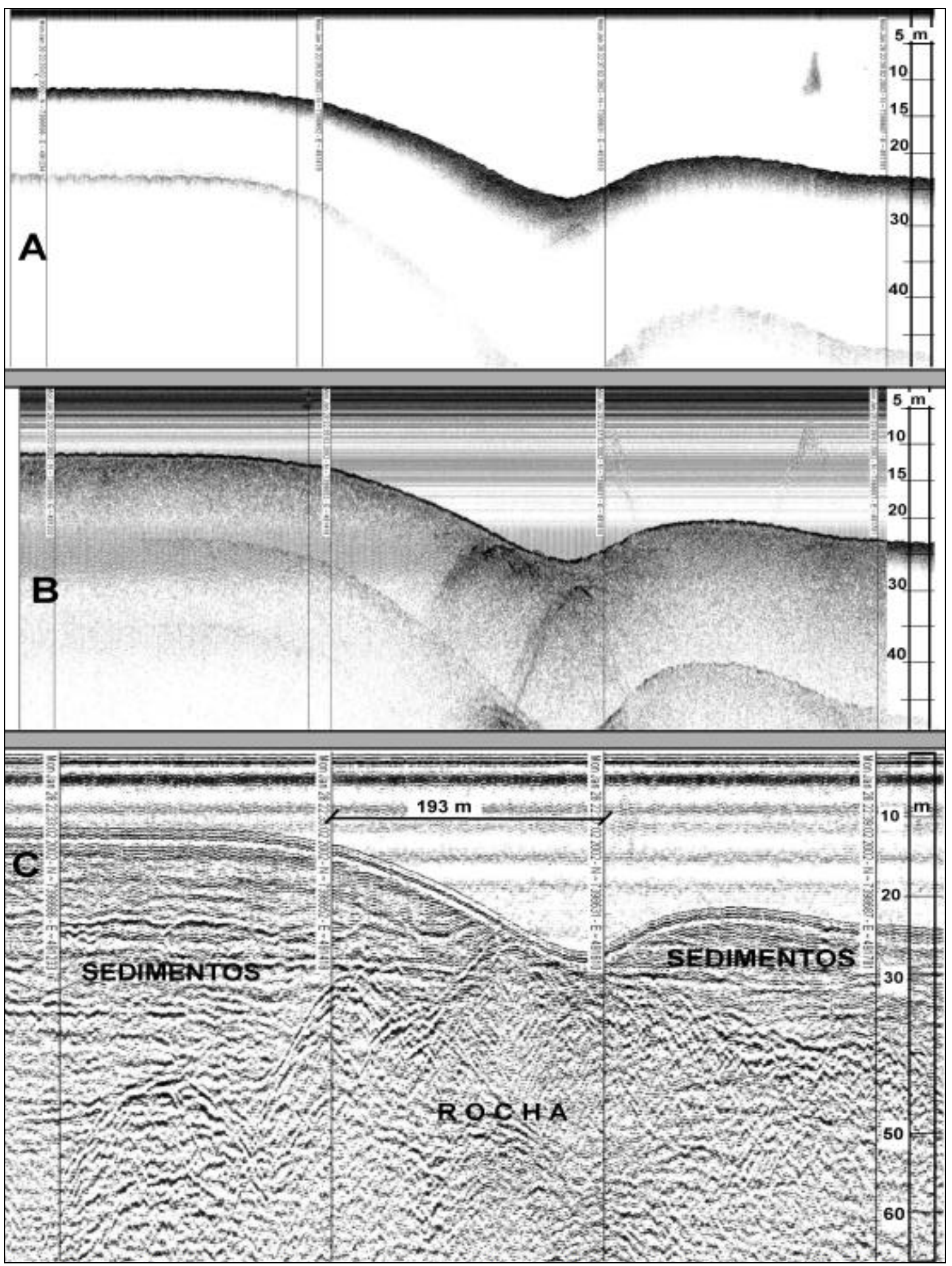

Figura 9.18:: Perfil sísmico executado com a utilização simultânea de três fontes acústicas distintas: a) pinger $(24 \mathrm{kHz})$; b) chirp (2-8 kHz) e; c) boomer (0.1-1.5 kHz). Observa-se nitidamente nestes perfis o desempenho diferenciado das três fontes acústicas utilizadas, com relação à penetração do sinal nos estratos sedimentares subjacentes. No perfil A obtido por meio do pinger $(24 \mathrm{kHz})$ e no perfil B obtido pelo chirp (2-8 kHz) não se evidencia, na superfície, qualquer anomalia na topografia de fundo que pudesse sugerir a existência de corpos rochosos em subsuperfície. No perfil obtido pelo chirp, observa-se, em subsuperfície, a ocorrência de difrações do sinal, fenômeno acústico que sugere a existência de corpos rochosos em subsuperfície, sem todavia permitir qualquer análise quantitativa da ocorrência. No perfil obtido com o chirp, identifica-se ainda uma camada de sedimentos finos de espessura variável entre 1 e 4 m. No perfil C, obtido com a utilização de uma fonte acústica do tipo boomer, é possível delinear-se, além da topografia de fundo, o contorno do substrato rochoso em subsuperfície, que mergulha até a profundidade de 60 metros. Registros obtido na enseada do Flamengo, litoral norte de São Paulo. Registros cedidos pelo Prof. Dr. Michel M. Mahiques - IO-USP. 


\subsection{CONSIDERAÇÕES SOBRE A UTILIZAÇÃO DO GPR NA INVESTIGAÇÃO DE ÁREAS SUBMERSAS}

O GPR, assim como os demais métodos geofísicos discutidos neste trabalho, constitui-se num método de investigação não-invasivo ou não-destrutivo e é executado ao longo de um perfil de forma contínua, permitindo amostragem da superfície (espessura da coluna d'água) e subsuperfície (espessura das camadas de sedimentos finos) de fundo com alta resolução, quando comparado aos demais métodos geofísicos utilizados na investigação de águas rasas.

A maior ou menor penetração do sinal do GPR nas camadas subsuperficiais está diretamente relacionada com a escolha adequada da frequiência do sinal emitido pela antena (Tx). A energia do sinal do GPR decai com o incremento da profundidade. Nas freqüências mais baixas, este decaimento é mais lento, proporcionando maior penetração do sinal nas camadas de sedimentos. Por outro lado, analogamente à sísmica, baixas freqüências oferecem menor resolução.

Por esta complexidade da relação freqüência do sinal versus penetração, a tarefa mais exigente no planejamento de um levantamento de radar em água é justamente a escolha da melhor freqüência para uma determinada área, mesmo porque a penetração maior ou menor nas camadas sedimentares está também diretamente relacionada com as propriedades elétricas (condutividade elétrica) dos sedimentos em subsuperfície. Em áreas de baixa condutividade (água doce) os sinais do GPR penetram mais que em áreas condutivas (águas salgadas ou salobras).

Em meios de alta condutividade, o desempenho do sistema GPR será tão melhor quanto mais próximas da superfície de fundo estiverem as antenas. Deste ponto de vista, a melhor solução foi aquela encontrada pela empresas Art Engineering LLC (Art Engineering, 2005), EUA e CSO-Adviesbureau, Holanda que utilizaram sistemas de antenas submersíveis. Aliás, muitos dos sistemas modernos de perfilagem sísmica contínua utilizam também fontes submersíveis. Em ambos os casos, o objetivo é garantir a menor perda de energia do sinal emitido pela fonte, ao longo da coluna d'água.

O sucesso dos projetos desenvolvidos pelo IPT, SP pelo Observatório Nacional, TJ e pela Universidade da Bahia, e também por empresas nacionais (Geo-radar, MG e Alta Resolução, SP) e internacionais (Art-Engineering,EUA e CSO-Adviesbureau. 
Holanda) indica grande potencial da aplicação desta ferramenta geofísica em estudos de áreas submersas, notadamente em áreas continentais, em projetos de monitoramento de operações de dragagem, estudos de assoreamento de reservatórios, rotas de navegação e em projetos de locação de obras civis em áreas submersas, entre outras.

O interesse da comunidade técnica em tornar viável o emprego do GPR na investigação de áreas submersas passa pela carência nos dias atuais de ferramentas geofísicas eficientes para a investigação de áreas submersas muito rasas. Coluna d'água abaixo de 3-4m é comumente um grande desafio para a perfilagem sísmica convencional, aquela que usa fontes de superfície do tipo boomers ou sparkers. As reverberações dos sinais acústicos entre a superfície de fundo e a superfície da água geram reflexões múltiplas que sobrepujam as reflexões oriundas das camadas de sedimentos, dificultando ou até impossibilitando a identificação da espessura das camadas sedimentares rasas de dimensões decimétricas ou métricas.

Além disso, o GPR constitui-se de um conjunto de equipamentos leves e de fácil manuseio, o que proporciona certa rapidez operacional (aquisição de dados), tornando, conseqüentemente, mais barata a investigação da área de interesse. A possibilidade de utilização das antenas a uma certa distância da superfície d'água (Spicer et al., 1997) também se constitui numa grande vantagem deste sistema sobre os métodos convencionais (sísmicos), pois permite o desenvolvimento da aquisição de dados mesmo em condições operacionalmente complexas (períodos de cheias, por exemplo).

\subsection{CONSIDERAÇÕES SOBRE A UTILIZAÇÃO DA ELETRORRESISTIVIDADE NA INVESTIGAÇÃO DE ÁREAS SUBMERSAS}

A utilização da eletrorresistividade na investigação de ambientes submersos é complexa principalmente no mar, quando a alta condutividade da água é um componente importante. Neste ambiente, o melhor resultado será sempre obtido com a maior proximidade dos eletrodos da superfície de fundo, a despeito do efeito não desprezível da coluna d'água, altamente condutora, no caso do mar, que sempre existirá sobre os eletrodos, cujo efeito deverá se devidamente considerado nos cálculos de modelamento.

Por outro lado, embora se constate uma redução na sensibilidade quando comparado com o sistema de eletrodos instalados na superfície de fundo, o rebocamento dos eletrodos na superfície da água tem algumas vantagens. Uma delas é o fato de que 
as medidas podem ser feitas a velocidades muito maiores, o que permite cobrir grandes áreas num menor tempo. Outra vantagem está relacionada com a geometria dos eletrodos que pode ser melhor conservada ao longo do perfil, já que, obstáculos inexistem na superfície da água; os cabos e eletrodos propriamente ditos podem ser menos robustos, e, assim, menor será a chance de danos ou perdas materiais durante o levantamento. A aquisição de dados com eletrodos rebocados na superfície é bastante adequada quando do estudo de ambientes de águas rasas, pois neste caso, com a coluna d'água menor a resolução do sistema desloca-se para uma efetiva penetração na subsuperfície.

Atualmente as dificuldades em medir as propriedades elétricas no interior da Terra quando coberta por meios muito condutivos (água do mar, por exemplo) são, pelo menos parcialmente, superadas pelos avanços da tecnologia, que produzem equipamentos com alta sensibilidade e grande capacidade de identificação de contrastes muito pequenos das propriedades geoelétricas dos materiais.

A Tabela 9-2 ilustra uma simulação comparativa entre levantamentos elétricos no mar e um em água doce, mostrando a ordem de grandeza da sensibilidade necessária para a leitura das diferenças de potencial geradas num levantamento em cada um destes ambientes. Para esta simulação, fixaram-se alguns parâmetros: adotou-se o arranjo tipo dipolo-dipolo; um espaçamento entre eletrodos igual a $5 \mathrm{~m}$; e a resistividade aparente $\left(\rho_{a}\right)$ da água do mar de 0,2 ohm.m. Para a resistividade aparente $\left.\rho_{a}\right)$ da água doce, adotou-se, para efeito desta simulação, um valor médio 100 ohm.m, mesmo sabendo-se que, diferentemente da água do mar, este parâmetro pode variar muito a depender do conteúdo em sais na água (Gallas, 2000). Para efeito comparativo, foram simuladas quatro situações distintas com relação à corrente injetada nos eletrodos $(\mathrm{I}=800 / 1500 / 3000 / 10000 \mathrm{~mA})$. Nesta tabela, é possível observar as diferenças de potencial $(\Delta \mathrm{V})$ lidas em cada uma das situações simuladas, calculadas com base na expressão $\rho_{a}=K \frac{\Delta V}{I}$, onde $\mathrm{K}$ é um fator geométrico relacionado com as dimensões do arranjo. Nesta simulação, observa-se que, mesmo em condições extremas de injeção de corrente de $10.000 \mathrm{~mA}$, situação incomum em levantamentos geoelétricos, é crítica, em termos de ordem de grandeza, a leitura das diferenças de potencial já a partir do $5^{\circ}$ ou $6^{\circ}$ nível de investigação, sendo necessário leituras numa escala de microvolts $(\mu \mathrm{V})$. 
Ressalta-se que as profundidades referidas na segunda coluna desta planilha têm como base os valores propostos por Edwards (1997).

\begin{tabular}{|c|c|c|c|c|c|c|c|c|c|}
\hline & \multicolumn{8}{|c|}{ Arranjo dipolo-dipolo / dist. entre eletrodos $=5 \mathrm{~m}$} \\
\hline & & \multicolumn{8}{|c|}{$\rho a=0.2$ ohm $m=$ água do mar $1 \rho \mathrm{pa}=100$ ohm. $\mathrm{m}=$ água doce } \\
\hline & & àgua do mar & água doce & água do mar & água doce & água do mar & água doce & água do mar & agua doce \\
\hline NIVEIS & $\operatorname{prof}(m)^{2}$ & \multicolumn{2}{|c|}{$\Delta V(m V) p / l=800 \mathrm{~mA}$} & \multicolumn{2}{|c|}{$\Delta V(m V) p /=1500 \mathrm{~mA}$} & \multicolumn{2}{|c|}{$\Delta V(m V) p / l=3000 m A$} & \multicolumn{2}{|c|}{$\Delta V(m V) p / I=10000 \mathrm{~mA}$} \\
\hline 1 & 2.08 & 1.688 & 848.8 & 3.183 & 1591.5 & 6.358 & 3183.1 & 21221 & 10610.3 \\
\hline 2 & 3.49 & 0.424 & 212.2 & 0.796 & 397.9 & 1.592 & 785.8 & 5.305 & 2652.6 \\
\hline 3 & 4.81 & 0.170 & 84.9 & 0.318 & 159.2 & 0.637 & 318.3 & 2.122 & 1061.0 \\
\hline 4 & 6.10 & 0.085 & 424 & 0.159 & 79.6 & 0.318 & 159.2 & 1.061 & 530.5 \\
\hline 5 & 7.38 & 0.049 & 24.3 & 0.091 & 45.5 & 0.182 & 90.9 & 0.606 & 303.2 \\
\hline 6 & 8.65 & 0.030 & 15.2 & 0.057 & 28.4 & 0.114 & 56.8 & 0.379 & 189.5 \\
\hline 7 & 9.92 & 0.020 & 10.1 & 0.038 & 18.9 & 0.076 & 37.9 & 0.253 & 126.3 \\
\hline 8 & 11.18 & 0.014 & 7.1 & 0.027 & 13.3 & 0.053 & 26.5 & 0.177 & 88.4 \\
\hline 9 & $?$ & 0.010 & 5.1 & 0.019 & 9.6 & 0.039 & 19.3 & 0.129 & 64.3 \\
\hline 10 & ? & 0.008 & 3.9. & 0.014 & 7.2 & 0.029 & 14.5 & 0.096 & 48.2 \\
\hline 11 & $?$ & 0.006 & 3.0 & 0.011 & 5.6 & 0.022 & 11.1 & 0.074 & 37.1 \\
\hline 12 & $?$ & 0.005 & 2.3 & 0.009 & 4.4 & 0.017 & 8.7 & 0.058 & 29.1 \\
\hline 13 & $?$ & 0.004 & 1.9 & 0.007 & 3.5 & 0.014 & 7.0 & 0.047 & 23.3 \\
\hline 14 & $?$ & 0.003 & 1.5 & 0.006 & 2.8 & 0.011 & 5.7 & 0.038 & 18.9 \\
\hline 15 & $?$ & 0.002 & 1.2 & 0.005 & 2.3 & 0.009 & 4.7 & 0.031 & 15.6 \\
\hline
\end{tabular}

\begin{tabular}{|c|l|}
\hline niveis & niveis de investgacáo \\
\hline$p a$ & resistividade aparente (ohm, $m$ ) \\
\hline$\Delta V(m V)$ & diferença de potencial lida nos eletrodos AB \\
\hline$p r o f(m)^{*}$ & profundidade de cada nivel de investigaçăo segundo Edwards (1977) \\
\hline $\mathrm{I}$ & corrente injetada nos eletrodos AB \\
\hline
\end{tabular}

Tabela 9-2: Planilha ilustrando simulação comparativa entre leituras de diferença de potencial em levantamentos em água salgada e em água doce, em quatro situações distintas de injeção de corrente. Estão fixos nesta simulação a resistividade da água do mar (0,2 ohm.m) e da água doce (100 ohm.m) além do tipo de arranjo adotado (dipolo-dipolo). 


\section{CONCLUSÕES}

\subsection{APLICABILIDADE DOS MÉTODOS GEOFÍSICOS}

Estudos básicos dos processos sedimentares costeiros atuais e pretéritos, escolha de áreas para instalação de obras civis (marinas, diques, pontes, túneis, barragens), reconstrução de praias, otimização de rotas de navegação, assoreamento de reservatórios, prospecção mineral (material de construção etc.), mapeamento de dutos ou cabos enterrados, de objetos de interesse arqueológico e operações de busca e salvamento são alguns dos temas, no contexto da investigação de áreas submersas rasas, nos quais os métodos geofísicos, com suas respectivas propriedades específicas, têm muito a contribuir.

São vários os métodos geofísicos aplicáveis a estudos de áreas submersas rasas, e cada um possui propriedades ou características próprias, do que decorre suas vantagens e desvantagens específicas para a solução de um ou de outro determinado problema geológico ou geotécnico.

As análises desenvolvidas no presente estudo, do ponto de vista dos objetivos propostos, encontram-se sintetizadas na planilha apresentada no Anexo A Aplicabilidade dos métodos geofísicos na investigação de áreas submersas rasas. Esta planilha representa também uma tentativa de demonstração das relações existentes entre as relevantes demandas envolvidas no estudo de áreas submersas rasas e os principais métodos geofísicos empregados na investigação destes ambientes tendo, portanto, a intenção de contribuir com o meio acadêmico, tecnológico e com o poder público e privado na medida em que orienta tecnicamente os níveis decisórios para o processo de escolha do melhor método geofísico para a obtenção da solução mais adequada ao problema geológico ou geotécnico investigado, preenchendo desta forma uma lacuna na literatura nacional neste tema.

Métodos geofísicos, tais como gravimetria, geotermia, radiometria, métodos sísmicos (refração, sísmica de reflexão multicanal, sismologia), métodos geoelétricos (magnetotelúricos, eletromagnéticos, polarização induzida) e geofísica de poços não constam da análise discutida neste estudo por se tratar de métodos geofísicos nãoaplicáveis ou raramente aplicáveis em estudos de áreas submersas rasas, muito embora possam eventualmente contribuir em algumas situações. 
A planilha é composta de três partes principais. A primeira contém duas colunas (áreas de aplicação e temas de investigação) com a descrição dos principais itens contemplados no contexto do estudo de áreas submersas rasas.

A segunda, descrita na terceira coluna ( demandas julgadas como as mais relevantes no contexto discutido neste estudo. Estão diretamente relacionadas, na planilha, com as correspondentes "áreas de aplicação" e "temas de investigação" referidos na primeira e segunda colunas.

A terceira compõe-se de quinze colunas que representam os quinze principais métodos geofísicos utilizados na investigação de águas rasas. As cores azul, amarela, vermelha e verde das células da planilha representam, respectivamente, métodos geofísicos indicados, métodos geofísicos de uso secundário, métodos geofísicos nãoaplicáveis e métodos geofísicos com aplicação em desenvolvimento.

As letras maiúsculas na cor branca, $\underline{\mathbf{A}}, \underline{\mathbf{B}}$ e $\underline{\mathbf{C}}$, anotadas nas células azuis da planilha, representam a contribuição relativa, em ordem decrescente de $\mathbf{A}$ para $\mathbf{C}$, de cada "método geofísico indicado" para a solução de cada questão geológica listada na coluna "demandas". Analogamente, as letras minúsculas na cor preta, $\underline{\mathbf{a}}, \underline{\mathbf{b}}$ e $\underline{\mathbf{c}}$, anotadas nas células amarelas da planilha, representam a contribuição relativa, em ordem decrescente de $\underline{\mathbf{a}}$ para $\underline{\mathbf{c}}$, de cada "método geofísico de uso secundário" para a solução de cada questão geológica listada na coluna "demandas".

Os números $\underline{1}, \underline{2}, \underline{3}$ e $\underline{4}$ preenchendo as células da planilha representam os

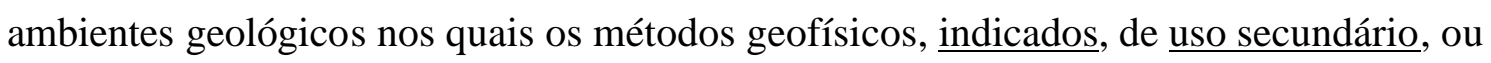
em desenvolvimento, são aplicáveis, respectivamente, plataforma continental interna, áreas costeiras, rios, lagos e reservatórios.

A primeira conclusão que se pode extrair desta planilha é que o ambiente geológico propriamente dito (rios, lagos, áreas costeiras ou plataforma continental interna) não se constitui por si só em fator limitante, ou de exclusão, para a aplicação preferencial de um ou de outro método geofísico. As únicas exceções ocorrem com relação ao método GPR, que não é aplicável em estudos do ambiente marinho, e com os métodos sísmicos que utilizam fontes acústicas do tipo sparker, que necessitam de meio condutor para que ocorra a efetiva emissão das ondas acústicas. 
No caso específico de fontes do tipo sparkers, existem adaptações especiais que tornam possível sua utilização em ambientes de água doce, porém são raramente utilizadas considerando a existência de alternativas mais viáveis.

Ressalta-se que as quinze colunas que representam dos quinze principais métodos geofísicos empregados na investigação de áreas submersas rasas estão agrupadas em dois conjuntos principais: métodos sísmicos e outros métodos geofísicos. Ambos se subdividem em dois subgrupos, obedecendo à abordagem adotada neste estudo: métodos aplicados na investigação de superfície e métodos aplicados na investigação de subsuperfície.

Adicionalmente, observa-se que a disposição, nesta planilha, dos métodos sísmicos obedece a uma ordem crescente da esquerda para a direita, em relação à capacidade de penetração do sinal acústico através da seqüência sedimentar investigada: colunas mais à direita representam métodos geofísicos com maior capacidade de penetração no substrato sedimentar.

Uma segunda conclusão é a ratificação da assertiva consagrada nos meios acadêmicos e técnicos de que os métodos sísmicos constituem-se na principal ferramenta geofísica de investigação de áreas submersas rasas, quaisquer que sejam os objetivos predeterminados da pesquisa.

Assim, os métodos elétricos, magnetométricos e o GPR, parcialmente abordados neste estudo, bem como outros métodos geofísicos não abordados, representam papel apenas secundário ou complementar na investigação de áreas submersas rasas.

Os métodos elétricos, a se destacar a eletrorresistividade, têm evoluído a cada dia e já denota papel relevante na caracterização qualitativa dos meios geológicos submersos, sendo, porém, discutível a interpretação quantitativa dos dados obtidos por meio deste método.

Vários autores estudam ainda hoje a relação dados geoelétricos versus quantificação. Dentre eles destaca-se Edwards (1977) que propôs um método para quantificação das anomalias geoelétricas, com enfoque na determinação das profundidades das mesmas, a qual é adotada em vários softwares de modelamento (inversão) geoelétrico. 
De qualquer forma, considerando a enorme variabilidade das propriedades geoelétricas para um mesmo meio geológico, a interpretação de dados geoelétricos é certamente aprimorada quando da existência de dados adicionais sobre a geologia da área estudada (dados de poços, de amostragens ou testemunhagens), ou mesmo quando associada à interpretação de dados originados de outros métodos geofísicos. Portanto, com este caráter essencialmente qualitativo, a utilização dos métodos elétricos na investigação de áreas submersas tem aplicações ainda restritas.

Analogamente, a magnetometria, quando aplicada em estudos de áreas submersas rasas, proporciona também resultados essencialmente qualitativos, porém, a um custo operacional baixo, certamente o menor dentre os demais métodos geofísicos aplicáveis em estudos de áreas submersas.

Nas questões aplicadas, a magnetometria tem ocupado posição de destaque na identificação de dutos metálicos enterrados em áreas costeiras ou em rios. Esta aplicação tem especial importância ao se considerar a relevância ambiental atual da presença, nestes sensíveis ambientes geológicos, de dutos que transportam óleo e gás das plataformas exploratórias marinhas para o continente, ou que distribuem estes produtos pelo continente, tendo geralmente que atravessar rios ou reservatórios.

Dezenas ou centenas destes dutos foram instalados ao longo dos anos, e se encontram em operação desde o período em que questões ambientais, em projetos desta natureza, não eram tratadas com a prioridade ou com a relevância dos dias atuais. Naquele período não fazia parte da maioria dos projetos a confecção do "as built", ou seja, o desenho do projeto efetivamente instalado. Assim, muitos destes dutos têm hoje sua localização desconhecida, o que dificulta as operações de manutenção e substituição, colocando em risco as áreas por onde passam.

Como pode ser observado na planilha (Anexo A), as principais aplicações da magnetometria estão reservadas à localização de dutos, de objetos metálicos de interesse arqueológico ou de embarcações naufragadas cobertas ou não por sedimentos.

Não é desprezível, entretanto, a aplicação da magnetometria na investigação de áreas submersas rasas com finalidades geológicas notadamente em levantamentos de reconhecimento, até mesmo pelo baixo custo envolvido num levantamento por meio deste método. 
O produto de uma coleta sistemática de dados magnetométricos em ambientes submersos possibilita a identificação de diques, depósitos de placeres metálicos, estruturas geológicas, contatos geológicos, entre outras feições que, de alguma forma, expressem propriedades magnéticas suficientemente contrastantes.

Embora limitado com relação ao ambiente, já que tem aplicabilidade restrita às áreas cobertas por água doce, o GPR, ou radar de penetração no solo, consiste no mais recente método geofísico com grande potencial de aplicação nos estudos de áreas submersas rasas. A partir de adaptações específicas com relação à flutuabilidade das antenas, já que foram originalmente desenvolvidas para emprego na superfície terrestre, este novo método geofísico tem mostrado resultados muito promissores nas recentes experiências realizadas na investigação de ambientes submersos.

A praticidade operacional, garantida essencialmente pela extrema portabilidade do sistema, constitui-se na primeira das principais vantagens de utilização deste método. Esta versatilidade operacional torna viável o uso do GPR em locais de difícil acesso, e/ou com coluna d'água muito rasa (inferior a $3 \mathrm{~m}$ ), condições em que são mais complexas as operações quando do emprego dos métodos convencionais (sísmicos). A avaliação do volume de sedimentos finos, ou resíduos, em lagoas de decantação em indústrias químicas, ou em estações de tratamento de água ou de fluidos em geral, constitui-se num dos ambientes onde o GPR tem grande potencial de aplicação.

Finalmente, a principal conclusão extraída da planilha (Anexo A) é que o fator limitante e determinante, para a escolha do melhor método geofísico a ser aplicado no desenvolvimento de projetos de investigação em áreas submersas rasas, reside na definição do objetivo da investigação, à parte da própria natureza do substrato geológico, que se constitui em fator naturalmente limitante.

$\mathrm{Na}$ abordagem proposta neste estudo, os objetivos da investigação de áreas submersas rasas são analisados em dois essenciais pontos de vista, o da investigação da

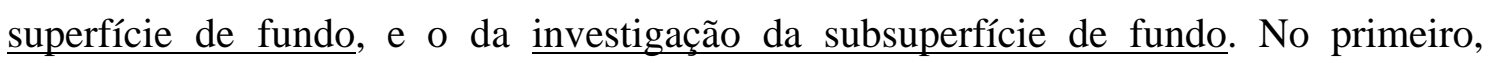
conforme pode ser observado na referida planilha, têm relevância expressiva os métodos sísmicos que se utilizam de fontes acústicas de altas frequiências, preferencialmente superiores a $30 \mathrm{kHz}$. No segundo, contribuem diversos métodos geofísicos, mas têm ainda expressiva relevância os métodos sísmicos que se utilizam de fontes acústicas que emitem freqüências inferiores a $20 \mathrm{kHz}$. 


\subsubsection{MÉTOdOS SÍSMICOS}

Como pode ser visto na planilha (Anexo A), são muitas as questões de geologia, de engenharia, de biologia e de arqueologia, entre outras áreas, cuja busca das soluções passa necessariamente pela investigação geofísica por meio da aplicação de métodos sísmicos. Entretanto, a utilização de um ou de outro método, dentre as várias possibilidades existentes, deve-se basicamente à definição do objetivo do estudo.

Se o objetivo da investigação é caracterizar o ambiente geológico de uma determinada área de estudo, tendo como base a identificação de características físicas que se expressam de alguma forma na superfície de fundo, tais como a própria topografia de fundo, contatos litológicos, afloramentos rochosos, estruturas sedimentares, estruturas geológicas (falhas, lineamentos etc.), os métodos sísmicos a serem aplicados são necessariamente aqueles que utilizam fontes acústicas de alta freqüência (em geral superiores a $30 \mathrm{kHz}$ ) e que, portanto, oferecem grande desempenho no quesito resolução, em sacrifício da penetração, que não é o objetivo, nestes casos.

Assim, conforme descritos na planilha, a sonografia e a ecobatimetria, incluindo-se nesta última os ecobatímetros de uma e de duas freqüências, os de varredura, e os classificadores de fundo são os principais métodos acústicos indicados.

Este conjunto de métodos geofísicos tem ainda utilização de grande relevância em questões aplicadas: na identificação de obstáculos à navegação (afloramentos rochosos, árvores submersas, embarcações naufragadas etc.), em projetos de hidrovias e em temas relacionados com a biologia, como por exemplo, a caracterização de habitats subaquáticos, localização de ocorrências de recifes de corais e recifes artificiais.

Assim, com a finalidade da investigação de superfícies submersas, são vários os modelos de equipamentos disponíveis no mercado atualmente.

No caso da batimetria, os equipamentos se diferenciam basicamente de acordo com a freqüência emitida, a sofisticação do processamento dos dados, em tempo real ou pós-processados, e, nos modelos mais modernos (de varredura), quantidade de sensores/emissores de sinais num mesmo módulo, propriedade que define maior ou menor cobertura lateral e resolução. 
Ecobatímetros de freqüências mais baixas $(30-50 \mathrm{kHz})$ são usados nas investigações de águas profundas; os de frequiências mais altas (ao redor de $200 \mathrm{kHz}$ ), na investigação de águas rasas.

Em qualquer situação, o uso deste tipo de equipamento tem sempre como objetivo a definição com precisão da espessura da coluna d'água e, por conseguinte, a caracterização ou o modelamento da topografia de fundo. Parâmetros tais como declividade das superfícies submersas e heterogeneidades do perfil topográfico, definidos a partir de levantamentos topográficos, são altamente correlacionáveis com áreas de ocorrência de afloramentos rochosos, depósitos de minerais de interesse econômico, recifes de corais, beachrocks, bancos e cordões arenosos, cânions, que por fim formam um conjunto de parâmetros que em muito contribui para a caracterização do ambiente geológico estudado.

Existem dezenas de fabricantes de ecobatímetros, porém os modelos mais sofisticados são fabricados pelas empresas tradicionais do ramo da investigação de áreas submersas, como a Kongsberg-Simrad (Noruéga), a Klein e a Edgetech (EUA), e a GeoAcoustics (UK), entre outras.

Dentre os ecobatímetros de dupla frequiência, destaca-se o modelo EA-400 da Kongsberg-Simrad (Noruéga), que oferece excelente desempenho e opera simultaneamente nas freqüências 38 e $200 \mathrm{kHz}$, entre outros pares de freqüências disponíveis. Este modelo, em especial, possui várias unidades em operação em diversas instituições do Brasil.

Quanto aos sistemas multifeixe, são também vários os modelos disponíveis no mercado. O GeoSwath Plus, que opera nas freqüências 125, 250 e $500 \mathrm{kHz}$, fabricado pela GeoAcoustics (UK), e o EM3000 Multibeam Sonar System, da Kongsberg-Simrad (Noruéga), que opera na frequiência de $300 \mathrm{kHz}$, são alguns exemplos de excelentes equipamentos disponíveis no mercado atualmente.

Quanto aos ecoclassificadores de fundo, ecobatímetros acoplados a processadores dedicados à análise do sinal acústico que retorna da superfície de fundo, os modelos principais disponíveis no mercado hoje são: o RoxAnn, da SonaVision (UK), o QTC-View, da Quester Tangent Corporation (Canadá), e o Echo-Plus, da Sea (UK). São muitos os exemplos na literatura do emprego, de forma integrada, de ecobatímetros e classificadores de fundo cujo produto final é o modelamento topográfico de precisão 
associado à classificação geológica da superfície de fundo, o que sem dúvida proporciona uma visão ampla, até então não-disponível. A Figura 10.1 mostra o produto da utilização conjunta destes equipamentos.

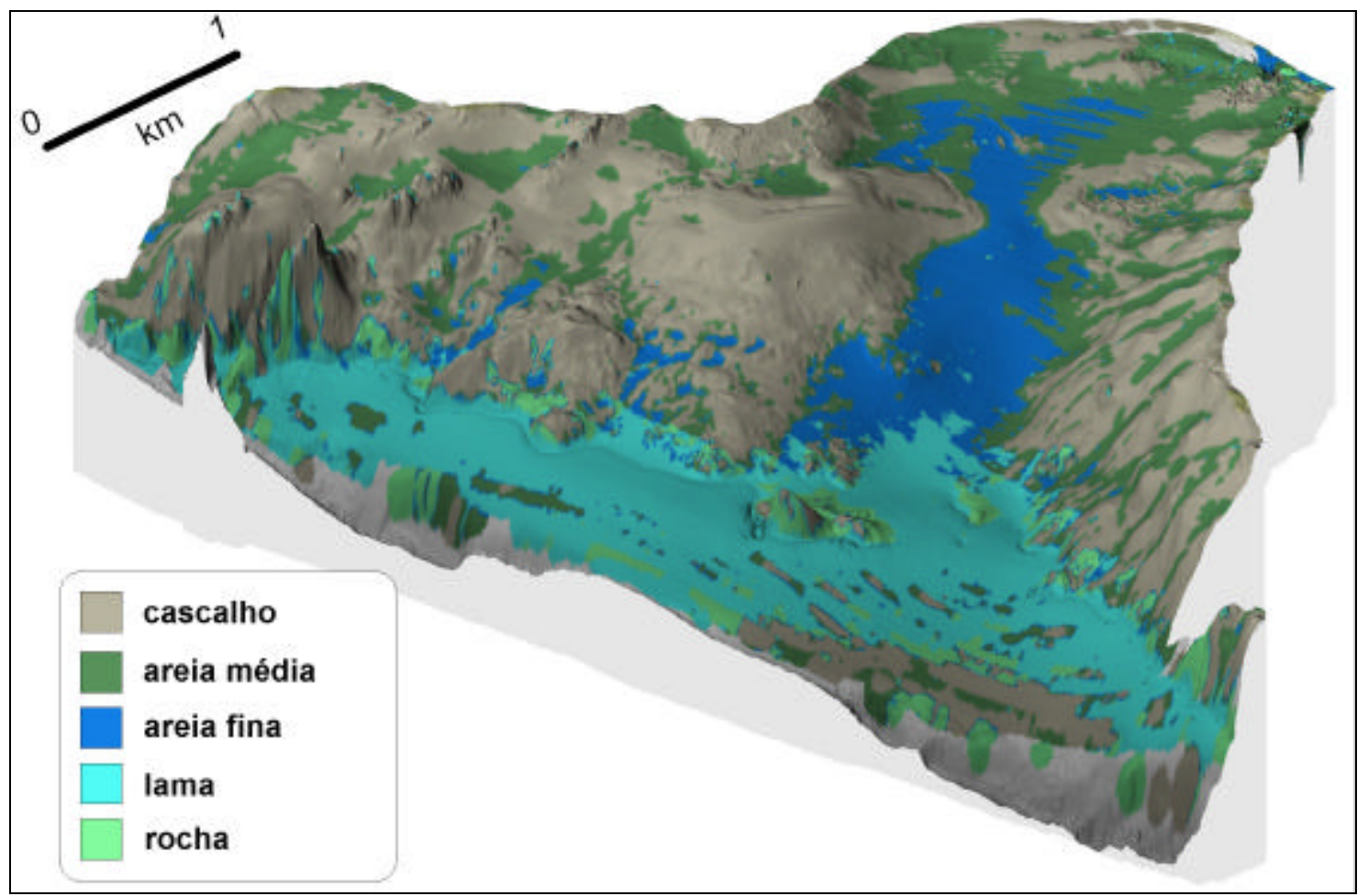

Figura 10.1: Exemplo de produto obtido da utilização simultânea de ecobatímetro de varredura (Simrad EM 3000) com sistema ecoclassificador do tipo QTC-View. Área proxima à Ilha de Vancouver, Canadá. Fonte: 〈http://www.questertangent.com>. Acesso: abril/ 2006.

Como pode ser observado na planilha (Anexo A), o sonar de varredura lateral constitui-se na principal ferramenta geofísica indicada, quando se trata da caracterização de superfícies submersas.

Nenhuma outra ferramenta geofísica possibilita visão tão detalhada de feições, geológicas, ou não, que se expressem de alguma maneira (textura, forma etc.) na superfície de fundo. A identificação precisa e detalhada de estruturas sedimentares do tipo marcas onduladas, contatos litológicos (não só aqueles mais conspícuos, como rocha-sedimentos, mas também os contatos menos evidentes, como sedimentos finosareias grossas) e feições estruturais, faz deste instrumento de investigação ferramenta imprescindível no estudo dos ambientes geológicos submersos. Além disso, as imagens obtidas do sonar de varredura lateral têm vasta aplicação em projetos de hidrovias, já que permitem a identificação de obstáculos à navegação, na arqueologia, na biologia etc. A Figura 10.2 mostra um registro de excelente qualidade, obtido por meio de um sonar de varredura lateral, ilustrando o excepcional desempenho deste método de 
investigação, na caracterização de superfícies submersas, em especial, na identificação de estruturas sedimentares.

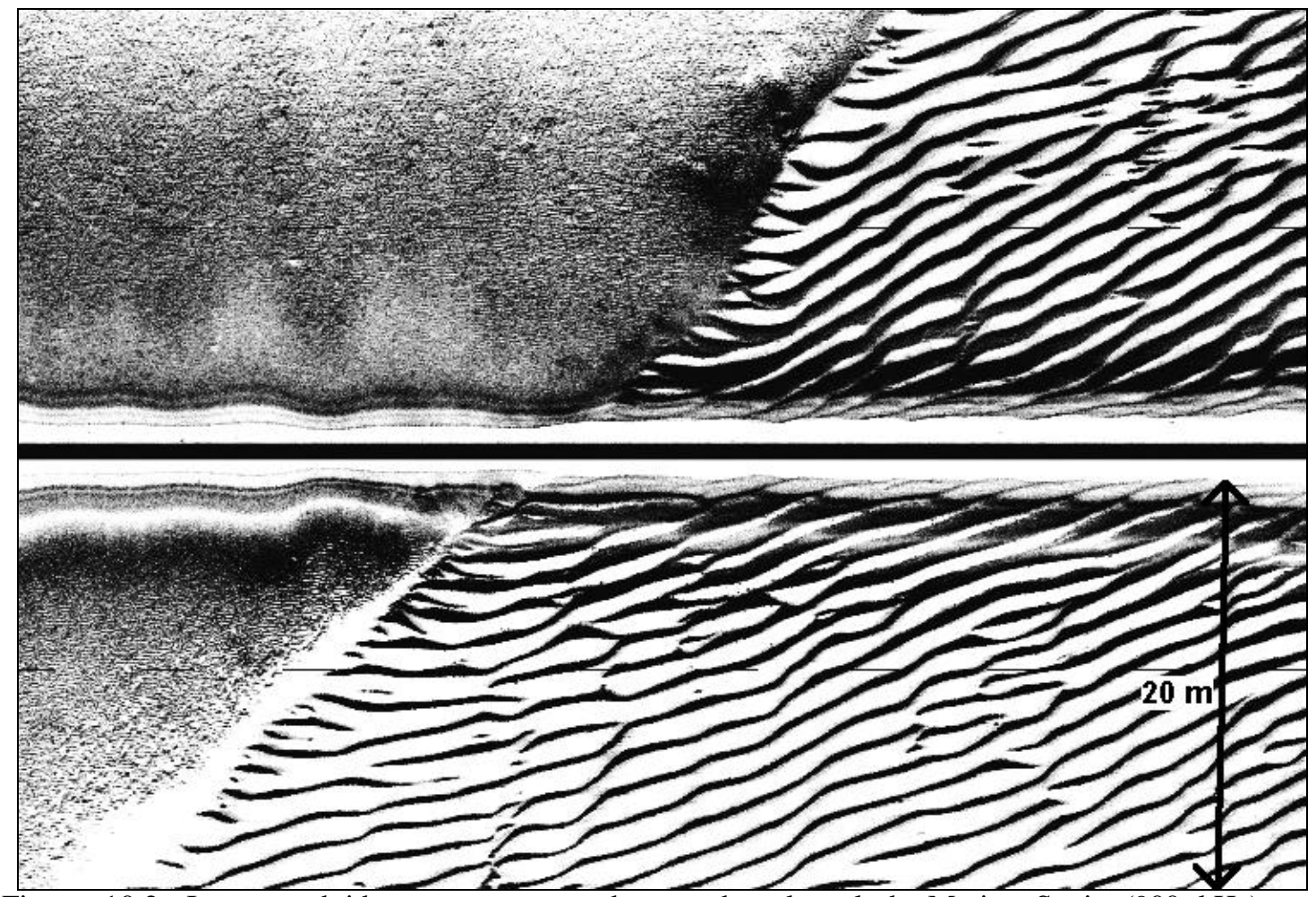

Figura 10.2: Imagem obtida por um sonar de varredura lateral da Marine Sonic $(900 \mathrm{kHz})$, em levantamento executado em área costeira da Nova Zelândia. Destaca-se nesta imagem o nítido contraste entre os dois padrões texturais de fundo identificados: de um lado, sedimentos compostos de areia grossa e fragmentos de conchas; de outro, sedimentos arenosos finos com expressivas marcas onduladas. Ressalta-se, a partir da excelente qualidade desta imagem, a relevante aplicabilidade de sistemas acústicos desta natureza em estudos de processos sedimentares em áreas costeiras. Imagem obtida por Don Wright and Bob Gammisch do Virgínia Institute of Marine Science (VIMS). Disponível em <http://www.marinesonic.com>. Acessso: jan/2006.

Com relação aos modelos de equipamentos disponíveis no mercado atual, são também muitas as possibilidades e, basicamente, se diferenciam com relação à freqüência do sinal emitido e a quantidade de emissores contidos nos transdutores laterais, além do nível de sofisticação com relação às possibilidades de armazenamento e processamento (em tempo real ou pós-processados) dos dados coletados.

Dentre os modelos disponíveis, destacam-se: Centurion (várias freqüências), da Marine Sonic; 4100 Side Scan Sonar System 272-T (100 kHz) ou 272-TD (100/500 kHz), da EdgeTech (EUA); Sonar System 3000 (100/500 kHz), da Klein (EUA); e o DSSS (114-410 kHz), da Geoacoustics (UK).

Sofisticados sistemas multifeixe de alta resolução estão também disponíveis atualmente, destacando-se o modelo Sonar System $5000(455 \mathrm{kHz})$, da Klein, e o modelo 4200-FS (120-410 kHz) da Edgetech. Estes modernos sistemas multifeixes são 
muito interessantes, pois, ao contrário dos modelos convencionais, que empregam apenas um feixe de sinais de cada lado, possuem quatro, cinco ou mais emissores de sinais de cada lado, o que garante $100 \%$ de cobertura da área investigada, grande resolução e rendimento, já que permitem o desenvolvimento da aquisição de dados com alcance lateral de até $300 \mathrm{~m}$ e em velocidades superiores a 10 nós.

Uma análise global da planilha permite concluir, do ponto de vista da investigação de superfícies submersas rasas que os demais métodos geofísicos pouco contribuem.

Por outro lado, na investigação de áreas submersas com o objetivo da penetração através da coluna sedimentar, seja em estudos básicos de estratigrafia rasa ou em demandas relacionadas com cálculos de volume de material inconsolidado, como, por exemplo, em projetos de dragagem de áreas portuárias ou em estudos de assoreamento de reservatórios, ou para cálculos de volumes de materiais de interesse econômicos (areias e cascalhos, p.ex.), passa a ser necessário e fundamental o emprego de métodos sísmicos de perfilagem com fontes acústicas que emitem sinais acústicos de frequiências inferiores a $20 \mathrm{kHz}$ (Anexo A).

A perfilagem sísmica possibilita identificar na coluna sedimentar uma série de características que, analisadas conjuntamente, contribuem para a caracterização do ambiente geológico investigado, tais como, contatos geológicos (verticais ou horizontais), espessura dos estratos sedimentares, profundidade do embasamento rochoso, paleocanais, estruturas de escavação e preenchimento, estruturas sedimentares (p.ex. estratificação cruzada), estruturas geológicas, entre outras.

Na planilha (Anexo A), sob a denominação de perfilagem acústica, distribuemse seis grupos de sistemas acústicos dispostos em ordem crescente da esquerda para a direita, com relação à capacidade de penetração do sinal emitido, ou seja, da esquerda para a direita, aumenta a energia e diminui a frequêencia emitida pela fonte acústica correspondente.

Sob a denominação de perfiladores sísmicos, podem ser incluídos sistemas que utilizam fontes acústicas do tipo $3.5 \mathrm{kHz}, 7 \mathrm{kHz}$, chirp, paramétricas, boomers e sparkers, e até mesmo alguns ecobatímetros de dupla freqüência, que em condições muito favoráveis (sedimentos lamosos, p. ex.) podem tornar viável a identificação das camadas sedimentares muito rasas (decimétricas) e, portanto, também perfilam a 
subsuperfície. O termo SBP, na primeira coluna do grupo perfilagem acústica, é consagrado no meio geofísico e significa subbottom profiler, é usado de forma genérica para designar perfiladores acústicos monoestáticos (fonte e receptor no mesmo corpo) que emitem sinais com freqüências geralmente entre 3 e $10 \mathrm{kHz}$.

Desta forma, denota-se que, no âmbito da análise dos fatores determinantes para a escolha do melhor método geofísico para abordagem do tema "investigação em subsuperfície de áreas submersas rasas”, a primeira questão a ser examinada está intimamente relacionada com as necessidades do projeto de investigação, ou seja, “quantos metros se deseja penetrar na superfície de fundo?” é a pergunta principal a ser respondida. Segue-se naturalmente a esta questão uma segunda, diretamente relacionada com o ambiente de sedimentação que gerou o contexto estratigráfico sobre o qual está sendo desenvolvida a atividade de investigação, que implica considerar "que tipo de material o sinal acústico emitido terá que atravessar?“.

As respostas a estas questões auxiliam necessária e suficientemente a tomada de decisão com relação ao método de investigação adequado a ser adotado e, conseqüentemente, sobre o tipo ou modelo de equipamento que deverá ser empregado. Cada situação a ser analisada deverá, portanto, levar em conta a relação tipo de fonte acústica versus tipo de fundo (característica geológica do ambiente a ser investigado). A Figura 10.3 mostra um exemplo desta relação em que se examina o desempenho de uma fonte acústica modelo GeoPulse Pinger-3.5 kHz, fabricado pela Geoacoustics, cujos resultados ratificam a assertiva de que sedimentos inconsolidados finos (argilosos) oferecem menor resistência à penetração dos sinais sísmicos que sedimentos mais grossos.

Penetrar através de uma coluna de sedimentos lamosos de espessuras métricas $(1,2,5$ ou $15 \mathrm{~m})$ envolve métodos distintos daqueles necessários para atingir as mesmas profundidades através de uma coluna de sedimentos arenosos. Outros métodos se fazem necessários também no caso de alvos a maiores profundidades, da ordem de dezenas de metros (20, 40 ou $100 \mathrm{~m})$, numa coluna sedimentar arenosa.

Se o objetivo da investigação é a determinação de espessuras decimétricas ou métricas de estratos de sedimentos lamosos essencialmente argilosos, saturados e moles, que ocorrem em ambientes de deposição de águas calmas, como bacias oceânicas, enseadas protegidas, baías, canais portuários, reservatórios ou em lagoas artificiais de decantação, bons resultados podem ser obtidos com equipamentos geofísicos que 
utilizam fontes acústicas com espectros de freqüências entre 10 e $40 \mathrm{kHz}$. Nestas condições, até mesmo ecobatímetros de dupla freqüência, como, por exemplo, o modelo EA 400 (38/200 kHz), da Kongsberg-Simrad (Noruéga), podem fornecer dados com resolução e penetração satisfatórios.

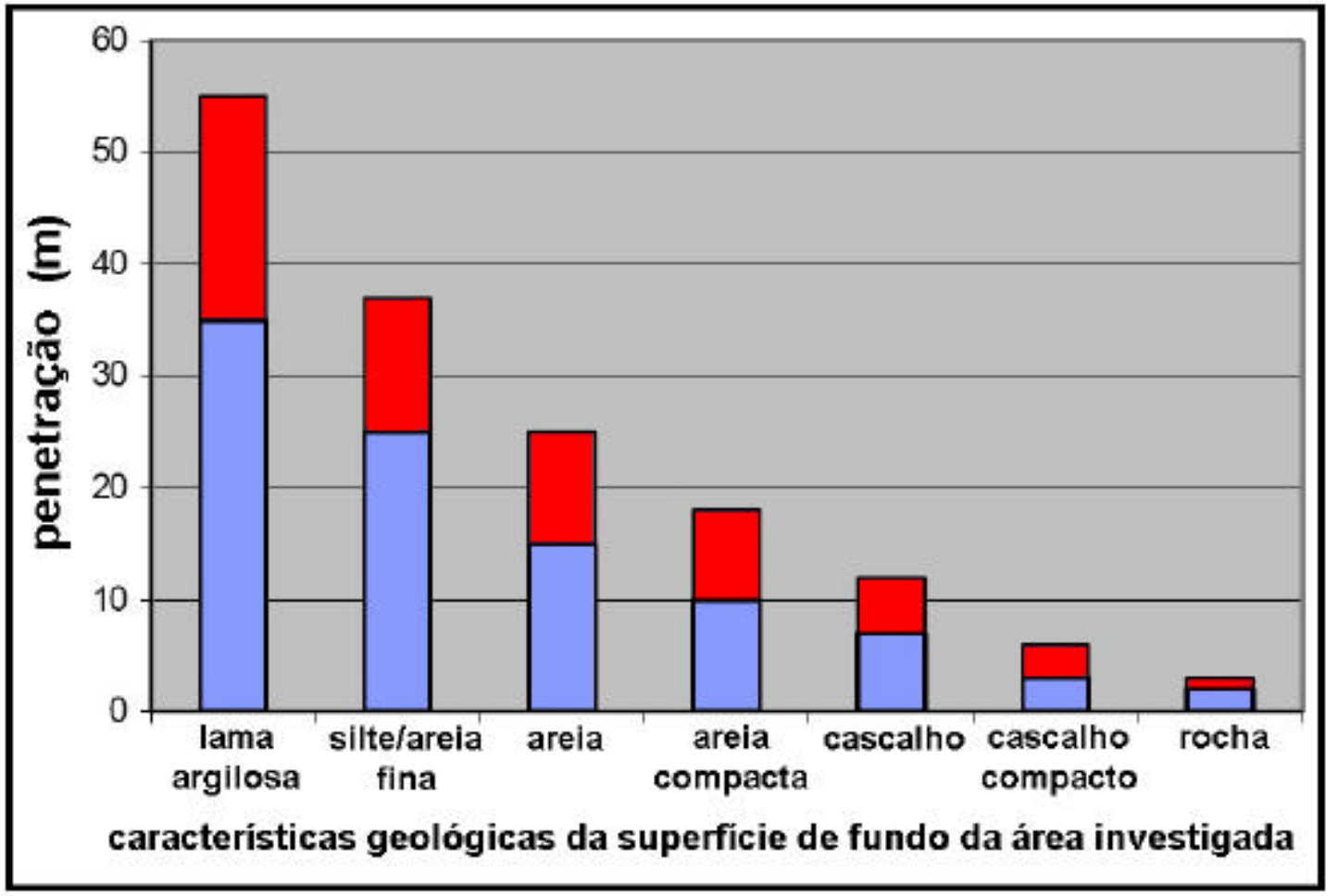

Figura 10.3: Desempenho da fonte acústica modelo GeoPulse Pinger $3.5 \mathrm{kHz}$, da Geoacoustics: penetração esperada (em azul) e a variabilidade possível (em vermelho) para a relação penetração do sinal acústico x tipo de fundo. Fonte: 〈http://www.geocoustics.com>. Acesso: abril/2006.

Entretanto, os melhores resultados serão obtidos com a utilização de perfiladores de alta resolução, como, por exemplo, o modelo Stratabox (10 kHz CW 300W), da SyQwest (EUA) ou o sistema MD-DSS (Pinger $24 \mathrm{kHz}$ ), da Meridata (Finlândia). Sistemas que utilizam fontes acústicas do tipo chirp de alta resolução como, por exemplo, o modelo SBP-3100-P-SB-424-200W (4-24 kHz), da Edgetech, proporcionam excelentes resultados quando aplicados no estudo de ambientes desta natureza.

Os equipamentos citados são excelentes exemplares de equipamentos geofísicos dedicados à investigação de alta resolução e que, portanto, permitem a identificação da espessura das camadas rasas de sedimentos, oferecendo grande resolução, e assim possibilitando a definição de camadas até mesmo centimétricas. Estes tipos de fontes acústicas têm vasta aplicação em temas relacionados com estudos geológicos básicos que envolvem a caracterização da estratigrafia recente (dezenas ou 
centenas de anos) e muito rasa, nos estudos de assoreamento de reservatórios e de lagoas de decantação, entre outros temas. Podem também eventualmente contribuir em estudos estratigráficos que buscam definir a coluna sedimentar holocênica, todavia não proporcionarão resultados satisfatórios quando o interesse for avançar estratigraficamente além da coluna sedimentar holocênica.

Por outro lado, se o objetivo é investigar os mesmos ambientes descritos no parágrafo anterior, com sedimentos nas mesmas condições, mas predominantemente siltosos ou mais arenosos (areias finas), ou avançar na coluna sedimentar no rumo dos estratos mais antigos e, portanto, mais profundos, equipamentos geofísicos com fontes acústicas que emitem espectros de frequiências inferiores a $10 \mathrm{kHz}$ se fazem necessários.

São bons exemplos de equipamentos geofísicos para esta finalidade os perfiladores que utilizam fontes acústicas do tipo $3.5 \mathrm{kHz}$, como, por exemplo, o modelo Stratabox $3.5 \mathrm{kHz}$ SBP-CW-600W, fabricado pela SyQwest, o modelo DPSTech $3.5 \mathrm{kHz} 2 \mathrm{~kW}$, fabricado pela DPS Technology (EUA), ou o modelo Geopulse Pinger SBP da Geoacoustics (UK) ou até mesmo os sistemas que utilizam fontes paramétricas como o modelo SES-96/2000 da Innomar (Alemanha).

Sistemas que utilizam fontes acústicas do tipo chirp apresentam também resultados muito interessantes na investigação de ambientes geológicos desta natureza. São bons exemplos deste tipo de fonte o modelo chirp SBP 3100-P SB-216S-200W (2$16 \mathrm{kHz}$ ), da Edgetech, o sistema MD-DSS (chirp 2-10 kHz), da Meridata e o GeoChirp II (0.5-13 kHz), da Geoacoustics.

A utilização destes modelos de equipamentos vai permitir, em muitas situações, a caracterização da coluna sedimentar um pouco mais profunda, atingindo, por exemplo, nas regiões costeiras e na plataforma continental interna, a base dos estratos sedimentares holocênicos, e não raramente, e em situações favoráveis, a base dos estratos sedimentares pleistocênicos.

Por outro lado, para a investigação de ambientes subaquáticos constituídos de estratos sedimentares predominantemente arenosos (areias grossas, cascalhos etc.), de ocorrência comum em ambientes fluviais, costeiros e na plataforma continental interna, fontes acústicas de alta potência que emitem sinais de apenas algumas centenas de hertz (inferiores a $1 \mathrm{kHz}$ ) possibilitam penetração dezenas de vezes superior àquelas descritas 
nos parágrafos anteriores. Nestes casos, equipamentos geofísicos que se utilizam de fontes do tipo boomers ou sparkers são os indicados.

Alguns exemplos de excelentes equipamentos disponíveis no mercado mundial para esta finalidade podem ser destacados: sistema MD DSS com boomer $250 \mathrm{~J}$ ou sparker $200 \mathrm{~J}$, da Meridata; sistema Mono Pulser Boomer 350 J, da DPS Technology; sistemas CSP50P-AA200 Boomer e CSP300P-AA300 Boomer ou o sistema AAESquid-500-sparker, fabricados pela Applied Acoustic; GeoPulse boomer/sparker da Geoacoustics.

Para penetrar através de estratos com sedimentos arenosos, existem também alguns sistemas que utilizam fontes acústicas do tipo chirp que se diferenciam do chirp convencional, já que são fontes de maior porte, maior potência e que emitem espectros com frequiências mais baixas.

O chirp 3200-XS-512i, da Edgetech, e o GeoChirp II, da Geoacoustics, são exemplos deste tipo de fonte acústica. Ambos os modelos constituem-se em sistemas de alta potência $(>2 \mathrm{~kW})$, ou seja, superior em pelo menos dez vezes a potência de um chirp normal, e emitem espectros com frequiências a partir de $500 \mathrm{~Hz}$, muito próximos ao conteúdo dos espectros emitidos por fontes do tipo boomer.

Fontes desta natureza trazem à luz informações de subsuperfície que dificilmente seriam obtidas por meio de qualquer outro método de investigação. A alta potência e as baixas freqüências emitidas por estes sistemas têm grande aplicação nos estudos estratigráficos em regiões costeiras e na plataforma continental interna.

À parte da perda inerente de resolução com a redução do espectro de freqüências emitido, os perfis gerados por estes tipos de fontes acústicas permitem a identificação dos refletores mais profundos na coluna sedimentar recente, evidenciando os contatos entre camadas sedimentares holocênicas e pleistocênicas, tornando-se ferramenta essencial para estudos que visam à reconstituição da história geológica recente de ambientes sedimentares. Além disso, os dados obtidos de levantamentos com este tipo de fonte contribuem efetivamente com vários outros temas de aplicação também em áreas submersas interiores (assoreamento de reservatórios, prospecção de material de construção etc.).

Adicionalmente, dentre os métodos de perfilagem apresentados na planilha (Anexo A), destacam-se aqueles que utilizam fontes do tipo boomers ou sparkers. $\mathrm{O}$ desempenho destes sistemas acústicos é amplamente reconhecido pela comunidade 
técnico-científica, pois oferecem sempre os melhores resultados quando o objetivo é penetrar em estratos sedimentares predominantemente arenosos.

Perfiladores acústicos que utilizam estes tipos de fonte acústica alcançam profundidades de investigação superiores, em muito, àquelas atingidas pelos perfiladores descritos nos parágrafos anteriores. Alguns autores afirmam que nenhum outro equipamento de investigação ou método geofísico possui desempenho tão eficiente quanto os sistemas acústicos que utilizam fontes desta natureza, quando aplicados na investigação de áreas submersas rasas.

São muitos os exemplos na literatura em que boomers e sparkers oferecem a melhor solução ao estudo proposto.

Sheridan et al. (2000) empregaram perfiladores sísmicos com fontes acústicas distintas (boomer, minisparker e mini-airgun), encontrando nos dados obtidos por meio destes sistemas, a melhor expressão da coluna estratigráfica da área costeira e da plataforma continental da região de Nova Jersey, EUA. Os dados sísmicos obtidos nas áreas submersas foram correlacionados com os dados de sondagens das áreas emersas, o que permitiu o estabelecimento do modelo evolutivo dos ambientes geológicos regionais, no contexto das variações do nível do mar naquela região.

Okyar et al. (2005), empregam também perfiladores sísmicos de alta potência (boomer - $400 \mathrm{~Hz}-14 \mathrm{kHz}-300 \mathrm{~J}$ ) para investigar, em escala de detalhe, a coluna estratigráfica da plataforma continental da costa mediterrânea da Turquia (Baía de Mersin).

Garcia-Garcia et al. (2005) obtiveram excelentes registros sísmicos em estudos sobre a evolução costeira do Quaternário da Ría de Vigo, Espanha. Para tal finalidade, utilizaram equipamento sísmico com fonte acústica do tipo boomer e o sucesso alcançado com a utilização deste método de investigação levou os autores a afirmarem que "este método de investigação provou ser a ferramenta perfeita para investigações desta natureza". A Figura 10.4 mostra um dos excelentes registros sísmicos obtidos por estes autores.

Os perfis sísmicos obtidos por Abreu \& Calliari (2005), que utilizaram perfilador sísmico com fonte do tipo sparker, representam também excelente exemplo da relevância da utilização de fontes deste porte, quando da necessidade de penetração através de camadas sedimentares arenosas (Figura 10.5). Por meio deste sistema acústico, estes autores identificaram drenagens pretéritas (paleocanais) na plataforma 
continental do Rio Grande do Sul, desenvolvidas sobre um ambiente de planície costeira, anterior à transgressão ocorrida no final do Pleistoceno e início do Holoceno. Paleocanais soterrados pelo prisma sedimentar atual da plataforma riograndense (em alguns locais com mais de $30 \mathrm{~m}$ de espessura) foram perfeitamente delineados nos perfis sísmicos obtidos.

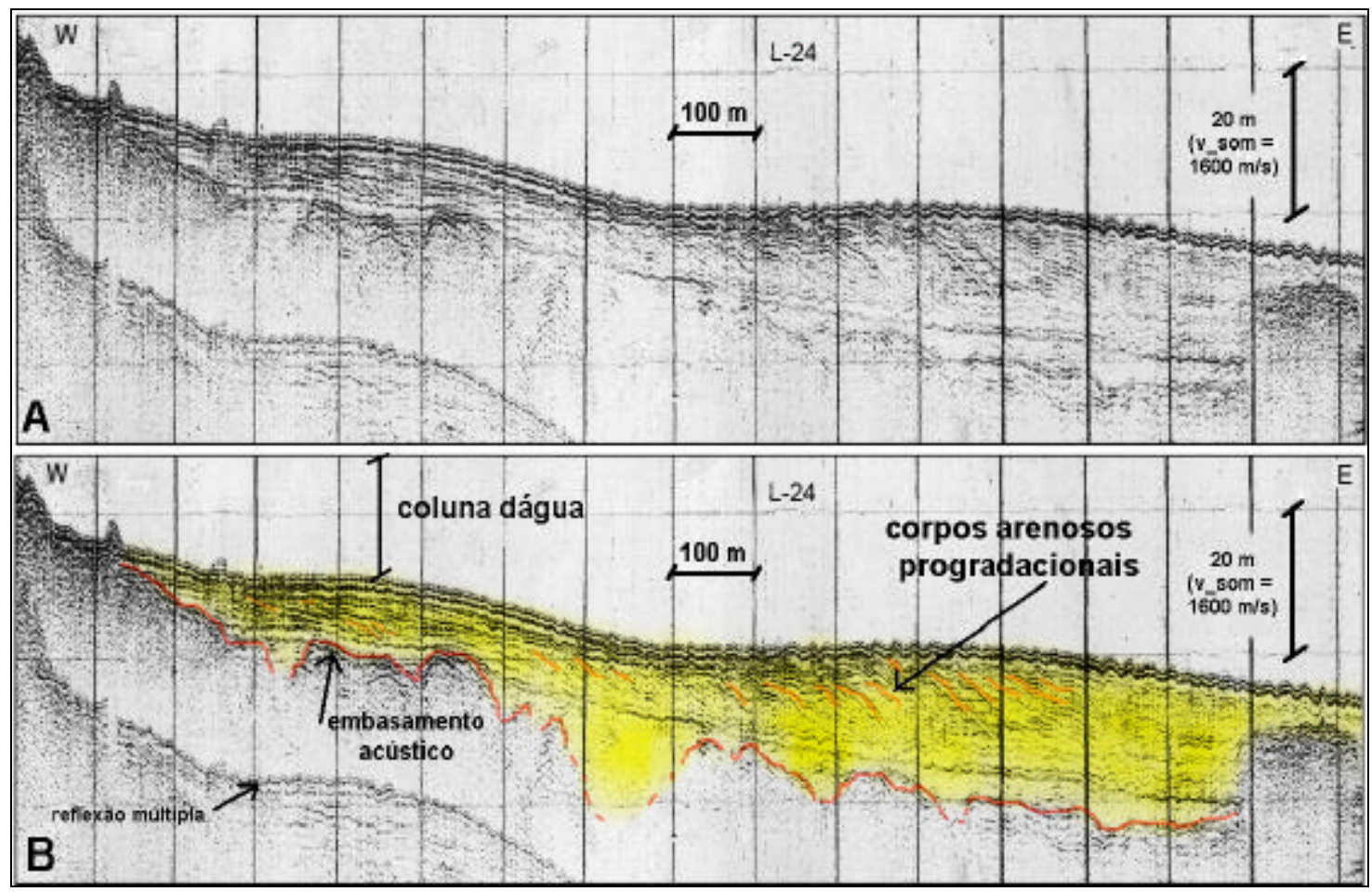

Figura 10.4: Corpos sedimentares arenosos progradacionais de mais de $30 \mathrm{~m}$ de espessura, identificados nos excelentes registros sísmicos obtidos por meio de fonte sísmica do tipo boomer. a) registro original; b) registro interpretado. Modificado de Garcia-Garcia et al. (2005).

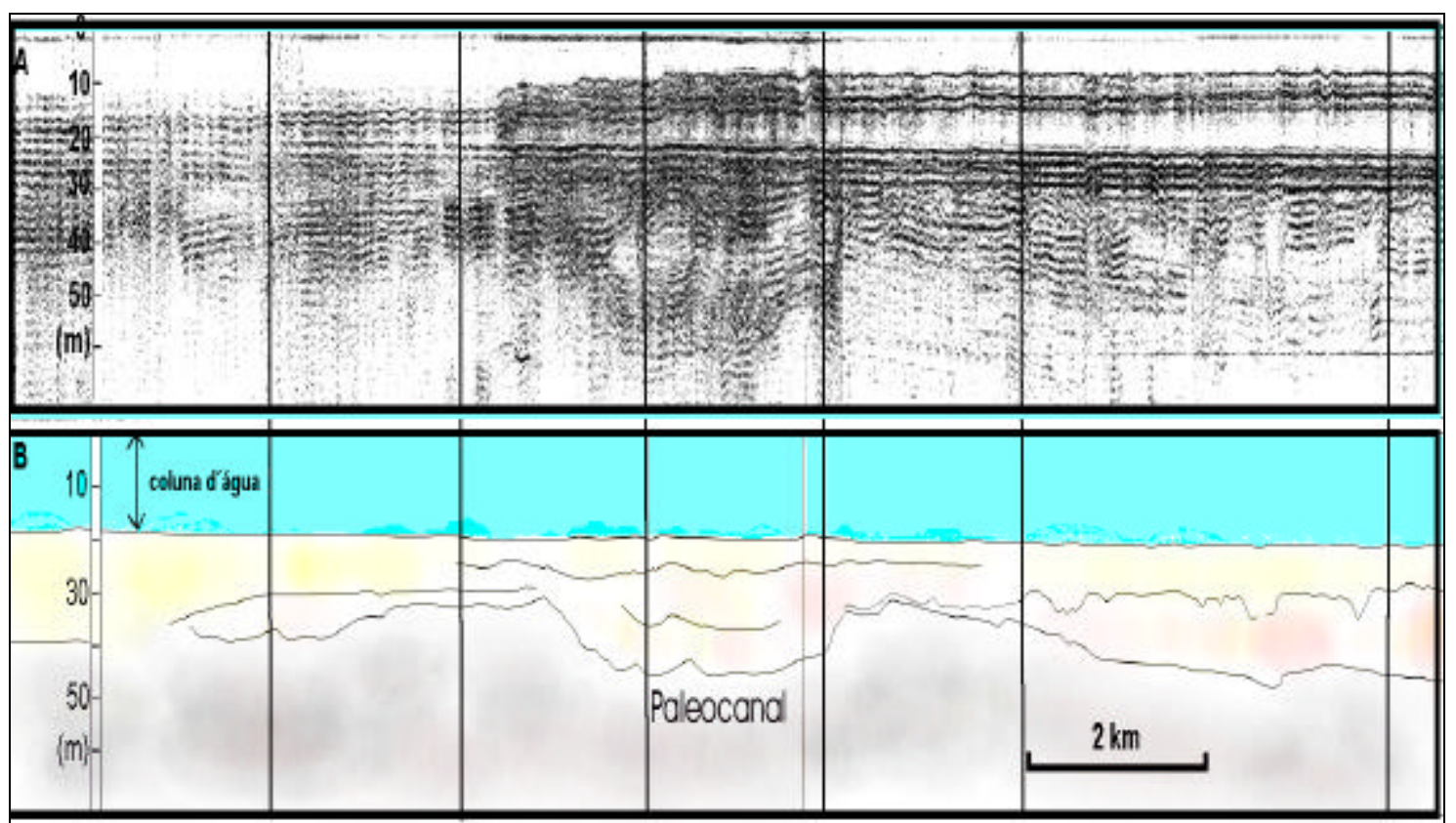

Figura 10.5: Refletores sísmicos e estruturas acanaladas, interpretadas como paleocanais, identificados na plataforma continental do Rio Grande do Sul, em perfis sísmicos executados com fonte acústica do tipo sparker : a) registro de campo; b) registro interpretado. Modificado de Abreu \& Calliari (2005). 
Uma notável vantagem a se destacar nos sistemas sísmicos que utilizam fontes acústicas do tipo boomer é o fato de que, em situações em que este tipo de fonte não ofereça resultado satisfatório, ou seja, não permita a identificação espessura dos estratos sedimentares até a profundidade desejada, fontes do tipo sparkers (fontes de maior energia) podem ser diretamente conectadas ao sistema, tendo em vista as similaridades operacionais entre estas duas fontes, já que ambas utilizam o mesmo sistema de transmissão de energia (banco de capacitores), de registro, de armazenamento e processamento de dados, além do mesmo sistema de captação dos sinais acústicos (hidrofones).

Uma experiência com sucesso de utilização destes dois tipos de fonte acústica num mesmo estudo encontra-se em Labaune et al. (2005). O estudo desenvolvido por estes autores na costa sudoeste da França, representa uma das primeiras tentativas de integração de dados sísmicos de alta resolução (HR) e de muito alta resolução (VHR) obtidos nas áreas costeiras e plataforma continental interna, com dados das áreas emersas contíguas, visando a configuração da arquitetura dos depósitos do Quaternário costeiro Superior daquela região. Ressaltaram estes autores, neste artigo, a relevância do uso combinado de dois sistemas acústicos que privilegiam resolução e penetração: um boomer $(1-12 \mathrm{kHz}-140 \mathrm{~J})$ e um minisparker $(0.05-1.5 \mathrm{kHz}-50 \mathrm{~J})$, respectivamente. $\mathrm{O}$ primeiro, apresentando resolução de $0,25 \mathrm{~cm}$ e penetração máxima de $20 \mathrm{~m}$; o segundo, resolução de 1-2 m, mas penetração de até $80 \mathrm{~m}$.

A partir desta discussão, conclui-se que a condição ideal para o desenvolvimento de uma pesquisa em áreas submersas é a execução de levantamentos sísmicos com a utilização simultânea de múltiplas fontes acústicas: sonar de varredura lateral, perfiladores de alta resolução (SBP, chirp ou fontes paramétricas) e perfiladores de melhor desempenho no quesito penetração, como boomers ou sparkers.

Um sistema com esta composição certamente garantirá uma abordagem completa da área investigada. Por abordagem completa, entende-se a possibilidade de obter, para uma mesma área de estudo, imagens detalhadas da superfície de fundo, seções geofísico-geológicas da coluna sedimentar rasa (métrica ou decimétrica) e da coluna sedimentar mais profunda (algumas dezenas de metros).

O Sistema MD-DSS da Meridata (Finlândia) é um excelente exemplo de equipamento geofísico integrado e multifonte (pinger, chirp e boomer ou sparker) que 
oferece resultados excelentes em várias situações, até mesmo em estudos de áreas mais profundas como a plataforma continental externa.

À parte das propriedades técnicas específicas de cada equipamento geofísico e das características geológicas da área investigada, que juntas definem a escolha do método adequado aos objetivos do projeto de investigação, a opção pela aquisição de um ou de outro equipamento geofísico é inevitavelmente regida também pela disponibilidade de verba da instituição ou do projeto.

Conjuntos sísmicos que utilizam boomers ou sparkers como fontes acústicas compõem-se de fontes de energia (sistemas de alta voltagem), sensores (hidrofones) multielementos (geralmente 8 ou 20 elementos) e uma central de controle, e por isso são mais caros que os sistemas que utilizam fontes do tipo chirp, geralmente compactas e com fontes acústicas e sensores instalados num mesmo corpo (monoestáticas).

Um perfilador acústico que utiliza fontes do tipo boomer ou sparker custa ao redor de cem mil dólares. Pela metade deste preço, é possível adquirir um bom sistema acústico de alta resolução que utiliza o chirp, ou similares, como fonte acústica. Por um terço daquele valor, um excelente sistema de ecobatimetria de dupla freqüência, digital, que, a despeito das inerentes dificuldades de penetração através dos sedimentos arenosos, proporciona levantamentos batimétricos de alta precisão e, não raramente, razoável penetração em estratos sedimentares lamosos.

Os investimentos das instituições de pesquisas, das universidades ou mesmo das empresas privadas, são sempre restritivos, em particular, num país como o Brasil onde outras demandas requerem maior atenção do poder público, ou oferecem maiores lucros, no caso da iniciativa privada. Assim, a decisão pela aquisição de um ou outro sistema geofísico, que efetivamente contribua para o melhor conhecimento das superfícies submersas, requer cuidados, e é condicionada basicamente pelos objetivos das instituições envolvidas, ou propostos especificamente para um determinado projeto.

Os preços dos equipamentos geofísicos são bastaste distintos e variáveis fundamentalmente com a necessidade de maior ou menor penetração através dos estratos sedimentares, mas também da maior ou menor resolução.

A Tabela 10-1 é resultado da composição dos preços (expressos em dólares americanos) dos principais equipamentos disponíveis no mercado e obtidos em recente consulta (dez/2005 - abr/2006) aos mais renomados fabricantes de equipamentos 
geofísicos no mundo, em alguns casos aos representantes dos fabricantes no Brasil, e outros, aos usuários brasileiros de sistemas acústicos desta natureza.

Esta planilha está construída respeitando a abordagem desenvolvida neste estudo, ou seja, subdivide-se em duas partes principais: investigação de superfícies

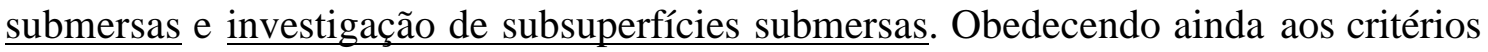
desenvolvidos neste estudo, a coluna "investigação de subsuperfície" está subdividida em três setores, que têm como base a profundidade de investigação estabelecida: rasa, intermediária e profunda, entendendo-se esta última com limite de penetração das fontes acústicas envolvidas na investigação rasa.

Faz parte também dos objetivos desta planilha sugerir conjuntos de sistemas acústicos que oferecem os melhores resultados para cada um dos quatro objetivos propostos, no contexto discutido neste estudo: investigação de superfícies e investigação $\underline{\text { de }}$ subsuperfícies $\underline{\text { com penetração }} \underline{\text { rasa, }}$ intermediária ou profunda. Mínimo, bom e excelente são os termos empregados para nomear conjuntos de equipamentos que oferecem solução mínima, boa ou excelente, respectivamente, em cada um dos quatro objetivos determinados.

A última linha da planilha exibe o valor total de cada conjunto de equipamentos idealizado para cada objetivo. Estes valores são resultantes de uma composição dos preços apresentados na coluna correspondente. Quando de equipamentos distintos, representam a soma dos valores, quando de equipamentos com finalidades semelhantes, a média. A última coluna representa a idealização de um conjunto completo (ideal) de equipamentos e o custo total correspondente.

Como podem ser observados nesta planilha, os custos para a composição de um conjunto de equipamentos para a investigação geofísica de áreas submersas rasas varia de acordo com os objetivos estabelecidos. No caso dos perfiladores, maior custo de aquisição relaciona-se básica e diretamente com o maior poder de penetração do sistema acústico; no caso do imageamento de superfícies, com o aumento da resolução e da quantidade de emissores acústicos na mesma fonte (multifeixes).

Para investigação de superfícies submersas, apresenta-se, nesta planilha, um conjunto mínimo de equipamentos (células na cor verde) constituído por um ecobatímetro simples (monofreqüência) e um sonar de varredura lateral (monofreqüência), o que perfaz um custo total de aquisição ao redor de quarenta e cinco mil dólares. Ainda no âmbito da investigação de superfícies submersas, um excelente 
desempenho poderá ser obtido com um conjunto de equipamentos que inclua um ecoclassificador e um sonar de varredura lateral multifeixe, o que implicaria um custo total de cerca de noventa mil dólares.

No contexto da penetração no substrato sedimentar, a planilha apresentada indica a necessidade de um investimento mínimo de cerca de trinta e dois mil dólares para a aquisição de, pelo menos, um sistema de perfilagem com uma fonte acústica de alta freqüência do tipo 10 ou $24 \mathrm{kHz}$, ou pelo menos um ecobatímetro de dupla frequiência com uma delas próxima de $30 \mathrm{kHz}$. Com investimentos ao redor de setenta mil dólares é possível a aquisição de sistemas com maior capacidade de penetração e portanto, com aplicação ampliada para ambientes com cobertura sedimentar arenosa (ambientes costeiros e rios, p. ex.).

No outro extremo da planilha, apresenta-se um excelente conjunto de equipamentos sísmicos que possibilita atingir-se profundidades de investigação de algumas dezenas de metros (80-100 m, eventualmente mais) e, portanto, apresenta excelente desempenho no quesito penetração. Estes sistemas compõem-se necessariamente por fontes acústicas do tipo boomers e sparkers, e o custo deste conjunto eleva-se para valores ao redor de cem mil dólares.

$\mathrm{Na}$ última coluna desta planilha, idealiza-se uma equipe sísmica com instrumentos que possibilitam a abordagem completa da investigação de áreas submersas rasas, reunindo, portanto, equipamentos que tornam viável a caracterização devida da superfície e da subsuperfície da área investigada. Para tal finalidade, um sonar de varredura lateral de dupla freqüência (multifeixe), um ecoclassificador, perfiladores de alta resolução (chirp ou similares) e perfiladores de alta energia (boomers e sparkers), formam um conjunto ideal de equipamentos que, conforme pode ser observado na referida tabela, alcança um custo total próximo de duzentos e cinqüenta mil dólares. 


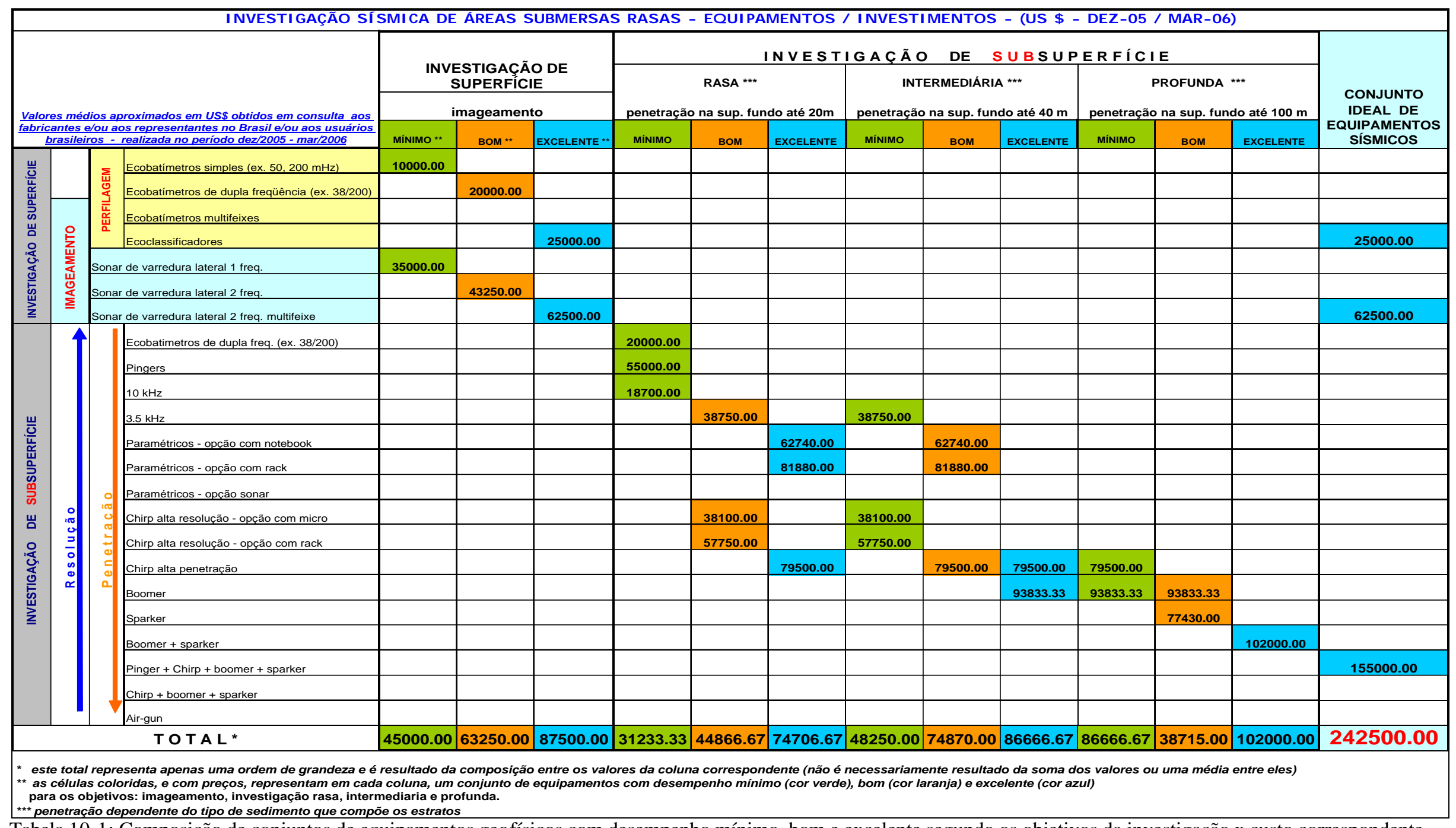

Tabela 10-1: Composição de conjuntos de equipamentos geofísicos com desempenho mínimo, bom e excelente segundo os objetivos da investigação x custo correspondente

(valores de equipamentos geofísicos resultantes de consulta realizada aos principais fabricantes de equipamentos geofísicos no mundo). 


\subsection{QUESTÕES OPERACIONAIS}

A planilha apresentada no Anexo A tem a intenção de contribuir no processo de escolha do método geofísico mais apropriado para a melhor solução para cada um dos problemas geológicos apontados. Entretanto, tomada a decisão pela utilização de um dos sistemas acústicos discutidos neste estudo, passa a ser fundamental e de extrema relevância o "controle de qualidade" dos itens relacionados com as questões operacionais.

Sob esta denominação, incluem-se basicamente a geometria do arranjo

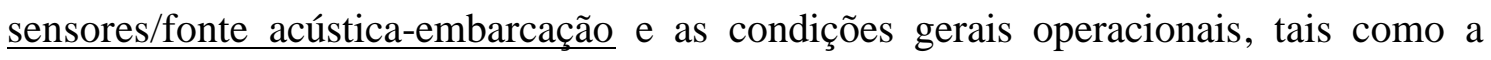
velocidade da embarcação na aquisição de dados, o tipo de embarcação e as condições do mar, com relação à navegabilidade. $\mathrm{O}$ resultado da atuação conjunta destes fatores tem expressiva responsabilidade sobre a qualidade dos dados adquiridos e, assim, sua correta administração contribui decididamente para o sucesso da investigação geofísica (Mosher \& Simpkin, 1999).

Cada um dos métodos geofísicos mostrados na planilha possui limites operacionais para obtenção do melhor resultado que devem ser levados em conta no planejamento da execução de um levantamento.

De maneira geral, o mapeamento acústico de superfícies submersas produzirá dados de melhor qualidade sempre que prevalecerem algumas condições operacionais básicas, a saber:

- arranjo geométrico fonte/sensores - embarcação privilegiando a maior relação sinal/ruído;

- maior proximidade da fonte acústica da superfície de fundo (o que não é possível em fontes do tipo boomer que são rebocadas na superfície);

- menor velocidade da embarcação durante aquisição dos dados;

- menor a distância entre os perfis de pesquisa (traçado das linhas);

- $\quad$ sistema preciso de posicionamento da embarcação durante a aquisição dos dados e,

- melhores condições de navegabilidade (estado da superfície da água).

No caso do sonar de varredura lateral, por exemplo, a manutenção da fonte acústica (peixe) a uma distância do fundo equivalente a 10-15\% do alcance lateral escolhido, é essencial para garantir dados de boa qualidade e boa representatividade. 
Locais com extrema variabilidade topográfica como, por exemplo, a Enseada Martel, na Baía do Almirantado, na Antártica (Rodrigues et al., 2003), onde existe alto risco de choque da fonte acústica com a superfície de fundo, o levantamento é executado sob uma geometria não desejada. Dados obtidos nestas condições trazem maior complexidade nos procedimentos subseqüentes, relativos ao processamento e à interpretação.

Alguns sonares modernos permitem, durante a operação de campo, a alteração do ângulo de inclinação do feixe principal dos sinais acústicos, tornando possível a aquisição de dados mesmo sob condições limites. Em algumas situações específicas, esta propriedade representa papel bastante relevante, como, por exemplo, em levantamentos de áreas muito rasas (coluna d'água até mesmo menor que um $1 \mathrm{~m}$ ), ou como no exemplo do levantamento da Enseada Martel.

No caso específico do sonar de varredura lateral, a velocidade da embarcação, durante a aquisição dos dados, não se constitui em fator limitante, se comparado ao efeito deste fator nos demais levantamentos acústicos. Os equipamentos modernos são geralmente acoplados aos sistemas de posicionamento (DGPS) das embarcações e, portanto, as correções na geometria das imagens obtidas, decorrentes das variações de velocidade, são automaticamente executadas. Por questões de segurança, recomenda-se, entretanto, que a aquisição de dados seja efetuada a velocidades nunca superiores a 5-6 nós.

A última geração de sonares de varredura lateral emite sinais acústicos a partir de multifontes (multibeam side scan sonar), ao contrário dos sistemas convencionais que possuem apenas uma fonte acústica de cada lado do "peixe". Estes modernos sistemas têm como notável vantagem tornar viável a aquisição de dados, com cobertura de $100 \%$, a velocidades superiores a dez nós.

As condições da superfície da água relativas à navegabilidade, seja no mar, em rios ou reservatórios, constituem-se sempre em fatores limitantes em qualquer levantamento geofísico. Superfícies agitadas sempre prejudicarão a qualidade dos dados obtidos, principalmente dos sistemas acústicos em que a fonte de sinais é rebocada na superfície. A utilização de sistemas de amortecimento do cabo de tração para as fontes mergulhadas na coluna d'água em muito contribui para a melhor qualidade dos dados (Figura 10.6). 


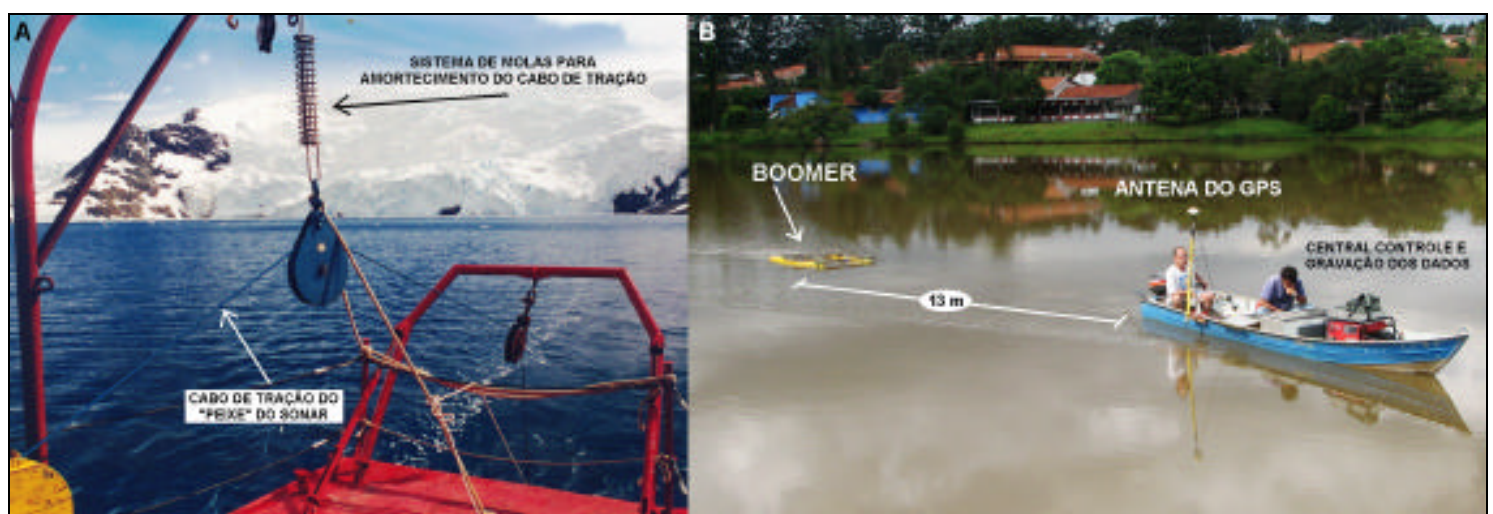

Figura 10.6: Fotos ilustrando condições operacionais básicas para garantia de controle de qualidade no processo de aquisição de dados: a) sistemas de molas usadas para amortecer cabos de tração de fontes mergulhadas, no exemplo, sonar de varredura lateral em operação na Antártica. Foto do autor; b) equipe de perfilagem sísmica contínua em operação em lago da região de Brotas, SP, de águas tranquilas com geometria do arranjo fonte acústica/sensores - embarcação, privilegiando uma boa relação sinal ruído (no caso distanciados de $13 \mathrm{~m}$ ). Foto: Ricardo S. Xavier.

Em levantamentos de perfilagem sísmica contínua a velocidade da embarcação e as condições de navegabilidade da superfície da água (Escala Beaufort) tornam-se fatores limitantes que, em muitos casos, até mesmo impossibilitam a execução dos ensaios, principalmente quando a fonte acústica é rebocada na superfície, como é o caso, por exemplo, do boomer.

Em sistemas de perfilagem sísmica em que a fonte é mergulhada a determinadas profundidades, analogamente ao sonar de varredura lateral, sistemas de amortecimento dos cabos de tração também propiciam melhorias na qualidade dos dados adquiridos. Em qualquer caso, para levantamentos geofísicos desta natureza, a velocidade da embarcação durante a aquisição dos dados não deve ser superior a 3-4 nós, sob pena da obtenção de registros extremamente ruidosos e, portanto, de interpretação complexa.

Levantamentos ecobatimétricos são também limitados com relação à velocidade da embarcação, mas notadamente com relação às condições da superfície da água durante a aquisição dos dados. Tendo em vista que os transdutores (emissores de sinais) dos ecobatímetros são fixados lateralmente na embarcação, o movimento da superfície da água, durante a aquisição dos dados, é transferido de forma direta ao transdutor, o que faz com que o feixe de sinais acústicos emitidos não seja direcionado (focado) para baixo, na vertical, ao longo da linha de navegação, conforme previsto. Deste modo, os dados de espessura da coluna d'água registrados podem não se referir exatamente ao perfil navegado. Estas limitações têm relevância ainda maior quando da utilização de ecobatímetros com grandes ângulos de abertura do feixe de sinais. 
$\mathrm{Na}$ investigação de áreas submersas por meio do GPR ou da eletrorresistividade, as condições de navegabilidade são ainda mais comprometedoras. Águas tranqüilas e deslocamento da embarcação a velocidades inferiores a três nós constituem-se em condições fundamentais para o sucesso dos ensaios geofísicos. Não é rara a necessidade de execução destes ensaios durante a madrugada, para evitar as turbulências inerentes da superfície da água devido à ação dos ventos ou conseqüência da passagem de outras embarcações nos locais dos ensaios.

Outro fator que também limita a aquisição de dados para alguns métodos é o tipo de embarcação e, em alguns casos, o tamanho. Em levantamentos de eletrorresistividade, magnéticos e de GPR, por exemplo, é imprescindível a utilização de embarcações construídas de materiais com propriedades que não interfiram nas variáveis medidas: eletrorresistividade, magnetismo e ondas eletromagnéticas. Nestes casos, embarcações de madeira ou fibra de vidro são as ideais para garantir a melhor relação sinal/ruído. O tamanho das embarcações para a execução destes ensaios não é fator limitante, pois, em todos estes casos, os equipamentos envolvidos são portáteis, facilmente adaptáveis às embarcações de pequeno porte.

O porte da embarcação não é fator limitante também para levantamentos ecobatimétricos ou sonográficos, pois se trata de equipamentos de pequeno porte facilmente ajustáveis a qualquer tipo de embarcações. Nestes casos, o tamanho da embarcação designada para a execução dos perfis de acordo apenas e tão somente, aos aspectos relacionados com a segurança da navegação.

Por outro lado, na perfilagem sísmica contínua, o tamanho da embarcação pode ser fator limitante, pois os equipamentos geofísicos propriamente ditos compõem-se de registradores, geradores de energia e transmissores de energia e cabos, conjunto este que exige área útil no interior da embarcação de, no mínimo, 4-5 $\mathrm{m}^{2}$, para o desenvolvimento dos ensaios.

Com relação à geometria dos ensaios, ou seja, a distância entre fonte, sensores e a embarcação, cada método geofísico possui especificações próprias, mas de maneira geral, na maioria dos ensaios, quanto maior a distância entre o conjunto fontes/sensores e a embarcação, melhor a qualidade dos dados.

Na execução de ensaios sísmicos, por exemplo, à exceção da batimetria que traz o transdutor conectado ao casco da embarcação, procura-se sempre posicionar fonte e sensores o mais distante possível da embarcação. O fator limitante neste caso é a 
extensão dos cabos de conexão entre as partes, que nem sempre são suficientemente longos, principalmente em levantamentos utilizando-se embarcações de grande porte. Não são raras as tentativas de execução de levantamentos com fontes acústicas do tipo boomers ou sparkers, por exemplo, utilizando embarcações de grande porte, onde o arranjo final fonte/sensores-embarcação é limitado pela extensão dos cabos de conexão o que obriga o reboque das fontes acústicas e dos sensores muito próximo dos setores ruídosos da embarcação (motores, geradores) e nestes casos, dados extremamente ruidosos são adquiridos.

Dos levantamentos geofísicos discutidos neste estudo, talvez os que mais exijam condições favoráveis e controladas durante a aquisição dos dados são aqueles executados por meio dos classificadores de fundo. O tipo de embarcação (tamanho, material de que é feita), a operação simultânea de outros equipamentos sísmicos, a variabilidade da velocidade da embarcação, as condições de navegabilidade (condições da superfície da água - Escala Beaufort) e o tipo de equipamento consistem em fatores que afetam diretamente a qualidade dos dados coletados e, portanto, o produto final da sua interpretação. Assim, levantamentos por meio destes sistemas devem ser monitorados constantemente, em cada detalhe, pois, com tamanha variabilidade de influências, dados coletados em dias diferentes, sob condições gerais distintas (meteorológicas, embarcações diferentes etc.), podem fornecer dados distintos para uma mesma área de estudo (Foster et al., 1999).

Em levantamentos com tamanha complexidade, para se obter um controle total do processo de aquisição de dados, recomenda-se, entre outros cuidados, o retorno ao local de origem ao final de cada dia para tornar possível a comparação dos dados coletados num mesmo local, num mesmo dia, mas em horários diferentes.

Um fator de extrema importância que deve ser analisado com atenção quando da utilização de classificadores de fundo é a topografia da superfície que, quando demasiadamente acidentada, inviabiliza a utilização deste método de investigação. Anomalias de amplitude do sinal acústico detectadas por estes sistemas, resultado da variabilidade das propriedades dos materiais que compõem a superfície de fundo, podem ser sobrepostas pelas anomalias acústicas geradas em virtude de enorme variabilidade topográfica do perfil de fundo.

O Prof. Dr. Jonathan S. Stark, do Australian Antartic Division (comunicação pessoal), dá conta de resultados insatisfatórios, na utilização de sistemas classificadores 
de fundo no mapeamento da superfície de áreas com expressivas anomalias topográficas em enseada próximo à Estação Antártica Australiana, ratificando assim as dificuldades inerentes com relação à utilização deste método de investigação para estudos de áreas cujo perfil da topografia de fundo apresente variações abruptas. Observou também que a inoperância deste sistema é ainda mais crítica quando da investigação de superfícies com grande variabilidade ou alternância de tipos de fundo, como é o caso das referidas enseadas na Antártica.

Finalmente, é importante destacar, no contexto das complexas questões operacionais envolvidas na aquisição de dados geofísicos, a questão digital.

Como a maioria dos equipamentos modernos é digital, cuidados específicos devem ser tomados durante a aquisição de dados ou mesmo durante o planejamento das operações de campo. São muitos os itens a serem analisados dentre as várias possibilidades de configurações do sistema de aquisição digital de dados, visando à melhoria da qualidade dos dados. A razão de amostragem constitui-se num dos principais itens, pois a escolha adequada deste parâmetro vai garantir que os dados gravados estejam íntegros e não contenham efeitos do tipo alias.

Existem inúmeros modos de processamento dos sinais, ou das imagens geradas na aquisição de dados geofísicos, em especial quando da aquisição digital. Qualquer das formas utilizadas terá sempre por objetivo a melhoria da qualidade dos dados, ou do aumento da resolução, entretanto, é essencial que no planejamento de uma campanha geofísica seja contemplado um rígido controle de qualidade na coleta de dados, pois não há como corrigir ou ajustar a posteriori dados coletados a partir de levantamentos malconfigurados. Por controle de qualidade rígido, entende-se não só a escolha dos adequados parâmetros digitais de aquisição de dados, como também do tipo de fonte, do arranjo geométrico fonte/sensores-embarcação, dentre outros.

\subsection{POTENCIAL NACIONAL}

Não são poucos os fatores que denotam o excepcional potencial do Brasil com relação à exploração de áreas submersas rasas. Dezenas de argumentos podem ser colecionados para se concluir que é absolutamente fundamental o desenvolvimento, no País, de projetos que tenham como foco principal a ampliação do parcíssimo conhecimento que se tem, até este momento, sobre áreas submersas rasas, costeiras e continentais, destacando-se: 
- a grande extensão da faixa costeira do Brasil e o grande potencial existente com relação aos recursos naturais;

- a grande área correspondente à faixa denominada de plataforma continental interna, que se estende até aproximadamente a isóbata de $50 \mathrm{~m}$, que juntamente com as áreas costeiras se constituem no principal setor de concentração de expansão da ocupação do homem (portos, vias navegáveis, plataformas exploratórias etc.);

- a inclusão neste contexto de, no mínimo, parte da área correspondente à plataforma continental externa, pois, além de se constituir também em área de ação/ocupação/exploração do homem, é também aplicável, neste setor, grande parte dos métodos de investigação discutidos neste estudo;

- a necessidade de constituição de uma política estratégica para o melhor conhecimento do potencial das águas territoriais nacionais (recursos minerais e pesqueiros, basicamente);

- carência de infra-estrutura (vias navegáveis, portos etc.) para suporte às atividades de exportação, que fundamentalmente saem do País por vias marítimas;

- a existência de natural estímulo à movimentação de cargas no País por meio da cabotagem, tendo em vista não só a precariedade das rodovias nacionais, mas principalmente, a melhor relação custo/benefício característica deste tipo de transporte;

- grande potencial para utilização do transporte hidroviário, já que muitos rios brasileiros apresentam características físicas e localizações adequadas ao transporte de carga e de passageiros, mas que há contudo, historicamente, uma subutilização de todo este potencial no Brasil (Padovezi, 2003);

- somente as principais hidrovias (Madeira, São Francisco, TocantinsAraguaia, Paraná-Tietê e Paraguai-Paraná) do País somam mais de 10.000 km de extensão e este número certamente dobra se se considerarem as hidrovias secundárias;

- grande quantidade de portos (mais de 50 de grande porte - marítimos, fluviais e lacustres, além de mais de 120 de uso privativo, usados para transporte dos mais diferentes materiais: manganês, ferro, madeira, cimento, celulose, petróleo, produtos químicos, grãos, fertilizantes, cana-de-açúcar, entre outros produtos);

- sensível aumento da carga transportada na absoluta maioria dos portos, o que denota uma retomada no País pela opção de transporte de cargas por hidrovias;

- necessidade de estudos de caracterização geológica das áreas submersas portuárias e das vias navegáveis, decorrente de novos projetos de embarcações para transporte de grandes cargas (Padovezi, 2003);

- surpreendente carência de estudos que busquem mecanismos de monitoramento e controle dos fatores ambientais impactados pela atividade hidroviária (Camargo Jr., 2000);

- emergente necessidade de avaliação precisa do estado crítico da grande maioria dos principais reservatórios de água do Brasil, principalmente ao se considerar o constante crescimento da demanda por energia, saneamento básico, água potável, irrigação e lazer, além da própria necessidade de 
contenção das cheias nas grandes cidades, decorrentes principalmente do uso e ocupação indevidos do solo;

- uma percepção generalizada na comunidade científica e tecnológica mundial de que os recursos hídricos representam o principal elemento estruturador do desenvolvimento de uma região e, portanto, exigem gerenciamento adequado, pois sua capacidade de renovação é finita (Camargo Jr., 2000);

- a arqueologia subaquática no Brasil, apesar da Lei Federal 10.166 (Brasil, 2000), deve desenvolver-se em direção contrária à simples apreciação e exploração econômica dos bens culturais submersos (Rambelli, 2003), caminhando, portanto, na direção da produção de conhecimento e proteção do patrimônio cultural nacional submerso, conforme ditam as regras internacionais sobre este tema (Unesco, 2001).

Em qualquer destes argumentos os métodos geofísicos se configuram em instrumentos de investigação essenciais para a caracterização das superfícies submersas, pelos motivos amplamente discutidos neste estudo.

Ecobatímetros, classificadores de fundo, sonar de varredura lateral e perfiladores sísmicos, acoplados a precisos sistemas de posicionamento (GPS), constituem-se em conjunto básico e fundamental de instrumentos de investigação que possibilitam a aquisição de conjunto de dados que permita o reconhecimento necessário das superfícies submersas rasas fornecendo subsídios para o desenvolvimento sustentado do Brasil.

Somente a partir de levantamentos geológicos e geofísicos extensivos e sistemáticos das áreas costeiras, da plataforma continental interna e de parte da plataforma continental externa, será possível formar um banco de dados que poderá auxiliar o desenvolvimento de estudos de reconhecimento do potencial de recursos naturais (minerais e pesqueiros) do País, bem como, estudos para a implantação de projetos de infra-estrutura em geral (hidrovias, portos etc.)

Um amplo reconhecimento passa necessariamente pela execução de estudos e levantamentos que permitam a caracterização não só das superfícies de fundo, mas também da subsuperfície, conjunto de informações que contribuirá para o estabelecimento de planos de ação prioritários e planos estratégicos de aproveitamento e uso sustentado dos recursos identificados.

No campo das áreas submersas continentais, estudos adequados de reservatórios, por exemplo, exigem conhecimento não só do volume disponível para armazenamento de água, o que pode ser realizado a partir de levantamentos batimétricos sistemáticos, mas também de estudos que forneçam dados que permitam a reconstituição histórica da 
evolução dos reservatórios quanto ao assoreamento. De posse destas informações, as autoridades públicas e as agências controladoras (ANA- Agência Nacional de Águas, Aneel - Agência Nacional de Energia Elétrica etc.) passarão a ter em mãos dados que permitirão o controle adequado dos reservatórios e a elaboração de planos de ação, que favoreçam a mitigação dos processos de assoreamento tão intensos nos dias de hoje, e, assim, o prolongamento da vida útil dos reservatórios.

Nos estudos de caracterização das superfícies de fundo dos rios, principalmente do ponto de vista da navegação, as ferramentas geofísicas de investigação cumprem papel também bastante relevante.

A favorável relação custo/benefício, para o transporte de cargas por hidrovias, tem sido ratificada a cada dia e, por conseguinte, constata-se aumento da carga total transportada por esta via em praticamente todos os portos do País (vide $<$ http://www.transportes.gov.br>).

Maior eficiência energética, maior capacidade de carga, menores consumo de combustível, emissão de poluentes, congestionamento de tráfego, custo operacional e de infra-estrutura, quantidade de acidentes e menor impacto ambiental estão entre o conjunto de propriedades a se destacar deste meio de transporte.

O Estado de São Paulo é um bom exemplo de evolução deste tema. O governo do Estado promoveu ao longo dos últimos 50 anos a construção de diversos barramentos nos rios Tietê e Paraná de aproveitamento múltiplo (equipados com eclusas), além da abertura de canais especiais, visando sempre a melhoria nas condições de navegação. Neste caso, o grande interesse, não só do governo mas também dos empresários, reside no fato de que a hidrovia Tietê-Paraná liga grandes centros de produção (soja, farelo de soja, milho, trigo, adubo, areia, cascalho, madeira/carvão e mandioca) aos centros consumidores e principalmente aos maiores portos exportadores. Dados do Departamento Hidroviário da Secretaria dos Transportes do Governo do Estado de São Paulo ilustram algumas vantagens da utilização deste sistema de transportes (Figura 10.7), bem como, o aumento do seu uso nestes últimos anos (Figura 10.8).

Considerando todo este conjunto de aspectos favoráveis à utilização deste meio de transporte para a movimentação de cargas, cabe aos órgãos administradores zelar por este setor para garantir condições adequadas e seguras à navegação. Com estes 
objetivos, os estudos necessários para a devida caracterização das vias navegáveis vão além de levantamentos ecobatimétricos sistemáticos convencionais.

Detalhados mapeamentos da superfície de fundo dos rios, utilizando principalmente o sonar de varredura lateral, se fazem necessários para o melhor conhecimento dos dinâmicos processos sedimentares modeladores da topografia de fundo, resultantes, em grande parte, das alterações nos regimes naturais dos rios em conseqüência da própria construção de barragens ao longo do curso natural dos rios.

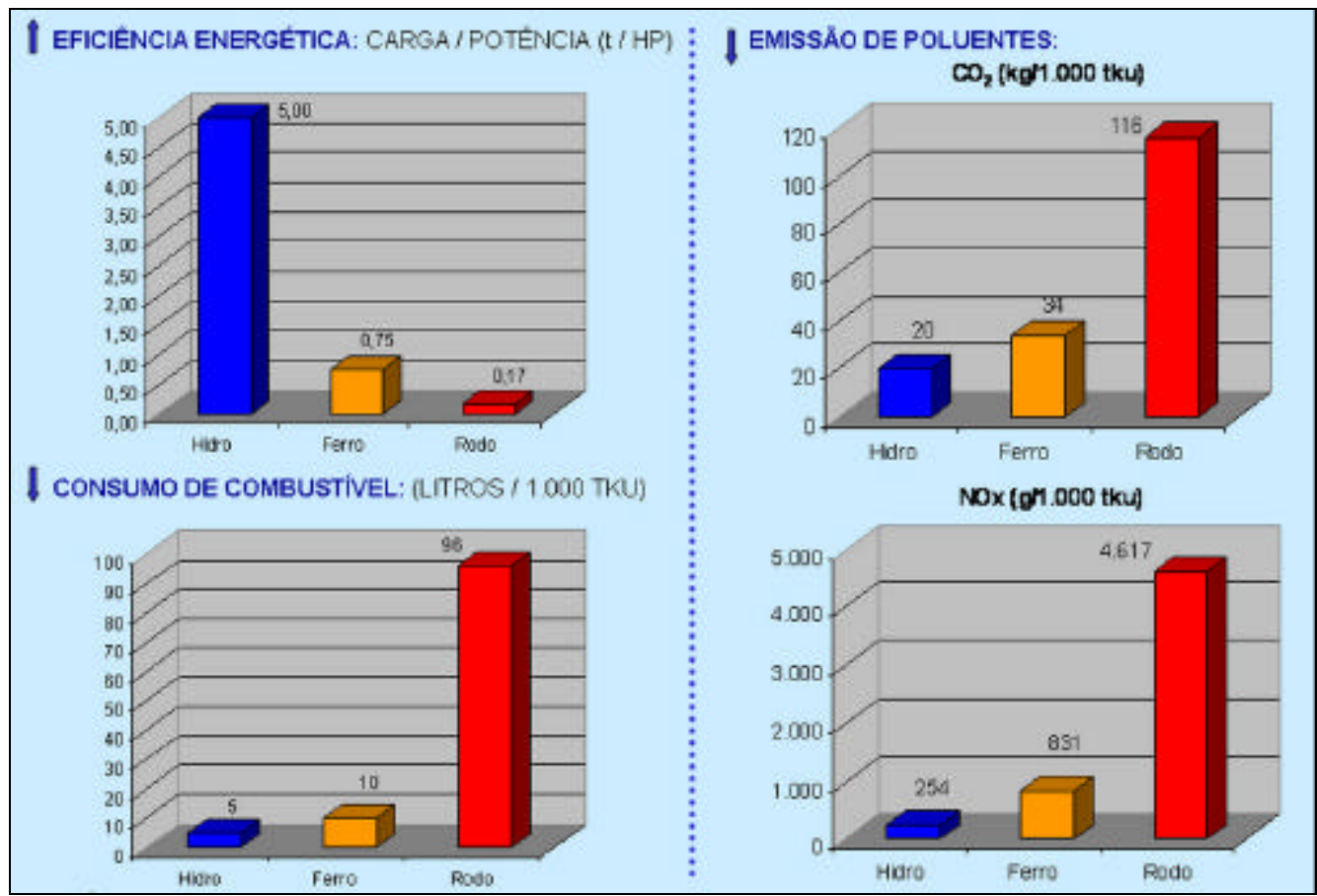

Figura 10.7: Parâmetros de comparação entre os meios de transportes: hidrovia, ferrovia e rodovia. Fonte: Departamento Hidroviário da Secretaria de Transportes do Governo do Estado de São Paulo.

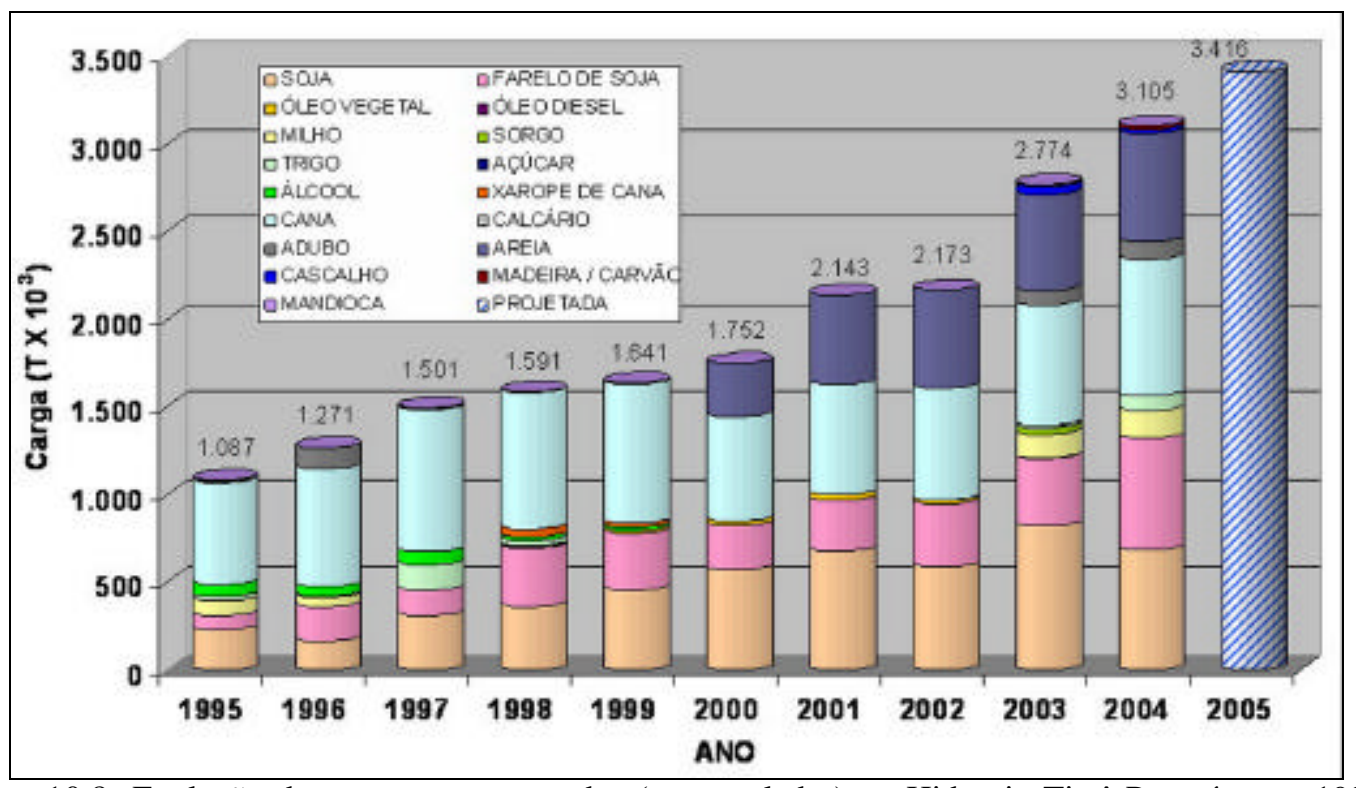

Figura 10.8: Evolução das cargas transportadas (em toneladas) na Hidrovia Tietê-Paraná entre 1995 e 2004. Fonte Departamento Hidroviário da Secretaria de Transportes do Governo do Estado de São Paulo. 


\subsubsection{CAPACITAÇÃO NACIONAL}

Os diversos equipamentos que constituem os métodos geofísicos, lidam com instrumentação eletrônica, em sua maioria importada de países desenvolvidos, tais como EUA, Inglaterra, Canadá, Alemanha, França, Noruéga, Finlândia e Suécia.

Não só a aquisição, mas também a manutenção destes equipamentos e de equipes devidamente treinadas exigem altos investimentos que, com a exceção da indústria do petróleo, é geralmente subsidiado pelo poder público (instituições de fomento à pesquisa, estaduais e federais).

Com objetivo de caracterizar ou identificar a capacitação nacional e o efetivo potencial atual das instituiçõos brasileiras (universidades, instituições de pesquisa) e também das empresas privadas, para os devidos e apropriados levantamentos geofísicos visando aos estudos de áreas submersas rasas, fez parte deste estudo a realização de ampla consulta nacional, cujo resultado está apresentado na Tabela 10-2.

As consultas, realizadas basicamente por via telefônica e por e-mail, tiveram a intenção de abranger todas as instituições de pesquisa que, de alguma maneira, têm envolvimento com o tema "Investigação geológica e ou geofísica de áreas submersas", a saber: universidades (USP, UFRN, UFPE, UFBA, UFC, UFF, UFRJ, UERJ, UNB, UFES, UFPA, UFPR, UFSC, UFRS, UFMT, Univali, Unesp e Unicamp), institutos de pesquisas (IPT, INPH, IEAPM, IEPA e CHM) e empresas privadas diversas (Fulgro, entre outras).

Apesar da relevância de todas as assertivas listadas no item 10.3, constata-se a partir da análise desta consulta, concluída em março de 2006 (Tabela 10-2), que o Brasil não dispõe de infra-estrutura física (equipamentos geofísicos) adequada para a realização de estudos amplos que tornem viável o reconhecimento devido, pleno e necessário das áreas submersas rasas, tanto as costeiras e plataforma continental interna, quanto as continentais (rios, lagos e reservatórios), se se considerar que, para a investigação de áreas submersas rasas, um conjunto mínimo de equipamentos deve proporcionar o reconhecimento de detalhe da superfície e da subsuperfície (vide Tabela $10-1)$.

Uma primeira análise da Tabela 10-2 permite concluir que a única instituição nacional devidamente capacitada para os objetivos a que se propõe é o CHM - Centro de Hidrografia da Marinha do Brasil, que possui ecobatímetros analógicos e digitais (simples e de dupla frequiência), ecobatímetro multifeixes e sonares de varredura lateral, de freqüências altas e baixas, o que o torna plenamente habilitado a atuar no campo dos levantamentos batimétricos em qualquer escala ou resolução. 


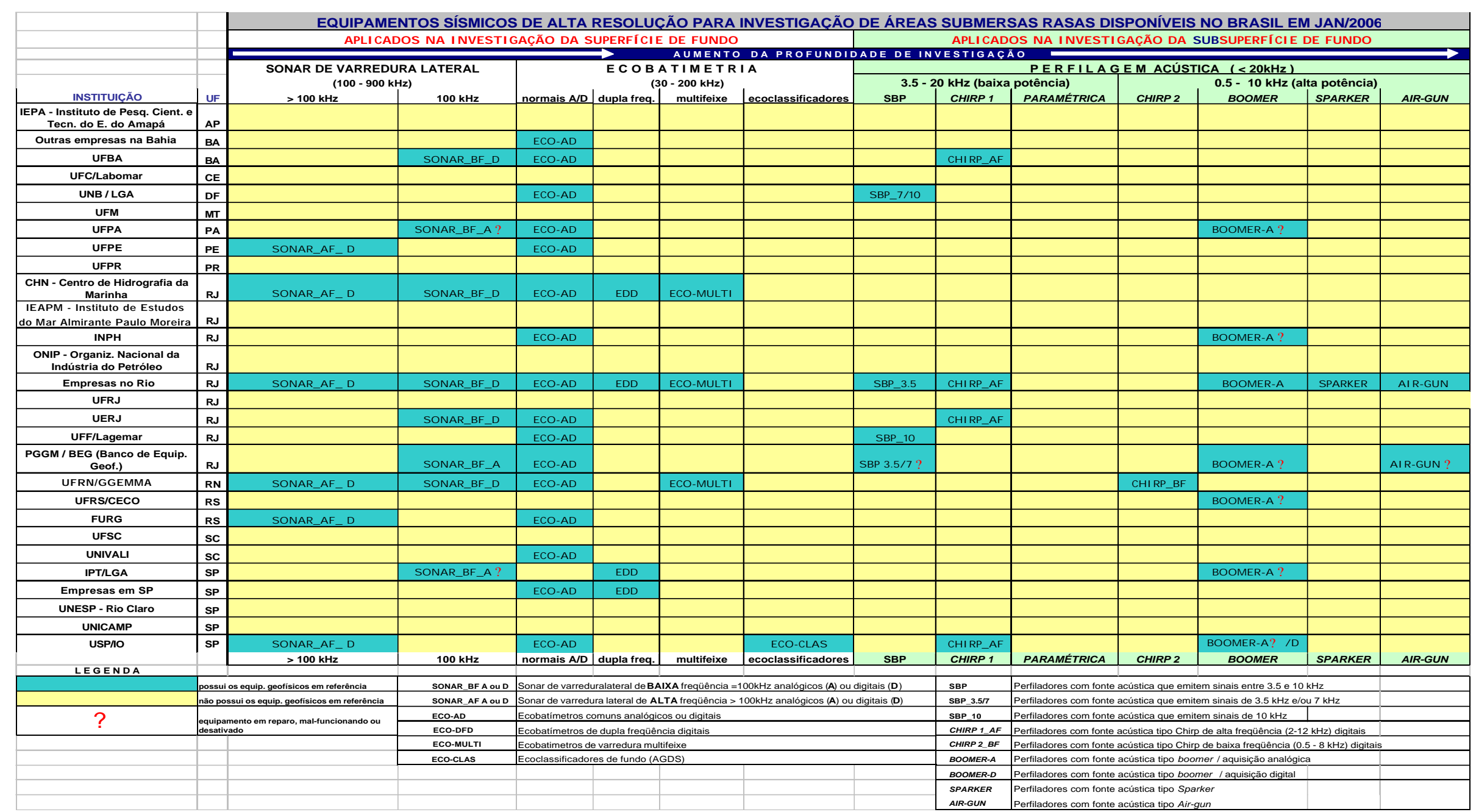

Tabela 10-2: Resultados de consulta nacional sobre o potencial (infra-estrutura geofísica) das entidades brasileiras (universidades, institutos de pesquisa e empresas privadas) para execução de levantamentos geofísicos em áreas submersas rasas. 
Ressalta-se, em especial, nos dados apresentados nesta consulta a precariedade do patrimônio nacional com relação a perfiladores sísmicos de alta potência (boomers e air-gun). Dos sete perfiladores acústicos existentes nas instituições públicas (seis boomers e um airgun) apenas o pertencente à Universidade de São Paulo (boomer) está em pleno funcionamento. Os demais funcionam precariamente ou estão desativados, sendo todos eles, inclusive, analógicos.

A análise dos dados resultantes desta consulta permite ainda observar que, dentre as universidades do País, se destacam apenas duas com plenas condições de empreender os estudos necessários para a melhor condução da investigação de áreas submersas rasas, a saber, a USP (Instituto Oceanográfico - IO) e a Universidade Federal do Rio Grande do Norte - UFRN. A primeira possui um moderno sistema digital de perfilagem sísmica contínua, ecobatímetros e classificadores de fundo, e um sonar de varredura lateral digital; a segunda, um moderno conjunto de equipamentos geofísicos, também digitais (ecobatímetros, sonar de varredura lateral e perfiladores sísmicos) além de estar em vias de adquirir um sistema ecobatimétrico multifeixe, tornando-se assim a primeira instituição pública do País a possuir tal equipamento.

Ambas as instituições possuem perfiladores sísmicos digitais e com fontes acústicas potentes o suficiente para o desenvolvimento de investigações em áreas submersas que vão além da simples identificação da coluna d'água ou da caracterização geológica da superfície de fundo ou das camadas sedimentares superficiais.

O Sistema Meridata (composto de três fontes acústicas: boomer, chirp e pinger) pertencente à USP, e o Sistema Edgetech (com fonte acústica do tipo chirp de alta potência, modelo 512i), da UFRN, constituem-se em sistemas de perfilagem de alto desempenho e que, efetivamente, permitem avançar nos conhecimentos do substrato sedimentar das áreas submersas costeiras, plataforma continental interna e áreas continentais, já que possibilitam a penetração através de dezenas de metros na coluna sedimentar, mesmo nos casos de camadas compostas essencialmente por sedimentos arenosos.

Para estudos que basicamente tenham por objetivo a caracterização das superfícies submersas e dos estratos sedimentares mais rasos, cujas informações podem ser obtidas por meio de sonar de varredura lateral e perfiladores de alta resolução do tipo chirp (de baixa potência), a Universidade Estadual do Rio de Janeiro (UERJ) e a 
Universidade Federal da Bahia (UFBA) são as únicas entidades que possuem equipamentos novos, modernos e digitais.

Embora com menor poder de penetração, se comparado com os sistemas que utilizam fontes do tipo chirp, os perfiladores modelo Stratabox $(10 \mathrm{kHz})$, da Universidade Federal Fluminense-UFF e da Universidade de Brasília-UNB, constituemse em instrumentos de grande aplicação em estudos de assoreamento de lagos naturais e reservatórios, pois, utilizando-se de altas freqüências, possibilitam alta resolução, tornando-se extremamente úteis em projetos nos quais as informações detalhadas dos primeiros decímetros da coluna sedimentar são mais importantes que a espessura total da coluna sedimentar (até o embasamento), propriamente dita.

Como pode ser observado na Tabela 10-2, não chega a dez o número de sonares de varredura lateral nas instituições públicas do País, alguns ainda analógicos, o que é insuficiente para a execução dos levantamentos necessários ao devido reconhecimento das áreas costeiras, plataforma continental interna e das áreas submersas interiores do Brasil. O mesmo raciocínio pode ser extrapolado para os perfiladores de alta potência (boomers e sparkers) que, além de poucos e na maioria, analógicos, se encontram, muitos deles, com restrições operacionais tendo em vista sua idade.

Da análise dos resultados da consulta realizada, constata-se ainda que a pobreza, do ponto de vista do patrimônio instrumental geofísico nacional, se estende também aos institutos de pesquisas. O Instituto Nacional de Pesquisas Hidroviárias - INPH, no Rio de Janeiro, e o Instituto de Pesquisas Tecnológicas do Estado de São Paulo - IPT, em São Paulo, são os únicos no País que possuem equipamentos geofísicos que, embora ainda analógicos e com limitações operacionais diversas, tornam viável nestas instituições, ainda que em condições precárias, o desenvolvimento de projetos aplicados de estudos de áreas submersas rasas, auxiliando estudos de áreas portuárias, hidrovias, assoreamento de reservatórios e projetos de pesquisa mineral (material de construção, principalmente).

Algumas universidades nacionais possuem equipes de pesquisadores e área de concentração focada na investigação de áreas submersas e caminham atualmente a passos largos para melhor se equipar em para a investigação destes ambientes geológicos. Neste contexto, destacam-se a Universidade Federal da Bahia - UFBA e a UNB. 
A UFBA adquiriu recentemente um sistema de perfilagem sísmica contínua, de última geração, da marca Edgetech, que utiliza fonte acústica do tipo chirp (modelo 216) e um sonar de varredura lateral da mesma marca, ambos de excelente qualidade. Embora a fonte acústica adquirida (chirp 216) seja limitada com relação à penetração em estratos de sedimentos arenosos, este equipamento certamente possibilitará grande avanço do conhecimento sobre as áreas submersas do Estado da Bahia, em especial sobre os processos sedimentares, presentes e pretéritos, atuantes nas regiões costeiras e plataforma continental interna.

A UNB possui um sistema de perfilagem de alta resolução modelo Stratabox (10 $\mathrm{kHz}$ ), idêntico ao modelo que também possui a UFF, que tem aplicação restrita à caracterização das camadas superficiais de sedimentos finos, objetivo comum em estudos de assoreamento de reservatórios, por exemplo. Todavia, o grupo de pesquisa desta universidade tem crescido com a contratação de novos profissionais e tem planos para ampliação de sua capacitação, até mesmo com a aquisição de sistemas de perfilagem mais potentes.

A Universidade Estadual do Rio de Janeiro - UERJ possui um conjunto de equipamentos geofísicos similares aos da UFBA, o que a credencia para representar papel importante nos estudos das áreas submersas do Estado do Rio de Janeiro. A proximidade geográfica da Universidade Federal Fluminense - UFF torna viável a atuação conjunta destas instituições com objetivos comuns, embora ambas sejam limitadas com relação a equipamentos necessários para o melhor desempenho no quesito penetração.

A consulta realizada abrangeu também o setor de empresas privadas. Conforme ilustra a Tabela 10-2, nota-se que neste setor é também pobre o parque de equipamentos, mesmo se constatando o enorme potencial e o constante crescimento da demanda, nestes últimos anos, neste campo de trabalho no Brasil. Duas ou três empresas no Rio de Janeiro, a se destacar a Fulgro - Geosolutions Serviços de Levantamento Ltda., são as únicas no País que possuem um conjunto de equipamentos geofísicos que viabilizam estudos geológicos/geofísicos adequados em áreas submersas rasas. Ressalta-se ainda que grande parte das atividades desenvolvidas por estas empresas está concentrada no setor de petróleo. Em São Paulo, ou em outras cidades do Brasil, nenhuma empresa possui qualquer equipamento geofísico que possibilite o desenvolvimento de estudos além dos meramente batimétricos. 
As empresas privadas nacionais não investiram neste setor nestes últimos anos e estão atualmente aquém da demanda existente. As excelentes perspectivas de expansão das exportações e, portanto, das atividades portuárias, o incentivo ao transporte nacional de cargas por cabotagem, e por hidrovias nos grandes rios brasileiros, a busca de recursos naturais nas áreas costeiras e na plataforma continental interna, ante as demandas resultantes do crescimento populacional e o conseqüente esgotamento das reservas no continente, são alguns dos tópicos que certamente reorientarão os investimentos para este setor nestes próximos anos.

Desta forma, faz-se premente que se propicie o desenvolvimento no País de programas ou projetos que suportem a aquisição de equipamentos geofísicos que tornem viáveis os estudos necessários para o melhor conhecimento das áreas costeiras e da plataforma continental interna, pois é sabido que o redirecionamento da força exploratória da sociedade é inexoravelmente em direção ao mar.

Além dos conhecimentos básicos, adquiridos no desenvolvimento de amplos programas ou projetos de estudos destes setores da costa brasileira, ressalta-se que a compilação e interpretação adequada das informações obtidas proporcionarão a constituição de um banco de dados que certamente darão suporte a dezenas de projetos exploratórios.

Instituições de fomento à pesquisa, estaduais e federais, têm papel fundamental e decisivo não só de suporte, mas de incentivo ao desenvolvimento de programas ou projetos nesta área do conhecimento. Os vultosos investimentos envolvidos para a constituição de equipes competentes e devidamente equipadas e treinadas, entretanto, sugerem uma administração no formato multiusuário. A formação de bancos de equipamentos regionais, centralizados em instituições de reconhecida capacitação, talvez seja a melhor forma de viabilizar a aquisição destes equipamentos otimizando os recursos e garantindo sua ampla utilização no formato multiusuário.

Acrescenta-se neste contexto que o uso multi-institucional dos equipamentos geofísicos garante que os vultosos recursos empregados sejam efetiva e integralmente aproveitados já nos primeiros anos da aquisição.

Os equipamentos geofísicos e eletrônicos, de maneira geral, tornam-se obsoletos rapidamente. A partir de 10 anos de uso, tornam-se complexas as operações de manutenção, e assim, a otimização da relação custo/benefício, para justificar o grande 
investimento na compra destes equipamentos, passa pela aquisição do máximo de dados possível durante sua vida útil, o que certamente será tanto maior quanto maior o número de seus usuários.

Uma experiência interessante, foi a criação do BEG - Banco de Equipamentos Geofísicos, do Programa de Geologia e Geofísica Marinha - PGGM, coordenado pela Universidade Federal Fluminense, em Niterói, RJ, hoje com funcionamento precário, devido a desatualização de seus equipamentos e, naturalmente, com sérios problemas eletrônicos, considerando-se as dificuldades inerentes à manutenção de uma equipe de especialistas para o necessário suporte técnico.

\subsection{DESENVOLVIMENTO FUTURO DA INVESTIGAÇÃO GEOFÍSICA DE ÁREAS SUBMERSAS}

As amplas possibilidades criadas pela evolução tecnológica dos últimos anos, associadas às crescentes demandas da sociedade foram, e continuarão sendo a alavanca propulsora dos grandes avanços nos métodos de investigação de áreas submersas rasas. Os progressos à vista advirão do desenvolvimento de fontes acústicas com maior capacidade de penetração e de resolução, de sensores mais eficazes na eliminação de ruídos e da capacidade de armazenamento e processamento de dados (também em tempo real) oriundos da investigação dos ambientes no escopo deste estudo.

Hidrofones com multiarranjos num único conjunto de sensores (nested arrays streammer), arranjos multicanais com fontes acústicas do tipo boomer, fontes acústicas com versatilidade de escolha dos espectros de freqüência a serem emitidos (p.ex. chirp), sonar de varredura lateral com multifeixe de sinais (multibeam side scan sonar) são exemplos recentes de desenvolvimentos tecnológicos que contribuem decisivamente para o aprimoramento do desempenho dos métodos sísmicos utilizados na investigação de áreas rasas.

O inevitável caminho no rumo da aquisição digital de dados contemplará a melhoria na qualidade dos dados.

Resolução e penetração constituem-se em dois itens fundamentais quando se lida com a investigação sísmica de subsuperfície, e certamente serão aprimorados se, juntos com a evolução dos sistemas de aquisição de dados (fontes e receptores), evoluírem os procedimentos de tratamento dos dados em tempo real, o que é viável em se tratando de aquisição digital. Computadores mais potentes e softwares dedicados serão os próximos 
itens contemplados na evolução dos sistemas de aquisição e processamento de dados sísmicos de alta resolução em tempo real.

Levantamentos sísmicos em alta resolução e em três dimensões (3D) são atuais desafios da investigação sísmica de áreas submersas rasas. Levantamentos 3D foram executados quase que exclusivamente para a prospecção de hidrocarbonetos e, apenas nos últimos anos, voltou-se a atenção para a adaptação destes sistemas na investigação de águas rasas (Missiaen, 2005; Bull et al., 2005; e Scheidhauer et al., 2005).

A execução de levantamentos desta natureza na investigação rasa não é, contudo, simplesmente uma questão de mudança de escala, como em princípio pode parecer (Missiaen, 2005).

Por lidar com altas freqüências, grandes volumes de dados são gerados, já que o registro de altas freqüências exige pequenos intervalos de amostragem, não somente em tempo, mas também no espaço, o que traz complexidades adicionais quanto ao processamento dos dados. A maior proximidade entre os elementos envolvidos na aquisição de dados (fontes acústicas e sensores) 3D de alta resolução requer alta precisão no posicionamento (vertical e horizontal) destes elementos, o que não se constitui num procedimento simples, tendo em vista a natural instabilidade da superfície das águas, principalmente marinhas (ondas, marés, correntes, ventos etc.), e o próprio movimento das embarcações.

Na tentativa de resolver esta questão, alguns autores sugerem a montagem de uma estrutura rígida de fonte e sensores, para garantir a precisão necessária no posicionamento destes elementos no arranjo para aquisição de dados (Bull et al., 2005). Já é uma realidade levantamentos 3D utilizando fontes acústicas do tipo chirp, com dezenas $(60,100)$ de sensores (hidrofones) acoplados a sofisticados sistemas de posicionamento DGPS, fornecendo, em tempo real e com precisão decimétrica, o volume de sedimentos.

A evolução dos sistemas de aquisição de dados sísmicos tem caminhado também na direção da caracterização do estado de materiais enterrados na coluna sedimentar, o que tem grande aplicação na arqueologia submarina. Até então, os métodos geofísicos contribuíram para a localização dos sítios, mas não para a efetiva caracterização (estado de conservação) dos materiais destes sítios. 
Existe certo consenso na literatura específica de que sítios arqueológicos submarinos devam ser preservados como estão e no lugar em que se encontram e, assim, a geofísica, principalmente pelo seu caráter remoto e não-destrutivo, cumpre papel de suma importância no monitoramento do estado de conservação destes locais e dos materiais que compõem estes sítios.

Arnott et al. (2005) realizaram ensaios sísmicos em sítios arqueológicos submarinos na Europa (navios antigos naufragados) com vistas na caracterização do estado de conservação das estruturas de madeira destas embarcações. Estes autores tomaram como base, para este estudo, medidas de impedância acústica e de atenuação, considerando-se que estas propriedades acústicas são aquelas que mais diretamente se relacionam com as propriedades físicas dos materiais (porosidade, constantes elásticas, granulometria etc.), propondo técnicas para a medida destes parâmetros. As experiências realizadas por estes autores permitiram concluir que o estado de conservação da madeira em sítios arqueológicos pode ser avaliado por meio do estudo dos coeficientes de reflexão coletados por meio de ensaios sísmicos remotos, ou seja, executados a partir da superfície da água.

A utilização do sistema GPR na investigação de áreas submersas avança a cada dia, e certamente antenas especiais serão desenvolvidas (alguns fabricantes já disponibilizam modelos para esta finalidade) para aplicação direta deste método de investigação nestes ambientes. Maior poder de resolução e de penetração dos sinais eletromagnéticos emitidos por este sistema será a consequiência imediata do desenvolvimento de sistemas (antenas) que possam ser tracionados próximos da superfície de fundo. Raciocínio análogo pode ser desenvolvido com relação aos métodos elétricos, pois sistemas com arquitetura apropriada para o emprego na investigação de áreas submersas rasas já se encontram disponíveis no mercado. 


\section{CONSIDERAÇÕES FINAIS}

Ambientes submersos de águas rasas, tais como reservatórios, rios, áreas costeiras e plataforma continental interna, podem ser classificados entre os mais dinâmicos ambientes de sedimentação atual, pois estão sujeitos a rápidos fluxos de sedimentos (aporte, retrabalhamento e exportação), principalmente por se localizarem nos setores onde a atividade humana é intensa. Embora se constituam em verdadeiros arquivos estratigráficos, já que guardam em si registros dos efeitos das mudanças ambientais mais recentes, e os conseqüentes impactos ambientais, estes ambientes são ainda pouco investigados no mundo.

Não só no Brasil, mas também em muitos outros países, constata-se a existência de enorme lacuna no conhecimento da superfície e da subsuperfície de fundo das áreas submersas rasas. Neste contexto, destacam-se, no Brasil, alguns temas ainda pouco explorados que carecem, portanto, de maiores investigações:

- a caracterização de depósitos sedimentares em áreas costeiras e na plataforma continental interna, visando ao conhecimento geológico estratigráfico, seja com finalidades acadêmicas ou por interesses econômicos;

- a caracterização do assoreamento de reservatórios visando ao conhecimento do real potencial de armazenamento de água, controle de cheias, navegação, lazer etc.;

- a caracterização das superfícies de fundo de vias navegáveis visando a segurança na navegação e controle ambiental da movimentação das embarcações principalmente nas áreas protegidas costeiras e interiores do País.

Parte das causas que levam à ausência de informações detalhadas sobre estes ambientes pode ser atribuída ao desafio tecnológico envolvido na investigação de águas rasas, já que não se trata de simples transferência para estes ambientes dos métodos ou das ferramentas, geofísicas ou não, de investigação utilizadas no estudo de áreas emersas e de águas profundas.

Os ambientes de águas rasas ou muito rasas favorecem a ocorrência de fortes reflexões múltiplas dos sinais acústicos, a qual inibe a identificação, nos registros sísmicos, das reflexões correlacionáveis aos estratos sedimentares propriamente ditos.

A ocorrência de canais estreitos ao longo de uma determinada área induz à reflexão lateral (ecos laterais), o que também prejudica a interpretação dos dados.

A presença de gás nas camadas rasas de sedimentos lamosos contribui também para maior complexidade na interpretação dos dados geofísicos oriundos destes ambientes. 
De qualquer forma, a evolução tecnológica ocorrida nestas últimas décadas, com relação aos métodos de investigação de áreas submersas rasas, ratificou a importância dos métodos sísmicos na caracterização destes subambientes, a despeito do recente crescimento da utilização de métodos elétricos e eletromagnéticos na investigação destas áreas.

Fontes acústicas do tipo boomer e chirp muito evoluíram nestas últimas décadas tornando possível associar a uma mesma fonte propriedades relacionadas com alta resolução e a boa penetração, o que viabiliza a execução de levantamentos sísmicos 3D de alta resolução também em águas rasas.

À parte da necessidade da escolha apropriada do método de investigação ante o objetivo do projeto, a obtenção de dados de boa qualidade na investigação de áreas submersas rasas é fortemente influenciada por alguns fatores que podem ser qualificados como operacionais. Um deles, e talvez o mais importante, refere-se à necessidade de utilização de equipamentos de boa qualidade e devidamente aferidos que, associados à devida e adequada geometria do arranjo fonte/sensores-embarcação, certamente contribui para garantia da coleta de dados de alta qualidade.

O melhor desempenho de um método geofísico tem ainda forte relação com a necessidade de um bom sistema de navegação (hardwares e softwares), um experiente condutor para a embarcação e uma equipe técnica bem treinada.

Da análise crítica da aplicabilidade dos métodos sísmicos na investigação de áreas submersas rasas, desenvolvida neste estudo, que se apresenta sintetizada na planilha do Anexo A, conclui-se que, a opção de uma instituição de pesquisa na priorização de investimentos para aquisição de um determinado conjunto de equipamentos geofísicos, passa necessariamente pela análise das linhas de pesquisas adotadas, que basicamente podem ter dois enfoques distintos: a investigação da superfície e da subsuperfície. Esta segunda pode ainda ser subdividida de duas sublinhas ao se considerar que existem métodos que priorizam a resolução e, portanto, tem penetração restrita às camadas sedimentares muito rasas e métodos que priorizam a penetração, em sacrifício da resolução.

Grupos de pesquisa guarnecidos prioritariamente com equipamentos sísmicos de alta resolução, dedicados ao imageamento e à perfilagem de superfícies submersas, estão aptos ao desenvolvimento de projetos em que a caracterização da superfície de fundo é suficiente para atingir os objetivos propostos. Incluem-se neste contexto, projetos que visam a caracterização de habitats subaquáticos, levantamentos batimétricos, mapeamento geológico (estruturas sedimentares, beachrocks, depósitos minerais, afloramentos rochosos, contatos litológicos etc.), mapeamento de obstáculos à navegação em projetos de hidrovias, entre outros. Neste contexto incluem-se equipamentos como ecobatímetros de dupla freqüência, multifeixe, ecoclassificadores e sonar de varredura lateral, que lidam comumente com sinais de freqüências superiores a $30 \mathrm{kHz}$. 
No caso de projetos de investigação onde seja fundamental a caracterização da coluna sedimentar, duas linhas de pesquisa podem ser estabelecidas e, assim, a escolha do método sísmico mais adequado, deverá levar em conta dois conceitos geofísicos fundamentais: resolução e penetração.

Em estudos de reservatórios ou de áreas restritas, como enseadas ou baías, ou mesmo em áreas costeiras, em que o objeto da investigação é a definição da espessura das camadas de sedimentos finos, os métodos de perfilagem denominados de alta resolução que utilizam sinais acústicos de freqüências variáveis entre 2 e $20 \mathrm{kHz}$, resolvem a grande maioria das questões colocadas. Com estes objetivos o emprego de equipamentos que utilizam fontes acústicas do tipo chirp, paramétricas ou $3.5 \mathrm{kHz}$, tem excelente desempenho, e em situações favoráveis, podem penetrar dezenas de metros na coluna sedimentar.

Em certos casos, como por exemplo, em estudos de depósitos de sedimentos muito finos em bacias de decantação, até mesmo perfiladores que lidam com freqüências entre 10 e $40 \mathrm{kHz}$, como é o caso, por exemplo, dos ecobatímetros de dupla freqüência, podem oferecer resultados bastante interessantes.

Por outro lado, se a investigação se desenvolve em áreas costeiras ou na plataforma continental rasa, tendo como objetivo identificar a espessura das camadas sedimentares, basicamente arenosas, oriundas principalmente dos processos de sedimentação resultantes das variações do nível do mar, se faz necessário o emprego de métodos sísmicos com fontes acústicas de alta potência e baixas freqüências. Raciocínio análogo pode ser desenvolvido se o objetivo de investigação for o mapeamento de depósitos arenosos (areia grossa e cascalho) em rios, lagos ou reservatórios. Em ambos os casos, boomers e sparkers constituem-se em bons exemplos de fontes sísmicas com excelente desempenho em ambientes desta natureza. Em certas situações, fontes do tipo chirp (de alta potência) também oferecem resultados satisfatórios.

Sistemas acústicos que utilizam boomers ou sparkers como fontes acústicas constituem-se em ferramentas de investigação capacitadas para desvendar a história geológica recente dos complexos ambientes costeiros, produto das variações do nível do mar durante o Quaternário. O acúmulo do conhecimento oriundo de levantamentos dessa natureza certamente irão subsidiar as ações da sociedade no rumo do atendimento das várias demandas que se avolumam a cada dia sobre estas áreas.

Equipamentos geofísicos deste porte possibilitam a identificação da espessura dos estratos sedimentares, da profundidade do embasamento rochoso, dos contatos litológicos, das estruturas geológicas, características estas de extrema relevância em projetos de mapeamento de superfícies submersas com objetivos no âmbito da prospecção de recursos minerais (cubagem de jazidas), da escolha de locais para instalação de plataformas exploratórias, de emissários e de dutos e cabos submarinos, entre outros. 


\section{BIBLIOGRAFIA}

Abreu, J.G.N; A.H.F. Klein; F.L. Diehl; J.T. Menezes \& M.I.F. Santos. 2005. A experiência da alimentação artificial de praias no litoral centro-norte do estado de Santa Catarina. In: Congresso Brasileiro de Oceanografia, 2. Vitória, ES, 9 a 12 de outubro de 2005. Anais. CD-ROM.

Abreu, J.G.N. \& L.J. Calliari. 2005. Paleocanais na plataforma continental interna do Rio Grande do Sul: evidências de uma drenagem fluvial pretérita. Rev. Bras. Geof. 23 (2): 123132.

Abril Coleções. 1996. Criaturas Misteriosas. Mistérios do Desconhecido. Abril Livros Ltda. Rio

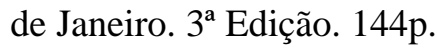

AGI - Advanced Geoscience. 2002. Lake resistivity Survey using towed Electrodes. Application Notes. Disponível em: <http://www.agiusa.com>. Acesso: 10/nov/2005.

AGI - Advanced Geoscience. 2003. Marine resistivity survey on the Lagoon of Venice, Italy. Application Notes. Disponível em: <http://www.agiusa.com>. Acesso: 10/nov/2005.

Almeida Filho, G. S. \& F. Campagnoli. 1998. Diagnóstico do assoreamento da lagoa da Primavera, município de Bauru, SP. In: Encontro de Engenharia de Sedimentos, 3. Belo Horizonte, MG, 21 a 25 de setembro de 1998. Anais, 1:120-126.

ANEEL - Agência Nacional de Energia Elétrica. 2000. Guia de avaliação de assoreamento de reservatórios. Brasília, DF, ANEEL, MCT, OMM e PNUD. 123p.

Angulo, R.J.; M.C.Souza; D.L. Castro; F.J.F. Ferreira; F.A.Veiga; L.G.Castro \& R.M.G.C. Branco. 2005. Feições regressivas e de crescimento de esporões identificados a partir de seções de GPR nas planícies costeiras paranaenses e norte catarinense. In: Congresso da ABEQUA, 10. Guarapari, ES, 9 a 16 de outubro de 2005. Anais. CD-ROM.

Antoneli, F.M. 2004. Caracterização da dinâmica sedimentar atual na região d'As Ilhas, São Sebastião, litoral norte do Estado de São Paulo. Dissertação de Mestrado. Instituto Oceanográfico da Universidade de São Paulo. 103p.

Applied Acoustic Engineering Limited. 2005a. Fundamentals of high resolution seismic surveying. Great Yarmouth, Norfolk, UK. Disponível em: <http://www.applied acoustics.com>. Acesso: 27/nov/2005.

Applied Acoustic Engineering Limited. 2005b. Sound source operating manual. Norfolk, England, Applied Acoustic Engineering Limited. 48p.

Aquino, W.F; A.G.Lopez; L.A.P. Souza; O.C.B. Gandolfo, \& M.A.B. Botelho. 1998. Aplicação do geo-radar em estudos de assoreamentos. In: Encontro Regional de Geotecnia e Meio Ambiente, 2 / Workshop de Geofísica Aplicada, 2. Rio Claro, SP, 19 a 20 de novembro de 1998. Resumos expandidos. CD ROM.

Aquino, W.F; J. Dehaini \& J.M.B. Mendes. 1998. Geo-Radar para a Detecção de Contaminação por Hidrocarboneto. In: Workshop de Geofísica Aplicada, 2. Rio Claro, SP, 19 a 20 de novembro de 1998. Resumos expandidos. CD-ROM.

Arnott, S.H.L; J.K. Dix; A.I. Best \& D.J. 2005. Gregory, Imaging of Buried Archaeological Materials: The Reflection Properties of Archaeological Wood. Mar. Geophys. Res., 26:135 $-144$.

Art Engineering LLC. 2005. PNBC Reserve Basin - Aquascan Ground Penetrating Radar Survey. Art Engineering LLC. EUA, Relatório Interno.

Asp, N.E.; I. Buynevich; E. Siegle; D. FitzGerald; A.H.F. Klein; W. Cleary \& R.J. Angulo. 2005. Coastal geomorphology of the Tijucas plain - Brazil: a preliminary evolution model. In: Congresso da ABEQUA, 10. Guarapari, ES, 9 a 16 de outubro de 2005. Anais. CDROM. 
Augusto Filho, O.; O.Y. Bitar; L.A.P. Souza \& M.C.J Almeida. 1992. Análise e zoneamento de risco associado à mineração em área urbana: o caso da extração de areia no lago de Carapicuiba (SP). In: Congresso Brasileiro de Geologia, 37. São Paulo, SP, 9 a 15 de dezembro de 1992. Boletim de Resumos Expandidos, 1: p.116-117.

Ayres Neto, A. \& A.C.K.V. Aguiar. 1993. Interpretação de reflexões de side scan sonar: uma proposta de nomenclatura e padronização de métodos. In: Congresso Internacional da Sociedade Brasileira de Geofísica, 3. Rio de Janeiro, RJ, 07 a 11 de novembro. Boletim de resumos expandidos. CD-ROM.

Ayres Neto, A. 2000. Uso da sísmica de reflexão de alta resolução e da sonografia na exploração mineral submarina. Rev. Bras. Geof., 18:241-255.

Badley, M.E. 1985. Practical Seismic Interpretation. Reidel Publishing Company. Dordrecht, Holanda. 257p.

Barnhardt, A.W.; B.M.Richmond; E.R.Grosman \& P. Hart. 2005. Possible modes of coral-reef development at Molokai, Hawaii, inferred from seismic-reflection profiling. Geo-Mar. Lett., 25:315-323.

Bastos, A.C. \& C.G. Silva. 1996. Evidências de períodos erosivos cíclicos na planície de cristas de praia do rio Paraíba do Sul. In: XXXIX Congresso Brasileiro de Geologia. Salvador, BA, 1 a 6 de setembro de 1996. Anais, 4: 379-383.

Baumgartner, F. 1996. A new method for geoelectrical investigations underwater. Geophys. Prospect., 44:71-98.

Belderson, R.H.; N.H. Kenyon; A.H. Stride \& A.R. Stubbs. 1972. Sonographs of the Sea Floor. Amsterdam, Elsevier Scientific Publishing Company. 507p.

Belo, W.C. 2002. O fundo marinho da baia da ilha Grande, RJ: evidências da ação de correntes e de ondas no canal central com base em formas de fundo observadas em registro de sonar (100 kHz). Rev. Bras. Geofis., 20:17-30.

Belo, W.C.; G.T.M. Dias \& M. S. Dias. 2002. O fundo marinho da baia da ilha Grande, RJ: o relevo submarino e a sedimentação no canal central. Rev. Bras. Geofis., 20(1):5-15.

Beraldo, P \& S.M. Soares. 1995. GPS - Introdução e Aplicações Práticas. Criciúma Ed. Livraria Luana Ltda. 148p.

Berkson, F.M. \& C.S. Clay. 1973. Transformation of side-scan records to a linear display. Int. Hydrogr. Rev., 50(2):55-59.

Bianchi, C.N.; R. Pronzato; R. Cattaneo-Vietti; L.B. Cecchi; C. Morri; M. Pansini; R. Chemello; M. Milazzo; S. Fraschetti; A.Terlizzi; A. Peirano; E. Salvati; F. Benzoni; B.Calcinai; C. Cerrano \& G Bavestrello. 2004. Hard bottoms. Biol. Mar. Medit. 11(suppl. 1): $185-215$.

Bornhold B.D.; C.V. Jay; R. McConnaughey; G. Rathwell; K. Rhynas \& W. Collins. 2005. Walrus foraging marks on the seafloor in Bristol Bay, Alaska: a reconnaissance survey. Geo-Mar. Lett., 25(5):293-299.

Botelho, M.A.B. \& F.F. Araújo. 1996. Emprego do radar para detecção de fraturas em corpos graníticos. In: Congresso Brasileiro de Geologia, 39. Salvador, BA, 1 a 6 de setembro de 1996. Anais, 2: 391-393.

Botelho, M.A.B.; Cerqueira Neto, J.X.C. \& Aranha, P. 1999. Estudo sobre a economicidade de jazidas de rochas ornamentais empregando o Geo-Radar (GPR). In: Congresso Internacional da Sociedade Brasileira de Geofísica, 6. Rio de Janeiro, 15 a 19 de agosto de. Expanded Abstract. CD-ROM.

Brasil. 2000. LEI $\mathrm{N}^{\mathrm{o}}$ 10.166, de 27 de dezembro de 2000. Altera a Lei $\mathrm{n}^{\circ} 7.542$, de 26 de setembro de 1986, que dispõe sobre a pesquisa, exploração, remoção e demolição de coisas ou bens afundados, submersos, encalhados e perdidos em águas sob jurisdição nacional, em 
terreno de marinha e seus acrescidos e em terrenos marginais, em decorrência de sinistro, alijamento ou fortuna do mar, e dá outras providências. Diário Oficial da República Federativa do Brasil, Brasília, DF, 28 dez. 2000.

Brown, C.J.; A. Mitchell; D.S. Limpenny; M.R. Robertson; M. Service \& N. Golding 2005. Mapping seabed habitats in the Firth of Lorn off the west coast of Scotland: evaluation and comparison of habitat maps produced using the acoustic ground-discrimination system, RoxAnn, and sidescan sonar, ICES J. of Marine Science, 62(4):790-802.

Brown, C.J.; K.M. Cooper; W.J. Meadows; D.S. Limpenny; \& H.L. Rees. 2002. Small-scale mapping of seabed assemblages in the eastern English Channel using sidescan sonar and remote sampling techniques. Estuar. Coast. Shelf S., 54:263-278.

Bull J.M.; M. Gutowski; J. K. Dix; T.J. Henstock; P. Hogarth; T.G. Leighton \& P. R. White. 2005. Design of a 3D Chirp Sub-bottom Imaging System. Mar. Geophys. Res., 26(2):157169.

Calliari, L.J.; L.S. Esteves e J.N. Cardoso. 1994. Padrões sonográficos e sedimentológicos de um afloramento de beachrock na plataforma interna do Rio Grande do Sul. do $38^{\circ}$. In: Congresso Brasileiro de Geologia, 38. Balneário de Camboriú-SC, 23 a 28 de outubro de 1994. Boletim de resumos expandidos, 1: 374-376.

Calliari, L.J. \& Abreu, J.G.N. 1984. Litologia da plataforma continental interna adjacente à cidade do Rio Grande, RS, através da interpretação de registros de sonar de varredura lateral e amostragem superficial. In: Congresso Brasileiro de Geologia, 33. Rio de Janeiro, RJ, 1994. Anais, 33 (4): 1553-1564.

Camargo Jr., A. 2000. Sistema de gestão ambiental em terminais hidroviários e comboios fluviais: contribuições para o desenvolvimento sustentável na Hidrovia Tietê-Paraná. Tese de Doutorado. Universidade Estadual Paulista - UNESP. 179p.

Camargo, P.F.B. 2002. Arqueologia das fortificações oitocentistas da planície costeira Cananéia/Iguape, SP. 2002. Dissertação de Mestrado em Arqueologia - Faculdade de Filosofia, Letras e Ciências Humanas da Universidade de São Paulo, São Paulo. 208p.

Campagnoli, F. 1998. O assoreamento como um geoindicador ambiental em áreas urbanas: o exemplo da região metropolitana de São Paulo (RMSP). In: Encontro Nacional de Engenharia de Sedimentos - ENES, 3. Belo Horizonte, MG, 21 a 25 de setembro de 1998. Anais, 1: 1137-1143.

Cardarelli, E. \& G.di Filippo. 2004. Integrated geophysical surveys on waste dumps: evaluation of physical parameters to characterize an urban waste dump (four case studies in Italy). Waste Manage Res., 22: 390-402.

Carrasquilla, A.G. \& M.A.R. Ceia. 2005. GPR simulations for pipeline oil drainage detection. In: Congresso Internacional da Sociedade Brasileira de Geofísica, 9. Salvador, BA, 11-14 Setembro, 2005. Anais. CD-ROM.

Carter, L \& R.M. Carter. 1986. Holocene evolution of the nearshore sand wedge, South Otago continental shelf, New Zealand. New Zeal. J. Geol. Geop., 29:413-424.

Carvalho, N O. 1994. Hidrossedimentologia Prática. Rio de Janeiro, Companhia de Pesquisas e Recursos Minerais - CPRM / Eletrobrás. 372p.

Castilhos, J.A. \& J.C.R. Gré. 1996. Erosão costeira nas praias da ilha de Santa Catarina. In: Congresso Brasileiro de Geologia, 39. Salvador-BA, 1 a 6 de setembro de 1996. Anais, 4 : 417-420.

Cazzoli, S \& A. Amarante. 1996. Extração de areias de praias no município de Santos, Estado de São Paulo. In: Congresso Brasileiro de Geologia, 39. Salvador-BA, 1 a 6 de setembro de 1996. Anais, 4: 396-398.

Ceia, M.A.; A.B.G. Carrasquilha \& J.M. Travassos. 2004. Levantamento GPR em afloramentos turbidíticos da Bacia de Almada, BA. Rev. Bras. Geocienc., 34:411-418. 
Chanson, H \& P. James. 1998. Rapid reservoir sedimentation of four historic thin arch dams in Australia. J. Perform. Constr. Facil., ASCE, 12(3):85-92.

Chanson, H \& P. James. 1999. Siltation of Australian reservoirs: some observations and dam safety implications. In: IAHR Congress, 28, Session B5. Graz, Áustria, 22 a 27 de Agosto de 1999. Proceedings. CD-ROM.

Chanson, H. 1998. Extreme reservoir sedimentation in Australia: a review. International J. of Sediment Research. 13(3):55-62.

Chesterman, W.D. 1974. The Ocean Floor. Contemp. Phys., 15(6):501-516.

Chesterman, W.D., P.R. Clynick \& A.H. Stride.1958. An Acoustic aid to sea bed survey. Acustica, 8:285-290.

Claudino-Sales, V. \& L.P. Maia. 2002. Impactos ambientais associados à instalação do complexo industrial e portuário do Pecém (CE). In: Congresso Brasileiro de Geologia, 41. João Pessoa, PB, 15 a 29 de setembro de 2002. Anais, 1:110.

Clay, C.S.; J. Ess \& I. Weisman. 1964. Lateral echo sounding or de ocean bottom on the Continental Rise. J. Geoph. Res., 69(18):3283-3835.

Cobo, P.; C. Ranz; A. Fernández; M. Cuesta; D.K. Anthony \& M. Siguero. 2005. Waveform Shaping of Sonar Transducers for Improving the Vertical Resolution in Sub-bottom Sediments Profiling. Mar. Geophys. Res., 26(2):87-95.

Collier, J.S. \& C.J. Brown. 2005. Correlation of sidescan backscatter with grain size distribution of surficial seabed sediments. Mar. Geol., 214(4):431-449.

Daly, J.; S. McGeary \& D.E. Krantz. 2002. Ground-Penetrating Radar Investigation of a Late Holocene Spit Complex: Cape Henlopen, Delaware. J. of Coastal Research, 18 (2): 274286.

Damuth J. E. 1980. Use of high-frequency (3.5-12 kHz) echograms in the study of near-bottom sedimentation processes in the deep-sea: A review. Mar. Geol., 38(1-3): 51-75

Damuth, J. E \& D.E. Hayes. 1977. Echo character of the East Brazilian continental margin and its relationship to sedimentary processes. Mar. Geol., 24(2):73-95.

Damuth, J. E. \& N. Kumar. 1975. Amazone cone: morphology, sediments age, and growth pattern. Geol. Soc. Am. Bull., 86:863-878.

Damuth, J. E. 1975. Echo character of the Western Equatorial Atlantic floor and its relationship to the dispersal and distribution of terrigenous sediments. Mar. Geol., 18:17-45.

Damuth, J. E. 1978. Echo character of the Norwegian-Greenland Sea: Relationship to Quaternary sedimentation. Mar. Geol., 28(1-2):1-36.

Damuth, J. E.; V, Kolla; R.D. Flood; R.D. Kowsmann; M.A.; J.J.C. Palma \& R.H. Belderson. 1983. Distributary channel meandering and bifurcation patterns on the Amazon deep-sea fan as reveled by long-range side-scan sonar (Gloria). Geology, 11:94-98.

Dantas, E.P.; M.M.V. Pereira \& R. Pereira. 1996. Erosão pluvial acelerada na costa lesta do Estado do Rio Grande do Norte - Estudo de casos. In: Congresso Brasileiro de Geologia, 39. Salvador-BA, 1 a 6 de setembro de 1996. Anais, 4: 405-409.

Davis, J. L., A.P. Annan. 1989. Ground-penetrating radar for high-resolution mapping of soil and rock stratigraphy. Geophys. Prospect., 37(5):531-551.

Denbigh, P.N. \& B.W. Flemming. 1982. Range prediction and calibration in side scan sonar. In: Russel-Cargill, W.G.A (ed). Recent developments in side scan sonar techniques. South África, Central Acoustics Laboratory, University of Cape Town. Cap. 4, p.80-100.

Dias, G.T.M. \& C.G. Silva. 2003. Levantamentos geofísicos na rota submarina planejada para o Metrô Rio Niterói. In: Congresso Internacional da Sociedade Brasileira de Geofísica, 8. Rio de Janeiro, RJ, 14 a 18 de setembro. Anais. CD-ROM.

Dias, G.T.M. 2000. Marine bioclasts: calcareous algae. Rev. Bras. Geof., 18(3):307-318. 
Dias, G.T.M.; M.A. Gorini; C.G. Gallea; C.R.S. Espindola; S.M. Mello; H. Dellapiazza \& J.R.J.C. Castro. 1982. Bancos de arenito de praia (beachrocks) submersos na plataforma continental SE brasileira. In: Congresso Brasileiro de Geologia, 32. Salvador, BA, setembro de 1982. Anais, 4:1540-1546.

Dias, M.S.; M.V.R. Carnevale; G.T.M. Dias; L. Bispo \& M. Bonardi. 2005. Sismo-estratigrafia do holoceno na Baía de Guanabara: porção ao norte da ilha do Governador. In: Congresso da Associação Brasileira de Estudos do Quaternário - ABEQUA, 10. Guarapari, ES, 9 a 16 de outubro de 2005. Anais. CD- ROM.

Dobrin, M. B.1976. Introduction to Geophysical Prospecting. New York. Third Edition. MacGraw-Hill. 630p.

Dunsiger, A.D; N.A. Cochrane \& W.J. Vetter. 1981. Seabed Characterization from Broad-Band Acoustic Echosounding with Scattering Models. IEEE Transactions of Oceanic Engineering, OE-6 (3): 94-106.

Edwards, L. S. 1977. A modified pseudosection for resistivity and induced-polarization. Geophysics, 42(5):1020-1036.

Elis, V.R. 1998. Avaliação da aplicabilidade de métodos elétricos de prospecção geofísica no estudo de áreas utilizadas para disposição de resíduos. Tese de Doutorado. Instituto de Geociências e Ciências Exatas. Universidade Estadual Paulista - UNESP. 264p.

Faflak E. 1998. GPR investigations at two prehistoric chert mining quarry sites in the northern Madison range, southwestern Montana. In: GPR'98 - International Conference on Groundpenetrating radar, 7. Lawrence, Kansas, EUA, 27-30 de maio de 1998. Proceedings. CDROM.

Ferreira, F.J.F. 1982. Alinhamentos estruturais - magnéticos da região centro - oriental da bacia do Paraná e seu significado tectônico. Geologia da Bacia do Paraná, São Paulo. Publicação Especial IPT, 12:143-166.

Ferreira, F.J.F; R.A.V. Moraes; M.P. Ferrari \& R.B. Vianna. 1981. Contribuição ao estudo do alinhamento estrutural Guapiara. Simpósio Regional de Geologia, 3. São Paulo, SP, novembro de 1981. Anais, 1: 226-240.

Figueiredo Jr., A.G. \& I. Brehme. 2000. Amostragem geológica na pesquisa mineral. Rev. Bras. Geofis., 18(3):269-280.

Figueiredo Jr., A.G. \& R.D. Kowsman. 1976. Interpretação dos registros de sonar de varredura lateral obtidos na plataforma sul riograndense durante a operação GEOMAR VII. Rio de Janeiro, CPRM. Projeto REMAC. Relatório Interno da CPRM.

Figueiredo Jr. A.G.; C.G. Silva; S.L.M. Mello; L. Artusi; S. H. F. Silva; V.F. Santos; C.Z. Gonçalves; L.M. Laut; V.Oliveira \& C.M.V. Figueiredo. 2003. GPR investigation on a beach ridge coastal plain, Paraíba do Sul River delta. In: Congresso Internacional da Sociedade Brasileira de Geofísica - SBGf, 8. Rio de Janeiro, RJ, 14 a 18 de setembro de 2003. Boletim de Resumos Expandidos. CD-ROM.

Fish, J.P. \& Carr, H.A. 1999. Sound underwater images: a guide to the generation and interpretation of side scan sonar data. EG\&G Marine Instruments. Burlington, p.11-15.

Flemming, B.W. 1976. Side Scan Sonar: a practical guide. Int. Hydrogr. Rev. 53(1), 28p.

Flemming, B.W. 1982. Causes and effects of sonograph distortion and some graphical methods for their manual correction. In: Russel-Cargill, W.G.A (ed). Recent developments in side scan techniques. South África, Central Acoustics Laboratory, University of Cape Town. Cap. 5, p.103-138.

Flood, R.D. 1980. Deep-sea sedimentary morphology: Modelling and interpretation of echosounding profiles. Mar. Geol., 38(1-3):77-92.

Forsgren, G; L. Malmgren; L. Brydsten. \& M. Jansson. 1993. Characterization of sediments by high-frequency echo-sounding. Environ. Geol. (Historical Archive). 21(1-2):14-18. 
Foster-Smith, B.; C. Brown ; B. Meadows \& I. Rees. 1999. Procedural Guideline 1-3: Seabed mapping using acoustic ground discrimination interpreted with ground truthing. Marine Monitoring Handbook, p.183-197. Disponível em <http://www.ncl.ac.uk/seamap>. Acesso: nov/2005.

Frazão E.P. \& H. Vital. 2002. Estudo batimétrico e sonográfico do estuário do rio Potengi-RN. In: Congresso Brasileiro de Geologia, 41. João Pessoa, PB, 15 a 29 de setembro de 2002. Anais, 1:90.

Frazão E.P. \& H. Vital. 2006. Estruturas rasas de gás em sedimentos no estuário Potengi (nordeste do Brasil). Revista Brasileira de Geofísica (no prelo).

Freitas R., A.M. Rodrigues \& V. Quintino. 2003. Benthic biotopes remote sensing using acoustics. J. Exp. Mar. Biol. Ecol., 285-286:339-353.

Furtado V.V.; L.A. Conti \& M. Rodrigues. 2000. Bottom Topography, sedimentation and origin aspects of São Sebastião Channel, SP, Brazil. In: International Geological Congress, 31. Rio de Janeiro, RJ, 6 a 17 de agosto de 2000. General Proceedings. Boletim de Resumos. CD-ROM.

Gallas, J.D.F. \& O. Augusto Filho. 1999. Ensaios de eletrorresistividade, SP, IP em área de risco associado a colapso de terreno. In: Congresso Internacional da Sociedade Brasileira de Geofísica, 6. Rio de Janeiro, 15 a 19 de agosto de 1999. Anais. CD-ROM.

Gallas, J.D.F. 1998. Eletrorresistividade aplicada à prospecção de água subterrânea em área de rochas cristalinas. In: Workshop de Geofísica Aplicada, 2. Rio Claro, SP, 19-20 novembro. CD-ROM.

Gallas, J.D.F. 2000. Principais métodos geoelétricos e suas aplicações em prospecção mineral, hidrogeologia, geologia de engenharia e geologia ambiental. Tese de Doutorado. Instituto de Geociências e Ciências Exatas. Unesp. Rio Claro. 259p.

Gallas, J.D.F.; F. Taioli; S.M.C.P. Silva; O.G.W. Coelho \& P.S.G. Paim. 2005. Contaminação por chorume e sua detecção por resistividade. Rev. Bras. Geofis., 23(1):51-59.

Gallea, C.G.; L.A.P. Souza \& R. Bianco. 1989. A geofísica Marinha de alta resolução: características e aplicações. In: Congresso Internacional da Sociedade Brasileira de Geofísica, 2. Rio de Janeiro, RJ, 27 de novembro a $1^{\circ}$ de dezembro de 1991 . Boletim de Resumos, 1:176-197.

Galli V.L \& L.A.P. Souza. 1999. GPR Exemplos de Aplicação. In: Congresso Internacional da Sociedade Brasileira de Geofísica, 6. Rio de Janeiro, 15 a 19 de agosto de 1999. Anais. CD-ROM.

Gandolfo, O. C. B. 1999. Aplicação da sísmica de reflexão de alta resolução e do radar de penetração no solo (GPR): um estudo comparativo. Dissertação de Mestrado. Instituto de Geociências e Ciências Exatas, Universidade Estadual Paulista - UNESP. 140p.

Gandolfo, O.C.B.; F.O.F. Miranda \& M.B.M. Silva,. 2001a. Levantamento geofísico utilizando o método GPR na Mineração Millennium (PB). In: Congresso Internacional da Sociedade Brasileira de Geofísica, 7. Salvador, BA, 28 a 31 de outubro de 2001. Boletim de resumos expandidos, 1:324-327.

Gandolfo, O.C.B.; L.A.P. Souza; M.G. Tessler \& M. Rodrigues 2001b. Estratigrafia rasa da Ilha Comprida, SP: Um exemplo de aplicação do GPR. Rev. Bras. Geofis., 19(3):251-262.

Gandolfo, O.C.B \& O. F. Miranda Filho. 2002. O método GPR utilizado para a detecção e mapeamento de interferências em zonas urbanas. In: Simpósio sobre túneis urbanos, 4. São Paulo, SP, 2002. Boletim de resumos expandidos, 1:197-201.

García-García, A.; F. Vilas \& S. García-Gil 1999. A seeping sea-floor in a Ría environment: Ría de Vigo (NW Spain). Environmental Geology, 38(4):296-300.

García-García, A.; S. García-Gil \& F. Vilas. 2005. Quaternary evolution of the Ría de Vigo, Spain. Marine Geology, 220(1-4): 153-179. 
Gardner, J. V., J.V. Gardner; P.B. Butman; L.A. Mayer. 1998. Mapping U.S. continental shelves. Sea Technol., 39(6):10-17.

Gasperini, L. 2005. Extremely Shallow-water Morphobathymetric Surveys: The Valle Fattibello (Comacchio, Italy). Test Case. Mar. Geophys. Res., 26(2):97-107.

Geoacoustics. 2001. Mapping image texture on side-scan sonar records. Dredging and Port Construction. Maio de 2001. 5p. Disponível em 〈http://www.geoacoustics.com>. Acesso: 10/mar/2006.

Geoacoustics. 2004. Shallow Water Surveys using Geoacoustics GeoSwath. Application Note, 9. 17p. Disponível em <www.geoacoustics.com>. Acesso: 14/nov/2005.

Giannini, P.C.F \& C. Riccomini. 2000. Sedimentos e processos sedimentares. In: Teixeira, W.; M.C. Toledo; T.R. Fairchild \& F. Taioli. Decifrando a Terra. Cap.9:167-190. São Paulo. Oficina de textos. 558p.

Gibs, R. J. 1974. Physics of sound in marine sediments. Loyd Hampton. 567p.

Gokasan, E; H.Tur; B.Ecevitoglu; T. Gorum; A. Turker; B. Tok; F. Çaglak; H. Birkan \& M. Simsek. 2005. Evidence and implications of massive erosion along the Strait of Istanbul (Bosphorus). Geo-Mar. Lett., 25:324-342.

Golf, J.A.; H.C. Olson \& C.S. Duncan. Correlation of side-scan backscatter intensity with grainsize distribution on shelf sediments, New Jersey margin. Geo-Mar. Lett., 20: 43-49.

Goodman, D.; Y. Nishimura; H. Hongo \& M. Okita. 1998. GPR Amplitude rendering in Archaeology. In: International Conference on Ground-penetrating Radar, 7. Lawrence, Kansas, EUA, 27-30 de maio de 1998. GPR'98 Proceedings. CD- ROM

Gorini, M.A.; G.T.M. Dias; S.M. Mello; C.R.S. Espindola; C.G. Gallea; H. Dellapiazza \& J.R.J.C. Castro. 1982. Estudos ambientais para a implantação de gasoduto submarino na área de Guamaré (RN). In: Congresso Brasileiro de Geologia, 32. Salvador, BA, setembro de 1982. Anais, 4:1531-1539.

Gracia, V.P. 1998. GPR survey to confirm the location of ancient structures under the valentine cathedral (Spain). In: International Conference on Ground-penetrating radar, 7. Lawrence, Kansas, EUA, 27 a 30 de maio de 1998. GPR'98 Proceedings. CD- ROM.

Grant, J.A. \& R. Schreiber. 1990. Modern swathe sounding and sub-bottom profiling technology for research applications: The Atlas Hydrosweep and Parasound Systems. Mar. Geophys. Res., 12(1-2):9-19.

Greenstreet, S.P.R.; I.D. Tuck; G.N. Grewar; E. Armstrong.; D.G. Reid \& P.J. Wright. 1997. An Assessment of the acoustic survey technique, RoxAnn, as a means of mapping seabed habitat. ICES J. of Marine Science, 54:939-959.

Hamilton, E.L. 1979. Sound velocity gradients in marine sediments. J. Acoust. Soc. Am., 65:909-922.

Hamilton, E.L. 1980. Geoacoustic modeling of the sea floor J. Acoust. Soc. Am., 68:1313-1336.

Hamilton, L. J.; P.J. Mulhearn \& R. Poeckert. 1999. Comparison of RoxAnn and QTC-View acoustic bottom classification system performance for the Cairns area, Great Barrier Reef, Australia. Cont. Shelf Res., 19:1577-1597.

Hesse, A. 1999. Multi-parametric survey for archaeology: how and why, or how and why not? J. Appl. Geophs., 41:157-168.

Houtz, R. E. 1973. Preliminary study of global sediment sound velocities from sonobuoy data. In: Physics of Sound in Marine Sediments. Loyd Hampton. New York. 550p.

Houtz, R. E. 1977. Sound-velocity characteristics of sediments from the eastern South American margin. Geol. Soc. Am. Bull., 88:720-722.

Houtz, R. E. 1981. Comparison of sediment sound-velocity functions from conjugate margins. Geol. Soc. Am. Bull., Part 1, 92:262-267. 
Hübscher, C.; A.G. Figueiredo-Jr.; L. Kruse \& V. SpieB. 2002. High-resolution analysis of the deposition pattern on the Amazon sub-aquatic delta and outer continental shelf. Mar. Geophys. Res. 23: 209-222.

Humborstad, O.B.; L. Nøttestad; S. Løkkeborg. \& H.T. Rapp. 2004. RoxAnn bottom classification system, sidescan sonar and video-sledge: spatial resolution and their use in assessing trawling impacts. ICES J. of Marine Science, 61:53-63.

Hussong, D.M. P. Fryer. 1983. Back-Arc Seamounts and the SeaMarc II Seafloor Mapping System. EOS, 64:627-633.

Hutchinson, D. R. \& R.S. Detrick, Water gun vs air gun: A comparison. Mar. Geophys. Res. (Historical Archive). 6(3):295-310.

IHO, 1998. IHO Standards for Hydrographic Surveys, $4^{\text {th }}$. Edition. International Hydrographyic Organization Special Publication 44. International Administration Bureau, Monaco. 7p.

Instituto de Pesquisas Tecnológicas do Estado de São Paulo - IPT 2003. Levantamento batimétrico no lago do parque Guaraciaba e caracterização geológico-geotécnica das encostas marginais - município de Santo André, SP. Relatório Técnico 66.080. 71p.

Instituto de Pesquisas Tecnológicas do Estado de São Paulo - IPT. 1979. Ensaios Geofísicos (Sísmica de Reflexão e Sísmica de Refração) e áreas de interesse para projetos da CHESF - Pão de Açúcar e Canindé - Rio São Francisco. CHESF. Relatório Técnico IPT nº. 12.434. 24p.

Instituto de Pesquisas Tecnológicas do Estado de São Paulo - IPT. 1985a. Aplicação do Sonar de Varredura Lateral na Investigação do assoalho marinho para fixação de plataforma exploratória de petróleo, Ilhéus, Ba. Engevix S.A. - Estudos e Projetos de Engenharia/Petrobrás. Relatório Técnico IPT n ${ }^{\circ}$. 22.199. 10p.

Instituto de Pesquisas Tecnológicas do Estado de São Paulo - IPT. 1985b. Aplicação do Sonar de Varredura Lateral na Investigação do assoalho marinho para fixação de plataforma exploratória de petróleo, Fortaleza, CE. Engevix S.A. - Estudos e Projetos de Engenharia/Petrobrás. Relatório Técnico IPT n ${ }^{\circ}$. 22.844. 10p.

Instituto de Pesquisas Tecnológicas do Estado de São Paulo - IPT. 1985c. Ensaios de Perfilagem Sísmica Contínua e Sonografia na costa da Ilha Comprida, Litoral sul do Estado de São Paulo, Cananéia, SP. SICT/Pró-Minério. Relatório Técnico IPT nº. 22.021. 40p.

Instituto de Pesquisas Tecnológicas do Estado de São Paulo - IPT. 1985d. Quantificação de dados de Perfilagem Sísmica e Sonografia obtidos na costa da Ilha Comprida, litoral sul do Estado de São Paulo, Cananéia, SP. SICT/Pró-Minério. Relatório Técnico IPT nº 22.928. $11 \mathrm{p}$.

Instituto de Pesquisas Tecnológicas do Estado de São Paulo - IPT. 1986a. Perfilagem sísmica, batimetria e sonar de varredura lateral no local de implantação da UHE de Ilha Grande. ELETROSUL. Relatório Técnico IPT n ${ }^{\circ}$. 24.087. 26p.

Instituto de Pesquisas Tecnológicas do Estado de São Paulo - IPT. 1986b. Ensaios de sísmica de reflexão no Rio Ji-Paraná na área de interesse do sítio JP-14, Estado de Rondônia. CNEC. Relatório Técnico IPT n ${ }^{\circ}$. 23.888. 98p.

Instituto de Pesquisas Tecnológicas do Estado de São Paulo - IPT. 1987. Ensaios Sísmicos no Rio Xingu, nos sítios Juruá, Kararaô, e Rota de Navegação - Estado do Pará. ELETRONORTE. Relatório Técnico IPT n ${ }^{\circ}$. 24.409. 4v. 115p.

Instituto de Pesquisas Tecnológicas do Estado de São Paulo - IPT. 1988. Ensaios Sísmicos em lâmina d'água na área do canal de Santos. Sondotécnica S.A. Relatório Técnico IPT no 26043. 12p.

Instituto de Pesquisas Tecnológicas do Estado de São Paulo - IPT. 1990a. Ensaios geofísicos em lâmina d'água - rio Paranapanema, SP. CESP. Relatório Técnico IPT no. 27225. 2v. 150p. 
Instituto de Pesquisas Tecnológicas do Estado de São Paulo - IPT. 1990b. Ensaios geofísicos complementares em lâmina d'água - rio Paranapanema, SP. CESP. Relatório Técnico IPT $\mathrm{n}^{\circ}$. 28899. 228p.

Instituto de Pesquisas Tecnológicas do Estado de São Paulo - IPT. 1992a. Estudo da dinâmica da erosão e assoreamento em sub-bacias contribuintes do reservatório de Capivara, Rio Paranapanema, SP. CESP. Relatório Técnico IPT nº. 30283.

Instituto de Pesquisas Tecnológicas do Estado de São Paulo - IPT. 1992b. Diagnóstico do assoreamento nos braços dos ribeirões Capivari, Bonito e Conjunto F: estimativa do assoreamento para o reservatório de Capivara. CESP. Relatório Técnico IPT n ${ }^{\circ} .30854$.

Instituto de Pesquisas Tecnológicas do Estado de São Paulo - IPT. 1993. Levantamentos geofísicos em apoio a estudo geológico em área de aterro industrial no município de Santo André, SP. Relatório Técnico IPT n ${ }^{\circ}$ 31.276. 59p.

Instituto de Pesquisas Tecnológicas do Estado de São Paulo - IPT. 1996. Adequação e controle da mineração da bacia do Guarapiranga: avaliação do potencial mineral. Secretaria do Meio Ambiente do Estado de São Paulo - SMA. Relatório Técnico IPT nº 34.663.

Instituto de Pesquisas Tecnológicas do Estado de São Paulo - IPT. 1998a. Ensaio geofísico com radar de penetração aplicado a engenharia na usina hidrelétrica de Santa Branca, no Estado de São Paulo. Promon Engenharia Ltda. Relatório Técnico IPT n ${ }^{\circ} 37378$.

Instituto de Pesquisas Tecnológicas do Estado de São Paulo - IPT. 1998b. Ensaio Geofísico com radar de penetração aplicado à engenharia no barracão de manutenção da ferrovia atlântico sul - Curitiba, PR. Ambienge Engenharia Sanitária e Ambiental. Relatório Técnico IPT n ${ }^{\circ}$. 37452.

Instituto de Pesquisas Tecnológicas do Estado de São Paulo - IPT. 1998c. Ensaios geofísicos para obtenção de subsídios técnicos para apontar possíveis causas Aos problemas de recalques e colapso ocorridos nas fundações da fábrica da Pirelli na região de Campinas, SP. Pirelli Pneus S.A. Relatório Técnico IPT n ${ }^{\circ} .37728$.

Instituto de Pesquisas Tecnológicas do Estado de São Paulo - IPT. 1998d. Ensaios geofísicos de eletrorresistividade, potencial natural e ground penetrating radar (GPR) em áreas da Solvay Indupa do Brasil S.A - SP. Solvay Indupa do Brasil S.A. Relatório Técnico IPT nº 38447.

Instituto de Pesquisas Tecnológicas do Estado de São Paulo - IPT. 1998e. Viagem de reconhecimento da via navegável do reservatório de Barra Bonita desde a Eclusa até a ponte de Anhumas. CESP. Relatório Técnico IPT n ${ }^{\circ}$. 38. 231. 2 vol., 58p.

Instituto de Pesquisas Tecnológicas do Estado de São Paulo - IPT. 1999a. Estudo das áreas de produção de sedimentos da bacia hidrográfica contribuinte do Porto de Santos, SP. DTA Consultoria scl. IPT n ${ }^{\circ} .39697 .62 \mathrm{p}$.

Instituto de Pesquisas Tecnológicas do Estado de São Paulo - IPT. 1999b. Estudos e Serviços de Engenharia para realocação do traçado da rota de navegação do Rio Paraná no trecho Icaraíma/Porto Caiuá. AHRANA - Ministério dos Transportes. Relatório Técnico IPT $n^{\circ}$. 42.696.

Instituto de Pesquisas Tecnológicas do Estado de São Paulo - IPT. 1999c. Levantamentos Geofísicos de GPR (Ground Penetrating Radar), SP (Potencial Espontâneo) e Eletrorresistividade, Estudos Geológicos-Geotécnicos E Hidrogeológicos, Em Local de Ocorrência de Colapsos. SABESP - Companhia de Saneamento Básico do Estado de São Paulo. Relatório Técnico IPT n ${ }^{\circ}$. 38434. 34p.

Instituto de Pesquisas Tecnológicas do Estado de São Paulo - IPT. 1999d. Ensaios geofísicos e análise geologia para subsídio de empreendimento habitacional popular no município de Cajamar, SP. Relatório Técnico IPT n ${ }^{\circ}$ 39.416. 27p:

Instituto de Pesquisas Tecnológicas do Estado de São Paulo - IPT. 2000. Estudos para verificação das condições de navegabilidade do canal de Guaíra - PR. Relatório Técnico IPT $\mathrm{n}^{\circ}$ 49.207. 42p. 
Instituto de Pesquisas Tecnológicas do Estado de São Paulo - IPT. 2001a. Levantamento com o sonar de varredura lateral como subsídio ao projeto "Estudos sistemáticos de sítios arqueológicos submersos ao longo do pólo lagamar/ Litoral Sul de São Paulo. IPT / MAE Museo de Arqueologia e Etnografia da USP. Relatório Técnico IPT n ${ }^{\circ}$. 56.035. 30p.

Instituto de Pesquisas Tecnológicas do Estado de São Paulo - IPT. 2001b. Monitoramento das erosões à jusante da barragem de Porto Primavera - Levantamentos Geofísicos - $1^{\mathrm{a}}$. Fase. Relatório Técnico IPT no. 55.008. 49p.

Instituto de Pesquisas Tecnológicas do Estado de São Paulo - IPT. 2002a. Levantamento geofísico com o sonar de varredura lateral para mapeamento de recifes artificiais na plataforma continental rasa do litoral sul do Estado do Paraná. IPT / Instituto Ecoplan. Relatório Técnico IPT n ${ }^{\circ}$. 58707. 75p.

Instituto de Pesquisas Tecnológicas do Estado de São Paulo - IPT. 2002b. Levantamento geofísico com o sonar de varredura lateral para mapeamento da superfície de fundo de um trecho do porto de Suape, PE. Microars - Consultoria e Projetos. Relatório Técnico IPT $n^{\circ}$. 63060. 34p.

Instituto de Pesquisas Tecnológicas do Estado de São Paulo - IPT. 2002c. Levantamento geofísico com o sonar de varredura lateral para mapeamento da superfície de fundo da área da Pedra das Palanganas, Porto de Paranaguá, PR. Microars - Consultoria e Projetos. Relatório Técnico IPT n ${ }^{\circ}$. 61850. 29p.

Instituto de Pesquisas Tecnológicas do Estado de São Paulo - IPT. 2003. Aspectos geológicos e geotécnicos da hidrovia Tietê Paraná no trecho próximo aos quilômetros 48 e 49. Secretaria de Estado dos Transportes - Departamento Hidroviário - DH. Relatório Técnico IPT $\mathrm{n}^{\mathrm{o}}$.64.299. 26p.

Instituto de Pesquisas Tecnológicas do Estado de São Paulo - IPT. 2005a. Levantamento geofísico para mapeamento de recifes na plataforma continental rasa do litoral sul do Estado da Bahia.. Conservation International do Brasil - CI. Relatório Técnico IPT $\mathrm{n}^{\circ}$. 74072-205. 41p.

Instituto de Pesquisas Tecnológicas do Estado de São Paulo - IPT. 2005b. Levantamentos sísmicos (ecobatimetria, sonografia e perfilagem sísmica contínua) em apoio a obra de implantação de duto sob o rio São Francisco - SE/AL. Geo-radar. Relatório Técnico IPT $\mathrm{n}^{\mathrm{o}}$. 82367-205. 33p.

Instituto de Pesquisas Tecnológicas do Estado de São Paulo - IPT. 2004. Avaliação das condições de estabilidade geotécnica dos taludes marginais da lagoa de Carapicuíba (SP). Pref. Munic. Santo de Carapicuíba. Relatório Técnico 70303. 53p.

Instituto de Pesquisas Tecnológicas do Estado de São Paulo - IPT. 2006. Aspectos geológicos e geotécnicos da Hidrovia Tietê-Paraná a jusante da eclusa de Barra Bonita, no canal de Igaraçu (SP). Secretaria de Estado dos Transportes - Departamento Hidroviário - DH. Relatório Técnico 86.544-205.

Jol, H. M; C.D. Peterson; S. Vanderburgh \& J. Phipps. 1998. GPR as a regional geomorphic mapping tool: shoreline accretion/erosion along the Columbia River littoral cell. In: International Conference on Ground-penetrating radar, 7. Lawrence, Kansas, EUA, 27-30 de maio de 1998. GPR'98 Proceedings. CD- ROM.

Jol, H.M. \& D.G. Smith. 1991. Ground penetrating radar of northern lacustrine deltas. Can. J. Earth Sci., 28:1939-1947.

Jol, H.M; D.G. Smith \& R.A. Meyers. 1996. Digital ground penetrating radar (GPR): a new geophysical tool for coastal Barrier research (Examples from the Atlantic, Gulf and Pacific Coast, USA). J. of Coastal Research, 12(4): 960-968.

Jones, E.J.W. 1999. Marine geophysics. Baffins Lane, Chichester, John Willey \& Sons Ltd. Inc. 466p. 
Kastens, K.A. \& A.N. Shor. 1985. Depositional processes of a meandering channel on Mississipi fan. The American Association of Petroleum Geologists Bulletin. 69(2):190202.

Kennett, J. P. 1982. Marine Geology. Englewood Cliffs, Prince Hall. 81p.

Kinoshita Y. 1998. Field Training on Seismic Survey in Rivers and Channels in the Chão Phraya Delta, Golf of Thailand - 1988. Department of Mineral Resources of Thailand/Geological Survey of Japan. Relatório Interno. 32p.

Kinoshita Y. 1999. Field Training on Seismic Survey in Rivers and Channels in the Chão Phraya Delta, Golf of Thailand - 1999. Department of Mineral Resources of Thailand/Geological Survey of Japan. Relatório Interno. 47p.

Kinoshita Y. 2000. Field Training on Seismic Survey in Rivers and Channels in the Chão Phraya Delta, Golf of Thailand - 2000. Department of Mineral Resources of Thailand/Geological Survey of Japan. Relatório Interno. 33p.

Klein, D. A. 2005. Registros de variações ambientais no canal de São Sebastião (Estado de São Paulo) durante o último ciclo glacial. Dissertação de Mestrado, Instituto Oceanográfico da USP. 124p.

Klein, D.A.; M. Rodrigues; M.M. Mahiques \& V.V. Furtado. 2004. Caracterização de beachrocks submersos no canal de São Sebastião, litoral norte do Estado de São Paulo. In: Simpósio Brasileiro de Oceanografia, 2. Arraial do Cabo, RJ, outubro de 2004. Anais. CDROM.

Klessig, L.L. 2001. Lakes and society: The contribution of lakes to sustainable societies. Lakes \& Reservoirs: Research and Management, 6:95-101.

Kongsberg-Simrad. 2004. EA-400 - Single Beam Hydrographic Echo Sounder. Operator Manual. Version 2.1.1.0. Horten, Norway, Kongsberg. 195p.

Labaune C.; M. Tesson \& B. Gensous. 2005. Integration of high and very high-resolution seismic reflection profiles to study Upper Quaternary deposits of a coastal area in the western Gulf of Lions, SW France. Mar. Geophys. Res., 26(2):109-122.

Lamour, M.R.; R.J. Angulo; F.A. Veiga; R.C. Zem \& C.R. Soares. 2005. Evolução batimétrica do complexo estuarino de Paranaguá. In: Congresso da Associação Brasileira de Estudos do Quaternário - ABEQUA, 10. Guarapari, ES, 9 a 16 de outubro de 2005. Anais. CDROM.

Langeraar, W. 1984. Surveying and Charting of the Seas. Amsterdam, Elsevier. 612p. (Elsevier Oceanography Series, 37).

Lancker, V.; J. Lanckneus; S. Hearn; P. Hoekstra; F. Levoy; J. Miles; G. Moerkerke; O. Monfort \& R. Whitehouse. 2004. Coastal and nearshore morphology, bedforms and sediment transport pathways at Teignmouth (UK). Continental Shelf Research 24:11711202.

Lastoria, G; M.A.C. Rondon; N.O. Carvalho. 1998. Estimativa do assoreamento do reservatório do Guarirova, Campo Grande, MS. In: ENES - Encontro de Engenharia de Sedimentos, 3. Belo Horizonte, MG, 21 a 25 de setembro de 1998. Anais, 1: 145-151.

Laughton, A.S. 1981. The first decade of GLORIA. J. Geophys. Res., 86(b12): 11511-11534.

Lavoie, D; E. Mozley; R. Corwin; D. Lambert; P. Valent. 1987. The use of a towed, directcurrent, electrical resistivity array for the classification of marine sediments. Washington,DC, NORDA Stennis Space Center. MS 39529:397-404.

Lawrence B \& L.B. Conyers. 1998. Acquisition, processing and interpretation techniques for ground-penetrating radar mapping buried pit -structures in the American southwest. In: International Conference on Ground-penetrating Radar, 7. Lawrence, Kansas, EUA, 27-30 de maio de 1998. GPR'98 Proceedings. CD-ROM. 
Lessa, G.C; A.C.S.P. Bittencourt \& A. Brichta, A. 2000. A reevaluation of the late quaternary sedimentation in Todos os Santos Bay (BA), Brazil. An. Acad. Bras. Ciênc., 72(4):573590.

Lima, A.F.2003. Comparação dos Sistemas Sedimentares Profundos da Bacia Sudeste-Sul do Brasil com ênfase no Sistema Misto Colúmbia. Tese de Doutorado. Instituto Oceanográfico da USP. 252p.

Lima, O.A.L. e M.J. Porsani. 1994. Monitoramento geoelétrico da contaminação aqüífera no pólo petroquímico de Camaçari, Bahia. Rev. Bras. Geofis., 12(2):147-161.

Lima, R.C.A.; P.N. Coutinho \& L.P. Maia. 2002. Estudo da erosão marinha na praia do Pontal da Barra - Maceió, AL. In: Congresso Brasileiro de Geologia, 41. João Pessoa, PB, 15 a 29 de setembro de 2002. Anais, 1:101.

Lobo, F.J.; F.J. Hernández-Molina; L. Somoza; V. Díaz del Rio \& J.M.A. Dias. 2002. Stratigraphic evidence of an upper Pleistocene TST to HST complex on the Gulf of Cádiz continental shelf (south-west Iberian Península). Geoo-Mar Lett : 22: 95-107.

Lopes, A.L.M; C.G. Silva \& G. T. M. Dias. 2003. Caracterização sonográfica das feições arenosas de fundo da plataforma continental interna e média a sul da Bacia de Campos. In: Congresso Internacional da Sociedade Brasileira de Geofísica - SBGf, 8. Rio de Janeiro, RJ, 14 a 18 de setembro de 2003. Boletim de Resumos Expandidos. CD-ROM.

López, R.A. \& S.C. Marcomini. 1996. Impacto Ambiental generado por asentamientos urbanos em zonas costeiras. . In: Congresso Brasileiro de Geologia, 39. Salvador-BA, 1 a 6 de setembro de 1996. Anais, 4: 484-488.

Lorenzo, H.; P. Arias; M. Pereira; F. Rial \& A. Tejeda. 2004. Use of GPR to map Prestige fuel layers below sand on the beaches of Galicia. In: International Conference on Ground Penetrating Radar, 10. Delft, Holanda, 21-24 de junho de 2004. Proceedings. CD-ROM.

Lowag J. 2000. Advanced Techniques for Dredging Applications. Hydro International. Setembro, 2000. Disponível em <http://www.innomar.com>. Acesso: fev/2005.

Luyendyk, B.; E.J. Hajic \& D.S. Simonett. 1983. Side-scan sonar mapping and computer-aided interpretation in the Santa Barbara Channel, California. Mar. Geophys. Res, 5:365-388.

Mac Dougall, N and K.D. Black. 1999. Determining sediment properties around a marine cage farm using acoustic ground discrimination: RoxAnn ${ }^{\mathrm{TM}}$. Aquac. Res., 30(6):451-459.

Macedo, H.C.; A.G. Figueiredo Jr.; L. Artusi \& S. R. Souza. 2005. Análise da propagação das ondas compressionais $(\mathrm{P})$ em sedimentos marinhos e sua aplicação na caracterização das propriedades acústicas do ambiente. In: Congresso Internacional da Sociedade Brasileira de Geofísica, 9. Salvador, BA, 11 a 14 de setembro de 2005. Anais. CD-ROM.

Machado, A. J. \& M.V. Menezes. 2004. Avaliação do assoreamento no reservatório da UHE Três Marias através da análise comparativa das seções topobatimétricas realizadas no reservatório em 1975 com seções realizadas em fevereiro de 2003. In: Encontro Nacional de Engenharia de Sedimentos, 6. Vitória, ES, 8 a 10 de dezembro de 2004. Anais, 1: 45-48.

Machado, L.M; L.D.Ribeiro; A. Kiperstok; M.A.B. Botelho \& M.F. Carvalho. 2004. Diagnóstico da contaminação por metais pesados em Santo Amaro - BA. Engenharia Sanitária e Ambiental, 9(2): 140-155.

Mahiques, M.M \& L.A.P. Souza. 1999. Shallow seismic reflectors and upper Quaternary sea level changes in the Ubatuba region, São Paulo State, southeastern Brazil. Rev. Bras. Oceanogr., 47(1):1-10.

Maia, L.P.; A.M. Carvalho \& L.H.U. Monteiro. 2002. Projeto de recuperação da praia de Iracema - CE. In: Congresso Brasileiro de Geologia, 41. João Pessoa, PB, 15 a 29 de setembro de 2002. Anais, 1:102.

Mala Geoscience. 2004. Mapping lake sediments and objects. Application Note. Mala GeoScience. Printed Matter no. 2884. Fonte: 〈http://www.malags.com>. Acesso: out/2005. 
Manso, V.A.V.; I.C.S. Correa \& N.C.Guerra. 2003. Morfologia e sedimentologia da plataforma continental interna entre as praias Porto de Galinhas e Campos - Litoral sul de Pernambuco, Brasil. Pesqui. em Geocienc., 30(2):17-25.

Manso, V.A.V.; P.N. Coutinho; A.B. Medeiros; A.L.S. Borba; A.R.A. Lira; F.J.A. Pedrosa; M.H.A. Martins; N.S. Chaves; R.X. Duarte \& P.S. Ivo. 1996. Proposta para a contenção da erosão marinha na praia da Boa Viagem - Recife (PE). In: Congresso Brasileiro de Geologia, 39. Salvador-BA, 1 a 6 de setembro de 1996. Anais, 4: 489-492.

Mansor, L.M. 1994. Disposição final de resíduos sólidos em áreas costeiras: avaliação geoambiental preliminar da planície costeira do RS. In: Congresso Brasileiro de Geologia, 38. Balneário de Camboriú, SC, 23 a 28 de outubro de 1994. Boletim de Resumos Expandidos. p.27.

Marlow, M.S.; J.V. Gardner \& W.R. Normark. 2000. Using high-resolution multibeam bathymetry to identify seafloor surface rupture along the Palos Verdes fault complex in offshore southern California. Geology, 28(7):587-590.

Mazel, C. 1985. Side Scan Sonar training manual. New York, Klein Associates. Inc. Undersea Search and Survey. 144p.

McGeary, S. J.F. Daly \& D.E. Krantz. 1998. High-resolution imaging of Quaternary coastal stratigraphy using Ground Penetrating Radar. In: International Conference on Groundpenetrating radar, 7. Lawrence, Kansas, EUA, 27-30 de maio de 1998. GPR'98 Proceedings. CD-ROM.

McGee, T.M. 1995a. High-resolution marine reflection profiling for engineering and environmental purposes Part A: Acquiring analogue seismic signals. J. Appl. Geophs., 33(4): 271-285.

McGee, T.M. 1995b. High-resolution marine reflection profiling for engineering and environmental purposes Part B: Digitizing analogue seismic signals. J. Appl. Geophs., 33(4): 287-296.

McKinney, T.F.; W.L. Stubblefield. \& D.J.P. Swift. 1974. Large-scale current lineations on the central New Jersey shelf: Investigations by side-scan sonar. Mar. Geol., 17(2): 79-102.

Mcquillin, R. \& D.A. Ardus. 1977. Exploring the geology of shelf seas. London, Grahan \& Trotman Limited. 230p.

Mcrea Jr. J.E.; H.G. Greene; V.M. O’Connell \& W.W. Wakefield. 1999. Mapping marine habitats with high resolution sidescan sonar. Oceanologica Acta, 22(6):679-686.

Mello, I.S.C.; F. Campagnolli; L.A.P. Souza \& J.F.M. Motta. 1996. Algumas características dos depósitos de assoreamento do reservatório de Guarapiranga. Workshop sobre a Qualidade da Água do Guarapiranga. Secretaria de Recursos Hídricos, Saneamento e Obras - Unidade de gerenciamento de Programa. Projeto Guarapiranga. São Paulo, SP, dezembro de 1996. Anais, 1: 1-6.

Mello, S.; C.G. Gallea \& H.R. Duque. 1988. Aplicação de magnetometria para mapeamento de dutos submarinos. In: Congresso Brasileiro de Geologia, 35. Belém, PA, 6 a 13 de novembro de 1988. Anais, 4: 1596-1598.

Mendes, A.C. 1996. Processos sedimentares e a erosão costeira no Amapá. In: Congresso Brasileiro de Geologia, 39. Salvador-BA, 1 a 6 de setembro de 1996. Anais, 4: 460-463.

Missiaen T. 2005. VHR Marine 3D Seismics for Shallow Water Investigations: Some Practical Guidelines. Mar. Geophys. Res., 26(2):145-155.

Missiaen T; N. Wardell \& J. Dix. Subsurface Imaging and Sediment Characterization in Shallow Water Environments - Introduction to the Special Volume. Mar. Geophys. Res., 26(2): 83-85.

Morais, J.O.; S.H.O. Magalhães \& A.C.B. Rodrigues. 1996. Processos de erosão e assoreamento no litoral a oeste de Fortaleza - CE. In: Congresso Brasileiro de Geologia, 39. SalvadorBA, 1 a 6 de setembro de 1996. Anais, 4: 413-416. 
Morang, A.; R. Larson \& L. Gorman. 1997. Monitoring the Coastal Environment; Part III: Geophysical and Research Methods. J. of Coastal Research, 13 (4):1064-1085.

Mosher, D.C. \& P. Simpkin. 1999. Status and trends of marine high-resolution seismic reflection profiling: data acquisition. Geosci. Can., 26:174-188.

Mosher, D.C. \& P. Simpkin. 1999. Status and trends of marine high-resolution seismic reflection profiling: data acquisition. Geoscience Canada, 26: 174-188.

Mosher, D.C. \& R.G. Currie. 1997. Monitoring of ocean disposal using side-scan mosaicing. Lead. Edge, p.1667-1970.

Mosher, D.C. \& R.G. Currie. 1997. Monitoring of ocean disposal using side-scan mosaicing. The Leading Edge, 1:1667-1970.

Moutinho, L.; J.L. Porsani \& M.J. Porsani. 2005. Deconvolução preditiva de dados GPR adquiridos sobre lâmina d'água: exemplo do rio Taquari. Rev. Bras. Geofis., 23(1): 61-74.

Murakami, F.; Y. Saito; Y. Kinoshita; M. Tateishi; N.T. Luu; L.B. Luu \& N.T. Tan. 2004. Shallow Seismic Reflection Survey in the Mekong River Delta. GSJ Now, 12(2):4-9.

Neal, A. 2004. Ground-penetrating radar and its use in sedimentology: principles, problems and progress. Earth-Science Reviews 66:261-330.

Nebrija E.L., C.T Young, R.P Meyer., J.R. Moore. 1976. Electrical prospecting methods applied to shallow-water mineral exploration. In: Oceans' 76 MTS-IEEE. Washington, D.C., EUA, 13 a 15 de setembro de 1976. Proceedings, 1: 2F1-2F11.

Nelson, C.H; K.R. Jonhson \& J.H. Barber Jr. 1987. Gray hale and walrus feeding excavation on the Bering Shelf, Alaska. J. of Sedimentary Research 57(3): 419-430.

Nelson, H. C. \& H.R. Jonhson. 1984. Gray Wales, tillers of the sea floor. Denver-CO, USGS. Highlights in Marine Research, 1: 99-107.

Neumann, V.H; S.N. Leitão; C.M.Queiróz \& L.P. Maia. 1996. Estudos sedimentológicos, geomorfológicos e impactos ambientais causados pela implantação do porto na Laguna de Suape - PE. In: Congresso Brasileiro de Geologia, 39. Salvador, BA, 1 a 6 de setembro de 1996. Anais, 4: 496-499.

Nishimura, K; K. Temaki \& F. Murakami. 1984. 3.5 kHz Echo Sounder Profiling Survey. GSJ Geological Survey of Japan. Report Cruise, 13:20-26.

Nuzzo, L.; G. Leucci \& S. Negri. 2004. GPR survey in the karstic área "Vore di Spedicaturo" near Nociglia (Lecce, Italy). In: International Conference on Ground Penetrating Radar, 10. Delft, Holanda, 21-24 de junho de 2004. Proceedings. CD-ROM.

Ogilvy, A.A. \& V.A. Bogoslovsky. 1977. The possibilities of geophysical methods applied for investigating the impact $\mathrm{f}$ man on the geological medium. Geophys. Prospect., 27: 775-789.

Okyar, M.; M. Ergin \& G. Evans. 2005. Seismic stratigraphy of Late Quaternary sediments of western Mersin Bay shelf, (NE Mediterranean Sea). Marine Geology 220: 113-130.

Olhoeft, G.R. 1999. Applications and frustrations in using ground penetrating radar. In: Ultra Wideband Conference. Washington, D.C., EUA, 20 a 22 setembro de 1999. Procedings. CD-ROM. Disponível em <http://www.uwb.org>. 13p. Acesso: mar/2005.

Oliveira, A.M.S. \& S.N.A. Brito. 1998. Geologia de Engenharia. São Paulo, ABGE. 586p.

Orange, D.L.; A. Garcia-Garcia; D. McConnell; T. Lorenson; G. Fortier; F. Trincardi \& E. Can. 2005. High-resolution surveys for geohazards and shallow gas: NW Adriatic (Italy) and Iskenderun Bay (Turkey). Mar. Geophys. Res., 26:247-266.

Orcioli, P.R.A. \& M.R. Santarelli. 1978. A Sísmica Marinha rasa como auxílio nas obras civis. In: Congresso Brasileiro de Geologia, 30, Recife, PE, novembro de 1978. Anais, 5: 22992311.

Ottoni, A. B. 1998. Caracterização do grau de assoreamento e da curva de eficiência de retenção do reservatório Soledade, MG. In: ENES - Encontro de Engenharia de Sedimentos, 3. Belo Horizonte, MG, 21 a 25 de setembro de 1998. Anais, 1:120-126. 
Padovani C.R.; N.O. Carvalho; S. Galdino; L.M. Vieira. 1998. Deposição de sedimentos e perda de água do rio Taquari no Pantanal. In: ENES - Encontro de Engenharia de Sedimentos, 3. Belo Horizonte, MG, 21 a 25 de setembro de 1998. Anais, 1:129-134.

Padovezzi, C.D. 2003. Conceito de embarcações adaptadas à via aplicado à navegação fluvial no Brasil. Tese de Doutorado. Escola Politécnica da Universidade de São Paulo. 284p.

Paiva, E.M.C.D; J.B.D Paiva \& E.M. Paranhos. 2000. Produção de sedimentos em pequenas bacias hidrográficas rurais, p.35-51. In: Paiva, E.M.C.D \& J.B.D Paiva. Caracterização quali-quantitativa da produção de sedimentos. Porto Alegre, RS, ABRH/UFSM. 435p.

Paiva, J.B.D; E.M.C.D. Paiva \& G.L. Del Forno. 1998. Avaliação de metodologia para cálculo de assoreamento de reservatórios na barragem do DNOS, em Santa Maria, RS. In: ENES Encontro de Engenharia de Sedimentos, 3. Belo Horizonte, MG, 21 a 25 de setembro de 1998. Anais, 1:154-160.

Paolo, F.S. \& M.M. Mahiques. 2005. Caracterização da morfologia e transporte sedimentar de fundo da desembocadura lagunar de Cananéia por sonografia de varredura lateral. In: Congresso Brasileiro de Oceanografia, 2. Vitória, ES, 9 a 12 de outubro de 2005. CDROM.

Pereira, A.J.; L.A. Gamboa; M.A.M. Silva; A.R. Rodrigues \& A. Costa. 2003. A utilização do Ground Penetrating Radar (GPR) em estudos de estratigrafia na praia de Itaipuaçu Marica (RJ). Rev. Bras. Geofis., 21(2):163-172.

Pereira, L.C.C.; C. Medeiros; I.C. Freitas; \& P.V.V.D.B.C. Carvalho. 1996. Morfologia e hidrodinâmica da praia da Casa Caiada. In: Congresso Brasileiro de Geologia, 39. Salvador-BA, 1 a 6 de setembro de 1996. Anais, 4: 472-476.

Pestana, R. C.; M.A. B. Botelho. 1997. Migração de dados de radar (GPR) com correção topográfica simultânea. Rev. Bras. Geofis., 15(1): 3-10.

Piauilino, P. O.; P.R. Maldonado \& G.X. Castanhos. 2002. Primeiros resultados do sonar de varredura lateral em águas profundas rebocado próximo ao fundo marinho. In: Congresso Internacional da Sociedade Brasileira de Geofísica, 6. Rio de Janeiro, 15 a 19 de agosto de 1999. Anais. CD-ROM.

Pinn, E. H. \& M.R. Robertson. 2003. Effect of track spacing and data interpolation on the interpretation of benthic community distributions derived from RoxAnn (TM) acoustic surveys. ICES J. Mar. Sci., 60(6): 1288-1297.

Placzek G. \& Haeni F.P. 1994. Surface geophysical techniques used to detect existing and infilled scour holes near bridge piers. USGS Water-resources Investigations. Report 954009. Disponível em http://water.usgs.gov/ogw/bgas/scour/. Acesso: 15/jan/2006.

Porsani J.L e A.R. Rodrigues. 1998. Aplicação do GPR em solos brasileiros: alguns resultados. In: Workshop de Geofísica Aplicada, 2. Rio Claro, SP, 19-20 novembro. Boletim de resumos expandidos. CD-ROM.

Porsani J.L; W.A. Sauck \& A. O. Souza Jr. 2006. GPR for mapping fractures and as a guide for the extraction of ornamental granite from a quarry: A case study from southern Brazil. J. of Applied Geophysics, 58: 177-187.

Porsani, J.L.; C.A. Mendonça; J.S. Bettencourt; F.Y. Hiodo; J.A.J. Vian e J. E. Silva. 2004. Investigações GPR nos distritos mineiros de Santa Bárbara e Bom Futuro: Província Estanífera de Rondônia. Rev. Bras. Geofis., 22(1):57-68.

Porsani, J.L.; F.Y. Hiodo \& V.R. Elis. 2002. Investigações geofísicas em rochas graníticas no município de Itu, São Paulo - Brasil. Rev. Bras. Geofis., 20(1): 73-77.

Porsani. J.L.; M.L. Assine \& L. Moutinho. 2005. Application of GPR in the Study of a Modern Alluvial Megafan: The Case of the Taquari River in Pantanal Wetland, West-Central Brazil. Subsurface Sensing Technologies and Applications, 6 (2): 219-233. 
Preston, J.M.; A.C. Christney; W.T. Collins \& S. Bloomer. 2004. Automated acoustic classification of sidescan imagens. In: Oceans 2004, 9 a 12 de novembro de 2004, Kobe, Japan.

Quaresma, V. S.; G.T.M. Dias \& J.A. Baptista Neto. 2000. Caracterização da ocorrência de padrões de sonar de varredura lateral e sísmica de alta frequiência $(3,5$ e $7,0 \mathrm{kHz})$ na porção sul da Baía de Guanabara. J. Rev. Bras. Geof., 18(2):201-214.

Rambelli, G. 2003. Arqueologia subaquática do Vale do Ribeira - SP. Tese de Doutorado. Faculdade de Filosofia, Letras e Ciências Humanas da Universidade de São Paulo. 259p.

Reinhardt, L.; H.R. Kudrass; A. Lückge; M. Wiedicke; J.Wunderlich \& G. Wendt. High resolution sediment ecosounding off Peru: Late Quaternary depositional sequences and sedimentarary structures of a current-dominated shelf. Mar. Geophys. Res., 23: 335-351.

Reynolds, J.M. 1990. High-Resolution Seismic Reflection Surveying of Shallow Marine and Estuarine Environments. Mar. Geophys. Res., 12:41-48.

Robertson, K.G. 1990. Deep Sea Navigation Techniques. Mar. Geophys. Res., 12:3-8.

Rocha, A. C. 2003. Aplicação de métodos diretos e indiretos na análise da dispersão de sedimentos na Baía de Santos. Dissertação de Mestrado. Instituto Oceanográfico da Universidade de São Paulo. 91p.

Rodrigues M.; M.M. Mahiques; L.A.P. Souza; E.O. Faria; C.V. Tolentino. 2003. Caracterização da superfície de fundo da Enseada Martel (Ilha Rei George, Antártica) por meio do Sonar de Varredura Lateral. In: Congresso Internacional da Sociedade Brasileira de Geofísica SBGf, 8. Rio de Janeiro, RJ, 14 a 18 de setembro de 2003. Boletim de Resumos Expandidos. CD-ROM.

Rodrigues, A.R. e J.L. Porsani. 1995. Aplicações do método GPR na geofísica ambiental: localização de área com tanque desenterrado e dutos. In: Congresso Internacional da Sociedade Brasileira de Geofísica, 4. Rio de Janeiro, RJ, 20 a 24 de agosto de 1995. Resumos Expandidos, 2: 942-944.

Rodrigues, A.R. e J.L. Porsani. 1997. Diferentes litologias, diferentes situações, diferentes respostas. A utilização do método GPR como ferramenta de suporte à geologia. In: Congresso Internacional da Sociedade Brasileira de Geofísica, 5. São Paulo, SP, 28 de setembro a 02 de outubro de 1997. Boletim de resumos Expandidos, 1: 540-543.

Rodrigues, M. 1996. Sedimentação Atual nas Enseadas de Ubatumirim e Picinguaba e Plataforma Interna Adjacente, Ubatuba, Estado de São Paulo. Dissertação de Mestrado. Instituto Oceanográfico da Universidade de São Paulo. 158p.

Rosenberg, R.; H.C. Nilsson; A. Grémare \& J.M. Amouroux. 2003. Effects of demersal trawling on marine sedimentary habitats analysed by sediment profile imagery. J. Exp. Mar. Biol. Ecol., 285-286:465-477.

Rukavina, N. 2001. Mapping and monitoring contaminated-sediment geometry and stability, Sci. Total Environ., 266(1-3): 33-39.

Rusby, J. S. M.; M.L. Somers; J. Revie; B.S. McCartney \& A.R. Stubbs. 1973. An experimental survey of a herring fishery by long-range sonar. Mar. Biol. (Historical Archive). 22(3): 271-292.

Rusby, J.S.M., 1970. A long range side-scan sonar for use in the deep sea (GLORIA project). Int. Hydrog. Rev., 47:25-39.

Santos, C.A. \& J.M.L. Dominguez. 2005. Sedimentação na plataforma continental entre Serra grande e Olivença - costa central da Bahia. Congresso da Associação Brasileira de Estudos do Quaternário - ABEQUA, 10. Guarapari, ES, 9 a 16 de outubro de 2005. Anais. CDROM.

Santos, M.S.T. 2005. Potencialidades do GPS em levantamentos geofísicos terrestres. Dissertação de Mestrado. Instituto de Astronomia, Geofísica e Ciências Atmosféricas da Universidade de São Paulo. 153p. 
Sauck W.A; L.G. Desmond \& R.E. Chavez. 1998. Preliminary GPR results from four Maya sites, Yucatan, México. In: International Conference on Ground-penetrating radar GPR'98, 7. Lawrence, Kansas, EUA, 27 a 30 de maio de 1998. Proceedings. CD- ROM.

Sauck, W.A. 1998. Long GPR profiles for geologic reconnaissance and mapping. In: International Conference on Ground-Penetrating Radar, 7. Lawrence, Kansas, EUA, 27 a 30 de maio de 1998. GPR'98 Proceedings. CD- ROM.

Sauniti, R.M.; L.A. Fernandes \& A.V.L. Bittencourt. 2004. Estudo do assoreamento do reservatório da barragem do rio Passaúna, Curitiba, PR. Bol. Paraná. Geocienc. 54: 65-82.

Scalon, K.M. 1984. The Continental slope off New England: a long-range sidescan-sonar perspective. Geo-Mar. Lett., 4:1-4.

Scheidhauer, M.; F. Marillier \& D. Dupuy. 2005. Development of a System for 3D Highresolution Seismic Reflection Profiling on Lakes. Mar. Geophys. Res., 26(2): 183-195.

Searle, R.C; T.P. Le Bas; N.C. Mitchell; M.L. Somers \& P.P.H. Patriat. 1990. Gloria Image Processing: The State of Art. Mar. Geophys. Res., 12:21-39.

Sheridan, R.E.; G.M. Ashley; K.G. Miller; J.S. Waldner; D.W. Hall \& J. Uptegrove. 2000. Offshore-onshore correlation of upper Pleistocene strata, New Jersey Plain to continental shelf and slope. Sedimetary Geology, 134: 197-207.

Silva, C.G. 2000. Placeres marinhos. Rev. Bras. Geofis., 18(3):328-336.

Silva, C.G; A.G. Figueiredo Jr. e I. Brehme. 2000. Granulados litoclásticos. Rev. Bras. Geofis., 18(3): 319-326.

Simpkin, P. G., A. Davis. 1993. For seismic profiling in very shallow water, a novel receiver. Sea Technol., 34:21-28

Simpkin, P.G. 2005. The Boomer Sound Source as a Tool for Shallow Water Geophysical Exploration. Mar. Geophys. Res., 26(2):171-181.

Sjogren, B. 1994. Shallow refraction Seismic. Cambridge, Cambridge Universisty Press. 270p.

Somers, M.L; R.M. Carson; J.A. Revie; R.H. Edge; B.J. Barrow \& A.G. Andrews. 1978. GLORIA II - An improved long range sidescan sonar. Oceanology International, 78:16-24.

Souza, C.R.G. \& K. Suguio. 1996. Processo erosivos na costa de São Paulo. In: Congresso Brasileiro de Geologia, 39. Salvador-BA, 1 a 6 de setembro de 1996. Anais, 4: 398-401.

Souza, H. \& E.S. Sampaio. 2001. Apparent resistivity and spectral induced polarization in the submarine environment. An. Acad. Bras. Cienc., 73(3):429-444.

Souza, L.A.P. \& M.G.T. Tessler. 1992. Levantamentos geofísicos na planície costeira CananéiaIguape. In: Congresso Brasileiro de Geologia, 37. São Paulo, SP, 9 a 15 de dezembro de 1992. Boletim de Resumos Expandidos, 1: 195-196.

Souza, L.A.P. \& M.G.T. Tessler; V.L. Galli. 1996. O Gráben de Cananéia. Rev. Bras. Geocienc., 26(3): 139-150

Souza, L.A.P. \& R.L Moura. 2005. Sonar de varredura Lateral aplicado ao estudo de áreas recifais: o exemplo de Abrolhos. In: Congresso Internacional da Sociedade Brasileira de Geofísica - CISBGf, 9. Salvador, BA, 11 a 14 de setembro de 2005. Anais. CD- ROM.

Souza, L.A.P. 1984. Side Scan Sea floor mapping on Tanegashima Western offshore area. Technical Reports Group Training Course in Offshore Prospecting. Japan International Cooperation Agency. Publicação Interna do Serviço Geológico do Japão - GSJ. V.1, p.1335.

Souza, L.A.P. 1988. As técnicas geofísicas de Sísmica de Reflexão de Alta Resolução e Sonografia aplicada ao estudo de aspectos geológicos e geotécnicos em áreas submersas. In: Congresso Brasileiro de Geologia, 35. Belém, PA, 6 a 13 de novembro de 1988. Anais, 4: $1551-1564$. 
Souza, L.A.P. 1995. A planície costeira Cananéia-Iguape, litoral sul do Estado de São Paulo: um exemplo de utilização de métodos geofísicos no estudo de áreas costeiras. Dissertação de Mestrado. Instituto Oceanográfico da USP. 201p.

Souza, L.A.P. 1998. Exemplos de utilização de métodos geofísicos na investigação de áreas submersas. In: Encontro Regional de Geotecnia e Meio Ambiente/Workshop de Geofísica Aplicada, 2. Rio Claro, SP, 19 a 20 de novembro de 1998. CD-ROM.

Souza, L.A.P.; A. Marrano \& W.S. Iyomasa. 2004. Geofísica aplicada a estudos de lagos em áreas urbanas. In: Simpósio Regional da Sociedade Brasileira de Geofísica, 1. São Paulo, SP, 26 a 28 de setembro de 2004. Boletim de resumos expandidos. CD-ROM.

Souza, L.A.P.; F. Campagnoli \& F.C.V. Garcia. 1999. Geofísica aplicada ao estudo de portos e rotas de navegação. In: Congresso Internacional da Sociedade Brasileira de Geofísica, 6. Rio de Janeiro, RJ, 15 a 19 de agosto de 1999. Boletim de resumos expandidos. CD-ROM

Souza, L.A.P.; I.S.C. Mello \& J.F.M. Motta. 1997. A utilização de métodos geofísicos na investigação de reservatórios: o exemplo do Reservatório de Guarapiranga. In: Congresso Internacional da Sociedade Brasileira de Geofísica, 5. São Paulo, SP, 28 de setembro a 02 de outubro. Boletim de Resumos Expandidos, 1: 430-433.

Souza, L.A.P.; J.L. Porsani; O.C. Souza \& L. Moutinho. 2002. Levantamento experimental GPR no rio Taquari, Bacia do Pantanal Matogrossense. Rev. Bras. Geofis., 20:67-71.

Souza, L.A.P.; J.L. Porsani; C. Souza \& L. Moutinho. 2001. Levantamento experimental GPR no Rio Taquari, Bacia do Pantanal Matogrossense. $7^{\circ}$ Congresso Internacional da Sociedade Brasileira de Geofísica. Salvador, BA, 28 a 31 de outubro. Resumo expandido. CD-ROM

Souza, L.A.P.; R.F. Silva \& W.S. Iyomasa. 1998. Métodos de Investigação. In: Oliveira, A.M.S.\& Brito S.M.A. (Eds.). Geologia de Engenharia. São Paulo: ABGE. Cap. 11. Publicação IPT 2551.

Sperle M.; C. Fontoura; G.T.M. Dias; D.O.Marques \& J.C Gomes. Determinação da espessura sedimentar no canal da Baía da Ilha Grande, RJ. 2003. In: Congresso Internacional da Sociedade Brasileira de Geofísica - SBGf, 8. Rio de Janeiro, RJ, 14 a 18 de setembro de 2003. Boletim de Resumos Expandidos. CD-ROM

Spicer, K.R.; J.E. Costa \& G. Placzek. 1997. Measuring flood discharge in unstable stream channels using ground, penetrating radar. USGS/CVO - Cascades Volcano Observatory. Disponível em: <http://vulcan.wr.usgs.gov/Projects/GPRadar/ ground_penetrating _radar.html>. Acesso: 10/mar/2006.

Suguio, K.; M.G. Tessler; V.V. Furtado; C.A. Esteves \& L.A.P. Souza. 1987. Perfilagens geofísicas e sedimentação na área submersa entre Cananéia e Barra de Cananéia (SP). In: Simpósio sobre Ecossistemas da Costa Sul e Sudeste Brasileira. Síntese de Conhecimento, 1. Publicação ACIESP 54-II. Cananéia, SP, Academia de Ciências do Estado de São Paulo. Anais, 2: 234-241.

Tamaki, K. 1978. Explanatory notes of Geological Map off Hachinohe (1:200.000). Tsukuba, JP, Geological Survey of Japan - GSJ.

Tamaki, K; F. Murakami; K. Nishimura \& E. Honza. 1979. Continuous Seismic Reflection Profiling Survey. Geological Survey of Japan. Cruise Report, 12: 48-51.

Telford, W.M.; L.P. Geldart; R.E. Sheriff e D.A. Keys. 1990. Applied geophysics. First Edition. Cambridge. University Press. 860p.

Tessler, M.G. \& L.A.P. Souza. 1996. Feições sedimentares identificadas na superfície de fundo do canal do mar pequeno, sistema Cananéia-Iguape, SP. III Simpósio sobre Oceanografia, 3. São Paulo, SP, 2 a 6 de dezembro de 1996. Boletim de resumos, 1: 357.

Tessler, M.G. \& L.A.P. Souza. 1998. Dinâmica sedimentar e feições sedimentares identificadas na superfície de fundo do sistema Cananéia-Iguape, SP. Rev. Bras. Oceanograf., 46(1): 6983. 
Tessler, M.G. \& M.M. Mahiques. 1996. Processos erosivos e deposicionais no litoral paulista. Estudo de caso no sistema Cananéia-Iguape. In: Congresso Brasileiro de Geologia, 39. Salvador-BA, 1 a 6 de setembro de 1996. Anais 4: 456-459.

Toldo, E.E.; S.R. Dillenburg; I.C.Correa; L.R.S. Martins \& N.L.S. Gruber. 1994. Espessura da sedimentação holocênica da lagoa dos Patos através de registros de eco $-7.0 \mathrm{kHz}$. In: Congresso Brasileiro de Geologia, 38. Balneário de Camboriú, SC, 23 a 28 de outubro de 1994. Boletim de resumos expandidos, 1: 371-372.

Toldo, E.E.; S.R. Dillenburg; I.C. Correa \& L.S.C. Almeida. 2000. Holocene Sedimentation in Lagoa dos Patos Lagoon, Rio Grande do Sul, Brazil. J. of Coastal Research, 16 (3):816:822.

Tomazelli, L.J.; J.A. Villwock; S.R. Dillenburg; F.A. Bachi \& B.A. Dehnhardt. 1996. A erosão costeira no Rio Grande do Sul. In: Congresso Brasileiro de Geologia, 39. Salvador-BA, 1 a 6 de setembro de 1996. Anais, 4: 435-438.

Tóth, T.; R. Vida \& F. Horváth. 1997. Shallow-water single and multichannel seismic profiling in a riverine environment. Lead. Edge, nov. 1997, p.1691-1695.

Trabant, P.K. 1984. Applied High-resolution geophysical Methods. International Human Resources Development Corporation. Boston, MA. 103p.

Trainini, D.R. 1994. Diagnóstico preliminar de aspectos ambientais do litoral norte do Rio Grande do Sul. In: Congresso Brasileiro de Geologia, 38. Balneário de Camboriú, SC, 23 a 28 de outubro de 1994. Boletim de Resumos Expandidos, 1: 26.

Travassos, J. \& A.A. Adepelumi. 2001. A GPR mapping survey on Jucui River. In: Annual Symposium Applications of Geophysics to Engineering and Environmental Problems, 14. Denver, CO, EUA, 4 a 7 de março de 2001. Proceedings. CD-ROM.

Tucker, M. J. \& Stubbs, A.R. 1961. Narrow-beam echo-ranger for fishery and geological investigations. J. Appl. Phys. 12:103-110

Unesco, 2001. Convenção sobre a proteção do patrimônio subaquático. Texto adotado pela $31^{a}$ Conferência Geral da Organização das Nações Unidas para a Educação, a Ciência e a Cultura (UNESCO) em Paris, no dia 2 de Novembro de 2001. Tradução de Francisco J. S. Alves, Diretor do Centro Nacional de Arqueologia Náutica e Subaquática do Instituto Português de Arqueologia do Ministério da Cultura, a partir das versões originais em inglês, francês e espanhol e revisão final de Isabel Costeira, Diretora do Mosteiro de Alcobaça, em atenção à versão de Flávio Lopes, Diretor da Regional de Lisboa e Vale do Tejo do Instituto Português do Patrimônio Arquitetônico do Ministério da Cultura. Lisboa, 13 de Junho de 2004

Unoue, E. \& Honza E. 1982. Marine Geological Map around Japanese islands.. Marine Geology Map Series 23. Escala 1:3.000.000. Tsukuba, Geological Survey of Japan - GSJ.

Unoue, E. \& Honza E. 1982. Marine Geological Map around Japanese island. Geological Survey of Japan. Marine Geology Map Series 23. Escala 1:3.000.000.

Urick, R.J. 1983. Principles of underwater sound. New York, McGraw-Hill Book Company, $423 p$

USACE - U.S. Army Corps of Engineers. 2004. Engineering and Design Hydrographic Surveying. Manual $\mathrm{n}^{\mathrm{o}}$. 1110-2-1003. 340p. Disponível em: <http://www. usace.army.mil/inet/usace-docs/eng-manuals/>. Acesso: mar/2006.

Ussami, N.; A.L. Padilha; S. Fesseha; J.L. Porsani; L.A.P. Souza; P.C. Boggiani \& M.J. Carvalho. 2000. Investigações geofísicas integradas na planície do pantanal matogrossense: implicações tectônicas e hidrológicas de subsuperfície. In: Simpósio sobre Recursos Naturais e Sócio-econômicos do Pantanal - Os desafios do Novo Milênio, 3. Corumbá-MS, setembro de 2000. Boletim de Resumos, p.125.

Veiga, F.A.. 2005. Processos morfodinâmicos e sedimentológicos na plataforma continental rasa paranaense. Tese de Doutorado, Universidade Federal do Paraná. 193p. 
Veiga, F.A.; F.P. Brandini, F.P; R.J. Ângulo; R. Dalalana \& R. Baracho. 2004. Arrecifes de arenito naturais da costa paranaense. Simpósio Brasileiro de Oceanografia, 2. Arraial do Cabo, RJ, outubro de 2004. Anais. CD-ROM.

Vital, H.; V.E.Amaro; I.M. Silveira; K.Stattegger; A.L. Alves; L.H.O. Caldas; I.M.G. Guedes \& W.F. Tabosa. 2002. Distribuição de sedimentos na região costeira e plataforma continental setentrional do Estado do Rio Grande do Norte. In: Congresso Brasileiro de Geologia, 41. João Pessoa, PB, 15 a 29 de setembro de 2002. Anais, 1:121.

Vogelsang, D. 1995. Environmental geophysics. A Practical Guide. Berlin, Springer-Verlag. $173 \mathrm{p}$.

Wever F. T; H.M. Fiedler; G. Fechner; F. Abegg \& I.H. Stender. 1997. Side-scan and acoustic subbottom characterization of the sea floor near the Dry Tortugas, Florida. 1997. Geo-Mar. Lett., 17:246-252.

Wilding, T. A.; M.D.J. Sayer; \& P.G. Provost. 2003. Factors affecting the performance of the acoustic ground discrimination system RoxAnn (TM), ICES. J. Mar. Sci., 60: 1373-1380.

Wilkinson, B.H. 2005. Human as geologic agents: A deep-time perspective. Geology, 33(3): 161-164.

Winterwerp, J \& W.G.M. Kesteren,. Introduction to the physics of cohesive sediment in the marine environment. Developments in Sedimentology 56. T. van Loon, ed. Amsterdam. Elsevier. 466p.

Woodruff, J.D.; W.R. Geyer; C.K. Sommerfield \& N.W. Driscoll. 2001. Seasonal variation of sediment deposition in the Hudson River estuary. Marine Geology, 179: 105-119.

Wong, H.K.; W.D. Chesterman \& J.D. Bromhall. 1970. Comparative side-scan sonar and photographic survey of coral bank. Int. Hydrogr. Rev., 47(2):11-23.

Wunderlich, J. \& G. Wendt. 2004. High-Resolution Echo-Sounding and Estimation of Sediment Properties using Nonlinear Acoustics. In: Near Surface 2004 European Meeting of environmental and Engineering Geophysics, 10. Utrech, Holanda, 6 a 9 de setembro de 2004. Proceedings. CD- ROM.

Wunderlich, J. \& S. Mueller. 2003. High-Resolution sub-bottom profiling using parametric Acoustics. International Ocean Systems, 1:1-7.

Wunderlich, J. 2003. Nonlinear Acoustics for High-Resolution Subbottom Echo-Sounding. Palestra ministrada pelo Prof. Jens Wunderlich, da Universidade de Rostock, Alemanha, na Universidade Hogeschool em Amsterdam, na Holanda. em setembro de 2003. Disponível em: <http://www.innomar.com>. Acesso: jan/2006.

Wunderlich, J.; G. Wendt \& S. Mueller. 2004. Detection of embedded archaeological objects using nonlinear sub-bottom profilers. In: European Conference on Underwater AcousticsECUA 2004, 7. Delft, Holanda, 5 a 8 de julho de 2004. Proceedings. CD- ROM.

Wunderlich, J.; G. Wendt \& S. Mueller. 2005. High-Resolution Echo-Sounding and Detection of embedded archaeological objects with nonlinear sub-bottom profilers. Mar. Geophys. Res., 26:123-133. 
Anexo A

APLICABILIDADE DOS MÉTODOS GEOFÍSICOS NA INVESTIGAÇÃO DE ÁREAS SUBMERSAS RASAS 


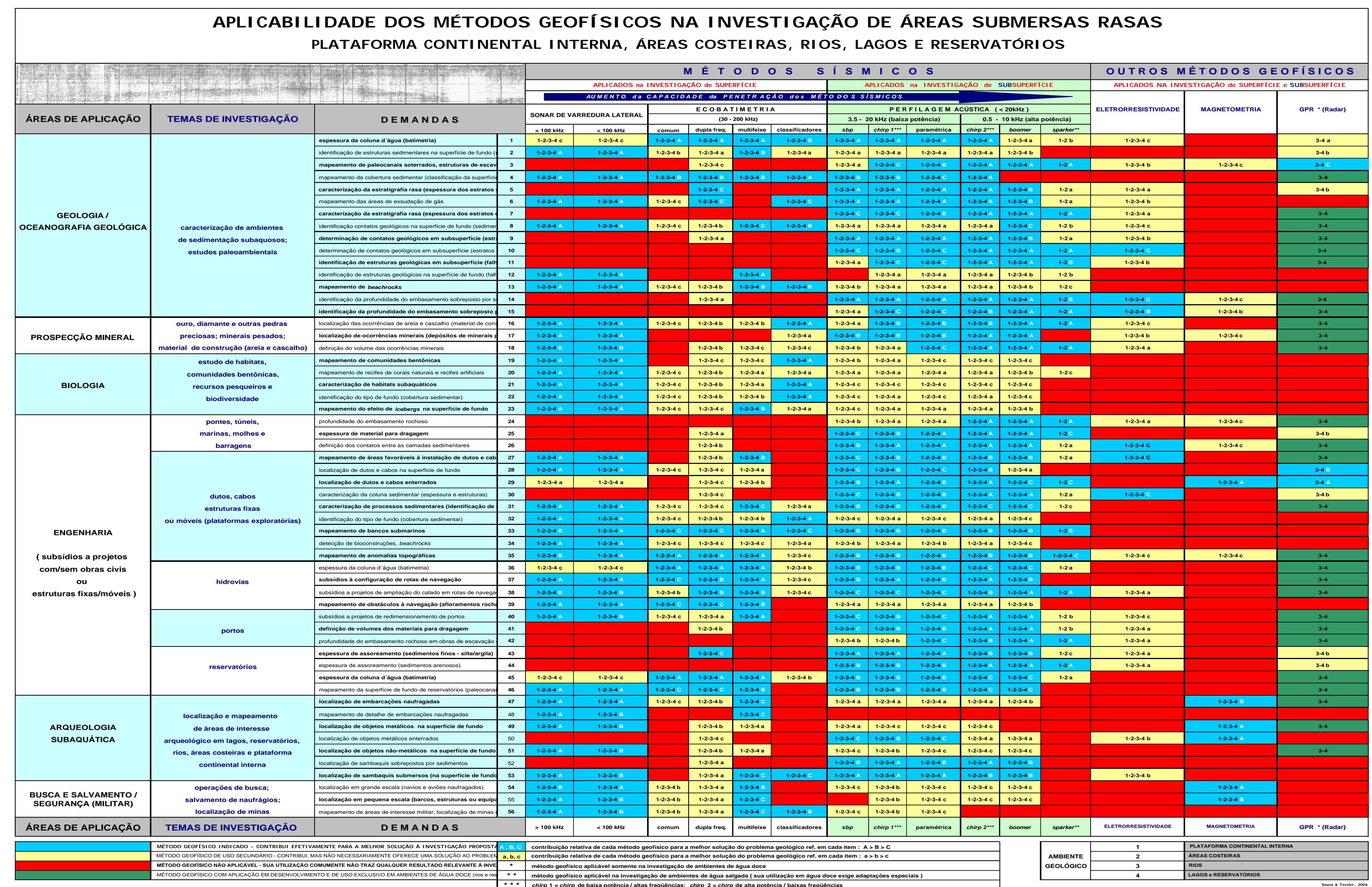

